(1)

$=$
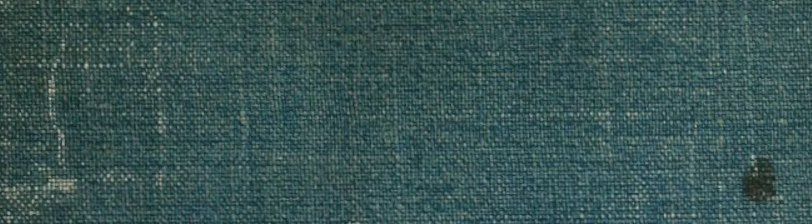

$4 \times 2 x^{2}$
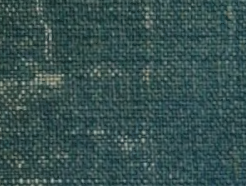

2.1.5.

t.

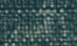

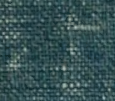

Fin.

(29.

5.

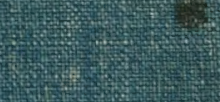






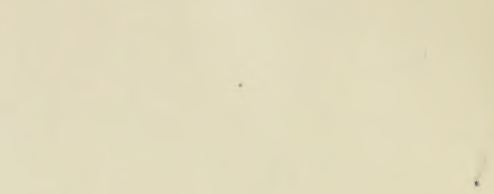




\section{THE EUSPORANGIATAE}

THE COMPARATIVE MORPHOLOGY

OF THE OPHIOGLOSSACEAE

AND MARATTIACEAE

BY

DOUGLAS HOUGHTON CAMPBELL

PROFESSOR OF BOTANY, LELAND STANFORD JUNIOR UNIVERSITY

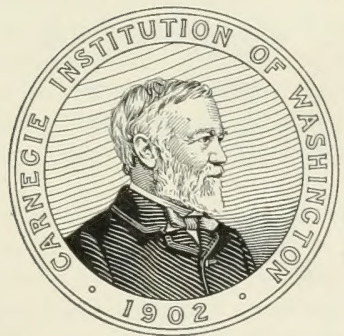

WASHINGTON, D. C.

Published by the Carnegie Institution of Washington 


\section{CARNEGIE INSTITUTION OF WASHINGTON \\ Publication No. 140}

Copies of this Book

wore first issued

AUG 291911

PRESS OF ISAAC H. BLANCHARD COMPANY NEW YORK 


\section{PREFACE.}

The great importance of the eusporangiate ferns as the nearest existing relatives of the Paleozoic ancestors of the higher types of flowering plants invests them with an especial interest for the student of plant evolution; and no apology is necessary for presenting at length a summary of our present knowledge of the structure and development of these important plants.

For more than twenty years the writer has been much interested in the study of the Eusporangiatæ and during this time has published a number of works dealing with them. He has had rather unusual opportunities for collecting these forms, and an extensive and representative collection of materials comprising a good many species has been accumulated, so that the time seemed ripe for a comparative study of the group, for the purpose of determining, as far as might be, the relationships existing between the different genera, as well as for throwing some light upon the question of their position in the great series of ferns.

The present memoir is an attempt to present the results of these studies, based mainly upon the writer's own materials, but supplemented by a careful study of the work of other investigators who have described the structure and development of the Eusporangiatæ.

The writer's grateful acknowledgments are due to a number of colleagues who have rendered assistance in various ways. Especially is he indebted to Prof. E. C. Jeffrey, through whose kindness a large number of admirably preserved prothallia and young plants of Botrychium virginianum were sent the writer, and in addition a number of valuable slides of the same. Without this material the work on Botrychium would have been very incomplete.

To my colleague in Stanford University, Prof. L. L. Burlingame, thanks are due for valuable assistance in the preparation of the photographic plates, as well as for the use of a number of important slides of Ophioglossum and Helminthostachys.

To Prof. J. C. Willis, of the-Botanic Gardens at Peradeniya, the writer would express his appreciation of many kindnesses and assistance in collecting during his stay in Ceylon.

It was the good fortune of the writer to enjoy the unequaled facilities for collecting material offered by the great gardens at Buitenzorg and Tijbodas in Java, where, through the interest and courtesy of the distinguished director, Professor M. Treub, whose recent death was such an irreparable loss to science, means were afforded for securing the most valuable materials used in the preparation of the present work.

Stanford University, April, igio.

Douglas Houghton Campbell. 
Digitized by the Internet Archive in 2010 with funding from University of Toronto

http://www.archive.org/details/eusporangiataec00camp 


\section{TABLE OF CONTENTS.}

Preface

\section{Part I. The Ophioglossales}

I. The Gametophyte

Germination in Ophioglossum .

The Adult Gametophyte of Ophioglossum

The Histology of the Gametophyte .

The Gametophyte of Botrychium

The Histology of the Gametophyte of Botrychium _ . . . . . . . . 18

The Gametophyte of Helminthostachys . . . . . . . . . . . . . . 19

The Endophyte . . . . . . . . . . . . . . . 2I

The Sexual Organs . . . . . . . . 22

The Antheridium.

The Antheridium of Ophoglossum .

The Antheridium of Botrychium

The Antheridium of Helminthostachys

Spermatogenesis .

The Archegonium

The Archegonium of Ophioglossum.

The Archegonium of Botrychium

Fertilization .

Fertilization in Botrychium virginianum. . . . . . . . . . . . .

Significance of the Endophyte .

II. The Embryo

- 34-54

The Embryo of Ophioglossum . _ _ _ _ _ . . . . . . . . . . . 34

The Development of the Primary Bud in Ophioglossum moluccanum. . . . . . . 40

The Embryo of Ophioglossum vulgatum . . . . . . . . . . . 43

The Anatomy of the Young Sporophyte of Ophioglossum . . . . . . . . 44

The Embryo of Botrychium . . . . . . . . . . . . . . 46

The Embryo of Helminthostachys . . . . . . . . . . . . . 54

III. The Young Sporophyte

The Young Sporophyte of Ophioglossum.

The Young Sporophyte of Botrychium . . . . . . . . . . . . . . 59

The Young Sporophyte of Helminthostachys. . . . . . . . . . . 67

Comparison of the Young Sporophytes of the Ophioglossacex . . . . . . . . $\quad 82$

IV. The Adult Sporophyte . . . . . . . . . . . . . . 85-116

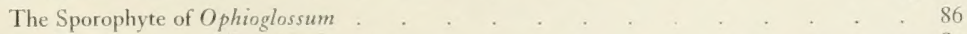

The Anatomy of Euophioglossum. . . . . . . . . . . . . 89

The Root in Euophioglossum . . . . . . . . . . . . . . 93

Anatomy of Ophioderma . . . . . . . . . . . . . . . . . 94

Anatomy of Cheiroglossa. . . . . . . . . . . . . . . . . . 99

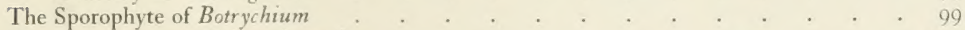

The Sporophyte of Helminthostachys . . . . . . . . . . . . . 104

The Sporangiophore of the Ophioglossales . . . . . . . . . . . I08

The Development of the Sporangiophore . . . . . . . . . 11 IO

The Development of the Sporangium . . . . . . . . . . . II2 
Part II. The Marattiales.

1. Tus Gasmorurts

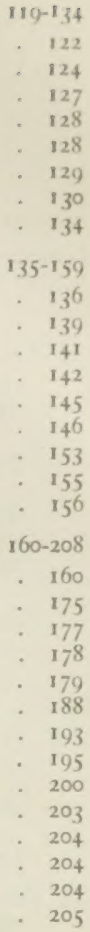

The Prothallium of Kaul/ussia.

The Prothallium of Danca

The Endophyte of the Maratriacez

The Sexual Organs

The Antheridium

Spermatogeriesis .

The Archegonium

Fertilization

11. Тив Емвкуо

The Embryo of Marattia .

The Embryo of Angiopteris

The Embryo of Kaulfussia

The Embryo of Danaa .

The Anatomy and Histology of the Young Sporophyte The Cotyledon

The Stem of the Young Sporophyte

The Root

The Second Leaf

III. The Ozder Sporophyte .

The Development of the Vascular System in Danca .

The Adult Sporophyte of Danaa

The Anatomy of the Leaf

The Apical Growth of the Roots

The Sporophyte of Kaulfussia

The Sporophyte of Marattia .

The Adult Sporophyte of Marattia .

The Sporophyte of Angiopteris

The Adult Sporophyte of Angiopteris

Archangiopteris .

- Macroglossum

Tissues of the Marattiacex

The Sporophyll of the Marattiacex . .

The Sporangium of the Marattiacea

PART III.

The Origin and Relationships of the Eusporangiatae . . . . . . . . . . 209

Conclusion . . . . . . . . . . . . . . 217

BIBLIOGRAPHY . . . . . . . . . . . . . . . . . . . 219

List of Plates . . . . . . . . . . . . . . . . . . 223

INDEX . . . . . . . . . . . . . . 225 


\section{THE EUSPORANGIATAE}

THE COMPARATIVE MORPHOLOGY

OF

THE OPHIOGLOSSACEAE AND MARATTIACEAE 


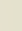




\section{INTRODUC'TION.}

It is pretty well agreed among botanists that most of the seed plants, perhaps all of them, are descendants of some fern-like Paleozoic ancestors. The geological record is remarkably perfect in many respects, and our knowledge of many of these Paleozoic fossils is extraordinarily complete. Among the most important contributions made of late years to our knowledge of these Paleozoic fossils is the fact that many of these Paleozoic "ferns" were really seed-bearing plants intermediate in character between the true ferns and the more highly developed flowering plants.

At best the fossil record is very incomplete in regard to many extremely important structural details, and therefore it is especially necessary that these points should be thoroughly studied in such of the existing ferns as, for any reason, seem to be at all closely related to the ancient Paleozoic types.

The name Eusporangiata was proposed by Goebel to include the two very peculiar families of fern-like plants, the Marattiacea and Ophioglossacea, which differ in several important respects from the much more numerous and specialized Leptosporangiata, the predominant ferns of the present day. The Eusporangiatx comprise 100 or more species of widely distributed ferns, of which the Marattiacex are mainly tropical in their distribution, while the (Ophioglossacea include a good many species of temperate regions as well. The Eusporangiata are distinguished primarily by the character of the sporangium, which is always much more massive than in the typical ferns, the Leptosporangiatx. In the latter, the sporangium can almost always be traced back to a single mother cell which usually arises from the surface of the leaf, while in the Eusporangiatze the sporangium is already multicellular when it is first recognizable.

The Marattiacex are in general appearance much like the typical ferns, and there is no question of their relationship to the Leptosporangiata. The resemblances are less obvious in the case of the Ophioglossacex, and some students of the ferns have expressed the opinion that the (Ophioglossacer should be separated entirely from the ferns and placed in a distinct class. (See Bower 9.) A careful comparative study, however, of the two families included in the Eusporangiatie shows so many close correspondences in structure, both of the sporophyte and gametophyte, that their association together is amply justified.

The Marattiacex are known to be very ancient forms, unmistakable members of this family occurring abundantly in Paleozoic formations. The Ophioglossacea, on the other hand, are very unsatisfactorily represented in a fossil condition, and for this reason doubt has been thrown on their antiquity, although their structures show strong evidences of an extremely primitive character. Certain of the oldestknown fossil ferns, the Botryopteridex, may possibly prove to be related to the Ophioglossacex, but the evidence at present is not entirely conclusive.

In spite of the unsatisfactory nature of the geological evidence, I am nevertheless strongly inclined to believe that the Ophioglossacex, on the whole, represent the most ancient type among the living ferns, this conclusion being based upon a very careful study of the structure of both gametophyte and sporophyte.

There are many practical difficulties in the way of studying these interesting ferns, and these difficulties undoubtedly account for the comparatively small number of researches that have been made upon their development. A few species, like Ophioglossum vulgatum and several species of Botrychium, are widespread in their 
samee and ecene in the remperase regions of Europe and America; but very much she larere number of these, including all of the Maratriaceat, are tropical or submepical plants and are very seldom seen in cultivation, hence material for their sturly most be colleced in their natural habitat.

The gametephytes, of sexual plants, are seldom encountered unless very' special seatch is made for them, and they have been but rarely collected; and even where the spores can be made to germinate, the long time necessary for the growth of ehe gametephyte under artificial conditions, and the ditticulties of rearing them en maturity, readily explain the small number of successful attempts to study these plants under artificial conditions.

As the result of several visits to the tropics of both the ()ld and New Worlds, the writer has collected material of all of the eusporangiate genera, except the recenty discovered Archangiopteris from southwestern China and Macroglossum from Bornes). It has seemed desirable, with this material as a basis, to make a somewhat comprehensive comparative study of the whole group of the Eusporangiata. In this study, especial attention will be devoted to the structure and development of the gametophyte and embryo and to the development of the young vegetative organs of the sporophyte. The general anatomy and histology of the mature sporophyte have already been pretty satisfactorily studied and described for most of the genera and a particularly satisfactory account of the development of the sporangium has been given us in the comprehensive memoirs of Professor Bower (Bower 5, 6), and a detailed investigation of these points has hardly seemed necessary, although, so far as possible, the results of the work of previous investigators have been verified.

The writer has already published various papers upon the development of both the Marattiacex and Ophioglossacex, and these have been freely drawn upon in the preparation of the present monograph; but these earlier studies have been materially extended by further work upon the species previously studied and investigations have been made upon a number of species which hitherto have not been examined at all, or have been studied only very incompletely. This is particularly true of the genus $D a n a$ a, which has received comparatively little attention hitherto. An especially fine lot of material of several species of Danca was collected in Jamaica in 1908 and an extended study of the gametophyte and young sporoplyyte has been made, the complete results of which are now published for the first time. Attention has also been given to the development of the young sporophyte in the other eusporangiates, particularly in the peculiar genus $K$ aulfussia, which, like Danca, has received less attention from the students of these plants than have the genera Marattio and Angiopteris.

() late there has been a tendency, especially among students of the fossil ferns, to lay great stress upon the importance of the structure of the vascular skeleton of the ferns in the study of their phylogeny. It is therefore highly important that a

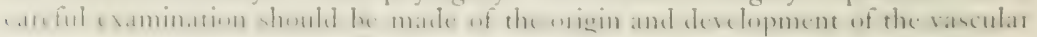
system in those forms, i. e., the linsporangiate, which, there is good reason to sup-

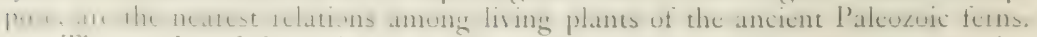

The results of the writer's studies on the development of the fibro-vascular bundles of the sporophyte in all of the eusporangiate ferns bave led to some rather unexpected conclusions as to the real nature of the vascular system in these ferns, conclusions decidedly at variance with the views generally accepted at present. These results have seemed sufficiently important to warrant a more extended treatment of this subject than was at first contemplated; and this will explain what might otherwise seem to be a disproportionate amount of space devoted to the origin

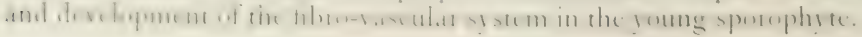




\section{PART I. THE OPHIOGLOSSALES.}

The Ophioglossales, the "adder-tongue" ferns, include three genera (of which two are practically cosmopolitan) and embrace numerous species, being sometimes further divided into several subgenera; the third genus is a monotypic one, confined to the tropics of the Old World. These three genera are evidently quite closely related among themselves and may without hesitation be referred to a single family, the Ophioglossacex. The genus Ophioglossum includes several species of the temperate regions of the whole world, and some of the species, like $O$. vulgatum, are very widespread; the tropical species are much more numerous, but the number of these is very uncertain and much confusion exists as to the limits of certain species. The second genus, Botrychium, belongs mainly to the temperate regions, only a small number of species occurring in the tropics, and these are principally confined to the cooler mountain regions. The third genus, Helminthostaclzys, with a single described species, $H$. zeylanica, is a not uncommon fern of the lowland forests of the Indo-Malayan region.

The Ophioglossacex are for the most part quite glabrous plants, of small or moderate size. The smallest species, like Botrychium simplex and some of the smaller species of Ophioglossum (e. g., O. californicum, O. bergianum, and some of the smaller forms of $O$. moluccanum) may be only 5 or 6 centimeters in height. The largest species of Botrychium and Helminthostachys sometimes attain a height of 50 centimeters or more, with ample, much-dissected leaves, while the long, ribbonlike, pendent leaves of the epiphytic Ophioglossum pendulum, the giant of the family, may reach a length of 1.5 meters.

Except for two species of Ophioglossum belonging to the sections Ophioderma and Cheiroglossa, the Ophioglossacex are terrestrial plants, usually growing in soil abounding in humus, and the gametophyte in all cases is a subterranean structure quite destitute of chlorophyll.

The stem is a rhizome, which is short and upright in the terrestrial species of Ophioglossum and in Botrychium, but is dorsiventral in Helminthostachys and the epiphytic species Oplioglossum pendulum. In most of the species of the temperate regions only a single leaf is developed each year, but there are some exceptions to this rule in Ophioglossum, especially in the tropical species, where there is no interruption of the growth.

The leaves are usually ample, and may be quite undivided, as in most species of Ophioglossum, or they may be dichotomously divided in $O$. palmotum and some forms of $O$. pendulum; or they may be much dissected, usually in a ternate fashion, in Botrychium and Helminthostachys. The sporangia are sometimes very large, and are borne upon characteristic spikes, or "sporangiophores," whose morphological nature is a matter of some controversy. The venation of the leaves is reticulate in all species of Ophioglossum, but in the other genera it resembles that of the typical ferns.

With the exception of Ophioglossum (Cheiroglossa) palmatum, the sporangiophore is normally attached to the adaxial side of the leaf, usually near the junction of the lamina and petiole; but sometimes it is inserted much lower down, or it 
may arise chose to the base of the periole and appear to be quite independent of the sterile leaf segment. The sporangia range in number from ahout half a dozen, in sume of the smallet forms of Botrythiom simplex and Ophioglossum, to many

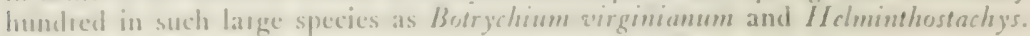
There is a mose interesting series of forms connecting the smaller and simpler types witls the large and complicated ones. With the increasing complexity of the sporangiopheres, there is usually a reducrion in the size of the sporangia, which, however, become beter difierentiated than in the simpler types.

There is no yuestion about the close relationships existing between the differene genera of the Ophioglossacex, but there is some difference of opinion as to their connection with other P'teridophytes. While they are probably sufficiently distinct to be relegated to a special order, Ophioglossales, their peculiarities hardly warrant separating them entircly from the ferns. As will be seen later, they offer many points of resemblance to the Marattiales, both in regard to the structure of the adult sporophyte and that of the gametophyte or sexual plant, and the early phases of embryonic development. 'These resemblances are too numerous and tou exact to make it at all likely that the two orders are unrelated.

\section{THL GAMETOPHYTE.}

The first discovery of the gametophyte of the Ophioglossacere was made by IIofmeister (Hofmeister 1) who, in 1854 , found the gametophyte of Botrychium Iunaria; two years later Mettenius (Mettenius 1) described much more fully the prothallium of Ophioglossum pedunculosum, which was cultivated in the botanical garden at Leipzig. No further additions were made to the subject until the writer (Campbell 4) succeeded in obtaining the first germinating stages of $O$. pendulum, collected in the Hawaiian Islands, and those of Botrychium virginianum; and the older gametophyte of the latter species was also described. In the year 1898 Jeffrey (Jetfrey 1) published a complete account of the gametophyte and embryo of Boirvinum virginianum. Later contributions to the subject are those of Lang 1. Ing 1) on the gametophyte of () phinglessum pindulum and of Helminthestathes; and the papers of Bruchmann (Bruchmann 1,2) on the prothallium of Botrychium lumuria and Oplioglossum vulgatum. In 1905, Lyon (Lyon 1) published a brief account of the embryo of Botrychium obliquum.

In 1906 I collected in Ceylon a few prothallia of a species of Ophioglossum which may have been $O$. reticulatum, and shortly afterward, during a stay in Java, a number of prothallia of $O$. moluccanum were found, as well as a few belonging to an undetermined species associated with the latter. During my stay in Java 1 was fortunate enough to obtain also a large number of prothallia of $O$. pendulum. An account of these has already been published (Camplell 8).

Alt species of the Ophioglossacex that have yet been examined agree in the

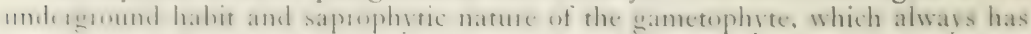
assuciated with it a peculiar endophytic fungus, or "mycorrhiza," which is undoubtedly connected with the assimilation of organic food. Mettenius states that chlorophyll may be developed if the prothallium appears above ground, and Bruchman forund that this was also true in $O$. sulgatum; but as a rule the prothallium remains subterranean and quite deseitute of chlorophyll.

The spores of the Ophioglossacea are always of the tetrahedral type, and when ripe possess a moderately thick sculptured outer membrane, which is usually colorless or pale yellow, so that the masses of spores are either white or a pale sulphur-yellow tint. The ripe spore as a rule is packed with gramular matter, which makes the 
contents appear opaque and obscures more or less the centrally placed nucleus. A marked exception to the ordinary type of spore was that found in an undetermined species of Ophioglossum collected at Buitenzorg in Java. This was supposed to be O. moluccanum, with which it was growing, but a comparison with typical specimens of the latter species showed marked differences, the most striking being the spores, which were larger than in the type, had much less dense contents, and were especially notable in that they had regularly two nuclei, a condition unique, so far as I know, among the ferns. (See Campbell 8, fig. 157.) The granular contents of the spores include numerous albuminous granules, together with more or less starch and oil.

\section{GERMINATION IN OPHIOGLOSSUM.}

The first successful attempts to germinate the spores of Oplioglossum were made by me in 1892 , when ripe spores of the epiphytic 0 . pendulum were collected in Hawaii and brought to California. This species was found in Hawaii, growing usually upon the trunks of tree ferns, and the spores were sown upon bits of the bark-like masses of roots, which in the commoner tree ferns of Hawaii (species of Cibotium) cover the trunk with a thick, felted mass. These masses of roots were kept in jars, and the spores were sown upon them, a good many of them germinating in course of time. The germination was very slow, the spores often remaining unchanged for months, and none of these young prothallia developed beyond the stage with three cells. This failure to develop further was undoubtedly due to the fact that they did not become infected with the mycorrhiza, which is essential to the full development of the prothallium.

In 1906 ripe spores of the same species were collected in Ceylon and Java. In Ceylon spores were secured at the botanical garden in Peradeniya and in the Barrawa Reserve Forest near Hanwella, where Lang obtained his material. In Java the spores were mostly collected at Tjibodas. In all of these later experiments the spores were sown in humus collected from about the base of the spore-bearing plants. These masses of wet humus were kept in stoppered bottles.

As in the earlier experiments, the germination was slow, the first germinating stages being found only after a month or more, and in some cases the spores remained unchanged for a very long period. The bottles containing the spores sown upon the humus were brought back to California, and a recent examination (September I gog) showed a considerable number of apparently normal spores, as well as living three-celled prothallia, presumably the result of comparatively recent germination.

Spores sown in Tibodas on April 18, I906, were first found germinating at Buitenzorg on May
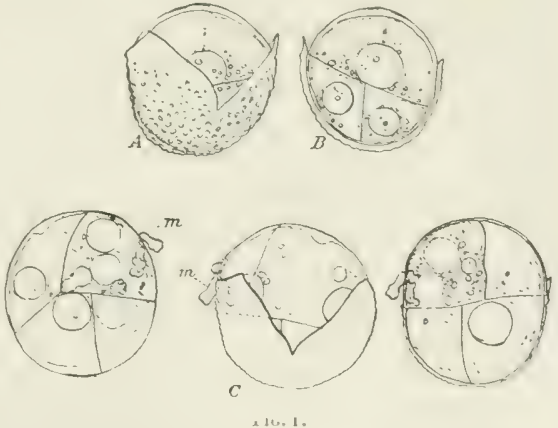

A. Germinating spore of Ophioglossum pendulum. $\times_{3} 60$.

B. Optical section of A.

C. Three views of a very young gametophyte of 0 . pendulum, showing infection by mycorrhizal fungus. $x_{3} 60$.

24 , germination at this time being pretty well advanced. On June 3 a number of these had three cells. The germination (fig. I) in all cases corresponded closely with the writer's former observations and closely resembles that which we shall see presently in Ophioglossum moluccamum. In no case could any chlorophyll be detected, 
and appasenely the prothallium of () . pendulum is stricty saprophytic throughone is existence.

The extremely favorable conditions for plant growth at Buitenzorg made this an umusually promising place for studying germination, and very soon after my arrival there a quantity of plants of Ophioglossum moluceanum, or what was supposed to be this species, was secured, and the spores were sown. Subsequent study showed that at least three species grew together at Buitenzorg, so that it is not at all certain that all of the germinaring spores and the prothallia which were collected later really belonged to $O$. moluccanum.

Since in all previous experiments with the Ophioglossacea germination had been very slow, it was with much surprise that the first lot of spores that were suwn, when examined a week later, were found to be germinating very freely and had evidently been growing for some days. New sowings were made, and in some cases the first germination stages were evident within three days from the time the spores were sown. Inasmuch as the spores contain no chlorophyll, this rapid germination is really remarkable. In the most favorable instances the greater part of the spores germinated and many thousand germinating spores were studied.

The hirst sowings were made upon earth taken from where the plants were growing; the earth was placed in small glass dishes and flooded with water; the spores were then scattered over the surface of the water, some sinking, but the greater part Hoating on the surface. In later experiments cavities were hollowed out in the earth and these were filled with water, while the rest of the earth was left wet, but not Hooded. It was found that the spores germinated more promptly. in the water than on the wet earth, and this suggested that probably under natural conditions germination occurs where the spores fall in slight depressions which are filled with water for a time after heavy rains. 'The prothallia of Hclminthostachy's, to judge from the locality where they were found in the Barrawa Forest, occurred only where the forest was subject to inundation, and it may be that immersion in water is necessary for the germination of Ophioglossum moluccanum, or at any rate facilitates germination. The older prothallia of this species which were found in Buitenzorg were growing in low ground between the projecting roots of trees, where water might very well stand for some days in wet weather.

The first sign of germination consists in the enlargement of the spore contents, which soon burst the rigid outer membrane along the three lines upon its ventral face, and through the cleft thus formed the spore contents, surrounded by the colorless inner membrane ("endospore" or "intine") protrude as a blunt papilla (plate I, fig. 2). The first division wall is transverse and is soon followed by a second wall in the upper cell (i. e., the one turned away from the opening). The second wall is at right angles to the first, and the young prothallium now consists of three cells, the basal one, which is partly exposed through the cleft at the upper side of the spore, and the two upper cells, which have more dense contents than the basal one. The basal cell in position corresponds to the first rhizoid in the germinating spore of the typical ferns, but it was never found to become extended into a true thizoid, and no rhizoids were seen in any of the very young prothallia.

While (O)hioglossum moluccanum and $O$. pendulum agree very closely in the early stages of germination, in the latter species no trace of chlorophyll can be detected at any time, but in 0 . moluccanum it is not uncommon to find from one to chree chloroplasts present. These chloroplasts are very pale in color, but it is certain that a small amount of chlorophyll is present in some cases.

While most of the voung prothallia of $O$ phinglossum molucsamum do not advance beyond a threecelled stage, a few were found in which there were four cells, but all 
attempts to carry them beyond this stage failed and after exhausting the spore contents they soon died. The small amount of chlorophyll occasionally found in these young prothallia is evidently insufficient for their independent growth, and after a few weeks the granular contents all disappear and the cells soon collapse, showing that the young gametophyte has died from starvation.

A number of specimens of the rare Ophioglossum intermedium were collected near Buitenzorg and a few ripe spores were also secured. These spores contain somewhat less dense contents than those of the other species described and have a more delicate epispore. Spores were sown on March 30 in Buitenzorg, and when examined about two weeks later no germinations were found, nor did a second examination about the end of April show any further results. On May 2I, however, two three-celled prothallia were found, and subsequently a small number of others, but no later stages were discovered. The young prothallia appeared in every respect like the similar stages in the other species (plate I, fig. 6).

In Ophioglossum pendulum a number of young prothallia were found which had increased very much in size and undergone further division. The first of these were observed on April 3 , and had developed from spores sown in Peradeniya on February 9. These young prothallia (fig. $1, c$ ) had from four to six cells. It was found that in each case the mycorrhiza had connected itself with the young prothallium, and evidently had caused a stimulus in its growth. In every case where the young prothallium had more than three cells there was found associated with it the mycorrhiza, which could be easily seen to penetrate into the basal cell. The infection was in all cases due to fragments of mycelium, and in no case to anything which could be interpreted as spores. The fungus was apparently growing free in the humus where the spores were sown. This soil, as we shall see, was taken from about the roots of the sporophytes which furnished the spores.

The free surface of the basal cell has its wall decidedly thickened, and it was here that the infection took place in all the specimens seen. The branching mycelium of the mycorrhiza was closely applied to the surface of the cell and a haustorium was sent down through the cell wall into the basal cell (fig. I, $m$ ). This haustorium is pointed at first, but after it penetrates into the cell it enlarges and assumes the form of a somewhat thickened worm-shaped body, much thicker than the free mycelium outside. In the cell infected with the fungus, the contents show the peculiar aggregated appearance characteristic of the infected cells of the older prothallia. On the 6 th of April a specimen with seven cells was found. About a month later, a number of other specimens were observed also, some of these having as many as thirteen cells (plate $\mathbf{1}$, fig. 9). This was the largest number found in any of the young prothallia.

The divisions of these young prothallia are mainly in the lower cells, so that the apex, as in the prothallium of the true ferns, develops mainly from the lower of the two original prothallial cells. The basal cell, however, also undergoes divisions, and there is no very marked difference between the lower and upper ends of the prothallium. At this stage there is a marked resemblance, except for the absence of chlorophyll, to the early germination stages of Lycopodium cernuum (Treub I). 'The meorrhiza penetrates the cells adjacent to the one first infected, but leaves the apical region free, and this region probably remains permanently free from the endophyte, as it does in the adult prothallium.

The number of young prothallia found was too small to make it possible to determine exactly what may be considered to be the normal succession of cell division, and whether at this early stage there is a definite apical cell could not be decided. As will be seen from the figures, there is evilenty a enowl deal of variation in the 
early divisions. In these larger prothallia there is already the beginning of an axial risste. Whether the cell $x$ (plate 1 , fig g) is to be regarded as an apical cell, it would he hard to sall:

()wing (1) my departuce from lava about three months after the first observations were made, it was impossible to trace the development of the prothallia further, but this much is ecrtain-without the infection of the fungus, growth will not proceed beyond the three-celled stage, and apparenty in $O$. pendulum no chlorophyll will develop under any conditions, and the prothallium from its earliest stages must be considered saprophytic in its nutrition. Whether the oval body described as the product of germination is to be considered as a sort of tubercle, such as is found in Lycopodium cornumm, must be decided by further investigations. Lang's descriptions and figures of the smallest specimens which he discovered would indicate that this is not the case in $O$. pendulum; but the tuberous body usually found at the base of the older prothallia in $O$. moluccomum (and this is true also in $O$. vulgatum) would indicate that in these species it is not impossible that a primary tubercle is first formed and subsequently the fertile branch.

\section{THE AISUT GAMETOPIYTE OF OHHIOGLOSSUM.}

In 1856 Mettenius (Mettenius 1) found the gametophyte of 0 . pedunculosum Desv., a tropical species, growing spontaneously in the pots where the plants had been cultivated in the botanical garden at Leipzig. He did not succeed, however, in making the spores germinate. These prothallia were slender, subterranean bodies, sometimes branched, sometimes without branches. They ranged in length from 1.5 lines to 2 inches $(\mathrm{fig} .3, A, B$ ). There was usually present a basal enlargement or tuber, from which the fertile part of the prothallium extended. The older portions were brownish in color; the growing tips of the branch white. From the surface there grew numerous short brown rhizoids. Archegonia and antheridia grew more or less intermingled and were formed in large numbers. Except for the greater size, these prothallia closely resemble those of $O$. moluccanum collected by me in Buitenzorg; and as $O$. pedunculosum Desv. has been held to be a synonym of $O$, moluccomum Schlecht, it is possible that Mettenius's plants were the same as those found by me growing in Buitenzorg in Java.*

The next account of the prothallium of Ophioglossum is that of Lang (Lang $\mathbf{1}$ ). He collected in Ceylon specimens of the prothallia of Ophioglossum pendulum. These were found in the Barrawa Reserve Forest, not far from Colombo, and were buried in the humus accumulated between the leaf bases of Polypodium quercifolium, an epiphytic fern to which $O$. pendulum is often attached. I visited this same locality in February, I906, but was unsuccessful in collecting the prothallia, although I obtained numbers of the sporophytes. Some time after, however, when in Java, I found a very large number of prothallia which were growing in much the same way as those collected by Lang, except that in this case the fern to which the Oplioglossum was attached was the widespread bird's-nest fern, Asplenium nidus.

Bruchmann has given a detailed account of the prothallium of the widespread $O$. sulgatum, which agrees closely in its essential details with $O$. pedunculosum and O. moluccanum. Bruchmann's specimens were collected in the Thuringian Forest, in a depression that was subjected at times to overflow, a condition paralleled by the lucations where the prothallia of Helminthostachy's were collected by Lang and

- Crisiensen in his recene Index Filicum (1906) recards 0 . moluceanum as a synonym of 0 . pridunculosum. Throught the kind. ness th l'rofessur $\mathbf{K}$. Gucbel, I recently had an opportunity of examining sume specimens of 0 . pedunculosum gruwing in the buratiol garden in Munich. These pasts were the Jescendants of the specimens in Ixipzig deveribed by Mettenius and certaindy very a busely resembled the typical (). moluccanum from Buitenzorg. 
myself, and also like the locality where most of my specimens of $O$. moluccanum were found in Java. This, in connection with my experiments in germinating the spores of $O$. moluccanum, makes it not unlikely that actual submersion is a necessary condition for the germination in the terrestrial species of Ophioglossum.

In April 1906, about fifty prothallia of $O$. moluccanum were collected by me at Buitenzorg, where, as we have seen, this species is extremely abundant. Only a small number of these were young enough to show the young reproductive organs, and most of them had alrealy developed the young sporophyte. The greater part of these prothallia were found growing together in a slight depression between the projecting roots of a tree.

These prothallia were slender bodies, from 5 to ro millimeters in length, and none of them branched. They showed a more or less conspicuous basal tuber, like that described by Mettenius for $O$. pedunculosum, and indeed they very closely resembled his figures of the simpler forms of that species, but are very much smaller. The youngest specimen found (plate I, fig. 10) consisted of a small, irregular tuberous body of a brownish color, from which grew a short appendage or branch, the tip of which was white. The older ones also showed this basal tuber, but the cylindrical branch was much longer. Owing to their slender form, the prothallia are not always easily distinguishable from roots, and in some cases a microscopic examination is necessary before one can be sure of their real nature. Growing from the surface are scattered short brown hairs like those described by Mettenius for $O$. pedunculosum. Archegonia and antheridia are formed at an early period, and can be traced to the base of the fertile branch, or in some cases may be found even upon the tuber. In these specimens the reproductive organs seemed to be formed in rather smaller numbers than is the case either in O. pedunculosum or O.vulgatum. Among the prothallia was one very much larger than the others which had very large numbers of old archegonia. It is highly probable that this represents a second species, but unfortunately there was no means of determining to which of the two or three forms associated under the name $O$. moluccanum it belonged.

The cells of the tuber and the lower part of the branch contain the characteristic endophytic fungus, but the greater part of the fertile branch is quite free from this, and the cells appear almost transparent, but they contain numerous small starch granules. The endophyte is much more abundant in the cells of the tuber. The hyphx, which stain readily with gentian violet, are irregular in outline and branch freely. Very often branches can be seen piercing the walls of adjacent cells.

In the living condition the pointed apex of the prothallium is pure white, and even with a hand lens the projection of the antheridia is clearly evident. Mettenius noticed this "varicose" appearance of the smaller prothallia in $O$. pedunculosum. A median section of the branch shows that the end is decidedly pointed and has a clearly defined apical cell. Owing to the very small amount of material available, no satisfactory transverse section of the apex could be made, and it can not be told whether the apical cell in transverse section is three-sided, as described by Bruchmann for $O$. vulgatum, or is four-sided, as it is in $O$. pendulum. In the smaller specimens antheridia were more numerous than archegonia, although several of the latter were present. The antheridia arise, in general, in acropetal succession, but it is not unlikely that secondary ones may be formed also. The archegonia are scattered among the antheridia apparently without any definite order. In some specimens, especially in the larger ones, the old archegonia were found in great numbers, many more than the antheridia. In other specimens a considerable part of the prothallium was quite destitute of either archegonia or antheridia, and in this respect the prothallium of $O$. moluccanum differs from that of $O$. pedunculosum or $O$. vulgatum. 


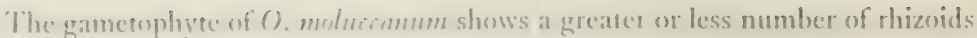
berh at the hase asod along the fierte branch (plate 1, fig. 10). In the more slender forms, lowever, these thiends are few. They are in some cases twe-celled, but more commonly consist of a single elongated cell. It is mot unusual to find with this the penctrating filament of the mycorthiza, as has been described for other species of () phioglossum. The rhizoids are much longer relatively than in (). pendulum. Accorling to Bruchmann, the thizoids are quite absent from the prothallia of $O$. enlgutum.

Metenius states that in $O$. pedunculosum the prothallia of fen appear above the surface of the earth, and they then become somewhat Hattened and sometimes divided into several small lobes, and in such cases chlorophyll is developed. Mettenius, hewever, does not note any further development of these green lobes. Bruchmann found that chlorophyll might also develop in 0 . vulgatum, when the prothallia were exposed to the light, but he did not find any thattening of the apex. Owing to the very small number of growing prothallia found by me, I could not rest the power of developing chlorophyll in 0 . moluccanum, but the occurrence of chromatophores in the germinating spores makes it highly probable that chlorophyll may be developed in the older prothallia under the stimulus of light.
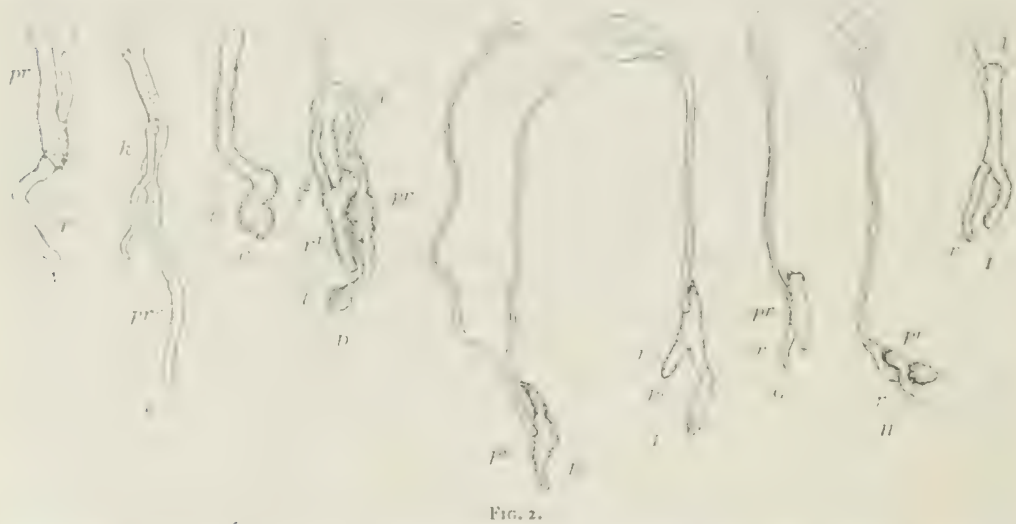

Gamefophtyes, fr, and young sporophytes of Ophioglossum moluccanum and allied species, slightly enlarged. C and E from IJakgala, Ceylon; the others from Buitenzorg, Jara; $k$, bud on primary root; $l$, primary leaf; $l^{2}$, wecondary leafi $l$, tuberou enlargement at hase of gametophyte.

The small size of the prothallium in 0 . moluccanum and the cessation of growth after the sporophyte is formed indicate that the gametophyte lives only for one season, and this is probably the case also in Helminthostachys. In this respect $O$. moluccamum and its allies differ markedly from $O$. pendulum and $O$. vulgatum, where the gametophyte lives for many years.

At Hakgala, in Ceylon, an undetermined species of Ophioglossum of the rype of $O$. reticulatum is common. After careful search, a few prothallia which closely resembled those of $O$. moluccanum were collected (fig. $2, C, F$ ). The material was toc scanty to make a detailed study possible, but from the external appearance it is likely that the structural details would closely resemble those of $O$. moluccumum.

The prothallium of Oplioglossum sulgatum, according to Bruchmann (Bruchmann 1), closely resembles that of $O$. molucomum, but is very much larger, sometimes reaching a length of 6 centimeters, and it is not infrequently branched 
(fig $3, C$ ). There is a more or less conspicuous basal tuber, like that found in $O$. moluccanum, and from this extends a branch bearing the reproductive organs; but, unlike the prothallium of $O$. moluccanum, there seems to be a complete absence of rhizoids. In general, the form is more irregular than that of $O$. moluccanum and moreover it is very longlived. The branches may become detached and thus form new individuals. From the rate of growth in specimens kept under observation for several months, Bruchmann concluded that they

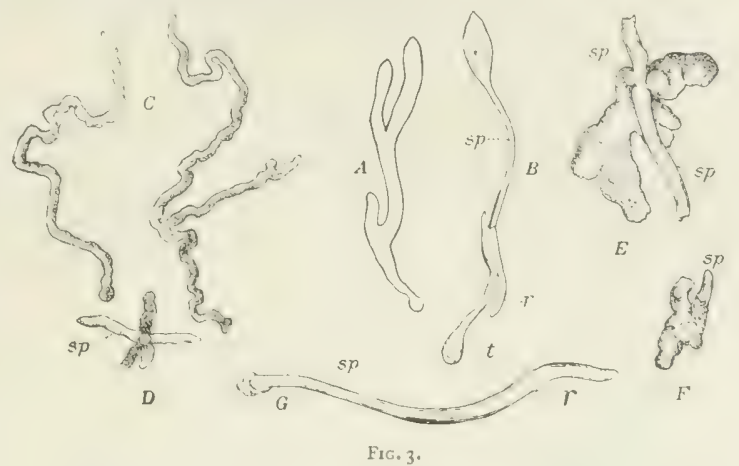

A, B. Gametophytes of Ophioglossum pedunculasum (after Mettenius). C, D. Gametophytes of O.vulgatum (after Bruchmann).

E-G. Gametophytes of $O$. pendulum. sp, young sporophyte; $r$, secondary root. might live for twenty years or more. Where the apical growth of a branch is interfered with, there may be a formation of adventitious buds, a phenomenon which is also common in $O$. pendulum.

Ophioglossum (Ophioderma) pendulum, a remarkable epiphytic species widespread through the tropics of the Old World and reaching to Hawaii, is the giant of the order, the pendent ribbon-shaped leaves sometimes attaining a length of I. 5 meters. The sporophyte grows rooted in masses of humus, either upon the rough trunk of a tree fern or palm, or hanging from the mass of humus accumulated about the base of certain epiphytic ferns. The bird's-nest fern, Asplenium midus, furnishes the favorite substratum for this species in the forest of Tjibodas in Java, where my material was collected.

The young prothallium in $O$. pendulum is an ovoid body, the somewhat smaller forward portion corresponding to the fertile branch in $O$. moluccanum (see Lang 1 , page 25). The older ones become very much larger than in any other species that has been described, and they branch freely in all directions, except as their growth is controlled by their position. They are always found buried in a mass of humus between the imbricated leaf bases of the fern, and are often much Hattened by the pressure of the leaves between which they are confined. Branches extend in all directions, but their growth is to some extent controlled by the inclosing leaf bases and also by the tangled mass of roots of the fern, which grow in all directions through the mass of humus and among which the branches of the prothallium of the Oplitoglossum extend. In one instance several hundred were collected from one large plant of Asplenium nidus. The prothallia closely resemble Lang's figures and descriptions, but in many cases are very much larger and more extensively branched than any of the specimens collected by him in Ceylon (plate 1 , figs. II-If). The larger prothallia may be stellate in form, but they are usually very irregular. The branches penetrate in all directions between the dense tangle of roots which the Asplenium sends into the humus between its persistent leaf bases, and on pulling these back a mass of fine humus is found, held together by the mat of roots so that it can be removed intact. The prothallia are excessively brittle, and it is practically impossible to remove the larger ones without a loss of some of the numerous branches. 
These heak off at que least enuch, and no doubt serve to propagate the gametopligte, which is apparencly eapable of unlinited growth in this way. It is often impossible (1) say whether the smaller gametophytes that are found louse in the humus are anything more than branches which have become spontancously separated from qhe larger prothallia.

The older parts of the gametophyte are dark brown in color, but the tips of the branches are white, as, in the other species. 'The branching, as we have seen, may' be very irregular, and old fragments kept moist often send out great numbers of adventitious buds (plate 1 , fig. $\mathrm{II}$ ) which apparently in time develop into normal prothallia. A number of the commoner forms are shown in the figures. Plate 1 , fig. If represents the largest one met with. 'This is by no means complete, as a
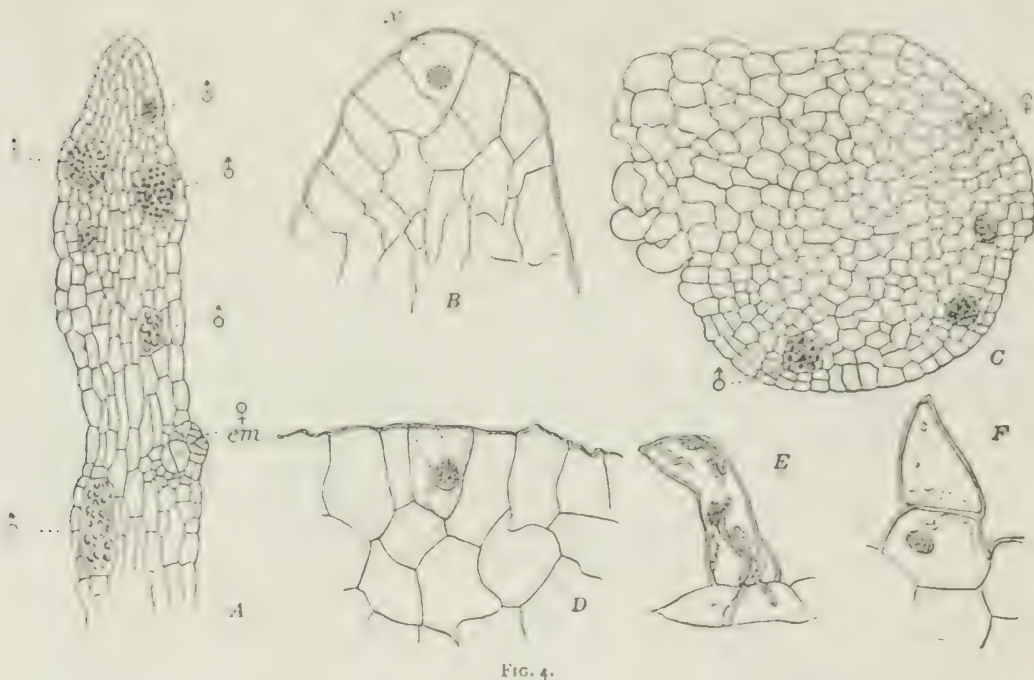

A. Longitudinal section of aper of gametophyte of Ophioglossam moluccanum. ô antheridia; $f$ arehegonia; em, two-celled embryo.

B. Apex more highly magnified, showing apical cell, $x$.

C. Transverse section of a branch of the gametophyte of 0 phioglossum pendulum.

D. Apical cell of same.

E, F. Short hairs from gametophyte of $O$. pendulum; in $\mathrm{E}$ may be seen the endophytic fungus filaments.

number of branches were unavoidably broken off in removing it from among the tangle of roots in which it was embedded. 'This specimen measured about is millimeters in diameter-more than twice the size of the largest specimen secured by Lang. The surface of the older parts of the prothallium shows a slightly roughened appearance due to the numerous very short papillate hairs which occur upon it. These are never of the slender form found in $O$. moluccamum and perhaps are not properly to be considered as rhizoids. Dotted over the surface are pale brown spots, easily seen with the naked eye, and these on examination are found to be the large, empty' antheridia. 'The branching is sometimes dichotomous, but lateral branches may arise at almost any point, and old fragments of the prothallia, as already indicated, often develop many adventitious buds, a condition of things which apparently obtains also in the long-lived prothallia of $O$. evulgatum. The rate of growth of prothallia kept by the writer for more than a year, as well as their 
position in the humus about the plant, where they are found in the older parts between leaves which must have been dead for many years, indicate that they are very long-lived and, as we have seen, by the ready separation of the branches they are easily propagated.

\section{THE HISTOLOGY OF THE GAMETOPHYTE.}

The younger portions of the growing branches are composed of thin-walled, colorless parenchyma, whose cells have a conspicuous nucleus, and usually numerous small starch granules. In the older portions of the gametophyte the tissue becomes infected with the often-described endophytic fungus. Practically all of the cells of the basal tuber are thus infested, but in the fertile branches the central tissue is usually free from the fungus, and this medulla-like central tissue is surrounded by a more or less definite mantle of cells, in which the endophyte is especially luxuriant. The outermost cells are practically free from fungus, although new infections probably may take place there through these outer cells. In $O$. moluccanum the endophyte is much less developed than in $O$. pendulum, this no doubt being correlated with the much briefer duration of the gametophyte in the former species. According to Bruchmann, the endophyte is strongly developed also in $O$. vulgatum. The endophyte, as in the other forms that have been studied, is quite absent from the apical region of the branches. The limits of the infested zone are not very clearly marked and any cell of the older tissue of the gametophyte may harbor the fungus.

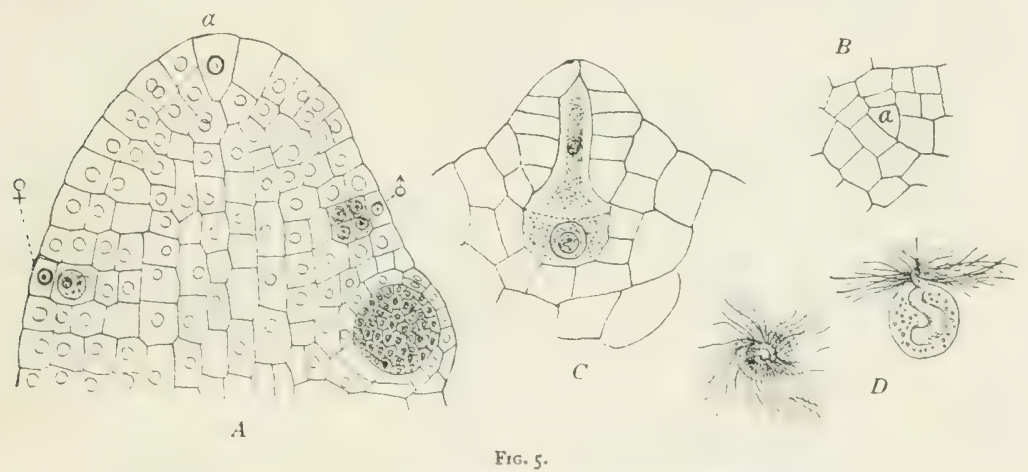

A. Longitudinal section of gametophyte apex of Ophroglossum vulgatum. X150.

B. Transverse section of gametophyte apex. $a$, the ap̧ical cell.

C. Arcbegonium. $\times 225$.

D. Two free spermatozoids. $\times 550$. (All figures after Bruchmann.)

The apical cell in O. pendulum is usually a four-sided pyramid, and not tetrahedral, as it is in $O$. vulgatum. In longitudinal section (fig. $4, D$ ), the apical cell appears triangular with a fairly regular segmentation, but there is also active division in the adjacent tissue and apparently the segmentation of the apical cell is not very rapid. Cross-sections show the apical cell to be approximately four-sided (fig. $16, A$ ), but the sides are not always of equal length and sometimes it is almost triangular in outline; possibly it may be that in some cases, as in $O$. vulgatum, it is tetrahedral. There seems to be no absolute rule, however, as to the succession of divisions in the young segments. A more or less definite superficial layer arises from the first periclinal divisions, but anticlinals follow rapidly. 


\section{IIII: (}

Ilofmeister (Ifofmeister 1), in his studies of else Archegoniates, has included Bofrychum lonaria, whose prothallium he discovered in 1854 . No fusther contrihutions to ong knowledge of the subject are recorded until 1893 , when the writer diseovered at Cirosse Ile, Michigan, a number of sld prothallia of B. virginionum, with the young spotophytes attached. The earliest germination stages of this species were also secured. In 1895 , l'rof. L. C. Jeffrey collected at several points in Canada a large number of prothallia of this species, and his accoune (Jetfiey 1) is much the most satisfactory one which had appeared up to that time. In the spring of 1903 Lyon ( I yon I) discovered prothallia of B. obliquum in Minnesota, and the following vear secured a few specimens of $B$. simplex and $B$. matricaricfolium, but he has only published a brief note in regard to these species. He states that the reproductive organs in B. obliquum "differ essentially from those of B. virginiunum," but he does not explain in what these differences consist. Bruchmam, who has added so much to our knowledge of the gametophyte of the European Lycopodiaceie and Ophioglossacese, has recendy given. a very satisfactory account of the prothallium and embryo of B. lunaria, which he found in various parts of Germany and Switzerland. Ile corrected certain errors made by Hofmeister in his account of the same species. (Bruchmann 2.)
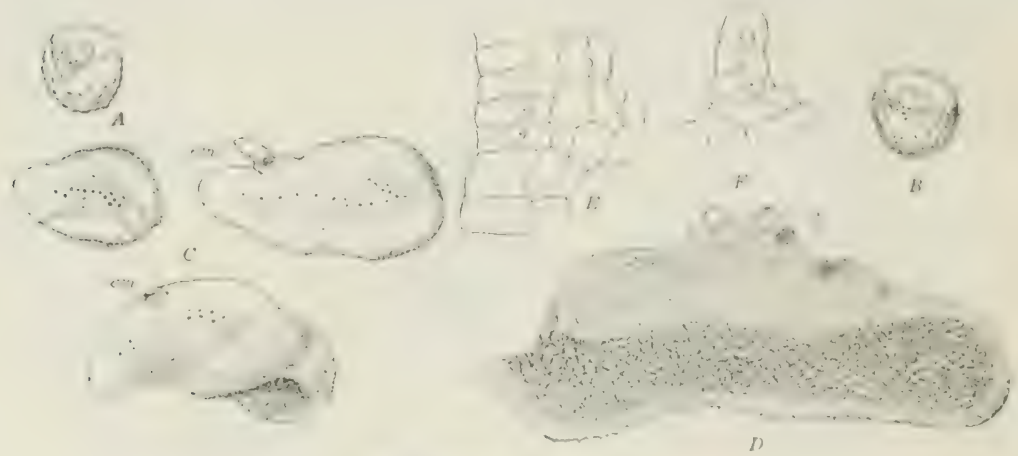

Fic. 6. - Botrultium zirginianum.

A, B. Germinating spore (B, optical section).

C. Three gamctoplunes, $X_{3} ; \mathrm{cm}, \mathrm{cmbryo}$.

D. Scetion of gamctophyte, $X_{12}$; the shaded region is that accupical by the endoplyte. S antheridia.

E. Apical recion of pamctophyte, $\times 150$.

F. Short multicellular hair or paraphysis.

Owing to the kindness of Professor Teffrey, a large number of prothallia and voung sporophytes of $B$. virginianum, together with several slides showing the sexual organs and embryos, were put at my disposal. This has made it possible for me to make a very satisfactory study of the reproductive organs and embryo in this species.

The spores of Botrychium, like those of Ophioglossum, are of the tetrahedral wpe and are quite colorless, their contents showing the usual granular appearance, but without any trace of chlorophyll. The early stages of gemination are exactly like those of Ophioglossum, the first division wall being transverse, this being then followed by a second wall in the inner cell at right angles to the primary wall (fig. 6 , $A, B)$. A few chloroplasts were seen in some of the cells, but this does not seem to be a constant character and perhaps was an abnormality due to the spores having 
germinated in the light. Bruchmann (Bruchmann 2, page 207) also found the earliest stages in B. lunaria, and these corresponded exactly to those in $B$. virginianum.

The gametophyte of $B$. virginianum is a large, tuber-like body, which grows at a depth of about 10 centimeters below the surface of the earth. The smallest of the specimens found by Jeffrey were 2 millimeters in length by 1.5 millimeters in breadth, exceeding in size the fully developed prothallia of B. lunaria. The older ones may reach a length of 20 millimeters. The young prothallia are quite smoothly oval in outline (fig. 6, C), while the older ones are more or less

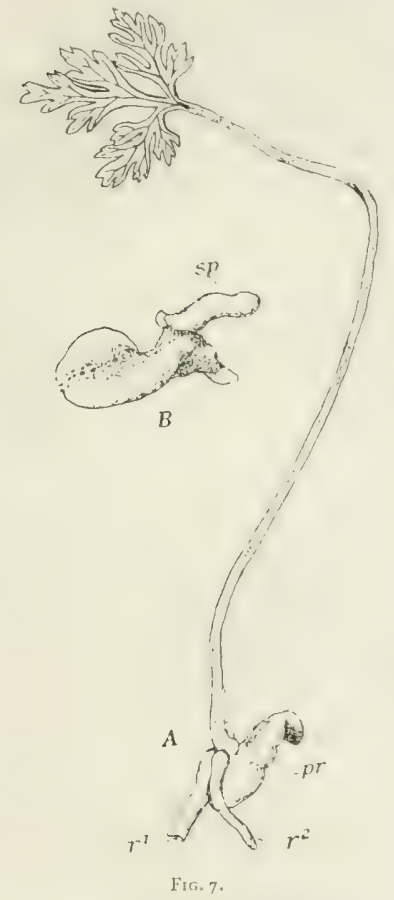

A. Young sporophyte of Botrychium virginianum attached to gametophyte, fr. $X_{2}$.

B. A gametophyte with small sporophyte, $s p$. $x_{4}$.
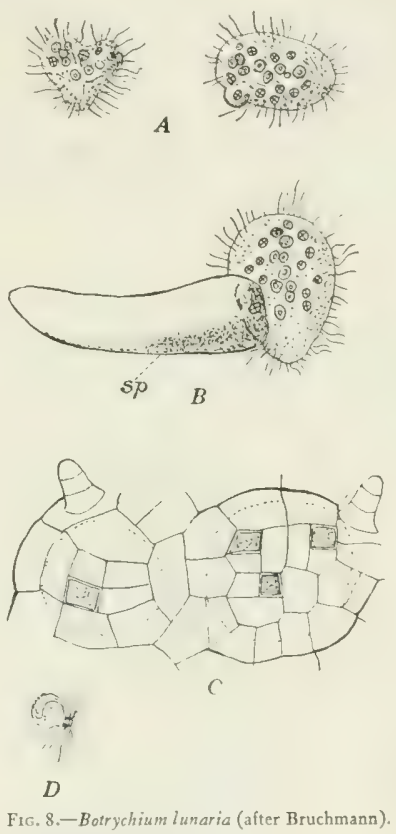

A. Two young gametophytes.

B. An older one, with sporophyte, sp, attached. $\times 16$.

C. Surface view of two antheridia, showing opercular cells (shaded). $\times 100$.

D. A spermatozoid. $\times 500$.

irregular, and occasionally the anterior end is divided into two equal lobes, probably as a result of dichotomy. As in Ophioglossum, the older parts of the gametophyte are brownish in color, while the young apex appears white. In their earlier stages they are covered with numerous rhizoids, which disappear more or less completely as the prothallium becomes older. The forward end is slightly pointed and there is a definite growing point. The antheridia make their appearance first, and together with the archegonia are formed only upon the upper surface of the dorsiventral thallus, which is noticeably different in form from the cylindrical radially constructed prothallium of Ophioglossum. 
The aneherdia form a more or less evident row, even in the very goung prothallium, and later this median row of antheridia is raised upon an elevared ridge, upen whose sides the archegonia later make their appearance (fig. $6, /$ )).

The ganetophrte of $B$. Innaria closely resembles the early stages of $B$. sirginianum. It is very much smaller and rarely exceeds a length of 2 millimeters, and, like the foung stages in $B$. virginionum, it is covered with many long rhizoids (hig. $8, .1, B$.) The smaller prothallia are globular or oval in shape; the larger ones somewhat heart-shaped. Iofmeister states that the antheridia occur upon the upper surface and the archegonia below; but Bruchmann found that both archegonia and antheridia were confined to the upper surface, as in 13 . virginimum. As in the latter, also, the dorsal ridge is present, bearing the antheridia upon its crest and the archegonia upon its Hanks.

The large prothallia of $B$. virginianum live for many years, and Jeffrey even found a plant bearing spores, which was still connected with a prothallium. It is probable that the very much smaller prothallia of $B$. Imaria have a shorter duration, but in this species also the prothallium persists for some time after the young sporophyte is established.

\section{THF. HISTOH,(Y OF THE GAMETOHHTE, ()F BOTRYCHLY.}

In $B$. virginianum the forward part of the prothallium is made up of colorless tissue, which extends for some distance beyond the youngest antheridia. The apical meristem in this species (fig. $6, E$ ) lies on the upper side of the prothallium; in a vertical longitudinal section it shows a group of columnar cells, one of which is

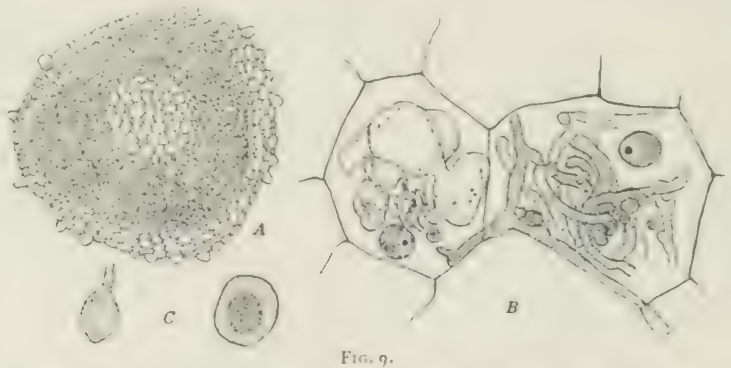

A. Transterse section of a gamctophvte of Opliomlossmm pendulum, shonwing position of endophytic fungus. $\times 20$. The shaded region is occupied by the endophyte.

13. Endophyte from prothallium of Bosrychium virginianum.

C. Sporancium-like enlargements of endophyte.

probably the apical cell; but this is not absolutely certain. In B. Iunaria (see Bruchmann 2, page 209) the apical meristem occupies the middle region of the anterior surface of the prothallium, and is of very limited extent. As in B. virginianum, its cells appear columnar in form, but neither in longitudinal section nor in a surface view could a single initial cell be recognized.

The rhizoids in $B$. sirginianum are from 1 to + millimeters in length and may be multicellular, especially those which arise from the crest and Hanks of the prothallium, while those which originate from the base are unicellular and longer than these multicellular ones. It is not unlikely that these multicellular structures are rather of the nature of paraphyses than true rhizoids. In B. Iunaria the rhizoids seem to be, usually at least, unicellular. In both species the rhizoids soon turn brown and their walls become strongly cutinized. Both Jeffrey and Bruchmann 
observed the penetration of fungus hyphre into the rhizoids, and they believe that the fungus which occurs within the thallus is, mainly at least, due to this method of infection. From a comparison with the early infection of the young prothallium in Ophioglossum, it seems to me more probable that the young prothallium in Botrychium also is infected at a very early period and that the endophyte, once established within its tissues, grows with the development of the gametophyte, the secondary infection through the rhizoids of the older gametophyte being of minor importance.

In both species of Botrychium the infected region comprises the greater part of the central tissue, leaving only a comparatively narrow peripheral region free from the endophyte. This uninfected area is thicker upon the upper surface and comprises the whole of the meristematic region, together with the developing sexual organs. As in Ophioglossum, this uninfected tissue contains small starch granules in considerable numbers, but not much else in the way of granular contents. The invasion of the fungus results in the destruction of the starch and the accumulation of large amounts of oil. This oil, according to Jeffrey, is not readily soluble in alcohol, and the cells containing it, both in fresh and stained sections, appear darkcolored.

\section{THE GAMETOPHYTE OF HELMINTHOSTACHYS.}

The monotypic Helminthostachys zeylanica is not uncommon throughout the lowlands of the Indo-Malayan region and often occurs in large numbers. The only account yet published of the gametophyte is that of Lang (Lang 1). The prothallia which he describes were collected in part by himself in the Barrawa Reserve Forest in Ceylon in March Igo $\mathrm{I}$. Other material studied by Lang was collected at the same place by Mr. Coomara Swamy. I made a visit to the same locality in February I go6, and also found a considerable number of prothallia, but all of these had been fertilized and had attached to them the young sporophyte, so that no young reproductive organs were found. The forest where they were collected is subject to inundation from a river which runs through it, and it was in the parts that had been overflowed that the young plants were discovered. This makes it not unlikely that, as in the case of Ophioglossum moluccanum, germination is favored by having the spores immersed in water, and this may be a necessary condition for the first stages of germination.

A quantity of ripe spores were collected and various attempts were made to germinate these, but without success, and, as none of the specimens obtained by Lang were very young, the early history of the prothallium still remains to be investigated.

As in the other Ophioglossacea, the prothallia are subterranean, occurring at a depth of from 5 to 6 centimeters in the earth. In form (figs. IO, II) they are somewhat intermediate between Botrychium and Ophioglossum, but are on the whole more like the latter. They are somewhat irregular in outline, with a broad base, recalling the basal tuber of $O$. moluccanum, but this tuber is relatively larger and more lobed. From this basal tuberous portion a short upright branch extends, much as in Ophioglossum moluccanum, but it is relatively thicker and shorter. The whole gametophyte is radial in structure, as in Ophioglossum, and thus differs strikingly from the dorsiventral gametophyte of Botrychium. The basal enlarged portion is brown in color and covered with rhizoids, which are mostly absent from the upper, more slender part upon which the reproductive organs are borne.

Lang found that there is a tendency to dicecism in the prothallia, some producing only antheridia (figure $11, A$ ), while in others archegonia predominate, 
altheugh in she lateer a few amferidia are almost always developed hefore the arehe-

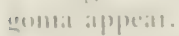

In the make puothallium the hasal "vegetative" portion is relatively small

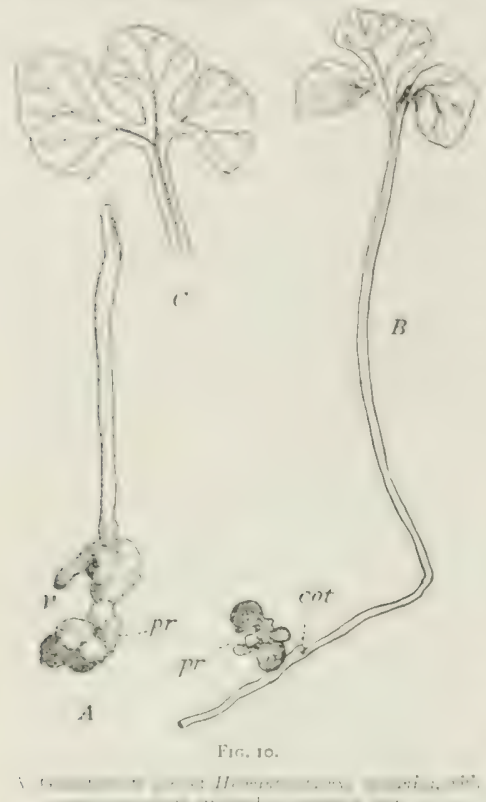

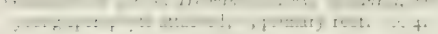
B. An cilder spormpliyte, wirh fully-develoged second leaf. ג2. cot, rudimentary cotyledon.

Voung second leal, showing renation. $\times 5$. and offen is irregularly lohed, these lobes being not of the nature of true branches, bue merely the result of une gasal groweh. The female gametophyte (fig. 10) has the basal region relatively larger and is cven more irregular in form than the male. while the fertile region is shorter and wider. Some of the more elongated types of the male gamotophyte are guite similar to the simple prothallium of (ophioglossum molucommom. As in the other genera, the endophytic fungus is always present and occupies much the same position as in Botryelsium.

Lang found that the groweth is due to the activity of a single apical cell having the form of a four-sided pyramid, much like that found in Ophioglossum pendulum. The lateral segments divide by periclinal walls, and from the superficial cells thus formed originates the layer of tissue from which the sexual organs arise. The inner cells contribute to the axial tissue of the gametophyte. The antheridia in the male plants are evenly distributed about the periphery, so that in cuss-section they form a nearly uniform circle. The axial tissue, especially in the male prothallium, has the cells much elongated, and Lang thinks they are useful in the conduction of plastic material from the basal region of the prothallium to the growing point.

The outer part of the basal region consists of two or three layers of somewhat Hattened cells, which, like the corresponding tissue in Botrychum, are free from the endophyte. From some of these superficial cells there are developed unicellular, chongated thizoids, with markedly cutinized walls. This cutinization extends to the outer walls of the superficial cells, while the inner walls of these cells, as well as those of the inner tissue, show the cellulose reaction. The formation of the lobes of the basal region are due, not to definite apical growth, but to irregular cell divisions in the outer layers, which remain free from the fungus which occupies the erreater part of the central region of the lobes, as well as the axis of the main shoot of the prothallium.

The central tissue is made up of about equal parts of infected and uninfected cells. The latrer, as in the other cases investigated, contain starch granules which are absent from the cells harboring the fungus. Fungus hypha were seen in many cases to penetrate the rhizoids, but it is highly probable that in Helminthostachys also there is a primary infection at an early stage in the germination of the spores.

Lang notes that in the older male prothallia the fungus is dead and the further growth of the prothallium is dependent upon the amount of reserve food (mainly 
starch) which is left in the cells. It is not clear what rôle the endophyte plays in the manufacture of the reserve food materials upon which the further growth of the prothallium depends. It is highly probable, however, that some of the necessary organic elements are derived from the destruction of the fungus tissues which serve as food for the further development of the prothallium. While no data are at hand to prove this, the lack of permanent growing tissue in the prothallium and the complete destruction of the fungus make it highly probable that the life of the gametophyte in Helminthostachys is restricted to a single season, as it is in Ophioglossum moluccanum.

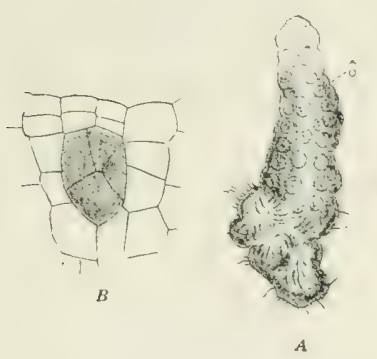

A

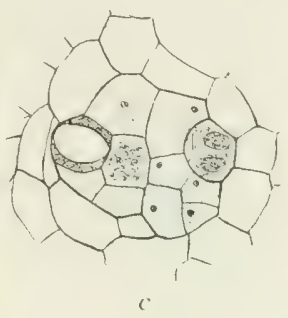

FiG. I1.

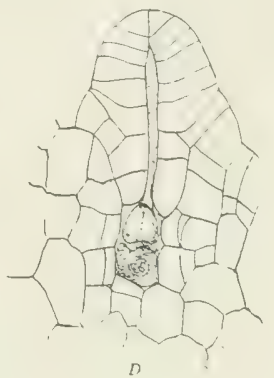

A. Male gametophyte of Helminthostachys. X\$. C. Surface view of ripe antheridium, showing opercular cells.

B. Young antheridium. $\times 225$.

(Figs. A-C, after Lang.)

THE ENDOPHYTE.

The endophytic fungus which inhabits the gametophyte in all of the Ophioglossacex is very much alike in all of the species, differing only slightly in size in different forms (fig. 9). A special study was made of this endophyte in Ophioglossum pendulum, where it is especially well developed. As we have already seen, the endophyte is absent from the younger parts of the prothallium, but in the older parts it is exceedingly conspicuous. Sometimes fragments of a fungus are found outside the prothallium, growing in the humus, and these are evidently the same forms that infect the very young prothallium when it arises from the germinating spores. These external hyphe in some cases have an occasional septum, and this is also the case in those forms which infect the young prothallium. In all of the hyphre seen within the prothallium, however, these septa seem quite absent. The infection of the prothallium through the rhizoids has been noted in all the species, but, as we have already stated, it is probable that the endophyte is derived mainly from the first infection of the very young gametophyte. An examination of the young cells before the entrance of the fungus shows a conspicuous nucleus and numerous starch grains, which stain very strongly with gentian violet. The invading mycelium, whether from the outside of the prothallium or from the adjacent cells, penetrates the cell wall and ramifies within the cell, the growth being entirely intracellular. The hyphe are noticeably thicker than those of the external mycorrhiza.

The endophyte is perfectly fixed with I per cent chromic acid and it stains well with the double stain of gentian violet and safranine, the walls assuming a violet color and the numerous nuclei staining deep red. In the younger hypha, which are of varying sizes, the protoplasm is densely granular, but in the older ones 
the gramular appearance disappears to a considerable extent, thengh the nuclei concinue $t$ stain serongly. The fungus is quite variable in form. Sometimes the filaments are nearly straight, running from cell to cell and branching sparingly. Somerimes a cell is complesely filled wish a dense tangle of hyphe, while in other cases there are sack-like vesicles of very irregular form. Not infrecpuently, quite regular, neasly globular hodies are seen, recalling the ouggonia of the Peronosporeac. These at first contain comparatively few nucled, scattered through the granular cyroplasm, but in the older ones the muclei are very mumerous and decidedly larger. lit looks sometimes as if this were a preparation for the formation of spores, but no certain evidence of the formation of such spores could be seen, although in several instances there was an appearance which might point to this. Structures resembling the "conidia," described by Jeftrey for Botrychium (Jeftrey 1, page 12), were seen and are probably the same thing.

As the fungus invades the young cells, irregular, strongly-staining clumps are formed by the aggregation and breaking down of the starch grains. The nucleus of the host cell appears to be but slightly affected by the growth of the fungus, and can usually be found quite unchanged, even in those cells which are almost completely filled by the endophyte. Finally, the thin-walled vesicular growths of the fungus are quite broken down and probably serve to nourish the cells of the gametophyte, which is thus parasitic upon the cells of the fungus. The systematic position of the fungus is doubtful. The varicose, swollen hyphe found at certain stages closely resemble a parasitic fungus, Completoria complens, which is sometimes extremely destructive to green fern prothallia. The oögonium-like organs, often present, suggest Pythium, a parasitic fungus belonging to the P'eronosporex. Jeffrey (Jeffrey 1, page 13) thinks the endophyte may fairly be regarded as an intermediate form between the two genera, Completoria and Pythium, and says that in this case Completoria should be placed in the Peronosporex instead of in the lintomophthorex, where it has been placed by some students of the Fungi.

\section{THE, SENUAL, ORGANS.}

THE. ANTHERIIIIM

The antheridium in all of the Ophioglossacere is of much the same type and closely resembles that of the Marattiacese and also Equisetum and Lycopodium. The mother cell does not project at all above the level of the adjacent tissue, and in all cases the first division separates a superficial or cover cell from an inner one, the latter by further divisions giving rise to a mass of sperm cells which may be very numerous. The cover cell also divides, sometimes only in one plan, sometimes (e. g., in Botrychium) having also periclinal divisions. At maturity the antheridium may project more or less strongly, but this is not always the case.

\section{THE ANTHERIDIT OF OPHIOGY,OSSTM}

The antheridium was first described by Mettenius in Ophioglossum pedunculosum, and later Lang described it for $O$. pendulum and Bruchmann for (). vulgatum. The present account is based mainly upon my own studies of $O$. moluccanum and (). pondulum.

The mother cell of the antheridium, which may arise very close to the growing point of the prothallium, lies flush with the neighboring cells, but later it may become more or less elevated above the surface, forming a prominence which, in slender prothallia, like those of ()phioglossum moluccanum, may give an irregular undulate outline to the branch which bears them (fig. fo $d$ ). In $O$. pendulum 
this projection is less marked, although this may be somewhat decided in the ripe antheridium. The first division in the inner cell is usually vertical, but may be transverse, at least in $O$. pendulum (fig. 13, A). The second walls intersect the first at right angles, and there are always four nearly equal inner cells resulting (fig. $13, D$ ). The third set of walls is vertical, and the next, in some cases at least, is in the same direction. This is not true, however, of the deeper and narrower type of antheridium. Further divisions occur until the number of spermatocytes is very large. The fully developed mass of spermatocytes is plainly visible to the naked eye, and in $O$. pendulum may reach a diameter of more than $325 \mu .250$ cells and upward may be counted in a single section of a large antheridium, and this would mean that there are several thousand in the whole antheridium-perhaps more than in any other Pteridophyte. In O. moluccanum (fig. 12), the number of spermatocytes is much smaller, while in this regard the antheridium of $O$. vulgatum appears to be intermediate between that of $O$. moluccanum and $O$. pendulum.

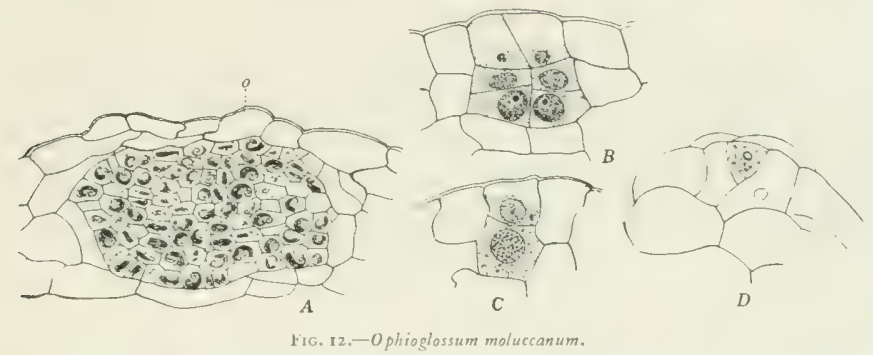

A. Ripe antheridium. $\times 180$.

B, C. Young antheridia. $\times 320$.

D. Surface view of antheridium, showing opercular cell.

The nuclei of the young cells show a conspicuous nucleolus, which becomes less marked in the later stages of the antheridium. According to Mettenius, the outer wall of the antheridium in 0 . pedunculosum is composed of two layers of cells; but both Lang and Bruchmann found that the central part of this outer wall of the

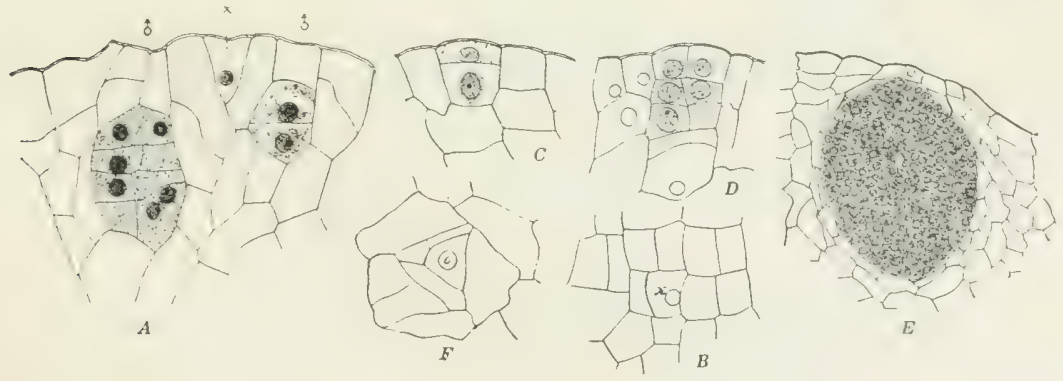

Fic. 13. -Development of the antheridium in Oplioglossum pendulum.

A. Median section of gametophyte, apex, showing apical cell, $x$, and two young antherilia, $\hat{\theta} . \times 175$.

B. Transwerse section of apex; $x$, apical cell.

C. D. Median sections of young antheridia.

E. Median section of a nearly ripe antheridium.

F. Surface view of ripe antheridium; 0 , opercular cell. 
anderidium is but one cell in thickness, and I have veribed this for hoth of the species under consideration.

The first wall on be formed in the cover cell is a nearly median one and vertical (fig. 12, B), and this is followed by a second wall which intersects it, as well as one of the lateral walls of the primary cover cell, so as to include a neasly triangular cell. In this triangular eell there are later formed, as both Bruchmann and Lang showed, a varying mumber of segments arranged spirally in the fashion of the segments of a three-sided apical cell (fig. 13, F). The same thing occurs in Lycopedium (Treub I). I have also found a similar condition in the antheridium both of the Marattiaceate and of Equisetum. The last-formed triangular cell is the opercular cell (fig. $13, F, 0$ ). firom the prothallial tissue which adjoins the sperm cells are cut off Hattened cells which surround the sperm cells with a more or less definite layer of "mantle" cells. "The limits of the original cover cell are usually plainly visible in both longitudinal and surface sections.

THE ANTHERLIUM OF BOTRLCHIUM,

The antheridia in Botrychium occur only upon the dorsal surface of the gam. etophyte, which is always monocious. 'The first antheridia in B. virginianum (see Jeffrey 1, page 8), form a small cluster which is not noticeably raised above the general level of the prothallium, and from this primary cluster extends a single median line of antheridia toward the apex of the gametophyte. Later this median region becomes raised and forms a conspicuous ridge along whose crest the antheridia are borne. In $B$. Iunaria, according to Bruchmann, the arrangement is much the same.

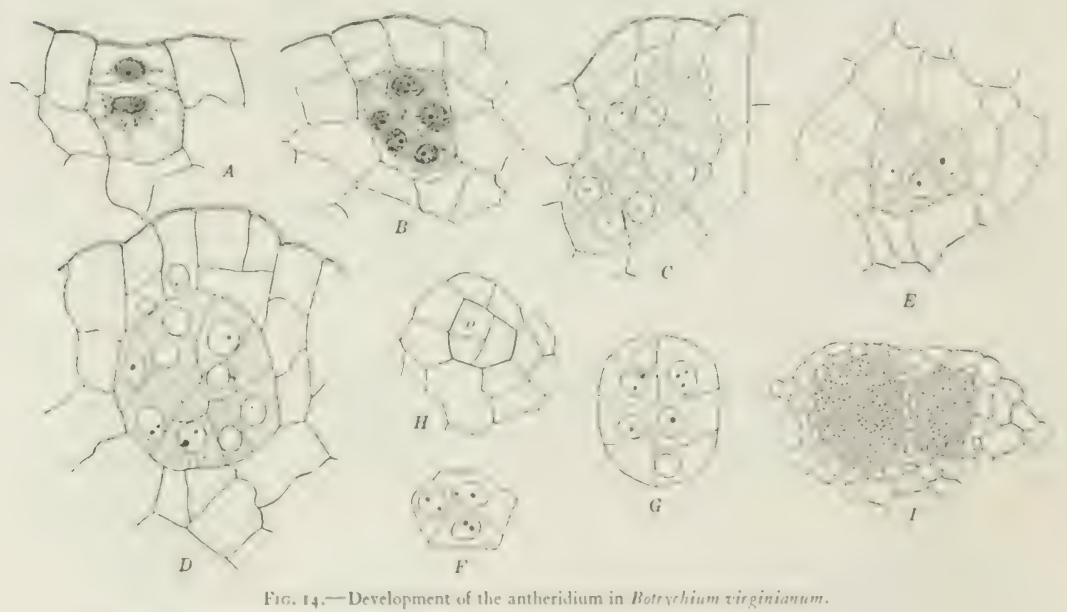

A-1). 1.ongitudinal sections of young antheridia. $\times 320$.

E-H. Transierse sections. F, G show only the young spermatucyles. H, surface view sluwing opercular cell, o, I, section of two ripe antherillia. X Xo.

The development of the antheridium is very much like that of Ophioglossum. The first division, as in the latter, is a periclinal one, separating the primary cover eell from the mother cell of the spermatocytes. The divisions in the cover cell, however, differ somewhat from those in Ophoglossum, in that periclinal walls 
are formed in some of these, so that the cover becomes to some extent double. Jeffrey states that the cover is two layers throughout, but Bruchmann found that some of the cells - two and sometimes three-remain undivided and that one of these undivided cells functions as the opercular cell. I have examined this point carefully in Botrychium virginianum and find that there is an opercular cell in this species also. The division walls in the primary cover cell usually intersect at right angles, so that the opercular cell is four-sided, instead of triangular, as in Ophioglossum (fig. 14, $H$ ); but exceptionally it may have the triangular form. In the dehiscence of the antheridium only a single opercular cell is destroyed, not two superimposed cells, as Jeffrey supposed to be the case.

The divisions in the central cell are very much the same as in Ophioglossum. Whether the first division is regularly transverse or vertical could not be determined, as no examples of the first division were found. The earliest stages seen after the first separation of the cover cell had four inner cells arranged quadrant-wise, but it was not clear which was the primary wall. The quadrant division is, usually at least, followed by an octant division, and these early divisions may sometimes be recognized for a long while, as there is not much displacement of the cells due to the subsequent divisions. In the later stages the primary divisions can no longer be made out clearly. The number of sperm cells finally formed may be very largemore than a thousand in the largest antheridia-- thus nearly or quite equaling the number found in Ophioglossum pendulum, although the sperm cells are very much less in size than in the latter and the antheridium correspondingly smaller. Sometimes the antheridium is divided into irregular chambers, apparently due to the persistence of some of the early division walls (fig. I5, B).
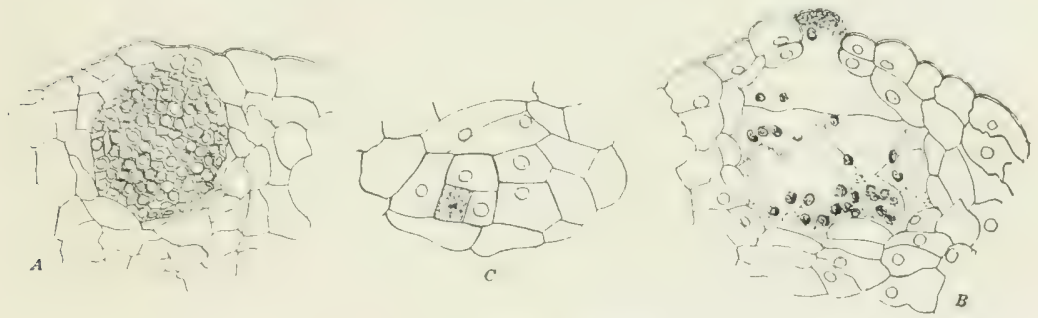

Fic. 15.-Botrychism virginianum.

A. Longitudinal section of a nearly ripe, but rather small, antheridium, $X$ about 200 .

B. Section of a ripe antheridium which has discharged the spermatozoids; some cell-1valls have remained, forming irregular chambers, and retaining some of the spermatozoids.

C. A surface view of a ripe antheridium, showing square opercular cell.

The antheridium of $B$. lunaria, according to Bruchmann, is smaller than that of $B$. virginianum, but the size of the spermatocytes and spermatozoids seems to be about the same (fig. $8, D$ ).

THE ANTHERIDIUM OE HELMINTHOSTACHYS.

The antheridium of Helminthostachys has been studied by Lang, and it is evident from his account that it resembles that of Botrychium much more than it does that of Ophioglossum. As in the former, the primary cover cell undergoes periclinal divisions as well as anticlinal ones, but there are from two to four cells which do not divide by periclinal walls, and one of these cells becomes the opercular cell (fig. I I, $C$ ). These four undivided cells stain more strongly than the other cells of the cover, but only one of them is broken down at the time of dehiscence. These 
colls, as in the case of Boprofimm lunario, are nearly square in outline, most of the walls in the cower cells being at right angles to each other, as in Botrychium.

The divisions in the central cell are very similar to those in Ophioglossum and Befrvelumm, and the original guadrant divisions are perceptible for some time. The number of spermatecetes, as in ()phioglessum and Bestrelvum, may be very large. The spermatorode were not seen by Lang, but from a comparison of the nuclei of the spemateryes they are apparently of about the same size as these of Botrychium.

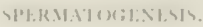

() plinglessum is especially suited to a study of spermatogenesis, owing to the very large size of the spermatozoids. These of $O$. pendulum are probably the largest known among the l'teridophytes. In material fixed with 1 per ecent chromic acid, or weak flemming's solution, and stained with gentian violet and aniline satranine, the coloring is beautifully clear and the blepharoplast stains with extraordinary sharpness. The spermatozoids of $O$. pendulum are larger than those of O. molvicanum or $O$. vulgatum, but the development is very much the same.

If the sperm cells are examined previous to the final division to form the spermatocyres (plate I, fig. 16), the nucleus will be seen to have a small but distinct nucleolus and a dense rericulum. The whole nucleus stains strongly with safranine. The cytoplasm is fairly dense, with granules of various kinds in it. In material fixed with Flemming's solution there are often small black specks, probably fatty bodies, which somerimes interfere somewhat with the study of the cytoplasm. In well-stained sections the blepharoplasts may be seen as two small, rounded bodies of a violet color (plate I, fig. 16, $/$, ) lying near the nucleus. Several cases of the final nuclear divisions were met with, but all of these were in material fixed with chromic acid, and the blepharoplasts were not very well differentiated (plate 2, fig. 22). The nuclear spindle is very distinct, and the very numerous chromosomes are so crowded that it was quite impossible to determine their number exactly, but it is very large. In the young spermatocytes (plate 2, fig. 26) the nucleus shows a more or less conspicuous reticulum, but the nucleolus has disappeared, as it usually does at this stage in all the forms that have been studied. "The further development of the

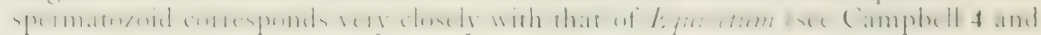
Belajeff 1,2). (Ine of the blepharoplasts in the primary spermatocyte groes with each daughter cell (the definitive spermatocyte) and can be seen as a distinct rounded body lying near the nucleus (plate 2, fig. 24). In some cases what appeared to be the blepharoplast was lying in a depression at the periphery of the nucleus, and looked very much like a nucleolus.

Before the nucleus undergoes any marked change, the blepharoplast begins to elongate (plate 2, figs. 26,27) and assumes the form of a pointed, slender, strongly staining body lying near the nucleus. This body is really somewhat ribbon-shaped, and more pointed at one end than the other, and it is also somewhat curved, even in its earlier stages. A transverse section appears crescent-shaped. The nucleus now elongates slightly and the reticulate structure becomes very conspicuous (plate 2 , fig. 25). There are large, strongly stained granules, which are probably composed of several more or less coherent chromosomes, as the number of these granules is very much less than the number of chromosomes in the nuclear plate of the dividing nucleus. The blepharoplast continues to elongate, and in favorable cases the young cilia can be seen growing from it, but none of my preparations showed the cilia nearly so plainly as Belajeff"s figures show them in Equisetum and Gymnogramme. There is no doube, however, that the cilia arise in much the same way as Belajeff describes. The nucleus now becomes indented on one side and assumes a crescent 
shape, elongating and also becoming more or less flattened. One end becomes narrower and sharply pointed, the other remaining thicker and rounded. The reticulum at this time stains with great intensity and shows a tendency to coalesce, which in the final stage results in an almost homogeneous, deeply-staining mass, composed apparently of the completely fused chromosomes. In successful preparations the nucleus at this stage stains a clear carmine red, in strong contrast to the bright violet of the blepharoplast. With the complete coalescence of the chromosomes the volume of the nucleus is noticeably decreased (plate I, fig. I9). 'The blepharoplast forms a spirally coiled narrow band, from which the cilia can be seen to grow, following its curve, but the blepharoplast is not in close contact with the nucleus.

The spermatocytes and the nuclei are rather smaller in Ophioglossum moluccanum than in $O$. pendulum. In the older stages of the spermatozoid, the nucleus in the former species is decidedly more elongated and more sharply pointed at both ends (plate I, fig. I8). In this respect it more nearly resembles the spermatozoids of Botrychium and those of the true ferns; while in the larger, comparatively short nucleus, as well as in some other respects, the spermatozoid of $O$. pendulum is strikingly like that of Equisetum. The number of cilia is large, but the exact number could not be determined.

Surrounding the spermatozoid and included in its coils is a considerable amount of cytoplasm. I was not successful in obtaining any living spermatozoids, although many attempts were made to do this, but in a number of sections of the opened antheridium some were found in which the spermatozoids had been retained. While these were usually more or less distorted, some were very well fixed and gave a good idea of the structure of the free spermatozoid (plate 2, fig. 28). The cilia were very much distorted in some cases, but in some they were clearly seen. There is one thick posterior coil mainly composed of the nucleus, which is very much larger than that of the sperm cell before it is discharged from the antheridium. The nucleus has the fom of a slightly coiled thick band, tapering somewhat at both conds, but more markedly so in front. Beyond this extends a second coil, composed, apparently, mainly of cytoplasm. This second coil extends into a third much smaller one, which seems to be a flattened band along whose upper edge the blepharoplast is closely applied (plate 2, fig. 28). The resemblance of the spermatozoid to that of Equisitum is very strong, but the nucleus is even more shortened than in the latter.

The spermatozoid of Ophioglossum pendulum is larger than that of any Pteridophyte that has yet been described. The cytoplasmic envelope and vesicle are not very clearly separated and probably are similar to those of the free spermatozoids of $O$. vulgatum or of Equisetum. Sometimes this protoplasmic envelope completely surrounds the lower part of the spermatozoid and reminds one somewhat of the peculiar spermatozoids of the Cycads. Owing to their large size, the spermatozoids were often sectioned, and in some of the sections the blepharoplast was free from the body of the spermatozoid and the attachment of the cilia was very easily seen (plate 2, fig. 29, a).

Mettenius figures the free spermatozoids of $O$. pedunculosum, but his figures are certainly not accurate. Buchmann, who has figured those of (). arulgatum (fig. $5, D$ ), shows that they closely resemble the spermatozoids of the true ferns, but are more massive, and the vesicle which envelops the posterior coils adheres more closely to the spermatozoid than is usual in the ferns. In these respects it resembles the spermatozoid of $O$. pendulum.

Jeffrey examined the development of the spermatozoids in Botrychium virginianum, which closely resemble those of Ophioglossum. Owing to the method of 
staining which he emploved, the hlepharoplast was not clearly evidene. I have examined the developing spermatomids in this species, using the material which l'rofessor Jefficy was so kind as to send me, but employing the double stain of safranine and genrian violer, which was used in the study of ()phegglessum. While. the differentation was inferion to that of ()phegglessum, where the material was fixed with filemming's solution, nevertheless the presence of the blepharoplast was unmistakable.

The spermatocytes are only about half as large as those of (Ophioglossum pendulum, and the spermatozoids correspondingly smaller; hence less favorable for the seudy of details. It is evident, however, that the changes in the nucleus and blepharoplast are essentially the same as in Ophioglossum (plate 2, figs. 3+ to 37). The nucleus, lowwever, becomes much more elongated and the spermatozerids are more slender, in both of which respects it shows a resemblance to the spermatozoids of the typical ferns.

The study of the free spermatozoids was contined to those which happened to have become fixed within the open antheridium and within the venter of recently opened archegonia. These were in some cases very satisfactorily fixed and stained, and showed very well indeed the general form of the spermatoroid. The cilia, however, were not as a rule very well fixed, and while they are evidenty mumerous their number could not be made out.

Bruchmann's figures (fig. 8, D) of the free spermatozoid of Botrychium lunaria agree closely in form and size with those of $B$. sirginianum. In both species the vesicle attached to the spermatozoid is more distinct than in Ophoglossum, and in this respect also the spermatozoid shows a likeness to the true ferns.

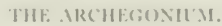

The archegonium in the Ophioglossacea is very much like that of the typical ferms in its general development. The mother cell of the archegonium, like that of the antheridium, is first divided by a periclinal wall into an outer cover cell, which later gives rise to the four rows of neck cells, and an inner cell which, as in the typical ferns, divides again by a transwerse wall into a lower or basal cell and a central cell, the latter subsequently giving rise to the egr cell and the canal cells. A marked feature in the archegonium of the Ophioglossacea is the inconspicuous character of the ventral canal cell, which very often it is impossible to show, and it is possible that in some cases the ventral canal cell may not be formed at all, although $I$ think this is doubeful. In general the archegonium is much alike in the thee genera, but

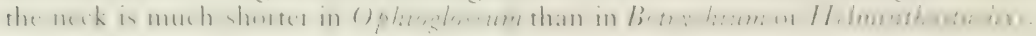

\section{THE ARCHFGONITM OF OHHIO(ZOSSLM.}

My own studies of the development of the archegonium of Ophioglossum were

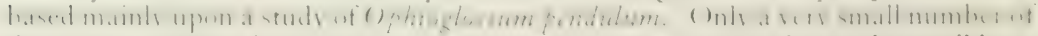
the young archegonia was secured in $O$. molucomum, and so it was impossible to make a complete study in this species. Lang accurately figures several stages of the archegonium in Ophioglossum pendulum, and Bruchmam has described quite completely its development in $O$. Eulgatum. Bruchmann failed to see the two nuclei of the neck canal cell which Lang correctly figures for $O$. pendulum. These iwo nuclei are invariably present in both $O$. pendulum and $O$. moluccamum, and it is to be expected that they will also be found in $O$. E'ulgatum, as they are constantly. present also in Botrychium sirginianum and in all of the ferns that have been aceurately examined. Neither I.ang nor Bruchmann saw the ventral canal cell, which is exceedingly difticult on demonstrate. 
In Ophioglossum the young archegonia may be found near the apex of the prothallial branch, but they may also arise at a considerable distance back of it. In general, like the antheridia, they arise in acropetal succession.

The mother cell, like that of the antheridium, is sometimes broad, sometimes narrow and deep, and the cover cell is correspondingly shallow or deep. The first division of the inner cell takes place shortly after the cover cell is cut off. The next division is in the cover cell, which first divides by a vertical wall, a second vertical wall being formed almost immediately, intersecting the first and dividing the cover cell into four practically equal cells, arranged quadrant-wise (fig. 1f, $f$ ). The middle cell next divides by a transverse wall into the primary neck canal cell and the central cell (fig. I $6, F$ ). The canal cell pushes up between the four primary neck cells, which presently divide by nearly horizontal walls, so that there are two tiers of neck cells. One or both of these divide again later, so that each row of neck cells consists of three or four. Rarely there may be five cells in one or more of the rows.
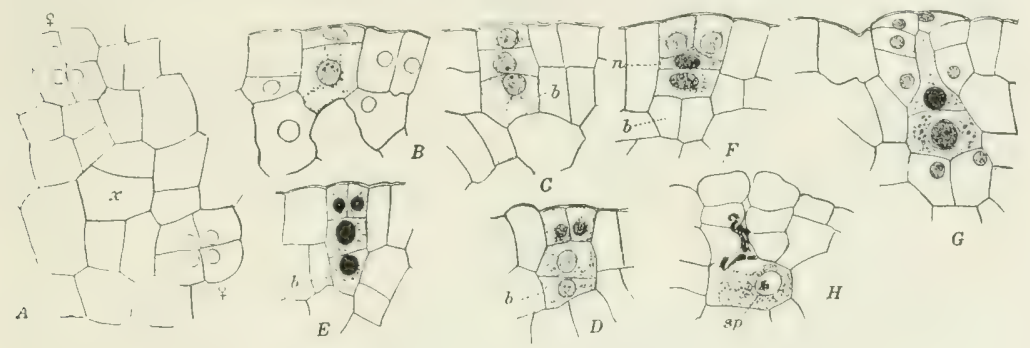

Fig. 16.-Development of the archegonium in Ophioglossum pendulum. $\times 180$.

A. Transverse section- of gametophyte apex, showing two young archegonia,, , and apical cell, $x$.

$\mathrm{B}-\mathrm{G}$. Successive stages in the development of the archegonium; seen in longitudinal section; $n$, neck canal cell; $b, b a s a l$ cell.

H. Recently fertilized archegonium; sp, a spermatozoid within the egg nucleus.

The neck canal cell is very conspicuous, its base being broad, and the upper part narrower and extending to the uppermost neck cells. The large and conspicuous nucleus soon divides into two, hut as a rule there is no division wall, although occasionally two distinct neck canal cells may be present. Sometimes both of the nuclei remain in the broad basal part of the cell, and sometimes one is at the base and one nearer the apex. This arrangement seems to depend upon the direction in which the nuclear division takes place.

The basal cell divides by a vertical wall at about the same time that the primary canal cell is cut off from the central cell. The basal cell subsequently undergoes further divisions, but its limits are readily distinguishable up to the time that the archegonium is mature (fig. I6, $G$ ).

In its earlier stages, the archegonium of Ophioglossum pendulum bears a striking resemblance to that of the Marattiacese, which the mature archegonium more nearly resembles than it does that of Butrvihum. Acoording to Bruchmann's account, (). Eulgatum has a neck somewhat longer, and this is also true of O. moluicanum. Even when mature, the neck projects but little above the surface of the prothallium, although there is some elongation of the cells at the time of dehiscence (fig. $16, G$ ).

The ventral canal cell is very difficult to demonstrate, and one is sometimes inclined to doubt whether it is formed at all in some cases; neither Lang nor Bruch- 


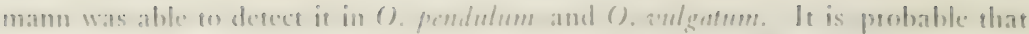
ies appaneme absence in mest of the atchegentia is due to the fact that it is formed very late and is exeremely inconspicusus. The same appasent absence of a ventral canal well in the ('veads and some Conifers has been sheww, on mere critical study of the material, of be due whe small size of the ventral nucleus and to its very evanescent character. In nealy all of the atchegenia examined, just hetere they opened there was present a resicular bedy above the egge, which was probably the ventral canal cell much distended with Huid preparatory to the opening of the arehegonium. A small mucleus, or what leoked like one, could sometimes be seen, but it must be said that its meclear nature was not above suspicion (plate 2, fig. 3.3).

Just before the archegenium is ready to open, the egg cell, which up to this rime is compressed above by the basal wall of the neck canal cell, becomes distended and pustes up the base of the canal cell, which thus becomes concave below. It is probably about this time that the ventral canal cell is cut off. Unfortunately, no cases were found showing mitesis in the central cell, but fhere seems no good reason to doubt that a ventral canal cell is, usually at least, cut off.

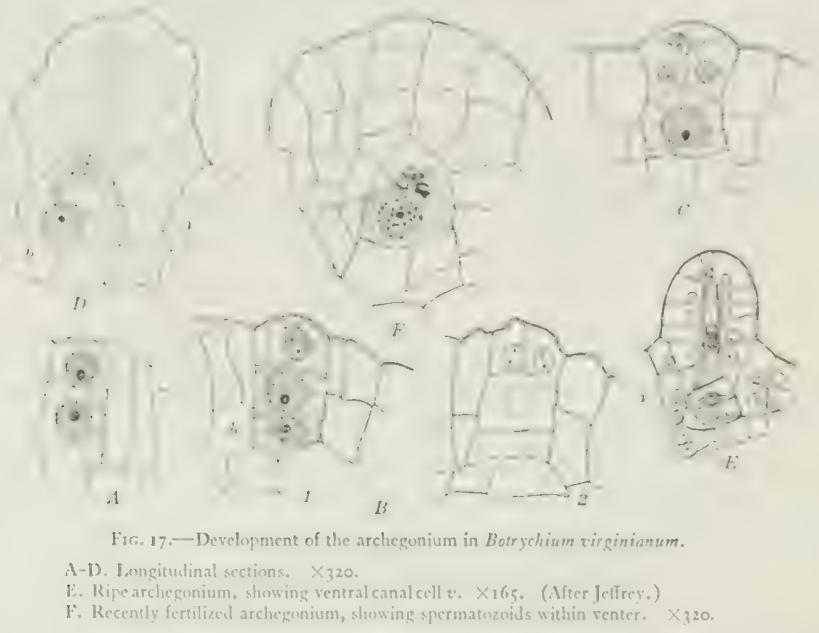

The neck canal cell does not show the complete disorganization which is common, but retains its form up to the time that the archegonium opens. With the opening of the neck there is some elongation of the outer neck cells, but there is decidedly less projection above the surface of the prothallium in $O$. pendulum than is the case in $O$. rulgatum. The nucleus of the egg cell is large, but it does not always stain readily, except the nucleoli, and it may be that the same resistance to stains is the reason why its sister nucleus in the ventral canal cell is so difficult to see.

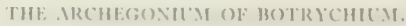

'The archegonia in Botrythum are found usually upon the flanks of the median ridge, upon whose summit are borne the antheridia. In their early stages they closely resemble those of Ophioglossum (fig. 17 ). As in the latter, there is some variation in the form of the mother cell, which may be quite deep and narrow, or relatively broad and shallow. The subsequent divisions in the central cell and in 
the cover cell agree very closely with those in Oplioglossum; but the neck cells are more numerous and at maturity the neck projects much more strongly than is the case in Ophioglossum. There may be as many as seven or eight cells in each row of the neck, which, except that it is quite straight, resembles that of the typical ferns. It is especially like that of Osmunda, in which the neck is also straight. The neck canal cell (fig. 17,D) becomes much elongated, and the nucleus divides, as in Ophioglossum, but in most cases at least there is no division of the canal cell itself.

As in Ophioglossum, the ventral canal cell is very inconspicuous, and often impossible to detect. Jeffrey (fig. I $7, E$ ) figures a very evident ventral canal cell, but the nucleus is much smaller than that of the egg or neck canal cell. I have also found what secmed to be a ventral canal cell in the archegonium shortly before it opened, but, as in the case of Ophioglossum, this was not absolutely certain. As in the corresponding stage in Ophioglossum, above the egg cell, with its large and conspicuous nucleus, there is a clear space containing a small round body, which showed no evident nucleolus, but otherwise stained very much like the nucleus of the egg, and was probably the nucleus of the ventral canal cell (fig. I7, $D, v$.) While no certain cases of mitosis of the egg nucleus for the cutting off of the ventral canal cell were encountered, in one case the egg nucleus looked as if it were in the early prophase of division. Bruchmann's figures of the archegonium of Botr ritum lunaria closely resemble that of $B$. virginianum, but he was unable to find a ventral canal cell, nor did he apparently see the division of the nucleus of the neck canal cell. The archegonium of Helminthostachys (fig. I , D) closely resembles that of Botrychium.

\section{FERTILIZATION}

In only a few cases were spermatozoids seen within the neck and venter of the open archegonium in Ophioglossum, but twice a spermatozoid was seen within the nucleus of the egg; as there were no other stages obtained, however, the details of nuclear fusion could not be followed (fig. I0, H). The spermatozoid pentrates the nucleus of the egg, where for a time it can be seen distinctly. It is probable that its fusion with the egg nucleus is much like that described by Shaw for Onoclea (Shaw 1, 2). In the mature egg cell the nuclear reticulum is often decidedly contracted, but whether this is normal or the result of reagents can not be said.

FERTILIZATION IN BOTRYCHIUN VIRGINLANUM.

Jeffrey observed a single spermatozoid within the venter of the archegonium and noted that at the time of fertilization the egg developed what he called a "receptive prominence." I have observed the same phenomenon in several cases (plate 2, fig. 46), and in a good many instances have also found one or more spermatozoids within the venter. In one case, what looked very much like a spermatozoid was seen within the egg nucleus itself, and the process of fusion is probably very much the same as that so fully described by Shaw for Onoclea. In the specimen shown in fig. $17, F$, one of the spermatozoids looks as if it has partially penetrated the egg, but it is impossible to be certain that it was not simply lving against it. In this case, just above the nulceus of the egg there was a slight bieak in the granulas cytoplasm that looked as if it might be a receptive spot, but the spermatozoid was not entering the egg at this point.

In another instance a curious thing was noted, but whether it was nomal or not it is impossible to say (plate 2, fig. $4^{\text {h) }}$. A spermatozoid had just entered the neck of the open archegonium and the egg had developed a very conspicuous receptive prominence. The nuclear contents were very strongly contracted and deeply stained and a portion apparently projected beyond the nuclear membrane 
info the teceprefe prominence. A similar sroupsis was noted in several cases. In most instances where fiec spermatengids were present in the venter of the arche-

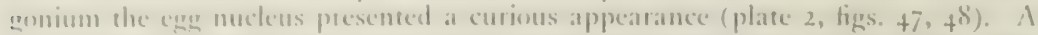
single large nucleolus was present, but scantered through the nucleus there were sonetmes a dozen or mote of infensely staining round bodies, which at first sight lenked like nuclesli, hut on more carceful examinasion were seen to ditfer from the large nucleobs in that they appeared less homegeneous and generally shewed at cenral vacuole-like structure. These granules stain very much like the body of the spermatezoded, and it was thenght that pessibly elocy mighe be derived from a fragmentation of the body of the spermatosed that had entered the nucleus, but this could not he satistactorily demonstrated and the nature of this phenomenon must semain for the present uncertain.

Fertilization in Relminthostachys has not been observed.

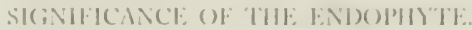

That the presence of the endophyte is essential to the existence of the saprophytic gametophyte of the ()phioglossacea is indicated by the failure of the germinating spores to develop unless they become associated with the fungus. Moreover, the universal occurrence of a similar endophyte in all humus saprophytes among the seed plants indicates that in all of these chlorophyll-less plants the presence of the fungus is necessary for the existence of the host. Although it has not been directly proved, it is generally assumed that one rôle of the endophyte is the elaboration of some of the carbonaceous constituents of the humus. The infrequent communication between the external hyphx and the internal mycelium makes it unlikely that the nutritive products are directly absorbed by the fungus, and it seems much more probable that the rhizoids of the gametophyte are the direct agents of absorption. How the humus constituents are changed by the action of the fungus so that they. are available for the cells of the host is not clear, and it is by no means impossible that some at least of the necessary carbon may be derived from the fungus itself, in the digestive process to which it is subjected in the cells of the host. This seems plausible from the fact that in the green prothallia of certain ferms, where presumably the gametophyte is entirely able to supply its own carbon compounds through photosynthesis, these digestive cells appear to be wanting; at any rate they were not observed in a number of forms that I have studied.

The experiments of 'Ternet\% (Charlotte Ternetz 1), show that certain fungi, including endophytic mycorrhize, are able to assimilate fiee nitrogen and confirm the assumption of earlier observers that the fungus is useful to the host in supplying it with nitrogen compounds; but, while this is probably a very important part of its functions, it seems to me that it is not pethaps the only one, and that the carbon also is supplied, directly or indirectly, through the agency of the fungus.

In an extended study of the endophytic mycorrhiza of the saprophytic orchid, Neotia, W. Magnus (IV. Magnus 1 ) has shown that two types of mycelium exhibited by the endophyte are of very different nature. The slender, cylindrical hyphe constitute the active portion of the fungus, which behaves like a parasite toward the cells which it invades, destroying the starch and probably other constituents of the cells, but not attacking the nucleus. The swollen vesicular myeclium, however, is a degenerating structure and is itself destroyed by the cells of the host, which actually digest these fungus mycelia in much the same way that the cells of the leaf of Drosera digest their prex. Magnus has very graphically shown that the relation of the two svmbionts is mutually antagonistic, each one acting as a parasite on the other; nevertheless the presence of the fungus is essential to the higher 
organism, so long as the latter is destitute of chlorophyll. The explanation of the widespread saprophytism exhibited by so many of the higher plants may be sought in this attempt to defend themselves against what was probably at first a strictly parasitic organism. Having acquired the power to attack and to feed upon the parasite, the photosynthetic functions were more and more subordinated, until a state of true parasitism (or saprophytism) resulted. The numerous semi-saprophytes like most of the green Ericales and many of the green Orchidacex, are good examples of transition stages, while the characteristic leatless humus sapophytes, such as Monotropa and Corallorliza, represent the fully developed phase of this peculiar form of symbiosis. We might say that such green prothallia as those of the Marattiacere and Gleichenia, which contain an endophytic fungus, bear somewhat the same relation to the subterranean prothallia of the Ophioglossacere that the green Ericales do to Monotropa.

The occurrence of a similar endophyte has also been noted in a number of liverworts. Cavers (Cavers 1) has studied this association with some care in the common liverwort, Fegatella, as well as in some other Hepaticae. He found in Fegatella that the endophyte is beneficial to the growth of the host, which was more vigorous when the fungus was present. He assumed that this was due to the assistance given by the fungus in the assimilation of organic matter from humus or other organic substrata. (See also Humphrey 1).

This occurrence of an endophyte in the Hepatica makes its occurrence in the green prothallia of ferns readily comprehensible. Whether in the latter it is an advantage to the host to have the endophyte present remains to be seen, but it is highly probable that such is the case. Once having acquired the habit of associating itself with the fungus, the gradual evolution of the purely saprophytic subterranean gametophyte of the (Ophioglossacex from green forms similar to those of the Marattiacea is readily comprehensible. 


\section{THE li.MBRIS().}

The development of the embryo in the Ophioglossacea has been more or less completely studied in (O) phioglossum pedunculosum, O. v'algatum, O. moluccanum, O). pendulum, Boorychium sirginianum, B. Innaria, and B. obliquum (Mettenius I, Bruchuann I and 2, Lang 1, Campbell 8, Jeffrey 1, Lyon 1).

The tirst division in the young embryo in all of these is usually approximately transverse, although there may be a good deal of variation in this respect. It is probable that in all cases the primary root, the stem apex, and the foot all arise from the epibasal region. The embryo reaches a very large size before the root emerges from the overlying prothallial tissue and all of the organs of the young sporophyte are very late in developing, so that it is not easy to trace their origin back to the carly cell divisions in the young embryo. Much the most conspicuous organ of the young sporophyte is the root, which may reach a very large size and an advanced stage of development before any evidence of the other organs is apparent. Indeed, several roots may be developed before the shoot is established. In Ophioglossum anlgatum and Botrychium lunaria, according to Bruchmann's account, the young
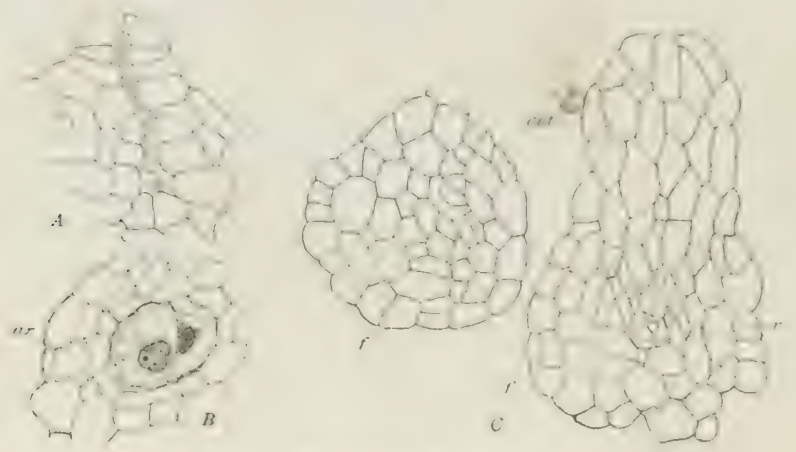

Fic. 18.-Ophroglassum moluctansm.

A. An old archegonium. $\times 180$.

B. Two-celled embryo within the archegonium. X180.

C. Two sections of an older embryo. Xifo. col, cotyledon; f, foot; $r$, mone.

sporophyte remains several years under ground before the first green leaf appears above the earth, and it is probable that in Ophioglossum pendulum there is also a long period of underground existence before the first green leaf is developed. In Ophioglossum moluccanum, however, and in Botrychium virginianum, the first leaf developed is a green foliage leaf, which grows rapidly and soon appears above the surface of the ground.

\section{THE F.MIRRYO OF OPHIOGLOSSUM.}

The first figures that we have of the embryo of Ophioglossum are those of Mettenius, but his figures of the embryo of $O$. pedunculosum are not at all satisfactory, although he shows correctly sections of the older sporophyte. Lang figures only one embryo, a somewhat advanced one of $O$. pendulum. Bruchmann figures a two-celled stage and a single more advanced embryo of $O$. vulgatum, but he describes and figures several stages of the young sporophyte. My own study of Ophioglossum was based mainly upon the development of the embryo in $O$. pendulum, where a 
fairly complete series of embryos was obtained and the development followed quite satisfactorily.

In $O$. moluccanum I found two quite young embryos, the youngest consisting of two cells (fig. I $8, B$ ), the other much more advanced, with the cotyledon already differentiated and the beginning of the primary root recognizable. In the first embryo the basal wall was nearly transverse to the axis of the archegonium and, to judge from the arrangement of the organs of the older embryo, it looks as if the whole of the hypobasal region formed the foot, the epibasal half giving rise to the cotyledon and root. The older embryo (fig. I8, $C$ ) was cut longitudinally in the plane of the cotyledon, which at this time comprises pretty much the whole of the upper part of the embryo, the hypobasal region being occupied mainly by large cells which constitute the foot. Unfortunately, in this series the section containing the apex of the leaf was missing, and so it is impossible to say whether at this stage a definite apical cell is present in the cotyledon; but, as in somewhat older stages such a cell seemed to be always present, it is probable that there was an apical cell in the cotyledon of the embryo in question. At the base of the leaf, and almost in the center of the embryo, there was a group of actively growing cells, evidently marking the position of the root apex, which arises deep in the tissue of the embryo, very much as we shall see to be the case in the Marattiacex; and it seems probable that in O. moluccantum, as in Danaa, the root grows downward through the foot and in a direction coincident with the axis of the young cotyledon.

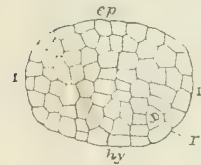

A
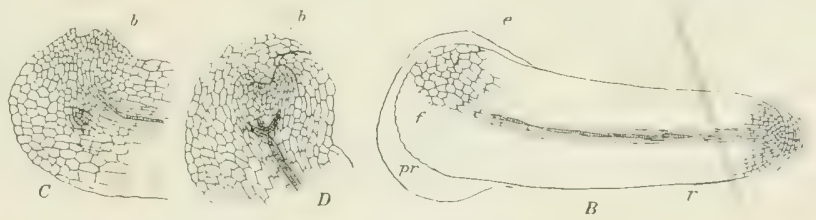

Fici. 19.-Ophioglossum vulgatum (after Bruchmann).

A. Median section of a young embryo. $\times 160$. B. An older embryo. $\times 25$

C, D. Older embryos, showing beginning of apical bud, $b ; r$, root. $\times 25$.

The cotyledon grows upward and soon ruptures the overlying prothallial tissue, while the root grows down in the opposite direction and pierces the prothallium at a point some distance below where the leaf emerges. As the root grows downward through the foot the latter becomes unrecognizable, its outer cells remaining, however, as a zone of large cells encircling the equatorial region of the very much elongated bipolar embryo.

The young root very early develops a tetrahedral apical cell, like that of the later roots. This cell is probably cut out from the central tissue of the embryo, close to the base of the leaf. The cell $r$ in fig. $18, C$, to judge from its position and the arrangement of the cells around it, is probably the initial cell of the primary root.

The young cotyledon grows rapidly and has first a conical form (fig. $23, B$ ), terminating in a definite apical cell. As it grows it develops a small oval lamina and a slender petiole, and presently the little green leaf appears above the surface of the earth.

The embryo of $O$. vulgatum differs remarkably from that of $O$. moluccanum in the late development of the leaf. Bruchmann was unable to obtain the younger stages of the embryo, so that the origin of the different members is still somewhat obscure. In this species it is the root which develops first, and it soon becomes 
exceedingly conspicuous. Bruchmann considers that the root and foot are both of hypobasal origin, hut he bases this on a comparison with the true ferms rather than upon actual study of embrys, as he was unable to obtain embryos sufficiendy young to demonstrate this, and all erace of the original divisions disappears before any sign of the stem and leaf is evident. It may be well questioned whether, as in Betrychium and (). pendulum, the foot does not take up the whole hypobasal region. It is not impossible that the position of the basal walt may also vary in (). s'ulgatum. From a comparison with the embryo of $O$. pendulum, I am inclined to assign more of the emberes of the former to the foot region than is done by Bruchmann.

In $O$. s'ulgatum there is, funally, a differentiation of the stem apex from the epibasal region, as in Botrychum and the true ferns, while in O. moluccunum there is no trace of a stem apex in the very young sporophyte, this developing later as a bud upon the first root.

From a study of Ophioglossum moluccamum and also of O. pendulum it is evident that the history of the young sporophyte in these species differs strikingly from that of the other l'teridophytes. In both of these species the detinitive sporophyte always arises secondarily, as a bud upon the root, in the same way that adventitious buds are commonly formed upon the roots of the adult sporophyte. Bruchmann notes in $O$. vulgatum the very precocious development of the primary
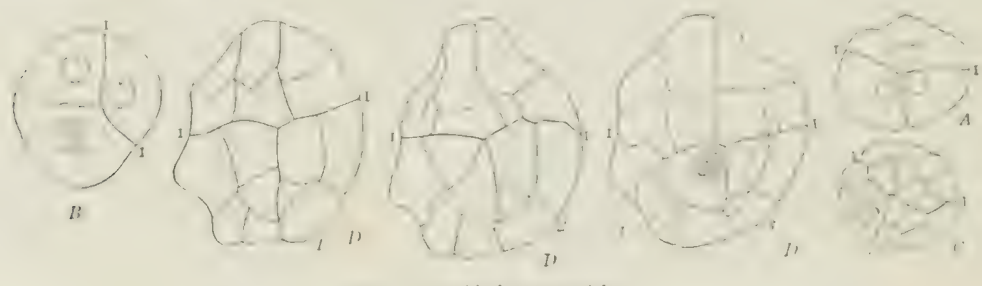

Fui. 20.-Ophrioglossam pendulum.

A. Transverse section of very young embryo, $\times 180$.

B. Longikudinal scetion of young cmbryo. $\times 180$.

C. Three transverse sections of an older embryo; $1-1$, basal wall; r, primary rest. $\times 1$ So.

1). An older embryo; $r$, primary root.

root and the late appearance of the stem apex and first leaf: but in this species the shoot apex, according to his statement, is derived directly from the epibasal half of the embryo, as it is in most P'teridophytes.

In Ophioglossum pendulum, where the development of the embryo seems to offer no check to the further growth of the prothallium, the position of the archegonium varies a good deal and it is impossible to tell from a section just what the position was in the living state, as the branches of the gametophyte extend in all directions and archegonia may be formed at any point upon their surface. To judge from the youngest stages of the embryo that were met with (fig. 20), the basal wall in this species is not necessarily transverse. In both of the cases figured it was oblique, and more nearly longitudinal than transverse. It is likely, however. shat it is horizontal, or approximately so. In the four-celled embryo shown in fig. $20, A$, the quadrant walls were at right angles to each other, and this was also the case in the five-celled embryo shown in fig. $20, B$. Somewhat older embryos $(C)$ show that there is a pretty regular octant formation, and Bruchmann states that this is also the case in $O$. viulgatum.

While in the typical ferns, and in Botrychium, all of the organs of the young sporophyte can be traced to certain regions of the young embryo, in Ophioglossum 
pendulum only one of the definitive organs, the root, arises in this way, and this becomes differentiated at a very early period. One of the octants next to the archegonium at once becomes the apical cell of the young root. This cell is very soon recognizable by irs size and shape, and quickly begins its regular segmentation. The primary cap-cell is soon cut off (fig. $20, D$ ), and from now on the young root is very conspicuous. The octant divisions are very clearly marked in this case, and in section 3 , which is the uppermost of the three, the large triangular apical cell of the root is very evident.

Two types of the embryo were seen in this species. One of these (fig. $2 \mathrm{I}, A$ ) is nearly globular in form; the other (fig. $2 \mathrm{I}, B, C$ ) is elongated. The former looks as if it originated from an embryo in which the basal wall was transverse to the axis of the archegonium; in the other it was probably more or less vertical.. It is probable that in the former instance the root initial is one of the epibasal octants, while the whole of the hypobasal portion gives rise to the large foot. In the second type it is difficult to say which half should be considered epibasal and which hypobasal, but, as in the other case, one half may be considered to be root, the other half foot, the

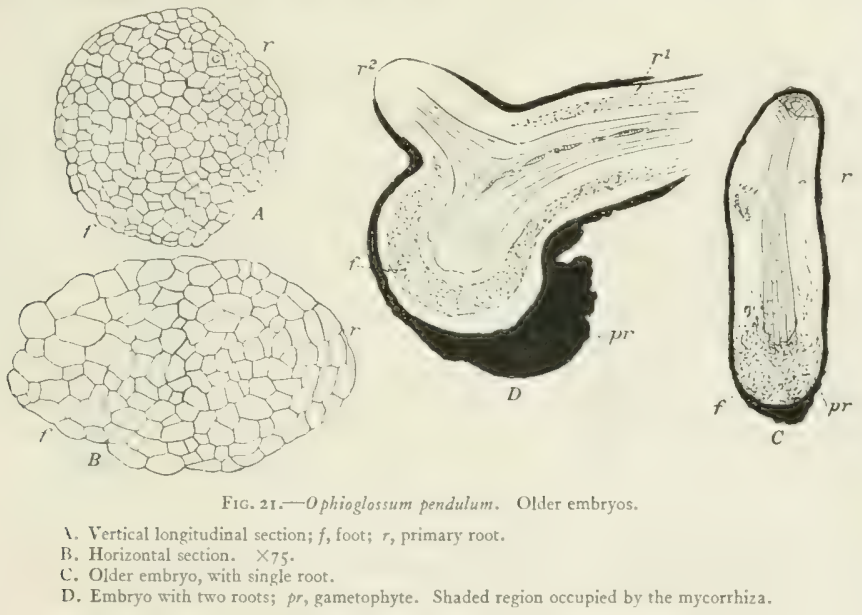

growth of both being nearly in a plane at right angles to that of the archegonium axis, and suggesting the relative positions of cotyledon and foot in the embryo of Ophioglossum moluccanum.

In form the first type somewhat recalls the embryo of Botrychium virginianum. The whole lower portion, or hypobasal half, forms the very conspicuous foot, while from the epibasal region the primary root is developing, and already the rudiment of the second root is visible. Whether the latter arises directly from the primary root, or whether it arises independently from the second epibasal quadrant, is not quite certain. The cells of the epibasal region are evidently actively growing, having abundant protoplasm and conspicuous nuclei. The cells of the foot are larger and much more transparent.

The second type of embryo (fig. 2I, $B, C$ ) resembles very closely the second state of the embryo of Ophioglossum vulgatum, where, as is said by Bruchmann, the embryo is "all root." 
In (). moluccumm the prothallium probably lives for a single season only, and the formation of the sporophyte stops its further development; but in $O$. pendulum, where embryos are much less frequently found, the large gametophyte continues its growth apparently unchecked by the development of the attached sporophyte, which retains its connection with the gametophyte for a very long time, as in $O$. indgutum and Botrychum virginianum.

The embryo reaches a very large size before it breaks through the prothallium. The primary root then emerges as a conical point (fig. $3, F, s p$ ). 'The second root remains shore for a time. There seems to be a good deal of difference as to the time of the appearance of the latter. In the globular type of embryo the second root appears very early, and it looks as if it might have been formed quite independently of the primary root. Sometimes, however, the primary root may attain a length of several centimeters, and may even begin to form rootlets before the second root emerges; while in other cases the two roots grow in opposite directions and seem to

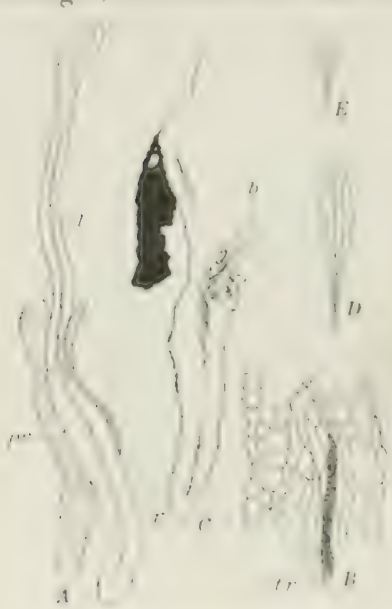

Fig. 22, $\rightarrow$ Ophioglossum moluccanum.

1. Median section of young sporophyte before formation of bud; l, cotyledion; $r$, ront. pr, the gametophyte. $\times 15$.

B. Ceneral region of same, more enlarged; tr, first tracheids.

C. An older sporophigte, showing bud, $b$, developing from primary root. Xis.

D, E. Lamina of cotyledon, showing venation. $\alpha_{3}$.

ciated by Raciborski under the name O. moluccanum (Raciborski 1 ).

As Mettenius correctly showed in O. pedunculosum, the first organ to be developed is the cotyledon, which soon pierces the earth and appears as a green foliage leaf. This primary leaf is continued directly into the primary root, but no stem apex is developed, nor is any sheath formed about the leaf base in the young sporophyte, which consists practically of leaf and root alone. The latter often penetrates for some distance into the prothallial tissue before it emerges, so that the central portion of the young sporophyte is surrounded by a sheath formed by the prothallial tissue. A longitudinal section of the sporophyte (fig. $22, A$ ) shows that the tissues of the leaf are continued directly into those of the primary root. A 
single axial vascular bundle traverses the whole of the young sporophyte without interruption, and there is no recognizable boundary between the tissues of the leaf base and those of the root. The central region of the embryo is somewhat thicker and its outer cells are enlarged, these outer cells probably belonging to the foot through which the root has penetrated and which at this period can not be clearly recognized. The strictly bipolar character of the young sporophyte and the way in which it perforates the gametophyte resemble most nearly the corresponding stages of Equisetum and the Marattiacex, and it may be said that Lyon's recent studies on Botrychium obliquum indicate that in this species also there is a similar bipolar arrangement of leaf and root.

Mettenius pointed out in $O$. pedunculosum that the definitive sporophyte arises as an adventitious bud upon the primary root, either close to the leaf base or, more commonly, at some distance from it. This is also the case in $O$. moluccanum and the other allied species. In one case observed by me two independent sporophytes were found growing from the same prothallium, but this is unusual, and in most of the cases where two sporophytes seem to be present, one of these is really the secondary sporophyte growing from the primary root.

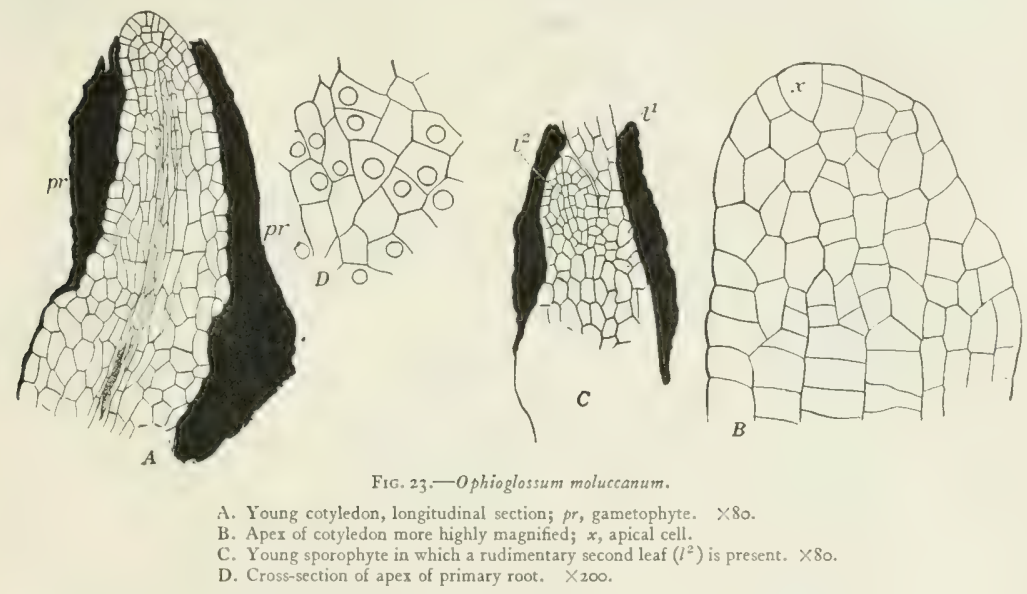

While in $O$. vulgatum the sporophyte stays under ground for several years, in $O$. moluccanum there is every reason to believe that there is only a brief interval between the first formation of the leaf and its appearance above ground. The small size and the character of the gametophyte, as well as the quick germination of the spores and the rapid growth natural to a tropical climate, indicate that the gametophyte is an annual and that it dies as soon as the young sporophyte is established.

In $O$. pendulum the primary root as it breaks through the prothallium elongates rapidly, but just how far it grows before the bud is formed upon it could not be determined. These roots are very brittle and easily broken off, and in no cases were young buds found upon roots which were still connected with the prothallium. The first root sometimes reaches a length of 3 or 4 centimeters before the second root can be seen at all. The growth of the roots in the young sporophyte is in all respects like that occurring in the older ones. There is a large tetrahedral apical cell, the divisions of which are quite regular, and the conspicuous axial vascular cylinder is 
develuped at an ear!y period. The stele of the second root joins that of the first where the later joins the foot (fig. $2 \mathrm{I}, D$ ). The primary root in $O$. pendulum is, usually ae least, diarch.

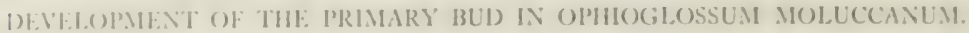

The several terrestrial species of Ophioglossum growing at Buitenzorg and associated under the name $O$. moluccanum differ strikingly from $O$. sulgatum in the further history of the young sporophyte as well as in the early development of the first functional leaf. This difference is also found in the young sporophyte of $O$. reficulatum (?) collected at Hakgala in Ceylon. All of these tropical species agree with O. pedunculosum, which was correctly described by Mettenius (Mettenius I), in the origin of the definitive axis which arises as an adventitious bud from the primary root of the young sporophyte. A similar condition of things probably is true also in (). pendulum, although in the latter no leaf is at first developed from the young sporophyte, which is composed exclusively of one or two roots in addition to the foot, so that the first leaf in $O$. pendulum is also an adventitious structure. Whether or not the primary leaf in $O$. pendulum, and probably at the same time the stem apex, arises as a bud from the primary root, or whether (which seems more likely) it is developed from a secondary root, can not be stated, as no young leafy buds were fund in connection with the gametophyte.

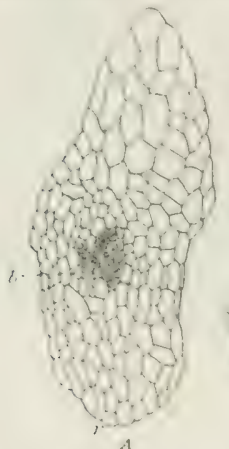

1

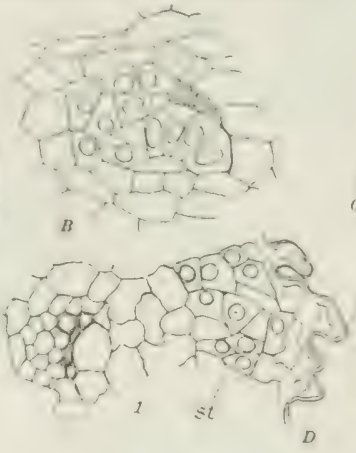

$D$

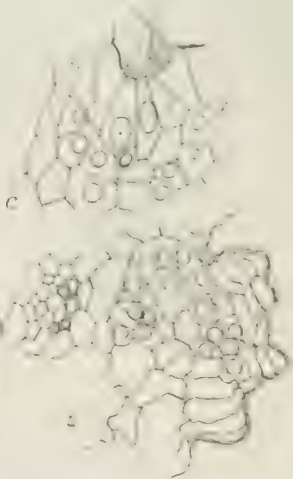

i

Fic. 24.-Ophioglossum moluceanum.

A. Taneential section of primary root, showing young, endogenous bud, $b . \times$ about 50.

B. C. Two sections of the same bud. B, the firse leaf; C, stem apex. Xiso.

D. Two transverse sections of a young bud; I passes through stem apex $s I ; 2$, through leaf.

Mettenius gives no detailed study of the development of the bud upon the root, nor does he state whether he recognized its endogenous origin. The bud arises. much in the same way that a secondary root does, and is not visible upon the outside of the root until it is far advanced in its development, the young leaf breaking through the overlying tissues in much the same way that a young root emerges. In two instances the rudiment of the young bud could be seen close to the apical meristem of the root, in a position which is exactly the same as that described for the leafy buds formed at the apex of the root in $O$. vulgatum. Nore commonly, the bud originated nearer the base of the root, but it may arise at any point between the base and the apex. Figure $2+$ shows sections of the youngest buds that were found. $A$ is a tangential section of the primary root, in which the young bud has formed at a point not very far back from the ront apex, $r$. The first leaf of the young 
bud and the young stem apex can already be recognized, and these have apparently developed quite independently of each other. The leaf rudiment, $B$, lies nearer the bundle of the main root and may perhaps have taken its origin from a single endodermal cell, but this could not be certainly determined. The young leaf soon forms a slightly projecting conical body, composed of a few cells with conspicuous nuclei, separated from the adjacent root tissue by a smalls,space. At this stage it is not quite clear whether the apical cell has been developed, but later stages show the presence of an unmistakable apical cell of approximately tetrahedral form. Lying nearer the periphery of the root is the young stem apex, composed of a small group of meristematic cells, one of which is unmistakably the initial cell for the stem. This apical cell is truncate below and the base is broader than the outer free face. Above the stem apex can be seen the cavity which separates the outer tissues of the young bud from the cortical tissue of the root.

Fig. $24, D$, shows two transverse sections of a bud of about the same age as the one just described. No. I passes through the stem apex and shows the conspicuous triangular apical cell; No. 2 shows a section of the leaf above the level of the stem apex with the basal tissue of the leaf extending around the stem region. This is the beginning of the hollow stipular sheath which incloses the stem apex of the bud and

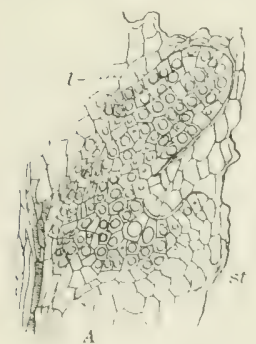

$A$

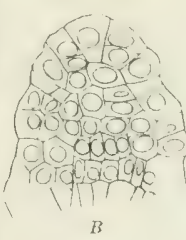

B

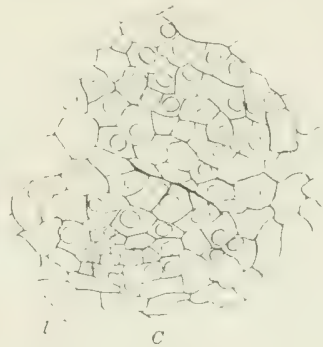

C

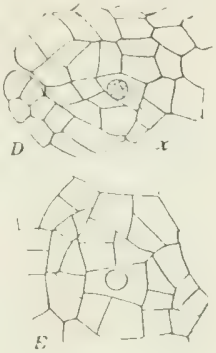

t)

Fig. 25--Ophioglossum moluccanum.

A. Bud about to break through primary root; $l$, first leaf; st, stem apex. $\times$ about 80.
13. Apex of leaf more bighly magnified.
C. Transverse section of a young bud passing through base of leaf, $l . \times 150$.
D. Section of same passing through stem apex, $x$.
E. Transverse section of stem apex from an older sporophyte. The apical cell is four-sided.

which is so conspicuous a feature in the stem apex of the older sporophyte. Probably the large central cell in the section of the leaf shown in No. 2 is the apical cell, but this is not quite certain.

A transverse section of a somewhat older bud (fig. 25, $C$ ) shows a nartow cleft at the base of the leaf in front, opening into a cavity within which the stem apex lies. It is impossible to say exactly how much of this stipular sheath really belongs to the leaf base and how much is derived directly from the adjacent cortical tissue of the root, since the tissues of the leaf base merge insensibly into the latter. From this time on, each new leaf develops this conical stipular sheath, which incloses the stem apex and the next youngest leaf, and which has so often been described in the older sporophyte.

If a median section of the young bud is examined just before the bud breaks through the overlying tissues of the root (fig. $25, A$ ), it can be clearly seen that the leaf, which now has the form of an elongated cone, lies above the level of the young stem apex, and by this time the differentiation of the vascular bundle of the leaf is well advanced. This bundle connects with the vascular bundle of the primary root 
and elere is no connection berween it and the tissues of the stem apex of the bud. The later consists of a shallow mass of tissue with the conspicuous apical cell in the center, but below it there is no sign of the development of any procambium. The stem apex lies in a depression formed by a shallow ridge, which encircles it and forms the beginning of the stipular sheath belonging to she base of the leaf. The exace limits of the basal tissue of the leaf, as we have already stated, can not be clearly defined. 'The cavity above the stem apex is still very evident, but how much of the tissue lying above the cavity belongs to the leaf base, and how much to the cortical tissue, is not clear. The section through the apex of the leaf (fig. $25, \mathrm{~B}$ ) shows a single large terminal cell which, without doubt, is the apical cell.

The young bud is now ready to emerge and, very soon after, the rapidly elongating apex of the young leaf pushes through the outer root tissue and emerges upon the outside. The stem apex remains buried within the root tissues and the sheathing base of the leaf. The leaf base is surrounded by a ragged sheath, formed by the ruptured outer tissues of the root.

The development of the bud upon the root in $O$. pendulum unfortunately could not be followed. The smallest leaves found were 10 centimeters or more in length, and, although these were probably the primary leaves, they were not recognized as such at the time the plants were collected, and so there was no opportunity of tracing their connection with the original root.

The fully developed cotyledon in what may be considered the typical form of O. moluccanum is more or less lanceolate in outline (fig. 22, D). There is a central vein from which branch secondary veins on either side, connecting with the central vein by anastomosing branches which inclose elongated meshes. In the form with broader leaves, probably another species, the mid-vein is more obscure and the meshes are broader and more numerous.

Three types of the embryo may be recognized in Ophioglossum, represented respectively by $O$. moluccanum, $O$. vulgatum, and $O$. pendulum. If, as seems not unlikely, $O$. moluccanum is the most primitive of the three, some interesting points arise as to the significance of the peculiarities exhibited by the embryo, which shows only two organs aside from the foot, viz, the cotyledon and primary root, these growing in an almost exactly opposite direction, without any clear line of demarcation between them. I have ventured to draw a comparison between the sporophyte of Ophioglossum and that of Anthoceros, assuming that the former has arisen from some bryophytic type not unlike Anthoceros, by the development of a root from the base of the sporogonium and of a special foliar organ from the basal meristem of such a sporogonium. The embryo of $O$. moluccanum approaches this hypothetical form, as it consists only of leaf and root, and no stem apex is developed from it, its growth being of limited duration. In this case the definitive sporophyte is a secondary structure developed as a bud upon the primary root. In $O$. vulgatum, however, the definitive stem apex, although of very late origin, is apparently a product of the original embryonic tissue, but the first foliage leaf is of much later origin. In $O$. pendulum the formation of the leafy sporophyte is also secondary, but neither stem apex nor leaf is developed from the embryo itself.

If, as the writer believes, Ophioglossum represents the most primitive type of the fern series, it is quite conceivable that in $O$. moluccanum and its allies the embryo represents the condition existing in the ancestral type from which these have sprung. On the supposition that the leafy sporophyte is derived from a large bryophytic sporogonium resembling that of Antloceros, there must have been a stage when the sporophyte consisted of two parts only, the upper sporogenous portion, which later developed into a sporophyll, as represented in Oplioglossum, and the root. Of 
course, it is quite possible that the peculiar origin of the definitive sporophyte in $O$. moluccanum and $O$. pedunculosum is secondary, but this is by no means necessarily the case. However, it seems highly probable that the extraordinary development of the roots in $O$. vulgatum and $O$. pendulum and the protracted subterranean life in these species constitute a secondary phenomenon associated with the pronounced saprophytic life of the gametophyte.

The apex of the shoot lies in a narrow depression between the base of the leaf and a narrow ridge which extends around it on the side opposite the leaf base. This ridge is the beginning of the conical sheath characteristic of the shoot apex of the older sporophyte. A transverse section of the young apex at about this time shows that the apical cell is triangular in outline.

The first root of the young bud does not emerge until the leaf is nearly complete. From this time on the futther growth is due to the activity of the stem apex, from which new leaves and roots presumably are developed in the same way as in other species that have been studied. How long it is before fertile leaves are formed was not ascertained, but in the rapidly growing species of a tropical climate it is likely that this takes place before long. The occurrence of very small fertile individuals (fig. $55, B$ ) points to this.

THE EMBRYO OF OPHIOGLOSSUM VULGATUM.

The embryo of $O$. vulgatum (Bruchmann 1) differs from that of both $O$. pendulum and $O$. moluccanum in its development, but in the earlier stages it closely resembles the former species. As in $O$. pendulum, the root is the first organ to be developed and it reaches a large size before there is any indication of the formation of a stem apex or cotyledon. Bruchmann states that the root apex arises from the hypobasal half of the embryo, but his figure (fig. I9, $A$ ) of the young embryo, where the root apex is just visible, closely resembles a corresponding stage in $O$. pendulum, where the root is certainly of epibasal origin; and, to judge from the elongated form of the two-celled embryo which Bruchmann figures, one is inclined to believe that the basal wall is really at right angles to the long axis of the embryo, and not parallel with it, as he figures, so that the whole of the hypobasal part might be interpreted as the foot, while the root would be of epibasal origin, as it is in 0 . pendulum.

The next stage figured by Bruchmann (fig. I 9, B) is very much like the type of $O$. pendulum, where only one root was developed at first, and in this case also we are inclined to consider the whole of the enlarged base of the embryo as the foot.

Before the cotyledon and stem apex can be recognized the first tracheary tissue of the root has already been developed, and about the same time the apex of the second root can be seen arising near the base of the primary root (fig. 19, $C$ ).

The cotleydon arises near the base of the root, upon the upper side of the embryo, and forms a small conical protuberance, which grows from a definite apical cell. At the base of the cotyledon, on the side turned away from the root apex, a shallow depression is formed, and in this there may be seen a single large superficial cell, which is apparently the apical cell of the very limited stem apex. Inclosing the cotyledon and the stem apex is an elevated ridge which grows up about them and finally forms a sheath, which rapidly grows so as to include the bud within a cavity completely closed except for a narrow canal which opens outivard.

While the cotyledon and stem apex are thus formed from superficial tissue in $O$. vulgatum, their early inclosure in the sheath suggests that we have to do with a condition intermediate between the completely endogenous shoot apex in $O$. moluccanum and the entirely exogenous shoot in Botrychium. 
The second roof arises quite independently of the stem apex, being developed below the insertion of the primary rout, and its vascular bundle joins that of the firse rone near its base.

A rudimentary vascular bundle is developed within the cotyledon, and also joins the bundle of the main root near its base, but no bundle at all is developed within the stem. The cotyledon reaches only a very' small size, but the second leaf soun appears mearly opposite the cotyledon.

The second leat also develops at an early period a vascular bundle, which connects with the vascular bundle of the primary root near its point of junction with the second rove, and this exactly resembles the arrangement of the bundles in the bud formed upon the root in $O$. moluccamum. It is evident that in the young sporophyte of $O$. sulgatum, as in $O$. moluccamum, the vascular system is made up entirely of the bundles of the roots and leaves, the stem itself having no proper stele.

'The second leaf finally emerges and appears above ground as the first sterile green leaf of the young sporophyte. Bruchmann states that the second leaf does not appear above ground until five years after it is first formed, and he believes that the sperophyte, at the time its first leaf appears above ground, is nine to ten years of age.

The third leaf may be fertile, but this is not always the case.

\section{THE ANATOMY (OF THI: YOUTA SPOROPHYTE OF OPHIOGI.OSSUII.}

In Ophioglossum pendulum the young primary root soon breaks through the prothallium and elongates rapidly, but owing to its britteness it is easily broken off, and it is impossible to state here just how far it develops before the bud is formed upon it. The development of the second root varies a good deal. The first root may reach a length of 3 or + centimeters before the second root can be seen at all. The growth of these earlier roots is in all respects similar to that of the later ones. There is a large tetrahedral apical cell whose divisions are quite regular,

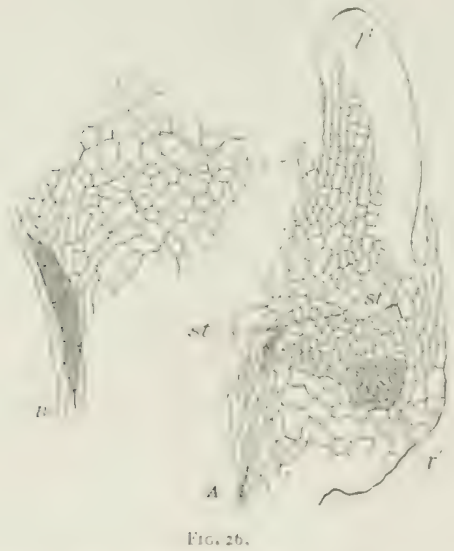

A. Insmgitudinai section of an older bud of Ophioglossum moluscanum. $\times 50$. st, stem aper; $l^{2}$ first leaf of hudi $f^{\prime}$, first rexit of the hus.

13. Stem apex of same. $\times 90$. section. The first ments appear at the foci of the elliptical section. The first appearance of the tracheary tissue is some distance back of the
apex and the development proceeds rather slowly. In the oldest part of the roots bundle which extends for some distance into the foot, where it ends blindly. The vascular bundle of the second root joins the first at the junction of the latter with the foot (fig. 21, D).

The first tracheary tissue appears at the point of junction, and is made up of short, somewhat irregular, pointed tracheids with reticulate thickenings. From this point the development of the tracheary tissue proceeds toward the apex of the roots. The bundle is diarch, as is plainly seen in cross-sections (fig. 27, E). The endodermis is very clearly defined and the characteristic radial markings are extraordinarily clear. especially in sections treated with a double stain of safranine and gentian violet. The tracheary tissue is also beautifully differentiated by this stain. The bundle is slightly. elliptical in form and the protoxylem eleand there is soon visible the axial vascular 
examined the two xylem masses were unequal in size, the larger showing about half a dozen tracheids in cross-section, the smaller two or three. Whether the two protoxylems are ultimately joined by intermediate tracheal tissue, so as to form a continuous plate, as in the older roots of the adult plant, can not now be stated, but in no cases examined was this true, and it is not unlikely that in the primary root the two xylem masses are permanently separated. The cells of the foot, as usual, are more or less papillate where they are in contact with the tissue of the gametophyte. They early become infected with the endophyte, which probably makes its entrance from the prothallial tissue, and not from the outside. This point, however, is not perfectly clear. The infected area follows the growth of the young root, but leaves the apical tissues free.

In O. moluccanum the leaf is the first part of the young sporophyte to develop. In the larger embryos the leaf forms a conical body, merging into a nearly globular basal portion, which is the foot, and within this, probably near the junction of the epibasal and hypobasal halves of the embryo, the apical cell of the root is developed. The leaf now shows a definite apical cell, triangular in section and exhibiting a regular segmentation. The inner cells of the segments form the axial strand of tissue, which is continued through the embryo into the root. The limits of the two
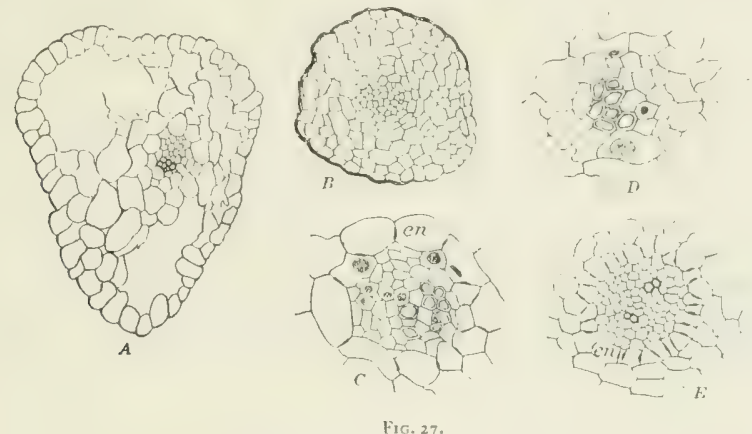

A. Section of petiole of cotyledon of 0 , moluccanum,

B. Section of young root.

C. Vascular bundle of median region of young sporophyte.

D. Vascular bundle of primary root.

E. Vascular bundle of primary root of $O$. pendulum; en, endodermis.

primary organs, the leaf and the root, remain quite indistinguishable. The central region, which remains surrounded by the prothallial tissue, is somewhat larger in diameter and the whole of this functions as a foot, although it is composed in part of tissue belonging to the root and the leaf. The young leaf elongates rapidly after it has ruptured the calyptra, and its apex begins to widen out, but still shows a single apical cell. As the upper part widens out there is a division of the original vascular cylinder, and there is developed within the leaf a reticulate system of vascular bundles or veins (fig. $22, D, E$ ).

As already indicated, the vascular strand of the young sporophyte is continuous through the cotyledon and root, and sections at different points show essentially the same structure. The petiole of the cotyledon (fig. $27, A$ ), which is traversed by two large lacunx, shows that the axial bundle is decidedly collateral in structure. The xylem consists of a group of about half a dozen tracheids at the inner limit of the bundle, and no endodermis can be recognized. As a section of the bundle is made 
in the mid-region of she sporophyte (fig. $27, C^{\circ}$ ), the enly difference noted is a slighty greater development of the xylem. The section of the root (fig. $27, D$ ) presents almost exactly the same appearance as that of the leaf. Whether we should call the goue bundle "monareh" or "collateral" is merely a question of terms. In the midregion the endodermis can be clearly seen, and it is then evident that the xylem is separated from it by a single layer of pericycle cells.
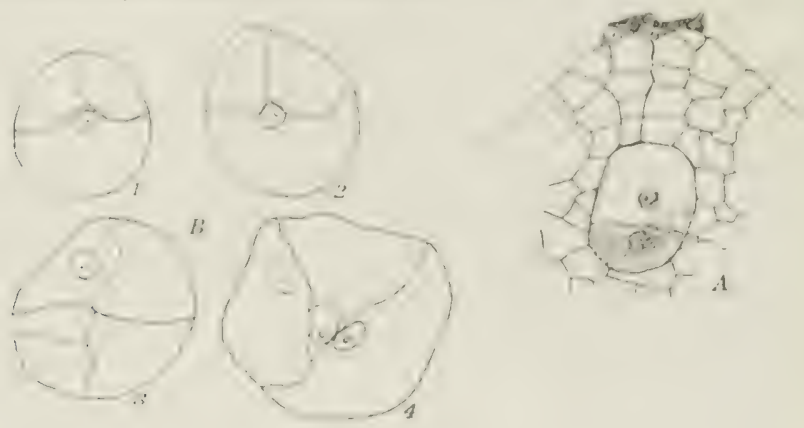

A. Archegonium of Borrychium virginianum, containing a two-celled embrym. $\times 275$.

B. Four longitudinal sections of an embryo with 7 cells. $\times 275$.

\section{THE, EMBRYO OF BOTRYCHIUM.}

The following account of the development of the embryo of Botrychium is based mainly upon material of $B$. virginianum furnished me through the kindness of Professor Jeffrey.

In this species, as in the other Kusporangiatie, there is a marked increase in the size of the fertilized ovum before the first division takes place. At the time of the

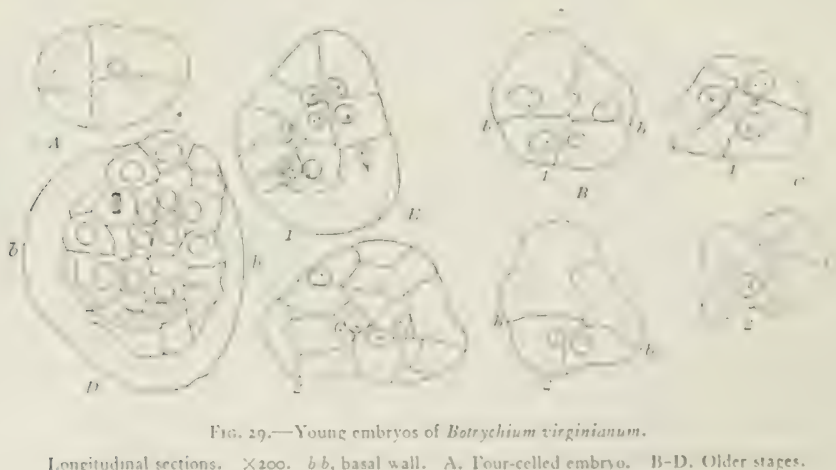

first division the ovum is generally more or less elongated, but this is not always the case. This elongation is less marked in B. lunaria (fig. $3^{6}$ ), while in B. obliquum the ovum becomes much elongated before the first division occurs (see Bower 9 , tig. 266). 
The first division wall, the basal wall, as in the other Eusporangiatx, is, usually at least, transverse to the axis of the archegonium (fig. 28, $A$ ). Each of the cells thus formed is next divided by a vertical wall, so that the embryo is divided into approximately equal quadrants. Jeffrey states that the quadrants are next divided by a third (transverse) wall, so that there is a regular octant formation (Jeffrey 1, page I6), but adds that this segmentation presents various irregularities and this is confirmed by my own studies of the young embryo. In B. lunaria, according to Bruchmann, the octant divisions are very regular.

In $B$. virginianum the young embryo is often somewhat pointed above, and transverse divisions of such embryos may show that the octant formation is suppressed in the epibasal region, and this tapering upper part of the young embryo suggests a suspensor similar to that developed in Danaa, but less clearly defined, and probably not determined by the first division of the embryo. Whether the suspensor found by Lyon in B. obliquum (Lyon 1) originates in a similar fashion remains to be seen. This elongation of the upper part of the embryo, whether it

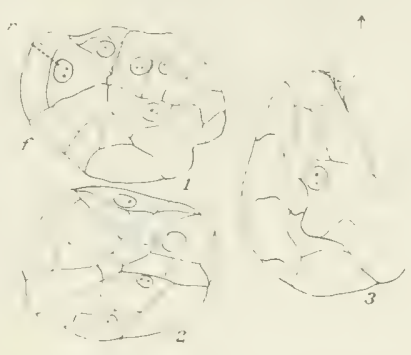

Frg. 30.-Three longitudinal sections of a young embryo of Botrychium virginianum. $r$, the root; $f$, the foot. $\times 200$. is considered as a suspensor or not, is doubtless, as Jeffrey has suggested, useful in pushing the developing embryo deeper down into the prothallial tissue.

For some time, only anticlinal walls are formed, this showing especially plainly in transverse section (fig. $3 \mathrm{I}$ ). Sooner or later periclinal walls are also formed, and it is possible that in some cases the first periclinal wall in one of the large epibasal cells may establish the initial cell of the root, but this is hard to decide. The early stages of the embryo are extremely difficult to embed without shrinkage, and this, together with the difficulty of securing a sufficient number of the right stages and the impossibility of regulating the direction in which they are cut, makes the determination of the origin of the primary organs of the young embryo a peculiarly difficult problem.
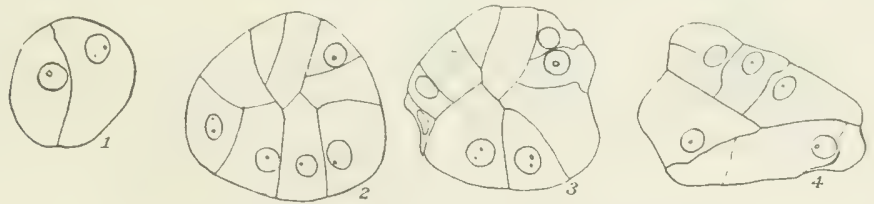

Fr6. 3r.-Four horizontal sections of a young embryo of $B$. virginianum.

$I$ is next the archegonium; 2 and 3 are nearly median sections.

Neither Jeffrey nor Bruchmann was able to recognize a root initial until the embryo had attained a large size, and its origin could not be determined. In the embryo shown in fig. 30 , I am inclined to believe that the cell $r$ is really the root initial. Unfortunately, stages between this and the one shown in fig. 32 , where the root initial is unmistakable, were wanting, but the position and state of development of the root in the latter harmonize with this supposition. My fig. 32 is evidently of about the same size as Jeffrey's fig. 46, and probably an examination of other sections of the series from which Jeffrey's figure was drawn would show the root initial, as well as traces of the stem apex and cotyledon. 
All of the organs of the young sporephyec arise, as Jefficy showed, from the cpibasal region, and in this respect Betrychiom airginianum agrees with the Marat-

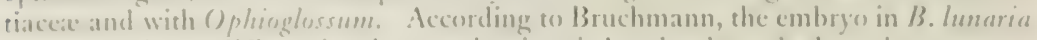
remains guite undifferentiated up to the time it breaks through the calyptra, even the rout apex being unrecognizable at this time. It is therefore impossible to say what relation the organs of the young sporophyte bear to the primary divisions of the embryo.
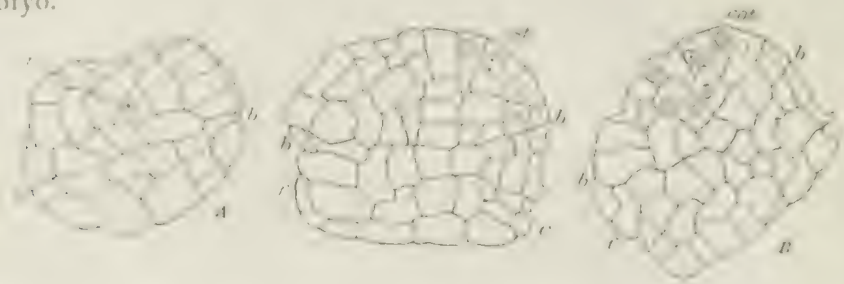

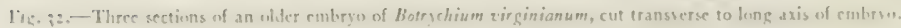

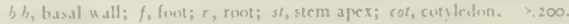

In B. sirginianmm traces of the quadrant formation are still evident at a comparatively late stage, and there seems no reason to doubt the correctness of Jeffiey's conclusion as to the epibasal origin of both the root and the coryledon. As in Ophioglossum pendulum and $($ ). r'ulgatum, the root is especially conspicuous and reaches a large size, while the stem apex and cotyledon are still inconspicuous. Indeed, in B. Inuaria, according to Bruchmann, no trace of either stem apex or
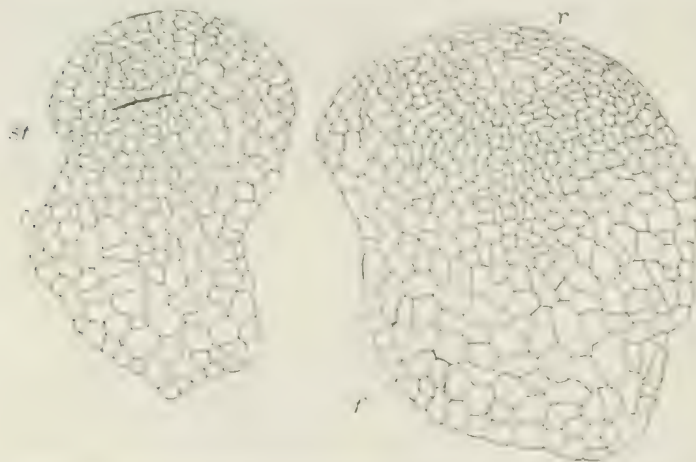

Fir.. 33.-Turo sections of an older embryo of Bosrychium tirginianum, cut in the plane of the cotyledon.

st, stem apex; t, root; f, foot. $\times 100$. cotyledon can be made out until the root has broken through the calyptra. At this stage (fig. $3(0, C, D)$ the embryo of 13 . Lunaria bears a striking resemblance to that of ()phioglossum qulgatum.

It was found by Jeffrey in B. Eirginianum that the stem initial was developed before the cotyledon could be seen, but I have failed to verify this in the specimens I have examined. Fig. 32 shows three sections of a series taken from an embryo of

about the age of Jeffrey's fig. $7^{6}$. 'This embryo was cut transversely to its long axis, and the root apex is thus seen in cross-section. The root here probably comprises the whole of one of the epibasal quadrants, from the other of which, or from part of it, perhaps a single octant, the stem apex and cotyledon arise in close proximity. It is probable that part of this quadrant goes to form the "suspensor," or that epibasal tissue which is not concerned in the formation of the young organs of the embryo. Fig. $32, B$ shows a section passing through the young cotyledon, whose single apical cell is already differentiated. This in section is triangular, and the cell is probahly of tetrahedral shape. Fig. $32, C$, shows the section passing through the stem apex. 
Probably the large cell $(s t)$ is the apical cell, but this is not absolutely certain. In form and position this cell resembles the apical cell figured by Jeffrey (Jeffrey $\mathbf{I}$, fig. $4^{8}$ ) in an older embryo. It may be said that in Jeffrey's figure the beginning of the cotyledon, situated between the stem apex and the root, although not lettered, is evidently present.

As the embryo grows the root rapidly increases in length, and together with the foot comprises the greater part of the embryo. The foot is very large, usually nearly hemispherical in form, but not infrequently a good deal elongated (fig. 35), and penetrates deep into the prothallial tissue.

The apical cell of the root is very conspicuous and can be made out without difficulty as a large cell, triangular in form, whether it is viewed in longitudinal or transverse section. Segments are cut off in regular sequence from all of the four faces, and as these are relatively large and contain but little granular contents the apical meristem shows very clearly against the smaller celled and more deeply stained

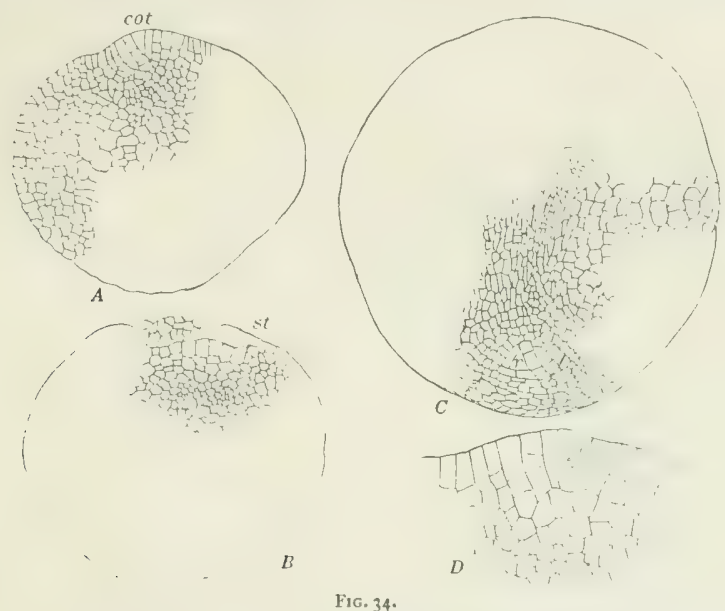

A-C. Three horizontal sections of an old embryo of Boirychium virginianum. $\times 75$.

D. The stem region. Xi50.

adjacent tissue. In the earlier stages the divisions in the segments cut off from the apical cell do not show absolute uniformity. The first wall in the young segment is probably anticlinal, and seems to be followed by a periclinal wall or walls, cutting off inner cells which contribute to the very large plerome cylinder of the young root. The root cap, which is very massive, is derived in part from segments cut off directly from the apical cell, and in part from cells separated by periclinal walls from the outer part of the lateral segments of the apical cell.

The development of the plerome begins very early, and it soon forms a conspicuous massive strand of procambium cells extending from the root apex to the junction of the root and foot, where it ends abruptly on the lower side, but bends upward on the upper side, and is extended as a simple axial strand of tissue in to the cotyledon.

The cotyledon, which is first recognizable at an early stage in the development of the embryo, at the stage in question (fig. $35, A$ ) projects slightly as a broad, flattened cone, strongly bent away from the root. Fig. $34, A$, shows the cotyledon cut 
rhough horizontally. At she slighty projeceing apex there is a single apical cell, although it is mot alway's quite certain which is the apical cell and which is its gromgest segment. The broad base of the cotyledon is extended laterally, like the stipules of the older leaves, and there is thus inclosed a slightly depressed area, very much as in the embryo of Ophioglossum rulgatum, and within this is situated the stem apex, close to the base of the cotyledon, which bends over it so as to leave only a narrow space above the stem apex. A section across the base of the cotyledon shows a group of small cells indicating the section of the young vascular bundle which lower down (fig. 3t, $C$ ) joins the young bundle of the primary root.

The relative position of the young organs just before the root ruptures the calyptra is best seen in a longitudinal section. Such a section (fig. $35, d$ ) shows the very large foot, occupying approximately half of the embryo, and deeply embedded in the prothallium. Above this is the root, occupying the major part of the epibasal region of the embryo and varying somewhat in position, perhaps due to the early divisions in the young embryo. It may lie in a plane almost coincident with the cotyledon, or it may make a marked angle with the latter. In the former case the

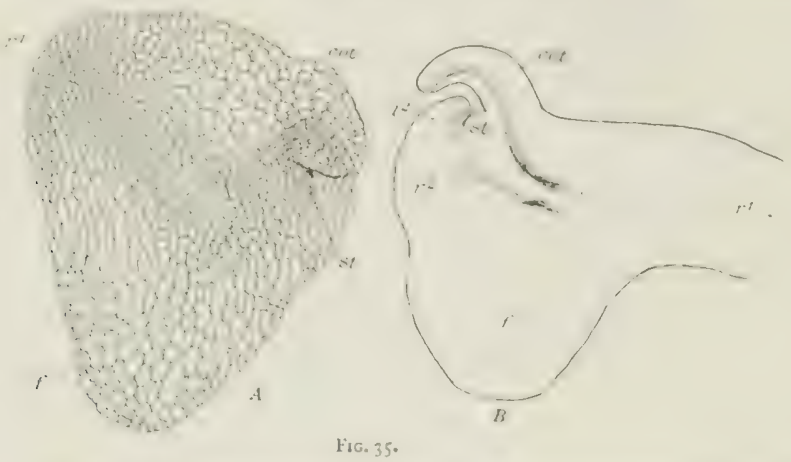

A. Mectian section of a young sporophyte of Botruchium tir ginianum about to emerge. $X$ about 50 .

11. An older stage; $l^{2}$, second leaf; $r^{2}$, second root. $X_{20}$.

young vascular cylinder is continued almost straight into the cotyledon; in the latter it bends sharply upward to meet it.

The stem apex, which is usually more or less oblique, is small and inconspicuous, but usually a single initial cell may be made out without difficulty, although sometimes it is not easy to distinguish this from the younger segments which have been cut off from it, as the apical meristem is very shallow, and in longitudinal section has the appearance of a columnar epithelium.' 'There seems to be, at least in the earlier stages of development, some variation in the form of the initial cell, which may have a pointed base, or may be truncate below, and while later it usually shows the form of a three-sided pyramid, in these earlier stages it often approximates the truncate form found in Ophioglossum moluccanum.

The apical meristem of the stem is very limited in extent and, so far as could be made out, the segmentation at first does not follow any regular scheme. While in both root and cotyledon a central strand of procambium is developed at a very early period, no trace of anything which can be interpreted as a "stcle" is formed in the young stem. The tissues derived from the further segmentation of the apical meristem remain undifferentiated parenchyma and contribute only to the central pith of the hollow woody cylinder which later traverses the axis of the young 
sporophyte. In short, the strand of vascular tissue in the young sporophyte at the time the first root emerges is composed solely of the coalescent strands of the root and leaf exactly as is the case in the young sporophyte of Ophioglossum moluccanum, and there is absolutely no trace of a cauline stele.

The foot is composed of large parenchyma cells, which become smaller towand the periphery, where they usually show moreor less dense contents and sometimes form a quite definite layer of epithelium-like cells, which stain much more deeply than the inner tissue of the foot. This outer layer of cells is presumably active in the absorption of nutriment from the adjacent prothallial tissue. Bruchmann states that previous to the emergence of the root of the young sporophyte of $B$. lunaria the cells of the embryo are densely packed with granular matter of apparently albuminous nature; but after the emergence of the root starch is developed abundantly in the cells of the foot. This appears to be true also of $B$. virginianum.

Compared with $B$. virginianum, the embryo of $B$. lunaria (fig. $3^{6}$ ) is characterized by the lesser development of the foot and the later appearance and rudimentary character of the stem apex and the cotyledon.

The stem apex in B. lunaria (Bruchmann 2) is first evident as a slight superficial depression near the base of the massive root. A single superficial cell becomes differentiated as the apical cell of the shoot, and a small group of cells is formed before the rudimentary cotyledon develops. Both stem apex and cotyledon remain very inconspicuous. The cotyledon is developed as a scale-like rudiment, which never develops into a foliage leaf. Bruchmann states (Bruchmann 2, page 223) that from seven to nine of these rudimentary leaves are developed before the first green leaf appears above the earth. Hofmeister (Hofmeister 1) believed that three of these rudimentary leaves were developed during the first year, and that the second year the first spore-bearing leaf appeared above ground. Bruchmann thinks that this is not the case and that the first spore-bearing leaf requires five years for its development, as it does in the older sporophytes, and that only one leaf is formed each year, as in the older plant.

The first organ to penetrate the calyptra is, as we have seen, the root, which in $B$. virginianum is very large and quite overshadows the relatively inconspicuous bud at its base (fig. $7, B$ ). At the time the root first emerges the vascular bundles still have the form of procambium, and it is not until the young root has a length of several millimeters ( 5 to 20 millimeters, according to Jeffrey) that the first tracheary tissue is developed. The first tracheary tissue arises at the base of the root and the development, as usual, proceeds toward the apex. The primary root in Botrychium virginianum is usually diarch, but triarch roots are sometimes found, and Jeffrey says that the size of the root has no relation to the number of protoxylems formed. The first tracheids are short and reticulately marked, as they are in Ophioglossum. The surface of the root is quite destitute of root hairs, as is the case in the adult sporophyte.

In $B$. Innaria the predominance of the root over the shoot is even more marked than in $B$. virginianum, for there are several roots, sometimes four to five, developed before the first foliage leaf is formed, and the bud remains extremely small and inconspicuous.

A longitudinal section of the cotyledon of $B$. virginianum, just before it breaks through the overlying calyptra, shows it to be strongly curved away from the root and overhanging the cleft within which lies the stem apex. If the section is exactly a median one, there may be seen near the tip, but lying somewhat toward the lower side, a marginal cell of triangular outline, which, from the arrangement of the cells about it, is evidently the apical cell. The cotyledon, instead of being straight as it 
is in Ophioglossum and Butrychium Iunaria, approaches the circinate form of that of she Maratriacea and the typical ferns. 'The young vascular bundle is now clearly' evident, lying somewhat toward the inner side of the leaf, and it can be readily followed downward until it joins the root bundle, with which it is continuous.

In B. virginianum, while the cotyledon is still quite small, the second leaf appears close to the stem apex and nearly opposite the cotyledon, the sheathing base of which surrounds the stem apex, together with the young second leaf. The growth of the second leaf is also probably from a tetrahedral apical cell, and this is the case with all of the later leaves. While the second leaf is still very small, there begins the differentiation of the corresponding leaf trace, which joins the bundle of the primary root close to the point at which it gives off another bundle destined for the second root, the apical cell of which is cut out from the tissue near the base of the second leaf, at a point almost directly opposite the cotyledon. Indeed, the second root may be said to bear much the same relation to the second leaf that the primary root does to the cotyledon (fig. $35, B$ ).

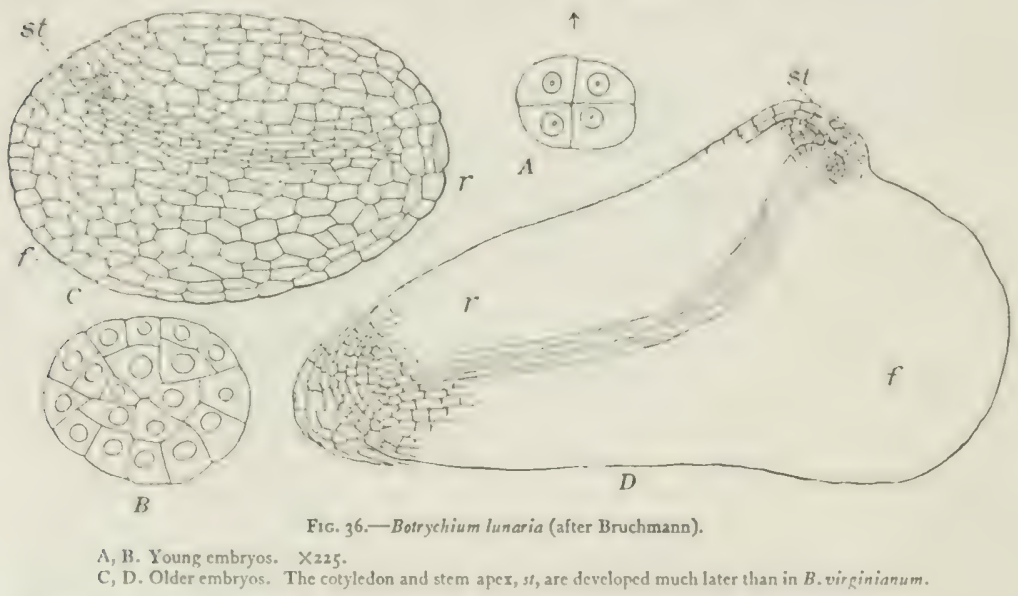

The cotyledon in B. virginiamum (fig. 7) is extraordinarily developed, reaching a size that probably is unequaled by any other fern. Its slender petiole reaches a length of 5 to 6 centimeters, and the lamina, unlike the simple oval primary leaf of Ophioglossum, is ternately divided and the segments deeply cut. The venation, instead of being reticulate as in Ophioglossum, is apparently pinnate, but this is really the result of an unequal dichotomy, as it is in the ultimate branches of the veins in most ferns.

The base of the petiole forms a stipular sheath like that found in the later leaves, and it is traversed by two vascular bundles, which unite into a single trace before joining the bundle of the root.

While in B. Iunaria all of the early leaves remain rudimentary, and the first one to appear above ground is a fertile one, there are sometimes intermediate stages which may show a small ternate lamina and traces of the fertile spike, although they never appear above ground (see Bruchmann 2, fig. 50).

If horizontal sections of the young sporophyte are examined, at about the time the cotyledon first emerges (fig. 41 ), the latter will be seen to have the form of a 
crescent, the horns of which unite at about the level of the stem apex, so that the latter, together with the section of the second leaf, is completely inclosed by the sheath formed at the base of the cotyledon. The leaf trace in both the cotyledon and the second leaf is broadly oval in outline, increasing in breadth lower down, so that the section there becomes crescent-shaped and the two together form an imperfectly closed ring of small cells, the procambium of the future vascular cylinder of the axis, which clearly is formed entirely from the united leaf traces.

The apical cell of the stem appears triangular in cross-section, and from it are cut off regular segments, but, as we have seen from the study of the longitudinal section, the tissues which are developed from these segments below the apical cell remain undifferentiated and form merely a mass of large parenchyma cells with thin walls, which fill the space within the ring formed by the confluent leaf traces, and thus constitute the pith or medulla of the stem.

Jeffrey (Jeffrey 1, page I9) refers to the occurrence of short tracheids in the prothallial tissue in one case which came under his observation. There was some evidence that an embryo had been present, but it had disappeared, and he thought it possible that this was a case of apogamy, similar to that which has been repeatedly. observed in Pteris cretica and in various other leptosporangiate ferns. If apogamy does really exist in $B$. virginianum it is the only case which is known among the Eusporangiatæe

Botrychium obliquum (Lyon 1) differs strikingly in the form of the embryo from either $B$. virginianum or $B$. lunaria, and these differences are so marked that Lyon proposes to separate $B$. obliquum and a number of allied species as a new genus, Sceptridium. The ovum in Botrychium obliquum becomes very much elongated after fertilization, and it is probable that the first wall separates the part next the archegonium from the inner cell, the former developing into a suspensor, very much as we shall see that it does in Danca, and this suspensor becomes well developed and is conspicuous in the later stages of the embryo. Unfortunately, Lyon gives no details of the further history of the embryo until the definitive organs are far advanced. He states that the suspensor becomes elongated, pushing down the rest of the embryo, which he calls the "protocorm," believing that it is homologous with the so-called "protocorm" of Lycopodium-a resemblance which would probably disappear were a more thorough study of the subsequent history available. This development of a suspensor is the first case described in the ferns, but, as we shall see presently, a similar suspensor is regularly present in the genus Danca, which in other respects shows some interesting resemblances to $B$. obliquum in the development of the embryo. Moreover, as we have seen, there is often an elongation of the upper cells of the young embryo of $B$. virginianum, which suggests a rudimentary suspensor.

Lyon figures only a very advanced stage of the embryo, at about the time when the root first emerges from the prothallium. At this time, aside from the presence of the suspensor, the most marked difference between $B$. obliquum and $B$. virginianum is the apparent absence of the foot in the former species, while this organ is so remarkably developed in $B$. virginianum. The root in $B$. obliquum penetrates the lower surface of the gametophyte, the cotyledon breaking through on the upper side, so that the relative position of the leaf and root is like that of Ophioglossum moluccanum, or the Marattiacex. In the orientation of the root and shoot, therefore, $B$. obliquum is much more like Danaa or Ophioglossum moluccanum than it is like $B$. virginiantm.

It is to be hoped that further investigations will be made upon this extremely interesting species. We anticipate that when the history of the earlier stages is 
known it will be found that a large foot is present in the embryo, as it is in the Matratriacese and the other Ophioglossacee, and the apparent absence of this fout in the older embryo is due to the root apex being formed deep in the central tissue of the (mbrye, as it is in the Marattiacese and in Ophioglossum moluccomm, and pushing its way downward through the foot, which thus becomes indistinguishable from the outer tissue of the root.

Lxcept for the absence of the foot the organs of the older embryo of B. obligun show the same relative positions as those of $B$. virginianum, and, as in the latter, the first leaf is apparently a functional green leaf which appears above the surface of the earth.

\section{TIIE EMBRYO OF IIELMINTHOSTACHYS.}

The embryogeny of Hclminthostachys, the third genus of the Ophioglossaceac, is unfortunately very incomplerely known. Lang (Lang I), to whom we owe the only published account of the gametophyte and young sporophyte, was unable to secure any young embryos and only very scanty material of the later stages. Lang says of the youngest forms which he found (I ang I, pace 40):

"The large hemispherical foot is deeply inserted in the tissue of the prothallium. The upper postion of the embryo had burst through the covering also of the latter: in it can be distinguished the primaty root-the first leaf-and covered oree hy the sheath of the first leaf) the depressed apex of the stem. The position of the organs is thus essentially similar to what is found in Botrychium rirginumum."

Lang's material was collected in the Barrawa Reserve liorest, in Ceyton, and in february 1900 I visited the same locality and collected a large number of young sporophytes, many of which were still connected with the gametophyte: hut none of the gametophytes were young enough to show young embryos. As we have

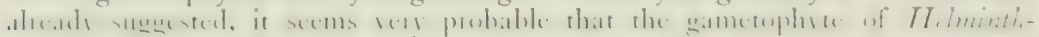
ostachys, like that of $O$ phioglossim moluccomm, is annual and produces normally a single sporophyte, after which it perishes. The development of the gametophyte is

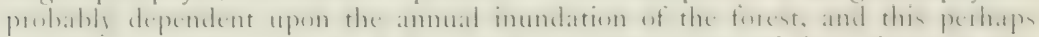
accounts for the fact that all of the young sporophytes were of about the same age.

The youngest specimen which $I$ found is shown in fig. 10. The petiole of the leaf was about $x$ centimeter in length, and at the tip the minute lamina, strongly bent over like the young leaves of Botrychium virginianum, could be seen, showing

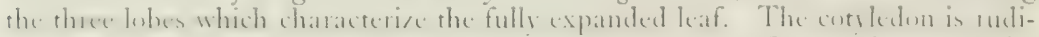
mentary in Helminthostachy's, the "cotyledon" described by Lang being really the second leaf. At the base, but separated from the root by a short internode, is a swelling which marks the position of the apical bud, inclosed within the hollow sheath at the base of the petiole. 'The root at this stage is still quite short, the first green leaf seeming to be more precocious than in Botrychium and thus resembling Ophioglossum moluccanum.

As the leaf grows the lamina expands and is seen to be ternate in form. Very often the two lateral lobes are of unequal size and show that the ternate form is due to an unequal dichotomy, such as is common in many ferns in the early leaves, which are transitional between the dichotomously divided cotyledon and the pinnate leaves of the older sporophyte. The ultimate divisions of the veins, as in Botryelsium, are dichotomous. *

- In a recent note (Lang 2 ) it is stated that a suspensor also occurs in ILelminithostachys. 


\section{THE YOUNG SPOROPHYTE.}

\section{THE YOUNG SPOROPHYTE OF OPHIOGLOSSUM.}

As we have seen, the single vascular strand in the young sporophyte of Ophioglossum moluccanum is continuous through the cotyledon and root, and sections at different heights show essentially the same structure throughout. The petiole of the cotyledon (figure $27, A$ ), which is traversed by two conspicuous lacunæ, shows that the axial bundle has a perfect collateral structure. The xylem consists of a group of about a half dozen tracheids on the inner side of the bundle, of which the endodermis, however, is not evident. If a section made in the mid-region of the plant is examined, the only difference between its bundle and that within the petiole of the leaf consists in the somewhat greater development of the tracheary tissue. The section of the root bundle also almost exactly resembles that of the leaf. Whether we call the root bundle monarch or collateral is merely a question of terms.
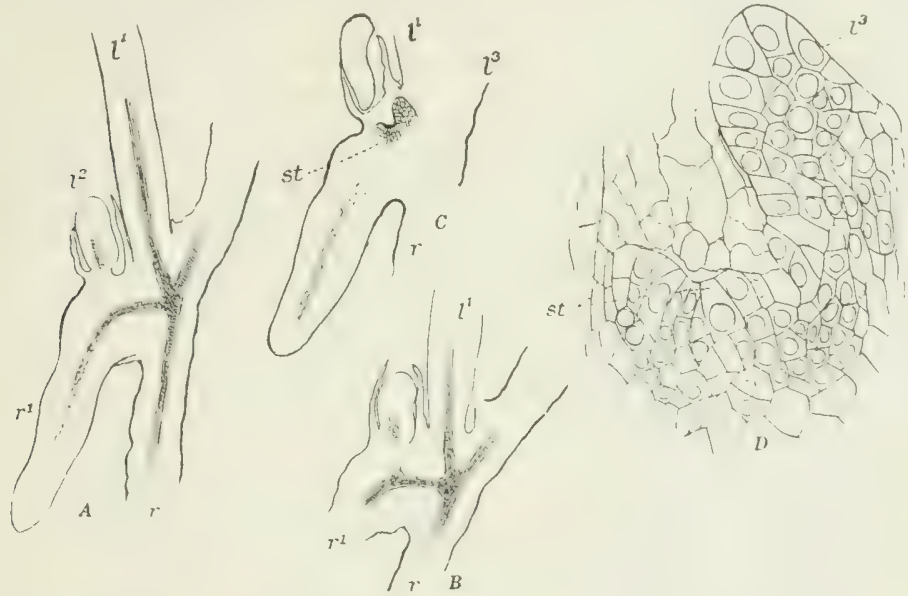

Fic. 37 .

A-C. Three sections of a young sporophyte of 0 phioglossum moluccanum with the first leaf, $l^{1}$, of bud fully developed; $r$, primary root of sporophyte; $r^{2}$, first root of bud; $l^{2}$, second leaf of bud.

D. The stem-apex more highly magnified, showing the third leaf, $l^{3}$.

In the mid-region of the sporophyte the endodermis is well marked, and this is even more the case in the root. In the mid region the xylem is separated from the endodermis by a single layer of pericycle cells.

About the time that the leaf emerges the first root of the bud begins to develop, and, like the leaf, it seems to arise quite independently of the stem apex. The tetrahedral apical cell is cut out from the cortical tissue of the root some distance below the apex of the young bud, and as soon as the apical cell is established active segmentation begins in the tissue below the bud and a strand of procambium is developed, connecting the young root apex directly with the vascular bundle of the primary root. Thus the vascular bundles of both the first leaf and the first root of the young bud are directly connected with the primary root of the young sporophyte and have nothing to do with the tissues in the apex of the stem of the bud, which is still very small. 
The two bundles, belonging respectively to the leaf and the root of the bud, join the bundle of the primary root very near together, and from near this point of junceron the development of the tracheary tissue proceeds toward the apices of the young organs. The first tracheids, like those found in the median region of the young sporophyte, are short reticulate ones.

The first leaf of the bud grows rapilly and closely resembles the cotyledon in firm and size, and at first it often looks as if two young sporophytes of equal size were growing from the prothallium, but a very slight examination shows that the second leaf belongs to the bud upon the primary root. The second leaf of the bud also seems to be formed independently of the stem apex and arises nearly opposite the first one (fig. $37, A$ ). Its development is practically the same as that of the first leaf, and it pushes through the outer tissue of the root at a point removed by an appreciable distance from the base of the first leaf, from which it is separated by a sheath about the base of the latter, formed by the outer root tissues.

The vascular bundle in the second leaf is soon developed and can be followed down to the bundle of the first root of the bud, to which it bears somewhat the same relation that the bundle of the first leaf of the bud does to the primary root of the sporophyte. Fig. 37 will show clearly the arrangement of the vascular bundles in a young bud in which the first leaf is fully developed, while the second and third are pretty well advanced. The latter $\left(l^{3}\right)$ shows very plainly the conspicuous apical cell and the beginning of the leaf trace. 'The apical cell of the stem at this time is sufficiently conspicuous, but the amount of tissue surrounding it is quite limited in extent. In fig. $37, D$, it is probable that the fourth leaf has begun to develop. Above the apex of the stem the cavity of the leaf sheath can be clearly seen. By this time the first root of the bud has emerged below the first leaf and the tracheary tissue is well developed in its basal region.

The second root of the bud originates below the apex of the stem in the vicinity of the base of the second leaf. The vascular strand of the third leaf joins it, and the third leaf seems to have somewhat the same relation to the second root that the second leaf does to the primary root.

The study of the development of the young bud shows that, up to the time of the production of the third leaf, the young organs arise quite independently of each other from the tissue of the primary root. The young sporophyte is, so to speak, made up by the union of several independent members. The third and fourth leaves arise from the stem apex as all of the later ones do, but the first and second leaves and the first root show no recognizable relation to the stem apex. Their vascular bundles are directly connected with the bundle of the primary root of the young sporophyte, and are in no way associated with the tissues which belong to the stem region of the bud. No material was available for the study of the origin of the leafy bud in $O$. pendulum, but the first leaf evidently develops very much later than it does in 0 . moluccanum. Young leaves 10 centimeters or more in length were found, which, there is some reason to suppose, were the primary leaves of the young plant; but they were not recognized as such at the time they were collected and it is therefore impossible to say whether they really were the first leaves developed. After the study had been made of the young sporophyte in $O$. moluccanum, and the secondary origin of the stem apex was made out, it was recognized that these small leaves in (). pendulum also were probably the primary leaves of the plant, but it was ton late then to trace the connection of the roots from which they developed to their connection with the primary root of the young sporophyte.

I was umable of determine just how soon the fertile leaves are developed from the young sporophyte in (). moluccanum. In all of the specimens that were sectioned, 
the first three or four leaves were sterile and practically like the cotyledon, and it is not certain which leaf, under ordinary circumstances, first gives rise to the sporebearing spike. In O. moluccanum and the other tropical species of Ophioglossum growth is continuous, and it is evident that the development of the leaves does not take the long period required in $O$. vulgatum and other species of temperate regions, where growth is interrupted each year and where only one leaf is developed in the

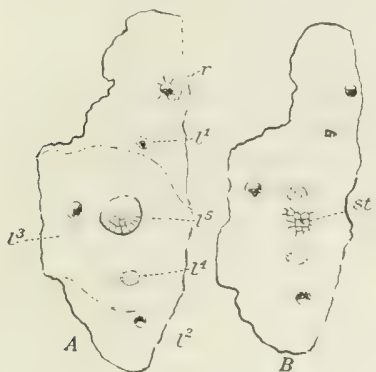

Six of a series of uranswerse sections of a young sporophyte of 0

FiG. 38 .

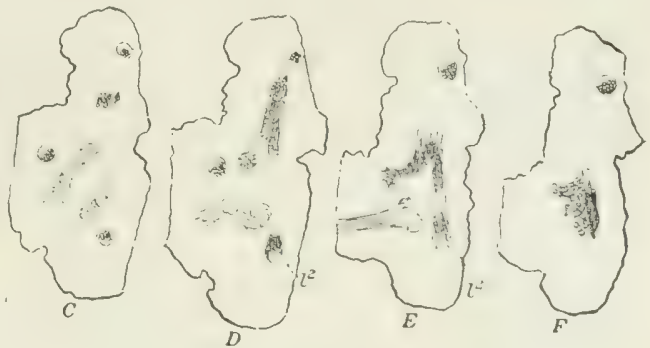
root, $r$. Section $B$ passes through the stem apex. $X_{35}$.

season. Mettenius states that $O$. pedunculosum, which, as we have seen, may perhaps be identical with $O$. moluccanum, develops three leaves each season. This was in the Botanical Garden at Leipzig, and it is highly probable, under the much more favorable conditions of its native tropical habitat, that this number would be exceeded. There was not time to make investigations in regard to this

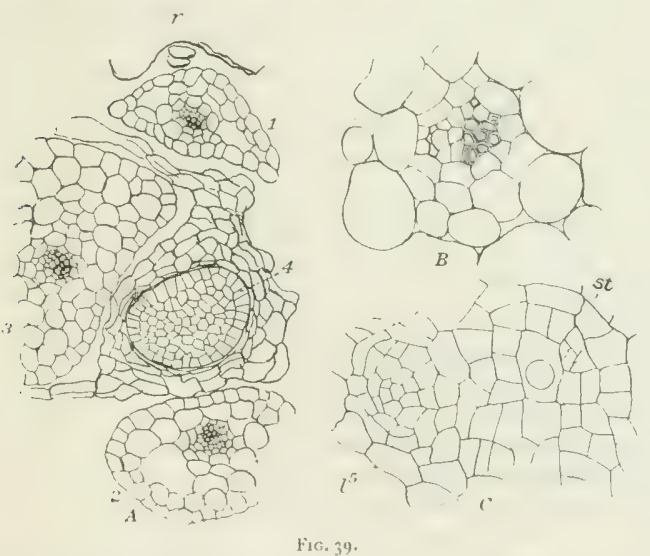

A. Section of the sporophyte shown in fig. 38 , showing arrangement of leaves; $r$ is the primary root. $X$ about 60 .

B. Vascular bundle of first leaf, more highly magnified.

C. Stem aper, showing youngest leaf trace, $I^{\text {s }}$; st, apical cell of stem. point, but it is very certain that several leaves are developed in the course of each year and that the development of the individual leaf does not require the long period necessary in the species of cold climates.

Figures 38 and 39 show several transverse sections forming a series taken from a young sporophyte with three fully developed leaves and two younger ones. This bud was developed from a small root, but it was not certain that this was the primary root of the embryo. The spirally arranged leaves show the two-fifths divergence. The second and third leaves of this bud were successively larger than the first leaf, but the section of the petiole showed a single centrally placed vascular bundle of the same type as that of the primary 
leaf and all of these leaves were sterile, nor could any indication of the develope ment of a central spike be seen in the development of the fourth leaf. The first leat of the bud, like the cotyledon, showed two large lacuna in the petiole, but in the second leat there was but a single one and this was interrupted at intervals, while the petiole of the third leaf appeared almost solid, there being only small, irregular, intercellular spaces, such as are always found in any loose parenchyma. All if the vascular bundles are collateral. In the lower portion of the third leat deven eracheids could be seen in the transverse section of the bundle, but higher up the amount of tracheary tissue was reduced.

liges. $38, A$, and $39, A$, were cut just above the stem apex and showed clearly the arrangement of the first four leaves. The youngest leaf is still entirely surrounded by the conical stipular sheath belonging to the third leaf. Fig. $38, A$, is taken immediatcly above the stem apex and passes through the very young fifth leaf. This section shows very satisfactorily the arrangement of the first five leaves. Section $C$ lies a short distance below the stem apex. $r$ is the root from which the bud has arisen, and the group of tracheids at its junction with the bud marks the point of union of the bundles of the first leaf and the first root of the bud. In the center of the section may be seen a mass of laree-celled parenchyma, the eentral pith of the stem, which is derived from the large-celled meristem of the stem apex. The broken ring of presambium surrounding the pith is composed of obliquely cut traces of the fourth and fifth leaves and the basal tissue of the second root of the bud. Clihe leaf traces from the second and third leaves are still free in the cortical tissue of the young stem. I: and $F$ pass through the base of the bud. The stout bundle of the first root is seen connected with the bundle of the root upon which the bud was dereloped, and the second leat trace $\left(l^{2}\right)$ bends in to meet the bundle of the root but is cut at al level above the point of junction. Close to the second leaf trace is the lower part of the fourth leaf trace, which is connected with the trace of the second roos of the bud. The steles of both the first and second roots of the bud run horizontally across its base before they emerge, and the leaf traces are almost perpendicular to these. The second leaf trace at the base of the bud joins the stele of the first root and the short tracheids curve out rrom the opposite side of the bundle of the first root to unite with the base of the third leaf trace, which does not, as might have been expected, show any very obvious relation to the second root. At the point where the first root bends downward to emerge from the overlying cortical tissue the tracheary tissue of this, with the bases of the leat traces, forms a large mass of irregular, broad, reticulate tracheids, occupying the center of the base of the young bud. It was probably the presence of this mass or tracheary tissue at the base of the hud which led Rostowzew to state that the bundle of the bud is at first solid. It is possible that the buds formed on the old roots of $O$. vulgatum may be somewhat different in structure from the early buds in $O$. moluccanum and that there really may be such a solid stele at its base.

According to Rostowzew (Rostowzew 1, 2) and Poirault (Poirault 2), the buds upon the older roots of $O$. vulgatum usually arise close to the apex, much as they sometimes do in the formation of the bud upon the primary root of $O$. moluccanum. Van Tieghem thought that the apex of the root itself became changed into the leafy shoot, but both Poirault and Rostowzew demonstrated that the young bud origimated from a segment of the apical cell of the root and not from the apical cell itself; the latter continues its growth and the root thus grows beyond the point of insertion of the young bud. Rostowzew states that an outer cell of the segment divides into two superimposed layers, of which the superior one, or the one nearest the root apex, gives rise to the stem apex of the bud, while from the lower 
one, $\mathrm{i}$. e., the one turned toward the base of the root, the first leaf arises. It thus appears that in these adventitious buds in Ophioglossum iulgatum there is much the same arrangement of the first organs of the young bud that we have seen to be the case in $O$. moluccanum, the leaf and the stem apex being virtually independent organs. From Rostowzew's figures it is evident that the bundle from the first leaf of the bud in $O$. vulgatum is connected directly with the main root in very much the same way as it is in the primary bud in O. moluccanum; but apparently the first root of the young bud is inserted higher up and does not connect directly with the primary root; this point, however, needs further elucidation. Moreover, according to his statements, there is a good deal of difference shown as to the time of the emergence of the leaves and roots, three or four roots sometimes being well developed before the first leaf expands. This reminds one of the behavior of the primary sporophyte, where Bruchmann found that several roots were developed before the first green leaf made its appearance.

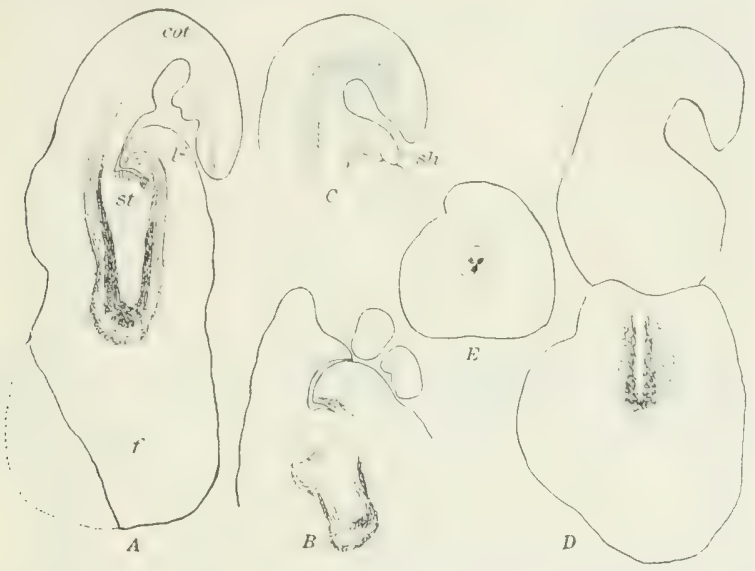

Frg. 40.- Vertical sections of a young sporophyte of Borrychium virginianum. The sections were cut at right angles to the axis of the root. sh, stipular sheath of cotyledon; E, section of primary root, which in this case was triarch. $\times_{20}$.

\section{THE YOUNG SPOROPHYTE OF BOTRYCHIUM.}

Jeffrey (Jeffrey 1) has described at some length the structure of the young sporophyte of $B$. virginianum, and Bruchmann (Bruchmann 2) has studied the earlier stages of the sporophyte in B. lunaria. The present account is based mainly upon my own studies of $B$. virginianum, made from material furnished me through the kindness of Professor Jeffrey. Xeffrey found that from the beginning the conspicuous stele found in the axis of the young sporophyte was a hollow cylinder, which he assumes to be a really cauline structure, and not made up of leaf traces. The results of my own studies indicate that, as in the case of Ophioglossum, the vascular system of the stem is made up exclusively of confluent leaf traces.

Fig. 35, $B$, shows a longitudinal section of a young sporophyte in which the first two leaves are evident and the continuation into these of the tissues of the vascular bundle of the root is very clear. The large central pith continues up into the stem apex, but the whole of the fibrovascular tissue is continued into the leaves, there 
being no trace of procambium inside of the leaf traces in the apical region of the stem itself. Fig. to shows a sporophyte which was cut at right angles to the primary root, which in this case had a triarch bundle. Near its base the three xylem masses increase in size and form a nearly complete ring of tracheary tissue, which higher up is continued into the leaf traces. The third leaf has already begun to form, but is still very small. Below it, however, can be clearly seen the beginning of its large leaf trace, which can be followed downward to its junction with the second root, which is now just about ready to emerge. 'The stele of the second root is connected with the central cylinder of the axis near its junction with this third leaf race. The stem apex occupies a very small area, crowded between the base of the second and third leaves. Its deep, narrow, apical cell is not as conspicuous as is often the case.
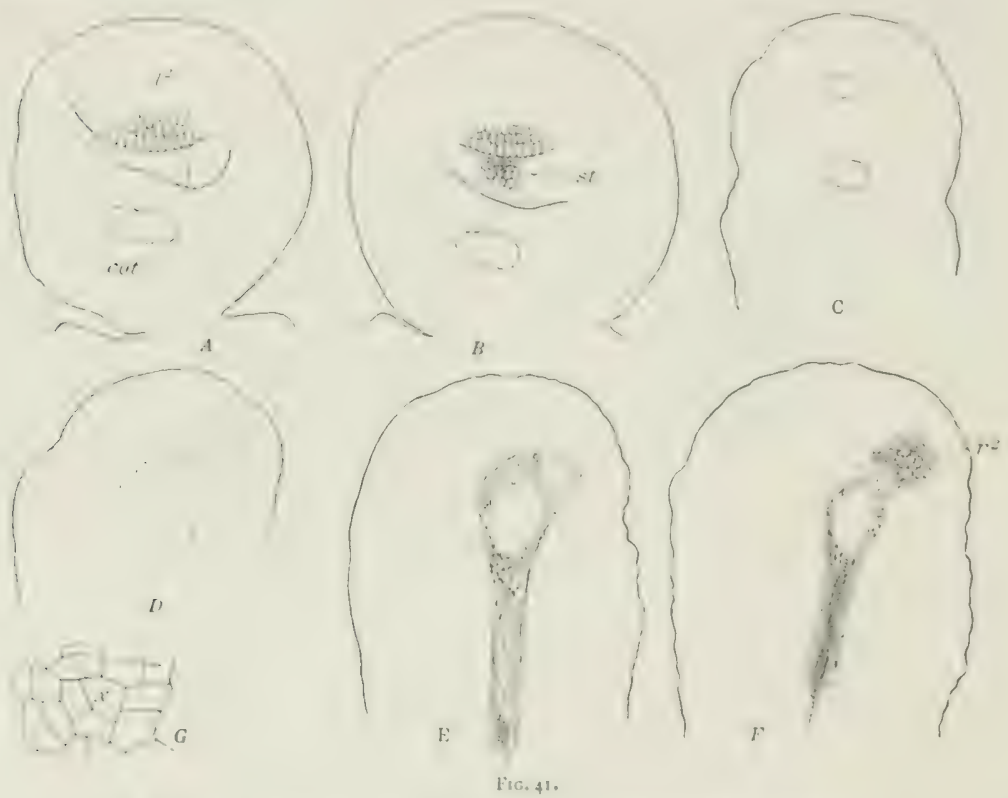

A-F. Six of a series of horizontal sections of a young sporophyte of Botrychium virginianum. X75.

13 passes through stem apex, st, which is shown more enlarged in $G ; r^{2}$, second root; $l^{2}$, second leaf.

A similar sporophyte is shown in cross-section in fig. 41 . This was cut in the plane of the first root, which makes a sharp angle with the base of the cotyledon. The thick stele of the root is much expanded where it joins the leaf traces to form the beginning of the tubular stele of the axis, and at the point of junction there is a large nearly solid mass of short, irregularly disposed, reticulate tracheids. This young sporophyte was evidently the further development of an embryo of the type showin in fig. $35, d$. The trace of the cotyledon makes a right angle with the stele of the root and on the side opposite to its junction with the stele of the rout there can be seen the trace belonging to the second leaf, which is already well developed. The apical cell is tetrahedral in Botrychium virginiomum and the cells are cut off in regular segments from its three lateral faces. Segmentation is 
evidently slow and there is usually a good deal of difference in the stage of development in the three segments composing a single cycle. The first division in each of the lateral segments cuts off a small inner cell from a large outer one, and the latter is then divided into two by an anticlinal wall. The divisions were not followed beyond this stage and the limits of the segments comprising the second cycle can not be easily recognized, as by this time the roungest leaf begins to grow and the stem apex is thus crowded into a very small area between the bases of the two youngest leaves. The shallow mass of meristematic tissue comprising the stem apex merges gradually into the large-celled parenchyma which makes up the pith cylinder inside the hollow stele of the axis.

Longitudinal sections of a much older sporophyte are shown in fig. +2 .

Except for the vascular bundles, the whole of the tissue of the young sporophyte is composed of large-celled parenchyma which, especially in the region belonging to the foot, contains large quantities of starch.

The form of the young leaves in $B$. virginianum is very different from that in B. lunaria. In the former the young leaf is bent forward over the stem apex and the apical cell is at the tip of this bent-ower portion. In B. lunaria, however, the

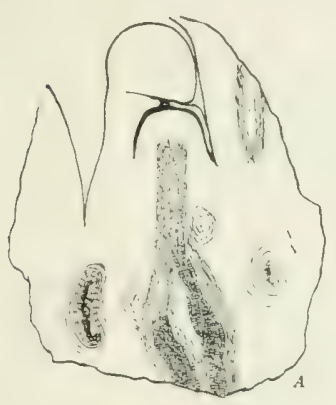

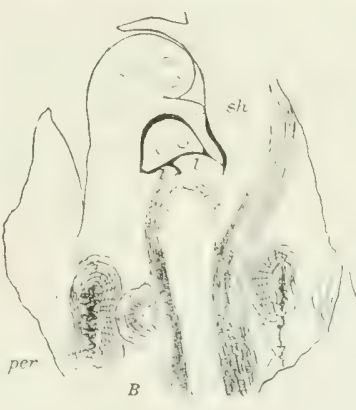

Fig. 42.

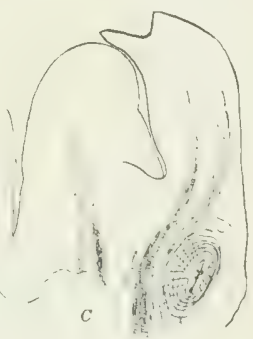

Three longitudinal sections of a young sporophyte of Botrychium virginianum, with several leaves. per, absciss layer of periderm; $l, l$, the youngest leaves; sh, stipular sheath. $\times 20$.

bent-over portion becomes the stipular region and the apical cell of the young leaf arises in the convex upper portion, so that the leaf grows straight upward instead of being bent over as it is in B. virginianum. The latter species in this respect resembles the Marattiacex.

The stipules in $B$. virginianum are lateral structures which extend around the next youngest leaf and the stem apex, but the sheath has a narrow cleft in front, so that we may really speak of two stipules instead of a single stipular sheath (fig. $42, A$ ). In this respect also there is a strong resemblance to the Marattiacea.

Fig. 43 shows a series of transverse sections of a young sporophyte of $B$. virginianum in which the fourth leaf was just evident. Fig. $43, A$ and $B$, are near the base of the fourth leaf and show the arrangement of the first four leaves. The base of the cotyledon (cot) is a good deal flattened and the petiole is seen to be traversed by very conspicuous lacunx, reminding one of those in the cotyledon of Ophioglossum moluciomum. The conspicuous stipules can be seen extending partly around the group of younger leaves, but not completely inclosing them. The two vascular bundles of the petiole are beginning to unite to form the single leaf trace which is found lower down. The xylem in each bundle forms a broad band 
of wood, which is surrounded by the phloem, although the lated is much less developed 1 pen the inner side than upon the outer and the bundles thus approach the onllaseral condition found in the race lower down. Small protophlobem elements oceur in the enser part of the bundle and are continued part way around toward the lower side, to the point where the ewo bundles are beginning to fuse, but here they are no longer visible.

The second leaf shows no lacunae and the base of the petiole is more nearly evlindrical than is that of the cotyledon. Iike the lateer, the petiole contains ewo vascular bundles which at the level of this section were still quite distinct, and the permanent elements were just begimning to form. The stipules in the second leat completely inclose the third, but there is a very narow slit in frone where the two stipules meet. The next section figured is taken just above the stem apex and cuts through the youngest (fourth) leaf. The two bundles of the petiole of the third leat are evidently still quite separate, but closely approximated, and as yet show no permanent tissue. The stipules of the third leaf are just becoming evident. At the level of the stem apex the bases of the third and fourth leaves are completely united,

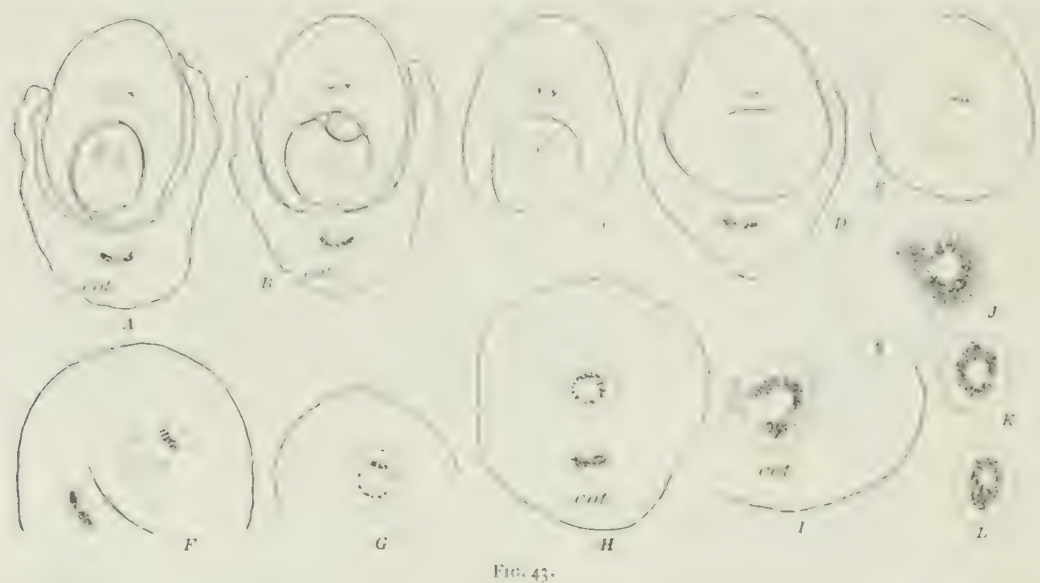

Series of transwerse sections of a young sporophyte of Bofryclitum virginianum, showing union nf feaf traces to form vascular c) liader. D and $\mathrm{E}$ show the separated leaf traces which unite further down; $\mathrm{K}$ shows the hundte of the axis near its junction with the stele of the primary root.

and the base of the second leaf is also partially fused with these. The two bundles from the second leaf are now beginning to unite to form the single leaf trace, while in the third leaf the process is complete and a single oval mass of procambium cells marks the position of the single trace of this leaf. On the opposite side of the apical meristem is a similar but less developed mass of procambium, representing the trace from the young fourth leaf.

For some distance below the stem apex the two bundles of the third and fourth leaf respectively are quite distinct, and are separated from each other by a mass of large-celled pith. Lower down the two bundles approach and coalesce, and on the side of the second leaf trace (which is turned away from the third one) a group of actively dividing cells can be seen which forms the beginning of the fifth leaf trace, although the leaf itself can not be recognized at the summit. These three masses of procambial tissue, viz, the young traces from the third, fourth, and fifth leaves, 
make a nearly continuous crescent-shaped mass of procambium. Fig. $4+, A, B$, shows the section of the central stele; and the space between the horns of the crescent, i.e., the space between the third and fifth leaf traces, constitutes the so-called "foliar gap" which faces the second leaf trace. The central cells of the young stele have already begun to form cambium, which in the older stem constitutes such a characteristic feature of the stele.

Before any tracheary tissue is formed in the young stele, a few thick-walled cells can be seen in the outer part of the portion of the stele corresponding to the third leaf trace. These are protophloem cells, and similar ones are developed later in the younger parts of the stele. The first tracheary tissue appears in the region of the steel section belonging to the third leaf trace. In the section shown (fig. $4+, C$ )
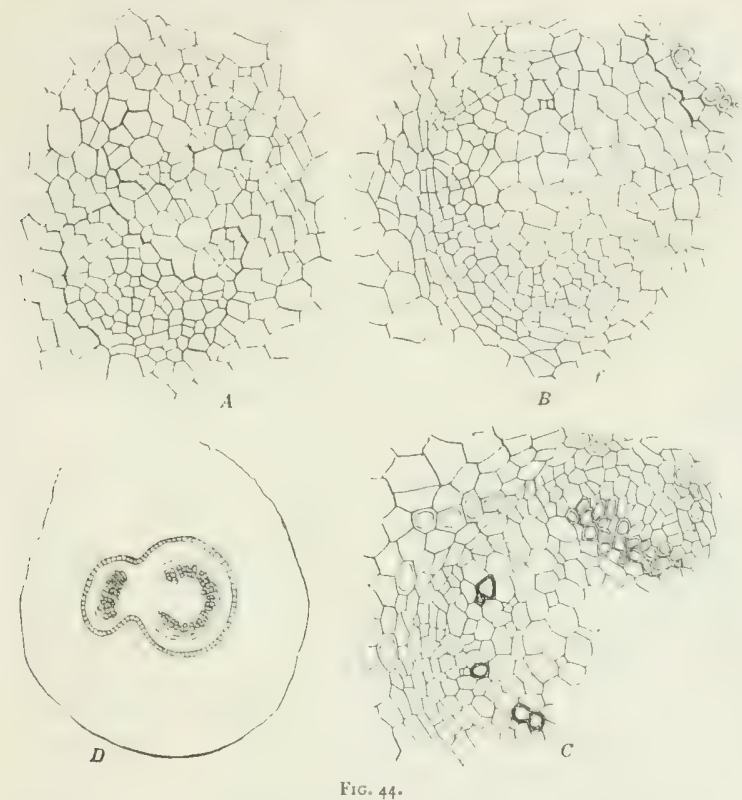

A, B, C. The young vascular bundles of sections E, F, G, of the series shown in fig. $43 . \times 150$.

D. Section of a young sporophyte of Botrychium virginianum, showing junction of a leaf trace with stele of axis. $\times 75$.

there are three groups of these primary tracheids, separated by a considerable interval and placed at the extreme inner limit of the young stele. In the older portions of the bundle the number of these increases and similar ones make their appearance in the next younger section of the stele, that belonging to the fourth leaf. Last of all, these primary tracheids are formed in the younger region of the stele and new ones arise between these first-formed ones, so that there is developed a nearly complete circle of tracheids marking the inner boundary of the tubular stele.

The second leaf trace approaches nearer and nearer the two horns of the crescentic stele section as it is followed downward, and finally joins it, filling up the gap between the regions belonging to the third and fifth leaf traces. Thus, for a 
time the section of she stele appears perfectly circular and continues downward until it reaches the next leaf trace, which marks the point of departure of the trace of the cortyledon. lixcept for the greater development of the xylem, which is composed of ewo to three concentric rows of tracheids, the section of the stele in this region presents much the same appearance that it does in the younger parts nearer the stem apex. The outer part of the stele at this point shows a somewhat broken row of thick-walled bast fibers within which are large sieve tubes. The cambium, lying just inside the phloem, is very much less developed in the basal region of the stele than it is higher up and can scarcely he said to be present. The stele in this region of the stem is quite similar to that of $B$. Innaria, figured by Poirault. The endodermis is also much less definite than it is later, and I could not satisfy myself that there was in B. Eirginionum any trace of the inner endodermis which Poirault states is present in the basal part of the stem in B. Innaria, but which disappears later. The medullary rays also, which are conspicuous in the stele of the older plant, are very imperfectly developed in this basal region.

In the intermediate region, between the base of the primary root and the trace from the cotyledon, a section shows a thick irregular ring of tracheary tissue with no clearly developed medullary rays (fig. $43, L$ ). Indeed, at the lowest part of this region the tracheary tissue forms an almost solid core with only a small amount of parenchyma interspersed, thus forming an inconspicuous and irregular pith. While the endodermis is not clearly delimited, some of the cells in the zone of tissue surrounding the stele show the radial thickenings of the walls; but these cells are not all of them in the layer immediately adjoining the stele, being irregularly disposed throughout the three or four layers of cells surrounding the stele. As sections are examined in succession upwards, the pith becomes better defined. Sections taken downward show a ring of tracheary tissue gradually separating into the two or three xylem masses of the primary root.

The primary root in the sporophyte which has just been described was diarch. The stele shows a very evident endodermis, within which is the pericycle, for the most part composed of two layers of cells. The xylems are composed of a large group of tracheids, of which the two or three smaller ones next the pericycle represent the protoxylems. Small, deeply staining protophloem elements can be seen toward the outside of the phloem, and within these are the other phloem elements,

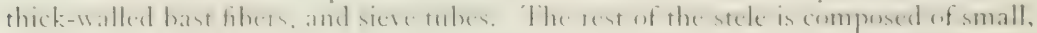
thin-walled parenchyma cells. The outer region of the root is made up of somewhat compressed cells suggesting the periderm cells which are found in parts of the older stem and which are also present in the cortex of the later roots. 'This outer layer of cells, however, show's no evidence of active division.

A cross-section of the petiole of the cotyledon, from the same sporophyte, taken at a point some distance above the stipules, shows within the epidermis about three layers of parenchyma cells with no conspicuous intercellular spaces, but within these are several very large lacuna, separated by narrow plates of tissue. In the center of the section are seen the two concentric bundles that traverse the petiole. As in the later leaves of this species, these bundles are truly concentric, thus resembling those of the Marattiacese and differing from the collateral bundles of Ophioglossum and the smaller species of Botrychium. The phloem is better developed upon the outer side and small protophloem elements can be seen at its outer limit, but these are continued partially around the inner side of the bundle, where the xylem is separated from the outside by about two layers of cells. No definite endodermis can be made out. The two bundles are continued up to the base of the lamina, where one of them passes into each lateral lobe of the ternate leaf. One of 
these divides and gives off a branch which passes into the terminal lobe of the leaf (see Jeffrey I, page 23).

In a section of the older stem, about where the fourth leaf trace becomes joined to the fifth and sixth, the section of the stele appears circular. In the portion belonging to the fifth leaf trace there are present about half a dozen isolated tracheids, arranged in a row, while in the sixth trace only a single small tracheid is developed. The two xylems of the fourth leaf trace are now no longer distinguishable and the woody part of the trace has the form of an irregular row on the inner side of the trace section, and is continuous with the xylems of the fourth and fifth traces. Even after the fusion of these three traces is practically complete, it is still evident that the ring-shaped section is composed of three parts, the break between the xylems showing the limits of the three component leaf traces. With the increase in the development of the xylem ring the limits of the individual leaf traces are finally completely lost and the section of the stele shows a thick ring of the tracheary tissue interrupted only at intervals by single rows of parenchyma cells in the medullary rays.

Outside the ring of tracheids there can be seen a zone of narrow cells arranged in radially disposed rows. This zone constitutes a genuine cambium, precisely similar in appearance to that found in the stems of Conifers and Dicotyledons. This cambium has long been known to occur in the older sporophytes of the larger species of Botrychium, and Jeffrey first noted it in the young sporophyte. The cambium is well developed in the leaf trace for a considerable distance above its junction with the central stele.

The primary tracheary tissue is in immediate contact with the pith. Occasionally the ring of tracheids is broken by a single parenchyma cell. Outside the tracheary ring the cells are arranged in radial rows and in these the formation of the walls is alwats periclinal, se that the cambium in these eanlier stages presents at very characteristic appearance. The rows of cambium cells continuous with the primary parenchyma cells lying between the tracheids of the primary row do not develop tracheary tissue, but remain parenchymatous and thus give rise to the medullary rays, which later are so conspicuous.

The extreme outer portion of the vascular cylinder is composed of a ring of thick-walled cells which are probably bast fibers, but the walls of these do not stain strongly with safranine and are hence much less conspicuous than the tracheids. These may possibly be considered as protophloem elements and evidently correspond to the zone of thick-walled cells figured by Poirault for B. lunaria (Poirault 2, fig. II). Just outside of this ring of thick-walled cells lies the endodermis, which has not as ret developed the characteristic radial thickenings which are so casily seen in the older parts of the stele. These thick-walled phloem elenents, as is the case with the protoxylems, do not form an unbroken ring, but are interrupted at the junctions of the confluent leaf traces (fig. $4+, C$ ).

In the older bundle, a zone of large cells, the young sieve tubes may be recognized lying inside the ring of bast fibers. Inside of the zone of sieve tubes lies the cambium, the cells of which gradually pass into the xrlem, to which constant but slow additions are made from the cambium; indeed, Jeffrey thinks that we can not speak of primary wood. He considers that all of the wood owes its origin to the activity of the cambium ring. The radial rows of secondary wood are interrupted at intervals by the medullary rays, and the resemblance of the stele at this stage to the section of a young coniferous stem is really quite remarkable. The endodermis has now become exceedingly conspicuous, as the lignified lateral walls stain very strongly with safranine and stand out strongly in contrast with the cells of the cortex lying outside the endodermis. The inner walls of the endodermal 
cells also stain more or less strongly with the safranine, indicating that they also are parrially lignified.

The junction of the second leaf trace with the central stele is shown in fig. +3 , $I: F, G$, and similar stages in the fusion of the first leaf trace are shown in fig. $+3, H, l$. The junction of one of the early roots, perhaps the third root, with the central stele is shown in fig. 43,1 . At the level where the second leaf trace departs from the central stele the xylem ring is composed of about three rows of cells. In both this second leaf trace and the third the endodermis is very conspicuous upon the outer side of the bundle, but is not developed upon its inner face. As the trace approaches the central cylinder it can be seen that the endodermis is interrupted across the leaf gap, but as the leaf trace approaches, endodermal cells are developed between the endodermis of the central cylinder and that of the leaf trace. This union takes place first upon one side, the gap being closed sooner on one side than the other, but later a similar process takes place on the other side of the leaf trace and the closing of the gap is complete, the endodermis now being continued without interruption around the whole of the circular section. The leaf trace where it joins the central cylinder is exactly like it in size and structure; indeed, it is nothing more than a sector of the hollow cylindrical stele, which is evidently built up exclusively of these fused leaf traces. There is no vestige of any tissue in the stele which is not referable to the bases of the leaf traces themselves. This becomes vervevident when the structure of the leaf trace is examined before it closes the gap where it joins the central stele.

An examination of the outer tissues of the older portions of the stem (fig. 42 ) show that at certain points there is a conspicuous border of periderm (per), forming a layer some four or five cells deep. This border of periderm occupies about a third of the circumference of the section and marks the position of an old leaf base which has fallen away. According to Jeffrey, this periderm is an "abciss" layer and results in the cutting off of the old leaf bases. He suggests that the layer of cork cells developed from the periderm closes the scar left by the dead leaf and may be efficacious in preventing infection from fungi in the soil. The presence of a periderm in the outer cortex of the Ophioglossacex was first pointed out by Russow (Russow 1), and was afterward confirmed by Holle (Holle 1). 'The periderm in B. virginianum is made up of the usual radially arranged rows of cells (fig. $42, \mathrm{per}$ ).

All of the tracheary tissue in the young sporophyte is composed of rather short, reticulately marked tracheids. The secondary tracheids increase in size and the thickened bars on their walls become broader, so that the larger elements have their walls pitted rather than reticulately marked, and these pits, especially in the older plant, are of the bordered type, not very unlike the round bordered pits found in the wood of Conifers.

The elongated thick-walled elements in the outer part of the phloem are probably bast fibers. In the older part of the bundle these stain quite strongly with safranine and show irregular pits upon their walls. The sieve tubes do not show at all clearly in sections mounted in balsam. They are evidently large, but the characteristic dotted sieve areas can not be made out and no special study was made of these. Between the large secondary tracheids and the phloem are the narrow, thinwalled cambium cells. These probably contribute only to the wond, and there is no secondary phlocm 
THE YOUNG SPOROPHYTE OF HELMINTHOSTACHYS.

The only account that has yet been published of the young sporophyte of Helminthostachys is that of Lang (Lang 1), who examined at some length the vascular system in the foung sporophyte. Lang states that the young sporophyte of Helminthostachys develops its first leaf as a large ternate foliage leaf, and when I first examined the young plants which were collected in Ceylon I reached the same conclusion; but on making sections of the young sporophyte it was found that in all of the young plants that were sectioned the supposed cotyledon was really the second leaf, the cotyledon itself being rudimentary and forming an inconspicuous papilla at the base of the second leaf, which was the first to develop a functional lamina. Further examination of a number of other specimens showed that this rudimentary cotyledon was also present and it is probable that the cotyledon in Helminthostachys, as in Botrychium lunaria and Ophioglossum vulgatum, is always a rudimentary organ which never appears above the ground.

The youngest sporophytes of Helminthostachy's which were found already had the second leaf well developed and the first root had emerged. The ternate second leaf (fig. Io, $C$ ) shows clearly that the ternate form is the result of an unequal dichotomy, such as is common in the early leaves of many ferns. The second leaf of Helminthostachys closely resembles the cotyledon of Botrychium virginianum and, like that, usually possesses two vascular bundles extending through the long, slender petiole. At the base of the leaf there is a conspicuous stipular sheath which completely incloses the next younger leaf, as it does in Botrychium lunaria. The two bundles of the petiole contribute to the two lateral lobes of the leaf as they do in the cotyledon of Botrychium virginianum, and one of these, forking again, gives rise to the terminal lobe and smaller lateral lobe. The venation of the second leaf, especially in its younger stages, is almost perfectly dichotomous and is more like the venation in the leaves of Botrychium lunaria than that of $B$. virginianum. With the enlargement of the leaf segments the venation more nearly approaches the pinnate arrangement found in the later leaves.

While the young sporophyte in Helminthostachys in its earliest stages shows a general resemblance to that of Botrychium virginianum, a difference is very soon noted. The young plant, rery soon after the formation of the cotyledon, develops a conspicuous intemode between the cotyledon and the root, and the stem rapidly elongates as the sporophyte grows, so that it soon shows the characteristic elongated rhizome of the older sporophyte.

Unfortunately I was unable to secure any very young sporophytes, my youngest specimens already having the second leaf nearly fully developed. According to Lang, the arrangement of the primary organs of the young sporophyte is the same as in $B$. virginianum, but I could make no study of the origin of the vascular system in the sporophyte before the first leaf and root had emerged from the prothallium.

To judge from longitudinal sections of the youngest plants obtained, the relation of the first leaf and root is the same as in Botrychium virginianum and the base of the young sporophyte closely resembles that of the latter. As in Botrychium, the foot is very large and conspicuous, forming a large, hemispherical body surrounded by the prothallial tissue. The large primary root grows out at right angles to the foot and is continued into the axis of the sporophyte, which grows up vertically. None of the specimens were young enough to show the relation of the stem apex to the first leaf and root, as in the youngest specimens the axis had already begun to elongate and an evident internode was formed between the base of the first leaf and the root. 
The lomerendinal section of the young sporophyee at this time shows that ehe ahick stete of the rout bends upward and is continued inte the axis, which already is a goud deal elongated and has carriced up the young leaves, which are separated

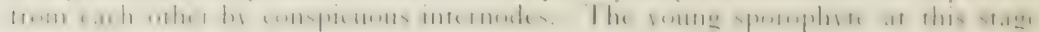
thus differs strikingly from the corresponding stages in Oplioglossum and Bofrychium, with their very closely crowded leaves with no appreciable internodes between them (lig. $f^{(0)}$.

A single stele extends through the axis from its junction with the rout stele and forks betow the insertion of the rudimentary first leaf, one branch passing into the cotyledon, the other continuing upward and forming the trace for the second leat, at whose base is seated the apical bud.

Whether in the younger stages, before the development of the second leaf, the vascular system of the young sporophyte would show the same actations of the steles of the root and cotyledon, as in Batrychum, remains to be seen; hut fiom the general similarity in the structure of the young sporophytes of the two this is quite likely:

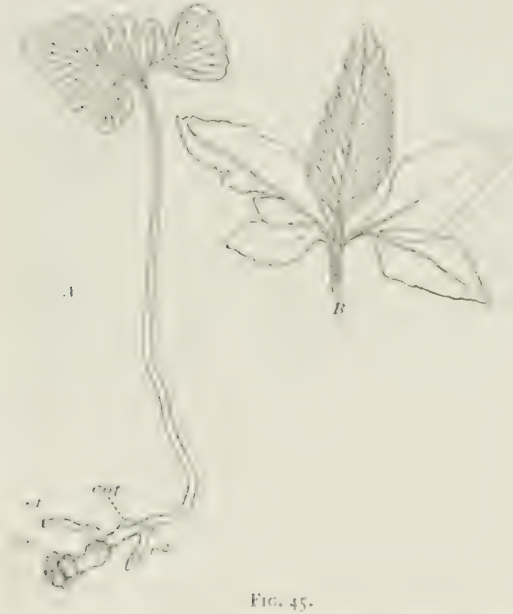

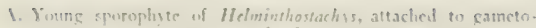
phiver, pr. cot, cotsledon; $r^{1}, r^{2}$, first and second roxts. $\times 2$. B. Leaf from an older sporophyte. $X_{1}$. yet it is possible that the stem apex is more prominent in the early stages of Helminthostacleys and part of the stele which is found in the elongated stem may be of cauline origin, although this is hardly indicated by the condition of things in the apical meristem of the youngest sporophytes that were examined.

The foot is composed of largecelled, thin-walled parenchrma, with no noticeable differences between the inner tissue and that of the periphery. The stele of the rost is comtinued upward without interruption into that of the shoot (fig. $f^{6, B}$ ). Probably at an earlier period there would have been, as in Botrychium, simply the continuous stele of the root and cotvedon. At the junction of the root stele with that of the axis there is a maked enlargement, and the short, somewhat irregular tracheids are decidedly broader than those either in the root or in the portion of the stcle above the junction. "The tracheids toward the outside of the central region are slender and have delicate reticulations, which closely approximate the form of true spiral thickenings. These are the protoxylem elements and can be traced upward and downward into the stem and root, respectively. The secondary tracheary tissue is marked by broad. reticulate thickenings, and these in the largest tracheids are replaced by conspicu-

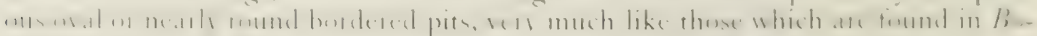
triclimm (fig. + $6, E)$.

Abowe the base of the root there is a long intemole below the cutyledon, and through this runs the single axial stele. On the same side of the axis as the primary root may be seen the cotrledon, which closely resembles in form the young cotyledon of Botrycinum rirginimum, but instead of developing into a functional leaf it is arrested in its growth before the lamina is fully developed. As in the cotyledon of 
Botrychium virginianum, the lamina, which although very greatly reduced nevertheless is present, is bent over sharply against the stout petiole, which is strongly convex on its adaxial side. In the specimen figured there was no trace of a stipular sheath developed in the cotyledon, but sometimes this is very well developed, although the upper part of the cotyledon remains quite rudimentary. The little cotyledon has the rudimentary lamina distinctly ternate in outline and very much resembles some of the rudimentary early leaves found in Botrychitum lunaria, as figured by Bruchmann. A single vascular bundle extends through the petiole of the cotyledon, nearly to the base of the lamina, but except in the basal region the development of the xylem is much reduced and is entirely lacking before the lamina is reached. The bundle of the cotyledon, where it bends at the base into the internode, is nearly as well developed as the bundle of the second internode which separates from the former just below the insertion of the cotyledon. On the opposite side of the second internode from the cotyledon, and extending downward through the first internode for a short distance below the level of the cotyledon, there is seen

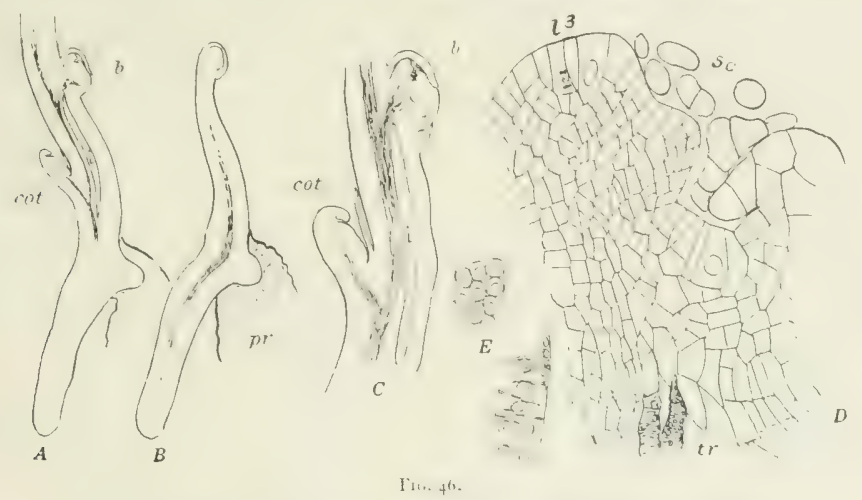

1, B. Two longitudinal sections of a young sporophyte of Helminthostachys; pr, gametophyte. $\times 6$.

C. Upper part of same, more enlarged; $b$, terminal bud; cot, cotyledun; $i$, lacuna in first internode.

D. Apical region. $l^{3}$, third leaf; se, epidermal scales. $X_{1}+2$.

E. Tracheids showing bordered pits and thickened bars. $x_{320}$.

in the specimen figured a large lacuna, separated from the outside of the internode by about half a dozen lavers of cells and on its inner side from the endodermis of the stele by two or three layers of cells. This lacuna, as Lang pointed out, is not always present. At the upper end of the second internode can be seen the base of the second leaf, the stipular sheath of which incloses the young bud at the summit of the axis.

On its inner (dorsal) side the terminal bud shows the young third leaf, opposite which is the section of the ridge surrounding the small free surface of the stem apex, very much like the condition in the young bud of Ophioglossum moluccanum. The form of the young leaf at this stage is more like that of Botrychium lunaria than that of $B$. virginianum. The young leaf is a blunt cone with a marked projection on its inner side, extending over the apex of the stem and marking the beginning of the stipular sheath, which is entire as in B. lunaria, and not divided inte two fice stipules as in $B$. virginianum (fig. $46, D$ ). A conspicuous strand of procambium extends into the leaf and joins the trace of the second leaf. As in Botrychinum and Ophioglossum, the stele of the internode does not extend upward beyond the base of the youngest leaf and there is no indication that it derives any of its tissues directly 
from the apical meristem of the shoot. The latter, as in the other (ophioglossacese, shows a large single initial cell, which in section closely resembles that of Ophioglossmm moluccanum, having a broadly truncate base and being narrower above (fig. $f(6, D)$. The apical meristem is of very limited extent and segmentation of the apical cell is probably very slow. The second root, which in the case under consideration arose near the base of the third leaf, is here very conspicuous and its stele joins that of the third leaf near the base of the internode. "The young leaf and root, with the inconspicuous stem between them, have very much the appearance of a bud at the base of the second leaf. The apex of the very young leaf grows from the conspicuous single apical cell (fig. $f(0, D)$ ). This appears triangular in longitudinal section and shows regular segmentation. The stele of the young leaf can be traced up to the inner cells, cut off from the lateral segments of the apical cell.

The apical cell of the stem is quite large and, as we have seen, is truncate below, as it is in Ophioglossum. Seen in its transverse section it is triangular, so that its form is really that of a three-sided prism. Both lateral and basal segments are cut off from it, but only the youngest segments can be clearly distinguished. Below the apical cell there is only a very small amount of tissue between the apex of the shoot and the point of the junction of the two leaf traces and the stele of the second root. This junction is marked by the presence of very irregular reticulate tracheids (fig. $\left.f^{6}, D, t r\right)$. The tissues on the upper side of the root stele extend to within a few cells

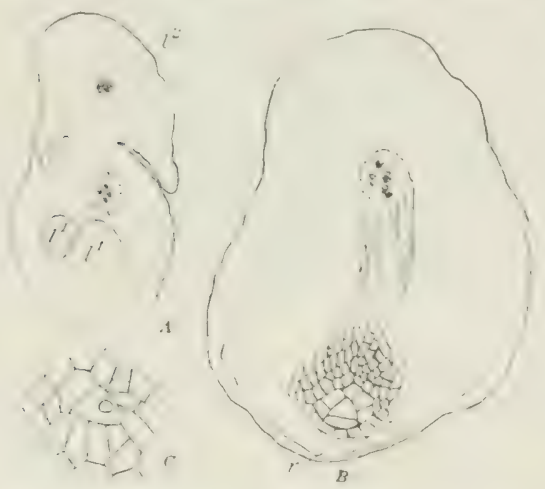

Fit. 47-Transverse section of young sforophyte of IIclmimthastachys, above termisal bud. $l^{1}, l^{1}, l_{\text {acunx; }} l^{2}$, second leaf. $\times 65$.

13. Section passing through base of bud. r, young ront. $\times 100$.

C. Stem apex. $\times 200$. of the stem apex and may possibly represent a portion of the internodal stele that is not connected with the leaf trace, but a study of later stages does not support this view, and it is almost certain that this youngest tracheary tissue is the beginning of the next leaf trace.

From the very first, as Lang pointed out, the shoot is perfectly dorsiventral, although at first it grows vertically upward. The leaves are all borne upon the dorsal side, while the roots invariably arise upon the ventral side.

The apex of the young root, which in this case is on the point of emerging, is occupied by a conspicuous triangular apical cell, the segmentation of which closely resembles that of the root of Botrychium. At first the root cap is mainly derived directly from the outer segments of the apical cell. These segments undergo periclinal as well as anticlinal divisions and the inner layers of the root cap (which at this stage is relatively thick) show a fairly regular stratification. The outer cells of the root cap are a good deal elongated, so that the free end of the root is decidedly pointed. At this time, except for the irregular conjunctive tracheids at the base, no permanent tissue can be seen in the stele of the young root.

In the cross-sections of a young sporophyte of about the same age the third leaf was rather further developed and the young fourth leaf could be seen, but the second root was not so far advanced, or it may be that the root at the base of the third leaf was the third root and not the second. The single apical cell, which was so prominent 
in the very young leaf, can no longer be recognized and the lamina is divided into two nearly equal lobes, of which one is lateral with reference to the other, but these two lobes probably arise as a result of the dichotomy of the original apex. A group of narrow marginal cells somewhat to one side of the terminal lobe evidently constituted a meristem tissue, and this was preparing for the second dichotomy, by which the ternate form of the young leaf is established. The branching of the lamina at this early period therefore appears to be the result of an unequal dichotomy, as it is in the first foliage leaf. The vascular bundles from each of the two primary leaf segments were just beginning to be recognizable and join into one at the base of the lamina. Surrounding the leaf is the sheath developed from the base of the second leaf. This sheath in the section appears as a closed ring some two or three cells in thickness and looking very much like the sheath of Ophioglossum. The top of the conical sheath is closed and does not show the pore found in Ophioglossum. The sheath becomes thicker lower down, where four rows of cells show in the section. Between the inclosed leaf and the surrounding sheath in the lower portion (fig. $49, B$ ) may be seen the section of flattened scales ( $5 c$ ) which grow from the base of the leaf
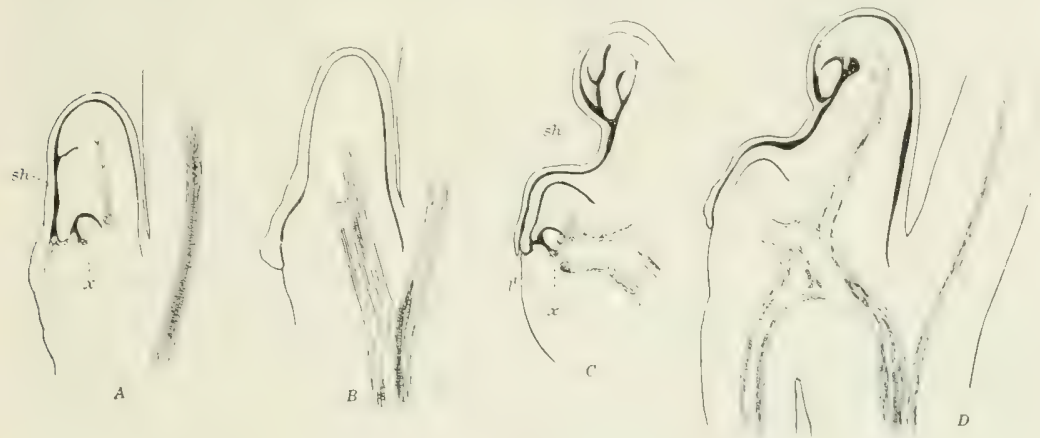

Fic. + s.

A, B. Two sections of terminal bud of a young sporophyte of Helmirthostachys.

C, D. Two similar sections from an older plant. $x$, stem apex; sh, petiolar sheath.

and from the tissue immediately about the stem apex. At its base the sheath of the third leaf is already completely developed and surrounds the young fourth leaf $\left(l^{4}\right)$, which in this section was cut horizontally and shows plainly its large apical cell. The stem apex, which lies directly below the younger leaf, was cut obliquely in this series and did not show the form of the apical cell plainly, but in a young plant of about the same age (fig. $47, C$ ) the apical cell showed that it was regularly triangular in form, seen in cross-section.

At the level of the stem apex the second leaf shows a single vascular bundle which may be continued undivided upward, or it may divide into two bundles in the petiole. In regard to the structure of the petiole, therefore, Helminthostachys is to some degree intermediate between Botrychium and Ophioglossum. The young trace of the third leaf can be seen at this level as an oval mass of undifferentiated cambium. Immediately below the stem apex the cells are smaller than is the case in the young sporophyte of Botrychium, but one can not make out the beginning of a central procambium cylinder. The smaller cells in the region immediately underlying the stem apex may be explained by the fact that in these young plants there is no pith developed within the axial stele as there is later on. The youngest root in this 
specinen was less developed than that in the specimen that we have just described. This youngest root was cut obliquely, but at its base there could be seen the undifferentated mass of procambium forming its stele, and she apex showed the rerathedral apical cell, presenting much the same form as the lengitudinal section. The apical portion of the young root was somewhat shrunken away from the surrounding tissuc, so that there was a very evident space surrounding it. Whether or mot this was the result of artificial shrinkage was not certain.

Below the terminal bud the third leaf trace proceeds downward into the interneste below, and the tracheary tissue, which is just beginning to develop in the bud region, increases rapidly in amount and forms a central mass of wood which does

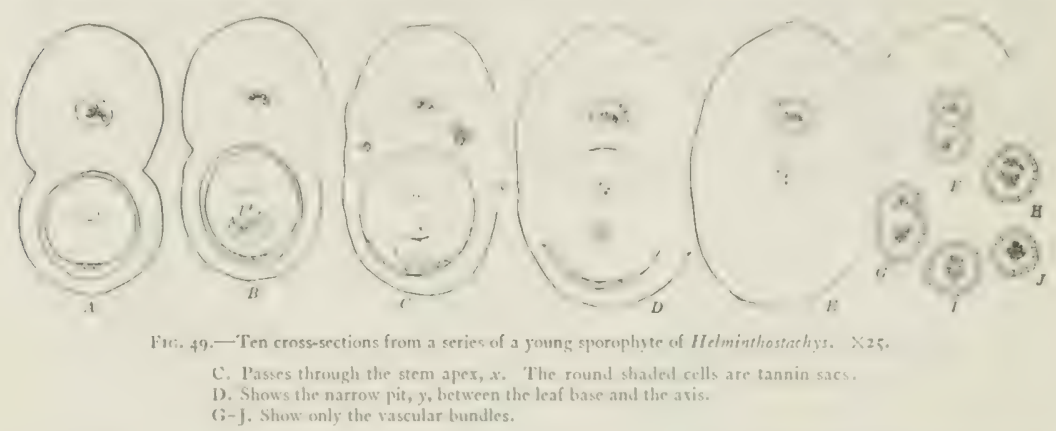

not appear solid, but is made up of two groups of tracheids, of which the one nearest the second leaf trace has the larger tracheids. At this stage the bundle somewhat resembles the section of a diarch root. Only a little further down the two xylem masses are joined by the development of tracheids in the middle of the bundle, which thus comes to have a solid xylem core. In the section ligured there may be seen a single small isolated tracheid on the side turned toward the second leaf trace. which has now approached so close to the central bundle as to touch it (fig. $50, A$ ). The central bundle in the internode at this point is beyond question the leaf trace for the third leaf. There is no difficulty in tracing its progress upward to where it enters

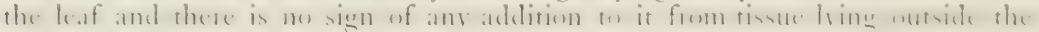
original leaf trace. 'The central stele of the upper part of the second internode is throughout nothing more than the basal portion of the leaf erace from the third leaf. At this point it is concentric in structure. Surrounding the solid xylem core can be seen about three rows of phloem cells, some of the outer ones being small protophlocm elements. The large ones lying inside are presumably sieve tubes. A single layer of rather large pericycle cells separates the phloem from the large endodermal cells,

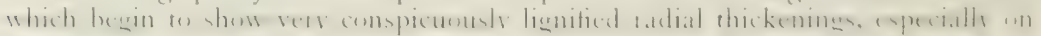
the side of the bundle adjacent to the second leaf trace. The section of the second leaf trace is somewhat extended transversely and the xylem band is composed of about a dozen tracheids. In the mid region of the section the $x y l e m$ is separated from the inner side of the bundle by a single layer of cells, possibly sieve tubes, but at one point the xylem is in contact with the pericycle, which is only imperfectly developed and wanting at certain points. Upon the dorsal side the phloem may be in diect contact with the endodermis, which is quite wanting at this point upon the ventral side of the bundle. Higher up, where the trace is quite free, the endodermis extends completely around it. While the second leaf trace, therefore, may 
be said to be concentric, it nevertheless approaches closely the collateral type of the other Ophioglossacea.

The fusion of the two leaf traces to form the single axial bundle in the basal part of the internode is very much like that found in the young sporophyte of $B_{0}$ trychium (fig. 49, D, F). The endodermis of the two bundles becomes continuous and there may be seen intermediate stages of a single bundle, oval in section, but with two conspicuous xylems, separated by the mass of large, thin-walled tissue which gradually disappears as the bundle is followed downward; and finally, in the lower part of the internode, the section of the stele appears quite circular, the center being occupied by the solid xylem formed by the complete coalescence of the xylems of the fused leaf traces (fig. $+9, J$ ). The arrangement of the phloem, pericycle, and endodermis is the same as in the single leaf trace in the upper region of the internode.

The base of the stipular sheath can be followed downward to about the level where the two leaf traces begin to coalesce. Its anterior free portion, between which and the internode is a narrow slit, finally becomes quite free and its section is visible as an oblong mass of cells lying quite separate from the section of the internode.

Longitudinal sections

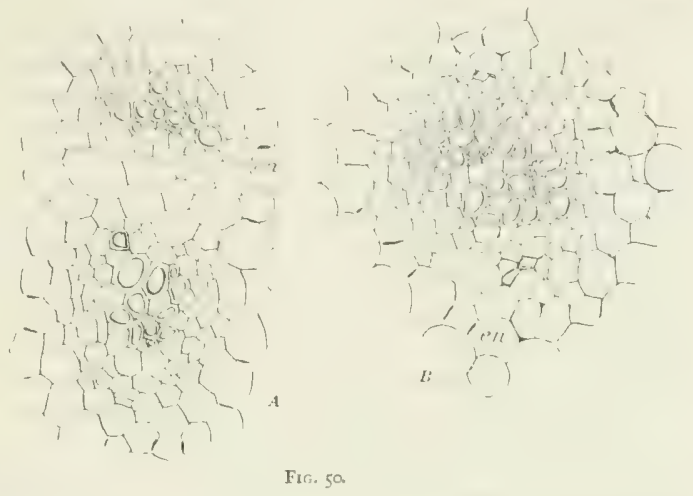

Two sections of the vascular bundles from the series of Helmimhostachys shown in fig $4 \%$, showing junction of two leaf traces to form central stele. en, endodermis. $\times 150$.

of a somewhat older sporophyte are shown in fig. $48, A, B$; the third leaf is pretty well develeped, with the stipulat sheath completely overarching the stem apex and the fourth leaf, which already is conspicuous. The third leaf is still completely covered by the large stipular sheath of the second leaf, which apparently forms a closed cavity; but an examination of the adjoining sections showed that the anterior margin of the sheath is quite free in front and that there is a narrow cleft between it and the internode. The real nature of the sheath and its relation to the leaf base is very clearly shown in the median section of the terminal bud from an older plant (fig. $48, C, D$ ), and the resemblance to the terminal bud of Botrychium lunaria, except for the dorsiventral arrangement of the parts, is most striking. This is equally marked in the adult sporophyte, as Farmer has already pointed out.

The specimen under consideration differed somewhat from the younger one that was described in the relation of the young organs. The cotyledon was better develeped and although the lamina was rudimentary the stipular sheath was large and inclosed the base of the second leaf, while in the younger specimen discussed no sheath was developed at the base of the cotyledon. There was a different relation of the roots also, probably associated with the greater development of the cotyledon in the specimen under comsideration. The second root, instead of being formed at the base of the third leaf in the terminal bud, was developed a short distance above the cotyledon, near the base of the second leaf, while in the younger specimen no root was developed above the primary root until the third leaf had 
hegun to develop; hut this second ront developed much earlier in its relation to the development of the next leaf than was usually the case.

In the present plant the root corresponding to the third leaf, which was the third root in this case, was in a very early stage of development and had not begun to elongate at all. The third leaf in median section was already pretty well advanced and the apical portion was very strongly incurved, as it is in the young leaves of Borrychum sirginionum, which it resembles more than it does that of $B$. Iunaria, and it also suggests the form of the young leaves in the Marattiacere. The basal part of the young leaf, however, is exactly like that of $B$. Innaria. The stipular sheath forms a thick body, projecting forward and about equal in height to half the eotal length of the young leaf. It is strongly concave below, and the next leaf is fitted into the cavity (fig. $+8, C^{\circ}$ ). 'The forward margin extends downward as a sort of lip which elongates rapidly and keeps pace with the growth of the young leaf inclosed within it, and this is completely concealed until it has reached a large size. The sheath tinally forms a long, conical protuberance at the base of the leaf to which it belongs.

The cavity below the sheath is extended backward, so that the base of the leaf is hollowed out in front and in section appears much narrower than the part of the petiole above the insertion of the sheath; this brings the stele of the leaf very close to the epidermis at this point. The narrow cleft thus formed between the posterior wall of the stipular cavity and the petiole of the leaf in front is the "canal," which Gwynne-Vaughn described as occurring at the base of the petiole of the older plant and opening above the insertion of the stipule. These canals are easily seen in longirudinal sections of the young bud ( $f \mathrm{~g} .48, B$ ) and it is very clear that they are, in truth, nothing but the narrow spaces between the bases of the adjacent leaves. GwynneVauglin's statement that they open above the insertion of the stipules is incorrect unless the stipules of a given leaf are considered to be derived from the sheath surrounding the base of the leaf, this sheath properly belonging to the next older leaf. This canal can be seen as a narrow slit in the young leaf, extending below the insertion of the next younger one, the young stele of the leaf being separated from the epidermis at this point by only about three rows of cells.

The stele of the young leaf can be traced nearly to its tip, and then continues downward toward the inner side of the leaf into the internode, below where it joins the young stele belonging to the next younger leaf.

As in the younger sporophyte, the stem apex is of very limired extent and the apical cell shows the same form. In the section figured (fig $48, C$ ) the youngest leat is cut almost in a median plane and though externally no differentiation is visible the young stele is already conspicuous and can be followed down without difficulty. Passing on one side of the stem apex and above the leaf trace, there is no evidence of procambium in the apical region of the stem. In the young sporophyte, therefore, it is perfectly certain that no cauline stele is present. Farmer (Farmer 2) states that in the older sporophyte the stele can be traced above the insertion of the youngest leaves, but we believe a careful study of this point in the older plant would show, as in the younger one, that the stele is developed in the young leaf at an exceedingly early period and that the stele of the internode is composed entirely of leaf and root traces. The procambium tissue developed on the ventral side of the stele near the apex can be shown, by a study of its transverse sections, to be due entirely to tissue derived from the leaf traces, which are extended downward until they meet on the ventral side of the internode.

Near the stem apex are numerous small scales and hairs filling up the space about it and probably associated with the prevention of drying up of the sten 
apex, which is doubly protected by these scales and its complete inclosure in the young leaf bases. It is possible that these scales secrete some mucilaginous substance, although there was no evidence of this in the stained sections.

In this plant the internodes were quite solid and there was no trace of the large lacunæ which were described for the younger plant. Whether the presence of the lacunæ is due to any differences in the environment remains to be seen. The specimens were all collected under apparently the same conditions, but it is possible that there may have been differences in the amount of water in the soil in which they were growing, and this difference in the amount of water may have something to do with the development of the lacunx.

The root at the base of the third leaf was cut transversely and was in a very early stage of development. The root was still completely buried in the cortex and the stele still imperfectly developed, but showing its connection with the stele of the fourth leaf above the junction of the third leaf trace with the stele of the internode. No tracheary tissue was developed and the course of the leaf trace was but little disturbed by the formation of the root.

In longitudinal sections taken from a much older sporophyte (fig. $48, C, D$ ) the arrangement of the organs at the apex is seen to be exactly the same as in the younger plants, but of course the parts were all larger. The youngest leaf $\left(l^{1}\right)$ still resembles in form and size the corresponding leaf in the younger stem, but the next older leaf is relatively broader than the early leaves of the younger sporophyte, and although the stipular sheath is now well developed the upper portion of the leaf is still quite undifferentiated and the apex is scarcely bent forward at all. The resemblance, therefore, to the young leaf of Botrychium lunaria is even more marked than it is in the younger sporophyte. The apical region of this young leaf is occupied by an epithelium-like layer of columnar cells, and it is doubtful whether any one of these can be certainly denominated the apical cell. Somewhat the same doubt exists also as to the point of a single initial cell in the youngest leaf. In the latter there was some shrinkage in the group of large meristem cells at the apex, which made it still more difficult to decide this point, but a median section showed somewhat indistinctly a single cell, apparently triangular in outline, which from its form and the arrangement of the adjacent cells may very well have been the apical cell. The small group of meristem cells forming the stem apex is crowded in between the base of the youngest leaf and the elongated ridge which surrounds the stem apex upon the ventral side. In consequence of this crowding the outer faces of the apical cell and its youngest segments are very small. The base of the apical cell is more than twice as broad as its free outer face. The ventral face of the apical cell is convex and the young segments cut off from it are strongly curved. The inner or basal wall is oblique, so that the axis of the young cells in the tissue below the apical cell makes an angle with the long axis of the apical cell.

Below the apical region may be seen the section of the large central stele of the internode. This is composed, apparently, of two strands of procambium separated by a broad band of pith. As Farmer pointed out, in the older plant there is no question that procambium tissue is developed upon the ventral side of the bundle which extends into the apical region and which is, apparently, not connected with the leaf traces. From this he believes that the stele is really a cauline structure.

A study of the cross-sections, however, as will be presently seen, shows that this ventral tissue really does belong to the leaf traces, although it is possible that the basal tissue of the roots may add to it in part, but I have not been able to satisfy myself that any of this stelar tissue can be properly assigned to the activity of the stem apex. 
As in Beorvelium and Ophioglessum, the tissue derived inmediatedy from the activity of the apical meristem, after the central pith is developed in the stele, contributes only en this central region or pith, which is really not part of the stcele proper. ( $n$ the dersal side of the stele the whole of the procambial strand can easily be followed into the leaf, and when this is followed downward it is seen of rum obliquely through the youngest internode, at the base of which it joins the next leaf. The latter already has its lamina developed and strongly bent over, but is still inclosed in the stipular sheath belonging to the next older leat.

These older leaves have only a single leaf trace, but it divides into ewo strands above the level of the stipular sheath. A median section of the thick central stele in

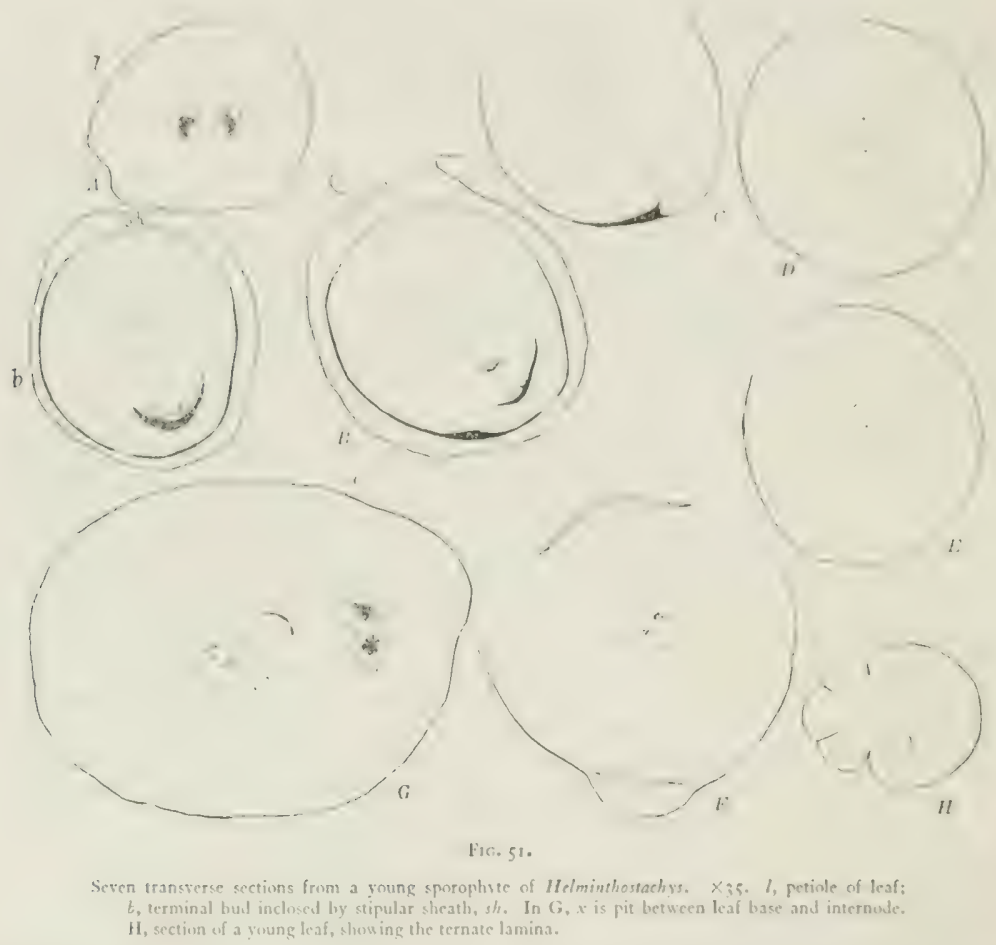

the upper region shows conspicuous protoxylem elements made up of much elongated tracheids, whose thickenings are between annular and spiral in form, but very different from the coarsely reticulate and the conspicuously pitted tracheids of the metaxylem developed in the older parts of the stele. In all cases where truly median sections were seen the protoxylem elements occupied the innemost region of the xylem and no metaxylem was seen within these, so that the bundle (at first, at any rate) is endarch, as in the other (Ophioglossacere. It is impossible to see in this section that metaxylem was developed inside of the protoxylem, as Farmer found to be the case in the older sporophytes. 
In fig. $48, D$, there is shown an insertion of a root upon the stele and its very broadly expanded base with the irregular conjunctive tracheids. This ver broad base of insertion and the obvious continuity of the tracheary tissue of the root with that of the central stele of the stem suggest that the ventral part of the stele might be made up, in part at least, of root traces.

Cross-sections of older plants, such as that shown in the series indicated in fig. $5 \mathrm{I}$, show essentially the same arrangement of the parts as do the younger ones. At the apex there may be seen in section the three youngest leaves, which we will designate respectively 1,2 , and 3 , No. I being the oldest leaf shown. In this section the oldest leaf shows two vascular bundles in the petiole, and this is true also of the second leaf, which is contained within the stipular sheath of the oldest leaf. The lamina of leaf No. I already shows the characteristic temate form. The young leaves make an angle of about $30^{\circ}$ with each other. Section $B$ passes directly through the stem apex and shows the sections of the basal part of the sheath of the two older leaves. The stipular sheath of the youngest leaf partially incloses the stem apex, and surrounding the apical region is a loose mass of cells, derived partly from the tissue immediately around the stem apex and party from the edges of the sheath of the youngest leaves. These cells are really sections of hairs and scales which perhaps secrete mucilaginous matter, but there was no evidence of this in the sections. Tumed toward the dorsal side of the section may be seen the leaf trace from the second leaf and separated from it by a considerable space on the ventral side is a rather vaguely defined mass of young procambium, which marks the trace of the youngest leaf. On the ventral side of the latter is the stem apex itself. Further down, as has already been described for the younger stem, the two leaf traces approach. At the level of the stem apex the trace of the second leaf is clearly defined and nearly oval in outline, but more convex upon the dorsal side. The bundle is inclined toward the side of the stem opposite the insertion of the first leaf. Further down the trace becomes much broader, this being mainly due to the development of the tissue upon one side, which begins to bend downward toward the ventral side of the stem. The trace of the youngest leaf is now somewhat better defined and appears somewhat kidney-shaped in section, the convexity, like that of the second leaf trace, being turned toward the dorsal side. This trace also begins to show the extension of tissue toward the ventral side of the stem and this is developed on the side opposite to the extension in the next older leaf trace. Ultimately these ventral extensions of the two bundles meet as the two leaf traces come nearer together, and the dorsal ends also finally come into contact, so that the two bundles, the section of each of which is approximately semicircular, form a complete ring inclosing a greater or less amount of the ground tissue, which thus forms the pith of the hollow stele. The stele resulting from the union of the two leaf traces is not at first perfectly circular in section, but shows plainly for a long time that it is composed of two separate bundles (fig. $5 \mathbf{I}, F$ ).

The first development of permanent tissue in the older leaf trace is evident before it joins the younger one. The first elements are thick-walled cells (which may be called protophloem) in the outer zone of the phlesem, and a little later at the inner limit of the bundle a small group of protoxylem elements appears. Very soon after this a similar differentiation takes place in the younger leaf trace, so that when the two leaf traces are completely fused the protoxylems have the appearance of having arisen toward the central part of the bundle, but in reality the component bundles, at least at their earlier stage of development, may be described as endarch and agree, therefore, with the bundles of the other Ophioglossacere. In the leaf traces of the older part of the stem, however, there may generally be found inside 
the proescylem a few seatered, large eracheary elements, so that the hundle may be said to be mesarch, as farmer states is the case in the older rhizome.

During its earlier stages the stele shows no leaf gaps where the leaf traces depart, and the leaf gaps are only gradually developed. Soon after the stele has assumed the form of a hollow cylinder the leat gaps are for some time absent, or they are developed only in a very small degree and close almost immediately upon the departure of the leaf trace.

In none of the young plants that I examined could I detect any of the inner endodermis which occurs in the older rhizomes. Farmer, however, states that the inner endodermis is only imperfectly developed and concludes that it is the result of the invagination of the outer endodermis through the leaf gap; or, to put it in another way, it is the persistence of the inner endodermis of the leaf traces of which the hollow stele is made up. The bundle at this stage most nearly resembles that of Botrychum lunaria, differing from that of $B$. virginianum in the absence of a true

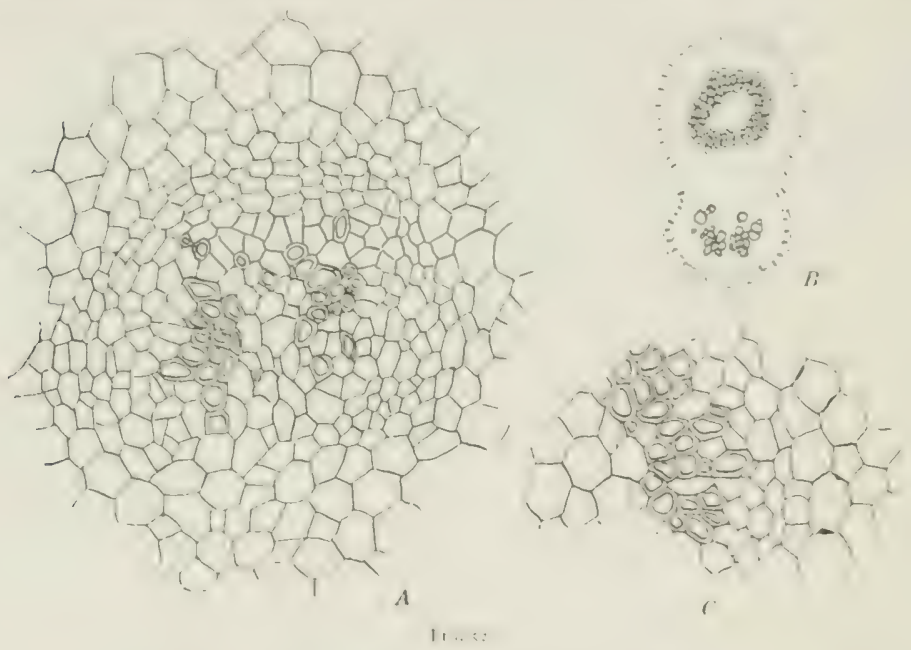

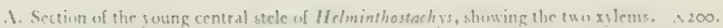

13. Stele from lower part of an older sporophyte, show ing junction of a leaf trace with ecntral serle. Yiso.

C. Eart of ecneral stele, more bighly magnifiet.

cambium, the outer wood cells being directly in contact with the inner cells of the phloem. Occasionally, however, there may be seen on the outer edge of the xylem ring a few imperfectly developed tracheids which probably represent a very rudimentary development of secondary wood, but there is no other sign of the definite cambium zone which is so conspicuous in the stele of Botrchium sirginianum.

From this study of the development of the leaf traces, following them from the stem apex downward, it appears that the cylindrical stele in Helminthostachys arises in precisely the same way as that of Botrychium, viz, by the union of the leaf traces. The appearance of procambium upon the ventral side of the stele, which in longitudinal section appears to be derived directy from the stem apex, can thus be explained by the ventral extension of the broad leaf traces which meet on the lower side of the stem as well as above, and the cylindrical stele is thus developed. 
It is not impossible that the root traces may also contribute to some extent to the development of this ventral portion of the stele. The xylem masses belonging to the two leaf traces remain quite distinct for a long time, the one belonging to the older trace being better developed than that from the younger one (fig. $52, A$ ). The metaxylem consists of scattered tracheids arranged regularly in an arc outside the protoxylem of the older bundle, but there are a few scattered smaller ones lying in the tissue separating the two primary xylems, so that, as we have seen, the bundle may perhaps be described as mesarch, and not endarch as it is in Ophioglossum and Botrychium.

The two xylems of the separate bundles are finally connected by intermediate tracheary tissue, so that a nearly complete ring of wood is formed; but the xylem of the older leaf trace is still clearly recognizable on account of its greater thickness. In the section figured (fig. 52, C) there is no tracheary tissue yet formed inside the protoxylem and there is a well-marked pith occupying the center of the stele. The endodermis is now well developed and inside it are about two rows of pericycle cells. The protophloem is less conspicuous than in the younger stele and is best developed in the outer portion of the older leaf trace. The rest of the phloem is made up of

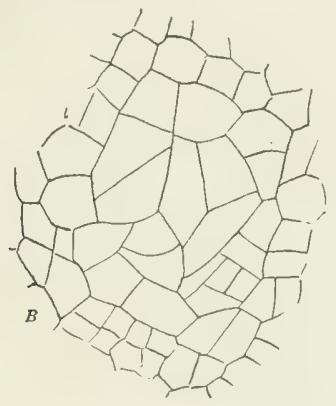

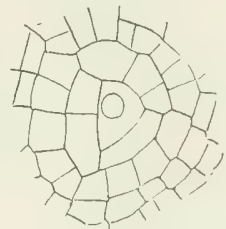

A

FiG. 53 .
A. Transverse section of apex of first root of Helminthostachys, showing a single tetrahedral apical cell. $\times 200$.
B. Apex of a later tetrarch root, with apparently no single initial cell.

thin-walled cells, the larger of which are presumably young sieve tubes. The section is taken from a much older part of the stem and shows that the bundle has attained practically the same condition as in the adult stem, except for the absence of the inner endodermis. The central pith is surrounded by an unbroken ring of wood, averaging about three cells in width. The outer part of the bundle is essentially the same as in the one that has been described.

The canal described by Gwynne-Vaughn for the older sporophyte is plainly evident here and extends backward from the sheath cavity, appearing in crosssection as a narrow cleft between the inner side of the leaf stalk and the internode (fig. $49, D, y$ ). It is evidently not a cavity in the cortex, but merely an invagination of the epidermis, which is continuous with that of the inner surface of the stipular sheath.

A peculiar feature of the ground tissue in the young stem and petiole in Helminthostachys is the presence of cells containing roundish bodies which stain very strongly with Bismarck brown, and these cells closely resemble the tannin cells of the Marattiacex, with which they are probably homologous (fig. 49, C). Lang figures these cells (Lang 1, fig. 65), but makes no mention of them in his text. 
The race for the second leat, the list functional one, is ustally previded wioh a sinele undivided bumdle passing through the petiole, hut somerimes this divides info two, as it does in the cotyledon of Botrychum sirgimianum. Where a single bundle oceuss in the petiole it oceupies a nearly median position and is concentric in structure, although the phloem is somewhat less developed upon the adaxial side. The xytem consists of a large mass of tracheids surmunded by the phlocm, which is reduced en about two rows of eells upon the adaxial side. Whether the largest cells in this portion were sieve tubes was not detemined. Where two bundles are present they ate somewhat smaller and are more nearly circular in outline than the single bundle, which they resemble in structure. In the ground tissue ale large intercellular spaces which disappear at the base of the leaf, where the ground tissue in cooss-section appeats almost solid. This development of lacunae in the first foliage leat recalls the similar ones in the cotyledons of Botrychiom and Ophioglossum.

In the older part of the rhizome there is a slight development of periderm on the dorsal side, which liarmer found on be the ease also in the older rhizone. 'This periderm is restricted to the dorsal region and is obviously associated with the leaf bases, as it is in Botrychiom and probably also in Oplioglossum. It presumably.
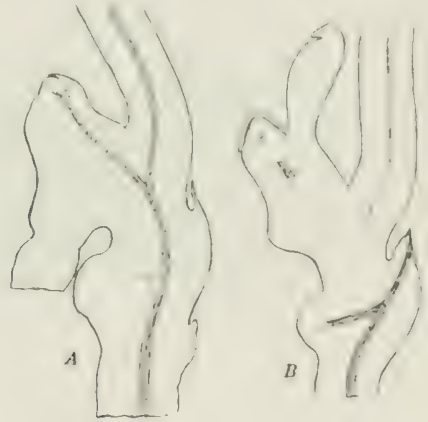

Fig. 54 .

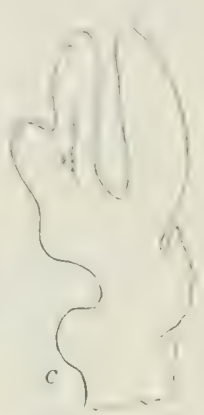

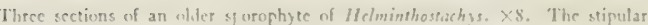
sheath is stisent from the thiri youngest leaf.

acts as an absciss layer, such as Jeffrey demonstrated in Botrychium, and this not only causes the separation of the old leaves but perhaps also acts as a protective layer to the leaf scars. The absence of periderm from the ventral side is no doubt connected with the strictly dorsal position of the leaves.

The later roots, like the first one, grow from a single tetrahedral apical cell, very much like that of Ophioglossum and Botrychium. "The root cap is not very. prominent and is usually somewhat pointed. It apparently owes its origin entirely to the activity of the outer segments of the apical cell. The primary segments of the root cap underge periclinal divisions, but, as in Botrolitum, the stratifications of the older lavers is much less marked than it in the ordinary ferns. Fach of the lateral segments of the apical cell divides by a somewhat radially placed anticlinal, so that a transverse secrion of the three youngest segments shows six cells having a nearly radial arrangement. Periclinal walls may arise and the inner cells of the segments give rise to the central cylinder of the root, while from the outer ones is developed the cortex. As in the other (Ophioglossacea, no root hairs are formed. 
The primary root, as Lang pointed out, is usually triarch, but occasionally diarch roots occur, as they usually do in Botrychium and in Ophioglossum pendulum. In this case, however, one of the xylems was rather larger than the other. The later roots are tetrarch and in the older sporophyte, as liarmer showed, the roots generally have six xylem masses, or occasionally seven. This type of root is most like that of the Marattiacea. The endodermis is pretty well developed, but not so conspicuous as it is in Botrychium.

In the cortical region of the first root there is a zone of cells in which occurs an endophytic mycorrhiza, such as is common in the roots of other Ophioglossacere, and probably the same as the endophyte which is found in the tissue of the prothallium. Whether the infection of the primary root is direct from the prothallium or whether there is a new infection from the soil was not determined. Lang states that the mycorrhiza is only developed in the first two or three roots, the fourth root and those formed later not having the endophyte. In these later roots the cortical cells are densely filled with starch.

The rhizome continues to grow upright for a good while and it was not determined at just what time it assumes the prostrate position which it has in the adult form. At first there is usually one root formed for each leaf, but in the older plants this regularity is lost, and Farmer states that there may be three or four roots developed for a single leaf. On the other hand, the number of roots may be less than that of the leaves, especially in the younger plants.

A curious abnormal form was seen in a young sporophyte, where for some reason several of the earliest leaves had remained in the rudimentary condition of the cotyledon. Five of these rudimentary leaves could be seen formed in succession. The sheaths were fully developed and there was a long internode between each pair of leaves. Three of these had developed roots, but the others had failed to do so. This rhizome was nearly 3 centimeters in length, but it had hardly increased at all in thickness. A single ternate leaf had expanded at the summit, but whether this was the first functional leaf that the plant had developed could not be determined, as the rhizome was broken off below and there may have been one or more functional leaves developed below the first of the rudimentary ones.

This repetition of vestigial leaves recalls the condition of things in Ophioglossum vulgatum and Botrychium lunaria. For a good while the new leaves are of the same ternate form as that of the first foliage leaf, but sooner or later, probably dependiner on the vigor of the plant, the ternate form is gradually replaced by five folliate leares. the later divisions being the result of an unequal dichotomy of the lateral leaf segments, similar to that by which the second lateral segments of the primary leaf ate separated from the terminal leaflet. In these five foliate leaves the characteristic "pecopterid" venation of the adult sporophyte is fully attained (fig. $+5, B$ ). Each lateral vein forks twice, the ultimate veinlets extending to the margin of the leaflet. A section of the petiole of one of these leaves shows that it contains four vascular bundles, arranged in pairs. The dorsal bundle of each pair is decidedly larger than the ventral one. The base of the petiole is almost perfectly cylindrical, but furthes up it becomes winged, so that a groove appears on its inner face extending for some distance below the junction of the lamina and the periole. There is a ren slighty developed hypodermal tissue composed of two or three layers of cells, the walls of which are colorless and considerably thickened, some of them showing thickened corners like the collenchyma found in the leaves of the Marattiacex. 


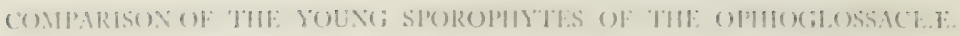

If, as we believe, the type of sporophyte found in ()phioglossum moluccanum is really primitive, we may assume that the sporophyte at first had a single axial stele, collateral in structure and essentially the same in leaf and root. "This primitive sporophyte had no stem at all, but consisted simply of leaf and root. From the primitive vascular skeleton, composed of a single unbranched strand, we can derive she different types characteristic of the older sporophyte in the ehree genera. As to the first origin of the stem apex, we can only conjecture; whether it originally arose, as it does in Ophioglossum, as an endogenous structure repeating, as it were, the origin of the primary root, we have no means of knowing, but this seems to be the most probable explanation of the origin of the stem apex in the primitive sporophyte from which are descended the different types of the Ophioglossacex. After the establishment of the stem apex the secondary leaves contributed their quota to the developing skeleton of the sporophyte. In Ophioglossum these leaf traces remain largely free and anastomose only to a limited extent, thus giving rise to the open tubular dictyostele with very large meshes. The structure of the individual strands of the dictyostele is essentially the same as that of the free leaf traces.

In Hclminthostachys the early leaf traces fuse completely and there is formed a solid stele in the younger internodes with a central xylem core; composed of the united xylems of the two leat traces. These leaf traces are approximately collateral in structure, although it may be that they have a small amount of phloem upon their imner face. After entering the petiole of the young leaf, however, these assume a distinctly concentric form. As the leaves increase in size their traces become broader and in section appear more or less crescentic, so that when the leaf traces come together there is left between them a certain amount of the ground rissue which after they have united appears as a pith lying inside of the tubular stele. This pith, however, it must be remembered, is not part of the stele proper, but is merely an included portion of the ground tissue. With the complete fusion of these two broad leaf traces the tubular form is established and the wood appears in section as a continuous ring. In Botrychium, especially in the large forms like $B$. sirgin-

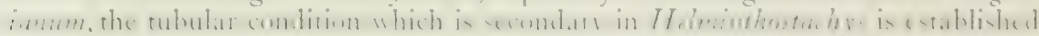
at once; this is probably to be explained by the fact that the vascular bundles of the first leaves are much better developed, there being two strands in the cotyledon and in the second leaf, and the leaf traces belonging to these ate correspondingly broad and on fusing include at once a certain amount of the ground tissue, so that the stele appears tubular from the beginning. Botrychium sirginianum undoubtedly represents the most specialized type of the Ophioglossacer, and the development of the cambium with a permanent secondary thickening of the wood is an evidence of a higher degree of specialization in the vascular system than is found in any other living Pteridophyte. While a very slight indication of this secondary thickening has been found in Ophioglossum, and I have also noted some slight traces of it in Hilminthostachys, there is never developed in these the genuine cambium ring, such as we find in Botryitum sirginianum. In the development of the spiral protoxylem elements Helminthostrithys differs from the other Ophioglossacea and suggests the true ferns. In the early development of its vascular system there rare strong suggestions of some of the Marattiacea, especially Kaulfussia and Damera. The development of concentric bundles in the petiole in Hclminthostachys and Botrychum also sugrests the Marattiacex.

Assuming that the collateral bundle, which is typical of the stem in all of the Ophioglossacere and occurs also throughout in Ophioglossum, is primary, the con- 
centric bundles as they occur in the petiole of Helminthostachys and Botrychium must be considered as secondary. The monarch root of Ophioglossum moluccanum and the other members of the section Euophioglossum is to be considered as a relic of the primary condition where the single axial stele, as in the young sporophyte of $O$. moluccanum, had the single strand of practically uniform structure, extending through the leaf and root. The development of diarch roots, such as those of $O$. pendulum and Botrychium, is probably also secondary and perhaps associated with the early development of the second leaf in these forms. The diarch root appears again in the young sporophyte of the Marattiacex and is permanent in most of the leptosporangiate ferns. The roots of the larger species of Botrychium and especially those of Helminthostachys, with their increased number of xylems, are undoubtedly secondary developments, perhaps associated with the large size of the roots; and we again find this same type developing in the Marattiacex. In regard to this point, Helminthostachy's is the most aberrant of the Ophioglossacere and approaches nearest to the Marattiacex.

The leaf in the smaller species of Ophioglossum is probably a very primitive structure and the closed stipular sheath - which is not exclusively foliar in origin, but at first owes part of its tissue to that of the cortex of the root, from which the sporophyte arises - is probably an older structure than the strictly foliar, stipular sheaths in Botrychium and Helminthostachy's. The simpler types of Botrychium, like $B$. simplex and $B$. Innaria, show a transitional condition between the closed sheath of Ophioglossum and the open sheath of $B$. virginionum, which may really be spoken of as composed of two stipules, in this respect recalling the Marattiacea. Helminthostachys, in the development of the stipular sheath, agrees exactly with the simpler types of Betryinum. In these forms the sheath is hood-shaped, opening by a transverse slit in front and below, and the upper portion of the sheath is broken through when the inclosed leat emerges, so that the two apparent stipules in Hitminthost hes are really secondars, caused by a tearing of this hood-shaped sheath, and are not proper stipules as they are in Botrychium virginianum.

The simpler and probably more primitive species of Botrychium, like $B$. simplex and $B$. lunaria, are obviously intermediate between Ophioglossum and the larger and more specialized species of Botrychium. This is shown in the form and venation of the leaves, as well as in the character of their tissues. Instead of the pimate renation found in the leaves of $B$. arginimum, these more primitive species show no midrib in the leaf, but the veins all radiate from the veins of the leaflet, dividing dichotomously, so that they are arranged in a fan-like fashion. Were the ends of the veins connected there would result a reticulate venation, exactly like that of Ophioglossum. These leaves, moreover, are fleshy in consistence and have stomata upon both sides, while in Botrychinm virginianum and in Helminthostachys the stomata are restricted to the lower surface of the leaf. In all of these particulars Ophioglossum and the simpler species of Botrychium are evidently more primitive than the other genera.

In Botrychium virginianum, as we have seen, the cotyledon is extraordinarily developed, more so than that of any other Pteridophyte. The contrast between this highly developed cotyledon and the very rudimentary one in Botrychium lunaria, where the young sporophyte passes several years under ground before the first green leaf emerges, is very striking. It is, however, to be assumed that the rudimentari condition of the leaves in Ophioglossum vulgatum and Botrychium lunaria is a secondary condition, connected with their long life under ground.

Helminthostachys, on the whole, approaches more nearly to $B$. lunaria in its early stages of development than it does to $B$. virginianum. This is shown in the 
rudimentary condition of the cotyleden and in the venation of the firse follage feat, which, alehough it has a ternate lamina, is quite molimentary. We have already referred, however, on the rudinentary leaves of $B$. Innaria, which alses sometimes develop a very small temate lamina. The venation of the first leaf in $/ /$ dmimeses-

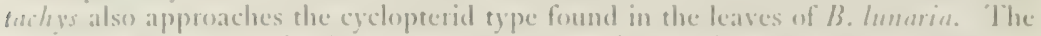
structure of the stele in the young stem also, after attaining the tubular form, is more like that of $B$. Innorio than like that of $B$. virginionum.

()n comparing the early stages of development of the ()phionglossacea and Maratracea we shall find that they have a good many points in common, which will be discussed more at length after we have described the structures of the lateer. Ophioglessum, as to the formation of the cotyledon, is very much like Kunlfussion, while /lelminthostateys is more suggestive of Danaca. The stipular structures of the two families are unquestionably homologous and the entire conical stipular sheath, found in the lower members of the Ophioglossacea, is probahly an older type than the free stipules found in Botryclium virginianum and the Maratriacea.

In both the Ophioglossacex and Marattiacese the young sporophyte at first is made up almost entirely of leaf and root, and the whole vascular system is composed of the leaf traces with no proper cauline vascular tissues, so that one might almost say that the stem is made up entirely of the bases of the leaves, the dominance of the leaf being the most noteworthy feature in the morphology of these plants. On the whole, probably Hclminthostacly's most nearly resembles the Marattiaceat. This is true both of the character of the venation of the leaves, the structure of the root bundles, and the development of tamnin cells in the young sporophyte. These tannin cells seem to be quite absent from the tissues of both Ophioglossum and Botrychium. 


\section{THE ADULT SPOROPHYTE.}

The essential characteristics of the sporophyte are established while it is still quite small and the subsequent differences are mainly an increase in the size of the parts and finally the development of the spore-bearing structures which constitute the peculiar spike or sporangiophore so characteristic of these plants. As the structure of the tissues has been repeatedly studied and described, no attempt will be made here to take up a detailed study of these.

The Ophioglossacex in general, except for the rather elaborate vascular bundles of the stem, especially in Botrychium, are marked by great simplicity in the structure of the tissues. The surface is usually smooth except in the younger plants, where there may be a development of scales and hairs, presumably for the protection of the young tissues of the stem apex. The hard hypodermal tissues and bands of sclerenchyma, so common in the leaves and stems of many ferns and developed to a less degree in the Marattiacea, are practically entirely absent from the Ophioglossacex.

Except for the vascular system of the stem the bundles are usually less developed than is common in the more highly differentiated ferns, this being especially the case in Ophioglossum, where the very delicate bundles forming the veins of the leaf run through the spongy green tissue of the leaf without causing any projecting veins at the surface. This condition is true also in the simpler types of Botrychium and in the young leaves of Helminthostachys. The great bulk of the ground tissue in leaf, root, and stem is parenchyma. The development of periderm in the outer tissues of the stem is probably always associated with the leaf bases and serves, as we have seen, both to separate the dead leaf bases and to protect the scar thus left after the leaf has fallen away.

The roots are characterized by the complete absence of root hairs. The outermost layer of cells often has the walls much thickened and they may show the reaction of cork. The bulk of the cortex of the root, however, is composed of unmodified parenchyma. The vascular cylinder in the root remains monarch in the section Euophioglossum, but is diarch in the smaller roots of Ophioderma and in the smaller species of Botrychium, and ranges to hexarch in the larger roots of Helminthostachys. The roots, especially in the larger species, are thick and fleshy and as a rule branch sparingly and somewhat irregularly. In the section Euophioglossum no lateral roots are formed and branching is rare. When it does take place it is the result of a true dichotomy of the apex. The root, as in the youngest stages in the plant, grows almost always from a single tetrahedral apical cell, which is much alike in all the genera.

The most characteristic feature of the Ophioglossacex is the peculiar sporangial spike referred to. There is a certain correlation in the degree of development of this spike and the sterile leaf segment with which it is associated. The fertile leaves may arise very early in the history of the sporophyte. Bruchmann states that the first leaf to appear above ground in Botrychium lunaria is already a fertile one and in Uphioglossum zulgutum the second green leaf to be developed usually bears spores. This early development of the ferrile leaf is probably an indication of the primitive nature of these plants, as we must assume that the ancestral form must have at once developed a sporangial structure on the first leaf, or what corresponded to that in the embryo. In Botryclium lunaria Bruchmann figures young spore-bearing plants which are still connected with the prothallium, and Jeffrey states that in B. virginianum he once found a fruiting plant with which the prothallium was still connected. 


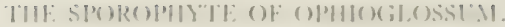

(of the three existing genera of the ()phioglossacee, the genus (Ophioglessum is much the largest and most widespread. The number of species, however, is very imperfectly understood, as there is great confusion in the nomenclature, owing to the inadeguate study of the tropical species, of which the number is undeubtedly much greater than has generally been supposed. The smaller terrestrial species look very much alike and it is evident that collectors have often failed to discriminate among them. My attention was especially called to this while I was collecting material of Ophioglossum in Java, where there is evidently a considerable number of species. Raciborski (Raciborski 1), who has described the P'teridophytes of this region, mentions only a single species as occurring in the neighborhood of Buitenzorg, where most of my collecting was done. But in that immediate neighborhood I collected at least three very distinct species, and two were collected at T jibodas, some $t, 000$ feet above Buitenzorg. Raciborski, however, mentions only a single species as occurring at Tibodas. There is no doubt that a critical study of these plants from other regions where they abound will greatly increase the number of species to be recorded.

The great majority of the species of Oplioglossum belong to the subgenus Euophioglossum, which should probably be separated completely from the very different forms which comprise the other subgenera. The species of Ewophioglossum are all small or moderatesized plants with undivided leaves which are generally lanceolate or broadly oval in outline and have the sporangial spike borne on a very long stalk attached to the sterile part of the leaf near the base of the lamina. These plants are always terrestrial, the leaves growing from an upright rhizome, which is sometimes a good deal enlarged, sometimes more slender in form. From the rhizome there extend numerous roots which are sometimes developed one for each leaf, but this is by no means always the case. 'The sporophyte of Euophioglossum seldom exceeds a height of 30 to 40 centimeters and some of them are very much smaller (fig. 55. also plate 3 ).

Except for their larger size the later leaves do not differ essentially from the primary leaf of the young sporophyte. The venation is always reticulate, usually without any definite midrib, although sometimes there is a central vein which is slightly stronger than the others. In many species, e. g., O. moluccamum, O. a'ulgatum, small branches ending blindly are found within the large meshes. In oeher species, e. g., O. Iusitanicum, there are no free veins within the areoles.

In many of the species but one leaf is formed each year, but in others, especially many of the ropical species, there may be as many as four or five formed in a 
single season. In $O$. vulgatum the development of the leaf is very slow, the leaf remaining three years inclosed in the bud and emerging in the fourth season. So far as I know, no study has been made of the development of the leaves in those species of the temperate climates where more than one leaf is developed in the season, and it remains to be seen whether the leaves which unfold in the same season are of the same age or not. In the rapidly growing tropical species it is exceedingly unlikely that more than a few months are necessary for the complete development of the leaf, which unfolds as soon as it is mature, but no data are available on this subject.

While the spike in Euophioglossum is usually inserted at the base of the sterile lamina it may be attached much further down. This is especially noticeable in the small species 0 . bergianum, from South America (see Bower 9, page 435). In $O$. bergianum the leaves do not show a clear separation into lamina and petiole and the spike is inserted close to the base of the linear leaf, so that it appears to be an entirely distinct structure.

In nearly all of the species of Euophioglossum the later roots, like the primary ones, are monarch, but in $O$. bergianum they are diarch. In most cases at least, as Holle (Holle 1) showed, only one root is formed for each leaf. This seems to be the case in $O$. moluccanum, which was investigated with some care.

Ophioglossum pendulum (plate $4, \mathrm{~B}$ ) is the best-known representative of Ophioderma, the second section of the genus. This differs a good deal in its general characters from the small terrestrial species of Euophioglossum. It is not uncommon throughout the eastern tropics, where it grows as an epiphyte upon the trunks and branches of various trees. The rough stems of certain tree ferns and some palmlike species of Phanix form a favorite habitat for this fern in certain regions and, as we have pointed out in the study of the gametophyte, it is frequently found rooting in the masses of humus between the old leaf bases of some epiphytic ferns like Asplenium nidus. The stem, instead of being upright, is markedly dorsiventral, but is short, with the leaves crowded together near the end and all growing upon the dorsal side of the rhizome, as they do in Helminthostachys (fig. 63). The leaves are very much elongated and the ribbon-like lamina merges very gradually into the extremely stout petiole. These leaves in large specimens may reach a length of I. 5 meters, or even more, and the long, strap-shaped leaves hanging down from the boughs of the trees present a very characteristic appearance. In larger specimens it is not uncommon to find the lamina dividing dichotomously (see plate $4, \mathrm{~B}$ ) and it is said that sometimes this dichotomy may extend to the petiole, in which case each segment of the leaf bears a separate spike.

The venation of the leaf is reticulate, the veins inclosing long, narrow meshes with no free veins, and the venation thus resembles the type represented in Euophioglossum by Ophioglossum lusitanicum. The larger plants always have several leaves which are expanded at the same time and growth goes on uninterruptedly, The leaves are crowded together and there is no evident internode between them. but it is clearly seen that they are arranged in two rows on the flanks of the short rhizome (fig. 63, $d$ ). The remains of the stipular sheaths surround the bases of the leaves and these sometimes present the appearance of two small stipule-like organs. As in Euophioglossum, adventitious buds are frequently formed upon the roots. As a rule they are not terminal, but lateral structures and probably do not differ essentially in their development from those of $O$. moluccanum.

The rhizome is more or less buried in the humus and the roots ramify through this. Even in the very young plant the roots are branched and this branching becomes very marked in the larger sporophyte. There seems to be some difference 
in the number of routs, but in most cases two were found connected with each leaf, instead of one as I stated in my earlier description of the plant (Campledl 4). The rexts are very stout, sometimes attaining a diameter of over 3 millimeters. The smalled rents are diarch, but in the large roots there may be three, four, or even five xylems.

() phirglossum pendulum is much the largest member of the Ophioglossacex and the sporangial spike as well as the individual sporangia far exceeds in size those of any osher species (plate $+, 13,3^{-6}$ ). The spike is attached by a short peduncle and hangs down from the pendent lamina. In large specimens the spike may reach a length of 20 centimeters or more with a breadth of about a centimeter. Above the insertion of the spike the leaf is thin, but the slender peduncle is continued downward into a thick, Hattened midrib which merges gradually into the petiole, so that the spike has very much the appearance of being a terminal structure with the sterile lamina adlerent to it.

The young leaves in $O$. pendulum emerge while they are still very young and the sporangial spike is in an extremely rudimentary condition 'The general develupment of the leaf is therefore very easy to follow in this species, as these young luves are entirely free.

The second species of the section Ophioderma is the rare $O$. intermedium (fig. 69; plate + , A). This for a long time was known only from one locality in Borneo, but has lately been collected at other points in the Mlalayan region. The specimens figured were collected by the writer near Buitenzorg in Java. In the account of the Ophioglossacea given in Engler and Prantl's "Natüliche Pflanzenfamilien" (Bitter 2 ) it is suggested that $O$. intermedium is only a terrestrial form of $O$. pendulum; but there is no doubt at all that it is a very distinct species. The plants described here were growing in masses of humus at the base of old clumps of bamboo. The stem is usually very short, forming a small tuberous body, from which, in most cases, only a single leaf was growing, although two were sometimes found. A careful examination of this short rhizome showed that, like Ophioglossum pendulum, it is dorsiventral. The roots were short and in all cases observed were without branches. In one of the specimens a bud very similar indeed to the corresponding buds in $O$. pendulum was found growing from one of the roots. Ophioglossum intermedium differs from $O$. pendulum in being rigidly upright. The peduncle is longer and the lamina of the leaf much smaller and more clearly differentiated from the petiole. As in O. pendulum, however, the petiole is prolonged into the peduncle of the spike with the same midrib-like thickening, caused by the coherence of the basal part of the peduncle with the lamina.

This plant is exceedingly variable. In the larger specimens, except for the much shorter lamina, the plant a good deal resembles small specimens of $O$. pendulum. In others, however, the lamina is almost completely suppressed and this condition closely approaches the third member of this section, Ophioglossum simplex (fig. 7 I). This latter species is at present known only from one locality in Sumatra, and is distinguished from all the other species of Ophioglossum by the practically complete suppression of the sterile portion of the leaf (see Bower 8 ). The form of the rhizome and the habit of the plant in $O$. simplex most nearly resemble $O$. intermedium, to which it is probably not very distanty related. Whether or not we regard the alosence of the lamina of the leaf as a case of reduction, the fertile leaf in $O$. simplex certainly rery dosely resembles what one would assume to have been the primitive condition of the leat in the ancestors of the Ophioglossacea.

The third section, Cheiroglossa, contains a single very peculiar species, $O$. polmatum (plate 5). This occurs throughout tropical America, but does not seem to be a common plant. It has been reported from florida, where, however, it is 
very rare. It has been collected in various parts of South America and in the West Indies, and apparently the same species is known also from the Island of Bourbon and from the Seychelles in the Indian Ocean. The specimens from which the figures and descriptions given here were made were collected in the summer of I go 8 in the Blue Mountains of Jamaica, and were found in one place only, growing upon a rotten tree stump.

The rhizome in Ophioglossum palmatum is an almost globular tuber, which is radially constructed and in this respect resembles that of Euophioglossum more than that of Ophioderma. The leaf bases are covered with long brown hairs, which give a characteristic appearance to the rhizome. The roots are numerous and more slender than those of Ophioglossum pendulum. They are sparingly branched and the branching may have the appearance of a true dichotomy, but the material arailable did not allow of a critical investigation of this point. However, since in Euophioglossum the branching of the roots is actually dichotomous, it is not impossible that the same may be true in Cheiroglossa. The smaller roots, as in $O$. pendulum, are diarch and, as in all of the other forms, a mycorrhiza is developed in the cortical region.

In sections of one of the largest roots available the bundle was triarch. This root was rather young and the tracheary tissue was only partially lignified. The mycorrhiza was also less evident than in the smaller roots taken from a younger plant. Two young plants were found which probably had arisen from buds upon the roots of the older sporophyte. One of these is shown in figure $70, A$. It had developed a single nearly lanceolate leaf very much like the early leaves of $O$. pendulum. A single root had developed near the base of the leaf and this was joined to the small globular rhizome. A second root could be seen above this, but whether this second root belonged to the leaf or was part of the root upon which the bud had arisen could not be determined.

The older leaves may reach a length of 60 centimeters or more (plate 5). They are more or less deeply palmately cleft into narrow segments, which give the leaf a curious superficial resemblance to certain kelps, such as Lammaria digitata. The base of the fan-shaped lamina is abruptly narrowed into a nearly cylindrical petiole, about equal in length to the lamina itself. The venation is rather of the trpe of (). vulgatum, having numbers of free veins in addition to the elongated closed meshes.

In some of the smaller leaves (plate 5,3 ) there is present a single small median spike, which, like that of $O$. pendulum, has a short peduncle, but it is inserted below the lamina, in this respect again being more like Euophioglossum. In the larger leaves there are sereral sporangial spikes arranged in a series on either side of the petiole, usually betow the insertion of the lamina, but sonetimes some of them are inserted above the junction of the lamina and the petiole. Bower (Bower 9, page 436) has figured a series of specimens of this species showing the great variation in the number and arrangement of the spikes. He emphasizes the fact that although these spikes are apparenty marginal, in reality they always arise from the adaxial side of the leaf. He shows that in this species also there may be a branching of the individual spikes similar to that which occurs in Oplioglossum pendulum and less frequently in certain species of Euophioglossum.

\section{THE ANATOMY OF EUOPHIOGLOSSUM}

The stem apex of the adult plant has been repeatedly studied in the widespread Ophioglossum vulgatum, but there is little information in regard to this point in other species. From a somewhat careful examination of $O$. moluccanum it is evident that this species agrees closely with $O$. vulgatum, and a study by one of my students, 
Mr. C. S. Morris, of this species and also of a broad-leaved form from Ceyton, probably $O$. reficulatum, showed that the same characters prevail in the species he examined as in $O$. vulgatum. It therefore seems likely that all species of Euophioglossum agree in the main in the structure of the stem apex and the development of their tissues.

We have seen that in the young sporophyte the stem apex is completely inclosed in a small cavity formed by the hood-like stipular sheath of the youngest leaf. This condition, once established, is permanent (fig. 56 ) and there is no essential difference in the appearance of the stem apex between a young plant in which two or three

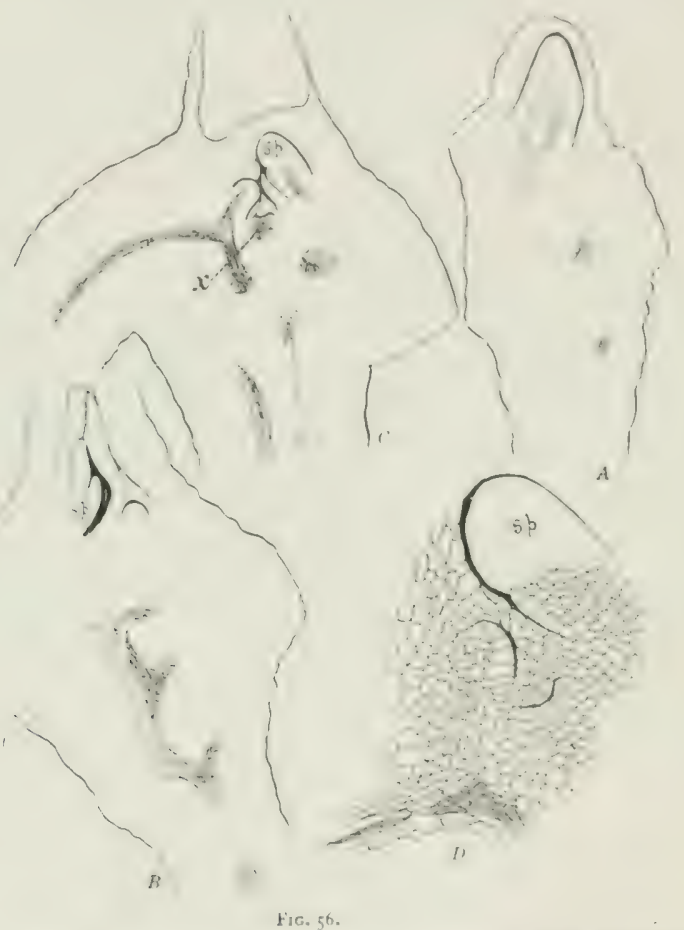

Longitudinal sections of an older sporophyte of Ophioglossum moluccanum, showing arrangement of vascular bundles; $x$, stem apex; sp, young sporophills. D) shows apical region more enlarged.

leaves have been developed and the full-grown sporophyte. The stem apex is of limited extent, crowded in between the bases of the young leaves, and in $O$. moluccanum the single apical cell is of the same form as that which was found in the early condition of the young bud; i. e., in longitudinal section it is four-sided, with a broad base and a narrower outer face. According to Holle (Holle 1), the apical cell in $O$. rulgatum is pointed below; but Rostowzew (Rostowzew 2 ) in his figures shows the same form as the apical cell in $O$. moluccanum. It is not at all impossible, however, that both forms may occur, as in cross-sections the apical cell in $O$. molmicanum may be cither three-sided or four-sided (figs. 39 and $56, D$ ). The apical 
cell in O. moluccanum may therefore be described as a three-sided or four-sided prism or a truncate pyramid.

As in the young plant, the stipular sheath of each new leaf is formed mainly from the basal tissue of the leaf itself, but includes also tissue from the margin of the stem apex. The sheath is open above by a narrow pore through which it communicates with the space between it and the next stipular sheath. In $O$. moluccanum, as in $O$. vulgatum, three leaves of different ages can generally be seen inclosed in the bud and sometimes the first indication of the fourth young leaf can
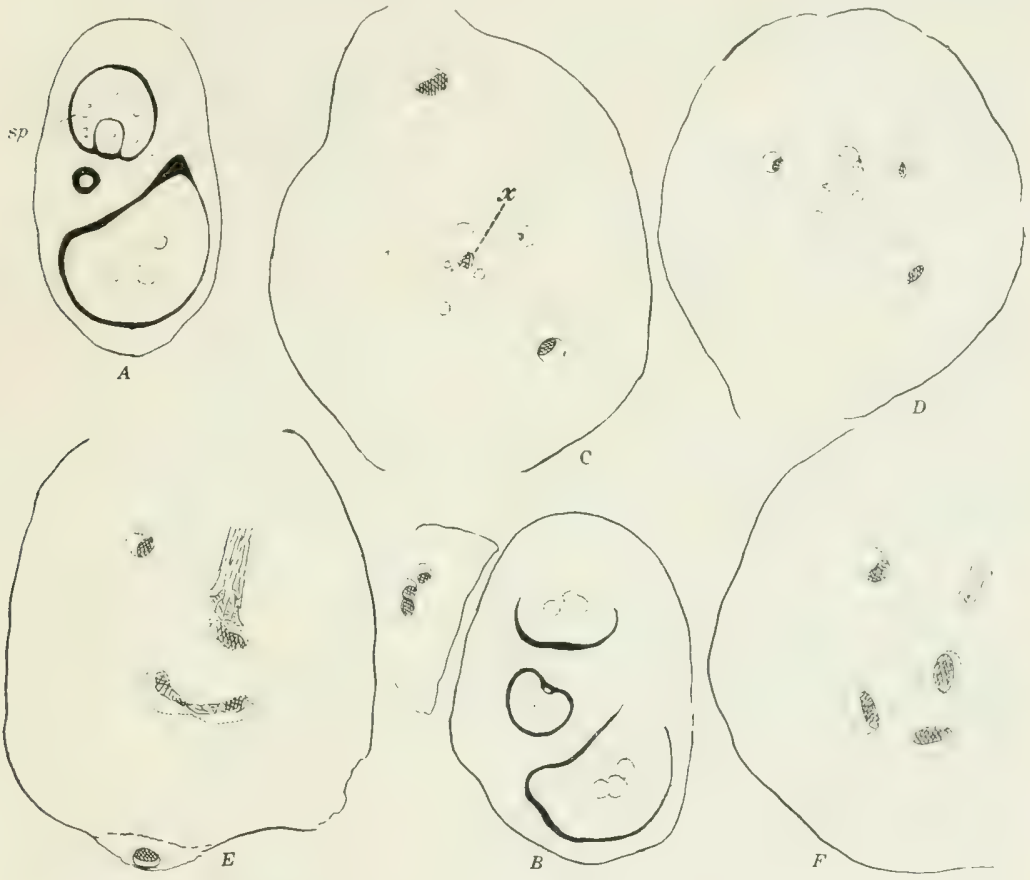

Fig. 57 .

Six of a series of cross-sections from a sporophyte of Ophioglossum moluccanum. sp, young sporophyll; $x$, stem apex.

also be distinguished (fig. $56, C, D$ ). A cross-section of the youngest sheath shows the pore as a minute opening, separated from the stem apex below by a very narrow space.

A careful study of the older stem gives no reason for assuming that the tissues of the very open reticulum forming the fibrovascular system of the rhizome is in any part due to additions from the apical tissue of the stem. Whether longitudinal or transverse sections are examined it is perfectly clear that the strands of this reticulum are made up entirely of leaf traces which can be readily followed into the young leaves or the tissue immediately below. The immediate apical region of the stem, as in the younger sporophyte, is unmodified parenchyma which adds only to the large central pith, if pith this can be called, as the separate bundles of which the vascular reticulum is composed run free for long distances through the ground tissue 
of the stem, which is identical in appearance in the cortical and the central regions. The bundle from each young leat can be traced to a junction with a root stele and fiom this point of junction it extends through the ground tissue of the stem, running almost herizontally until it joins the trace from the next older leaf. In this way is buile up the open, large-meshed vascular cylinder. So far as could be determined in (). molucianum only one root was formed for each leaf. The tissues of the root base are continued upward to connect with the young leaf and downward to join the stele from an older one.

No endexdermis can be detected in the bundles of the stem in $O$. vulgatum and the same is true for $O$. moluccanum, but in $O$. bergianum, $O$. capense, and $O$. clliptrimm, according to l'oirault (l'oirault 2 ), both an inner and outer endodermis occur in the older part of the rhizome; these however, disappear in the younger region higher up.

A transverse section of the mature rhizome (fig. 57) in Oplioglossum moluccamum shows the widely separated sections of the strands of the vascular cylinder as a circle of small collateral bundles without any endodermis, the mass of wood being in immediate contace with the thin-walled parenchyma of the ground tissue or separated from it at most by a single row of pericycle cells. In some of the smaller species the leaf traces are relatively broader and there is an approxination to the ringshaped section presented by the cylindrical stele of Botrychium or Helminthostachy's, and sometimes the same appearance may be approached in sections of the older rhizome which happen to pass through a region where there are numerous anastomoses of the bundles forming the reticulum (fig. $57, \mathrm{E}$ ).

lixcept for the vascular bundles, the tissue of the stem is made up almost exclusively of simple parenchyma. The development of periderm, which takes place to a limited extent in the outer region, is doubtless associated with the old leaf bases, as it is in Botrychium.

The leaf structure of Euoplioglossum is aredingls vimple. The messphell is made. up of thin-walled green cells, practically uni-

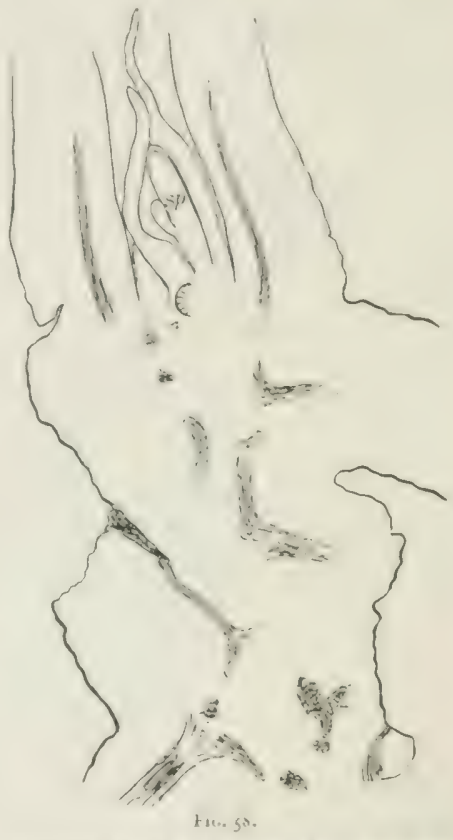

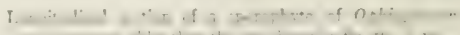
t.... form throughout; and through this spongy mass of mesophyll the delicate veins pass without forming any projections at the surface. Both sides of the leaf are provided with a simple epidermis, stomata being developed on both sides of the leaf. In those species in which the leaf lies more or less horizontally, as it does, for example, in (). reticulatum, the stomata are less numerous upon the upper sufface.

The arrangement of the bundles in the petiole has been already studied in the commoner lumpean species, $O$. sulgatum and $O$. lusitanicum. In all of the species belonging to the section linophioglossum there is given off from the vascular system of the rhizome a single leaf trace, which divides at the base of the leaf into two 
strands. Each of these strands may divide, or only one of them (fig. 60). In some of the smaller species there are only three bundles in the petiole, and in these forms there are no anastomoses of the bundles above the base. In the larger species these branches divide further and the number of bundles in the section is greater. Thus, each of the two ventral bundles may divide again in the upper region of the petiole so that a cross-section at this point would show five bundles, a large dorsal one and two pairs of smaller ventral ones. A similar condition of things is found in the
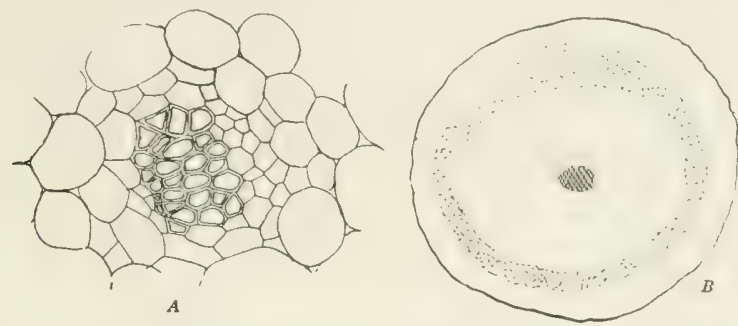

Fic. 59 .

A. Vascular bundle from an adult rhizome of Ophioglossum moluccanum. $\times_{150}$

B. Section of an aduit root showing monarch vascular cylinder. $\times_{35}$. The shaded zone is occupied by the mucorrhiza.

small species, $O$. californicum. As sections are examined below the junction of the lamina and the petiole, it can be seen that further forking of the bundles has taken place preliminary to their entering the lamina itself. Some of the species have the tissues of the petiole quite compact, others show a greater or less development of lacunæ or air-spaces in the petiole.

THE ROOT IN EUOPHIOGLOSSEM.

The early roots in $O$. moluccanum grow from a large tetrahedral apical cell showing a fairly regular segmentation, much like that of the typical ferns; but the root cap is not so well developed nor does it show as definite a stratification. In the
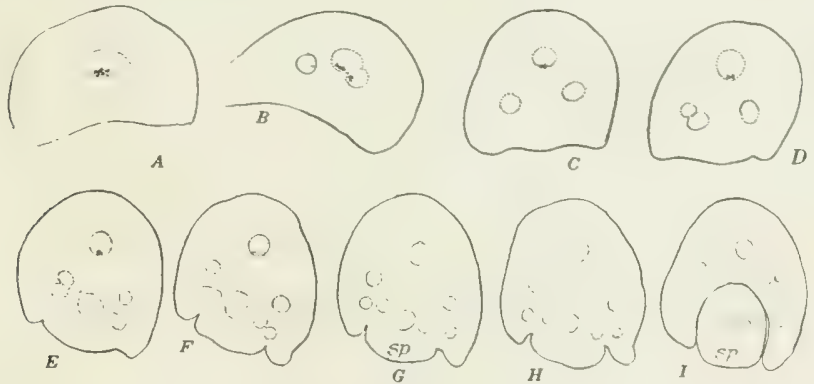

Fig. 6o.

Nine of a series of sections of a young sporophyll of Ophioglossum moluccanum. sp, the sporangiophore.

early roots the whole of the root cap seems to be derived from the outer segments of the apical cell. In the later and larger roots there seems to be somewhat less regularity in the segmentation and no sections were found which showed the apical 
cell and its segmentation as clearly as in the younger roots; however, only a small number of these later roots were sectioned and it may be that they were not all quite normal.

A section of an adult root is shown in fig. 59,13 . The cortical region is made up of simple parenchyma and the mycorrhizal zone is very conspicuous. The endodermis is not very clearly defined, less so than in the earlier roots, and its limits are

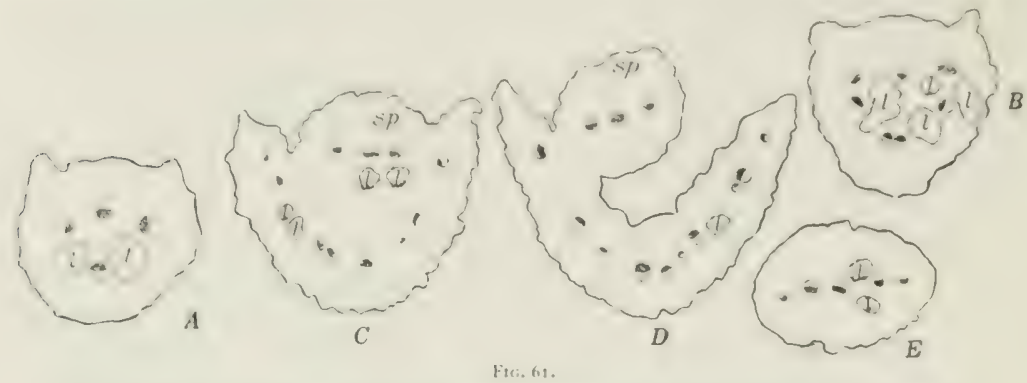

Vive sections of a full-grown sporophyll of Ophioglessum moluccanum. E, scction of peduncle of spike; 1 , lacune.

not easily determined. The cortical cells inside the mycorrhizal zone are densely. filled with starch. More than half of the section of the bundle is occupied by the large solid mass of wood. This is separated from the endodermis by a single layer of pericycle cells. The single mass of phloem lying next the wood is not much more than half as large.

\section{A.АTOMY (HF OHH() H:RMA.}

()wing to the dorsiventral position of the rhizome and to the more rapid development of the leaves, the section of the stem apex in Oplioglossum pendulum differs a good deal from a similar section of Euophioglossum (fig. 64). The base of the leaf is bent sharply upward, this being the case also in the very young leaf which is inclosed within the bud. The leaves break through the inclosing sheath in a very rudimentary condition, although of such size that a section through the base of the youngest visible leaf shows usually but a single younger leaf inside the sheath, instead of the three or four that are seen in a similar section of the bud in Euoplioglossum. Within the sheath at the base of the youngest visible leaf there is found a cavity in which is the growing point of the stem and the youngest leaf. The apex of the stem forms a strongly inclined, nearly plane surface and, as in Euophioglossum, the growth is from a single apical cell which, so far as could be determined, has the form of a three-sided pyramid, whose

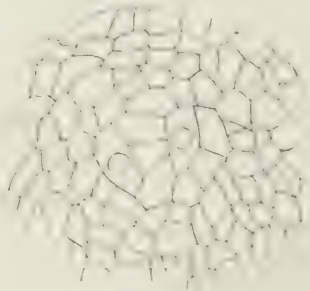

Fig. 62.

Apex of root of Ophroglossum moluecanum, showing dichotomy. $\times 150$. lateral faces are more or less strongly convex and whose apex may be truncatc. From the few cases observed it is not possible to say definitely whether basal segments are regularly cut off as well as the lateral ones. The segments cut off from the lateral faces are large and the divisions irregular.

Owing to the large size of the sporophyte there are practical difficulties connected with the study of the vascular system of the rhizome from a series of microtome sections. The numerous bundles in the leaf base do not unite into a single 
leaf trace, but pass downward through the cortex separately, and even if it were possible to make a satisfactory series of the sections of the large rhizome the task of following the course of the very numerous individual bundles would be a difficult one. From free-hand sections of the large base of the leaf, however, one can see without difficulty the general plan of the vascular skeleton. The stout petiole is slightly contracted at its base, but a section presents very much the same appearance as one made higher up.

In specimens that have been preserved in alcohol so as to become decolored, the tissues of the thick leaf base are sufficiently transparent to show quite clearly the course of the bundles even without sectioning, by simply slitting the petiole through the middle. The bundles are seen to anastomose freely at the extreme base of the leaf, very much as they do in the lamina. If such a section is examined where the leaf base joins the rhizome (fig. $63, D$ ) the circle of bundles can be seen to become
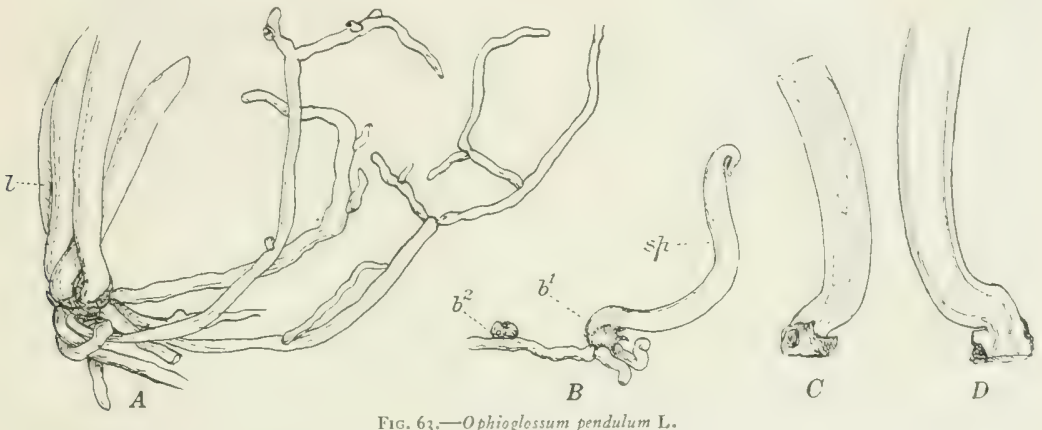
A. Stem showing dorsiventral form and branched roots. $l$, bases of leaves.
B. Buds attached to a root fragment. The older bud, $b^{1}$, has developed a young sporophyll, $s p$, and two secondary roots.
C. Base of a large leaf, showing arrangement of vascular bundles.
D. Section of same.

smaller as the bundles enter the cortex, but the bundles remain for the most part quite separate, although there may be an occasional anastomosing of these, as occurs in the petiole itself. This group of bundles composing the leaf trace-if such it can be called - forms a circle about the opening in the vascular cylinder of the stem where it joins the latter. A section of the vascular cylinder within the rhizome itself presents the appearance of a nearly complete ring, which is probably formed by fusing of the bundles derived from the leaf bases. The much greater development of woody tissue in the stem of $O$. pendulum as compared with that of Euophioglossum is doubtless due to the very much larger size of the leaves and the correspondingly greater number of vascular bundles contributed by them to the woody cylinder of the rhizome.

The very young leaf, such as is shown in fig. $6_{3}, B$, has a thick, fleshy leaf base, terminating in a very small and pointed lamina strongly bent over as it is, e. g., in the young leaf of Botrychium virginianum. This differs from the species of Euophioglossum, in which the leaf is straight in the bud. Under the arching hood formed by this folded-over lamina is the young spike, almost equal in length at this time to the lamina itself. A somewhat older stage is shown in fig. $82, B$. The leaf has now become somewhat flattened, but as yet there is no sharp distinction between the lamina and the petiole. In this early stage of development the interpretation of the spike as a terminal structure seems very plausible. An interesting 
case is shown in fig. 82 , $\mathrm{E}$, where the lamina is almost emiely supposesed and the terminal character of the spike is very evident.

As the leaf develops, there is a very great incease in size in the lamina, which, as we have seen, may reach a great length. The anatomical stucture of the leaf

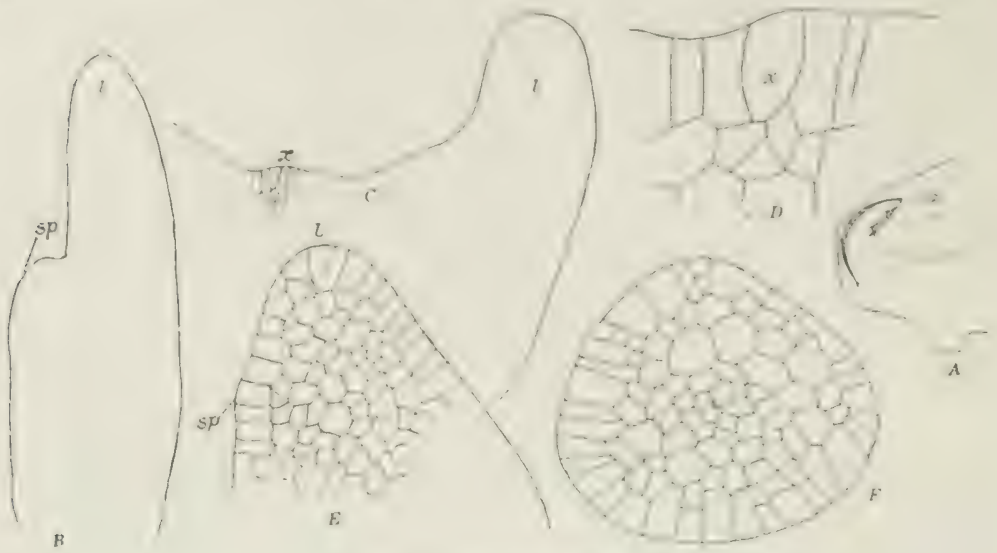

Fic. 64. -Ophioglossum pendulum.

A. Section of stem apex. $\times 3$.

D. The stem apex, more enlarged.

B. Young sporophyll. sp, sporangiophore, $X_{35}$.

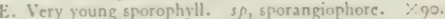

C. Stem apex, $x$, and youngest leaf, 1 .

F. Crossusection of young sporangiophore.

closely resembles that of Enophioglossum, but the stomata are much larger and around the stoma is a concentrically arranged series of cells, indicating that probably. the formation of the mother cell of the stoma is preceded by a series of preliminary

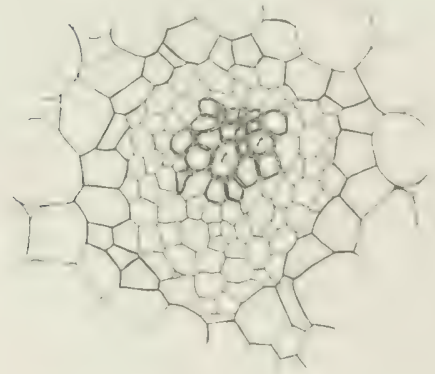

Fig. 65.- Vascular bundle from periole of 17 phioglossum perdulam.

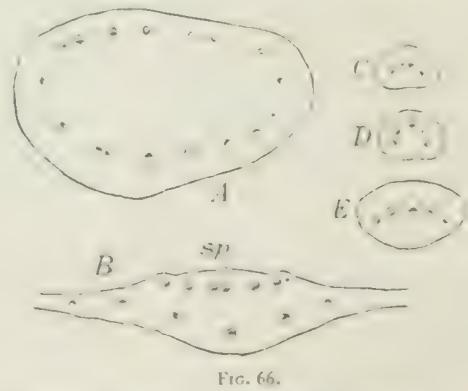

A. Section of petiole of a spurophyll if $f$. peratalum.

H. Section near base of lamina. sp, base of spthe.

C-E. Sections of peduncle of spihe. C and I) are frm il.e same leaf; E frim a latecr onr.

divisions in the epidermal cell. The tissues in the petiole are very like those in the lamina of the leaf except that they are somewhat more compact. 'The walls of the ground tissue in this region are very deeply pitted.

The structure of the vascular bundle of the petiole (fig. 65 ), is much like that in Euophioglossum, except that there is a rather greater development of tissue upon the 
inner side of the wood, so that there is a slight suggestion, at least, of a concentric structure of the bundle, such as is found in the petioles of Botrychium. The xylem is composed entirely of tracheids with reticulate markings. The rest of the bundle is made up of sieve tubes, mingled irregularly with smaller, thin-walled elements. It

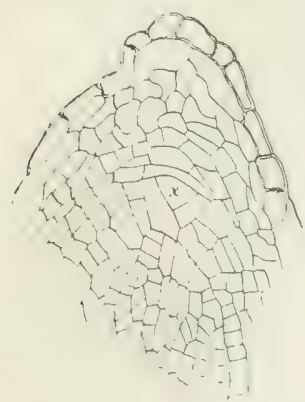

$A$

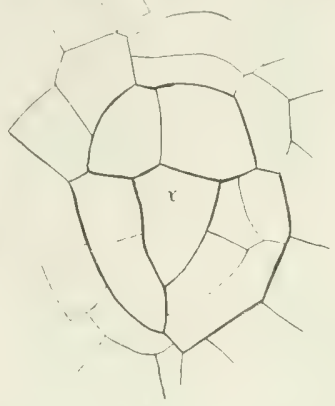

B

lic: 67.

A, longitudinal; $\mathbf{B}$, transverse section of the root aper of Ophioglossum pendulum could not be certainly determined whether any sieve tubes were developed on the inner side of the wood.

The number of bundles in the petiole, especially in large specimens, is much greater than in any of the species of Euophioglossum. In a specimen of medium size (fig. 66) eighteen bundles could be seen, of which probably seven or eight are destined to supply the spike. In the fertile leaves these form a complete circle, but in sterile leaves there are no bundles on the adaxial side of the section. In the free portion of the peduncle, which is relatively slender, the number of bundles is much less than in the broad basal portion. In the smaller specimen figured there were but three bundles in the middle part of the peduncle. The complete absence of the adaxial strands in the petiole of the sterile leaf, even at its base, is a strong confirmation of the view suggested by both the older leaf and the younger stages, that the peduncle is really an independent structure whose bundles are joined directly to the rhizome.
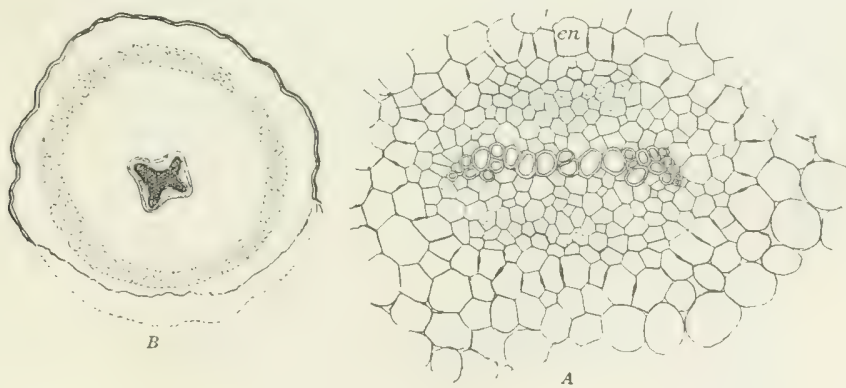

Fic. 68 .

A. Diarch root-bundle of $O$ phioglossum pendulum.

B. Tetrarch root of the same, $x_{20}$. Dotted area is mycorthizal zone,

O. intermedium (fig. 69) closely resembles $O$. pendulum in its anatomy, like the latter developing stomata upon both sides of the leaf, and these stomata are very large and show accessory cells similar to those found about the stomata of $O$. pendulum. Except for the difference in size, the arrangement of the vascular bundles in the peduncle and their structure is closely similar to that in $O$. pendulum. 
The anstemy of () simplex, so far as it has heen investigated (see Buwer 8) corresponds closely with that of the other species of the section () phiodermon.

The roots of $($ ). pendulum also show the teerahedral apical cell (fig. (6)), hut the
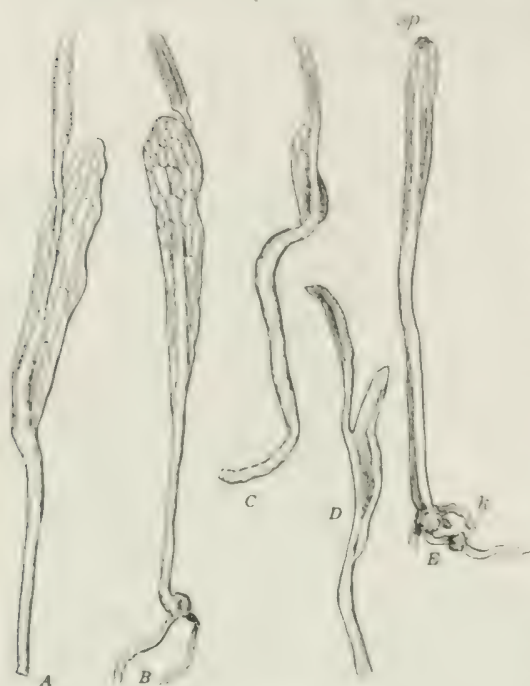

Fis. fig.

Five specimens of 0 . intermedium Hk., slightly reduced. $\mathrm{C}$ and $\mathrm{D}$ have a very much reduced lamina. divisions are much less regular than in O. moluccanum and probably the other species of the liursphirghtossum. The segments divide slowly and increase a good deal in size before the first divisions rake place, so that the youngest segments may equal the apical cell in size, and there is thus a certain resembance to the apical meristem in the root of the Marattiacese. It is probable that, as in the Marattiacese, the lateral segments of the apical cell also contribute to the root cap, which is rather better developed than it is in (). moluecanum.

There is a good deal of difference in the structure of the root bundle (fig. 68). This is diarch in the primary. root, as we have seen, and also in the smaller ones of older sporophytes; but in the larger roots, which may reach a diameter of over 3 millimeters, it is triarch: tetrarch bundles are also common, and in one very large root which I examined the bundle was pentarch, but one of the xylem rays was shorter than the others, the xylem forming a solid central mass having the form of an irregular five-pointed star.

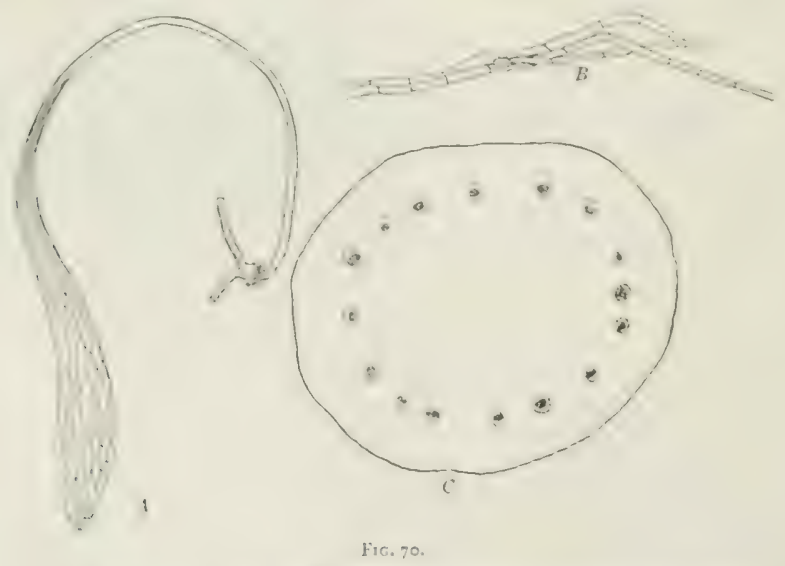

A. Small plant of Oplifoglossum palmatum I... growing as a bud upon a root fragment B. Hairs from hase of leaf.

C. Section of periole of a large leaf. $\times 7.5$. 
ANATOMY OF CHEIROGLOSSA.

Material was lacking for a study of the anatomy of the rhizome in $O$. palmatum (fig. 70), but the structure of the petiole is very much like that of $O$. pendulum and probably the same relation of the leaf bundle's to the bundles of the thizome obtain as in 0 . pendulum. The difference in the venation has already been pointed out and the leaves differ also from those of $O$. pendulum in the fact that stomata are developed only upon the lower side. A feature of this species is the presence at the base of the leaves of very conspicuous multicellular branching hairs, quite different from those found in any other species of Ophioglossum (fig. $70, C$ ). I find that the cells are much more elongated in my specimens than those figured in the account of the Ophioglossacea given in the Naturliche Pflanzenfamilien. *

\section{THE SIOROPHYTE OH BO'TRYCHILM.}

There is much the same uncertainty as to the number of species of Botrychium that there is in Ophioglossum. Some of the species are exceedingly variable and their limits are difficult to determine. Bitter, in his account of the ()phioglossacere in Engler and Prantl's "Natürliche PHanzenfamilien," states that there are sixteen species. Underwood (Underwood 1) says "about thirty," of which fifteen occur in the United States. Christensen in his Index Filicum recognizes thirty-four species.

Many of the species are very widespread, being most abundant in the North Temperate Zone. According to Christ (Christ 1), B. lunaria is not only widespread throughout the colder parts of the Northern Hemisphere, but occurs again in the corresponding regions of the Southern Hemisphere, having been reported from Patagonia, southern Australia, Tasmania, and New Zealand. A few species occur in the mountain regions of the tropics; thus $B$. lanuginosum is not uncommon in the highlands of Ceylon, where I collected it at an altitude of about 7,000 feet.

The simplest member of the genus is Botrychium simplex, a very variable species occurring at various places in North America, northern Asia, and Europe. Its smaller forms closely resemble a small Ophioglossum (fig. $72, A, B$ ), except that the sporangia are more distinct. From this primitive type, obviously not very remote from Ophioglossum, there is an interesting series of forms leading up to the large species like $B$. virginianum and $B$. silaifolium. This latter species, which grows in the mountains of western North America, is perhaps the largest of the genus (plate 7). The plant is sometimes 2 feet high, the leaf nearly a foot in width, and the very large panicle of sporangia 6 inches or more in length.

In the evolution of the leaf in Botrychim, the sporangiophore shows a development parallel with that of the sterile leaf. In the forms of $B$. simplex, having an entirely undivided sterile lamina, the sporangiophore has the form of a simple spike with a single row of large sessile sporangia on either side (fig. 72, $A$ ) and very closely resembles a small Ophioglossum. As the sterile leaf segment becomes more and more dissected, there is a corresponding branching of the sporangiophore which,

\footnotetext{
* Professor Bower, at the last meeting of the British Association for the Advancement of Science, read a paper on the Anatomy of Ophroglossum palmatum. This has not yet been published, but Professor Bower has kindly furnished me with an abstract of his paper from which the following extract is quoted.

"It was thought probable that $O$. palmatum (the only species of section Cheiroglossa) would share with the species named (i.en, the species of $O$ phinderma) the character of a divided (leaf) trace, and material collected in Jamaica has shown that it does. The axis is much distended by parenchymatous storage tissue in pith and cortex, and as a consequence the meshes of the stele are transversely widened. From their margins right and left, but not quite simultaneously, arise two strap-shaped strands, which are thus widely apart in their origin. After subdivision into numerous smaller strands, these range themseives into two fan-like semicircles, which spread till their margins meet, forming the circle of strands of the petiole. A remarkable feature of the stock is the intrusion of roots into the bulky pith; this is especially obvious towards the base, where they pass out as thick mycorrhizic roots."

This behavior of the roots recalls that of the Marattiacex,
} 
in the large forms of $B$. sirginianum and $B$. silaifolium, forms a large panicle 15 centimeters or more in length and bears many hundred sporangia. Two types of leaf division may be noted, a pinnate form represented by $B$. Iunaria and its allies, which are sometimes separated as a special genus Eubotrychium, and a ternate division which is found in all of the larger species. These larger species form a second section, Phyllotrichium. A third genus, Osmundopteris, has been proposed to include Botrychium virginianum and its allies. In most of the species of Botrychium

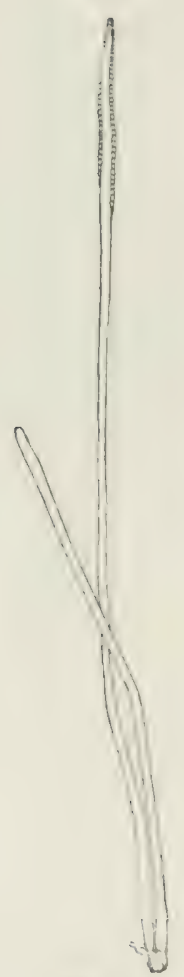

Fic. 71 .

Ophioglorsum simplex Ridley (after Bower). The fertile leaf has no sterile lamina.

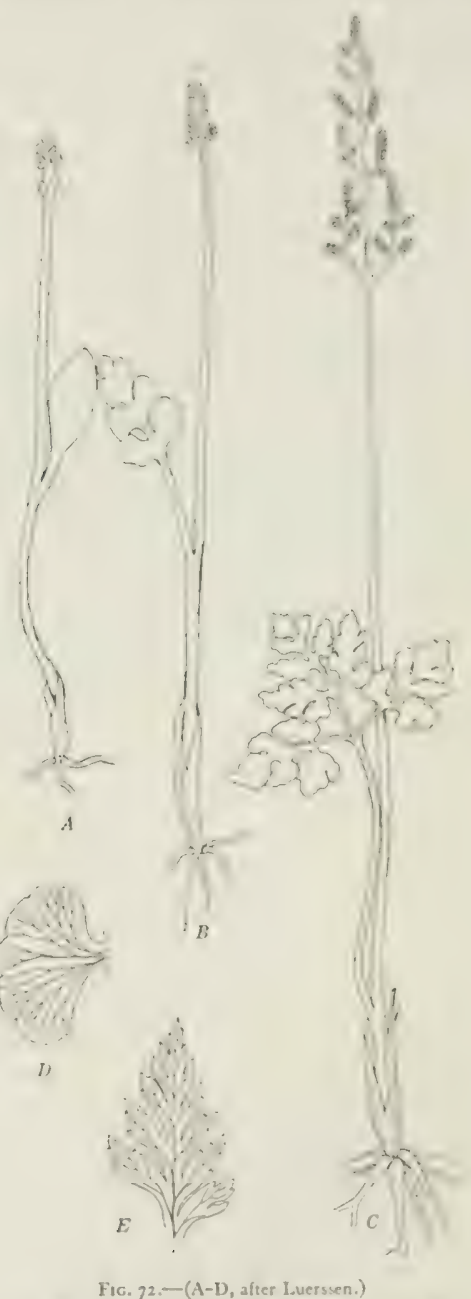

A, B. Botrychium simplex Hitcheock. C, B. Iermarum Swz. D, B. Iunaria (L.) Swz. E, B. virginianum (L.) Swz. 
the texture of the leaf is soft and fleshy, like that of Ophioglossum, but in B. virginianum it is thin and membranaceous, like that of many true ferns. In B. lunaria (fig. $72, D$ ) the venation comes nearer to that of Ophioglossum than is the case in the larger species. The fan-shaped leaflets have no midrib and the veins branch dichotomously from the base of leaf, radiating from this point in the manner described as "cyclopterid." In the larger species the leaflets have a distinct midrib
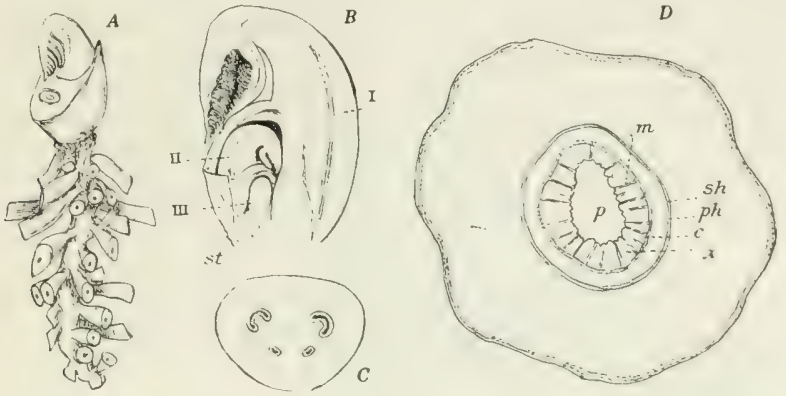

FiG. 73.

A. Rhizome of a strong plant of Borrychium virginianum. $X_{1}$. The base of the expanded leaf is cut away.

B. Section of the terminal bud, $s t$, stem apex. $1,11,111$, the three youngest leaves. $\times 2.66$.

C. Section of petiole, enlarged.

D. Section of rhizome; $p$, pith; $m$, medullary rays; $x$, sylem; $p h$, phloem; $c$, cambium; sh, endodermis. $X 16$.
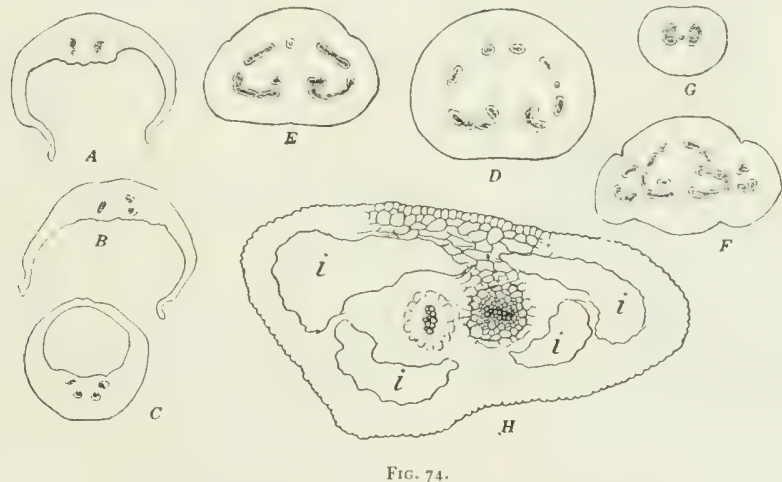

A-G. A series of sections of the sporophyll of Botrychium lanuginosum Wall. C is reversed in position. G, section of peduncle.

$H$. Section of the petiole of the cotyledon of $B$, virginianum. $i, i$, lacunæ.

and the forking veins are attached to this laterally (fig. $72, E$ ). The type of $B$. lunaria is without question the more primitive, and were the ends of the veins united so as to inclose areoles there would be exactly the same type of venation as is found in Ophioglossum.

In Eubotrychium the anatomy of the leaf is almost exactly like that of Ophioglossum, stomata being developed upon both sides of the leaf; the mesophyll is composed of absolutely similar cells throughout and the vascular bundles running 
through the mesophyll do sot project at the surface as veins. In the section $P / b y l l o-$ trithum, where the sterile lamina is horizontat, stomata are developed only upon the lower surface. In these forms the mesophyll is more compact upon the upper side, but does not develop a distinct palisade layer. The epidermal cells may be simply elongated, e. g., B. lanuginosum, or they may be undulate, e. g., B. virginianum. The development of the stomata was examined in B. Ionuginosum and the stoma was found en arise directly from an unmodified epidermal cell. The section kuboirychium shows a further approach to Ophioglossum in the character of its stipular sheath, which, as we have seen, forms a hood-like appendage at the base of the leaf, while in B. virginianum the stipular sheath is open in front, so that there are really two stipules. Moreover, the leaf in the latter is sharply bent over in the bud in a way to suggest somewhat the circinate vernation of the Marattiaceat. For the most part the surface of the plant is quite smooth, as in Oplioglossum, but the sheaths

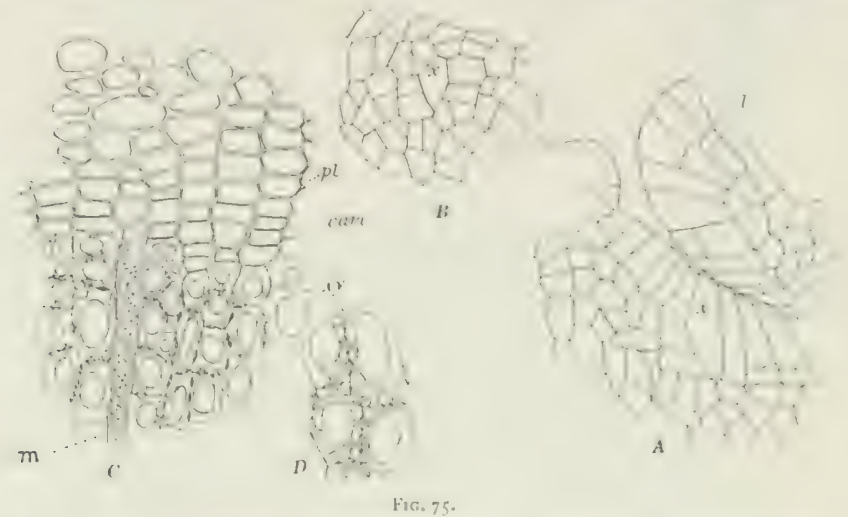

1. Stem apex of young sporophyte of Botrychium tirginianum. $x$, apical cell; $l$, youngest leaf. $\times 200$.

13. Cross-section of stem aper.

(C. Part of yascular cylinder of stem. pl, phloem; cam, cambium; $x y$, xylem; m, medullary ray.

1). Some of the tracheits, more enlarged, showing bordered pits.

enveloping the young leaves, as well as the very young leaves themselves, are of ten hairy, and in a very few species, like B. lanuginosum, long and slender unicellular hairs are sparsely scattered over the surface of the adult leaf. The stem, as we have seen, is always an upright rhizome and usually unbranched, but adventitious buds may be developed (see Bruchmann 2). 'These adventitious buds may develop into lateral branches. In one specimen of $B$. lanuginosum examined by me there were two equal branches, presenting the appearance of a dichotomy, but a careful examination indicated that the original apex had been destroyed and that these two branches were lateral shoots, which had probably arisen as adventitious buds. In Eubotrychium the leaves are arranged spirally upon the rhizome, as they are in Euophioglossum. This is also true of certain members of the section Phyllotrichium, but others, e. g., B. ternatum, are arranged in two rows, thus suggesting the dorsiventral arrangement found in Helminthostachys.

The structure of the adult stem does not differ, except in size, from that of the younger plants already described. In Eubotrychium the cambium is absent and apparently there is no secondary increase in diameter, but all of the larger species of $P / y$ yllotrichium show a greater or less development of the cambium, which we have 
noted in the bundle of $B$. virginianum. The position of the sporangiophore is somewhat different in different species. In Eubotrychium it is attached, as a rule, close to the junction of the sterile lamina and the petiole, very much as it is in Euophioglossum. In $B$. ternatum and $B$. obliquum the long peduncle is inserted very much further down, sometimes almost at the level of the ground, so that at first sight the sporangiophore seems to be quite independent of the sterile leaf. In $B$. virginianum

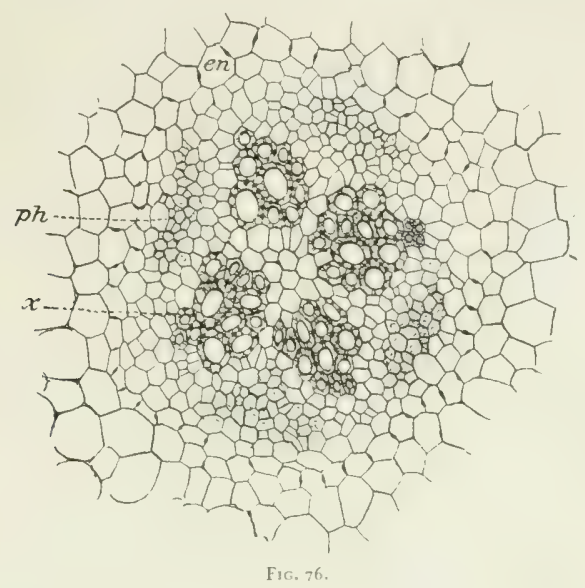

Tetrarch root of Botruchium virginianum en, endodermis; 2 , xylem; ph, phloem.
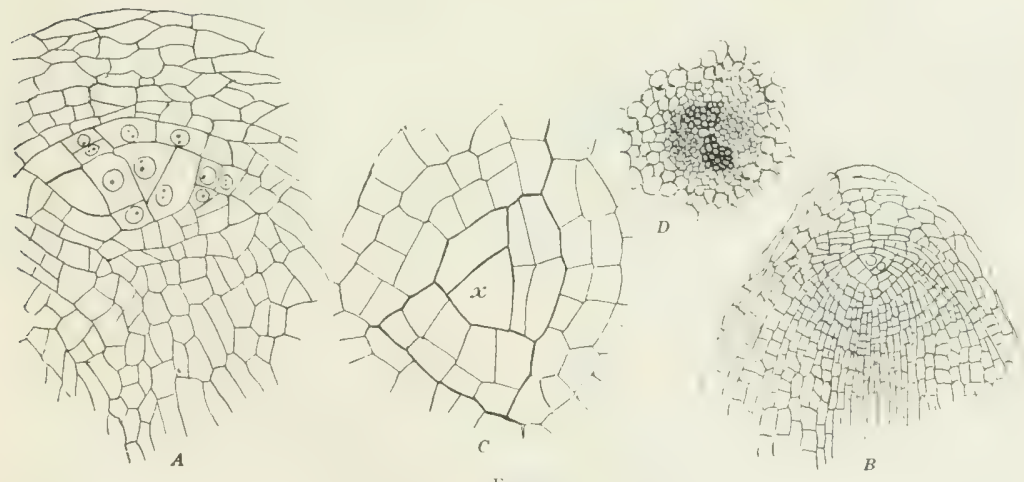

A. Apex of primary root of Botrychium virginianum. $\times 200$.

C. Apex of large root, iransverse section.

B. Apex of second root. $\times_{125}$

D. Diarch vascular bundle of the primary root.

and $B$. lanuginosum it is inserted close to the base of the sterile lamina or even above its base, and in the latter species there may even be sometimes a second sporangiophore developed on the fertile leaf above the insertion of the primary one.

Certain species show various monstrosities, this being particularly the case with $B$. lunaria. In such forms certain of the segments of the sterile lamina may bear sporangia. A number of these curious forms are figured by Goebel (Goebel 2). 
In fig. $73, A$, is shown the terminal bud of a strong plant of $B$. virginimmum. The base of the oldest leaf is cut away so as to show the young leaf for the next year, which is seen to be strongly bent over, and the young leaf segments are rolled inward in a way that very strongly reminds one of the young leaves of the typical ferns. The young leaf is covered with hairs. The roots are thick and fleshy, probably one corresponding to each leaf, although this is not always easy to determine. They are much contracted at the point of insertion. The roots branch freely, the branching being monopodial, thus resembling Oplioglossum pendulum. An examination of the section of the bud shown in fig. 73 shows that the young leaf, which is to unfold the next year, is already well advanced and the formation of the young sporangia has just begun. The sporangiophore is also evident upon the leaf for the following year, and the leaf which is to unfold in the third year can be recognized. but its parts are not yet differentiated.

While the roots branch freely in $B$. virginianum, this is much less marked in B. Iunaria. In large plants of $B$. lanuginosum which were examined somewhat carefully it was found that the roots appeared to be quite unbranched, although equaling those of $B$. virginanum in diameter and showing, like them, a similar tetrarch structure of the vascular cylinder. A more careful examination showed, however, a few very short branches on some of the roots, but these were rare. It may be that the rudiments of these lateral roots are formed, but that they do not develop, and in this respect there is a certain resemblance to the condition which obtains in Helminthostachys.

The anatomy of the roots does not differ from that of the younger sporophyte already described, except that in the larger specimens the roots are regularly tetrarch. while in Eubotrychium they are permanently diarch.

The earlier roots, as in Ophioglossum, have a tetrahedral apical cell which shows a more regular segmentation than is found in the later roots and in these earlier roots, at least in $B$. cirginianum, there seems little question that the tissue of the root cap is derived entirely from the outer segments of the apical cell. In the larger roots, taken from the older sporophyte, this regularity is not so marked and it is probable, although this could not be determined absolutely; that the lateral segments of the apical cell may also contribute to the tissues of the root cap. 'The regularity of the segmentation is still less marked in the later roots of $B$. obliqurm. A slight development of periderm may be seen in the older roots, but this does not form a continuous layer, being developed only in irregular patches. The secondary increase in diameter of the roots is apparently due almost entirely to simple enlargement of the cortical cells.

\section{THE SPOROPHYTF, OF HEL.MINTHOSTACHYS.}

While Helminthostachys differs very much in habit from the other Ophioglossacer, it nevertheless shows that it is unmistakably related to them and especially to Botrychium. The dorsiventral prostrate rhizome with the ample palmately divided leaves give it a very individual aspect, but, as is shown from a study of the early history of the sporophyte and the gametophyte, there is no question that it should be associated with the Ophioglossacex. As yet but a single species is generally recognized, which grows throughout the Indo-Malayan region, extending from the Himalayas through the Malay archipelago to northern Australia (plate 8).

The anatomical details of the adult plant have been very thoroughly investigated by Farmer and Freeman (Farmer 2), and from a comparison of the seructure of the adult spowphyte with that of the younger stages it is clear that the essential 
characters are established at a comparatively early period. The rhizome (fig. 79) has the leaves arranged in two rows on the dorsal side, somewhat as in Ophioglossum pendulum, but the leaves are less crowded and the internodes are evident, although less marked than is often the case in the very young sporophyte. The youngest leaves, still inclosed in the stipular sheath of the next older one, are conspicuous as blunt projections, situated between the apex of the rhizome and the first expanded leaf. As the leaf breaks through the stipular sheath of the next older one the sheath is split into two stipule-like flaps, which much resemble superficially the stipules of the Marattiacex. From near the base of the leaves on the flanks of the rhizome and belonging to the ventral portion of the stem there arise the thick fleshy

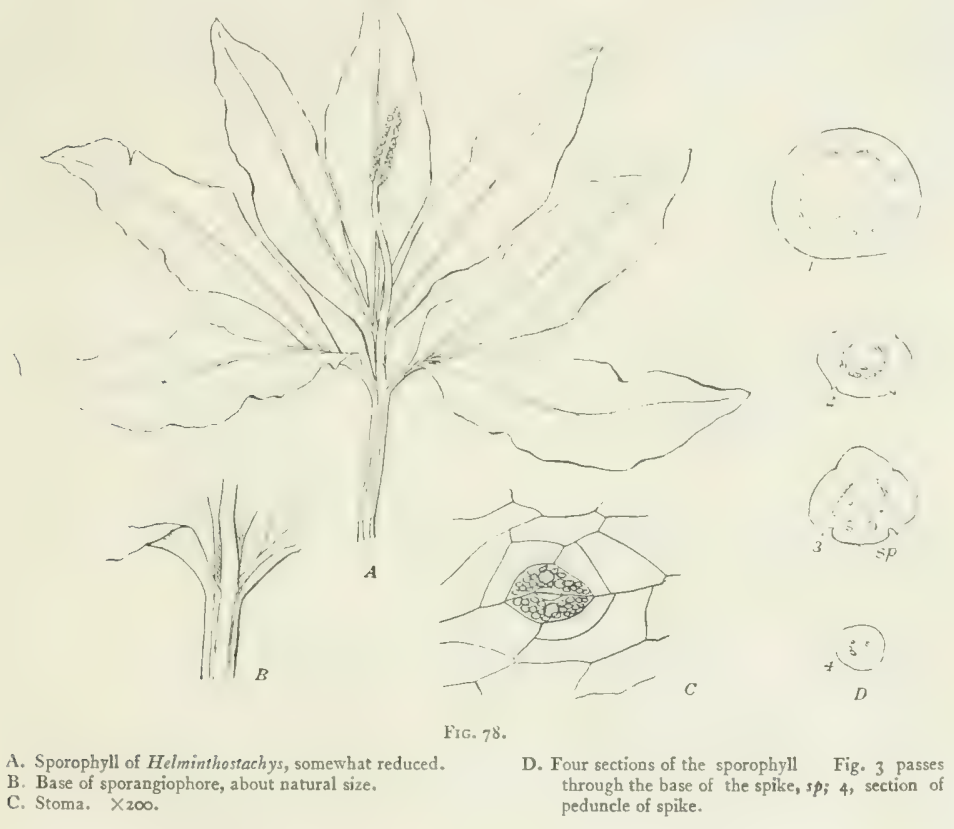

roots, which resemble those of the other Ophioglossaceæ. According to Prantl (Prantl 1) and Farmer (Farmer 2), the roots bear no definite relation to the leaf, and the number as a rule somewhat exceeds those of the leaves. The roots branch monopodially, as in the larger species of Botrychium, but Farmer states that the lateral rudiments often prove abortive, or fall away at an early period, so that the roots are apparently unbranched. This behavior recalls the condition found in Botrychium lanuginosum.

The leaves are very different in general aspect from those of the other Ophioglossacex, but are really not very different in their method of branching from the ternate forms of Botrychium. There are still traces of the three primary divisions of the first leaves which undergo subsequent divisions, so that the leaf has a palmate form (plate $8, B$ ). To a certain extent, however, these divisions are the result of 
unequal dichotomy, like that which results in the first divisions of the primary leaves. In larege plants the leaves may reach a length of 30 or focentimeters. The petiole is nearly cylindrical at its base, but higher up becomes slightly winged at the margins, these wings passing inte the lamina. A section of the petiole taken a litte way below the insertion of the sterile lamina shows that the peduncle of the sporangiophore is recognizable for a long distance below the point at which it becomes free, its adaxial surface projecting as a rounded ridge between the wings on the margin of the petiole (fig. 78,1$)$ ). In texture the leaves are firmer and more leathery than in any of the other Ophioglossacee, and in this respect, as well as in their venation, they closely resemble such Marattiaceie as Danaa and Angiopteris.

The sporangiophore is to sone extent intermediate in character between that of Ophioglossum and Bobrychium. It is inserted near the junction of the lamina and petiole, but, as already stated, can be traced for some distance below the point where it joins the petiole. The fertile portion of the sporangiophore, which may reach a length of nearly 10 centimeters, is composed of crowded, short branches, upon

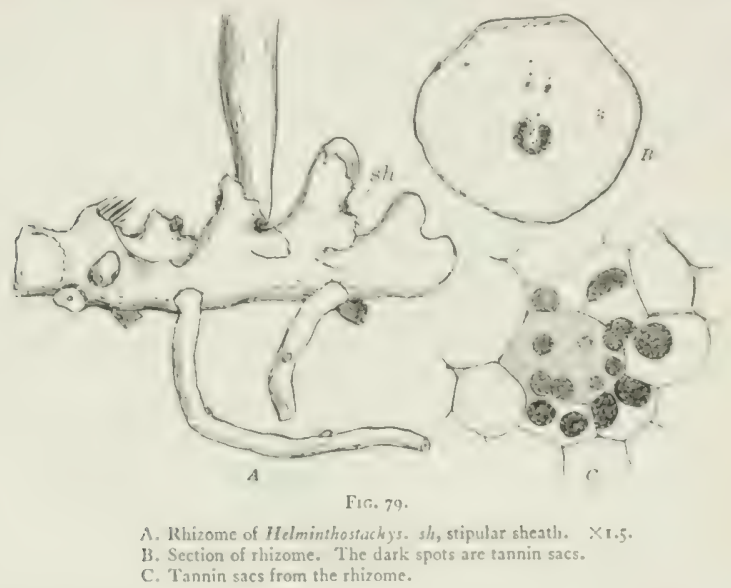

which are borne groups of nearly globular sporangia much like those of Botrychium. The ends of the branches which bear the sporangia may be expanded into small leaflike organs which, under exceptional conditions, look much like small leaves, upon which the individual sporangia are borne (see Bower 9, fig. 239). The stem in Helminthostaclyys almost always remains unbranched, except that there may be formed adventitious buds somewhat as in Botrychium. The origin of these buds, however, has not been investigated. The rhizome is rather fleshy in texture and may reach a diameter of about a centimeter. Usually but one leaf is fully developed at a time, but it is not uncommon to find two leaves produced the same season. Farmer's description and figures of the structure of the terminal bud show that it is essentially the same as we have found it to be in the younger plant, and, as has already been pointed out, it shows strong resemblances to the terminal bud in Botrychium lunaria.

The stomata (fig. $78, C$ ) are confined to the lower surface of the leaf and are surrounded by a series of concentrically placed cells like those around the stoma in Ophioglossum pendulum. They are much smaller in size, however, and in this 
respect may better be compared to the stomata of Danca, one of the Marattiacea, which shows a similar concentric arrangement of the accessory cells. A cross-section of the leaf shows that the mesophyll is better differentiated than in Botrychium. There is a single compact layer of palisade cells below the epidermis, and below these the mesophyll has very large intercellular spaces which communicate with the stomata. In the anatomy of the leaf, therefore, as well as in its venation, Helminthostachys more nearly resembles the Marattiacex than it does the other Ophioglossacea. The section of the petiole is not unlike that of Ophioglossum pendulum (figure $78, D$ ). A section made near the base of the petiole is almost circular in outline and there is a ring of separate bundles. On the adaxial side, however, two other bundles are seen inside the outer circle. Farmer and Freman (Farmer 2) state that the number of bundles is about seven or eight, but the larger specimens which I have examined show a greater number. If a section of the petiole is examined higher up it no longer appears circular, but is slightly lobed, these lobes corresponding to the bases of the three divisions of the sterile lamina, and on the adaxial side may be seen a fourth lobe which marks the position of the peduncle of the sporangiophore. In this upper region of the petiole the bundles become more or less coalescent, but two adaxial bundles remain quite distinct and are continued upward into the spike. The structure of the bundles is concentric and the general appearance of the section is quite similar to that found in the larger species of Botrychium.

The anatomy of the stem in the older sporophyte does not differ in any particular, except in the greater size of its parts, from that of the sporophytes already described. The rascular crlinder forms a hollow mbe with narrou leat gaps above, but quite solid on its ventral face. Farmer states that there is both an outer and an inner endodermis and that wood is formed inside of the protoxylem, so that the bundle is mesarch.

Reference has already been made to the invaginated canals communicating with the stipular cavities and tirst described by Gurome-Vaughn (Gwonne-Vaughn 1). In connection with these he describes slight projections of tissue fiom the vascular cylinder, which are surrounded by the endodermis. These projections he thinks may perhaps be the vestiges of buds which formed at the axils of the leaves and never developed. Whether this explanation is the correct one or not there is no means of determining. Farmer found in the older plants that the roots were prevailingly hexarch, ranging from pentarch to heptarch, and that tetrarch roots were rare.

The endodermis in the bundles of the later roots is much less distinct than it is in the primary root, where it is very easily demonstrated. Within the endodermis is a layer of pericycle cells, separating the endodermis from the radially arranged masses of xylem and phloem. Farmer states that the apical cell of the root appears triangular in section (presumably in longitudinal section), but that it is very often destroyed and as a result of the proliferation of the adjacent tissut an area of cells results recalling the condition obtaining in the Marattiacea. He also remarks that most of the roots that he examined showed this abnormal condition.

I made sections of a number of roots taken from young sporophytes where the root tips appeared to be quite normal. The result was rather interesting. In the early roots there was usually present a tetrahedral apical cell, very much like that of Botrychium and showing a pretty regular segmentation (fig. $80, C$ ). The segments cut off from the apical cell are large, and even in the early routs it is pretty certain that the root cap owes its origin, in part at least, to the outer cells of the lateral segments. Cross-sections of the apical cell show the same triangulat form as longitudinal sections and the divisions in the segments of the apical cell seem to be very 
much as they are in Botrychium. In one small root, however (fig. 80, 1), the apex was occupied by three cells which together formed a triangular group, but these cells were of about equal size and it is not at all certain that the triangular cell $x$ was really elie apical cell.

In longitudinal sections of the larger roots there is a close approximation of the condition found in the Marattiacese. There is probably still a single apical cell, as there is in the early roots of the Marattacex, but this cell is somewhat truncate below (fig. 53, B) and in a cross-section, taken from a tetrarch root, a single apical cell was not clearly to be distinguished. The lateral segments are very large and

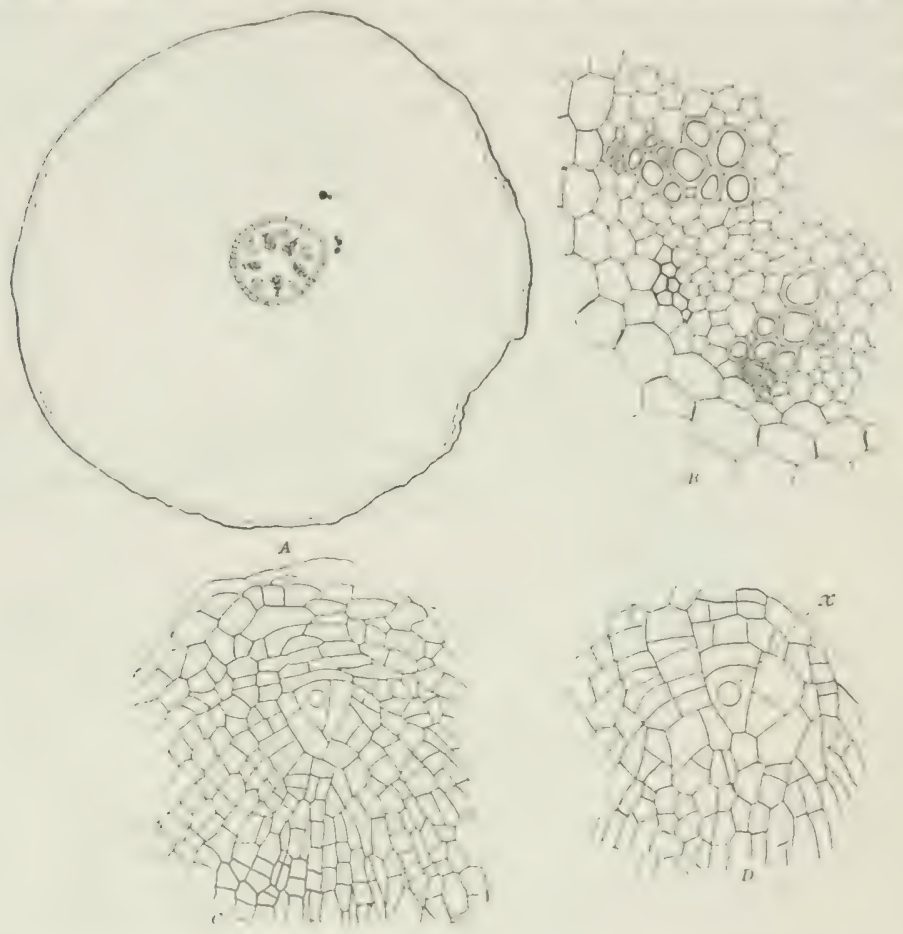

Fici, Ro.

A. Section of pentarch root of Helminthostachys. X20. C. Root of young sporophyte, with ietrahedral apical cell. Xiso. 13. Part of the vascular bundle. $\times 150$.

D. Root of an older sporophyte, with truncate apical cell, $x$.

there are cut off from them cells which contribute to the root cap. In short, the apical growth in the later roots of Helminthostachys is evidently more like that of Danca, for example, than it is like Botrychium.

\section{THE SPORANGIOIMORE OF THE OPHIOGLOSSALES.}

In all of the Ophioglossacex the sporophyll, as we have seen, consists of two parts, the fertile spike (or sporangiophore) and the sterile lamina. There is very great diversity of opinion as to the real nature of the sporangiophore. The earlier views were strongly influenced by the old theory that the sporangial parts were 
secondary modifications of an originally sterile leaf. At present it is the belief of most students of the ferns that the fertile structures of the sporophyll are older than the sterile ones, and this has led to a quite different interpretation of the real nature of the fertile segments.

Bower (Bower 9) has treated at length the different theories that have been proposed to explain the nature of the fertile spike in the Ophioglossacere. We can only refer briefly to some of the more important of these. Mettenius (Mettenius 1) considered that the two parts of the leaf were of equal value, but he gives no data as to their origin. Later writers, e. g., Holle (Holle 1), Goebel (Goebel 1), and very recently Chrysler (Chrysler $\mathbf{1}$ ), consider the fertile spike to be the equivalent of the fertile pinne of such a fern as Aneimia. Holle and Chrysler think that the single median spike is the equivalent of two united pinne. Goebel thinks that the spike represents a single pinna which has arisen in a median position instead of upon the margin. Chrysler's results are based mainly upon a study of the distribution of the vascular bundles in Botrychium. His results, however, do not take into account the early development of the sporangiophore and its relation to the primordium of the very young fertile leaf.

Bower, who has made the most complete study of the development of the sporebearing parts in the Ophioglossacex that has yet been published, concluded in his earlier work that the spike of Ophioglossum is morphologically equivalent to the single sporangium of Lycopodium. In this view he was supported by Strasburger and Celakovsky (Celakovsky 1). More recently, however, he has modified his view (Bower 9) and concludes that the sporangial spike is a distinct organ, for which he suggests the name "sporangiophore." This later interpretation we believe to be the correct one.

In Ophioglossum the sporangiophore develops a peduncle which is often very much longer than the sterile portion of the leaf and forms much the most conspicuous portion of the sporophyll (fig. 55). The fertile portion of the sporangiophore is a flattened spike along whose margins the two rows of large sporangia are borne. These project very little, the cavity of the sporangium being deeply sunk in the tissue of the spike and covered by several layers of cells forming the outer wall of the sporangium. The number of the sporangia in a spike may be only six or seven in some of the small forms of Euophioglossum, or it may be very large, as it is in the great spikes of $O$. pendulum.

In $O$. pendulum and $O$. intermedium the spike is more flattened than it is in the species of Euophioglossum and the central sterile portion is wider in proportion. Stomata are almost entirely absent from the epidermis of the spike in $O$. pendulum, although occasionally a few are found in the central region. In $O$. intermedium they are more numerous than in $O$. pendulum, but much less abundant than in the species of Euophioglossum. In the latter they may occur even upon the epidermis of the wall of the sporangium. The most marked exception in the position of the sporangiophore is seen in the section Cheiroglossa (plate 5). In this form there are several sporangiophores developed upon the leaf. Although these are apparently marginal in position, it is claimed by Bower that they are really always developed upon the adaxial surface of the leaf. Some of the smaller forms may show a single spike which occupies a central position, very much like that of $O$. pendulum (plate 5, 3).

In some of the simpler forms of Botrychium simplex the sporangiophore is very much like that of a small Ophioglossum, except that the individual sporangia are more distinct, although the base of the sporangium is coherent with the margin of the sporangial spike. In all of the other species of Botrychium, however, the sporangiophore branches, the degree of branching following very closely that of the 


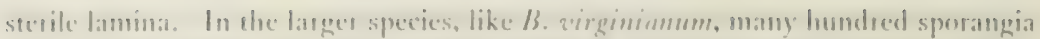
may he developed upem a single spentangiophere. In shese latger and mere specialined forms the spotangium is usually smaller and is better differentiated, allways having a mose or less distinet pedicel.

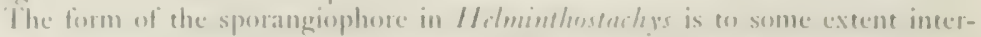
methate hetween that of ()phioglessum and Botrychum, hut on the whole comes nearer to Botrolumm. The sporangia are densely erowded along the flanks of the spike, ehus forming two rows somewhat as in ()phioglessum, hus they are very much more croweded and are formed in groups or symangia which pojece fiee above the sutace of the voung spike. The sporangia di not arise singly, but are berne upen short branches or secondayy sporangiophores which suggest the lateral branches of the sporangiophore in Botrychum, but are far less regularly disposed. By the further growth of the sporangia the axis of the spike is entirely concealed and a casual examination would indicate that the sporangia were formed equally at all points of its surface, but a study of the development shows that they atre lateral in structure. as they are in Ophioglossum.

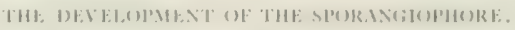

The sperangiophore in both Ophioglossum and Borrychium becomes visible at a very early period. In Ophioglossum moluccamum I have found that the sporangiophore can be recognized even earlier than Bower has stated for $O$. sulgatum and $O$. reticulatum. A median section of a very young fertile leaf in $O$. moluceamum is shown in fig. $56, D$. The apex of the leaf has scarcely become free and the apex,

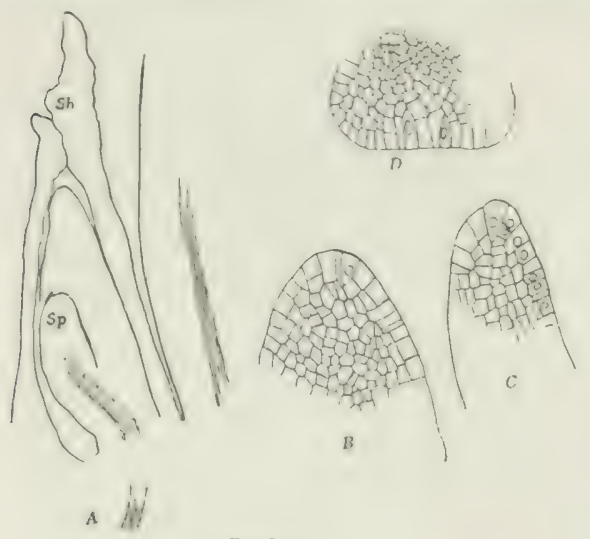

Fig. 81.

A. Longitudinal section of young sporophyll of O phioglossum moluccanum, still inclosed in the stipulas sheath, sh X 50 .

B. Aper of sterile lamina. sp, sporangiophore.

C. Aper of sporangiophore. $\times 125$.

D. Transwerse section of a very young sporophyll, showing dichotomy of apex. $\times 125$.

sporophyll, and the turo branches (viz, the sterile segment and the sporangiophore) sporophyll, and the two branches (viz, the sterile segment and the sporangiophore) are structures of equal rank. It would thus appear that the old view put forward by Mettenius of two equal branches of the fertile leaf is probably the correct one. It is probable that younger stages than those figured by Bower for $O$. vulgatum and $O$. reticulatum would show the same condition of affairs that we pointed out in as well as nearly the whole of the adaxial surface, is made up of large columnar meristem cells, of which it is difficult to say that any one is the single apical cell of the leaf. The leaf trace is already evident, passing into the base of the young leaf, which is strongly inclined forward so that the real apex of the leaf is not directed vertically upward, but is on the adaxial side of the leaf rudiment. The apex of the young sporangiophore arises from the tissue immediately below the apex of the sterile segment, and the whole of the adaxial portion of the leaf below the apex of the young sporangiophore may be said to belong to the latter and not to the sterile portion of the leaf. There is thus practically a dichotomy of the apex of the young 
$O$. moluccanum and $O$. pendulum, and the conclusion that the young sporangiophore is an outgrowth of the sterile part of the leat is the result of the subsequent rapid growth of the upper sterile portion of the leaf, which thus carries its apex far beyond the apex of the young spike.

The young sporophyll in $O$. pendulum (fig. $64, E$ ) resembles that of $O$. moluccanum, except that all the parts are much larger. The apex of the young sporangiophore appears upon the adaxial side of the very broadly conical young sporophyll.

Bruchmann's studies on Botrychium lunaria indicate that in this species the separation of the fertile and sterile segments of the sporophyll is the result of a dichotomy of the apex of the sporophyll at a very early stage in its development.

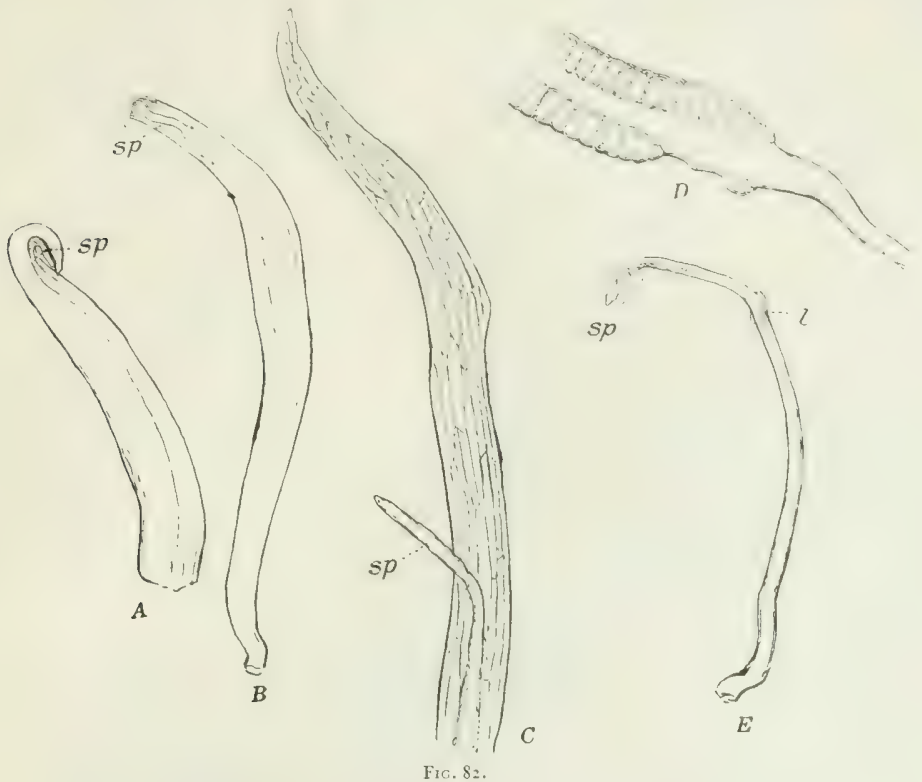

A. Young sporophyll of Ophioglossum pendulum. sp, the sporangiophore, $X_{2}$.

B. An older sporophyll. $\times \mathbf{r}$.

C. A still older stage, showing venation of lamina.

D. Base of a full-grown sporangiophore.

E. Sporophyll with rudimentary lamina, $l$.

The sporophyll, however, is larger at this time than is the case in Oplioglossum moluccanum (Bruchmann 2, fig. 57).

The earliest stages in the development of the sporangiophore have not been studied in Helminthostachys. Bower says (Bower 9, page 455):

"The origin of it is similiar (i. e., to Ophioglossum) and its early stages not unlike. It appears at first as an outgrowth on the adaxial side of the sterile frond, and it is curved over while young so that the actual apex is pointed downward."

In the latter respect it might very well be compared to the strongly bent-over sporangiophore of Botrychium virginianum. 
Aler the separation of the fertile and sterile portions of the sperophyll the sterile segument at first grows much more rapidly than the sporangiophore and som extends beyond it, so that the sporangiophore has the appearance of being merely an adaxial appendage of the sporophyll. These changes in the relative importance of the points can be very well shown by a study of the very large sporophylls of () . pendulum. In this species the young leaf emerges from the sheath while it is still in a very early stage of development. These young leaves (hig. 82 ) have a very thick, lieshy leaf base, ending in the small pointed lamina, bent over and almost hiding the young sporangiophore which is attached to its inner surface. This curved-over form of the young sporophyll differs from that of Euoplioglossum, where the young leaf is straight, and in this respect there is a suggeseion of Botrychium or of the true ferns. The young spike at this stage is almost equal in length to the sterile Iamina.

If the very young sporophyll of Ophioglossum moluccanum is examined, it will be seen that the vascular bundle leaving it passes downward and joins a young root trace. Very soon after the bundle enters the young leaf it divides into two branches, one of which passes into the base of the spike and the other and larger one into the sterile section of the sporophyll. This latter bundle now divides again into two, one of which passes to the dorsal side of the sterile segment while the other is turned toward the ventral side of the leaf, which probably represents tissue belonging to the sporangiophore. In the cross-sections of older leaves the periole, which includes the completely fused base or peduncle of the sporangiophore, shows three distince bundles, a large abaxial one and two smaller adaxial bundles. The former remains undivided for some distance above the base of the insertion of the peduncle of the sporangiophore. The two adaxial bundles divide into several branches, this beginning just below the point where the lamina of the sterile leaf becomes differentiated from the petiole. The lamina has its edges infolded so that it has a conical form, open in front and inclosing the young spike (figs. 56, 57). 'The successive branching of the two adaxial bundles follows in quick succession, and the outer bundles contribute to the veins of the lamina; the inner ones pass upward in to the peduncle of the spike.

In a previous paper (Campbell 7) the conclusion was reached from the study of a series of sections at different heights, taken from the full-grown sporophyll, that the two adaxial bundles belonged exclusively to the spike. A study of the devel-

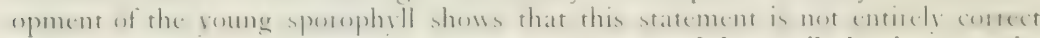
and that a considerable part of the vascular system of the sterile lamina owes its origin also to branches from the two adaxial bundles before the latter enter the peduncle of the sporangiophore. Of the two adaxial bundles, one represents the original bundle of the sporangiophore derived from the primary forking of the leaf trace; the other is derived secondarily from a subsequent division of the second branch of the leaf trace, this also giving rise to the large abaxial bundle of the petiole.

THE DEVEIOPMENT OF THE SP(ORANCBILM.

Much the most complete account of the development of the sporangium of the ()phioglossaceic is that of Bower (Bower 5), who has made a very exhatrstive examination of the development of the sporangium in all three genera. My own studies have been for the most part confined to Ophioglossum pindulum. O. molucianum. and Botrychium virginianum. Burlingame (Burlingame 1) has more recently examined the development of the sporangium in a species of Ophioglossum from the Philippines, which was assumed to be O. reticulatum. Beers (Beers 1) has also published recently a somewhat incomplete account of the sporangium in $\mathrm{Hel}_{\text {- }}$ 
minthostachys. Through the kindness of Prof. L. L. Burlingame I have also had an opportunity to examine some of his preparations of Ophioglossum reticulatum and Helminthostachys.

An examination of both longitudinal and cross sections of the young spike in $O$. moluccanum (and this is true also of $O$. pendulum) shows that they agree entirely with Bower's account of the development in the species studied by him. There

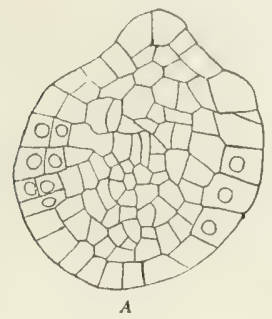

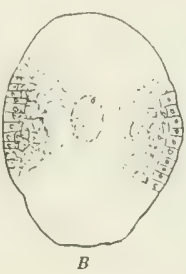

Fig. 83 ,

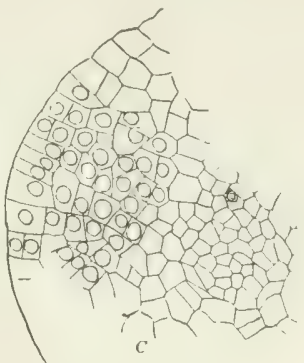

A. Transverse section of a very young sporangiophore of Ophioglossum moluccanum. X15o.

B. Section of an older sporangiophore. $\times 75$. The shaded areas mark the "sporangiogenic" bands.

C. Part of B, more highly magnified. The nucleated cells mark the sporangial region.

seems to be no question that, as Bower first pointed out, there is formed a continuous band of tissue on each side of the sporangiophore, this band being the so-called "sporangiogenic" band, from which the individual sporangia are differentiated later. The sporangia arise from this sporangiogenic band at more or less definite intervals, these fertile areas being separated by bands of sterile tissue. In the sporangial areas periclinal walls are formed by which an inner mass of tissue, the
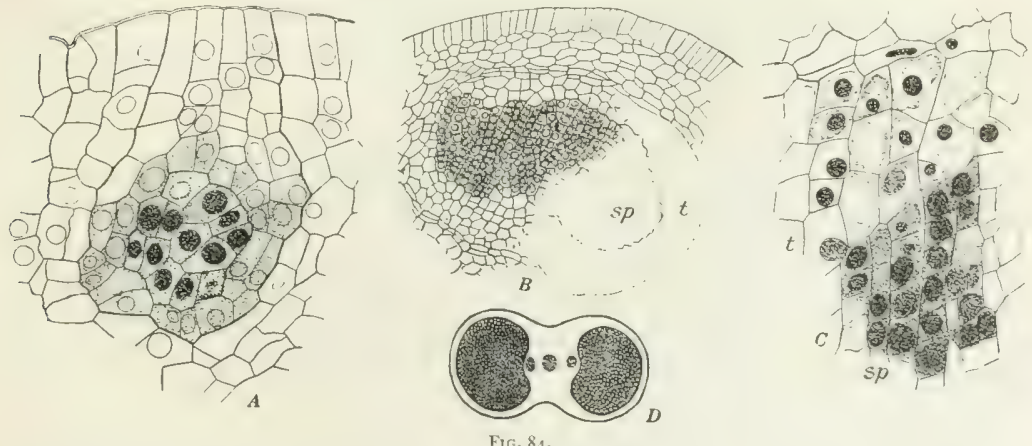

Development of the sporangium in Ophioglossum pendulum. The darkly shaded nuclei in A mark the archesporium; 1 , tapetun: $3 p$, sporogenous tissue. A is a longitudinal section; B, a cross-section; C, part of B, more highly magnified: D, section of two mature sporangia. $\times 8$.

archesporium, is separated from the outer cells which are to form the wall of the future sporangium. The inner cells constituting the archesporium later give rise to the masses of spores. Between the young sporangia there lie partitions or septa formed from the intervening sterile cells of the sporangiogenic band. The cell groups which form the archesporia and the sterile septa are derived from sister cells 
of the original sporangiogenic bands. Bower thinks that all of the sporogenous tissue can not be traced back to a single primary archesporial cell, and that sporebearing eissue is formed secondarily by periclinal divisions in the cells outside of ehe original archesporium. In some of the very young sporangiophores of $O$. pendulum there can sometimes be seen a single large epidemal cell which may possibly be the mother cell of a young sporangium, but it is very difficule to determine this point satisfactorily.

After the archesporium is differentiated there is a rapid division in its cells and there is thus formed a very large mass of cells, whose limits, however, are not always very clearly marked. Later on the contents of these cells become denser and are more easily distinguished from the surrounding sterile tissue.

The cells lying outside the archesporium divide rapidly both by longitudinal and transverse walls and give rise to the thick outer wall of the sporangium. In longitudinal sections through the sporangium two rows of cells may be secn extending from the mass of archesporial cells $t w$ the outside of the sporangium. These two rows of cells mark the point where the transverse cleft arises by which the sporangium opens at maturity. The outercells derived from the archesporial complex
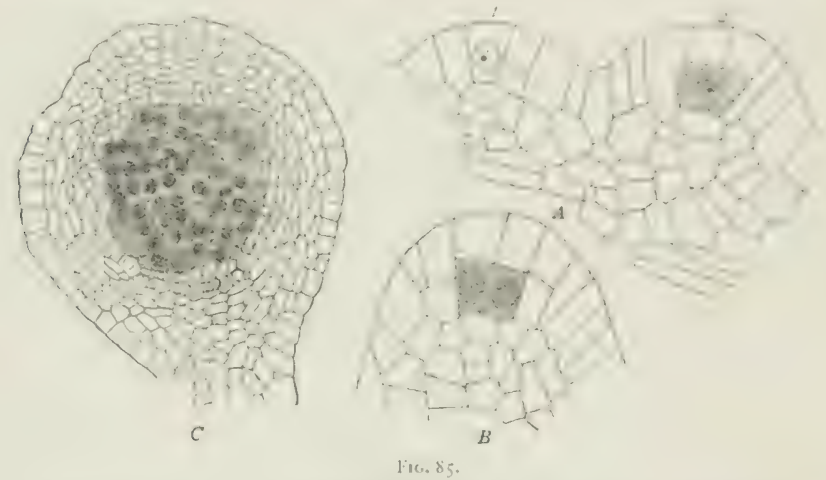

$\therefore$, B. Young spurangia; $\mathbf{C}$, an oldes sporangium of Botruchium zirginianum. In $\mathbf{C}$, the sporengenums tisuc is shailed; the nucleated cells ailjoining form the tapetum.

do not develop into spores, but constitute the tapetum, which later becomes disorganized and forms a sort of plasmodium extending among the growing spore mother cells, and is, no doubt, of great importance in the further development of these. Bower thought that some of the inner cells of the archesporial tissue contributed to this plasmodium, but a further study has led him to the conclusion that this is not the case and that all of the inner cells of the archesporium develop into spores. This view is confirmed by the recent paper of Burlingame (Burlingame 1), who investigated the development of the spores in $O$. reticulatum.

At maturity the sporangium opens by a transverse cleft whose position is already evident in the younger stages of the sporangium. As the cells shrink with the drying of the ripe sporangium the spores are crowded out through this cleft, but there is no special mechanism like the annulus found in the sporangia of the higher forns which facilitate the dispersal of the spores.

Our knowledge of the development of the sporangium of Botrychium has been based largely upon the study of $B$. Imaria. I have investigated with some care the development in $B$. evirginianum, which differs mainly from $B$. Junaria in the smalles 
size of the sporangium and the fact that it has a well-marked though short pedicel. In the simplest forms of Botryclutum, such as $B$. simplex, the sporangia are much larger and are sessile.

In $B$. virginianum (fig. 85 ) the development of the individual sporangia begins just about a year previous to their ripening, and if the plants are taken up about the time the spores are shed the earliest stages of the sporangia will be found in the leaf which is to expand the following season. At this time the sporangiophores in the larger specimens are thrice pinnate, and the youngest recognizable sporangia are borne at the tips of the branches. These young sporangia form slight elevations which become smaller as they approach the tip of the segments, and if an exact median section is made of one of these young sporangia it will be seen to have at its apex a large pyramidal cell with a truncate base. Holtzman (Holtzman 1), states that the whole sporangium may be traced back to a single cell and that the divisions at first are like those of a three-sided apical cell. I have not been able to satisfy myself as to the accuracy of this statement, but the youngest stages which $I$ have been able to find would not forbid such an interpretation, although there seems no question that the basal part of the sporangium is derived, in part at least, from the surrounding tissue.

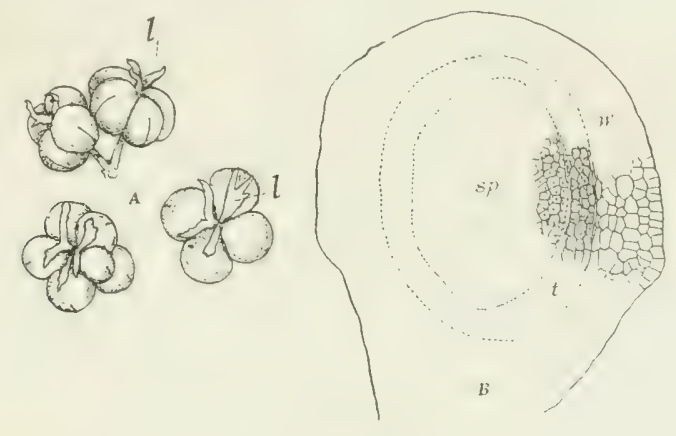

Fig. 86.

A. Sporangiophores of Helminhostachys. The twu lower figures seen from above. $l$, stcrile appendages. $x_{3}$.

B. Section of a young sporangium, showing sporogenous tissue, sp; tapetum, $t$; and wall, $z$. (From preparation made by Prof. L. L. Burlingame.)

The terminal cell of the sporangium is divided by a periclinal wall into a single inner cell which forms the archesporium, and an outer one which contributes to the wall of the sporangium. The outer cell rapidly divides and similar divisions occur in the archesporium. By active growth in the basal part of the sporangium it projects more and more until it assumes the form of a projecting globular body with a short stalk, thus differing strikingly from the deeply sunken sporangia of Ophioglossum. It is impossible to detect any definite succession of divisions in the archesporium, which ultimately becomes changed into a large globular mass of cells with the usual dense contents, separated from the outside of the sporangium by half a dozen or more layers of sterile cells. The cells immediately adjoining the sporogenous tissue constitute the tapetum. Bower states that the tapetum is exclusively derived from this outer sterile tissue, but it must be said that, in Botrychium virginianum at least, the limits between the sporogenous tissue and the tapetum are by no means easy to detect. The wall of the ripe sporangium has from four to six layers of cells and the dehiscence is by a vertical cleft, whose position may sometimes 
be recognized in the young sporangium hy cells arranged very much as ehey are in the sporangium of () phioglessum. The stalk is eraversed by a short vascular bundle which can first be recognized when the sporogrenous cells are pretty well advanced in their development.

The sporangia of $/ 1$ dminthostachys on the whole more resemble those of Boprythim than those of Ophioglossum. In the very young sporangiophore ehere is developed a hand of tissue on either side much like that in Ophioglossum (see Bower 9, page +55). Transverse sections of the fertile spike show that the sporangiophores originate from certain groups of cells of this sporangiogenic band. These young sporangiophores, however, project above the surface and later form crowded projections which may undergo a greater or less degree of branching, so that the number of sporangia borne upon a single one of these secondary sporangiophores may be considerable. These sporangiophores become irregularly lobed and the final divisions of these develop into the sporangia in a manner which is very similar indeed to that of Botryclsimm, but the individual sporangia are usually less distinct. Bower's account of the further development may be quoted as follows:

"It has already been noted that the position and number of the sporangia which they bear are inconstant. In early stages it is impossible to distinguish the cells which will give rise to the sporangia, but from rather older stages it appears that the sporogenous groups, together with the superficial cells which cover them are referable in origin to the segmentation of a single superficial cell. Moreover, the first periclinal division of the cells defines the whole of the sporogenous tissue from the protective wall. As the sporangia grow older they project from the surface of the sporangiophore. The sporogenous mass increases rapidly in bulk, while the cells surrounding the sporogenous mass to the extent of several layers assume the character of a tapetum which gradually becomes disorganized; finally the sporogenous cells separate and divide into tetrads. As the sporangia approach maturity the upper part of the sporangiophore maly sors out inte an irregular rosette of lacinia of vegetative tissue."

A study of the older sporangia of Helminthostachy's shows that the tapetum is extraordinarily developed, constituting a very thick layer surrounding the mass of spores (fig. 86). The clusters of fully developed sporangia are often very regular in finm (fig. Sn. /), and remotely suggest the synangium of a Maratriaceous fern. 


\section{PART II. THE MARATTIALES.}

The members of the second order of the Eusporangiata-the Marattialesresemble quite closely the typical Leptosporangiatx. Both in the form and venation of the leaves and in the development of the sporangia upon their lower surface they recall the common ferns. But the structure of the sporangium is very different, and both in its structure and development the sporangium shows certain evident resemblances to that of the Ophioglossacer.

The Marattiaceous type is a very old one, and this fact lends a special interest to these few survivors of the ancient Paleozoic fern flora. Like the Ophioglossaceæ, the leaves of the Marattiacex are thick and fleshy in texture, but usually firmer than is the case in the Ophioglossacex. Some of the smaller species of Dance a are only 2 or 3 decimeters in height, but the larger species of Marattia and Angiopteris are among the largest of the ferns. The latter, which is common in the eastern tropics and extends to Australasia, is a noble fern whose great caudex, covered with the persistent leaf bases, is nearly as big as a barrel, and the gigantic leaves reach a length of 5 or 6 meters, with stalks almost as thick as a man's arm. In the dense, wet forests of Tjibodas in Java, for example, the development of this fern is especially luxuriant, and groups of them form one of the most striking features of this rich, tropical Hora.

The Marattiacex frequent, for the most part, the moist, shady forests of the tropics, where they form a characteristic feature of the vegetation. Along the steep banks of moist, shady ravines or streams they sometimes occur in profusion.

The number of living Marattiace $x^{*}$ is small, some authorities recognizing only about thirty species. There is, however, a good deal of difference of opinion as to the number of species in some of the genera. This is especially true of Angiapteris, which many authorities consider to have only one single, extremely variable species, while others recognize many species. One of the genera, Maratia, is widespread throughout the tropics of both hemispheres, where there are about 25 species. (See Bitter I, Christensen 1.) One of these, M. douglasii, extends to the Hawaiian Islands, where it is a common and conspicuous fern. Angiopteris is widespread throughout the tropics of the old world and reaches beyond the tropics into Australia and southern Japan. Archangiopteris, with a single species, $A$. henryi, is a recently discovered form occurring in southwestem China. Kunlfussia, also a monotypic species, occurs throughout the Indo-Malayan region and extends as far as the Philippines. The genus Danan is exclusively neo-tropical and comprises about 20 to 25 species, most of which occur in the West Indies, northern South America, Central America, and Mexico. A sixth genus, Macroglossum, from Borneo, has recently been described (Copeland 1).

Of these, Kaulfussia is the most aberrant, differing markedly from the other genera in the form and venation of the leaves, as well as in the shape and position of the synangia. Kaulfussia and most species of Danca have dorsiventral rhizomes, while the other genera have an upright, radially-constructed caudex.

The gametophyte, in all of the investigated species, is a large, dark-green, fleshy thallus, much resembling superficially such a liverwort as Pillia. The reproductive organs are very much like those of Ophioglossum, and chlorophyll is formed in abundance in the gametophyte. The large liverwort-like gametophyte

* Christensen (I) recognizes 62 species of Angiopreris, 1 of Archangiopter is, 26 of Danaea, of Kaulfussia, and 28 of Maratia. 
and the characere of the reproductive organs are marked indications of the primitive nature of these ancient ferns. The embryo also shows many points in common with that of the (Ophionglossacese. As in the latter, the organs of the young sporophyte are all of epibasal origin and the vascular system in the young sporophyte belongs exclusively to the leaf and root, the stem being entirely destitute of a proper stele.

In Danto a short suspensor is usually developed, but the other gencra have as yet shown no examples of this.

The sporophyte is very much alike in its early development in all of the Maratracese. The young plant consists at first mainly of the primary leaf and root, which are traversed by a single axial vascular strand as in Ophogglossum molucomum, but a stem apex is developed at an early period, although it remains relatively inconspucuous.

Kaulfussia, Damea, and Archangioperis are all ferns of moderate size and comparatively simple structure; but Marrattia, Angiopteris, and Macroglossum are very large, and the arrangement of the vascular bundles in the stem becomes excedingly complex, corresponding to the numerous bundles in the enormously developed leaves.

The form of the leaf in the Marattiacea ranges from a perfectly simple leat in Danca simplicifolia to the gigantic decompound leaves of Angiopteris and Marattia. Most of the species of Danat (and this is true also of Archangiopteris and Macroglossum have simply pinnate leaves, while in Kaulfussia the leaves are palmately divided into from three to seven leaflets, the larger leaves looking curiously like a horse-chestnut leaf in outline, whence the specific name. The ternate form, which is often found in Kaulfussia, recurs in the early leaves of the other genera and is sometimes retained in quite large leaves in Marattia (plate 12, B). 'This recurrence of the ternate leaf form suggests Helminthostachy's and the ternate species of Botruchim. The leaves are usually quite smooth, but in the earlier stages there is sometimes a sparing development of hairs and scales. 'The latter are especially noticeable upon the leaves of the young sporophyte in Danca.

The leaves are furnished at the base with very conspicuous Heshy stipules which remain adhering to the stem after the leaves fall away, and these leaf bases, with their attached stipules, more or less completely cover the surface of the stem. As the leaves fall away they leave a characteristic scar marked by the remains of the vascular bundles. The leaf base as well as the stalks of the leaflets shows a more or less marked enlargement, recalling the pulvinus which occurs so commonly in the Leguminose. It is at this point that the leaf stalk separates, the smaller divisions of the leaf often breaking away from the main or secondary rachis, in the same fashion as the main leaf stalk falls. In the large species of Marattia and Angiopteris this enlarged leaf base with the two thick, Heshy stipules curiously resembles in shape and size the hoof of a horse.

The leaves when young are coiled up in the same fashion as those of the typical ferns and their venation in general is decidedly fern-like, the ultimate veins being dichotomously branched and the venation very much like that of $H$ clminthostachys or certain species of Botrychium. In $K$ aulfussia, however, the venation is reticulare and strikingly like that of the typical Dicotyledons. In its earlier stages, however, there is a marked resemblance to the venation of Ophioglossum.

The fleshy leaves do not, as a rule, show a very large development of mechanical tissues; but there is developed, especially in the larger leaves, a thick layer of hypodermal tissue, which is usually sclerenchyma, somewhat like that of the typical ferms. but mat he thick-angled tissue or collenchyma, such as is common in many Howering plants. A markerl anatomical feature is the presence of large mucilage ducts. 


\section{THE GAMETOPHYTE.}

The first account of the germination and development of the gametophyte in the Marattiacex was published by Luerssen (Luerssen 2), who studied the germination in Marattia cicutefolia and in Angiopteris. Not long afterward the Dutch botanist, Jonkmann, published an account of the development of the prothallium in both Marattia and Angiopteris. His original paper (published in Dutch, but afterward translated into $F$ rench) gives an extremely satisfactory account of the germination and development of the prothallium and reproductive organs (Jonkmann 1). Somewhat later he also published a preliminary account of the germination in Kaulfussia, but apparently the work was never published in full (Jonkmann 2). In I892 Farmer (Farmer 1 ) described the gametophyte and embryo in Angiopteris evecta and in 1894 the writer (Campbell 3 ) gave an account of the prothallium and embryo in Marattia douglasii collected in Hawaii. Two years later Brebner (Brebner 2) described the prothallium and embryo in Danca simplicifolia. In I 908 the writer published an account of the prothallium and young sporophyte of Kaulfussia (Campbell 9) and in I909 a preliminary note was published in regard to Dancea (Campbell, 10).

The following account of the germination is based mainly upon the work of Jonkmann. I have, however, examined the early germination stages in Marattia douglasii for comparison with Jonkmann's account, and, so far as my experiments went, it agrees entirely with the species described by Jonkmann.

The ripe spores of the Marattiacex are small and may be either of the bilateral type or tetrahedral (radial). According to Jonkmann, the bilateral spores are much more abundant in Marattia than the radial spores, but in Angiopteris the radial spores predominate. The wall of the spore (see Jonkmann 1, pp. 203, 204) shows a differentiation into an inner membrane or endospore and a middle layer, the exospore, which is often found divided into layers. There is a very thin external coat, the perispore or epispore, which is generally thrown off in the early stages of germination or even before germination begins. All of the membranes except the epispore are colorless, while the latter is a more or less pronounced yellowish brown tint. The surface of the spore is roughened by small papillæ which arise from the exospore. The spores contain no chlorophyll, but there is a considerable amount of oil present, which appears as drops of varying size, and there are also other granular contentsstarch and albuminous granules. The nucleus lies in the center of the spore and is connected with the peripheral protoplasm by delicate protoplasmic filaments. Germination begins quite promptly under favorable conditions and within about a week the spores, which hitherto were quite colorless, begin to show a greenish tint, due to the development of chlorophyll. Jonkmann states that the chlorophyll appears first as flocculent masses near the nucleus, but these apparently amorphous masses are really composed of very small, faintly tinted chromatophores, which lie between the large oil drops and rapidly increase in size and depth of color as germination proceeds, their number increasing by the usual division. The chloroplasts later become very conspicuous and are distributed in the periphery of the now very much enlarged spore, the outer membranes of which are ruptured so as to expose the endospore, containing the nucleus and numerous large and conspicuous chloroplasts. Starch granules are also to be seen in most cases.

The cell remains undivided until it has attained a size many times greater than that of the spore. The first division wall, which is formed about a month after the spores are sown, is transverse both in Angiopteris and Marattia, and, like that in the germinating spore of Ophioglossum, divides the primary cell into two nearly 
equal parts (fig. $8 \bar{\gamma}_{-}$, ). A shizoid may be cut off either before or atter this firse eransverse wall is developed, hut freequently no rhizoids are formed until a much lafer period, as in Ophioglossum. The primary rhizoid, when present, is formed much as in the eypical ferns, the papilla foom which it develops being cut off from the larger eell, and it esntains litele or no chlorophyll. Each of the primary prothallial cells divides, in typical cases, by a Iongitudinal wall, so that the young gametophyte consists of four cells, a rising quadrant-wise (fig. 88, $A$ ), and closely resembling corresponding stages in Ophioglossum, except for the absence of chlorophyll in the latter. Where the young plants are crowded or light is deficient, as for instance when the germination occurs within the sporangium, there is a tendency to the development of a filament, a phenomenon often met with also in the typical ferns.

Usually one of the upper pair of cells in the four-celled stage assumes the role. of an apical cell, and for some time, as in the typical ferns, there is growth from a two-sided apical cell (fig. $88, C^{\prime}$ ). As soon as the apical cell is established, it grows

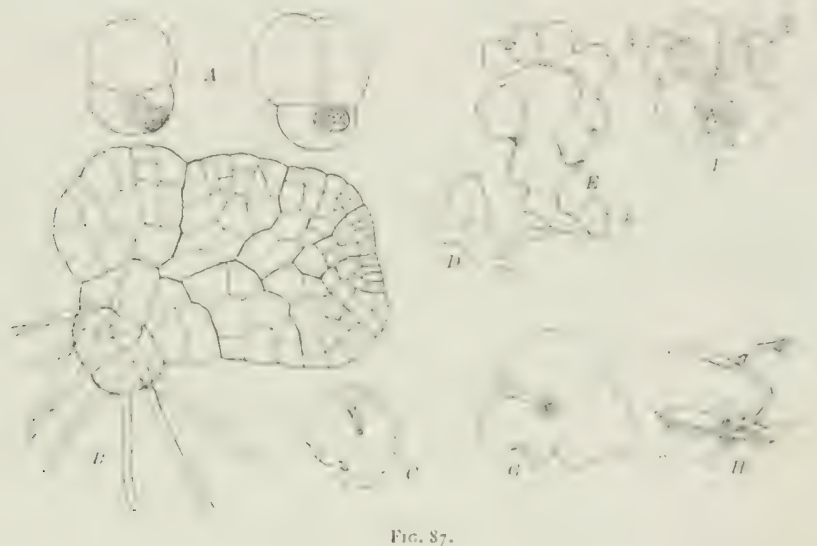

1. Two germinating spores of Maratria frasinea Semith. X200. The remains of the spure membrane can be seen.

13. Young gametophyte of same species. $\times 75$. ( $\mathrm{A}, \mathrm{B}$, after Jonkmann).

C. Marartia sambucina Hlume. $\times 1.5$.

D-H. M. douglasii llaker. D-F, $\times$ i.5; $\mathrm{G}, \mathrm{H}, \mathrm{X}_{3} . \mathrm{G}, \mathrm{H}$, show the young sporophrte.

$\mathrm{D}$ and $\mathbf{E}$ represent the same prothallium after an interval of about a vear. F is the rentral vien of $\mathrm{E}$. $k$, adrentitious bud.

very much as it does in such a liverwort as Aneura and produces a thallus of the same form and structure. But as the prothallium grows older a periclinal wall is formed in the apical cell, and in the outermost of the two cells thus produced there is a longitudinal wall dividing it into two equal cells, and from this time on it is impossible to recognize a single apical cell in the prothallium, the apex of which is occupied by a group of apparently similar marginal initial cells.

At first the prothallium has a spatulate form, but before the single apical cell is replaced by the group of marginal initials the outer cells of the younger segments grow more rapidly than the inner ones, so that they project beyond the apical cell, which thus comes to lie in a depression between the two lobes, and the familiar heart-shaped form so commonly found in the prothallium of most ferns is established. The marginal initial cells vary in number with the width of the depression in which they lie. In a horizontal section they appear oblong in form, but in the vertical sections made they have a semicircular outline (fig. $88, D, E$ ). 
Basal segments are cut off by a wall extending the whole depth of the prothallium and the segment thus cut off is divided at once by a horizontal wall into a dorsal and ventral cell of nearly equal size (fig. $88, E, d, v$ ). Cell divisions are more active in the ventral segments, more manifestly so at some distance back from the apex. It is due to this more active cell division in the ventral segments that the strongly projecting cushion-like mass of tissue is formed upon the ventral surface of the prothallium, upon which the archegonia later make their appearance. The superficial cells of both surfaces of the prothallium have a thick cuticle which often makes it difficult to embed the prothallia without bad shrinkage. From the under side of the prothallium numerous rhizoids are developed, which in the case of $M$ arattia and Angiopteris are unicellular and thin-walled, but in Dancea become divided into several cells. Sometimes there seems to be no definite apical growth in the early stages, but on the other hand Jonkmann states that both of the superior cells may function as apical cells, thus inaugurating the early dichotomy of the young prothallium, and even a third branch may arise from one of the inferior quadrants, which assumes the character of a third apical cell.

Among the leptosporangiate ferns, the forms which most nearly resemble the Marattiacere in the development of the gametophyte are the Osmundacex, especially
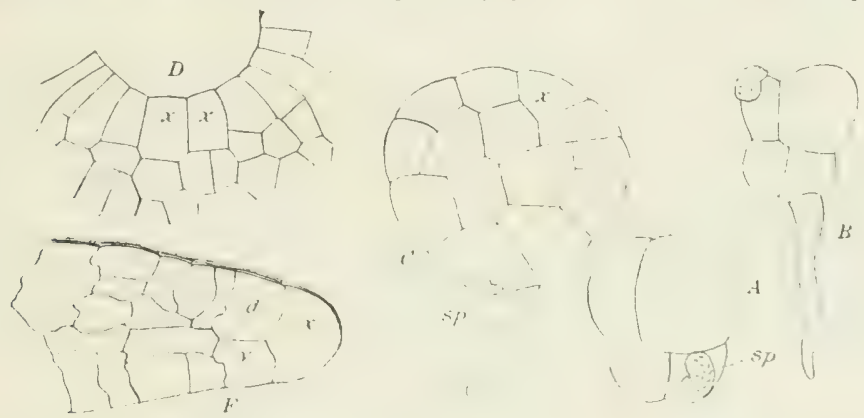

Fic. 83 .

A-C. Three young gametophytes of Angiopteris. sp, spore membrane. A, $X_{200} ; \mathrm{B}, \mathrm{C}, X_{160}$. (After Jonkmann.)

$\mathrm{D}$, horizontal, E, longitudinal, sections of the prothallium apex of Maratria douglasij. $x$, initial cells.

the genus Osmunda (Campbell, Mosses and Ferns, 2d ed., pp. 347, 348). In Osmunda there is often a tendency also to the formation of a massive structure at an early stage in the development, due to the formation of cell divisions in three planes, so that the prothallium becomes from the first more than one cell thick. This tendency in the Marattiacere becomes much more pronounced as the gametophyte grows and very soon there is evident a very thick midrib, which often becomes exceedingly conspicuous in the older gametophyte, unlike the typical ferns, where the thickening of the prothallium is confined to the region which bears the archegonia. In the Marattiacex this thickening extends almost to the margin of the prothallium, so that it is only at the extreme edge that the prothallium shows but a single layer of cells. The very old prothallia in Marattia branch dichotomously (fig. $87, E, F$ ), and the process is entirely similar to that found in many thallose liverworts. The original growing point becomes divided by the development of a median lobe, thus inaugurating two growing points, and the midrib back of the growing point forks in exactly the same way as in many liverworts.

Besides this dichotomous branching, it is not at all uncommon to have adventitious buds developed upon the margin of the thallus. These form small secondary 
proshallia, which may be detached and become independent plants; or reproductive organs may be developed upon them, usually only antheridia, while they are still connected with the mother plant. The prothallia are very Iong-lived and apparently may grow indefinitely so long as the archegonia are not fecundated. I kept prothatlia of Marattia douglasii for nearly two years, during which time they erew vigorously and finally reached a length of over 2 centimeters. At the end of (wo years there was no indication of the slightest decrease in their vigor.

The prothallia are monocious, although it is not uncommon on find small prothallia which bear only antheridia. They are very deep green in color, which together with their more massive texture makes them easily distinguishable from the prothallia of the ordinary ferns, and they very often look more like such a liverwort as Pellia or Anthoceros. The prothallium of Angiopteris very closely resembles that of $M$ arottic, but is often somewhat shorter. The difference in shape in the prothallia

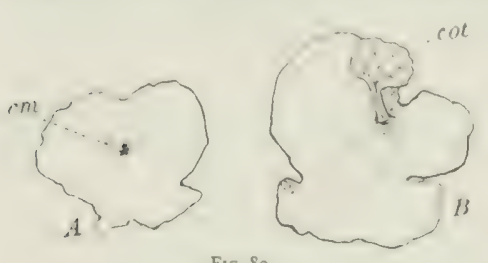

Fic. 89.

Twa gametophytes of Angiopteris with young sporophyte artached. em, embryo; col, cotyledon. $\times_{3}$. of the form studied by Jonkmann ( $A$. pruinosa var. hypoleuca) and the Ceylonese form studied by Farmer and myself may be taken as an argument in favor of recognizing a specific difference between these two forms.

The archegonia in both Marattia and Angiopteris, so far as my own observations extend, are confined to the lower surface of the midrib. Jonkmann, however, states that occasionally he observed archegonia developed upon the upper surface as well. The antheridia, while more abundant upon the lower surface of the prothallium, are quite commonly met with also upon the upper surface and are not restricted to the midrib, but may be found quite near to the margin. The rhizoids in both Angiopteris and Marattia are probably always unicellular, and their walls, which are quite strongly cutinized, are dark brown in color.

\section{THE I'RO'THALIIUM OF KAULFUSSIA.*}

The prothallia of Kaulfussia are usually much larger than those of either Marattia or Angiopteris. They are very massive, strongly resembling a Pellia or Aneura. The specimens described here were collected in Java in a small ravine near the foot of the volcanic mountain Salak. The youngest prothallia found were about 5 millimeters in length and, like the older ones, were decidedly elongated, with a deep sinus in front (fig. 90, $A, B$ ). There were a few antheridia occupying the forward part of the thick midrib, which is very largely developed in $K$ aulfussia, as it is in the other Marattiacex. The older prothallia are relatively somewhat broader and these larger ones usually bear archegonia. Only in a few cases were young antheridia found upon the prothallia with the archegonia. Whether this is always true could not be decided from the small number of prothallia found. The antheridia in Kaulfussia seem to be strictly confined to the lower surface of the midrib and occupy much the same position that the archegonia do. After the antheridia have matured and discharged the spermatozoids, archegonia arise in the same position in regard to the apex. Unlike most ferns, the walls of the empty antheridium do not become discolored, so that they are easily overlooked. Careful examination of the sections of the older prothallia, however, will almost always show the empty antheridia and it is probable that the prothallia are usually 
proterandrous and not diœcious, as might be supposed from a casual examination. The margins of the large prothallium are more or less irregularly lobed and it is not unlike that of Osmunda, but as in the other Marattiacere the wings of the prothallium are several cells in thickness near the midrib, and only at the extreme edge are they reduced to a single cell in thickness.

The full-grown prothallia are a centimeter or more in length and nearly as broad. One very large specimen was found (fig. 90, $F$ ). This bore a young sporophyte with two fully developed leaves, and the prothallium measured nearly 2.5 centimeters in length by 1.75 in extreme width, and was also very thick. A second archegonial cushion was present, but whether this was due to a forking of the original apex, such as not uncommonly occurs in Marattia and Angiopteris, was not determined, although this was very probably the case.

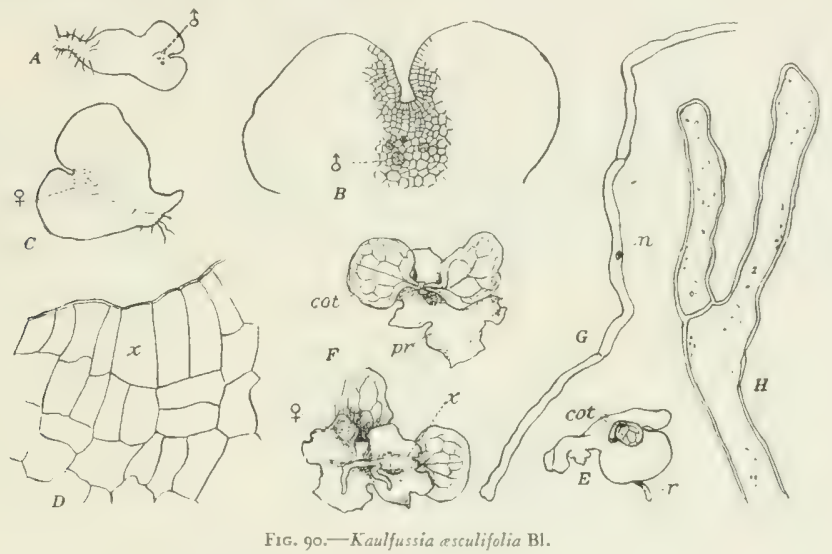
A. Young gametophyte. $x_{4}$.
B. Apex of $A$, showing the antheridia, $\delta^{-1} \times 20$.
C. An older gametophyte, with archegonia, $0 . x_{4}$
D. Apical region of an older gametophyte; $x$, apical cell
E. An older gametophyte, with young sporophyte attached, cot, cotyledon; $r$, root.
F. Two views of a large gametophyte, with attached sporophyte, natural size.
G. Rhizoid. $\times 50$.
H. Apex of rhizoid, more highly magnified. A single nucleus only is present.

The rhizoids are stout and they have thick but quite colorless walls. They o.ten show apparently transverse septa and the extremity is not infrequently forked (fig. 90, $H$ ). An examination of these rhizoids shows that these septa are not the result of true cell division, as only one nucleus can be found in the whole rhizoid. As the nucleus is large and conspicuous, and only one can be seen, it looks as if the formation of septa is secondary and not connected with cell division. The structure of the apex of the prothallium is exactly as in Marattia and Angiopteris. The apical meristem shows the usual row of marginal initial cells, of which one (fig. go, $D, x)$ is often somewhat larger than the others and may possibly represent a single apical cell. 


\section{THE PROTHALIAIIM OF DANAA.}

In July, 1908 , the prothallia of three species of Danoa were collected in Jamaica. As the genus $D$ anea has received comparatively litte ateention, especially as regards the gametuphyte, it seemed very desirable to secure as complete a series of the prothallia and young sporophytes as could be done, and to this end the erip was made to the West Indies. The genus Danaa is confined to the American tropics and comprises, aceording to Christensen, 26 species of extremely characteristic ferns. The eype is evidently an old one, as some of the fossil Marattiacea are closely allied to) the living genus Dance and may possibly be referred to it. The only account of the prothallium hitherto published, so far as I am aware, is the paper of Brebner (Brebner 2) on D. simplicifolia, a species from British Guiana.

In 1807 I collected a small number of specimens of prothallia of Danca, probably D. jenmani, and in the summer of 1908 the same locality was visited, as well as some others in the same district, and material of three species was secured. These

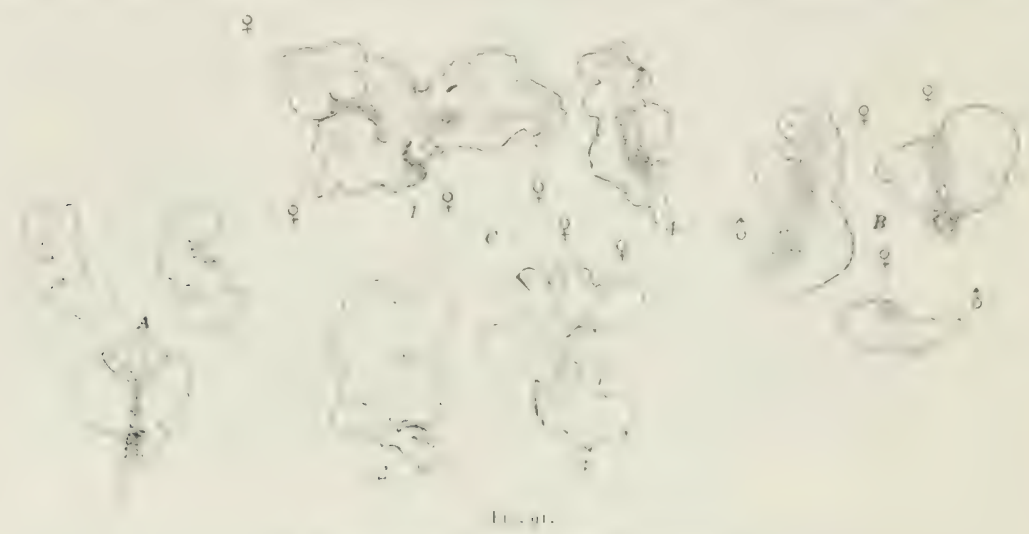

A. Three gametophstes of Daniea jenmani Underwoad. $\mathrm{X}_{2}$.

B. Three young gametophytes of $D$. jamaicensis Underwood. $X_{4}$.

C. Four large gametophytes of $D$, jumaicensis. $\times 2$.

C, 1 , shows four groups of archegonia, + .

collections were all made in the vicinity of Cinchona, a mountain station at an elevation of about 5,000 feet. As I have found in collecting other Marattiacex, the most favorable collecting ground for the prothallia is upon moist, clayey banks where the fruiting plants are growing. In the shady crevices in such positions a careful search will usually be rewarded by the discovery of numerous young plants, and with these there are often associated prothallia in various stages of development. Brebner described the prothallia of $D$. simplicifolia as being nearly circular in outline, but very few of the prothallia of the species collected by me showed this form; but they were usually decidedly elongated, sometimes very strongly so, and were, as a rule, very much larger than the specimens of $D$. simplicifolia described by Brebner.

The three species collected by me were $D$. jamaicensis Underwood, $D$. jenmani Underwood, and $D$. clliptica Smith. In all three species the larger prothallia are usually decidedly elongated and very irregular in outline, often showing conspicuous leaf-like marginal lobes, like those occurring in the prothallia of Osmunda and Gleichenia. 
The germination of the spores and the early stages are quite unknown in Danca, but probably resemble those of the other genera which have been studied. To judge from the younger stages collected, there is a good deal of variety of form, as is the case also in the other Marattiacex. The youngest specimens collected belonged to $D$. jamaicensis. These were very broad in outline and unsymmetrical, one wing of the prothallium being much better developed than the other (fig. 9I, B).
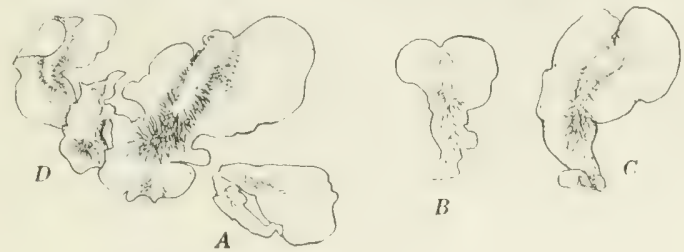

F1G. 92,-Four gametophytes of D. ellipsica Smith. $X_{2}$. B-D, seen from below:

Fig. 92 shows some older specimens of D. elliptica which were greatly elongated, the very much attenuated posterior region being quite thin and delicate in texture, with no midrib and the archegonial cushion being confined to a small region just back of the growing point. The marginal region in these young prothallia was composed of a single layer of cells and a considerable portion was made up of but

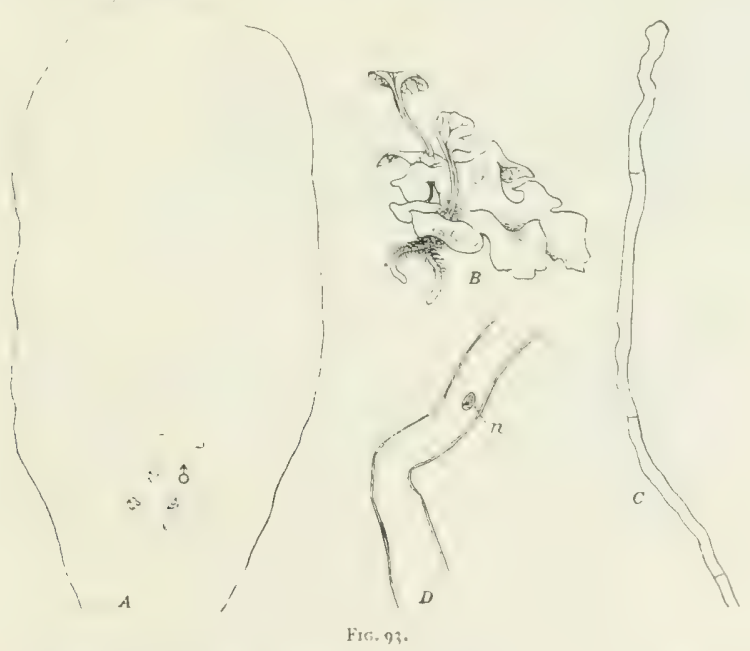

A. Young gametophyte, probably developed from an adventitious bud of Danad jamaicensis. $\times 20.8$ antheridia.

B. Large gametophyte of $D$, elliptica, with two sporophytes. $\times 2$.

C. Multicellular rhizoid. $\times 100$.

D. A cell of the rhizoid, showing nucleus, $\pi \cdot \times_{210}$.

two layers, while the mid region, where the antheridia and later the archegonia are developed, was not more than four to five cells in thickness. In general the prothallia of Danaa are more delicate in texture than those of the other Marattiacex that have been studied. 
A midrib usually begins to form at an carly period assed in the older prothallia maly become very conspicuous, sometimes reaching a thickness of eight on ten cells. The margin, as we have seen, is always more or less irregular in sutline and offen develops large leaf-like lobes which are particularly conspicuous in $D$. jumniccnsis (fig. $91, C$ ), but are noticeable also in the other species. The large prothallia, which are sometimes nearly $3 \mathrm{~cm}$, in length, are often branched (fig. $92, D$ ); the branching

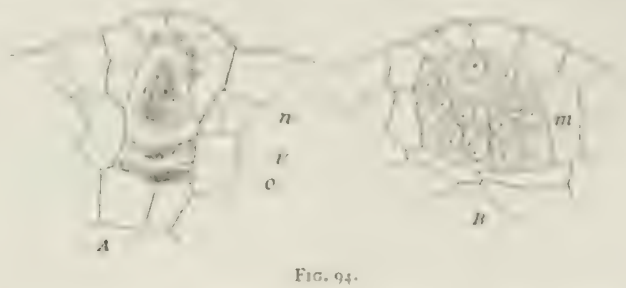

A, archegonium; B, antheridium of Maratia douglasii. ", neck canal cell: $v$, ventral canal cell; 0 , ege; $m$, mantle cells.

is sometimes unmistakably a true dichotomy, but again it seems to be adventitious. In one large prothallium of $D$. jamaicensis of very irregular form, four groups of archegonia were present, widely separated from each other. It could not be certainly determined whether these arose from a repeated forking of the original apex or whether one or more of them was of adventitious origin (fig. 91, C).

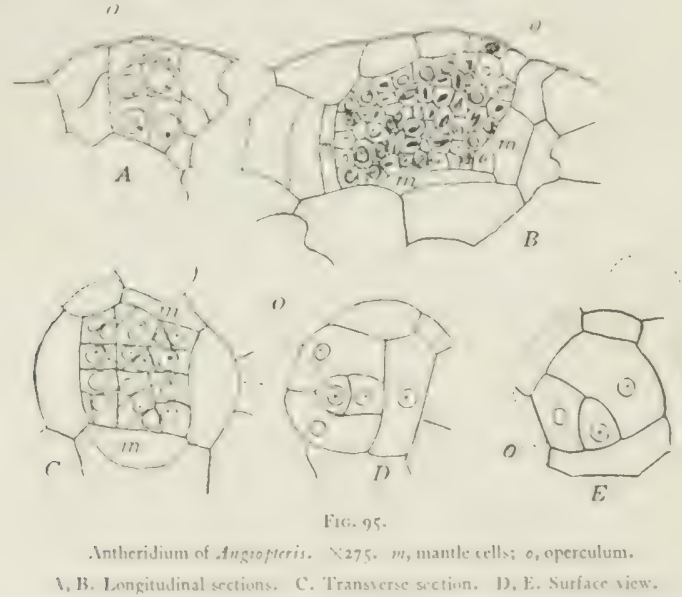

The apex of the prothallium in the younger stages is usually indented by a simus, but in the older ones the heart shape is almost completely lost and the apex may even project as a rounded protuberance, bearing the archegonia upon its lower surface, or it may be fan-shaped, with little or no indentation at the growing point.

The prothallium is the usual dark-green color found in the other Marattacea. but as we have seen is rather more delicate in texture. Of the three species examined, Danca clliptica resembles more nearly the prothallia of the other Marattiacex in the thickness of the central portion, which may show from eight to ten 
layers of cells. The form and division of the apical cells is exactly the same as in the other Marattiacex. Stiff brown rhizoids are developed upon the lower surface and are mainly confined to the midrib, over which they may be evenly distributed, or there may be certain regions of considerable extent which are quite destitute of them. The rhizoids in all the species which have yet been examined are truly multicellular, as was correctly shown by Brebner to be the case in $D$. simplicifolia. The nuclei are not very large, but can be readily demonstrated.

The distribution of the reproductive organs is not always the same. Apparently the usual course of development is present here, the antheridia appearing first upon the lower side of the midrib and the adjacent points of the prothallium; later, nearer the apex and upon the lower side, the archegonia arise. Sometimes, however, as in the other forms, there is a more or less marked tendency to dioecism and some of the smaller prothallia seem to bear only archegonia or antheridia, and it is common to find antheridia developing exclusively upon the lateral lobes, which
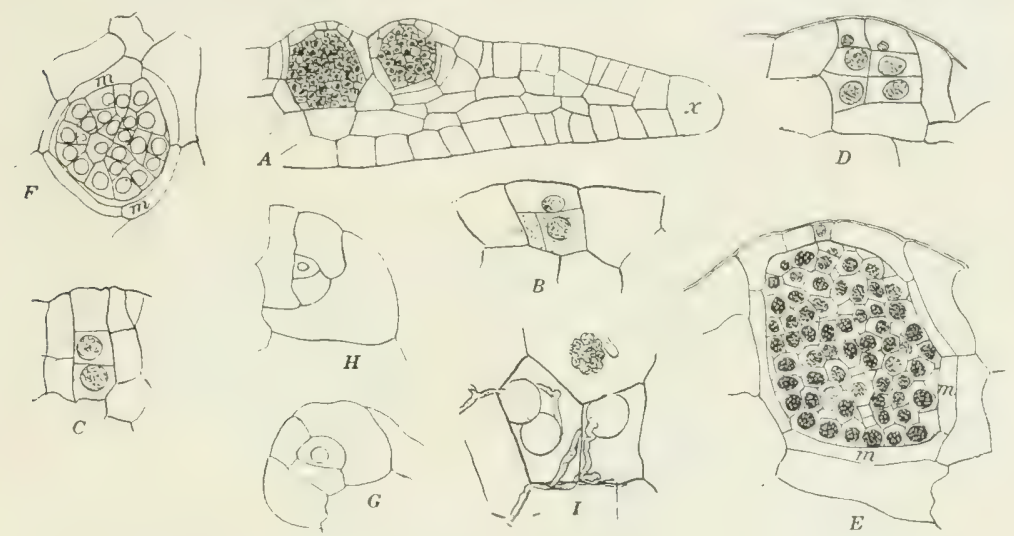

Fic. 96.-Kaulfussia.

A. Section of a young prothallium, showing two antheridia on the ventral side (reversed in the figure). $\times 80$. B-E. Longitudinal sections of antheridia.

F-H. Tranbverse sections. G, $\mathrm{H}$ are surface vicws showing the opercular cell. $m$, mantle cells. $\times \mathbf{I} 80$. I. Cell from interior of prothallium, showing the endophyte.

apparently never produce archegonia at all. Antheridia may also occur upon the upper surface, but this is not common, and in no cases were archegonia seen except upon the lower surface of the midrib. The reproductive organs are sometimes found in great numbers upon the older prothallia, the whole lower surface of the midrib being beset with archegonia. Quite as often, however, extensive areas along the midrib are quite sterile and the archegonia thus appear in patches, separated by sterile intervals.

\section{THE LNIOU'HYTE OF THE MARA'TIAC'F.}

In all of the Maratiacex that I have studied, an endophytic fungus very much like that which occurs in the prothallium of the Ophioglossacex has been found occupying the central cells of the prothallium in nearly all cases. The endophyte which infests the green prothallium of the Marattiacex, when compared with that found in the strictly saprophytic prothallia of the Ophioglossacere, shows some differences which are probably not without significance. The structure of the myce- 
lium and its general hehavior are so much like ehe form which oceurs in ()phive ghossum as on leave litele room for doube that the ewo forms are eidere identical on very closely related. The conidia (fig. g(), I), while occurring in the Maratriaceat, are perhaps less frequent, hut in form and structure are much like those of the condophyte of Botryihum. The most noticeable difference is the absence of she digestive cells, i. e., those that contain the varicose swollen mycelium. No evidences were found in the Maratriacese of the destruction of the fungus by the cells of the host and it is likely that the endophyte in these green prothallia is more nearly at true parasite than is the case in the saprophytic gametophytes of the (Ophisglossacex. In the infested cells of the green gametophyte the starch and chromatophores are destroyed by the action of the endophyte, but the nucleus of the cell remains intact.

\section{THE: SFIUAL, ORG IINS.}

THF. ANTHERIDIUW.

The development of the antheridium, except for the details of spermatogenesis. was correctly described by Juerssen and Jonkmann for Marattia and Angiopteris. 'The other genera agree closely with these in the essential structure of the antheridium. The development of the antheridium in the Marattiacea agrees very closely indeed with that of Ophioglossum.
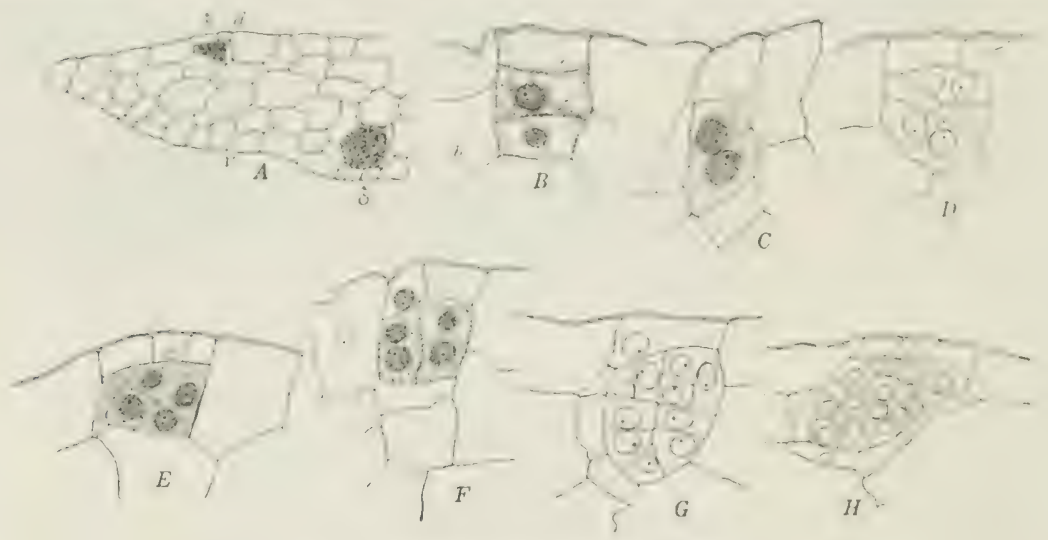

Fig. 97.-Development of the antheridium in Danas.

A. Section of prothallium, bearing antheridia on both surfaces. $\times 80$.

B-H. Longitudinal sections. $\times 300 . \mathrm{E}-\mathrm{H}, \mathrm{D}$. elliptica; the others, D. jamaicensis.

The mother cell of the antheridium, as in Ophioglossum, divides first by' a periclinal wall into an outer cell, the primary cover cell, and an inner one, from which the mass of spermatocytes is developed (figs. 96, 97). The mother cell of the antheridium shows much the same variation in form as that of Ophioglossum, sometimes being relatively broad and shallow and at other times deeper and narrower (fig. 96 , $B, C)$. The first division in the inner cell is usually transverse, but in the broader type of antheridium this first wall may be longitudinal. The primary wall is followed by a second one at right angles to it and the four cells thus formed are again divided so that there result eight nearly equal cells. The first wall occasionally is somewhat oblique, but even in such cases the regular quadrant and octant walls arise at right 
angles to the primary division wall. The next divisions are, usually at least, anticlinals (fig. 97, G), but before long the periclinal walls also are developed and subsequent divisions do not show any recognizable regularity in their sequence; there seems to be a good deal of variation in this respect, even in the same species. The number of cells ultimately formed varies a good deal, but the number of spermatocytes finally developed is probably never so great as that found in some of the Ophioglossacex. Kaulfussia, both in the size of the antheridium and that of the spermatozoids, approaches nearest to Ophioglossum. The number of spermatozoids may reach several hundred, fifty or more being visible in a single section of a large antheridium, and nearly or quite as many may sometimes be found in Danca, where, however, the spermatozoids are much smaller than in Kaulfussia.

In the cover cell the divisions are all anticlinal and horizontal sections or surface views show that the successive walls are arranged spirally in a way suggesting the segmentation of a three-sided apical cell. The last-formed wall cuts out a small, nearly triangular cell, the opercular cell (fig. $95 \mathrm{D}, E, 0$ ). In most cases, at least,

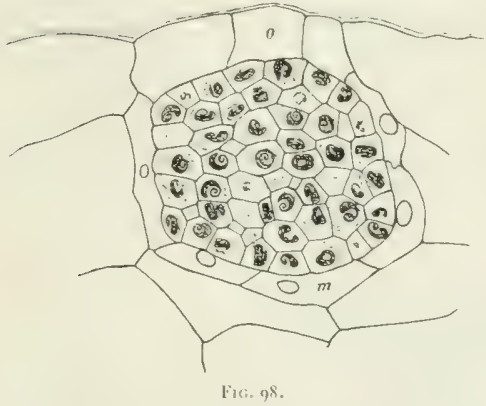

Ripe antheridium of $I$ ). jamaicensis. $m$, nantle cells. 0 , opercular cell. $\times 350$.

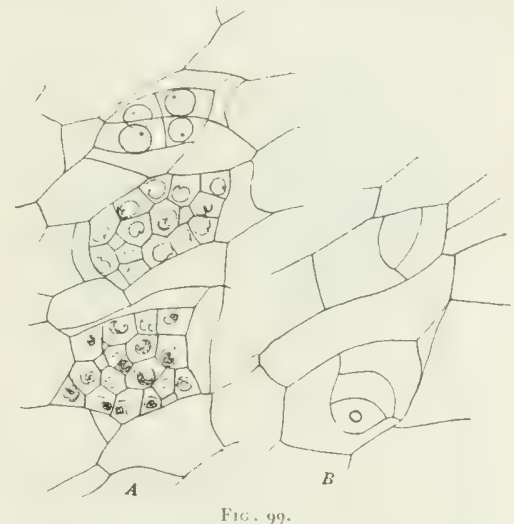

A. Transwerse section of three young antheridia of $D$. jamaicensis. B. Surface view of the two youngest ones. o, opercular cell. $x_{3} 80$.

this opercular cell is thrown off when the antheridium opens, leaving a small aperture through which the spermatozoids are ejected. Surrounding the mass of spermatocytes is a layer of mantle cells cut off from the adjacent cells of the prothallium. These mantle cells, at the time of the opening of the antheridium, become very much distended and project strongly into the cavity of the empty antheridium (fig. $100, B, m$ ). They no doubt play an important part in the dehiscence of the ripe antheridium.

$$
\text { SPERMATUGENESIS. (Plate 2, figs } 38-44 \text {.) }
$$

Of the Marattiacea, $K$ aulfussia is the most satisfactory for studying the details of spermatogenesis, owing to the much larger size of the spermatozoid. The development of the spermatozoids agrees very closely in its details with that of Ophioglossum. If the spermatocyte is examined just before the final division the two blepharoplasts can be seen and the division of the cell into the two spermatocytes proceeds very much as in Ophioglossum. After the final division the nucleus of the spermatocyte appears coarsely granular and, as in other cases, no nucleolus can be seen. In favorable cases the blepharoplast is visible as a round body, stained 
rather strongly and lying near the nucleus. The blepharoplast soon rakes on the curved form and becomes much extended and the cilia begin to develop form it before the nucleus has materially changed its shape.

The nucleus now becomes slightly pointed at one end and hegins so sereech out so as to appear somewhat crescent-shaped, very much as in Ophioglossum and as it does in other ferns that have been described. With this change in the form of the nucleus, the blepharoplast becomes still more elongated and strongly colored and the cilia increase in length. The nucleus of the spermatozoid in Kaulfussia is less elongated than is usual in the ferns, and in this respect, as well as in its larger size, it more nearly resembles Oplioglossum than it does the other Marattiacea. The granular appearance of the nucleus is maintained until the spermatozoid is almost fully developed, when there seems to be a fusion of the chromosomes so that it appears almost homogeneous; this is accompanied by a noticeable diminution in the size of the nucleus. The nucleus occupies only the large posterior coil of the spermatozoid, while the anterior portion, which shows about two coils, is composed of the blepharoplast with probably a certain amount of other cytoplasmic matter.
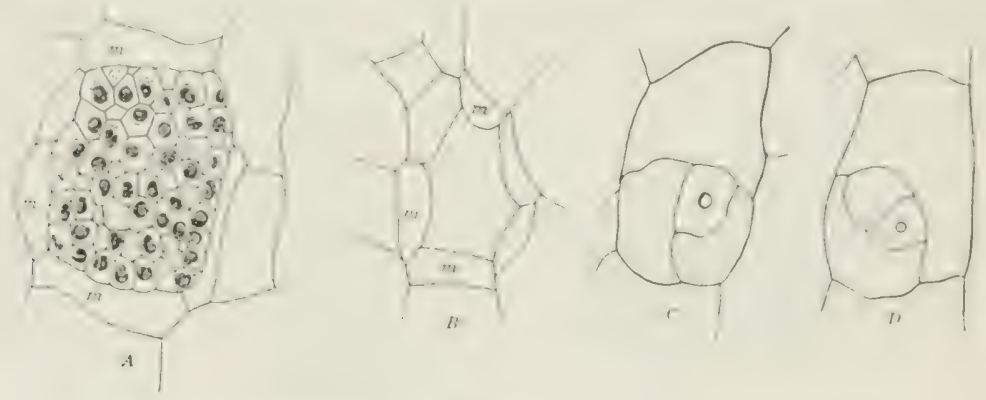

Fic. 100 .

1. Cross-section of a ripe antheridium of $D$, jamaicensis.

13. Cross-section of an empty anthesidium; m, mantle cells.

(-1). Surface views, showing opercular cell.

All figures $\times 350$.

In Maratia and Angiopteris (plate 2, fig. 4 ) the nucleus of the spermatocyte becomes much more extended and the whole spermatozoid is more slender than in $K$ aulfussin. Indeed there is very little difference between the appearance of the spermatozoids of Angioptcris and Marattia and those of the typical leptosporangiate ferns. Some observations were made also upon Dana $a$, in which the spermatozoid is somewhat intermediate in character between that of Angiopteris and $K$ aulfussin (plate 2, figs. 42,43 ). In size the spermatozoids are more like those of Angiopteris, but the nucleus is much less elongated and the general form of the spermatozoids is more like that of $K$ aulfussin.

THE ARCHE(;0)तIT.

The archegonium in the Marattiacere, like the antheridium, very much resembles that of Oplinglossum, but the neck of the archegonium is even less developed than in the latter. Jonkmann (Jonkmann 1) has given a fairly complete account of the development in Maratic and Angiopteris, and Farmer (Farmer I) has described and figured the archegonium of the latter genus.

Usually, at least, the archegonium is developed only upon the cushion of tissue back of the apex, the young archegonia arising in acropetal succession. Jonkmann 
states, however, that he has found them also upon the upper surface of the prothallium, but none of the specimens I have examined have shown this. The mother cell of the young archegonium is scarcely distinguishable in form from the young antheridium and like it is first divided by a periclinal wall into an outer cover cell and an inner cell, the latter usually, but not always, divided subsequently into a central and a basal cell (figs. IOI-IO3), as in Ophioglossum and in the typical ferns. Sometimes the mother cell of the archegonium is seen in transverse section to have been cut out very much as the axial row of cells arises in the archegonium of the Hepatica. There seems no question that the so-called mother cell of the archegonium in all the ferns is really homologous only with the axial row of cells of the bryophyte archegonium, the four rows of neck cells being a further development of the terminal cap cell of the liverwort archegonium.

The inner of the two primary cells, as we have already stated, may have a basal cell cut off from it before the further divisions arise, by which the egg cell and the canal cells are divided. The neck canal cell is very broad and may become divided into two cells, but usually the division is confined to the nucleus, which probably divides in all cases. The ventral canal cell cut off in the usual fashion from the egg is, with the exception of Danaa, very large and conspicuous, thus differing from
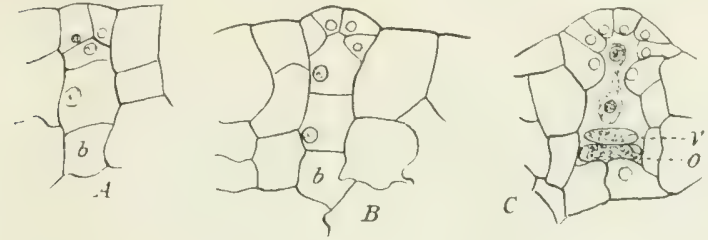

Fit.. 101.

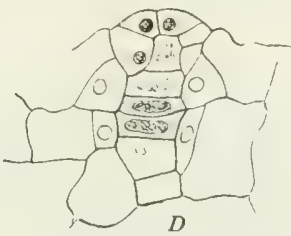

$D$

Archegonia of Angiopteris. $\times 275$. b, basal cell; $0, \mathrm{cgg} ; v$, ventral canal cell.

Ophioglossum, where the ventral canal cell is so difficult to demonstrate; but in Danca there is the same imperfect development of the ventral canal cell that is found in Ophioglossum.

As the archegonium approaches maturity a layer of mantle cells, much like those which surround the antheridium, is cut off from the tissue surrounding the venter of the archegonium. The archegonia of Marattia denglast are confined to the lower side of the midrib and begin to form at some distance back of the growing point; so far as can be determined, any superficial cell of the apical meristem can develop into an archegonium. The mother cell divides, as we have seen, into three superimposed cells, of which the lowest, $b$, usually divides later by vertical walls, and forms the base of the archegonium. From the central one, by transverse divisions, are formed the canal cells and egg, and from the uppermost the neck. Compared with the typical ferns, the most striking differences are the short neck and the very broad canal cells. The cover cell undergoes division into four, by two intersecting vertical walls, as in Ophioglossum, and each of these four cells then undergoes division by nearly horizontal walls, hut the cells romain short, so that the neck projects very little and there are only three or four cells in each row; occasionally there may be only two. Jonkmann states that, as a rule, two of the rows of the neck contain three cells and two contain four, but that there may occasionally be as many as five. The neck canal cell often shows a trace of a division and there may be an actual division wall formed (fig. IOI, D), but in Marattia douglasii 
chis is me ordinarily the case. In one instance in this species I observed a division by a vertical wall, so that two neck canal cells were formed, placed side by side, in a way recalling very strongly the division of the neck canal cell described by Jeffrey in certain species of Equisefum ( Jeffrey 2 ). The central cell is divided again by a horizental wall into ewo nearly equal cells, the lower one being the egg, the upper one the ventral canal cell. The mature ege is nearly elliptical in form, the upper third being almose homogeneous and quite colorless, forming the so-called receptive spot. The nucleus is of moderate size and does not stain very strongly. The archegonium of Ingiopleris closely resembles that of Marattia, but is perhaps somewhat narrower (fig. IOI).

Jonkmann figures the archegonium of $M$. cicutcfolicl, which shows that this species also is, in the relative size of the canal and neck cells, very much like Angiopteris. Farmer thought that a basal cell was usually, if not always, present, and my own studies tend to contim this.
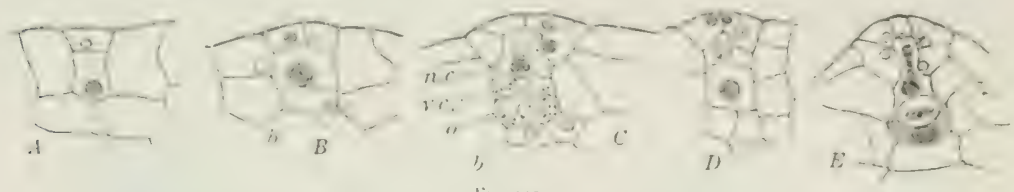

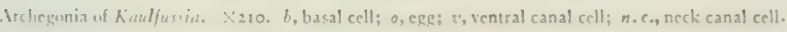

In Kinlfussia (fig. 102) the archegonia form, as a rule, only after the antheridia have ceased to develop. Compared with the other Marattiacea they are decidedly. large, and in this respect Kaulfussia approaches Ophioglossum. Like the mother cell of the antheridium, there is a good deal of variation in the width of the young archegonium in Kaulfussia. Some of the narrower types recall the archegonium of Anthoceros and emphasize the resemblances between the archegonium of the Anthocerotacex and the eusporangiate ferns. The neck of the archegonium is very short, each of the four original neck cells often dividing only once, so that there may be but two cells to each of the four rows. More commonly, however, there is a

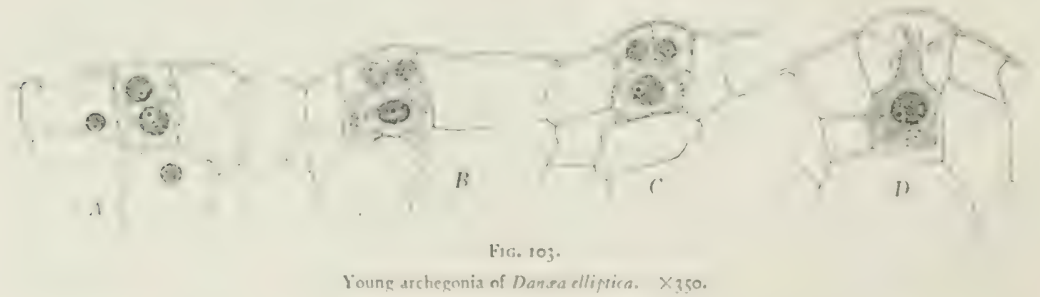

second division in some of the cells, so that each row consists of threc cells. The nucleus of the broad neck canal cell probably always divides, but the number of available specimens was too small to decide whether or not there is ever formed a division wall between these, although it is not at all unlikely that this may occur. The ventral canal cell is conspicuous and equals its sister cell, the egg, in breadth. In the peripheral portion of all the axial cells of the archegonium there are many small granules of starch. Jonkmann figures similar starch granules in both Marattia and Angiopteris. 
The archegonium in Danca, while resembling that of the other Marattiacex, in its position and early development shows some marked differences, the significance of which is not quite clear. The division of the mother cell into the primary neck cell and the central cell follows in the same way as in the other forms, but the inner cell, usually at least, does not have a basal cell separated from it, but develops at once into the egg cell and canal cells. The absence of the basal cell is by no means unknown, however, among the other Marattiaceæ. The primary neck cell gives rise to the usual four cells, each of which divides into three or four, and exceptionally into five. There is a marked elongation of the inner cell before its separation into the central cell and the neck canal cell (fig. 103, D).
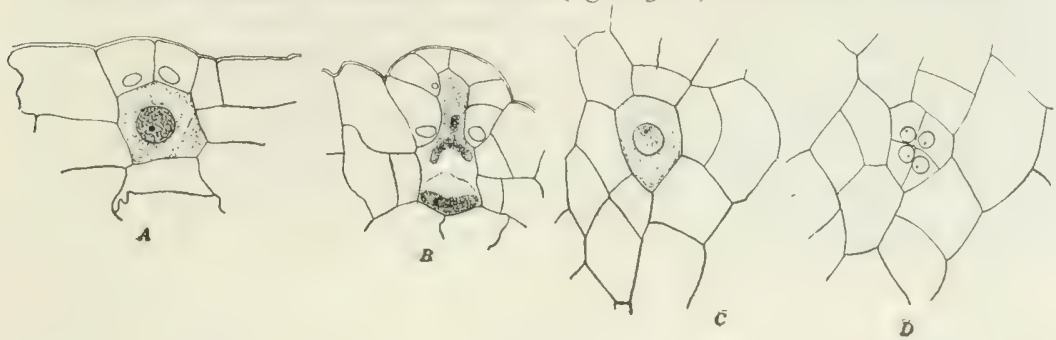

Ers. 104.

A, young, B, nearly mature, archegonium of $D$. jamaicensis. $x_{3}$ fo.

$\mathrm{C}, \mathrm{D}$, cress-section of a young archegonium of same species. D shows the four primary neck cells.

Up to this point there is nothing peculiar in the development of the archegonium in Dancea, but while in most of the other Marattiacere a conspicuous ventral canal cell is formed, its sister cell being the egg, in Danca the formation of a definite ventral canal cell could not be satisfactorily demonstrated. In a number of cases (fig. 105; plate 2, fig. 45) a small nucleus-like body could be seen in a large, clear
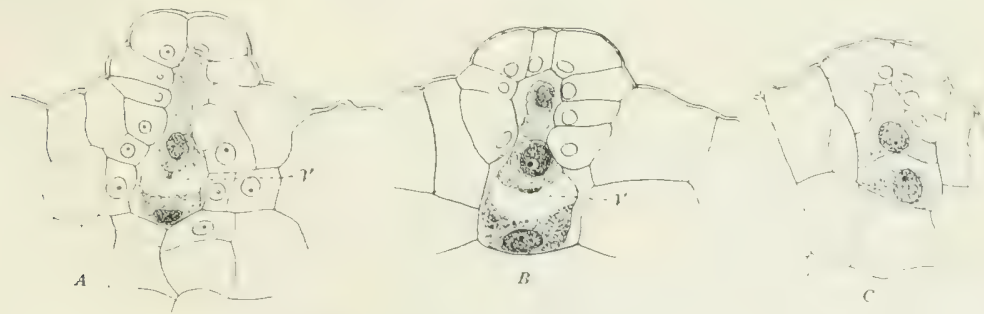

Frg. 105 .

Three mature archegonia of Dance ellipica. $\times 350$.

$\mathrm{A}$ and $\mathrm{B}$ show traces of a ventral canal cell; $t$, in $\mathrm{B}, \mathrm{a}$ division of the neck canal cell.

space just above the somewhat contracted mass of protoplasm, with its large and conspicuous nucleus, which constitutes the egg cell; but this ventral canal cell nucleus, if such it is, is very different in appearance from the large and conspicuous one found in the other Marattiaceæ, and in the absence of any division stages its nuclear nature must for the present remain somewhat doubtful.

There is somewhat the same uncertainty in regard to the primary division of the neck canal cell. This possesses a large and conspicuous nucleus which in large and apparently mature archegonia was still undivided. In a few cases a division of the protoplasm in the neck cells was observed; in other cases, without any such division, 
a second hody of rather indefinite outline and staining much less strongly than the lower nucleus could be made out; but up to the present time I have not been able (1) satisfy myself that the division of the neck eanal cell nucleus, which always occurs in the other Marattiacese, takes place here. The very uncertain nature of the ventral canal cell recalls strongly the condition of affairs in Ophioglossum, where it is eyually difficult to demonstrate satisfactorily the presence of a true ventral canal cell.

\section{FERTITITATION}

It has not been possible of follow in detail the process of ferrilization in the Marattiacea, but several stages were found in preparations of Marattia douglasii. The entrance of the spermatozoid into the archegonium was not seen, but in a number of cases the material had been killed immediately after, and twice spermatozoids were found which had penetrated into the egg. In these cases the spermatozoid was quite unchanged in form, but had not yet entered the nucleus itself. One case was observed where there were apparently two nuclei in close contact, but the egg nucleus was much contracted and it is doubtful whether this was really a normal appearance. It is probable that the details of fertilization are quite similar to those observed in other ferms. 


\section{THE EMBRYO.}

The study of the embryogeny of the Marattiaceæ offers many difficulties. Fertilization does not seem to be of common occurrence and a very large number of prothallia must be examined before even a small series of embryos can be secured; moreover, the earlier stages of the embryo are peculiarly liable to shrinkage in preparing them for sectioning and it is exceedingly difficult to secure really satisfactory preparations of these early stages.

A marked peculiarity of the young sporophyte, which was first shown by Luerssen and Jonkmann for Marattia and Angiopteris, is the orientation of the primary organs of the young sporophyte with reference to the archegonium. The primary or basal wall in the embryo is always transverse, as it usually is in Ophioglossum, instead of being vertical as in most of the typical ferns. The first leaf, instead of being formed from the portion of the embryo nearest the archegonium, as it is in the common ferns, arises from the half of the embryo which is turned away from the archegonium, and grows straight upward, bursting through the prothallium upon its upper surface, instead of appearing upon the lower side of the prothallium and curving upward. The external organs of the young sporophyte are differentiated $x$
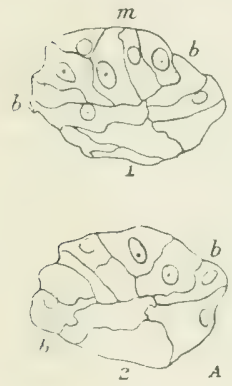

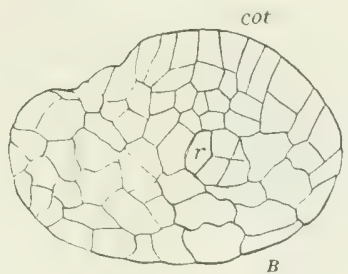

Fig. 106.-Maratia douglasii.

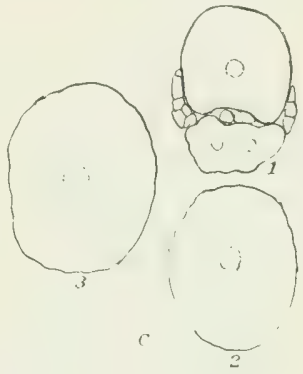

A. Two longitudinal sections of a young embryo. $b$ b, basal wall. $\times 200$.

B. A similar section of an older embryo, cot, cotyledon; $r$, root initial.

C. Three transverse sections of a much older embryo, showing junction of the two first leaf traces. $X_{50}$.

much later than is the case in the Leptosporangiates, and the Marattiaceæ in this respect closely approach the Ophioglossacex.

It has been generally assumed that, as in the leptosporangiate ferns, the cotyledon and stem are of epibasal origin, the root and foot hypobasal. This conclusion was reached by both Jonkmann and Farmer, and my early studies on Marattia douglasii led me to the same conclusion. A further study of this species, however, as well as an examination of the embryos of Angiopteris, Kaulfussia, and Danaa, has shown that this is not the case, but that the whole of the hypobasal region is devoted to the formation of the foot, and the root is developed secondarily from the epibasal region, from which are also derived the stem apex and the cotyledon.

While in the typical ferns the young organs of the embryo at a very early stage show a definite apical growth, the apical cells being readily traceable to the primary octants of the embryo, this is by no means so readily shown in the Marattiacer. In the later stages, such initial cells can be seen in the root and stem at least, but the relation of these initial cells of the root and stem to the early divisions of the embryo is very difficult to determine. In M. douglasii (Campbell 3) I stated that there 
was probably a single initial in the stem and in the primary rout, and firmer also thenght that a single root initial was always present in Angiopteris, but concluded that such an initial cell was not present in the stem of the young sporophyte. Brebner (Brebner 2) says that in Danea simplicifolia such a single initial cell seemed (1) be always present in the stem, and my studies on Angiopteris, Kaulfussia, and Donera indicate that a single initial is developed at an early period in the stem apex and persists until the sporophyte has developed several leaves.

Before any division occurs in the embryo the fertilized cell increases markedly in size, after which there is formed the horizontal basal wall (figs. $106,109, b$ b). 'This is probably followed at once by' the median wall (except in Danaa), so that the cmbryo at this stage is divided into four approximately equal quadrants (see fonkmann 3, fig. 9).

The genus Danara, at least this is true for $D$. jamaicensis and $D$. elliplica, differs in the early divisions of the embryo from the other Marattiacea. The expe cell after fertilization elongates in a way which closely resembles that found in Botrychium obliquum ( Lyon 1). The primary hypobasal cell either divides no further or only once and forms a short suspensor, so that all the organs of the young embryo, including the foot, are really of epibasal origin. As yet no trace of such a suspensor has heen found in the other Maratraces.

\section{THE EMIBRYO (IF WARNITIA.}

Luerssen (Iuersen 2) found the one-celled embryo and young plants of Marattia cicutafolia, but was not able to procure the older embryos. The writer (Campbell 3) succeeded in procuring several stages of the embryo in Marattia douglasii, and somewhat later Luerssen described and figured some of the earlier stages in $M$. fraxinca and $M$. iveinmanniafolin. These, so far as I am aware. complete the list of records upon the embryo of Maratia.

The fertilized ovum in Marattia douglasii becomes much enlarged before it divides and completely fills the venter of the archegonium. The granular contents of the egg cell become evenly distributed without any apparent increase in yuantity as the fertilized ovum grows, so that the one-cell embryo contains compararively little granular contents, but the nucleus is very conspicuous. At the time of the

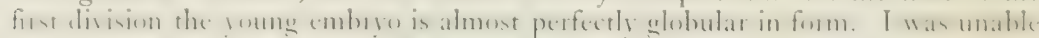
to find the stages immediately following this, but Jonkmann has figured an eightcell embryo of $\mathbf{M}$. fraxinca (see Jonkmann 3 , fig. 9 ). The basal wall is transverse and this is followed successively by the median and transverse walls, so that the globular embryo is divided into approximately equal octants. From the hypobasal half, which is nearest the archegonium, there is developed the foot alone, while all of the other organs arise from the epibasal portion, which is turned away from the archegonium.

The youngest embryo (except the one-celled stage) which I found in $M$. douglasii, is shown in fig. 106, $A$. "This is about the same stage as the one shown in Jonkmann's figs. II and I3. Unfortunately this embryo was rather badly shrunken in the process of embedding and the division walls were a good deal distorted, so that it is rather hard to determine exactly their correct relation to each other; but probably the wall $b b$ represents the basal wall and $m$ the median wall. The embryo has now lost its original globular form and become oval, the long axis lying transversely. The secondary divisions in the octants are mostly anticlinals, and the first periclinals have just appeared in a few of the cells. Figure 106, $d$, shows two consecutive median sections. It will be seen that cell division is more acrive in the epibasal portion than in the hypobasal region. 
In my original study of Marattia I concluded that the primary divisions resulted in the establishment of the organs of the young sporophyte in a manner similar to that in the Leptosporangiatx, i. e., that the stem and leaf were derived from the epibasal quadrant, the root and foot from the hypobasal ones. Farmer thought that this was true for Angiopteris and Jonkmann assumes that it is the case also in Marattia. A further study of my preparations, however, has led me to believe that the whole of the hypobasal region is devoted to the foot, while the root, together with the leaf and stem apex, are of epibasal origin. . A large cell (fig. 106, $A$ ) occupies approximately the same position as the stem apex in the older embryo and it is possible that this may be the apicalicell of the stem, but in the absence of the intermediate stages this can not be positively asserted. For a long time the embryo retains the oval form and there is scarcely any sign of the young organs of the sporophyte which in the leptosporangiate ferns are so early manifest; indeed, Jonkmann states that there is no differentiation at all, but a careful study of the older embryo shows unmistakable indications of the definitive organs. The development of the tissue in the epibasal region is not uniform, but somewhat to one side of the center (fig. Io6, B) there may be seen a group of columnar superficial cells, which mark the position of the future growing point of the stem. Whether one of these superficial cells is the definitive apical cell it is impossible to determine, but from a comparison with the older stages, as well as with corresponding stages of the embryo in the other genera, it seems probable, at least, that this is the case, and perhaps this initial cell may be traced back to the centrally placed cell noted in the younger embryo. A considerable portion of the epibasal tissue is not included in the meristematic region, which is derived mainly, at least, from only one of the original epibasal quadrants. The
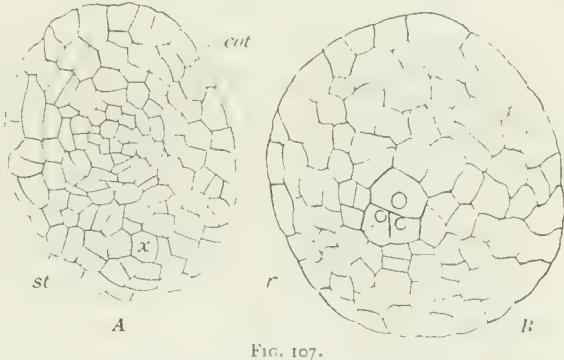

Two cross-sections of an old embrjo of Maratia douglasii. A passes through the stem apex, st, and base of cotyledinn. $\mathrm{B}$ passes through root apex, $r$. $\times 200$.

tissue adjacent to this meristematic region is made up of large cells with less dense contents and smaller nuclei and differs in no war from the large cells of the foot, into which this tissue insensibly merges and of which it may be said to constitute a part.

In the embryo figured, it was not quite certain whether the root apex had begun to form or not. It seems probable that the cell $r$ is really the apical cell of the young root, but except for its position it was not noticeably different from the cells adjacent; however;/as in Angiopteris and Dancea there is no question that the root originates in this position, it is probable that this cell is really the initial for the young root and is cut out from the base of the epibasal tissue near its junction with the foot. This marked endogenous formation of the root is very much like that in the embryo of Ophioglossum moluccanum, but differs entirely from the superficial origin of the apical cell of the root in the embryo of the Leptosporangiates.

The stem apex in the older embryo is of very limited extent, consisting of only a few cells, of which one, as we have said, is probably the definite apical cell, although it must be said that this point is very difficult to decide, as all of the central cells of this apical group look a good deal alike, but a careful study of both transverse and longitudinal sections seems to point to one of these as the apical cell, which in shape is a good deal like that in the stem apex of Ophioglossum. In longitudinal 
sections this is somewhat wedge-shaped, the narrow end rumed outward and the hroad hase helow: In cross-section this cell is nearly square in shape (fig. 107, $\lambda, x$ ) and there maty be seen a fairly regular series of four segments cut from the lateral faces. From the broad truncate base of the cell, segments are also cut off which contribute tu the inner tissue of the stem.

Much the greater part of the epibasal meristem contributes to the cotyledon, which is soon evident as a broadly conical protuberance, somewhat flatsened on the side adjacent to the stem apex and merging gradually on she outer side into the largecelled cissue which adjoins the foot. To judge from the limited number of young embryos which I could examine, it seems that the growth of the cotyledon is not due (1) the activity of a single apical cell, but this point was somewhat uncertain.

By the time that the cotyledon is established, growth has progressed in the young root, which now is seen to have a conspicuous apical cell, which divides rapidly so that the root quickly elongates in a direction opposite to that of the cotyledon (fig. 108). The apical cell of the primary root in $M$. donglasii is not triangular in outline, but more or less quadrilateral, whether seen in longitudinal or cross sections (fig. $107, B$ ). In form and segmentation it perhaps more nearly resembles that of Damoto than it does the tetrahedral apical cell which occurs in the young
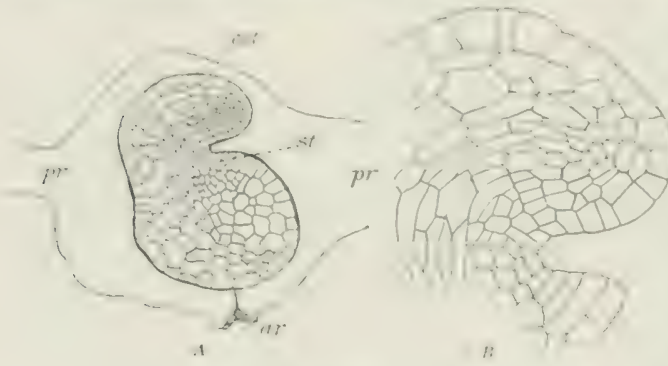

Fic: 108 .

A. Secrion of an advancel embryo of Marattia douglasii, just hefore emergence of cotviledon.

13. The cotslecton, more enlarged. young sporophyte apparently at this time being composed almost entirely of the cotyledon and the very large root, with the stem apex, lying near their junction. From a comparison with younger stages, however, it is perfectly evident that the enlarged central region of the embryo at this time is composed mainly of tissue belonging to the font, which is, so to speak, perforated by the root in its downward growth.

The development of the vascular bundles at a very early period is first evident in she cotyledon, which almost as soon as it can be recognized at all is seen to have a strand of procambium extending below it. If this procambium strand is traced downward, it is seen to continue without interruption into the base of the root, exactly as it does in Ophioglossum moluccanum. No trace of a procambial cylinder can be found extending into the stem apex, which gives rise only to the parenchyma of the central pith. This early development of the vascular bundles in the cotyledon and root was correctly observed by Jonkmann and Farmer, both for Marattia and

"In a very recent paper in the Botanical Gazette (Feb. 1911), Miss Charles states that the apical cell of the seem in . Moratia atate is at first iriangular in cross-section. In older sporophytes the single apical cell was replaced by a group of initial cells. 
Angiopteris, but they seem to take it for granted that a vascular strand is also developed in the stem; at any rate they make no reference to the absence of such a vascular strand from the stem region. In my earlier study of Marattia, I supposed that a strand was developed which belonged to the stem itself, but a further examination of many plants, after a study of this point in the other genera, has made it pretty clear that this supposed stem bundle really belongs to the second leaf, the rudiment of which appears at a very early period.

\section{THE. EMBRYO OF ANGIOPTERIS.}

In Angiopteris the embryo very early becomes more greatly elongated transversely than is the case in Marattia, so that in a longitudinal section it appears as a very much depressed oval (fig. I09); the epibasal region is larger than the hypobasal

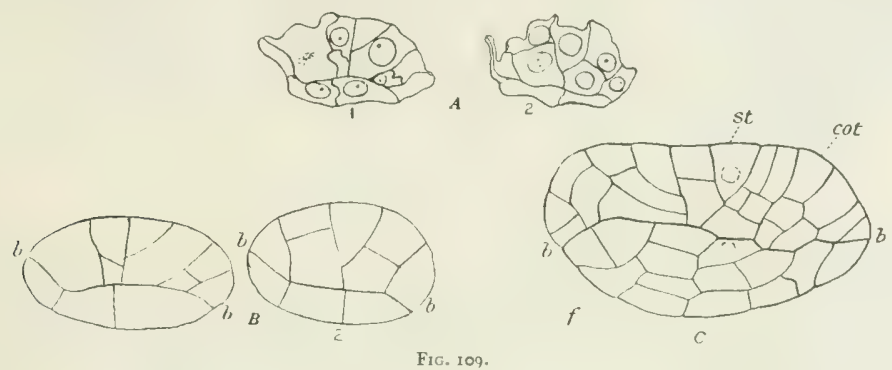

A. Two sections of a young embryo of $A$ giopteris. The cells were badly shrunken.

B. Diagrams showing arrangement of cells of same embryo.

C. An older embryo. $b b$, basal wall; st, stem a pex; cot, cotyledon; $f$, foot.

and the quadrant divisions are often still evident. Whether octant divisions are formed in all the quadrants could not positively be determined, but Jonkmann states that such is the case. There can usually be found in the young embryo a nearly centrally placed large cell (fig. Iog, $C$, st), which probably is the initial cell of the young stem. The position of this cell is not unlike that which occurs in the
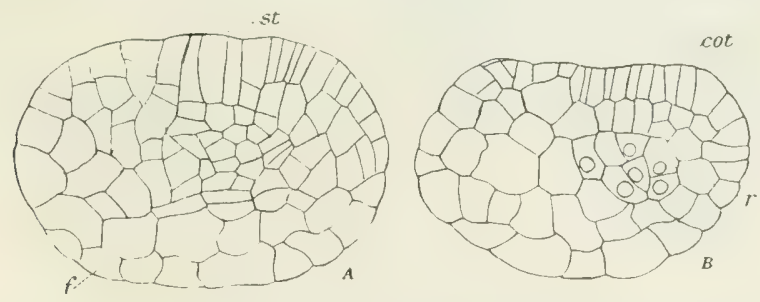

Fic, Iro.

Two longitudinal sections of an older embryo of Angiopteris. $\times 200$. The young root, $r$, is shown in $B$. st, stem apex; cot, cotyledon; $f$, foot.

embryo of Equisetum, and at this stage there is also a certain resemblance to the embryo of Botrychium virginianum. As the embryo grows it tends to assume a more nearly globular form (fig. I Io). The basal wall can still be imperfectly followed, the hypobasal portion of the embryo being made up of the large cells forming the foot, while above the basal wall the cell divisions are more active and the rudiments of 
the stem and cotyledon can be recognized, although the embryo still retains its oval outline. As in the embryo of Marattia, growth is most active in the central region of the epibasal part of the embryo and there can generally be recognized a large central cell, which is presumably the single initial of the stem apex, although, as in the case of Marattin, it is not absolutely certain that a single initial cell is always present. Cell division is especially active on one side of the stem apex, and this area marks the position of the young cotyledon. The limits of this growth area are
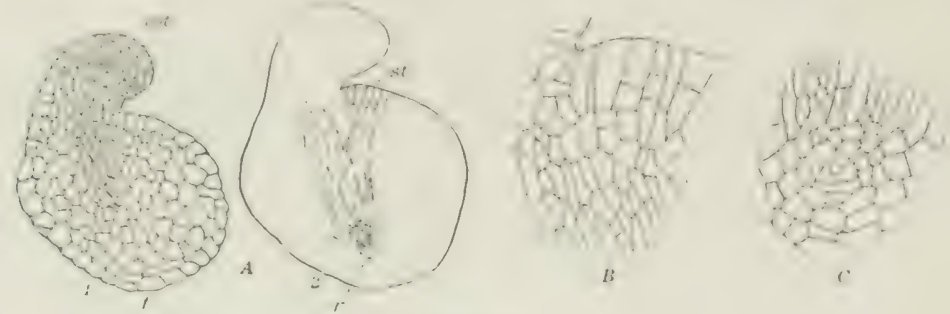

Fic. III

A. Two longitudinal sections of an old embryo of Angiopteris. $\times 75$

13. Stem region of same embryo. $\times 160$.

C. Ront aper. $\times 1$ ito.

not very sharply defined and it is ditficult to say whether it can be traced back to a single quadrant or octant cell, but it is probably not always constant in its position; indeed, the stem looks as if the stem apex and the cotyledon both arose from the same quadrant, the second epibasal quadrant contributing, at least in part, to the foot.

As seems to be true in all the Marattiacex, the root makes its appearance at a comparatively late period and it is evident that the root, as in the embryo of Marattin, is a strictly endogenous structure. The first indication of the root is the development
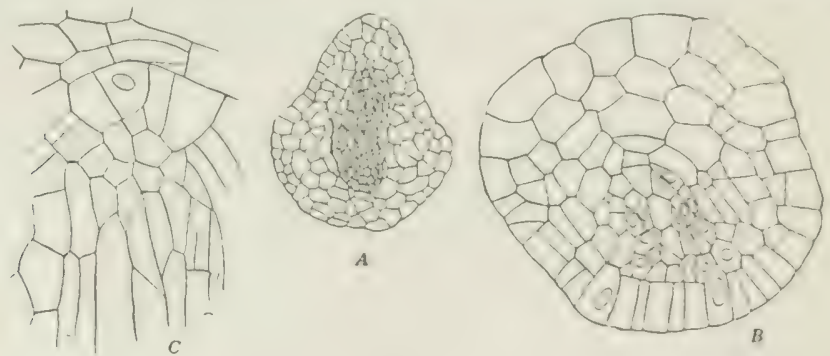

Fir. Irz.

A. Longitudinal scction of an advanced embryo of An giopteris, cut in the plane of the lamina of the cotvledon. $\times 50$.

13. Cotyledon of same cmbryo, showing dichotomy of a pex. $\times 220$.

C. Root apex of same. $\times 220$.

of a group of actively dividing cells, almost in the center of the embryo below the stem apex. This meristematic region is probably always of epibasal origin, but it is close to the basal wall and it is possible that sometimes it may arise below it. The apical cell, which in the early stages almost always appears triangular in section, becomes conspicuous and was recognized by Farmer in his study of the embryo of 
Angiopteris (Farmer 1). The root initial now divides by regular segmentation and the root apex pushes rapidly down through the underlying foot and ultimately emerges on the lower side of the prothallium. In the meantime the cotyledon grows actively and there is a rapid elongation of the whole embryo in a vertical direction. As in the case of Marattia, it is difficult to prove that the cotyledon grows from a single initial cell. The cotyledon has very much the form of that in Marattia, growth being more active on the outer side, so that it curves over the stem apex very much as the cotyledon does in the embryo of Botrychium virginianum. About the time that the cotyledon is ready to emerge, the apex becomes flattened out and (sometimes, at any rate) there is a true dichotomy of this apex (see fig. II2, $B$ ).

In the primary root there seems to be no question of the presence of the single initial cell which, at first at least, has the tetrahedral form, but later on is apt to have the base truncate, although it usually has three series of lateral segments. I have not been able to confirm Farmer's statements that the single apical cell is later replaced by a group of similar initials, as in the later roots of the sporophyte, although it is not at all impossible that such may sometimes be the case. The development of the embryo of the vascular bundles in the young sporophyte is exactly the same as in the corresponding stages of the embryo in Marattia.

\section{THE EMBRYO OF KAULFUSSIA.}

So far as I am aware, no account has been published of the embryo in Kaulfussia, except one of my own (Campbell 11). Only two young embryos were found, so that it was impossible to follow in detail the early history of the young sporophyte. The basal wall, as in the other Marattiacex, is transverse and, to judge from a comparison of similar stages of the embryo in Marattia and Angiopteris, all of the organs of the young sporophyte in Kaulfussia, except the foot, are also of epibasal origin. Figure II $3, A$, shows a nearly median longitudinal section of the young embryo. This is very much elongated transversely, and to judge from the position of the cells the basal wall is probably followed by the median walls, forming nearly equal quadrants. The large cell $(s t)$ in one of the epibasal quadrants corresponds in position to the similar cell found in the embryos of the other genera and very likely may represent the primary initial cell of the stem. The embryos, however,
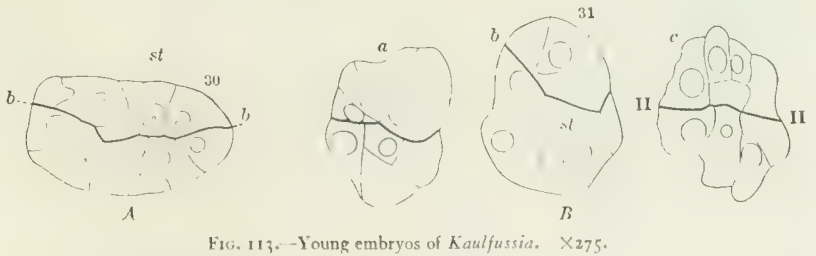

Fic. 113,- Young embryos of Kaulfussia. $\times 275$.

A. Longitudinal section.

B. Three cross-sections of a similar embryo, b b, basal wall; 1 , quadrant wall.

were too young to make clear the relation of the cotyledon and primary root to the stem. Three nearly transverse sections of an embryo of about the same age are shown in fig. $I_{13}, B$. To judge from the structure of the older sporophyte at the time when it first emerges from the prothallium, $K$ aulfussia agrees in the main with Marattia and Angiopteris in the origin of the young organs of the sporophyte. 


\section{'TII: I.MBRYO OF IDANAA}

Brebner (Brebner 2) has described the older embryo of Donea simplicifolia, but did not secure the earlier stages. The youngest specimens he figures closely. resemble in form a corresponding stage in the species studied by me, and the slightly pointed hasal region suggests the possibility of the presence of a short suspensor in D. simplicifolia like that which I have found in D. jamaicensis and D. ellipsica. While my own collection of young embryos is not as complete as might be wished. still enough stages were secured to show that at least $D$. jamcicensis and $D$. clliptica

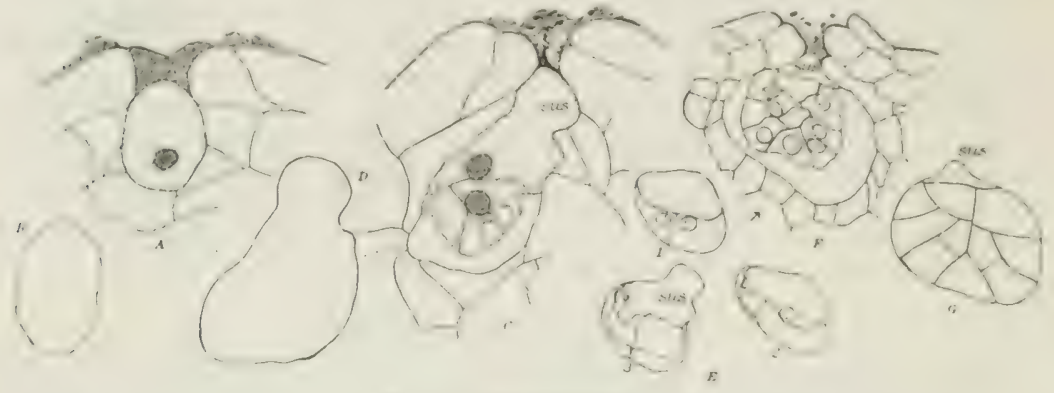

Vic. 114 - Danta jamaicensis.
A. Arcliegonium containing a one-erlled embryo.
B. Outline of next section of same cmbryo.
E. Three longitudinal sections of a four-celled embryo.
C. Threc-celled embryo, showing suspensor, suc.
F. An older embryo, which was shrunlien.
1). ( )utline of next section of the same embryo.
G. Diagram of $\mathrm{F}$, showing probable arrangement of cells.

differ remarkably from the other Marattiacea that have been studied in the development of a short suspensor, thus showing an interesting analogy with the embryo of Botrychium obliquum, described by Lyon (Lyon 1). Whether D. jenmani shows the same peculiarity was not determined, on account of the failure to obtain the young embryo of this species; but as in its later development it corresponds very closely to the other species, it is highly probable that a suspensor is developed.
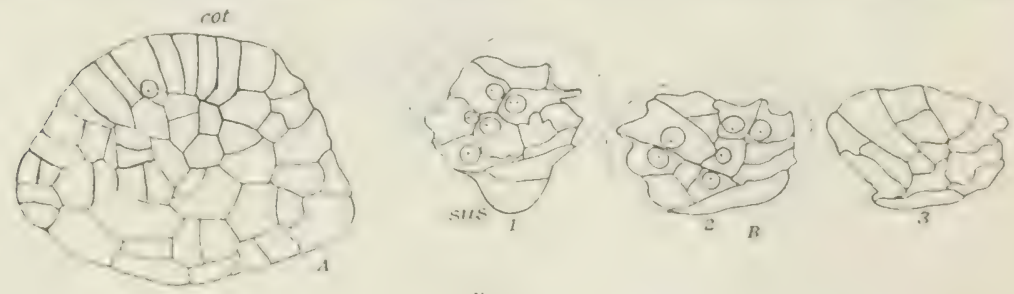

Fis. IIs

1. A nearly nedian section of an older embryo of $D$. jamaicensis. The suspenser dues not show in this sectim.

B. Three sections of a young embryo of 1 ). ellipica. sus, suspensor. $\times 200$.

Before the first division takes place in the embryo, the fertilized ovum enlarges to several times its original size and becomes decidedly elongated. The first division wall, as in the other Marattiacex, is transverse, but of the two primary cells thus formed the hypobasal one divides no further, or only once, and forms a short suspensor which pushes up into the neck of the archegonium whose cells become more or less completely disorganized (fig. I $4, d$ ). The next division wall is a nearly. median one in the epibasal cell, and this is soon followed by a second wall in each 
of the epibasal cells, so that this portion of the embryo is divided into four nearly equal quadrants. There is some evidence that these are followed by horizontal octant walls, so that the epibasal region is thus divided into octants in much the same fashion as obtains in the whole embryo in other Marattiacex and in the leptosporangiate ferns. How far these divisions are constant can only be conjectured, owing to the small number of young embryos which were available. The elongated pear-shaped embryo in Danca appears very different indeed, in these early stages, from the broadly elliptical and much depressed embryos of corresponding stages in the other Marattiacex (fig. I I $, C, D, E$ ).
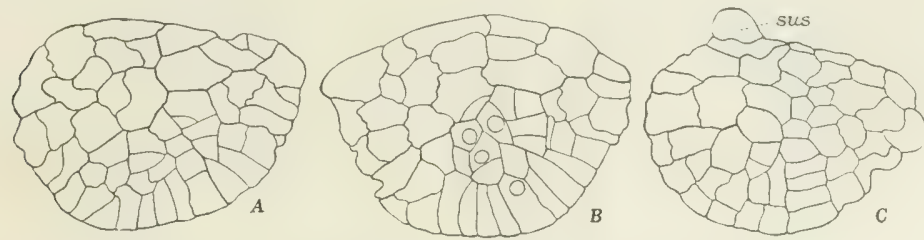

Fic. $116 .-D$. jamaicensis.

Three sections of an older embryo. X200. Section B is a nearly median section;

$A$ is the next section in the series; $C$ shows the suspersor, sus.

A further study of the embryos shows that all of the lower half of the epibasal region, probably that derived from the four lower octants-i. e., the four octants that were in contact with the suspensor-develops into the foot, while all of the other organs of the embryo (leaf, stem, and root) arise from the four terminal octants.

Quite early in the development of the embryo, there appears the same centrally placed large, cell which we have observed in the embryos of the other genera and which, as we have seen, probably represents the primary stem initial. Brebner concluded that a single initial was present in the stem of $D$. simplicifolia and this is true of the three species examined by me. The initial of the stem in Dana a becomes
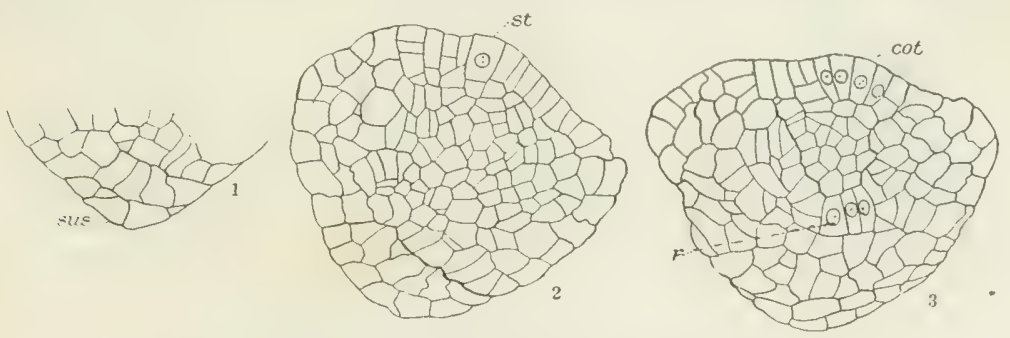

Fir. 117.-D. dliprica.

Three sections of a large embryo. Xr 50 . sus, suspensor; sl, stem apex; col, cotyledon; $r$, root initial.

very easily seen in the older stages and is perhaps more clearly defined than it is in any other of the Marattiacece. Whether or not this cell can be traced.back to one of the original terminal octant cells is difficult to say, but it is quite possible.

No single initial could be made out for the cotyledon, and it seems quite likely that the position of the cotyledon is not always exactly the same, being determined perhaps by the position of the embryo with reference to the light or to some other factor. The cotyledon, as in Maratia and Angiopteris, first appears as a slight prominence close to the nearly centrally placed stem apex, and there is soon visible 
a gente of acrivedy dividing cells which constitute its growing point, bus no one of these can le certainly named as the apical cell (fig. 117, 3). The embryo now rapidly increases in breadth until the apex is almost flat, except for the slight projecrion in the center, where are situated the stem apex and the young cotyledon. The whole embryo at this stage may be described as "top-shaped." The stem and coryledon occupy a comparatively small pertion of this broad terminal area and are surmunded by a ring of large absorbent cells, physiologically, at least, belonging to the foot and merging insensibly into the similar cells which make up the lower half of the embryo.

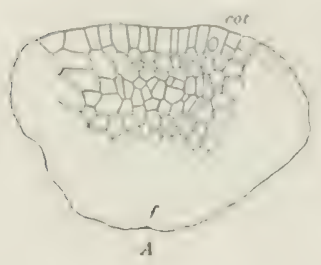

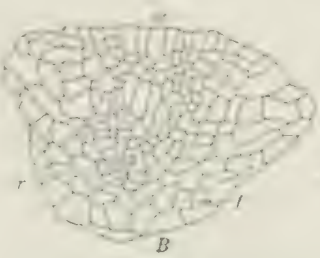

Kig. $118,-D$. jamaicensis.

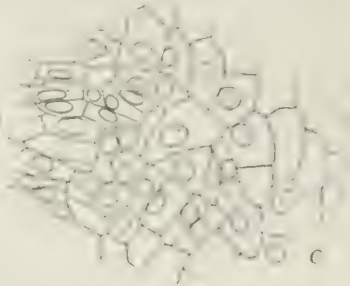

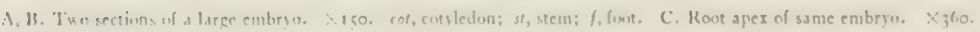

As in the other Maratiacede, the very young enbryo shows no trace at all of the root and this appears only after the embryo has reached a comparatively large size. The origin of the root is exactly the same as in the other genera and it is a strictly endogenous structure. The single initial cell arises deep down in the tissue of the embryo, usually below the cotyledon and probably from the same octant as that from which the cotyledon is formed, but owing to the displacement of the original division walls this can not be determined positively and it may be that the position of the root is not always exactly the same. The apical cell of the root soon

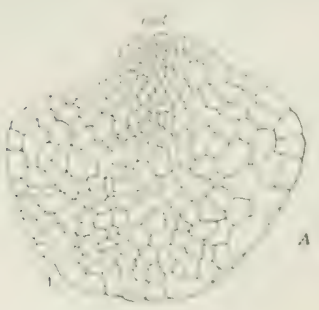

$A$

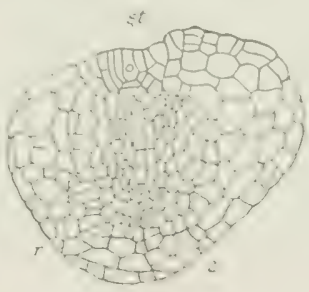

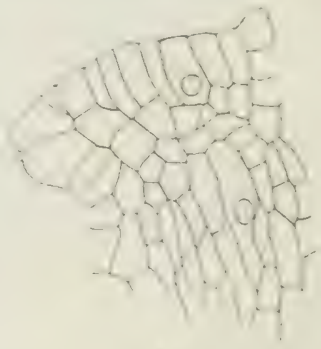

li:

litt. 31\%.-1), jamairensis.

1. Twe sections of an advanced embryn. X100. 13. Stem apex of the same embryo. $\backslash 220$.

becomes conspicuous, but it does not usually show the triangular form as seen in a longitudinal section, but appears more nearly square, as in Maratio. This root initial cell is quite variable in form, but more commonly it appears in longitudinal section with a truncate base (fig. I17,r). In transverse section it approaches the triangular form, but is more or less irregular in outline. The lateral segments cut off from the initial cell are large and contribute later to the root cap as well as to the inner root tissues, and it is not impossible (as Farmer believes to be the case also 
in Angiopteris) that sometimes more than one of these terminal cells function as the apical cell.

As soon as the root apex is established its growth is very rapid and, as in the other genera, there is a rapid elongation of the whole embryo, whose vertical diameter very soon becomes greater than the transverse diameter, and ultimately the whole embryo becomes very much elongated. In the axial region of the embryo just below the stem apex there is a marked elongation of the central cells which might at first sight be taken to represent the central vascular cylinder, but these elongated cells do not give rise to vascular elements, but remain as elongated parenchyma and belong really to the pith. The part of the foot which lies below the growing root apex acts as a very massive root cap and is pushed down with the growth of the root until the latter emerges from the lower side of the prothallium. The cotyledon in the meantime grows actively upward and finally penetrates the prothallium, emerging
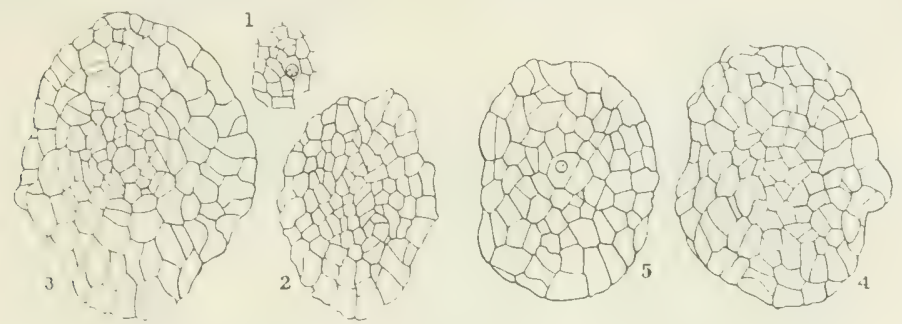

1iv. 120.-1), jamaicensis.

Five of a series ff transverse sections from an advanced embryo. X200. I passes through stem apex; 5 shows apex of runt .

on the upper side. The growth of the stem is slight and the cotyledon and root form nearly a straight line, as in the other Marattiacex and in Ophioglossum, so that the young sporophyte may be described as bipolar. The equatorial region is surrounded by the large absorbent cells in contact with the prothallium and all of these may be said to function as the foot, although it is impossible to say how much of this tissue is derived from the original foot.

\section{THE ANATOMY AND HISTOLOGY OF THE YOUNG SPOROPHYTE.}

The young sporophyte, at the time the root emerges from the prothallium, is very much alike in all of the genera (figs. I08, III, I2I). The cotyledon at this stage is a thick, conical protuberance, strongly curved inward over the stem apex, owing to the more rapid growth upon its outer side. Close to its base lies the very limited growing region of the stem, adjacent to which is the rudiment of the second leaf, which at this time projects very slightly above the level of the stem apex. The cells of the latter, and also those of the young leaves, are evidently actively growing cells with conspicuous nuclei and are quite different in appearance from the large, transparent cells that compose the enlarged mid-region of the young sporophyte. This is largely made up of the original tissue of the foot, but this tissue merges insensibly into the basal region of the cotyledon and the upper part of the root, these two organs forming in their growth almost a straight line. Whether or not we term this middle region of the young plant the "stem," it must be borne in mind that it does not arise from the activity of the extremely limited meristem, forming the true stem apex. The young sporophyte is traversed by a single conspicuous vascular bundle which extends through the cotyledon and root without inter- 
rupeion, and it is quite impossible to say just exactly where the point of junction is. In Angiopteris elongated tamnin cells, which stain very strongly, accompany the vascular bundle, both in the root and cotyledon; but these are cither entirely wanting or but slightly developed in Marattia and are quite absent from the young sporophyte at this stage in the other genera. In the relation of the primary root and leaf, therefore, the embryo of the young sporophyte in the Maratiacea shows a most strikin. resemblance to the condition found in Ophioglossum molucianum. The cotyledon, as in Ophioglossum, is not to be looked upon as an appendage of the stem, but as an organ sut generss.

Almost as soon as the second leaf is recognizable, there is evident, connecting it with the primary vascular strand, a short group of procambium cells, and the stem apex is seen to occupy the space between these two leaf traces. No procambium is developed in the stem above the junction of the leaf traces, but the inner cells, derived from the apical meristem, contribute solely to the medullary tissue of the sporophyte (fig. $12 \mathrm{I}, d$ ).
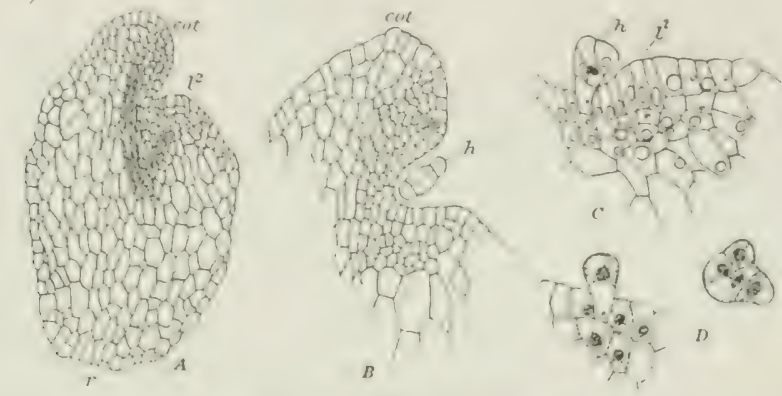

Firi. 121,-Daniea jamaicensis.

A. Large embryo. col, cotyledon: $l^{2}$, second leaf. $\times 50$.

13. Median section of cotyledon; $h$, cpidermal scale. X95.

C. Second leaf. $\times 150$.

D. Trichomes from apical region.

The first tracheary tissue arises in the mid-region of the young sporophyte and consists of a group of short reticulate tracheids. From this point the development of the tracheary tissue proceeds upward into the cotyledon and downward into the root. The single strand of tracheary tissue in the cotyledon is seen to be continuous with one of the xylem masses of the diarch root. The second xylem of the root arises somewhat later and is connected with the xylem of the second leaf. This second xylem mass is decidedly smaller than the first one, at least in $D$ anca, where I have studied this point carefully, and an examination of the other genera points to a similar inequality in the xylems of these as well, but this may not always be the case.

THF COTYLEDOX.

The cotyledon at a very early period bends strongly over the stem apex, very much as it does in Botrychium virginianum, and very soon afterwards begins to Hatten out, so as to indicate the separation of the lamina from the petiole. The Hattening of the apex is followed, in many cases at least, by a true dichotomy, which is soon repeated, so that the lamina becomes fan-shaped, with a strictly dichotomous venation (fig. $87, G, H$; fig. 127 ). This shows especially well in Marattia douglasii. In $M$. sambucina (fig. $87, C$ ) the cotyledon is more nearly orbicular than in $M$. douglasii, but the venation indicates a similar carly dichotomy of the apex.

In Angioptcris, the form of the cotyledon is extremely variable (fig. 124). Farmer states that it has a distinct midrib extending to the apex of the cotyledon 
and that the secondary veins are pinnately arranged with reference to the midrib. These later veins, however, may show dichotomous branching. I made an examination of a considerable number of young sporophytes collected at the same place where Professor Farmer secured his specimens, but very few of the plants that I collected showed this pinnate venation in the cotyledon, although it is usually conspicuous

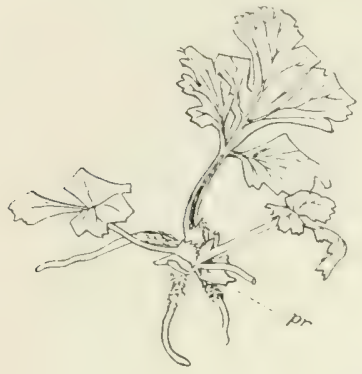

FiG. 122 .

Young sporophyte of Maratio douglasii still attached to the gametophyte, pr; Natural size.

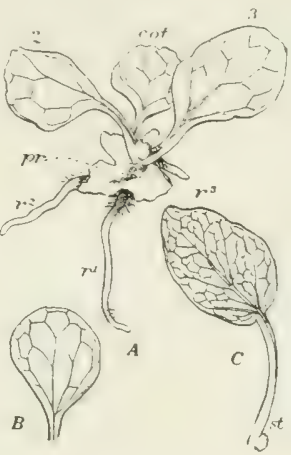

FiG. 123.

A. Young sporophyte of Koulfussio attached to gametophyte, $p r . \times 2$.

B. Cotyledon from another plant. $\times 2$.

C. Alater leaf; st, stipule. $X_{1}$.

in the second leaf. Figure $124, C$, shows drawings of a number of the forms from my collection, showing the variation from a strictly pinnate to a perfectly dichotomous venation. Many of them show an intermediate venation, but with very few exceptions, even where a midrib was present, this was forked at the apex, indicating
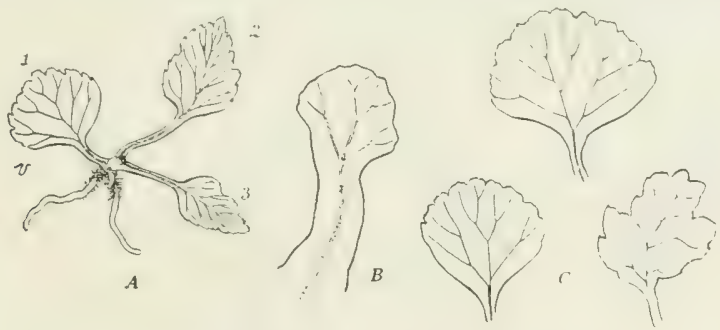

Fig. 124

A. Young spotophyte of Angiopteris, with three leaves. 1 , the cotyledon. $x_{2}$

B. Young cotyledon. $\times 20$.

C. Three cotyledons, showing the variation in form. $x_{3}$.

that there had been an early dichotomy. This primary dichotomy of the apex was well shown in a section through a very young leaf (fig. $112, B$ ) where there was no question that such a dichotomy was taking place.

In Dance a there is much the same variation in the form of the cotyledon as in Angiopteris. Brebner's figures of $D$. simplicifolia show that the cotyledon in this species has a midrib with two lateral veins near the base, but sometimes the midrib forks at the summit, indicating again the early dichotomy of the cotyledon. In one 
of his figures, where there is no forking of the mid-vein, the lateral veins seem to follow the margin of the leaf and rejoin the central vein, thus inclosing two large atcoles like ehose found in she cotyledon of $K$ aulfussia; no mention of this, however. is made in the text. D. jumationsis (fig. $125, A$ ) shows a very similar form and vena-
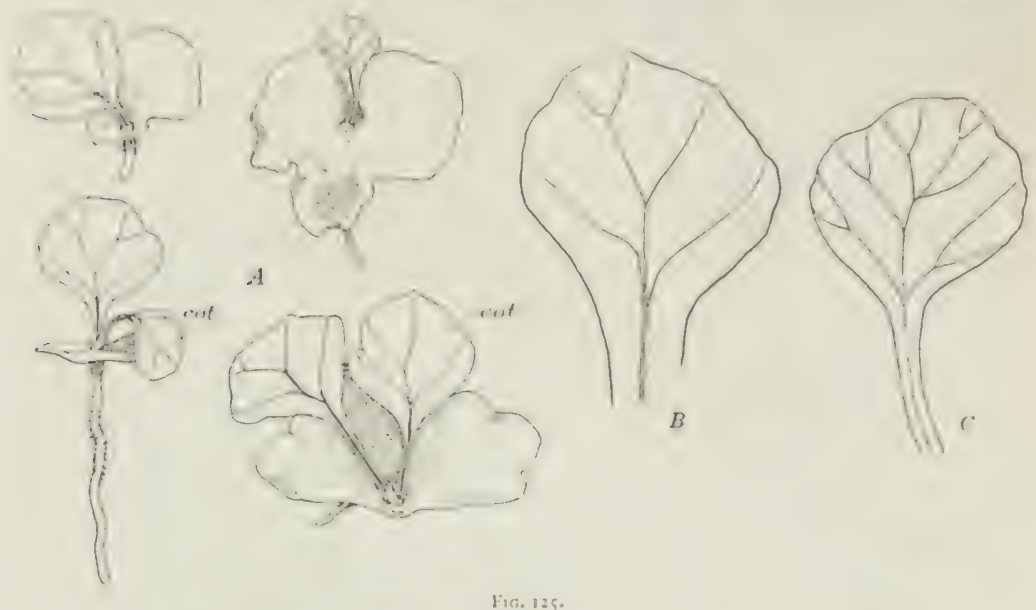

A. Four young sporophytes still attaclied to the gametoplaste of Datrits jamaticensis. $\therefore 2$

B. Young cotyledon of D. elliprica. $\times 15$.

C. An older cotyledon of D. ellipica. $\times 3.5$.

tion, but the cotyledon is larger and there is sometimes a forking of the lateral veins. In this species also there may sometimes be found a fan-shaped lamina with true dichotomous venation like that of Marnttia, but as I had little material of this species I can not say how common this form is. It is probable that an examination

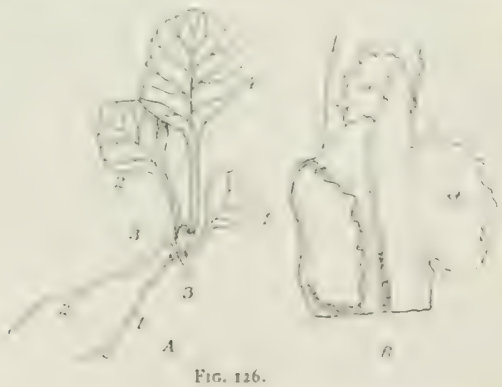

A. Yousg sporophyee of $l$ ). jamaicensis, with four leates, stighily enlarged. 1, the cotyledon.

B. Base of the fourth leaf, showing stipules, $s t$, and peleate seale, sc. $\times 20$.

of a large series of young plants would show examples of the same type of cotyledon as in the other species. The cotyledon of D. clliptica (fig. $125, B, C$ ) is of much the same form as that of $D$. jamaicensis, but the cotyledon is larger as a rule and the venation may be more complex, although conforming to the same general type. 
The cotyledon in Kanlfussia (fig. 123) is spatulate in form and not unlike that of Dancea in shape and also closely resembles in outline the broader leaf forms of Ophioglossum moluccanum. The resemblance to the latter is much increased by the venation, which is reticulate and extraordinarily like that of the cotyledon of Ophioglossum. As in Ophioglossum, there is usually a mid-vein, but this is not, however, noticeably thicker than the laterals. The latter, instead of extending free to the edge of the leaf, are connected at their distal ends with the mid-vein so as to inclose more or less elongated areoles. The central vein does not extend to the tip but, as in Danca, divides into equal branches which join above so as to inclose

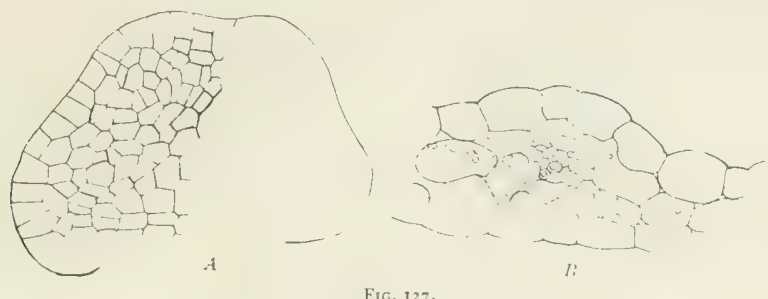

A. Lamina of young cotyledon of Marattia douglasii. $\times 260$.

B. Section of lamina of cotyledon. $\times 300$.

a terminal areole. A careful examination of the secondary veins shows that their divisions are really dichotomous, as in the lateral veins of the other Marattiacex. and some of the ultimate branches may reach the margin of the leaf, or more rarely they may end freely within the areoles.

As the cotyledon develops there is more or less elongation of the petiole, which, however, very seldom exceeds the lamina in length. The petiole is usually more or less deeply channeled upon its inner face. In Marattia douglasii (fig. 133) the base of the cotyledon is much enlarged just above the level of the stem apex, which is
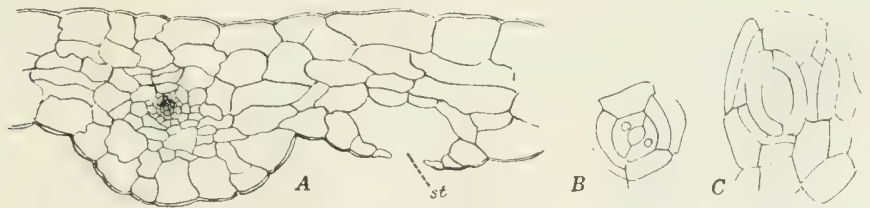

Fig. 128 .

A. Section of lamina of cotyledon of Kaulfussia, traversing one of the large stomata, st. Xioo.

B. A young stoma.

C. An older one.

thus almost inclosed in a sort of cleft in the base of the cotyledon, very much as it is in the case of Botrychium or Helminthostachys. In Angiopteris there is but slight contraction at the base and the stem apex forms a strongly oblique surface, hardly covered at all by the base of the cotyledon. The base of the cotyledon is still more conspicuously hollowed out in Dancea and especially in Kaulfussia (figs. 136, 137), and in the latter there is a circular ridge completely surrounding the stem apex, exactly as is the case in the young bud in Ophioglossum moluccanum. Traces of this ridge can be seen also in Danca and Marattia, but this is much less conspicuous than in Kaulfussia. In the latter this cavity is especially marked, so that one might almost speak of a stipular sheath, and this resemblance to Ophioglossum in the 
retation of the leaf base and stem apex, especially in connection with the Ophioglossum-like venation in $K$ caulfussion, is not without significance in its bearing upon a possible relationship between the Marattiacese and the Ophioglossacese.

In all of the genera the lower part of the cotyledon and sometimes the stem apex are more or less covered with hairs and scales. These are less abundant in Marattia and Angiopecris, where they are, for the most part, short hairs whose terminal cells contain a great deal of tannin and stain very strongly. In Kaulfussia, and especially in Dance, conspicuous scales of peculiar form are abundant.

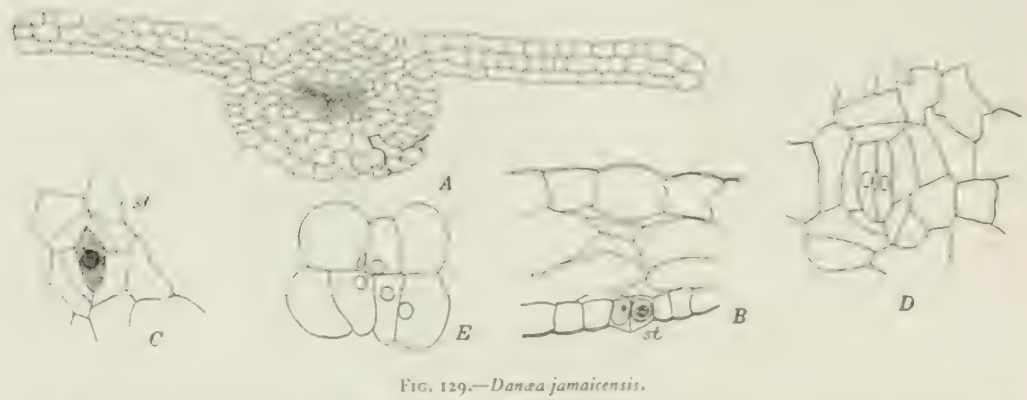
A. Section near base of lamina of cotyledon.
D. An older stoma. $\times 200$.
B. Part of the lamina. st, stoma. $\times 200$.
E. Cross-section of a peltate scale, from young cotyledon. $\times 200$.
C. Young stoms.

In Marattia douglasii the nearly cylindrical petiole is somewhat channeled on its inner side and the single and nearly centrally placed vascular bundle appears almost circular in section. The xylem forms a somewhat crescent-shaped body', completely' inclosed by the phloem, but the phloem is less developed upon the inner side and the bundle closely approaches the collateral type. Tannin cells occur, but are not so conspicuous as they are in Angiopteris. The lamina of the cotyledon is similar in structure to that of the latter, the leaves differing mainly in the much smaller development of the mesophyll, which is often reduced to a single layer of cells (fig.

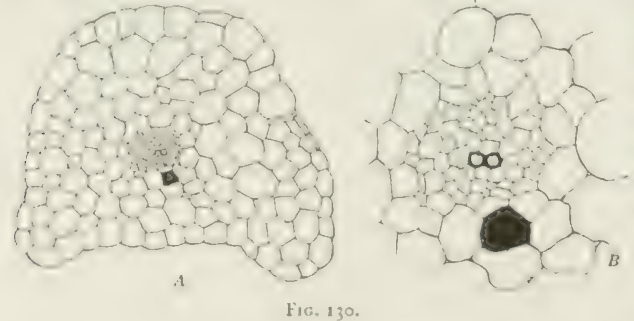

A. Section of petiole of cotyledton of Angioperis. $\times 95$.

13. Vascular bundle. $>200$. The shaded cell is a tannin sac. $127, B)$. The smaller veins have the xylem reduced to a fewone to three-small tracheids situated upon the upper side of the bundles, so that the bundles are strictly collateral. Stomata of the ordinary form occur upon the lower surface of the leaf and these sometimes show a series of concentrically arranged cells about them.

The periole of the cotyledon in Angiopteris resembles in section that of Marattia, but it is slightly winged (fig. 130), and the tannin cells adjacent to the vascular bundle are more conspicuous than in M/aratia.

In Kaulfussia (fig. 137,C), where the petiole is stouter than in the other genera. the section is more nearly circular than in Angiopteris, but it is also slightly winged. these wings being developed almost to the proportions of stipules at the contracted 
basal portion. The vascular bundle has a greater development of xylem than in the other genera and the xylem forms a band of considerable extent in the oval section of the bundle. The structure of the bundle is concentric, but, as in other cases, the phloem is better developed upon the outer side. Below the free base of the cotyledon, where the trace enters the stem, there is a reduction of the inner phloem, or the inner phloem entirely disappears, and the bundle there becomes truly collateral. No definite endodermis can be recognized and the tannin cells found in the cotyledon of Angiopteris are quite absent.

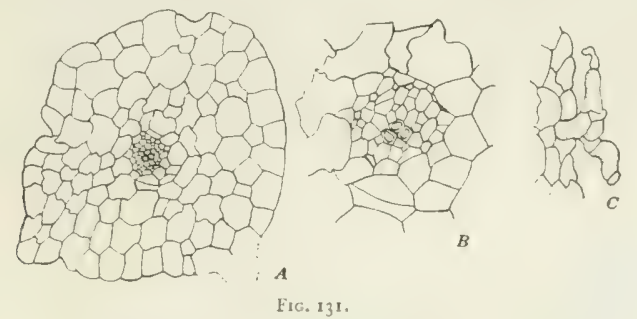

\footnotetext{
A. Section of petiole of cotyledon of Dansa elliprica. $\times 75$.

B. The vascular bundle. $\times 200$.

C. Section of a peltate scale. $\times 75$.
}

The section of the petiole of the cotyledon in Danca (fig. I3I) is nearly circular, and the wings found in the other forms are almost entirely obliterated. The ground tissue is composed of undifferentiated parenchyma, with no trace of tannin cells. The vascular bundle is circular in outline, with a small group of three or four tracheids placed somewhat toward the inner side of the bundle, but separated from the outside by about two rows of cells, probably phloem, but not showing any differentiation. Small protophloem elements, staining darkly, can be seen upon the dorsal side of the bundle and an occasional similar cell can be

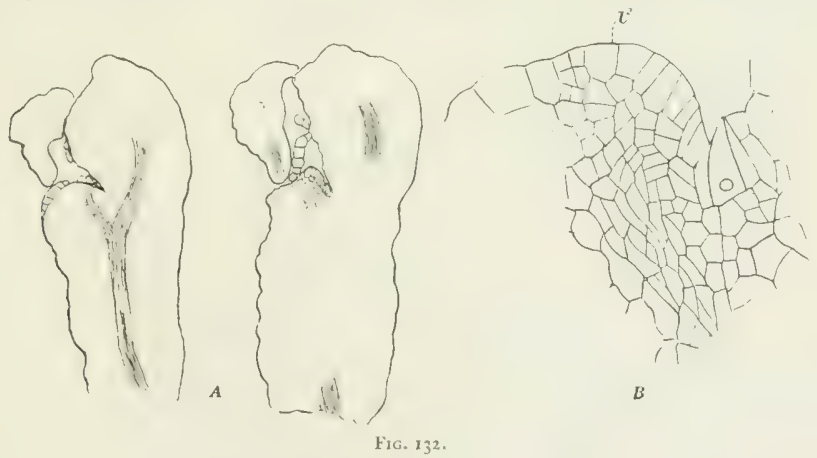

A. Two longitudinal sections of a somewhat older sporophyte of $M$, douglasii.

B. Apical region of stem, showing apical cell and second leat, $l^{2} . \times 200$.

seen toward the ventral side, but most of the ventral surface is destitute of these. The petiole broadens at its base, becoming flattened, and in this region the inner phloem disappears and the bundle becomes collateral, as it is in Ophioglossum. The tracheary tissue of the cotyledon in all of the Marattiacex is composed of slender, reticulately marked tracheids, like those of Ophioglossum. Sieve tubes are prob- 
ably presene in the phloem, bue in material mounted in Canada balsam the sieve eubes are very poorly differentiated.

Upon the cotyledon as well as upon the later leaves in Danaa very characteristic peltate scales are developed. These arise as single club-shaped cells, the swollen end of which is cut off by a cross wall. In the upper cell, which broadens rapidly, a series of vertical walls arises, sometimes arranged very regularly (fig. $129, E)$. In the case figured there had evidently been two median, intersecting walls, so that the cells were arranged in a somewhat quadrant fashion; more commonly the divisions are less regular and the cells increase considerably in size by further divisions. A section of an older scale may be seen in fig. 131, C. Stomata are developed upon the lower surface of the cotyledon in all of the Maratiacea. These have already been referred to in the case of Marattia, and in Angiopteris they are very similar to those found in Marattia. In Danca, previous to the formation of the stoma, there are several preliminary divisions, the cells being cut
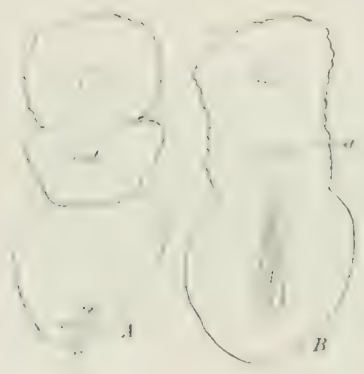

Fic. I33.
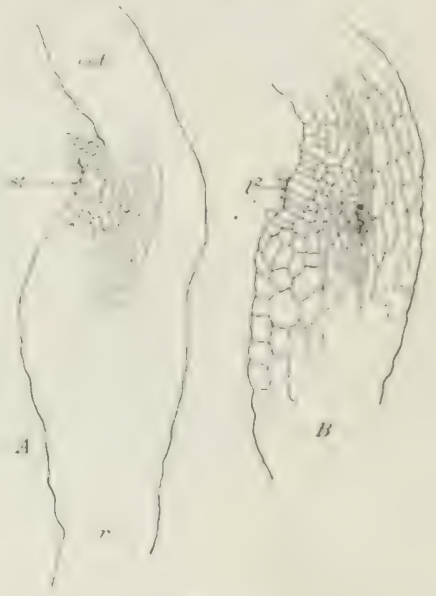

Fic. 134 .

Two nearly median sections of a young sporophyte of Ingiopieris. cot, cotyledon; $s t$, siem apes. $l^{2}$, second leaf. X75. The bundles of the cotyledon and primary romt are continuous.

off in a spiral fashion, the last division resulting in the formation of the mother cell of the stoma (fig. $129, C$ ). The complete stoma appears, therefore, surrounded by a series of somewhat concentrically arranged accessory cells (fig. $129, D$ ). Similar accessory cells, but much less developed, can be recognized in Maratiia also.

The stomata of $K$ aulfussia have long been known for their great size and the fact that they form permanently open pores, a peculiarity already developed in the stomata of the cotyledon. These are very much larger than those of the other genera and can be readily recognized by the naked eye as little dots. The guard cells become very large (fig. 128 ) and strongly curved, so that the stoma appears almost circular in outline, with a very large permanently open central pore. This large pore is surrounded by concentrically arranged series of cells, suggesting that the mother cell of the stoma is cut off very much as in Danas, but material was wanting for a thorough investigation of this point. 
THE STEM OF THE YOUNG SPOROPHYTE.

The stem apex projects very little or not at all, and occupies but a limited area close to the base of the cotyledon. Its outer surface is nearly horizontal, except in Angiopteris, where it is generally strongly inclined (fig. 134). There probably is always a single apical cell. Segments are cut off from the sides, and very often also inner segments, where the base of the apical cell is truncate. The lateral segments also have, cut off from their inner faces, cells which contribute to the growth in length of the stem, which remains, however, very short in the young sporophyte, the leaves being very much crowded together. As we have already stated, no central cylinder properly belonging to the stem can be demonstrated at this time, all of the procambial
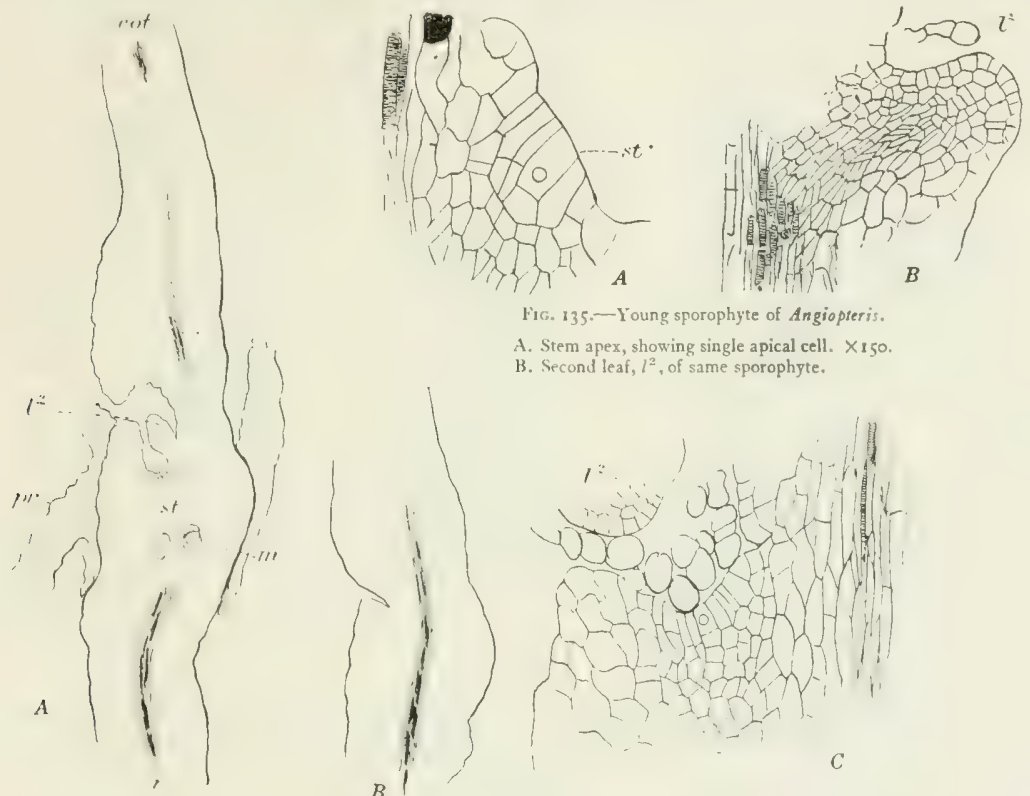

Fig. 135.- Young sporophyte of Angiopleris.

A. Stem apex, showing single apical cell. $\times \$ 50$. B. Second leaf, $l^{2}$, of same sporophyte.

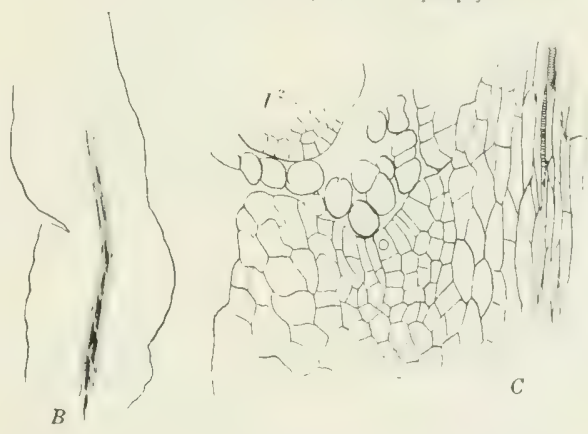

Fig. 136 .

A. Nearly median section of a young sporophyte of $K$ aulfussia. $1^{2}$, second leaf; $m$, mucilage ducts; $s t$, stem apex; $p r$, gametophyte. $X$ about 20 .

B. Another section of same, showing continuity of bundles of cotyledon and root.

C. The stem apex.

tissue belonging either to the cotyledon or to the root. In the older embryo of Marattia douglasii the apex of the stem (fig. 139, B) is occupied by a group of relatively large cells, which at first sight seem to be pretty much alike; but a careful examination of these makes it probable that one of them may be considered as the real initial cell. This, in cross-section, appears almost square and shows a fairly regular segmentation. While it must be said that the segmentation is not so regular that one can assert without question that all of the meristem is really due to the activity of a single cell, I believe that this is probably the case.

My own investigations of the stem apex in Angiopteris have led to the conclusion that there is a single initial cell here also in the young sporophyte, although Farmer 
in his earlier studies of this plant failed to find a single initial cell; however, in a more recent paper (Farmer 3 ) he has decided that a single apical cell is present in the young sporophyee of Angiopteris, and he gives figures of this. In longitudinal section (fig. 13t) the apical cell appears oblong, with a markedly truncate base, white in transverse section it is imperfectly triangular in outline. The apical cell of the stem in Kunlfussia (fig. $136, C$ ) is usually somewhat broader than it is in Angiopteris, and closely resembles that of Oplioglossum moluccanum. It has a broadly truncate base and is somewhat narrowed above. In eransverse section it approaches the triangular outline of the apical cell in (Ophigglossum, but the segmentation is less regular and in this respect it is not unlike that of Angiopteris. The stem apex was examined in three species of Danca, all of which seemed to agree
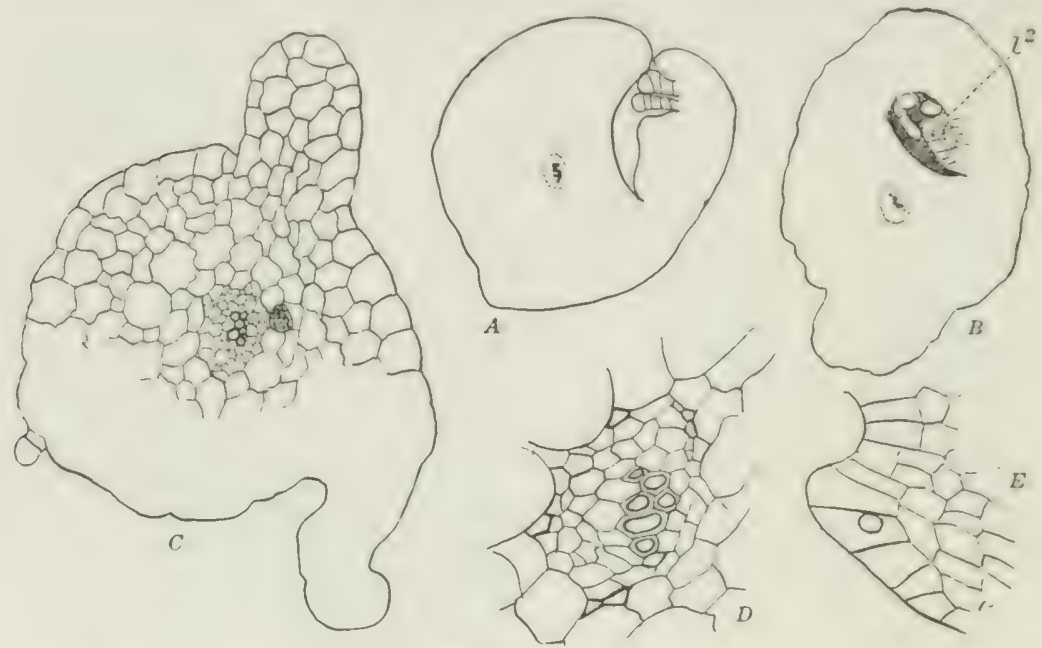

Fic. 137. - Kauifusidi.

A, B. Two transterse sections of a young sporophyte, above level of stem aper, showing closed steath formed by base of cotyledon. $l^{2}$, second leaf. $\times 50$.

C. Transwerse section of petiole of cotyledon. Xyo.

D. Vascular bundle of cotyledon, more enlarged.

E. Second leaf.

closely in the form of the apical cell, which is much more definite in Danca than it is in any of the other genera. Brebner's account and figure of the apical cell in $D$. simplicifolia agree closely with my own preparations of $D$. clliptica, $D$. jenmani, and $D$. jamaicensis.

The apical cell (fig. I $40, A$ ), seen in longitudinal section, is very deep and, unlike that of the other genera, is not usually, at least, truncate below, but pointed, so that it closely resembles in form that of Botrychium or Helminthostachy's. In transverse section it also usually appears triangular, so that it is tetrahedral like that of Botrychium. While the segmentation is somewhat less regular than in Botryclium, nevertheless the limits of the younger segments can be followed without much difficulty, especially in longitudinal sections, although the exact sequence of the divisions in the segments themselves did not seem to be absolutely regular.

In all of the species the tissue derived from the inner cells of the segments of the apical cell, or cut off from the base of the apical cell itself, remains as undifferentiated parenchyma and coneributes only to the central pith of the stem. Lixcept 
that the leaves arise from the segments of the apical cell of the stem, and their tissues are therefore indirectly derived from the stem apex, we may say that the stem apex takes no part in the differentiation of the fibro-vascular system, which in the young sporophyte is composed entirely of the leaf and root traces.

THE ROOT.

Only a small number of sections of the primary root were obtained in Marattia douglasii, and these showed some variation, so that it is not possible to state positively what is the typical form of its apical cell, but there is no question that the primary root grows from a single initial cell, as in the other genera. In longitudinal section it appears oblong, with a broadly truncate base from which segments arise, as well as from the lateral faces. There seem to be regularly four sets of lateral
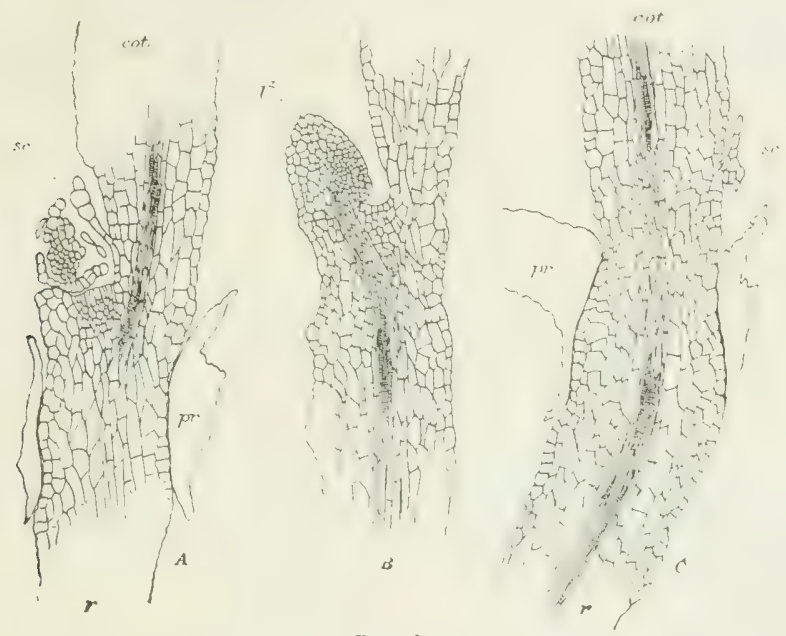

Fic, 138.

\footnotetext{
A. Nearly median section of a young sporophyte of Dansa jamaicensis, passing through stem apex. $X$ about 40 .

B. Another section of same, passing through second leaf, $l^{2}$

C. Section of another similar sporophyte cut at right angles to that shown in A and B, and showing continuity of bundles of cotyledon and primary root. pr, gametophyte; sc, scales.
}

segments, although cross-sections of the apical cell sometimes appear almost triangular. The root cap is formed in part from segments derived from the outer face of the apical cell, in part from similar segments cut off from the outer portion of the youngest lateral segments of the apical cell. The central cylinder of the root is formed in part from the basal segments of the apical cell, but the lateral segments also contribute to it (fig. I 4 I, D).

In Angiopteris (fig. I I I, $C$ ) the apical cell in the earlier stages of the root may appear triangular in longitudinal section, but in the later stages it is usually more or less truncate.

The primary root in Kaulfussia, in the few cases where satisfactory sections were made of it, did not show the tetrahedral apical cell, but this was truncate at the base and in cross-section appeared four-sided (fig. I +2 ). In this respect it seems to approach Marattia. The primary root in all of the Marattiacea is ordinarily diarch; 
the statement (Campledl 3, page If) that in Marattia donglasii the primary root is eetrarch I have found to be based upon a mistake, the root which was so deseribed not being the primary root, but evidently one of the later ones. I have

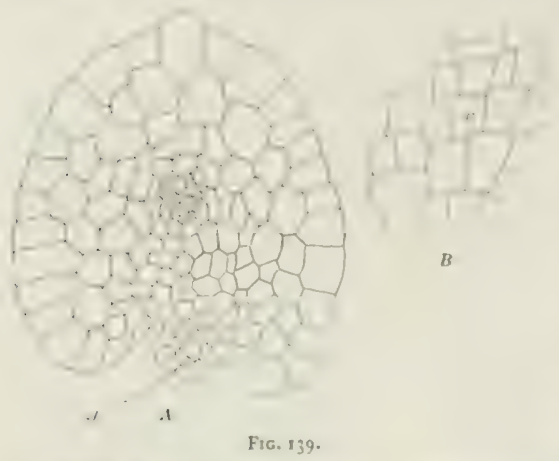

A. Transwerse section of a young sporophyte of Maratria douglasii. st, stem apex. $\times 150$.

13. The stem apex. $\times_{3} 60$. occasionally found very strong plantlets in Danaa, where the primary ront was triarch, as it sometimes is in Botrychium, and very commonly is in Helminthostachys; but such specimens are not common. The root bundle is bounded by a conspicuous endodermis, whose cells show very plainly the characteristic radially thickened bands (figs. $1+3, e n ; 1+4$ ). 'The endodermis gradually loses its definite appearance at the junction of the root and leaf bundles, and 1 have not been able to recognize it above the level of the base of the cotyledon, although it is not at all impossible that with proper staining it might be traced further up.

THE SECONI LEAT,

The second leaf hegins to develop while the cotyledon is still small, and by the time the latter ruptures the overlying prothallium rissue the second leaf is clearly

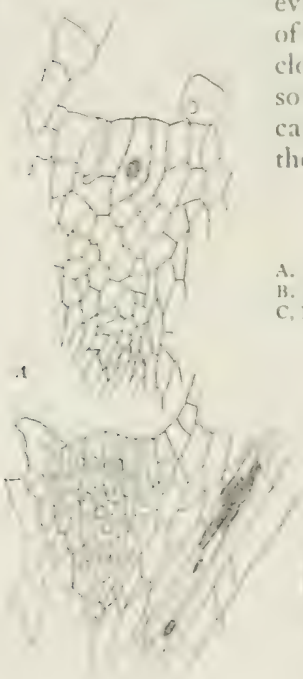

l: evident as a Hattened cone, closely resembling the early stage of the cotyledon. In $K$ aulfussia the second leat arises quite close to the cotyledon and on the same side of the stem apex. so that the dorsiventral character of the stem is already indicated at this early stage of development. In the other genera the second leaf arises nearly opposite the cotyledon, but nor

Fig. If0,

A. Stem apex of a young sporophyte of Damata jamaicensis, showing single apical cell. Xito.

B. Second leaf from same.

C, D. Sections of primary roots, showing apical meristem. X180.
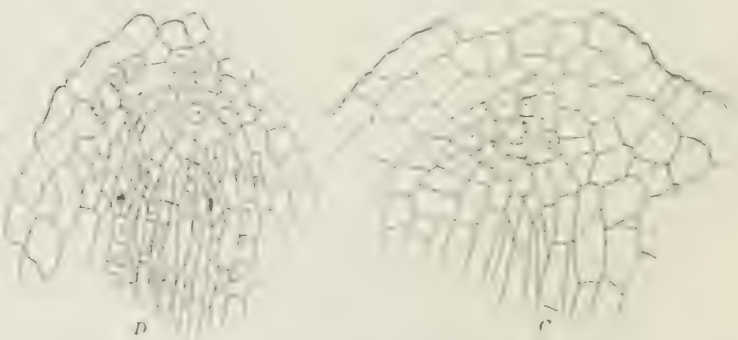

exactly so, and the subsequent leaves form a spiral, and for a time at least, except in Kaulfussia, the anatomy of the shoot is radial. This radial arrangement is retained permanently in Marattia and Angiopteris and also in some species of 
Dance, e. g., D. elliptica; but in D. jenmani and in D. jamaicensis, as well as in most of the other species, the stem finally becomes dorsiventral, as it is from the first in Kaulfussia.

The development of the second leaf is marked by an increased activity in the apical meristem, quite close to the apical cell, and it is clear that the leaf arises from the younger segments, but it is impossible to state exactly what the relation of the young leaf is to the younger segments of the apical cell, or to say whether the whole
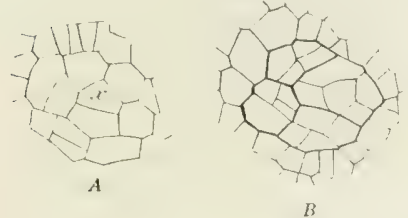

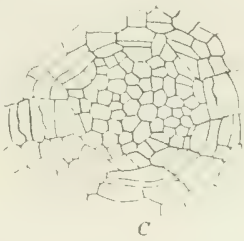

Fic. $1+1$.

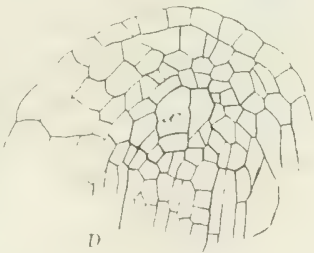

(1)

1-C. Three transverse sections of primary root of Marattia douglasii.

D Longitudinal section of apex of primary root.

of the loaf is the derivative of a single segment. When the young leaf can first be distinguished it is elevated very slightly above the level of the stem apex and its growing point is composed of a group of columnar cells. Sometimes, especially in Danca, there may be recognized near the center of this group of cells a single, somewhat larger one, which may be interpreted as a single apical cell, but this is not always recognizable.
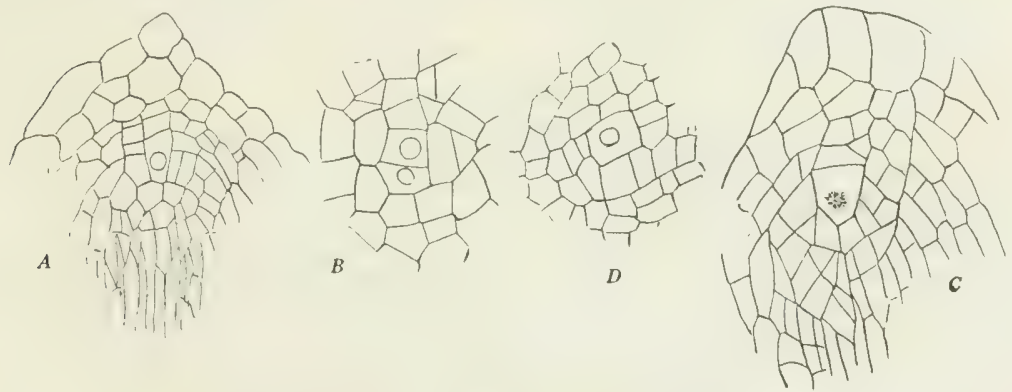

Fisi, 142 .

A, longitudinal, B, transverse, sections of apex of primary root of Kanlfussia. Xzoo

C. Apex of second root.

D Transverse section of root apex.

Even before there is any noticeable projection of the leaf rudiment, there is developed beneath it the beginning of the short strand of procambium which is to form its vascular bundle, and this can be followed downward to a point below the stem apex, where it joins the trace from the cotyledon. Above this junction there is no evidence of procambium tissue extending into the stem apex, but the whole tissue lying between the junction of these two primary vascular bundles and the apical meristem of the stem is made up of undifferentiated parenchyma.

The outer surface of the stem apex may be nearly horizontal or (especially in Angiopteris) it may be strongly inclined and a single fairly conspicuous initial cell 
may usually be recognized witheut dithoulde. This cell is uswally quite deep and in all of the genera execpe Damea has a trumcate hase in longitudinal section. In D) anea, however, the base is usually pointed and the cell clusely resembles the corresponding cell in Botrychiom, or the typical leptesporangiate ferns. The groweh of the stem is usually rather slow and the leaves of the young plant are much crowded.

In all of the forms examined, the tissue derived from the inner cells of the segments and from the basal segments of the apical cell, where such segments were formed, remained as undifferentiated parenchyma and contributed only to the internal pith of the stem. lixcept that the leaves arise from the segments of the apical cell of the stem and all of their tissues are therefore indirectly derived from it. the stem apex of the young sporophyte takes no part at all in the development of the fibrovascular system of the stem, which, except for the bundles of the roots, is entirely composed of the leaf traces.

The second leaf in Angiopteris usually shows a pretty well-defined but slender midvein, which may, however, fork at the apex, and this is true also of the third leaf. It is in the third leaf, both in Marattia and Angiopteris, that the characteristic stipules are first developed. These appear as lateral wing-shaped bodies close to the

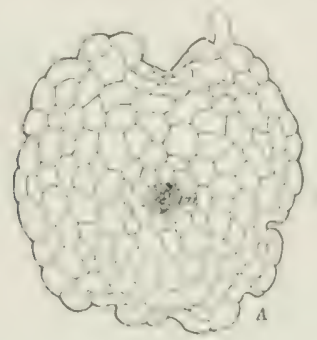

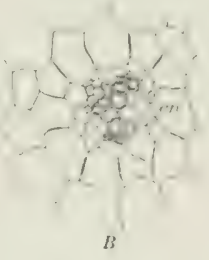

Fig. 143.

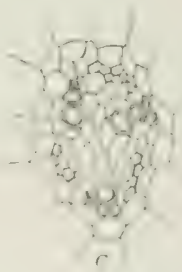

A. Section of primary root of Danaa jamaicensis. $\times 70$.

B. The vascular bundle. Xits. en, endodermis.

C. Triarch bundle from a primary root of $D$, ellifrica.

base of the petiole, partially inclosing the next youngest leaf and the stem apex. The third leaf in Angiopteris and several others succeeding it assume a more and more pronounced lanceolate form with a prominent midrib and pinnately arranged lateral veins which usually fork once. The margin of the leaf is serrate. After several of these lancelate leaves have been developed, leaves are formed in which the base is provided with auricles, and these gradually pass into the next type of leaf, which is ternate, the terminal leaflet being very much larger than the lateral ones (plate 13 , figs. 4, 5). These ternate leaves then pass by intermediate stages into the pinnate form of the leaves of the adult plant.

In Kaulfussia the second and third leaves closely resemble the primary one. except that they are somewhat larger (fig. 123). The second leaf develops wellmarked stipules which are found in all of the later leaves. The earlier leaves do not show a definite midrib, though there is usually a delicate midvein at the base of the lamina, but this vein forks usually about half-way up. In the older leaves (fig. 123. C) there is developed a stout midrib, from which extend distinct pinnately arranged lateral veins, much as in Angiopteris, but these lateral veins are connected by a system of anastomosing veins, so that the leaf most strikingly resembles that of a typical Dicotyledon. It is not until a very late period that the leaves in $K^{\prime}$ aulfussia assume the compound form of the older plant (plate I I, fig. I). 
In Danca a dozen or more leaves may be formed before there is any branching of the lamina. While the cotyledon may show an approach to the pinnate venation of the older leaves, there is almost alivays a dichotomy of the apex of the slender midvein, and this is generally true also for a number of the subsequent leaves, although in these later leaves the midrib becomes well marked and the lateral veins are developed apparently monopodially. In $D$. simplicifolia the leaves remain permanently unbranched, but in all of the other species the later leaves are once pinnate. The intermediate leaves have the ternate form found in Marattia and Angiopteris, and after a few of these, about two or three, have been formed, five foliate leaves appear and the number of leaflets gradually increases, as new leaves are formed, until the full number of leaflets is developed. The early ternate leaves often have the terminal leaflet much larger than the lateral ones, and the leaf
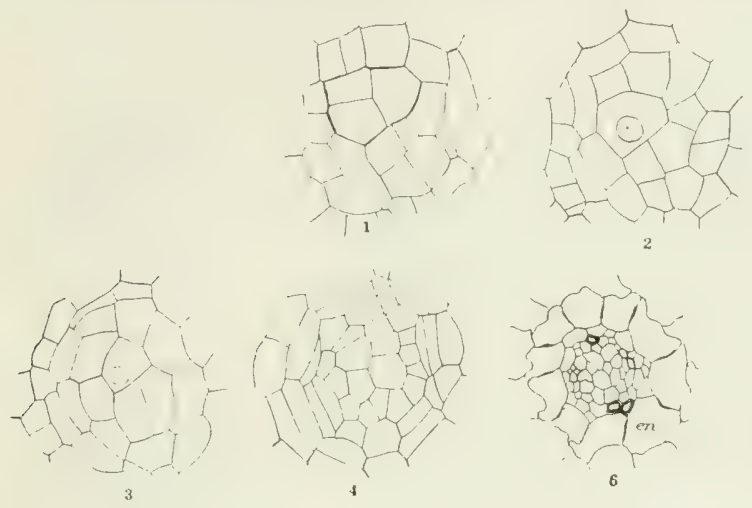

Fig. I44.
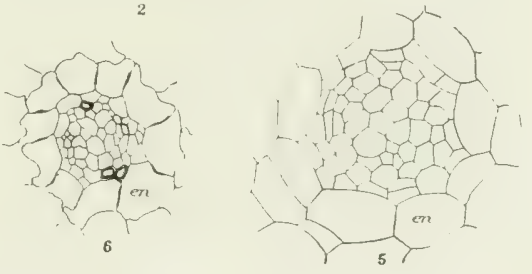

I-5. Transverse sections from a series of a young root of Danca jamaicensis. 2 shows apical cell.

6. Section of bundle frem fully developed primary root. en, endodermis.

closely resembles the corresponding stages in Angiopteris. The petiole in most species is more or less obviously winged. In Danca the stipules are (sometimes, at least) not formed until the fourth leaf. In the fourth leaf (fig. I26, $B$ ), however, they are well developed, appearing as two conspicuous wing-like organs with serrate edges.

In all of the genera there is a root formed for each leaf in the earlier stages of the sporophyte, but how late this continues was not determined. In the older sporophyte more than one root may be formed for each leaf. In Kaulfussia the second root is developed earlier than in the other genera, beginning to develop while the second leaf is still very small, and in general the roots in Kaulfussia seem to develop earlier than in the other genera. The second root is especially late in developing in Danca, the very first rudiment of the root making its appearance between the first and second leaves, after the latter is already quite well advanced. 


\section{TII: (),DIER SP()R(MPIYTI:}

The vascular system of the adule sporophye in the Maratiacea is extremely complex, especially in the larger species of Marattia and Angioperis. In Danca and Kiulfussia it is simpler, but in these also the arrangement of the bundles in the adult stem is by no means easy to trace. A thorough study of the condition in the early stages of the sporophyte is therefore specially important for understanding the much more complex arrangement of the bundles in the older plant.

In view of the conditions that we have found to exist in the ()phioglossaceat, and parricularly the nature of the vascular system in the young sporophyte of Ophioglossum moluccanum, a careful reinvestigation of the developmental history of the vascular system in the young sporophyte of the Marattiacea, especially the simpler and presumably more primitive genera Danca and Kaulfussia, was very much needed. To this end series of sections were made of young sporophytes of both of the latter genera, ranging from individuals in which the second leaf was still undeveloped to those in which a dozen or more leaves had been formed. These series were fairly complete and made it possible to trace quite satisfactorily the evolution of the vascular system in the young sporophyte of both Danca and K'aulfussia. Brebner (Brebner 3 ) has given an accurate account of the distribution of the bundles in the young sporophyte of Dance simplicifolia, which agrees quite closely with the

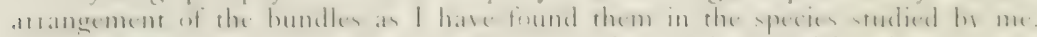
Jeffrey (Jeffrey 3) has described and figured a few specimens of D). alata (?), but his material was too incomplete to make the study at all satisfactory.

The available material of Marattia was much less complete, although a number of stages were secured. Farmer has made an exhaustive study of the vascular system in the young sporophyte of Angioptcris (Farmer $\mathbf{3}$ ), and an extended study of $\mathbf{A n}$ giopteris did not seem necessary, therefore, except for a study of the early stages to determine the origin of the vascular bundles. All of the writers mentioned concerned themselves almost exclusively with the fully developed bundles, beginning their study at the base of the stem and working upward. No attempt was made to follow out the development of the vascular bundles from the meristematic region of the apex and proceeding downward, a method of study which we think would have materially modified the conclusions drawn by these observers in tegard to the relation of the different parts of the vascular system.

In my studies as to the origin of the vascular system in the young sporophyte of the Marattiacex the course of the bundles has been carefully followed in series of microtome sections, passing downward from the apical meristem to the base of the sporophyte, where the axial primary bundle passes into the primary root. These series of transverse sections were then compared carefully with series of longitudinal sections of young plants of approximately the same age, and in this way a clear conception was obtained of the arrangement of the vascular system within the stem of the young sporophyte.

\section{THE IOEFIOPMEN OF THE VASCUIAK SISTHA IN DAN.FA.}

lispecial attention has been given to the development of the vascular system in Danoa and Kaulfussia, as these have received less attention than Marattia and Angiopteris, and moreover are probably more primitive forms whose structures have departed less from the ancestral type than those of either Marattia or Angiopteris.

A longitudinal section of the young sporophyte of Danca jamaicensis at the period when the root is just about to emerge is shown in fig. $121, d$. The root in this species, as in D. simplicifolia, described by Brebner, is the first organ to appear 
outside the prothallium; the cotyledon at this time is still very small and the lamina is scarcely developed. The root apex does not show in the section figured and all that can be seen is the upper portion of its stele, which joins the two young vascular bundles that extend respectively into the cotyledon and the second leaf, which can already be recognized. The greater part of the young sporophyte is made up of large thin-walled cells. Figure I2 I, $B$, shows a median section of the young cotyledon from this same embryo, which is strongly bent over the stem apex. It is possible that the square terminal cell, which in the drawing has the nucleus indicated, is the apical cell of the leaf, but this is not at all certain. The outer part of the cotyledon is made up of large thin-walled cells like those which compose the bulk of the sporophyte, but at its apex there is active cell division, and traversing the young cotyledon and placed somewhat toward its inner side, can be seen the primary vascular bundle, made up of elongated procambium cells. This bundle can be easily followed down into the body of the sporophyte, where, as we have seen, it is
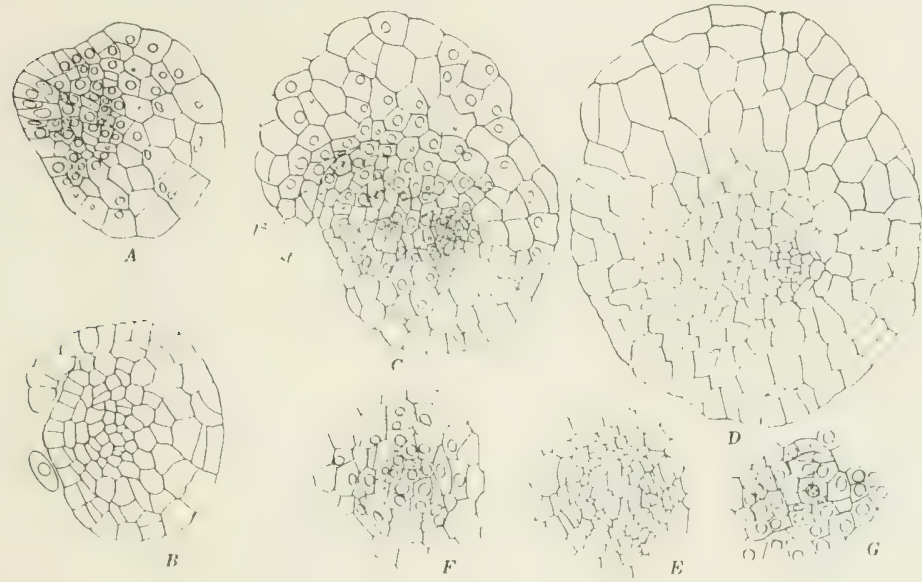

Fig. 145 .

Iranswerse sections of a very young sporophyte of Danca jamaicensis. $X_{150}$.

$A$ shows cotyledon apex; $C$, apices of the stem and second leai; $G$ shows root apex.

continued without interruption into the stele of the primary root. The stem apex, which does not show in the figure, is in a slight depression close to the base of the cotyledon and shows, as usual, a single deep apical cell. Nearly opposite the cotyledon is the beginning of the second leaf $\left(l^{2}\right)$; this is shown in median section in fig. I2I, $B$. The group of narrow columnar cells that compose its apex does not show a recognizable single initial cell. A short distance below its apex, the procambium of its vascular bundle becomes differentiated and is continued downward until it joins the bundle from the cotyledon. The tissue arising above the junction of these two bundles and continuing upward into the apex of the stem is composed of absolutely undifferentiated parenchyma and there is no evidence at all of any stelar tissue in the stem above the junction of these two primary leaf traces; indeed, the stem apex lies decidedly on one side of the plane which traverses the vascular bundles of the two leaves. Fig. I 45 shows a number of cross-sections from a series taken from a large embryo of Danaa jamaicensis, before the emergence of the cotyledon $(A)$, 
whose apex is still undivided. C shows the apices of the stem and second leaf, the former being shown on a larger scale in $G$. The secron of the cotyledonary bundle, lying to the right of the stem apex, is plainly evident in section $C . D$ shows the separated bundles of the cotyledon and very young second leaf, which lower down unite into a single strand.

Whether we can properly speak of a seem at all in connection with the tissues composing the eentral region of the young sperophyte is questionable. It is perfectly evident that this central region is composed partly of tissue belonging to the base of the cotyledon, which is in no sense to be looked upon as an adjunct of the

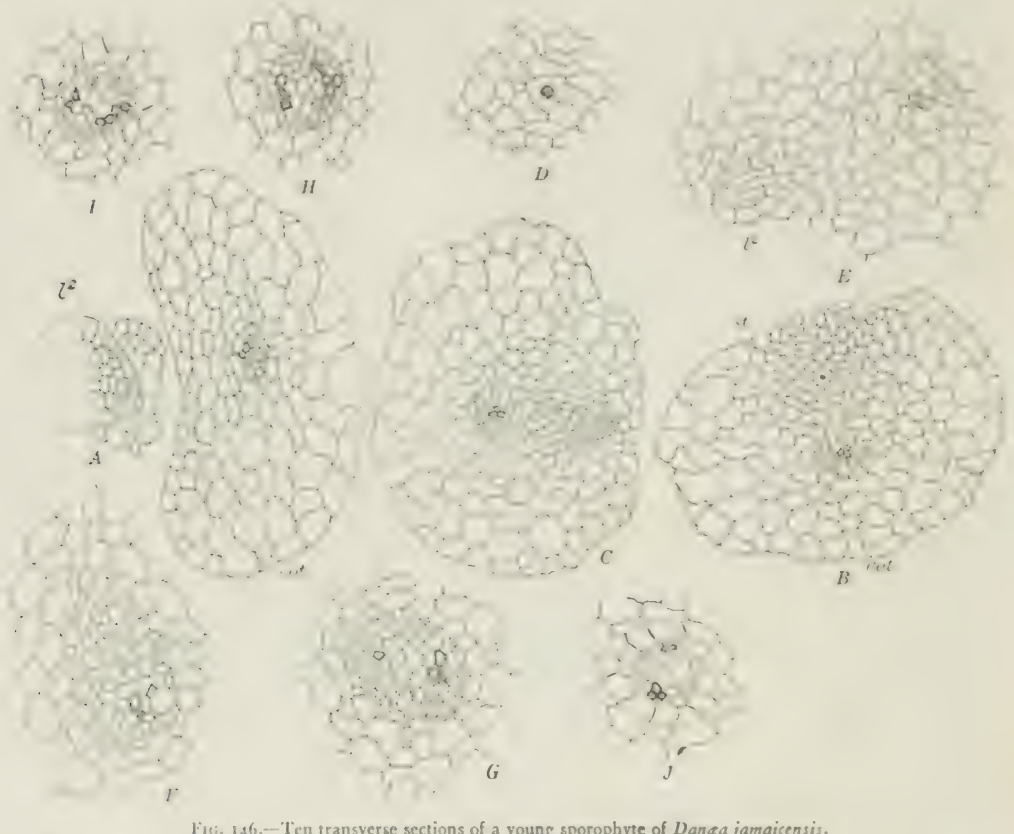

A-C. Three sections near the sem apes, which is shown in $\mathbf{B}$ and more highly magnified in D. Fig. C is teversed in position with reference to $\mathrm{A}$.

E. The central region of $\mathrm{C}$.

F-J. Show the condition of the vascular strand in the lower region of the sporophyte.

H, I. Are in the transition region.

J. Shows the root stelc. $\times 200$.

stem, and partly of the root base; the two structures, i. e., the bases of the root and the cotyledon, merge insensibly into each other. 'To this tissue, derived from the root and the cotyledon, must be added a large amount of superficial tissue derived originally from the foot of the cmbryo. In speaking of the axis of the young sporophyte as a "stem" it must therefore be borne in mind that this stem is really a composite structure, partly leaf, partly root, and partly foot.

Fig. $138, A$ and $B$, shows two longitudinal sections of an older stage after the emergence of the cotyledon. A passes through the stem apex and it is evident that there is no vascular bundle extending into the stem. The tracheary tissue is now well developed in the leaf trace. B shows the trace from the second leaf at its point of junction with the bundle from the cotyledon. In fir. $138, C$ is a similar 
stage to that shown in $A$, but cut at right angles to it, so as to show the continuity of the bundles of the cotyledon and primary root, which together constitute the primary axial vascular bundle of the sporophyte, as they do in Ophioglossum moluccanum. The similarity of such a section as that figured to the similar stage in $O$. moluccanum is sufficiently obvious. The stem apex is shown in fig. I $40, A$, and the rudiment of the second leaf is shown in fig. $140, B$.

Figure 146 shows ten transverse sections from a series made from a young sporophyte of $D$. jamaicensis of almost exactly the same age as that shown in fig. $138, B$. $\mathcal{A}$ is cut above the level of the stem apex and passes through the cotyledon and apex of the second leaf. The arrangement of the cells at the apex of the latter suggests the possibility of a single apical cell. The base of the petiole of the cotyledon is much Hattened and is made up of large, thin-walled parenchyma with no traces of tannin cells or mucilage ducts. The vascular bundle is oval in outline and decidedly collateral in structure. There is no recognizable endodermis, and I shall not attempt to say whether the cells immediately surrounding the bundle should be sproken of as endodermis or pericycle. Except for two small tracheids on the inner side of the bundle the vascular bundle is composed of delicate tissue, apparently parenchyma, but some of the larger elements undoubtedly represent sieve tubes. Brebner states that the sieve tubes in D. simplicifolia (Brebner 3, page 524) do not show clearly in sections mounted in Canada balsam, but when examined in other media they show thick, glistening walls and pitted areas. This point was not further examined in the species under consideration, but would probably agree with the observations made by Brebner upon $D$. simplicifolia.

Section $B$ passes through the stem apex, whose apical cell is shown on a larger scalc in $D$. The cotyledon trace in this section shows three tracheids. In $D$ the section is made a short distance below the stem apex and shows the second leaf trace bending in to join the trace from the cotyledon. The central part of the section is shown more enlarged in $E$, and it is perfectly clear that the region immediately below the apex and lying between two leaf bases shows nothing which can be interpreted as a cauline stele. $F$ and $G$ show sections taken still further down, illustrating the coalescence of the two leaf traces to form the single axial stele. In $G$ there is seen the first tracheid belonging to the leaf trace from the second leaf, and in $H$ the central bundle is complete and there are seen the two xylem masses corresponding respectively to the two leaf traces. One of these, belonging to the primary leaf trace, is more developed than the other one. The larger xylem mass in this case had five tracheids and the smaller one three. $I$ and $J$ are transitional stages between the bundle of the cotyledon and the root, and, proceeding downward, the bundle becomes somewhat smaller and there is a reduction in the number of tracheids, which, however, are plainly seen to be continuous in their development with the two xylem masses in the central bundle of the stem, formed by the junction of the two primary leaf traces, which maintain their identity until they merge into the two xylem masses of the diarch root. Within the root itself the endodermis surrounding the bundle is very conspicuous. The cells making up the endodermis are of large size and the characteristic markings upon their radial walls are very easily seen. The limits of the endodermis become much less clear in the transitional region, and higher up it is difficult to make out a clearly defined endodermis. Brebner figures a very irregular endodermis in the stem of $D$. simplicifoliu, and perhaps we may assume that a proper endodermis is present also in the young stem of $D$. jamaicensis, but it is certainly very inconspicuous, to say the least, in the central region of the young sporophyte, in strong contrast to the very conspicuous endodermis in the root. Farmer (Farmer 3 ) was able by treatment with sulphuric acid 
to demonstrate an extemal endodermis in the stem bundles of Angioperis, Marattia,

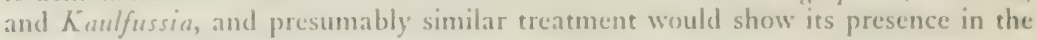
young stem of Danaca.

It is evident that we can not speak of the young sporophyte in Dance jamaicensis as possessing in its early stage a "protostele," or "haplostcle," to use Brebner's terminology, unless we choose to call the single leaf trace of the cotyledon a protostele. Just so soon as the two first leaf traces unite, the axial vascular bundle of the young sporophyte has ewo quite independent xylems.

Figure $1+7$ is a longitudinal section of a sporophyte of D. alliptica, slightly older than that of $D$. jamaicensis shown in fig. 138 . The second leaf $\left(l^{2}\right)$ had already. begun to develop the lamina, whose apex was forked so that there were two veins present. A longitudinal section of one of the two leaf lobes is shown in $D$. The stem apex closely resembles that of $D$. jamaicensis, the apical cell having much the same form and size. The stem apex does not lie in the same plane as the leaf traces

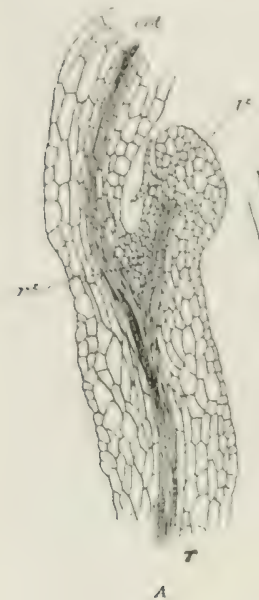

1

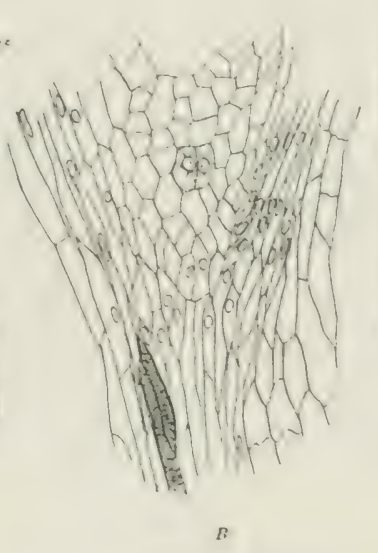

Fine 147.--Danca cllipica.

A. Nearly median section of a young sporophyte, showing origin of second rent, $r^{2}, X_{35}$.

B. Central region. Xijo,

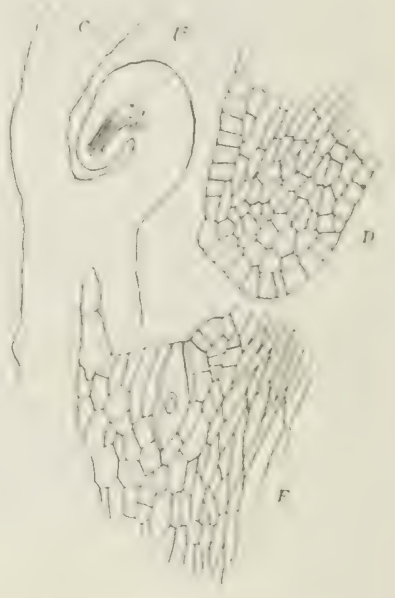

C. Median section of second leat. $\times 35$. b. Apex of second leaf. Xiso. E. Stem aper. Xigo.

and hence does not show in the figure, which is a section passing directly through the leaf traces. This plant showed very clearly the very earliest stage of the second root (fig. $1+7, A, r^{2}$ ). The apical cell of the young root is cut out from one of the cells of the parenchyma below the stem apex, lying almost exactly half-way between the two primary leaf traces. (Only a single segment had been cut off from the apical cell in this case and both the apical cell and this primary segment were easily distinguished from the surrounding tissue by their denser contents. There is nothing to indicate that the cell which had assumed the function of the root initial was in any way essentially different from the neighboring cells. If it is an endodermal cell there is no way of recognizing this, as the endodermis could not be recognized in this part of the sporophyte. Figure $147, B$, shows an enlarged view of this young root initial, lying above the junction of the two primary leaf traces. Conspicuous reticulate tracheids with pointed ends are present in the trace from the cotyledon, but as yet no permanent tissue has been developed in the bundle from the second leaf. 
A somewhat older sporophyte from $D$. jamaicensis is shown in fig. I48. In this plant the third leaf was plainly visible and the second root had developed into a short conical body which was pushing its way through the tissues between the
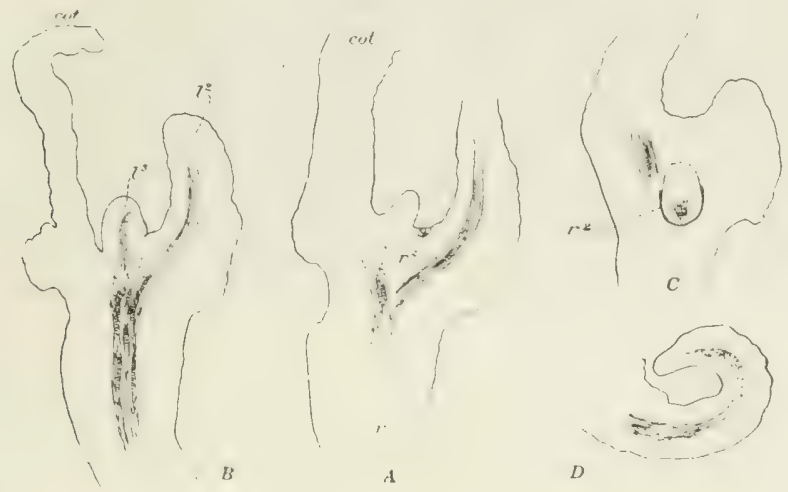

FIG. 148 .

A, B, C. Three sections of a sporophyte of Danca jamaicensis with three leaves D. Median section of the second leaf. In $C$ is shown the second root, $r^{2} \cdot \times_{20}$.

insertion of the first and second leaves. By this time tracheary tissue has developed in the bundle from the second leaf, and now for the first time we note the presence of large tannin cells in the neighborhood of the vascular bundles. Three of these are shown in fig. I 49, lying next the bundle of the second leaf. The irregular ring
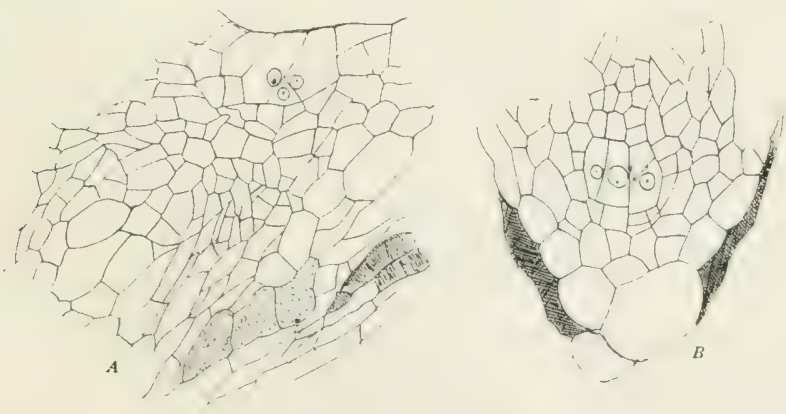

Fic. 149 .

$A$, the stem aper; $B$, apex of the second root of the sporophyte shown in fig. $I_{4} 8 . X_{150}$ The shaded cells in $A$ are tannin sacs.

of narrow cells shown in the figure and lying below the apical meristem marks the point of insertion of the second root. Figure $149, B$, shows a nearly median section of the apex of this second root. The apical cell is nearly oblong in form and the lateral segments are very large and periclinal segments which contribute to the root 
cap are cur off from them. The outer cells of the root cap are very much enlarged and there is an evident space between the root and the surrounding tissues. The trace from the third leaf joins that of the second one close to its union with the bundle from the cotyledon (fig. $148, B$ ).

In fig. 150 are shown nine cross-sections from a series made from a plant of $D$. jumaicensis, in which four leaves were evident. A microscopic examination of the stem apex showed, however, that a fifth leaf was also present, which stood nearly directly opposite the cotyledon. A shows sections only of leaves 3 and t, the latter having the stipules conspicuous, while these are absent or scarcely developed at all on the first three leaves, at least in the specimen in question. Between the leaves are seen secrions of the numerous scales which beset the surface of the young leaves. $B$ is taken somewhat lower down and includes a section of leaf 5 . C passes through the stem apex and shows clearly the spiral arrangements of the first five leaves, each of which has in its petiole a single concentric bundle which becomes larger in
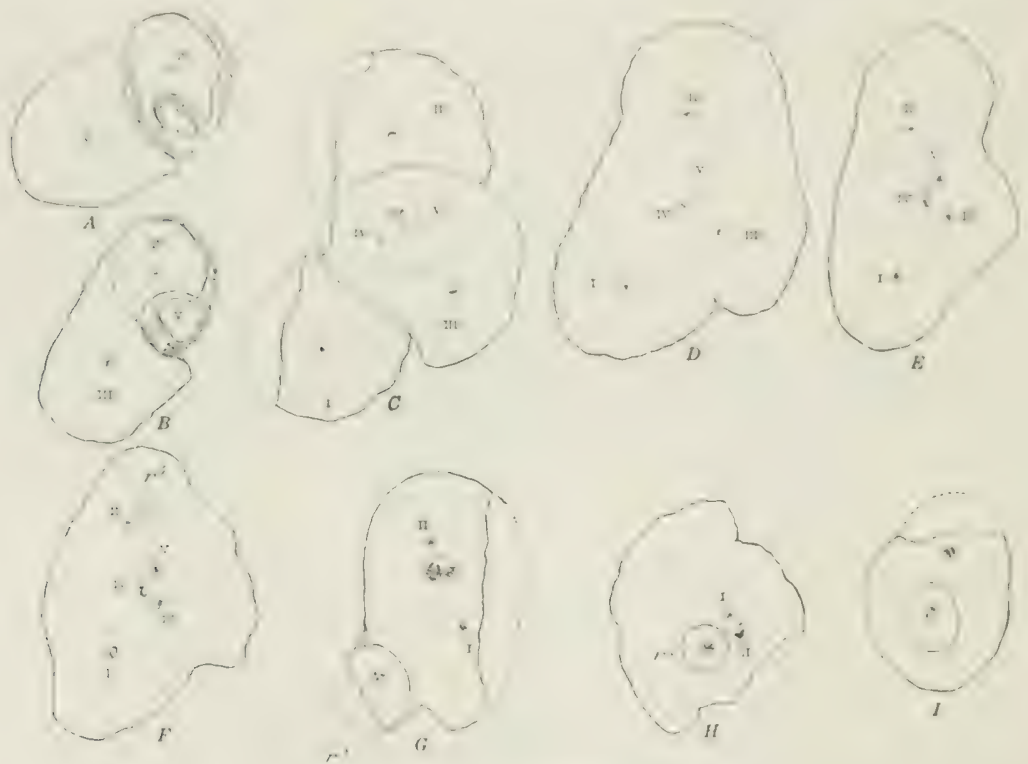

114.. 150,-D. jamaicensis.

Series of trancwetse vections of a sumne spurophyte, with three fully-developed leaves and two rounger ones. $\times 20$. Section C paw thromgh the stem apex. Reman figures indicate successive leaves,

each successive leaf, with a corresponding increase in the development of the xylem. As the secrions are examined, farther and farther down in the stem ( $D$ to $F)$, one can see very clearly the way in which the single bundle in the lower part of the stem owes its origin to the coalescence of the leaf traces. Proceeding downward the traces of leaves + and 5 are seen to approach gradually and finally to become completely coalescent; and still further down $(F)$ the leaf trace from 3 joins that from + and a single bundle results, crescent-form in section, but showing clearly its compound nature. The three xylems never become entirely contluent. 
For a long time sections of the stem show this single central bundle of crescentic form, at first derived from the coalescence of the third, fourth, and fifth leaf traces, but continued upward in the same form and added to by the addition of the traces from the subsequent leaves. This crescentic stele, which, for convenience may be spoken of as the stele of the stem, is entirely of foliar origin. The crescent never becomes completely closed and its opening in the earlier stages of development can not be properly called a foliar gap. The parenchyma which is inclosed within its curve belongs from the first to the ground tissue and is not part of the stele. Some of the surrounding cells show traces of the typical endodermal markings and it is perhaps safe to say that the stele is bounded by an endodermis, as Farmer states is the case in Angiopteris and Brebner in D. simplicifolia. The limits of the endodermis, however, especially upon the concave side of the stele, are very vague. The stele, after the complete fusion of the three leaf traces, may perhaps best be described
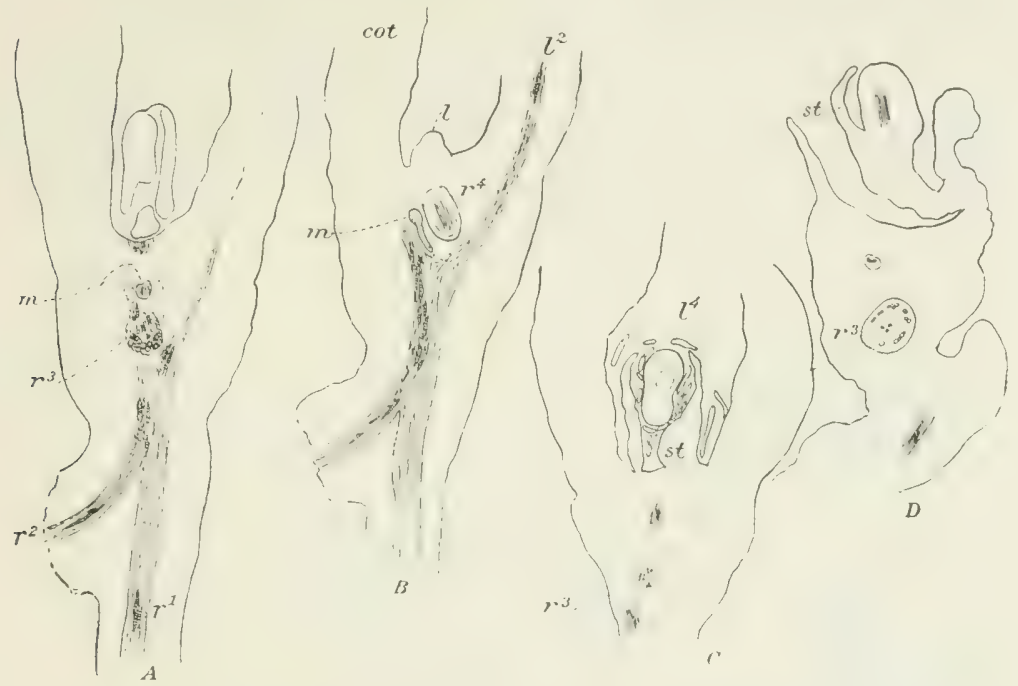

Fig. 351.

Four longitudinal sections of a young sporophyte of Danca elliptica, $\times 18$. The fourth leaf, $l^{4}$, has the stipules well developed; $r^{3}$, sections of the third root. $m$, mucilage duct; st, stipules.

as concentric in structure, with phloem developed all around the xylem, but there are probably traces of phloem also between the three xylems which represent the three confluent leaf traces.

In the older portions of the stem the bundles become still more completely fused and the compound bundle is oval in outline, but still shows plainly the three xylems of its constituent leaf traces (fig. I50, G). In this region the endodermis is rather better developed than it is higher up, but its limits are still rather vague. At this level the traces of the leaves, $I$ and 2 , are still free, but have approached nearer to the central bundle than is the case higher up.

Still lower down, the trace from the second leaf joins the bundle formed from the later leaf traces, which no longer dearly shows the separate xilems, but approaches the condition which has been described as "protostelic," or "haplostelic," using Brebner's terminology. 'The xylem elements, however, do not form a solid 
core, hut are mose or less scatrered, with thin-walled elements hetween. After fusion of the second leaf trace with this is complete, the section of the stem shows only two bundles, representing the two first leaf traces, and finally (fig. 150, $/ I$ and $I$ ) the section of the stem shows the condition already described for the sporophyte with but two leaves. 'These finally merge into a single primary axial bundle (I), which, followed downward, merges imperceptibly into the stele of the primary root. Near the middle of these lower sections can be seen a section of the second root, which pursues a downward course through the cortical tissue for a very long distance, but finally emerges and grows downward, side by side with the primary rout. The third root (fig. $150, G, r^{3}$ ) emerges much higher up and breaks through the cortex at about the level of the junction of the three youngest leat traces.

Fig. 153 shows the details of the central tissue from the same sporophyte as that just described. A passes through the stem apex and shows the apical cell cut somewhat obliquely, and near it the section of the trace from the fifts leat. $D$ is a section of the fourth leaf trace from the same level. This shows but two tracheids at a point near the inner limits of the bundle, while on the outer side there is a conspicuous curved line of protophloem cells. $B$ is a section taken somewhat lower down and shows the bending in of the leaf trace as it descends into the stem. This is still more marked in the fifth leaf trace, which, at this level, has a crescentic form.
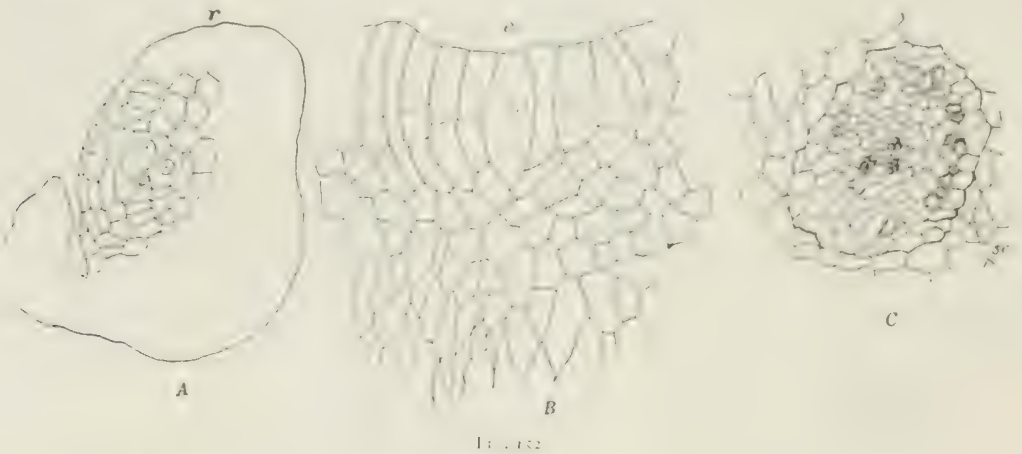

A. Apes of fifth leaf from sporophyte shown in fig. $151 . \times 150$.

B. Stem apex of same.

C. Base of third root, showing triarch bundle and ring of sclerenchyma in cortex. $\times 90$.

but no permanent elements yet developed. It is probable that a portion of this crescentic mass of procambium represents the sixth leaf trace. The fourth leaf trace at this point shows three tracheids which are decidedly larger than those higher up, and still lower down the tracheids increase still more in size and several tannin cells can be seen in contact with them. The section of the fourth leaf trace is comnected with the lasge but undifferentiated tsace of the hith leaf hy an inthmus of procambium cells, so that the sections of the two bundles form the crescent-shaped section, similar to that seen lower down (fig. 153,C). The tracheary elements of the fused portion of the fourth leaf trace are noticeably larger again than those in the free portion of the leaf trace. We now notice, for the first time, traces of the mucilage ducts which afterwards become so conspicuous in the stem. These first appear in section as rounded cells $(m)$, and it is evident, as Farmer has shown in Angiopteris, that the earliest mucilage canals are of lysigenous origin, i. e., they are formed by a 
fusion of cells and not by a splitting apart of the cells and the development of secreting cells about this intercellular space. In his earlier paper Brebner states that the mucilage ducts are schizogenous, but in his later paper he admits that they may be of lysigenous origin, which certainly is the case in the species of Danca described here.

The details of the older central bundles of the sections $F$ and $G$, fig. I50, are shown in fig. 153,E, $F$; the shaded cells in $C$ are tannin cells.

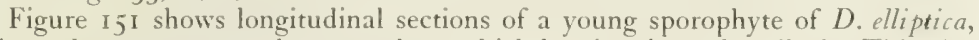
of about the same age as the sporophyte which has just been described. This also shows three fully developed leaves, while the fourth and fifth leaves are well advanced.
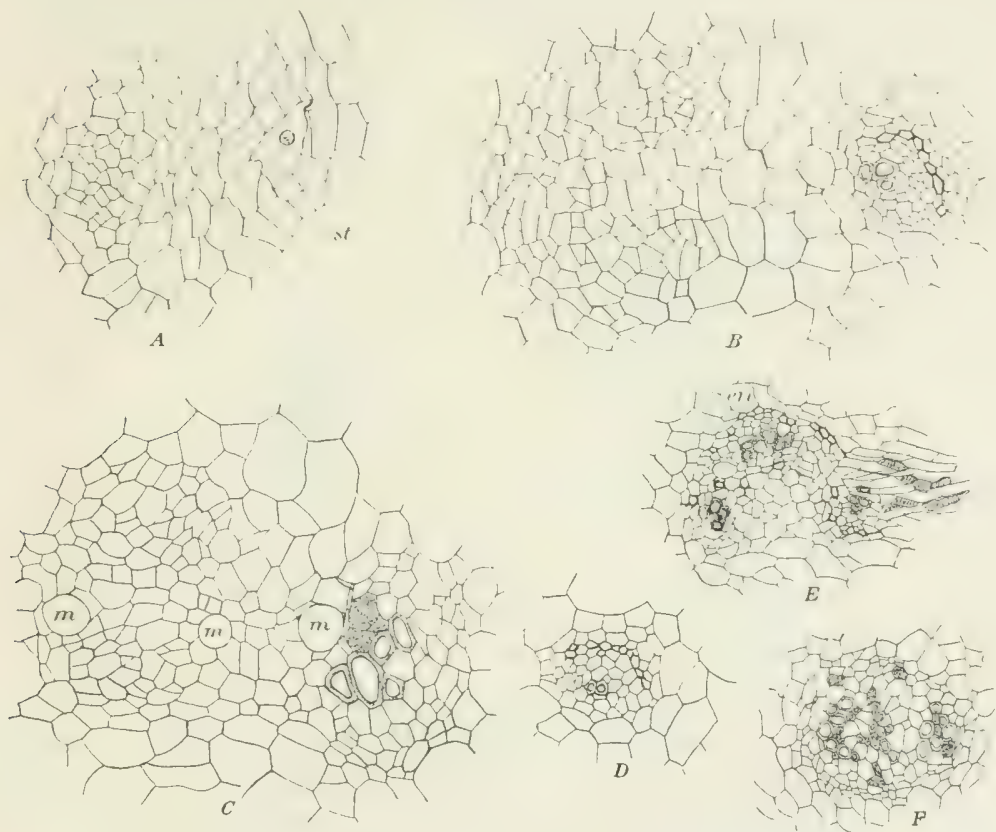

Fic. 153.-Details of the vascular system of sporophyte shown in fig. 150 .

A. Passes through the stem apex; $B$ and $C$, lower down, showing the fourth and fifth leaf traces. $X$ iso. D. A single leaf trace. $\times 150$. E, F. Vascular bundles from the lower part of the stem. $m, m$, young mucilage ducts.

The central bundle of the stem formed by the junction of the three first leaf traces is now conspicuous and forms a stout central strand, continuing downward into the primary root $\left(r^{2}\right) . A$ is a nearly median section, passing through the stem apex, whose large and conspicuous apical cell is shown in fig. $152, B$. The apex of the fifth leaf is seen just above this and a more enlarged figure of this is shown in fig. 152, $A$. The apex of the fifth leaf (which is here cut transversely) is occupied by a small group of large cells, of which the central one may perhaps represent a single initial cell. Below the stem apex, but separated from it by a considerable amount of tissue, can be seen the bases of the leaf traces from the fourth and fifth leaves respectively. These are joining the central bundle of the stem near the junction 
of the third leaf trace, and at this point there may be seen the base of the third root $\left(r^{2}\right)$. Between the funth and fifth leaf traces is presene a section of the first mucilage duct. $B$ is a section some distance to one side of the apex, also passing through the primary mucilage canal and the fourth root, which arises between the fourth and lifth leaf traces. Figures $C^{\prime}$ and $I$ ) are sections on opposite sides of the stem apex firm B. The fourth leaf, with its conspicuous stipules (st), shows in these sections, and the third root can also be seen. Fig. $152, C$, is a more enlarged view of the third root shown in fig. 151,1 . The root is triarch and in the peripheral part of the cortex there is visible a row of very conspicuous cells whose walls stain very strongly with safranine and in section closely resemble large tracheary elements. A longitudinal section of these cells, which are also conspicuous in the later roots (fig. 155), shows that they are elongared sclerenchyma cells whose thick walls are conspicuously pirted. Farmer (liamer 3) observed similar cells in the roots of Angiopteris.

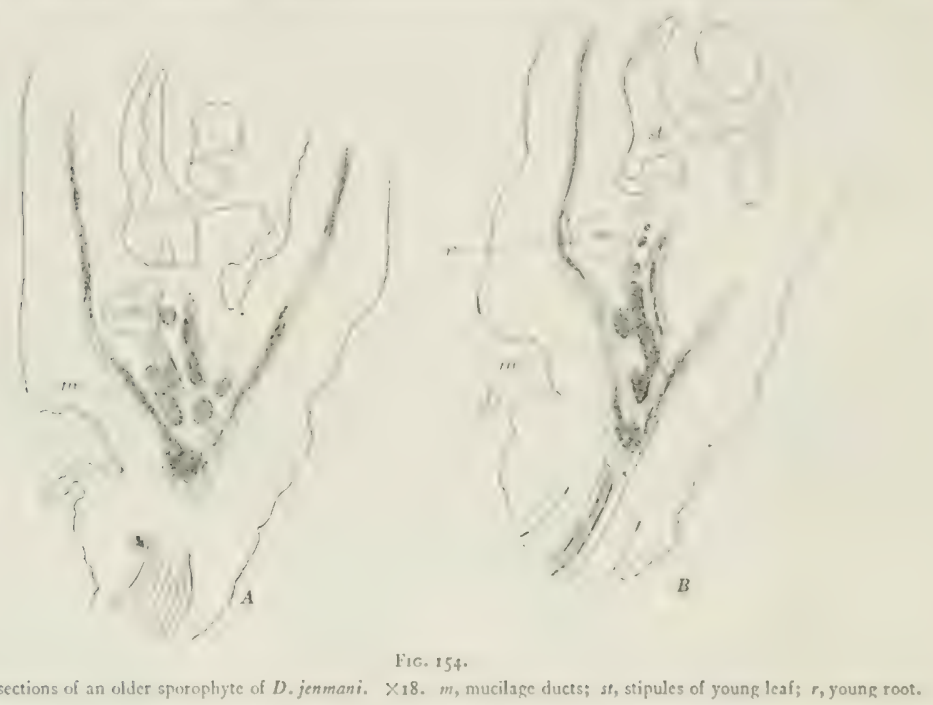

Figures I $5+$ and I 55 show three longitudinal sections of a pretty well advanced young sporophyte of $D$. jenmani. The root (shown in the figure emerging at the base) is probably the second root. The stem has already begun to assume a dorsiventral form, and the basal part of the root, which is strongly curved, is cut away and so does not show in these sections. The earliest leaves are no longer recognizable and it is impossible to determine just how many leaves have been formed. The leaves first formed have the single trace characteristic of the first leaves in all of the species, but the youngest leaves show that the leaf trace is double. In this section (fig. $155, d$ ) is shown a very young leaf, cut through parallel to its surface and showing clearly the stipules at its base and also the young vascular bundles. Within the leaf are two bundles, which are scen to join at its base, but separate again lower down, the wo bundles thus forming two distinct traces in the stem. In fig. $15 t, B$, the section passes through the youngest root, which is seen to have its stele joined to one of the leaf traces from the youngest leaf. Several conspicuous mucilage ducts are now present in the stem near the vascular bundles; these are 
formed of rows of large cells which become more or less fused together and their contents, composed of a dense granular mucilage, stain very strongly, either with safranine or with Bismarck brown, which were the principal stains used in preparing the sections. Numerous tannin cells are also present, scattered irregularly through the cortical tissue and also in the vascular bundles.

Figure $155, B$, is a median section through the base of one of the later roots, showing its connection with the corresponding bundle in the stem. The elongated cells $(s i)$ are the cortical sclerenchyma cells already referred to. These are shown on a larger scale in $C$ and $D$, where the conspicuous pitted walls can be seen. The shaded cells in the figure are tannin cells.

Figure 156 shows cross-sections taken at different heights from a sporophyte of D. jermani, a plant of about the same age as that which was shown in the preceding series of longitudinal sections. Sections made near the apical region, $A, B$, and $C$,

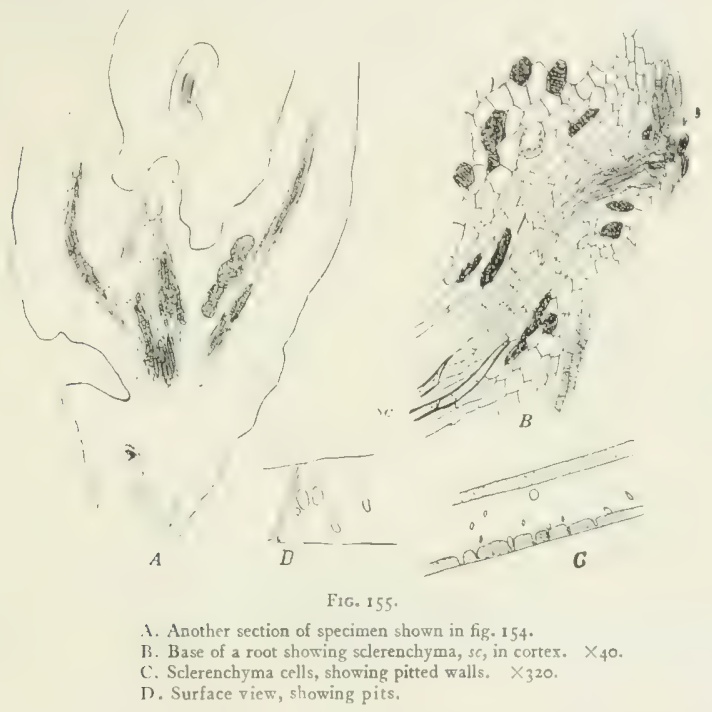

show two pretty well advanced leaves and the first trace of a third, the apex of which is indicated in $C$ and $E$. Unlike the earlier leaves with their single leaf trace, these later leaves, as we have seen, have the petiole traversed by two vascular bundles whose sections are plainly visible. These, as we have remarked from a study of the longitudinal sections, fuse into one near the base of the leaf $(A)$, and two small bundles are also present on either side, belonging to the stipules. As the sections are followed downward, the main bundle is found to divide into the double leaf trace entering the stem, and the two small stipule bundles become united with these, so that within the stem, at about the level of the stem apex, two distinct bundles are seen, corresponding to each leaf. The leaves are now arranged in two series, indicating that the dorsiventral character of the stem in this species is established and the youngest leaf lies almost opposite the next youngest one, whose leaf traces can be seen. E shows the stem apex with the apical cell, $x$, and the youngest leaf rudiment, $l$. 
Below the level of the stem apex, the stele of the axis closely resembles that already described from the somewhat younger plant and forms a somewhat irregular crescent, evidenty composed of two portions which are joined on the side facing the two leat traces from the oldest leaf which shows in this section. The opening of the crescent at this level is eurned away from the leaf. No permanent elements are present in the central stele as yet. Following this downward, the crescent is seen to open on the side next the two oldest leat traces and there is thus formed a foliar gatp, while on the opposite side the space becomes closed. In section $D$, which is taken lower down, the pusition of the section of the central stele is reversed. At

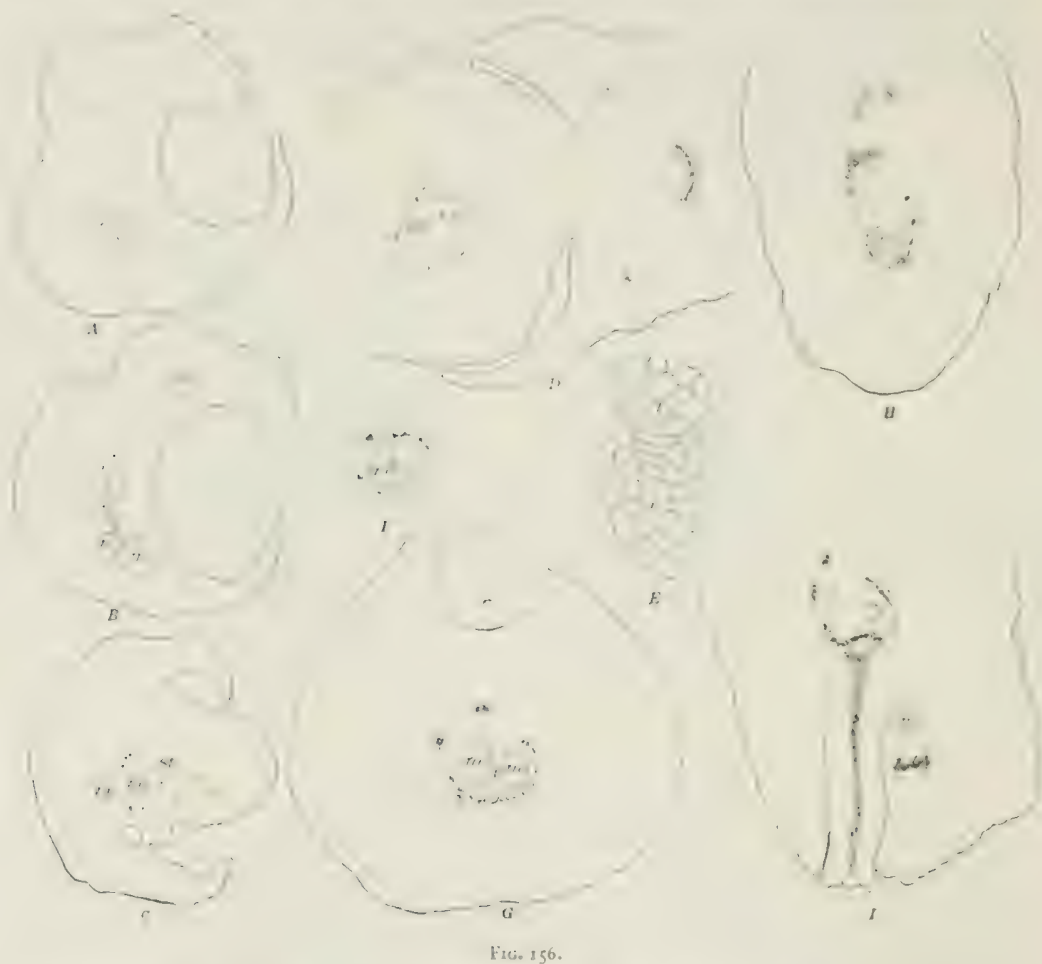

A-D. Four transwerse sections of a young sporophyte of $D$. jenmani, $\times 20$. Section $C$ shows stem apex.

E. The apical meristem with apical cell of stem, $*$, and a leaf initial, $l$. XiSo.

F-I. Four sections from the same serics, but taken lower down. $X_{20}$. Figs. F, G, show fusion of double leaf trace with eentral stele. $m$, mucilage ducts. Between the mucilage duets in $G$ can be seen the small commissural strand.

this point the section of the central stele forms a crescent of tissue, most of which has not passed beyond the procambial stage. This crescent-shaped mass is evidently composed of two parts and represents mainly the basal undivided bundles of the two youngest leaves. Tracheary tissue has begun to develop in the older of these two masses. Occupying the space within this crescentic stele are three young mucilage canals, but none are yet developed in the cortical tissue of the stem. Within this central space there can also be seen the section of a small isolated group 
of procambial cells. This is the single axial stele or commissural strand which had not yet begun to develop in the plant with five leaves. The older leaf base, shown in this section, has a single large vascular bundle, crescent-shaped in outline and concentric in structure, and there are also seen the two small concentric bundles belonging to the stipules.

All the leaf traces in the older leaves are concentric in structure, with welldeveloped internal phloem, and thus differ from the collateral traces of the earliest leaves. This concentric structure of the bundle is already well marked in the fourth leaf, where, however, the protophloem is mainly developed upon the outer side. $F$ shows the arrangement of the bundles in a section somewhat further down. The two strands from the oldest of the three leaves seen in the apex have joined the horns of the crescentic central bundle, which still shows clearly its dual nature. In the younger of the two portions of these sections the first tracheids have just appeared near the free end, while in the older half a line of tracheids extends nearly through the whole of the center. The mucilage ducts at this level are much larger and their cells have become confluent. Close to the large mucilage canal can be seen the

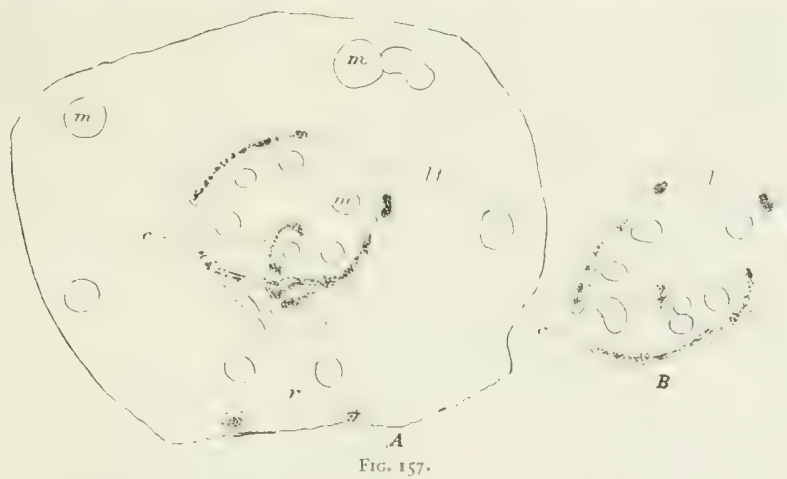

A. Section of an older stem of Danca jenmani, showing cortical mucilage ducts, $m$, and central of commissural strand, $c$. $/ 1$, leaf trace. $r$, root. $\times 20$.

B. Shows a section higher up, with free leaf traces and commissural serand.

section of the axial vascular strand, which somewhat higher up turns outward and becomes fused with the inner face of the crescentic central stele. The leaf traces soon become completely merged with the broad crescentic stele and their limits can no longer be recognized. The foliar gap gradually closes up and the two portions of the crescent separate at a point opposite so as to form a leaf gap, nearly opposite the first one; but I have seen no cases where a section of the central stele appears as an unbroken ring, although it is possible that this might occur for a brief period. Much the same condition of things is seen lower down and it is clear that in all cases, after the double leaf trace has been developed, one bundle fuses with an older and one with a younger leaf trace. The axial bundle shows a central mass of tracheary tissue, and in somewhat older stages an endodermis is pretty well developed. Finally this bundle can be traced downward to where it connects with the main stele, composed of the united leaf traces. The main stele gradually passes down into the base of the stem, where it shows the stracture already descolbed for the younger sporophyte.

In older sporophytes the crescentic central stele becomes broken up permanently into two elongated masses when seen in section (fig. 157), but the junction of the 
leaf traces with these takes place exactly as in the younger plant. Fig. 157, B, shows she separate leaf races and the free axial strand, while in $d$ the leaf traces atre becoming fused with the broad eentral strands and the axial strand is also anastomosing with one of the latter. This has taken place at the point of junction with a reot. While in the younger sporophyte the mucilage duces are confined to the ecntral region, in the older plant they occur also in the periplueral region of the stem (fig. $157, m)$. The details of the vascular bundles are shown in figs. 158 and 159 .
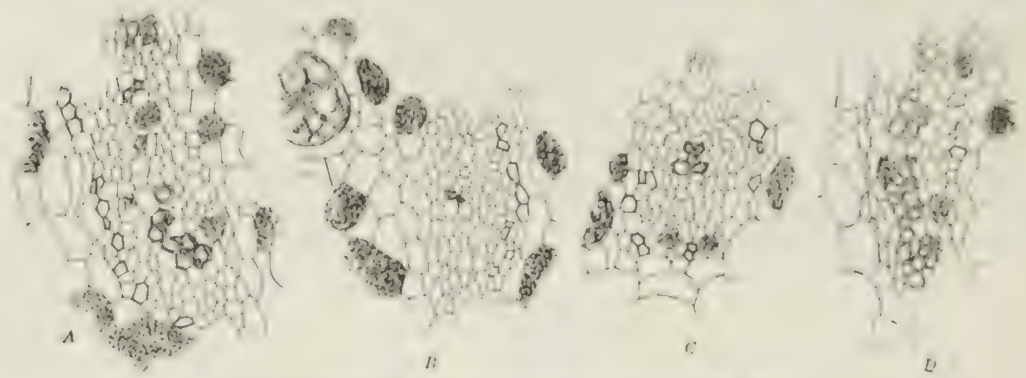

Fic. 158.-Detatls of vascular bundles from sections shown in fie. 156.

1 and 13 are the ends of the erescentic bundle shown in fig. 156, 1 ; $C$, is a leaf trace and 1$)$ part of an wher bundle. 150 .

To recapitulate: The vascular system in the young sporophyte of Dancen begins as a single axial strand, which is continuous through the cotyledon and rost. At a very early period a second vascular bundle or stele is formed in the second leaf connecting with the primary strand, and this is followed by a similar single strand or stele in each succeeding leaf, up to about the seventh. Up to this time, except for the steles of the secondary roots, the whole vascular system is buile up of united
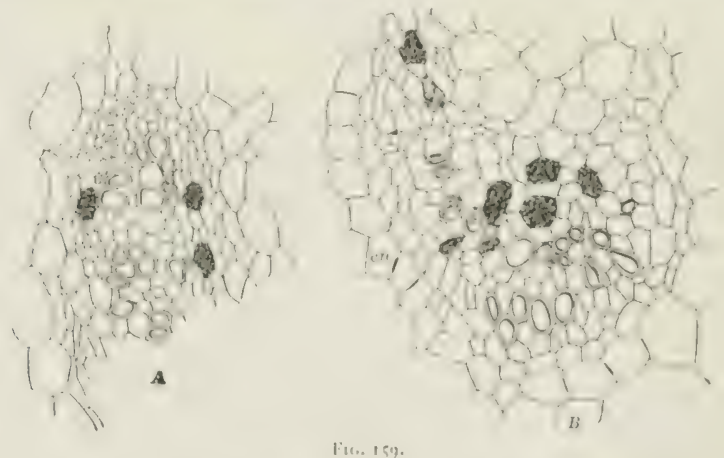

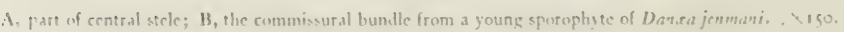

leaf traces and there is no cauline bundle in the strict sense of the word, alehough we may speak of the bundle, or stele of the stem, as soon as there is a solid central strand formed below the junction of the earlier leaf traces. This primary stele never has the form of a true protostele, however, as the xylems betonging to the separate leaf traces can be recognized and the compound nature of this central bundle is unmistakable. 
At a later stage, probably about the time that the seventh leaf is formed, there arises the single axial (commissural) strand, which is cauline in its origin and which, as Brebner has stated for $D$. simplicifolia, is the only strictly cauline portion of the vascular system of the stem. This can first be seen at about the same time that the first double leaf trace appears.

The development of the vascular system was not traced further, as it has already been adequately described by Kühn (Kühn 2), and except for the increased number of leaf trace and commissural strands the vascular system is essentially the same in a young plant like that shown in fig. 157 as it is in the adult sporophyte.

Brebner's account of the development of the roung sporophite in Dana'a simplicifolia agrees essentially with my own studies of $D$. elliptica, $D$. jenmani, and D. jamaicensis. He failed, however, to get successful sections of the transition region between the root and the cotyledon, or, as he puts it, "between the root and stem," and his statements that the central bundle begins as a "haplostele," i. e., a protostele, is not borne out by my studies on the other species. Moreover, his statement that "in this way the somewhat irregular adelosiphonic dictyostele of Danca is established now by a process which is, to all intents and purposes, a branching of the haplostele, due to the departure of the leaf traces of closely set, spirally arranged leaves," might better be stated, "the dictyostele arises by a process which is essentially the fusion of the leaf traces of closely sct, not necessarily spirally arranged leaves." He fully recognized the important part which the leaf traces play in the building up of the dictrostele of the stem, but he did not apparently recognize these as the sole factors in the development of the dictyostele of the older stem. He does, however, specifically state that the axial or commissural strand is the only part of the vascular system which is strictly of cauline origin.

\section{THE ADULT SPOROI'HYTE OF DANEA.}

The anatomy of what was supposed to be the sporophyte of Danca was first described by Holle (Holle 2), but the later investigations of Kühn showed that the plant investigated by Holle could not have been a Danca, nor could it even have belonged to the Marattiacere, since Holle describes the rhizome as developing a sheath of sclerenchyma, a condition of things which has not been found to exist in any Marattiacee. Kühn's account is very far from complete and the description of the sporophyte given by Brebner (Brebner 3 ) for $D$. simplicifolia does not deal with the adult sporophyte. The account given here is based mainly upon a study of $D$. jamaicensis and $D$. elliptica, but an investigation of certain points was also made in $D$. jenmani. The rhizome in D. jamaicensis and $D$. jenmani is a markedly dorsiventral one. These two species are a good deal alike, but are readily distinguished by the difference in the form of the leaves. In the former the leaves are rather larger and have more numerous pinnæ, while the terminal pinna is developed. $D$. jenmani has somewhat smaller leaves with from seven to nine pairs of leaflets, and the leaves are abruptly pinnate, the terminal pinna not being developed (plate 9 , A, fig. I).

The leaves are arranged very much as they are in Hclminthostachys or in Ophogghssum pendulum, the fleshy leaf base being provided with two very conspicuous stipules which are developed very early in the life of the sporophyte. The exact number of roots corresponding to a leaf is not easy to make out, but there are at least two, and it is quite possible that the number may sometimes be greater. These roots branch freely, especially toward the tips.

D. elliptica (plate 10) is a good deal larger than the other species and the stout rhizome, which, including the persistent leaf bases, has a diameter of 3 centimeters 
or more, is uprighe, the leaves being spirally arranged as they are in Maratia and Angiopteris. The petioles in this species are characterized by curious enlargements or nodes, which may occur in the other species also, but are much less prominent. The leaves of $/$ ). clliptica reach a length of about 50 centimeters and the leaflets, which are much larger than those in the other species, are less numerous, there being usually about eleven. The conspicuous nodese swellings seen in the periole are repeated on a smaller scale in the rachis at the base of each pair of leaflets. Sections of the stems were examined in D. jamaicensis and D. elliptica, which, excepe for a difference in size, agree closely in their structure. 'The ground tissue, as was first pointed out by huhn, consists entirely of parenchyma, through which are scattered many conspicuous tannin sacs which, in preserved material, appear to the naked eye as numerous black specks. The section of the vascular cylinder looks very much like that of the younger sporophytes already described, but the number of bundles seen in the section is larger, and there is a group of several bundles instead of the single medullary strand seen in the section of the younger stem. In a section from a large specimen of $D$. clliptica in which the rhizome, including the old leaf bases,

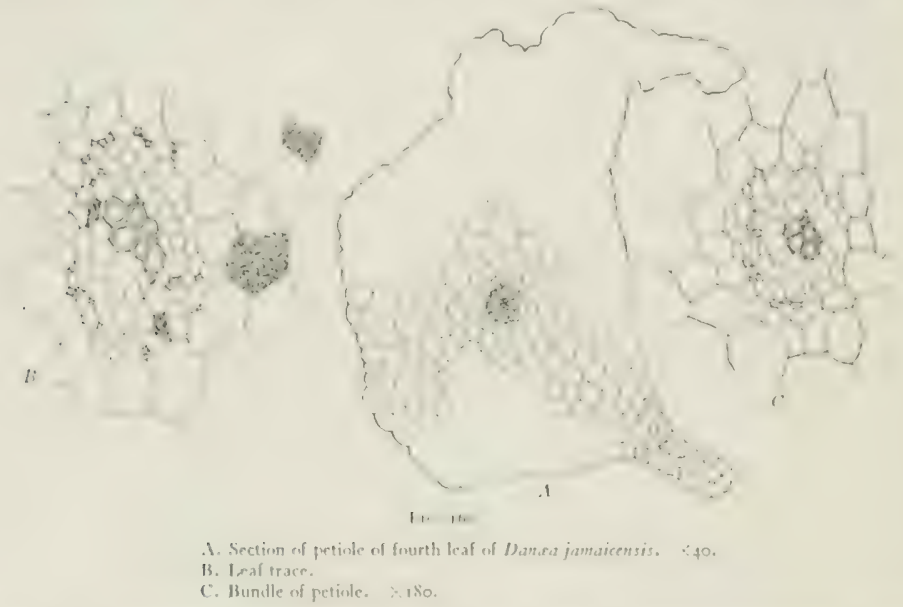

was about 3 centimeters in diameter, the outer ring of bundles contained thirteen. while within this was a smaller circle composed of five medullary bundles, three large ones and two smaller ones. In a similar section of a medium-sized section of 1). jamaicensis, in which the rhizome was about half the size of that in D). clliplica. there were nine bundles in the outer ring and four in the middle, two large ones and two small ones. In this section the junction of a root was cut through and the root stele was seen to be applied by its broad base to one of the larger of the medullary bundles (fig. $161, d$ ).

The relation of this central group of bundles in the stem to the primary medullary. strand was not investigated. Brebner has shown that in the later stages of the young sporophyte in D). simplicifolia the original medullary strand - which, as we have seen, is really the only part of the vascular system which is strictly of cauline originluses at certain points with the bundles of the outer ring, and at this point of fusion there may be a branching so that a section above this shows two of these medullary bundles. Whether all of the central group of bundles seen in the stem of the adult 
sporophyte in $D$. jamaicensis and $D$. elliptica are due to further branching of the primary medullary strand, or whether some of them may be new bundles of cauline origin, remains to be investigated.

The arrangement of the characteristic mucilage ducts is the same in the two species studied. There is a ring of these in the outer region of the cortex and a second group in the central region, these central ones usually being close to the vascular bundles.

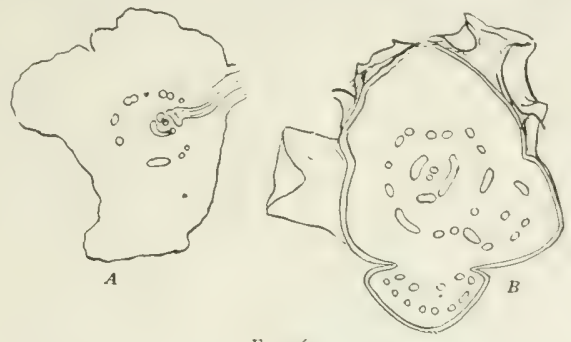

Fig. 161 .

A. Section of adult rhizome of Danas jamaicensis. $\times 2.25$

B. Section of rhizome of D. ellipica. $\times \mathbf{1 . 5}$.

The mucilage ducts are not shown.

THE ANATOMY OF THE LEAF.

A section of the petiole of the adult leaf appears very much like a similar section of the stem, except that there is developed in the cortical region, separated by several rows of cells from the epidermis, a band of sclerenchyma, yellowish or brownish in color, and very much indeed like that common in the typical ferns. Holle's statement that a similar mantle of sclerenchyma occurs in the stem was shown to be an error, the result of his having investigated a fern which was not a Danca. There certainly was no trace of sclerenchyma in any of the specimens I have examined.

The distribution of the vascular bundles in the petiole is very similar to that in Helminthostachys, except that inside the ring of bundles there is a single larger central one, instead of the two small ones which occur in Helminthostachys. All the bundles are continued into the stem as separate strands or there may be a certain amount of anastomosing among them, as there is in Ophioglossum pendulum, which

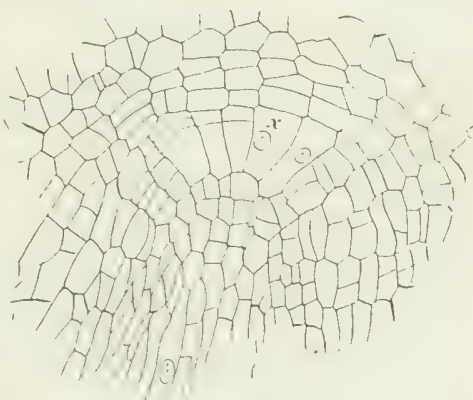
Danca resembles more in the character of its leaf traces than it does Helminthostachys, where the bundles of the petiole are united into a single trace within the cortex of the stem.

The distribution of the mucilage ducts in the petiole is very much like that of the stem. There is a definite ring of these inside the zone of sclerenchyma and several larger ones in the central region, near the vascular bundles. The form and venation of the leaf is essentially the same as in the younger sporophytes which have already been described, and stomata are developed only upon the lower side, the epidermal cells showing a strongly undulate outline, except for the series of narrow cells which 
immediafely surround the stoma. A section of the lamina presents an appearance

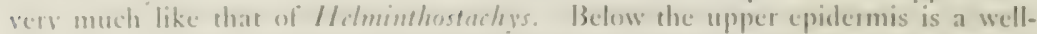
developed palisade layer, while helow this the spongy messphyll has the characteristic intercellular spaces found in the leaves of most of the higher plants. Danoe trichomonosides, a very small species from P'eru, has delicate membranaceous leaves, which probahly would show a much simpler structure than that of the coriaceous leaves of the lareer species. D. simlensis, a species from P'orte Rico, which is in the herbarium of the British Museum, has adventitious buds developed at the leaf rip.

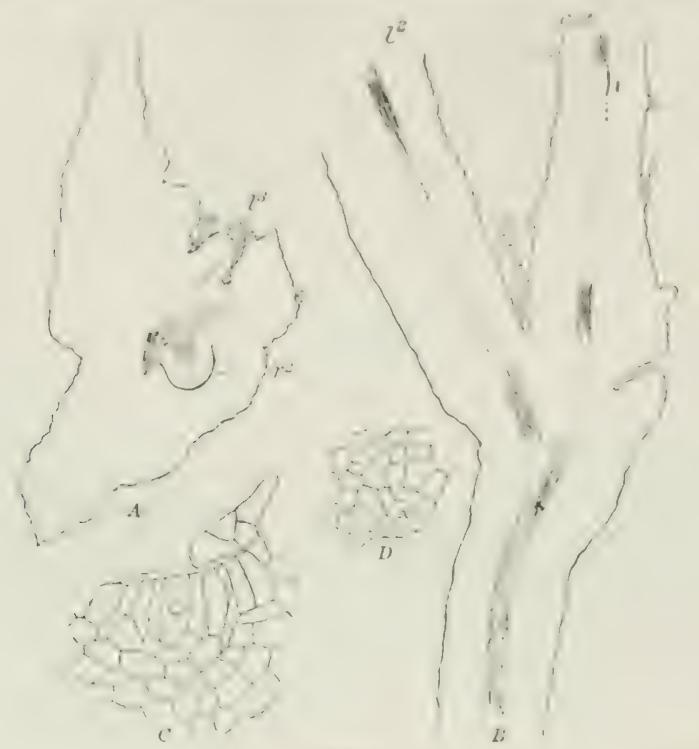

Fic. 163 .

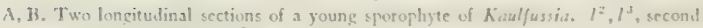
and third leaves; $r^{2}$, second root. $x \geq 0$.

C. Stem apex. $\times 180$. D. Apex of third leaf. Xitio.

IHE APICAL GROWTH OF THE ROOTS.

The earlier roots grow from a single initial cell, but this is later replaced by a group of similar initials which, in the large roots, are very much like those described

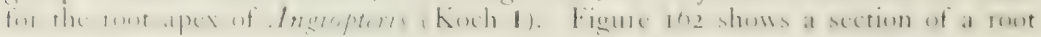
from the young sporophyte which is somewhat transitional in character between the form with a single definite initial cell and the larger root with its group of initials. The cell $x$, which is very much like the apical cell of the primary root, may perhaps still be considered as the single apical cell, but the adjacent segments are almost equal in size to this, and it is clear that they contribute to the plerome cylinder of che root as well as to the cortex and the root cap.

In sections of large roots taken from the adult sporophyte, there is found at the growing point not a single initial cell, but a group of apparenty similar initial cells

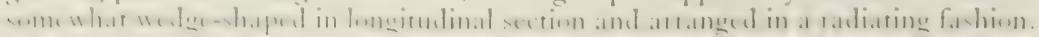
No single one of these can be clearly recognized as a primary initial cell. 'These

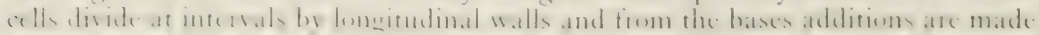


to the plerome cylinder, while from the outer cells of the meristem group arise the new cells for the root cap. The outer segments cut off from the peripheral cells of the apical group of cells undergo more rapid periclinal divisions than those nearer the center and the cells thus formed contribute to the cortex of the root.

Unlike the roots of most of the Ophioglossacex, those of Danca branch freely in a monopodial fashion. This is paralleled among the Ophioglossacex by some of the larger species of Botrychium, Helminthostachys, and Ophioglossum pendulum. Kühn's statement that the roots are unbranched is incorrect. The branching of the roots was perhaps somewhat more frequent in $D$. jamaicensis than in $D$. elliptica, but the latter species also shows numerous short lateral rootlets. The root hairs are not conspicuous on these older roots, but are readily seen upon the younger ones and are then found to be multicellular, as was first shown by Brebner for $D$. simplicifolia. Sections of the larger roots were examined in these two species and, while they agreed in the main, there were some slight differences. In a large root of $D$. elliptica, about 2 millimeters in diameter, the outer portion was occupied by about four rows of brownish thin-walled cells, very probably more or less suberized. Within this was a ring of brownish sclerenchyma cells about three cells in thickness, and between this and the exceedingly conspicuous endodermis was a broad zone of parenchyma, the cells containing much starch. A short distance outside of the endodermis was a ring of conspicuous mucilage ducts. There were twelve xylem rays alternating with as many rays of phloem. These did not extend to the middle of the stele, which was occupied by a pith of considerable size. The roots of $D$. jamaicensis were somewhat smaller and the main differences were: first, the thicker layer of tissue outside the ring of sclerenchyma, which was much less developed than in D. elliptica (in many places this ring was but one cell in thickness and very seldom more than two cells); second, the mucilage ducts were relatively very much larger; third, there were but nine xylem masses instead of the twelve in the root of $D$. elliptica.

The endophyte, which is usually found in the primary roots of all the Marattiacex is generally wanting from the larger roots of the adult sporophyte.

\section{THE SPOROPHYTE OF KAULFUSSIA.}

The development of the young sporophyte in Kaulfussia resembles that of Danaa in most respects, but from the first it is markedly dorsiventral, like the sporophyte of Helminthostachys. The cotyledon, while not provided with the characteristic free stipules of the later leaves, still has its base connected with a ridge which extends around the stem apex and youngest leaves, which thus lie in a cavity at the base of the cotyledon in much the same way that the stem apex is situated in the young sporophyte of Ophioglossum; but the sheath in Kaulfussia forms a shallow open cup, instead of the closed conical sheath found in Ophioglossum. This stipular sheath seems to be in all respects similar in its origin to that found in Ophioglossum.

The second leaf lies nearly opposite the first and the third next to the first, and so on, the distichous arrangement being evident from the beginning. We have already pointed out that in the very young sporophyte the vascular bundle from the cotyledon is continued directly into that of the root and that the bundle from the second leaf joins this common bundle, as shown in fig. I63. These primary bundles run on one side of the apical meristem, which, as in Danaa, is of very limited extent and does not contribute at all to these bundles.

The apical cell of the young sporophyte, up to the oldest stages that were investigated, is very much like that of the very young plant and is broader than that of Danca, more resembling both in cross and longitudinal sections the apical cell 
of (O) phiogh ossmm. The young leaves arise right and left in sucecession on either side of the stem apex, and from a very early period are strongly bene over, showing the characteristic circonate vernation of the Maratracese. Sections made through the apex of the young leat show that it hats at first a definite apical cell a geod deal like that which is found in the stem apex, and although no satisfactory cross-sections of this apical cell were found, there secms to be ne question that there is present a single detinite initial cell which probably has much the same form as that of the stem apex. The young leaf, at this stage, has the dorsal region strongly convex and composed of large parenchyma cells. The apex is bene over forward and downward.

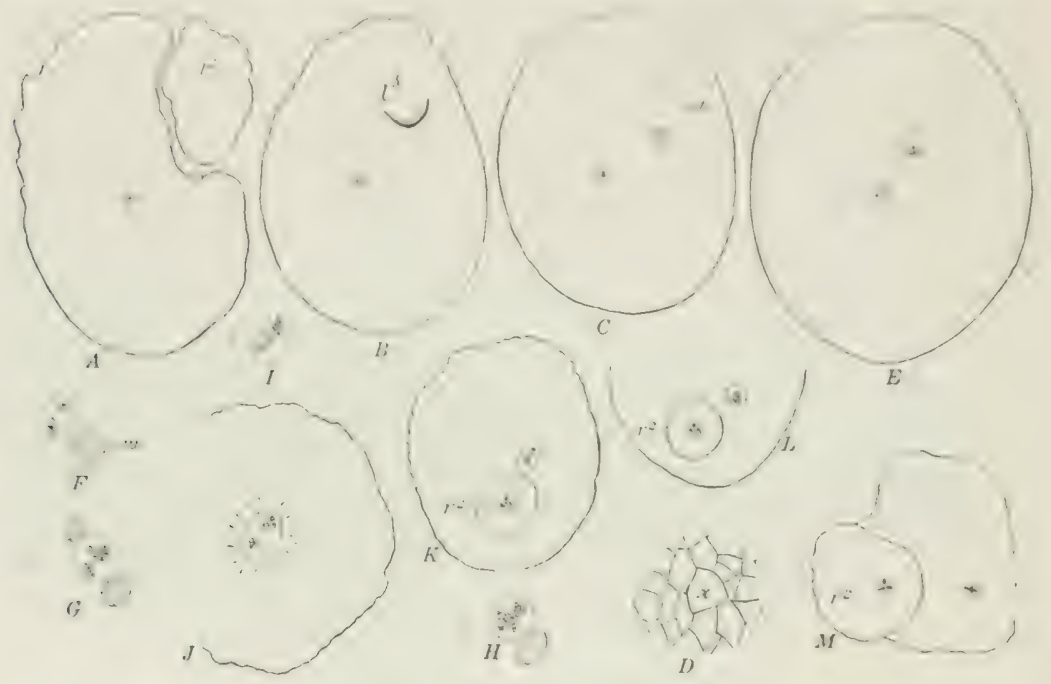

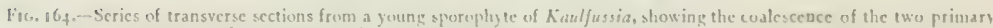
leaf traces. $l^{2}$, second leaf; $!^{3}$, third leaf; $r^{2}$, second rout. $x+$ o.

1). Stem apex more enlarged.

F-H. Central region of the sections. The fusion is complete in H. The shated area is a muctage duct.

'lihe tissues of the apex and the adjacent region are composed of small, actively' dividing cells. The young vascular bundle can be clearly seen extending nearly to the apex and continuing downward into the stem until it joins the bundle from the next older leaf.

The second root arises at about the same time that the third leat is recognizable and apparently its origin is exactly the same as it is in Danca. Its stele joins the central bundle of the stem near its junction with the third leaf trace. The young leaves, like those in Danca, are sparingly covered with hairs and scales, but these scales do not have the peltate form found in Danea, being usually short rows of stout cells; or the hair may have its base composed of an oblong mass of cells attached by a narrow stalk and having its apex drawn out into a slender filament composed of two or three elongated cells. The terminal cells of these hairs usually' stain very strongly, indicating that they contain tannin.

The young leaves are relatively stouter than in Dana a, but otherwise resemble them closely. In the young sporophyte, up to the time of the formation of the third leaf, there may be no trace of the mucilage ducts, although these may be developed 
at an earlier period. The mucilage ducts throughout the life of the sporophyte are less conspicuous in $K$ aulfussia than in Danca.

A section taken at the level of the stem apex in the very young sporophyte (fig. 137) presents an appearance not unlike that found in the bud in Ophioglossum. The base of the cotyledon extends around the stem apex, so that in the section the stem apex and the second leaf are inclosed in this cavity formed by the stipular sheath of the cotyledon. Higher up, the base of the cotyledon becomes free from the second leaf, but this takes place earlier on one side than on the other.

The development of the vascular system in the stem is exactly as it is in Danaa. The stem apex in the young sporophyte takes no part in the development of the vascular bundles, the stele in the stem being made up entirely of the united leaf traces. In the specimen figured (fig. 164 ), in which the second leaf was still quite young, the bundle from the cotyledon passes downward into the stem and continues its downward course until it joins the second leaf trace. The resulting solid stele at first shows the two separated xylems of the component leaf traces which lower down merge into a single thick band of xylem completely surrounded by the phloem

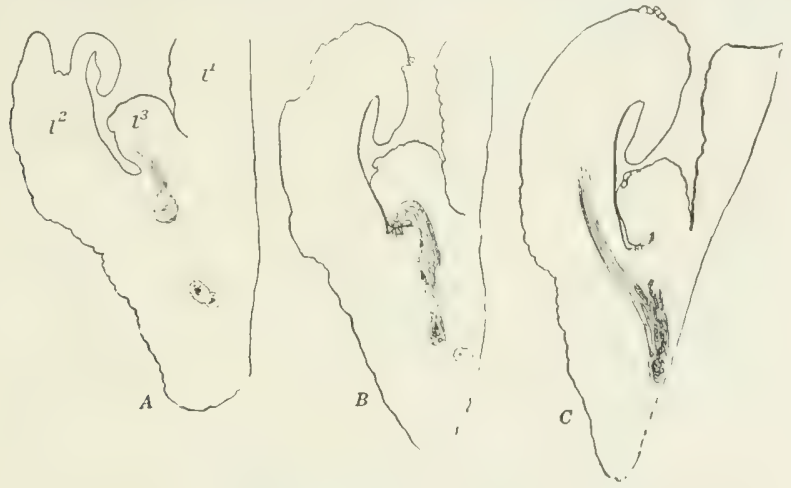

Fra. 165.-Three longitudinat sections of a young sporophyte of Kaulfussia, with three leaves. $\times 25$.

(fig. I64, E-H). This stage corresponds to Brebner's "haplostele" in Danca simplicifolia. This condition merges insensibly into the primary root with its diarch bundle, the two xylems in the younger part of the root being quite separate, but forming a single band at the base of the transitional region, between the root and the bundle in the stem. The bundle of the root shows a conspicuous endodermis which becomes less and less evident in the transitional region, although it probably never quite disappears. The primary root usually shows the presence of an endophytic fungus like that occurring in the prothallium and in the primary root of most of the Ophioglossacea.

Fig. I 66 shows cross-sections of a young sporophyte in which the fifth leaf is still quite small, but with its trace showing the first tracheary tissue. This fifth leaf trace unites below with the trace from the fourth leaf and forms a single bundle, with the xylems separate. The xylem from the fourth leaf above its junction with the fifth leaf trace forms at first a continuous band which divides into two parts, one of which unites with the xylem from the fifth leaf trace, while the other remains distinct. This separation of the xylem in the fourth leaf trace is the first indication of the formation of the double leaf trace, such as we shall find occurs in the later leaves. 
The separated $x y$ lems become joined lower down into a single transverse plate, just before the junction of the strand with the trace from the third leaf (fig. $160, / /$ ), with which it joins in the same way and is continted downward to the junction with the strand arising from the fusion of the second leat trace with the eotyledon. Above the junction of the first and second leaves, the stele of the second root, which grows vertically downward, joins the stele formed by the junction of the three youngest leat traces.

Above the junction the section of the bundle is nearly circular in outline, the large tracheids forming a broken group in the center of the bundle, quite like a

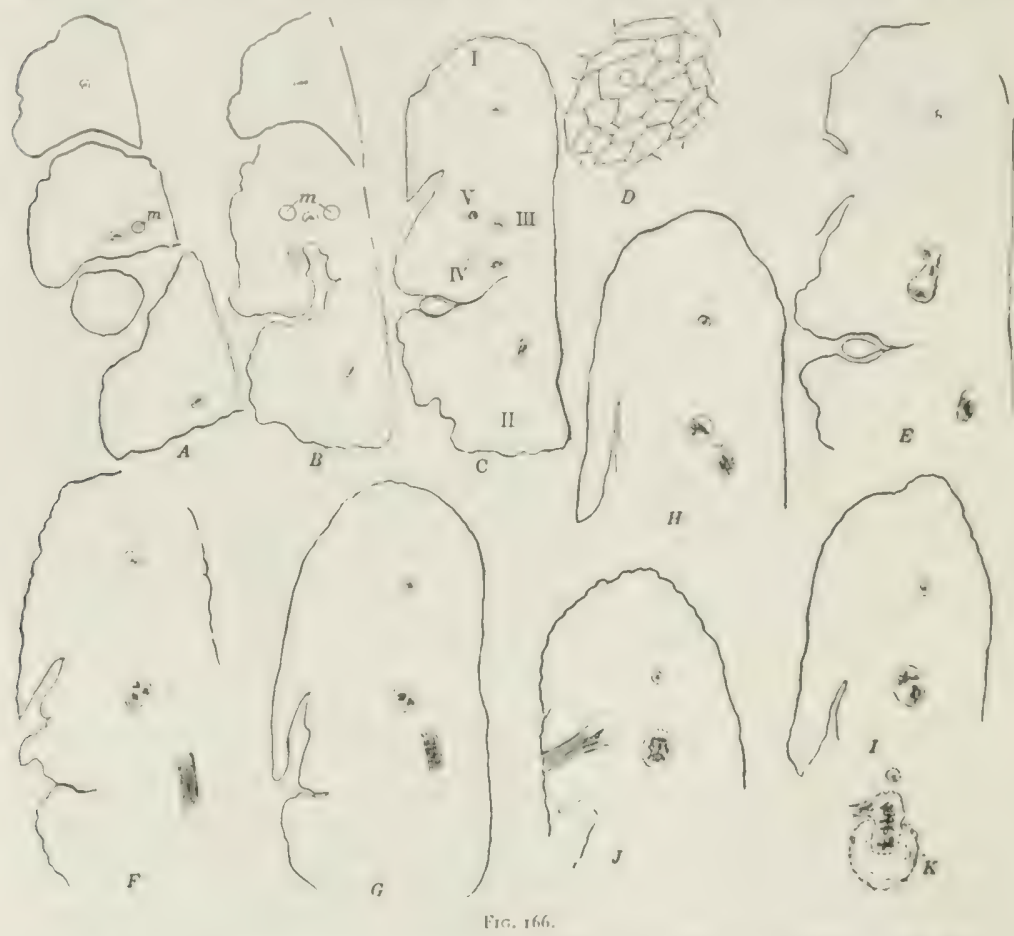

A-C. Series of transwerse sections from a sporophyte of Kaulfussia, of about same age as that shown in fig. $16 \mathrm{~g}$.

D. Stem apex.

11-]. Three sections lower down.

K. Central vascular cylinder still lower down.

corresponding stage in Dania. Some of the cells adjacent to the bundle show the typical thickenings on the radial walls, indicating that they belong to the endodermis, but the limits of the endodermis are extremely vague. In this plant two mucilage ducts had developed in the fourth leaf, one on each side of the vascular bundle (fig. $166, B, m$ ).

The second root is stouter than the primary one and its bundle is triarch. The mycorrhiza present in the first root could not be detected in the second root, but possibly may be developed at a later stage. All of the roots are provided with root 
hairs, which resemble those in Danca in being multicellular. In the larger roots there may sometimes be five or six cells, each with a conspicuous nucleus, making up these root hairs, and sometimes they show signis of branching at the apex.

It is evident that in Kaulfussia, up to the time that five leaves have developed, the vascular system of the stem consists of a single axial strand, a sort of sympodium formed by the completely united traces of the young leaves. The xylem may appear as a single mass at the points where fusion of the leaf traces is complete, but at most points the individuality of the component strands is maintained, so far as the xylem is concerned.

Figure I68 shows transverse sections from a much older sporophyte. The section of the petiole still shows the single vascular bundle having near its inner face a single large mucilage duct, which follows the leaf trace downward into the stem. As the bundle from the leaf enters the stem it broadens, and there is a separation of the xylems into two masses, first seen in the fourth leaf. In the specimen shown here the earliest leaves were not sectioned, and, as it can not be stated exactly how many leaves the young sporophyte had developed, it must therefore remain uncertain which leaf first shows the completely divided leaf trace. In the specimen in question the oldest leaf that showed had a single trace with two separate xylems,

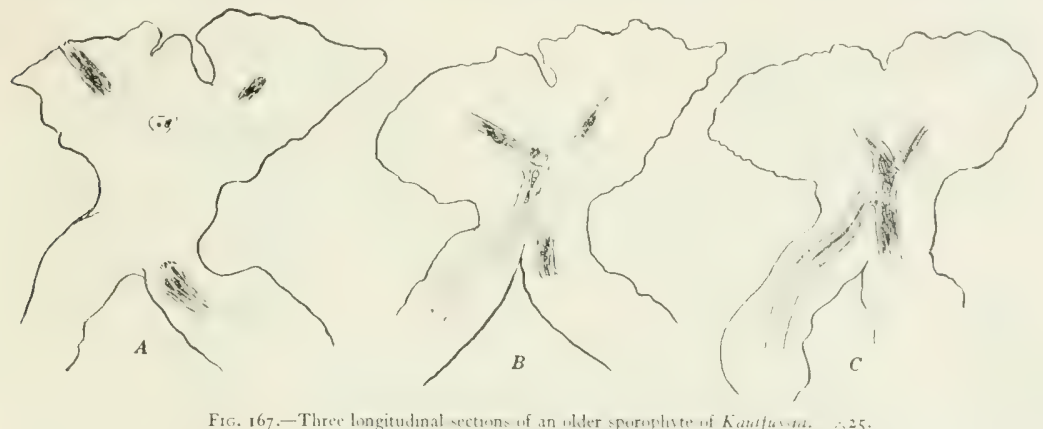

while the next leaf had the leaf trace completely separated and resembling a corresponding stage in Danca (fig. I68, $F$ ). As the traces from the two leaves approach preliminary to their fusion, the double leaf trace has its parts united again so that the traces become single before they join. The leaf trace now forms a single bundle, crescentic in section and very much like the single broad leaf trace from the earlier leaf. The two traces come nearer and nearer and finally fuse on one side, so that a section shows a single bundle almost circular in form, but broken on one side (fig. I68, $H$ ). This break is finally closed up, and the section of the bundle is completely circular and resembles very closely that of Brotrychium or Helminthostachys, except that phloem is developed inside the ring of xylem (fig. I68, $K$ ). A similar condition may sometimes be found for a very short time in the young plant of Danea also.

No certain evidence of an internal endodermis could be made out and the external endodermis is also somewhat vague, although there is probably no question of its presence. The outer phloem is bounded by a fairly well-defined pericycle, between which and the starch-filled cortical cells of the stem are two or three layers of transparent cells, some of which presumably constitute the endodermis. The endodermis is certainly present in the free leaf traces, although less conspicuous 
shan it is in the roots. In the upper region of the stem the leaf traces are further apart, and as the number increases a cross-section of the stem shows a circle of separate bundles closely resembling the arrangement in Ophioglossum. "The central "commissural" strand, which is found in the adult stem, had not developed in any of the young sporophytes 1 examined and evidently arises much later in the history of the sporophyte than it does in the other Marattiacea. In this respect, as well as in the arrangement of the bundles themselves, $K$ aulfussia is more like

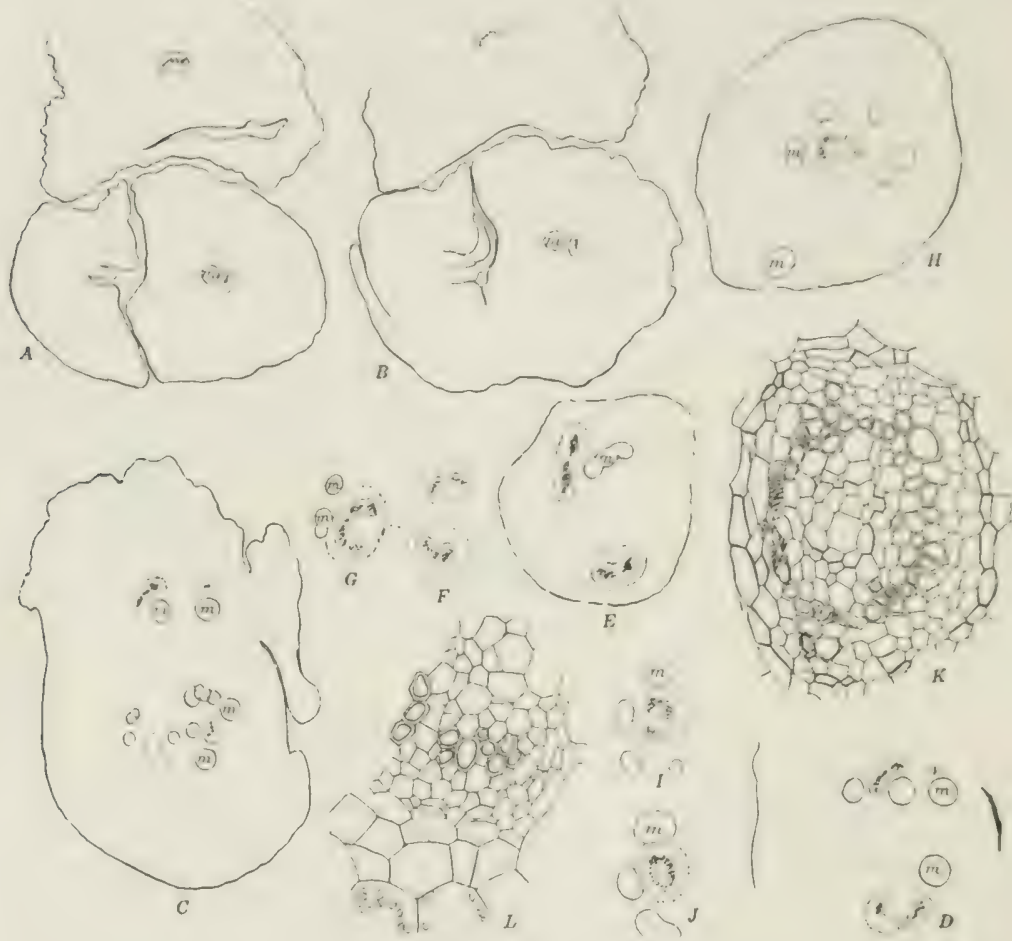

Fir. 168.

A, B. Twn sections above ievel of stem apex of a young sporophyte of Kaulfussia of about same age as that shown in fig. 167.

C-J. Sections taken lower down from same series. $m$, mucilage ducts.

$\mathrm{K}$. Central bundle of section $\mathrm{J}$. $\times 1$ iqo.

L. P'art of the bundle of section H, more enlarged. G, F, I, J, show only the central region of the sections.

Ophioglossum than it is like the other Marattiaces. In the intermediate condition between the single solid stele found in the very young stem and the entirely separated leaf traces of the older rhizome, there is a transitional condition with a "siphonostele," very much as in Helminthostachys (fig. 168, $K$ ).

In one very young sporophyte there was found, in the cortex of the primary root near its base, a large lacuna which recalled the similar lacuna found in the first internode of Helminthostachys. 
The young sporophyte of Kaulfussia is almost completely destitute of the tannin cells which are so conspicuous a feature in Danca, and these tannin cells are practically entirely absent from the sporophyte throughout its whole existence. In this respect there is a marked resemblance to Ophioglossum. The mucilage ducts are also somewhat less developed than in the other Marattiacex and are mainly confined to the central part of the stem in proximity to the vascular bundles. At a late period they may also appear in the cortical region. Their lysigenous origin is less evident than in Danca and it is not impossible that they may sometimes be of schizogenous origin, as Brebner states is often the case in Danaca.

The structure of the vascular strands is very much like that of Danca, as a reference to the figures will show. There are developed slender, spirally-marked protoxylem elements like those in Danca and which we have already seen occur also among the Ophioglossacere, in Helminthostachys.

The stipules in the young plants of Kaulfussia are much less definite than they are in Danca. A cross-section through the bases of the young leaves shows that instead of the bases appearing free, each with its distinct stipules, the leaf is confluent with the next one, one side being slightly extended and free. The leaf base thus incloses the next younger leaf completely on one side, but leaves it free on the

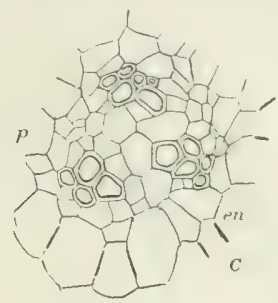

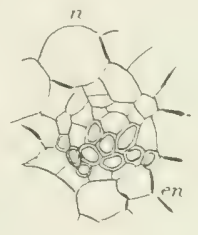

A

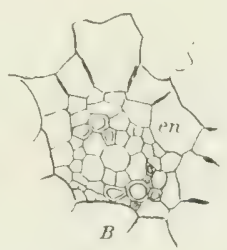

Fig. 160 .

A. Bundle from intermediate region of a very young sporophyte of Kaulfussia. $\times 150$.

B. Section of primary root. X150.

C. Section of bundle of second root. en, endodermis. Xiso.

other (fig. 168, B). In the later leaves the stipules become more conspicuous, but they are always connected by a very conspicuous commissure in front (fig. $17 \mathrm{I}, \mathrm{com}$ ) so that a section of the young leaf base shows a space between the front of the petiole and the stipular sheath. In short, the structure is very similar to the open stipular sheath of Botrychium virginianum and apparently arises in much the same way.

The structure of the adult sporophyte has been carefully investigated by Kühn, who pointed out that it is the simplest of the Marattiacer in the structure of the stem (fig. I I I, B). As in the young sporophyte, the stem shows in section a single circle of vascular bundles, but there is in addition a single median strand within the circle of bundles belonging to the dictyostele, and this bundle is presumably of cauline origin, like the corresponding one in Danaa.

The whole vascular skeleton of the stem, when removed by maceration, was found by Kühn to be a hollow cylinder with large open meshes. These are more elongated on the ventral side and from these ventral strands alone, according to Kühn, the roots are developed. In this respect Kaulfussia offers a certain analogy to Helminthostachys and perhaps to Ophioglossum pendulum..

As in the other Marattiacer, the ground tissue of the rhizome is composed of simple parenchyma. The outer layers have their walls brown in color and show the reaction of cork. Except for the presence of the central strand, a section of the 
rhizome of Kinalfussie presents almest the exact appearance of a similar section of () pluioglessum.

In a rhizome having a diameter of about a cenrimeter ewelve bundles showed in a cross-section taken through the internode, one of these being the medullary serand. The section of a periole of a leat raken from the same plant is shown in lig. 171, $C$, and the structure of the section closely resembles that of the rhizome. There were eight hundles arranged in a circle, within which were two medullary strands. The cortical region was composed of several rows of brownish cells, probably similar to those in the outer part of the rhizome, and within these, separated

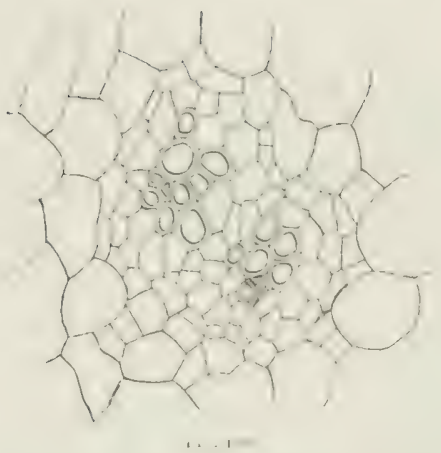

Cineral bundle from a young sporophyte of Kaulfussia, showing $($ win xylems, $\times 150$.

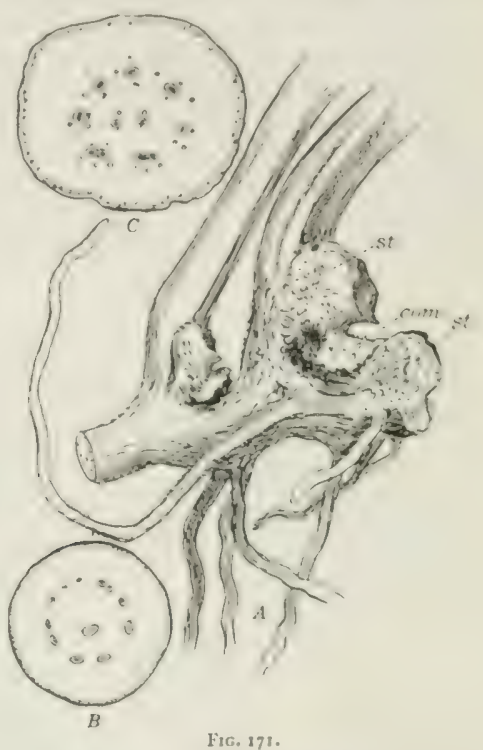

A. Rhizome of a large sporophyte of Kaulfussio. $\pi$, stip. ules; com, commissure. $\times$ aे.

13. Section of thiznme, $\times 2$.

C. Section of petinle. $\times 2$.

from them by three or four rows of cells, was a conspicuous band of collenchyma, a tissue characteristic of the leaves of most of the Marattiacee.

According to Kühn, the bundles of the leaves are continued separately into the cortex of the stem and do not unite into a single leaf trace. There are occasional anastomoses of the vascular bundles of the petiole, quite like those in the stem itself, and this becomes especially marked at the base of the leaf, so that the leaf trace (if such it can be called) forms a hollow reticulate cone, quite equaling in diameter the vascular cylinder of the stem itself, and attached to this by the open base, the separate strands forming a crescent-shaped group when seen in section. The arrangement of the bundles within the petiole itself and their method of junction with the vascular system of the rhizome are very much like those in Ophoglossum pendulum.

The vascular bundles, both in the petiole and rhizome, are concentric. The endodermis is not recognizable and the central xylem is completely inclosed by the phloem, sieve tubes being developed throughout. 
While mucilage ducts are present in both leaf and stem, they are less numerous and conspicuous than in Danaa. There is a ring of them in the outer cortex and several larger ones in the central region. Kuhn states that, although these mucilage ducts sometimes look as if they were of schizogenous origin, in reality they are always lysigenous, i. e., they are formed by the fusion of several mucilage-secreting cells.

In the cotyledon and the earlier leaves a section of the lamina shows, between the large-celled epidermis of the upper and lower sides, a mesophyll composed of about three layers of quite indifferent parenchyma, exactly as it is in Ophioglossum. In the adult leaves the upper part of the mesophyll is compact, but there is no proper palisade tissue developed. Toward the lower surface the mesophyll becomes looser.

Until the plant has reached a considerable size the leaves remain undivided and, except for the much greater size, closely resemble the early leaves of the young sporophyte (see plate I I, fig. I). The simple leaves are succeeded later by trifoliate ones, and finally five leaflets are developed. The long, fleshy petiole may reach a diameter of a centimeter or more and a length of some 50 centimeters in large specimens. The venation strikingly resembles that of a dicotyledonous leaf, the pinnately arranged, secondary veins being connected by a plexus of small veins, inclosing nearly square areoles within which a few free terminations are occasionally found. The large pores upon the lower side of the leaf, formed by the greatly enlarged stomata already referred to in the younger leaves, are plainly visible to the naked eye, and sections of these look curiously like the pores upon the thallus of certain Marchantiacex (fig. 128).

The stipules of the older leaves are very conspicuous and show much the same structure as that noted for the earlier leaves. The young leaf is included within the stipular sheath of the next older one, and near the apex the unbroken stipular sheath of the youngest expanded leaf shows very plainly that the large stipules are joined in front by a broad commissure, which extends entirely around the apex of the shoot, exactly as it does in Helminthostachys, from which the sheath differs mainly in the fact that it is divided above into the two stipules as it is in Botrychium rirginimum, and there seems no reason to doubt that we have to do with entirely homologous structures (fig. I7I, $A$ ). The stipules of the young leaves are covered with hairs and scales similar to those noted in the young sporophyte.

The roots arise from the ventral surface and flanks of the rhizome, and outnumber the leaves, to which they apparently bear no definite relation.

The apical growth was not studied in the root of the older sporophyte, but it is probable that in the large roots of the older plant the single apical cell found in the early roots is replaced by a group of initials such as are found in the other Marattiacex, although it is barely possible that the single apical cell may be retained here as it is in the Ophioglossacere. Unfortunately, material was not available for a study of this point. The roots in most cases are quite unbranched, as they are in Euophioglossum. The only cases where branches were seen, were young sporophytes in which the end of the root had been destroyed and two branches had arisen on each side of the destroyed apex. This looks somewhat like a dichotomy and it is barely possible that, as in Ophioglossum, there may be a real dichotomy of the root, but all of the cases that were found had much more the appearance of the formation of two lateral roots. The young roots of the sporophyte are provided with multicellular root hairs, like those of Danca, but these disappear as the root becomes older.

The central vascular cylinder of the root is surrounded by a circle of very large mucilage ducts. The endedermis is clearly evident and the roots which I examined 
from a medium-sized plant were ectarch. Kiihn states that pentarch and hexanch bouts also are formed. The reduced number of xylems in the soot of $K$ and-

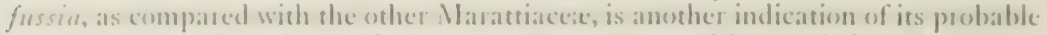
nearer relationship en the ()phioglossacese, the structure of the root being very similar indeed en that of II iminthestachys or Ophoighossum pendulum.

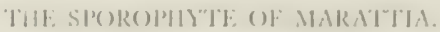

The published observations upon the young sporophyte of Maratio are far from complete. Kuihn (Kuhn I) has described the stem structure in young plants of $\mathrm{M}$. frowince, but it is evident that these plants were already too far advanced to show the early arrangement of the bundles, as the stems he described had reached a length of nearly 2 centimeters. Farmer and Hill (Farmer 3 ) have also given some details as to the early stem structure in the same species. These young plants, especially those described by Kuhn, have the stem relatively longer than is the case either in $\mathbf{~}$. douglasii, which I have studied somewhat in detail, or $\mathbf{M}$. alata, or $\mathrm{K}$. sambucina, which I have also examined. In all of these species the stem of the very young sporophyte is still quite short and very soon assumes the compact globular form with the crowded leaves that it has in the adult sporophyte. It may be said, however, that in $M$. alata the buds which develop upon the old leaf bases have the young stem somewhat more elongated, but not nearly' so much as Kühn's figures would indicate to be the case in $M$. fraxinca.:

In the youngest specimens examined by Kühn the cross-section of the stem showed a ring of bundles corresponding to the leaf traces and a central medullary strand, the whole arrangement being very similar to that which is found in the adult rhizome of Kaulfussia. 'This stage is also very similar to the condition found in the young sporophyte of Danaa.

Farmer and Hill describe the vascular skeleton of the very young plant of $M$. fraxinea as a "siphonostele" with much larger foliar gaps than those found in Angiopteris, and thus more nearly resembling Kaulfussia or Danar. The leaf traces are at first single, but the later leaves have double leaf traces, such as we have described in Danca and Kaulfussia.

The writer has already published some details in regard to the young sporophyte of Marattia douglasii (Campbell 3, 4), and some additional facts are here added to those that have already been published; but as the series of specimens available for study was not at all complete, further investigation is desirable to complete the history of the development of the vascular system in Marattia. 'The only material available for a study of the young sporophyte in $\mathrm{M}$. douglasii was a series of slides made a good many years ago from material collected on the island of Kauai in the Hawaiian Islands. This material was supplemented by a small number of very young plants of $M$. sambucina, collected in Java. Material of older sporophytes of $M$. alata was collected in Jamaica in the summer of 1908 . Unfortunately, all the preparations of $\mathbf{M}$. doisglasii, except the very youngest stages, were longitudinal sections, so that it was difticult to follow out satisfactorily the course of the vascular bundles in the later stages.

Longitudinal sections of a young sporophyte before the cotyledon was completely expanded are shown in fig. 133 . The section was cut nearly in the plane of the cotyledon and the bent-over apex of the latter was cut so as to show plainly the two lobes arising from the first dichotomy of its apex. The second leaf is already formed and differs in no essential particular from the corresponding leaf in $K$ aul-

- Since the above was written a pap:r has appar.d (Charles 1) describing the vascular system of the young sporophise uf M.alata. The stelc of the very yome plant is deseribod as a protostele which passes abruptly into a sulenostele. 
fussia or Danca. It was not quite certain whether a single apical cell was present at this stage, but a triangular cell which could be seen at the apex was probably the apical cell of the young leaf. The root apex of this specimen had been injured so that the form of the apical cell could not be clearly made out, but it was probably the same as we have already described for the young sporophyte. The apical cell of the stem meristem was broader in outline than that of Danca and truncate below.

The vascular system at this stage, as we have already indicated earlier, consists of the common bundle of the root and the cotyledon, which is joined at a point quite close to the stem apex by the second leaf trace. The first tracheary tissue is visible at this point in the form of short, reticulately marked tracheids such as we have already seen in the young sporophyte of Danaa. At this stage no mucilage ducts or tannin cells had developed. About the base of the young leaves are short hairs

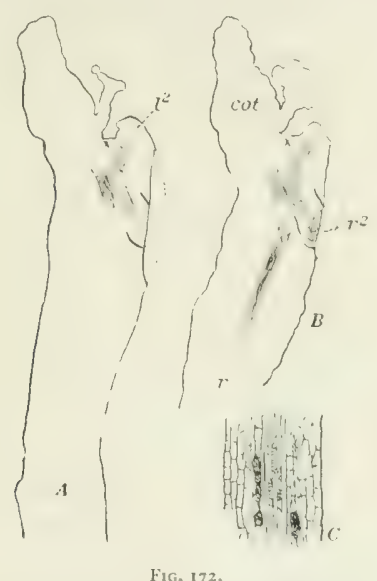

A, B. Two longitudinal sections of a young sporophyte of Maratia douglasii. $l^{2}$, second leaf; $r^{2}$, second root. $X_{1}+0$.

C. Part of primary root, showing cells infected by endophytic fungus.

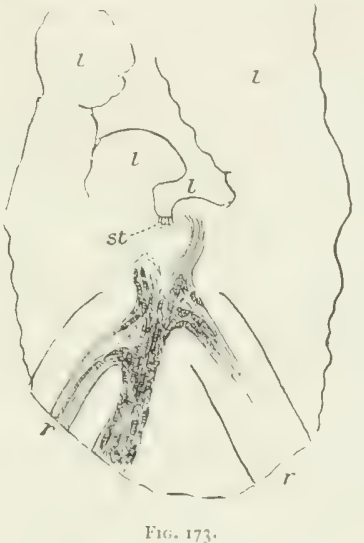

Section of a young sporophyte of Maratica douglasii. st, stem apex; l, young leaves; $r$, roots. $\times 25$.

and scales like those we have seen in the other genera. They are more like those of Kaulfussia than like the peltate scales found in Danca.

Sections of a somewhat older sporophyte are shown in figure 172 , this section being made at right angles to the one just described. The cotyledon in this specimen was fully expanded and the primary root had penetrated into the earth. The arrangement of the bundles was the same as in the younger sporophyte described, except that the third leaf was now visible and the second root was already well advanced. The section passed exactly through this root, the stele of which is seen to join that of the second leaf and is practically continuous with it. The roung trace from the third leaf joins the second leaf trace near its junction with the second root. The apical cell of the latter was readily seen and appears in longitudinal section of nearly triangular form, but with the base somewhat truncate (fig. 177, C).

The tracheary tissue in the middle of the sporophyte is pretty well advanced and the formation of the tracheary tissue has extended for some distance into the primary root and the cotyledon. In the former a single elongated tannin sac could 
be secen, like these which are mech mere developed in the primany ane of Angiopteris, and it was also seen that cestain of the cells in the cortex of the primary toots weac invaded by the endephytic fungus. In the cotyleden there was a single latge mucilane duct.

A series of transvetse sections was made of a young sposophyte of 1 . sumhucine and these agreed in all essential particulars with similar sections of Dance or Ǩnulfussiu.

In a young sporophyte of $\mathrm{M}$. douglasii, in which two ronts were developed in addition en the primary one, there could be seen at the apex two young leaves, probably the fourth and fifth, but as only the median sections of this series bad been kept the exact number of leaves could not be determined.

The central part of the stem in this plant (fig. 173) was occupied by a single thick bundle, but whether this was solid or open on one side, as Farmer states is

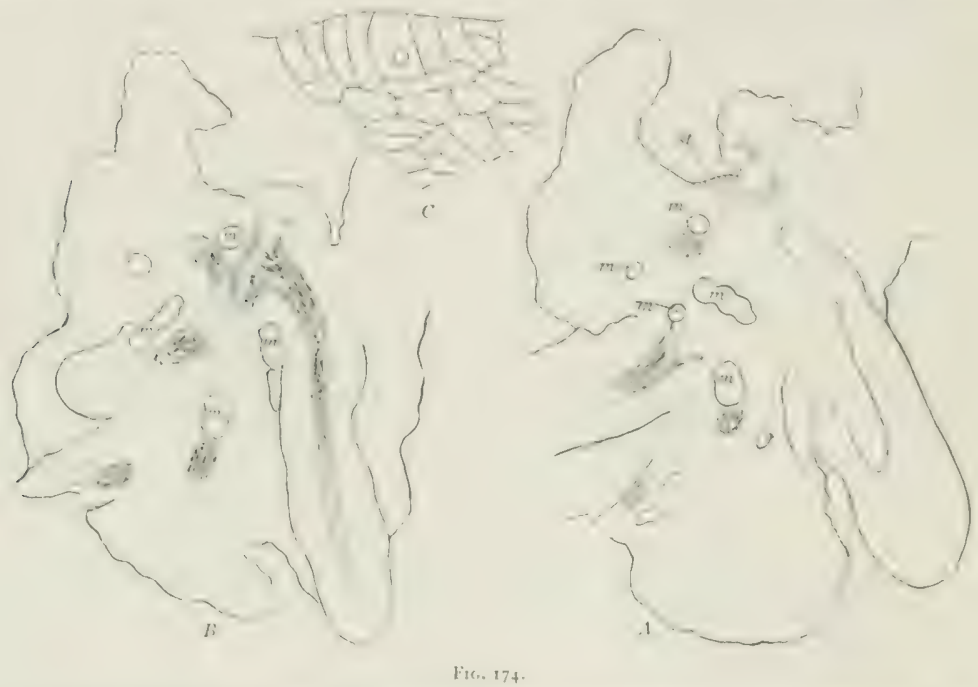

A, B. Two longitudinal sectiuns of an ohter sporophyte of Maraltia douglasii. st, stem apex; m, mucilage ducts. K25. C. stem apex, xitio.

the case in M. fraxinea, could not be satisfactorily determined. At this stage the section of the young plant almost exactly resembles a similar one in Damca, and presumably the single central strand is composed of the confluent leaf traces from the three first leaves, as it is in Dancen.

The xylem of the bundle is still composed exclusively of short, reticulate tracheids. Large mucilage ducts and numerous tannin sacs are developed in the petioles of the older leaves and the elongated tannin sacs, like those in the roots of Danca and Angiopteris, are sparingly developed in the young roots; but both tannin sacs and mucilage ducts were absent from the stem tissues at this peried.

In a still older plant (fig. $17+$ ) the single central bundle of the basal region is replaced by the separated steles of the single leaf traces, which are beginning fo form the open dictyostele characteristic of the adult sporophyte. The exact nature of its origin could not be followed in the material at my disposal, but it is presumably. 
much the same as that described for Danaa, since the appearance of the longitudinal sections in Marattia is exactly like that of corresponding stages in Danca. The apex of the stem, however, is much broader than in Danaa. There is in the middle of the apical region a cell which from its size and position may be pretty certainly denominated the apical cell (fig. $174, C$ ). There is present a strand of procambium which ends abruptly a short distance below the stem apex. This strand probably represents the primary commissural strand, which, as in Danca, is in all probability a truly cauline bundle and has no direct connection with the leaf traces. In the central region of the stem there are now several large mucilage ducts, but tannin cells are still absent. In the roots, however, the tannin cells are abundantly developed.

Farmer and Hill's brief account of the development of Marattia fraxinea agrees with my own observations so far as they have gone, except for the interpretation of the vascular bundles. The "protostele" found in the lower part of the stem is undoubtedly the common bundle of the primary root and the cotyledon, and the open "siphonostele" is really made up of separate leaf traces, which anastomose at certain points to form the large meshes of the very open dictyostele. Farmer and Hill call attention to the fact that the "foliar gaps" are much wider than in Angiopteris, and in consequence the separate strands, seen in section, form a circle of apparently quite separate bundles, evidently closely approximating the condition found in Danaa and Kaulfussia. Farmer and Hill do not make it quite clear that the commissures which they found developed later, connecting the strands of the dictyostele, were really parts of the central cauline strand, but they presumably assume that such was the case, as this is explicitly stated in the case of Angiopteris, which they also studied. The structure of the bundle in the latest stage described by Farmer and Hill agrees pretty closely with the condition described by Kühn in the youngest specimens which he studied, where the stem was about a centimeter in diameter.

The early leaf traces, as in the other Marattiacex, are single, but later on double traces are formed. According to Farmer and Hill, the two bundles of the leaf trace unite before joining the vascular cylinder of the stem. No material was available for a further study of the development of the bundle in $M$. douglasii, but it probably agrees with that of $M$. fraxinea.

Several young plants of $M$. alata were examined for comparison with the young germ plants of $M$. douglasii. The specimens in question (fig. 175) had arisen as adventitious buds upon the old leaf bases which had become separated from the stem. This manner of formation of the young plants is very common in this species (see plate 12, A). In one of these young plants, in which the stem was about 4 centimeters long and 1.5 centimeters in diameter, exclusive of the leaf bases, the oldest expanded leaf had a petiole of about 8 millimeters in diameter. In these young plants there is usually only one leaf expanded, so that they have a very different appearance from the fully developed sporophyte with its crowded circle of leaves, and these monophyllous plants remind one very much of sterile specimens of some of the larger species of Botrychium (plate 12, B). A section of the petiole of this specimen showed ten vascular bundles arranged in a circle, within which, on the ventral side, were two other bundles. The section resembled almost exactly that of the petiole of a fully developed leaf of Helminthostachys. At the base of the leaf are the two very conspicusus stipules, one of which overlaps the other. These stipules are connected by a commissure which joins the two stipules near the base and is entirely concealed within the cavity formed by the overlapping stipules, but can be seen on raising these, as a hood-like membrane, overarching the next 
younger leaf. lig. 175. K, shows a young leaf from another plant, in which one side has been cut away so as $(0$ show the relation of the stipules to the leaf base. This leaf was still conled up and its apex was quite concealed within the large overlapping stipules. Both as to its position and its relation to the stipules, the commissure exactly resembles the lip-like basal extension of the stipular sheath in

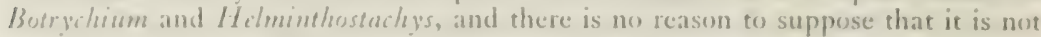
exactly homologeus with this.

Partially inclosed by the stipular sheath of the expanded leaf is the next younger leaf, which is cut in a plane nearly at right angles with that of the oldest leaf, so that the overlapping of the stipules, which entirely conceal the rest of the leaf, is very plainly seen (fig. $175,13, l^{2}$ ). Within the stipular sheath of this leaf is a still younger one, which is entirely concealed from view from the outside, but shows plainly in longitudinal sections, taken next to the center of the bud. The stem apex is entirely concealed within the sheath of the younger leaf. The resemblance of this section of
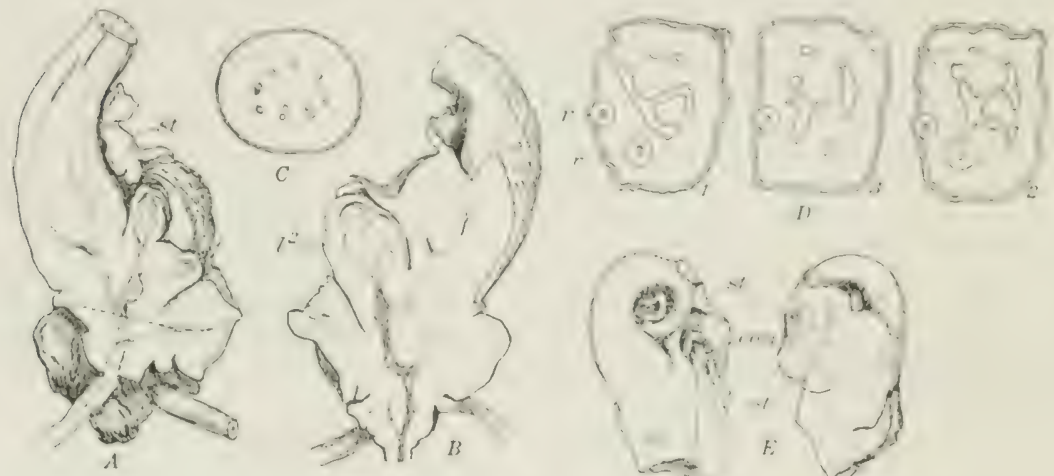

Fig. 175.-Martitu alate Smith.

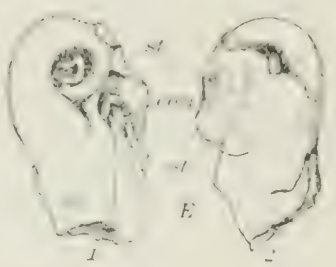

\footnotetext{
A, B. Young plane developed as a bud upen an old leaf base. The outer tissue has been cut away, and the twe sudes of the thick central section are shown. $X_{1}$.

C. Section of petiole of leaf.

D. Three sections of a rhizome of a sinall plant. $X_{\mathbf{I}} \cdot 3 \mathbf{3}$

E. Young leaf. The lamina is coiled up within the large stipules, st. In ( 1 ) une uf the stipules has been cut away to show the commissure, com. $\times_{1.93}$
}

the young plant to a similar section of the bud in one of the larger species of Borrychium or of Hclminthostachy's is sufficiently striking.

The bundles forming the ring in the petiole anastomose freely in the leaf base, as they do in Kaulfussia or Ophioglossum pendulum, so that the number of strands in the leaf trace is smaller than the number of bundles within the petiole.

The vascular bundles in the stem form a single very open mesh-work, with which the leaf traces join and which is, with little question, composed entirely of these leaf traces, as it is in the earlier stage. Indeed, except for the larger size of these plants, there is no essential difference between them and the young germ plants, described in $M$. donglasii. Several roots are usually developed before the first leaf of these young bud-plants unfolds. Probably one root develops for each leaf, but it is not certain that this is always the case. ()wing to the thickness of the cortical region which has to be traversed by the root before it emerges, the roots have already reached a large size before they appear upon the outside. This deep- 
seated origin of the roots of the Marattiacex has often been figured and described. The roots from the base of this plant showed the hexarch structure, the six xylem masses being united in the middle of the stele. About half-way between the stele and the epidermis of the root is a circle of large mucilage ducts, but these were quite absent from the outer cortex. No mycorrhiza could be found, except that in the outermost layers of cells, which constitute a rudimentary periderm,occasional fungus filaments can be detected, but these are very different in appearance from the typical mycorthiza found in the primary root of the germ plant. No root hairs could be found, but occasionally short stumps were seen which looked as if a root hair had been broken off.

Fig. 175, D, shows three consecutive free-hand sections of a stem from a plant of about the same size as the one we have just described, but evidently much older, as there were the remains of many leaves and the whole caudex, except for its smaller size, was very much like that of the adult plant. The broad vascular strands made up of the contluent leaf traces formed an irregular circle which in fig. $175, D, 2,3$, shows the free central strand which lower down forms the commissure across the central parenchyma. The arrangement of the bundles, therefore, in the young plant of Marattiacee is the same as in the adult rhizome of $K$ aulfussia. In these sections two roots are shown, one of which is cut through the point of junction with a strand of the dictyostele (fig. I75, D, I). As in the younger germ plants, tannin cells are quite absent from the stem, although in the roots they are conspicuous. A few large mucilage ducts, however, occur in the ground tissue of the stem.

Farmer and Hill give one figure of a cross-section of the stele from the young stem of Maratio which shows that it has essentially the same structure as that of Danaa. There is a fairly well-marked endodermis, within which lies a broad zone of phloem, entirely surrounding the central mass of xylem.

According to Kuhn, there is in the older plant a second circle of bundles within the first, but no satisfactory account is given as to the relation of the bundles making up this second circle with those of the outer dictyostele. However, it is probably composed also of elements derived from the leaf traces, but it is possible that some of the strands may be of cauline origin.

THE ADULT SPOROPHYTE OF MARATTIA.

The genus Marattia includes about 25 extremely variable species, some of which, e. g., M. fraxinca, closely resemble Angiopteris in their general habit (see Bitter 1, page ++1 ; Christensen 1). They occur in the moist, tropical regions of both the Old and New World, and one species, M. salicifolia, extends as far south as the Cape Region of South Africa. M. douglasil is a conspicuous fern of the Hawaiian Islands. This species I have studied somewhat in detail, as well as the West Indian $M$. alata, which is abundant in the mountain forests of Jamaica. These two species closely resemble each other in general habit and have the leaves very much more divided than is the case in M. fraxinea and its allies (see plate 12 ).

The stem in the adult plant is an almost globular, upright caudex, a foot or more in diameter in large plants. The closely set, spirally arranged leaves have very stout petioles, 5 or 6 centimeters in diameter at their base, which is enlarged and provided with two very large wing-like fleshy stipules, which, with the base of the leaf, remain attached and completely cover the caudex after the petioles have fallen away. There is at the base of the leaf, as in the other Marattiacex, a pulvinuslike enlargement, where the leaf breaks off, leaving a clean scar marked by the broken ends of the vascular bundles. The leaves may reach a length of 2 to 3 meters ir 
even mose. The thick, Heshy exeure of the leaflets, much like that of Bofryetrinm ternatum or B. silaifolium, at once distinguishes Maronta from any of the large leptespenangiate ferns with which it may be associated. The resemblance on the leaves of Botrolium is especially marked in the young plants geowing from the stipular buds. These leaves show a marked rrangular outline, curiously similar to that of ehe latger species of Botrychum (see plate 12, 13). The venation of the leaf-

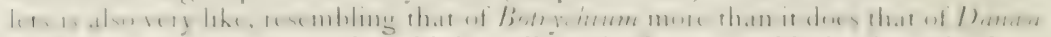
or Angiopseris. In the species with large linear leaflets, e. g., I/. froxinea, the form

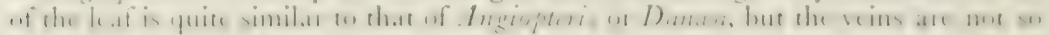
elosely approximated.

The structure of the leaf was particularly studied in $M$. alata, which closely resembles the Hawaiian $\mathbf{M}$. douglasii. In well-grown specimens the leaves measure 2 or 3 meters in length, with a petiole which is 5 or 6 centimeters in diameter above the insertion of the stipules and is somewhat larger lower down. Where it joins the stem there is a marked constriction and the leaves often become broken off at this pesint, the fleshy leaf base remaining alive and of ten giving rise to adventitious buds (plate $12, A, 3$ ). A section of the leaf base above the stipules shows the vascular

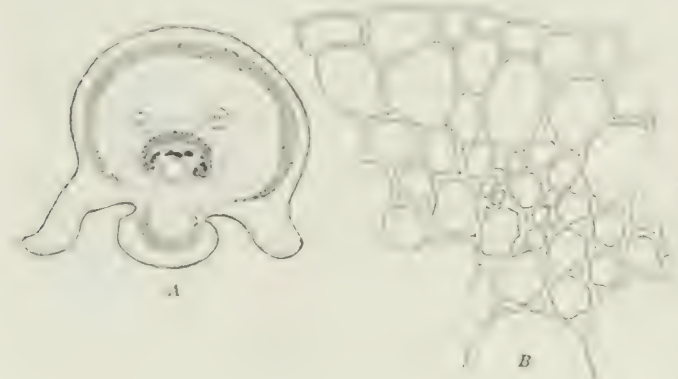

Fic. 176.

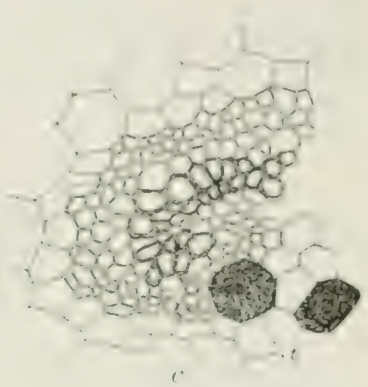

c.

1. Secsium of ultimate rachis of a leattet of . Marathia alata. The shaded area is cullenchyma; m, mucilace Jucts.

13. Collencluma cells, nore highly magniticd.

C. Vart of vascular tundle. The shaded cells are tannin sacs.

bundles to be arranged in two large concentric circles, within which is a smaller third ring corresponding to the two inner bundles found in the section of the younger leaf. Below this point there are numerous anastomoses of the bundles before they enter the cortex of the stem, and the leaf trace consists of a much smaller number of bundles, eight in the specimen examined, which are arranged in a single circle, open on the adaxial side. The distribution of the bundles to the stipules was not studied, but it no doubt corresponds to that in other species, where the veins form an extensively branched system, connected with the bundles of the petiole.

The large leaves of $\mathrm{M}$. alata, when fully developed, are five-pinnate, the ultimate

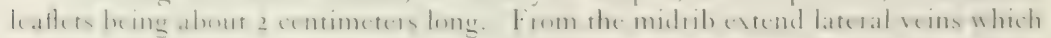
usually fork once but may remain undivided (plate 12, A, I). The bundles of the rachis in the later divisions of the leaf diminish in number and show the horseshoelike arrangement seen in the leaf trace after it leaves the petiole. In the final divisions the crescent of hundles seen in the larer rachis is always completely united and in section appears as a single horseshoe-shaped bundle (fig. $176, A)$. In the main stipe and secondary and tertiary rachis there is a conspicuous hypolemal sheath of sclerenchyma. This sclerenchyma passes into collenchyma near the base of the 
stipe and finally disappears entirely before the stem is reached. The sclerenchyma is also replaced by collenchyma in the rachis of the terminal divisions of the leaf. Tannin sacs are quite absent except from the immediate vicinity of the bundles, where they occur upon the inner concave side, either in direct contact with the bundle or actually within it. The leaf lamina is only about half as thick as that of the leathery leaf of Danca clliptica, but shows much the same structure. The palisade cells are not quite so well developed and there is a complete absence of sclerenchyma, but otherwise the structure is very similar. The cells of the epidermis are undulate in outline and the stomata, like those in Dana a, are surrounded by a series of accessory cells.

The large roots may attain a diameter of 6 to 7 millimeters. In the absence of the hypodermal sheath of sclerenchyma they more nearly resemble Kaulfussia than Danca, but they are more like Danca in the greater number of xylem rays, which number twelve in the largest roots examined. In these later roots the central part of the stele is occupied by the pith, the xylem rays not being united as they,
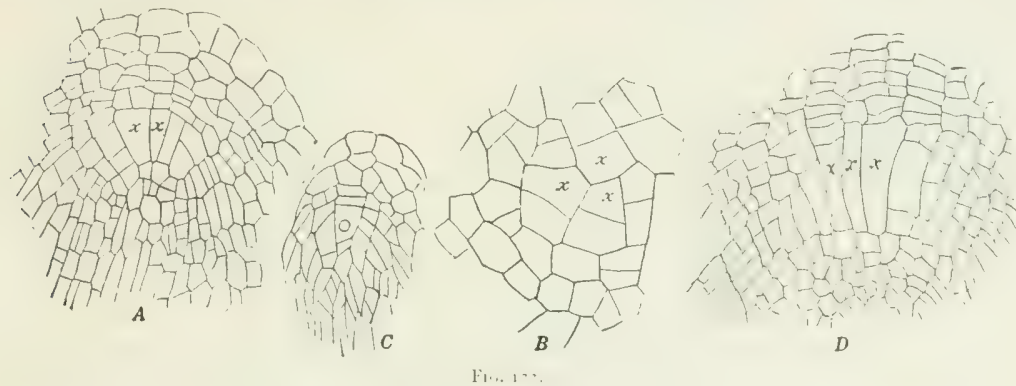

1. Apex of a small root of Marattia douglasii, showing two initial cells.

B. Transverse section of apex of a similar root.

C. Longitudinal section of the apex of the second root.

D. Apex of a large root of $M$. alata. $x$, initial cells. $\times 200$.

are in the roots from the younger plant, but in some cases a few scattered tracheids appear in the central region. There is usually a ring of conspicuous mucilage ducts in the cortex, but these were sometimes not very well developed. Numerous tannin sacs are scattered through the cortex and also occur within the stele.

\section{THE SPOROPHYTE OF ANGIOPTERIS.}

Angiopteris is the largest and most specialized of the Marattiacex. As we have indicated before, there is much difference of opinion as to the number of species which should be recognized and many botanists consider that all of the forms belong to a single extremely variable species. Bitter, however, in his account of the Marattiacere in the "Naturliche Pflanzenfamilien," thinks that from 20 to 30 species should be recognized, following in this respect the classification given by Presl and De Vries; while Christensen (Christensen 1) recognizes 62. I have examined material from Australia furnished by Mr. J. H. Maiden, director of the Botanical Gardens in Sydney, as well as material collected by myself in Ceylon and Java. Some of the specimens growing in the Botanical Garden at Buitenzorg are the largest that I have seen. Leaves 6 meters and upwards in length were measured and the upright caudex was almost as big as a barrel. The specimens seen in Ceylon were somewhat smaller. 
Forms of Angioperis oxcur from Lolynesia to Madagasear and northward as far as the llimalayas. The genus also occurs in norehern Australia.

The anatomy of the adult plant has been investigated more thoroughly than that of any other member of the Marattiacede. The most recent account of the anatemy is that given by Miss Shove (Shove 1), while farmer and Hill have carefully investigated the vascular system of the young sporophyte. A number of preparations were made by the writer for the purposes of comparison with the other genera, but no attempt was made to follow out in detail the extremely complicated vascular skeleton of the adule sporophyte. Farmer and Ilill (Farmer 3 ) have given a detailed aceount of the development of the vascular system in the young sporophyte of Angiopteris, so that it was not thoughe necessary to make a large number of preparations of this species, the material of which was collected at the same place where Farmer obtained his plants. However, as these authors did not trace the development of the young bundles from the apical meristem, it secmed worth while to examine this point for the purpose of supplementing their account based upon the study of the fully developed vascular skeleton.
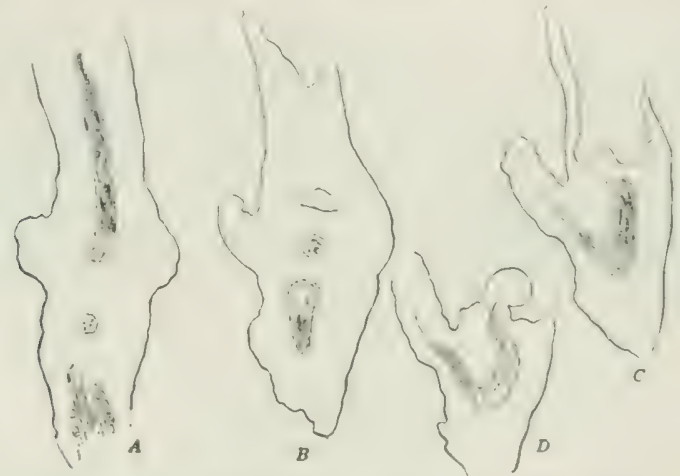

Fic. 178.-Four longitudinal sections of a young sporophyte of Angioperis.

The vascular system begins, as was recognized by Farmer in an earlier paper (Farmer 1), as a single strand connecting the root and cotyledon, exactly as is the case

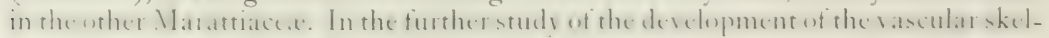
eton l'armer and Hill employed the method of constructing a model of the vascular system, built up of supermposed sheets of wax, corresponding with the outline of the vascular bundles seen in the serial sections. The figures which they give, drawn from such models, show very clearly the relation of the vascular strands which make up the complicated skeleton in Angiopteris. The assumption is made that the single stele found in the young plant is really a cauline structure, the leaf traces being subsidiary. The early history of the vascular system of the young sporophyte is given by ehem as follows:

"The vascular skeleton in the young plant of Angiopteris consists of an axile rod of tissue, from which strands are given off to the roots and leaves respectively:

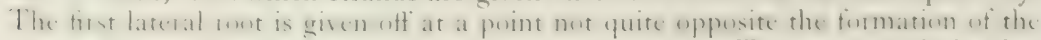
first leaf trace. It is separated from it by about $130^{\circ}$. The regular relation between the leaf and the corresponding root is, however, soon lost. The gaps produced by the early leaf traces are very small and are immediately made good above. The 
first deeply depressed aperture or gap occurs at about the sixth or seventh leaf. The leaf traces still continue to issue from the stele as single strands till a varying number have been formed, but they begin to bifurcate while still within the cortex of the stem.

"As the stem increases the leaf traces become more numerous and crowded and they take away a larger portion of the vascular tissue from the axile strand. The result is that the leaf gaps become less rapidly repaired. The stele is already hollow in this region, that is, it consists of a cylindrical vascular mass with perforations corresponding to foliar gaps and inclosing a core of parenchyma. Sooner or later, the gap above one leaf fails to be repaired until after the exit of the trace of the next leaf and then the original vascular cylinder becomes broken up and assumes a condition, in transverse section, conforming with that of polystely or dialystely."

There is thus a gradual transition from the solid stele found in the earliest stages to a hollow cylinder or siphonostele with a core of pith, and by the formation of larger and larger leaf gaps there is a transition to an open dictyostele like that found in the other genera. Finally there appears the commissural strand which forms a thick
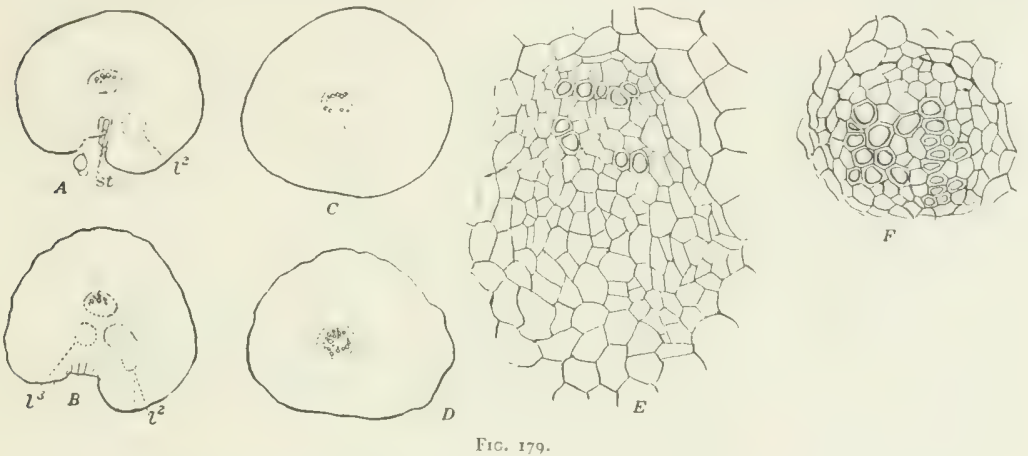

A-D. Four transverse sections of a tery young sporophyte of Angiopteris. A, traverses stem aper. B, C, show
the fusion of the first three leaf traces.
E. Central region of C. $\times 200$.
F. Central region of D. $\times 200$.

strond traversing the pith and undoubtedly of cauline origin. This central strand becomes more and more important as the plant develops and from its central position might be mistaken for the original axial strand of the young sporophyte. The vascular system at this stage is described as follows:

"The leaf traces become more complex and anastomoses take place at irregular intervals with the strands which can still be recognized as the relics of the original siphonostele, as well as with one another. Irregularities also commence to become apparent as to the relative heights at which the two members of the leaf traces become freed from the plexus of tissue, and a stage is thus reached at which the vascular skeleton appears to consist of a stout axile strand, surrounded by upwardly diverging zones of steles, which ultimately pass out above to the leaves."

It is evident that at this stage there is a condition which is very much like that figured by Kühn for Kaulfussia, and it is pretty clear that the whole of the dictyostele, exclusive of the axial or commissural strand, is made up of the "upwardly diverging zones of steles which pass out above into the leaves," i. e., in other words, the dictyostele is composed of a union of multiple leaf traces. 
Transverse scerions of a very young sporoplyte of Angiopteris show the same. refarion of the parts as in the other genera. The junction of the traces of the first. second, and third leaves takes place at a very short distance below the stem apex, which, as fiamer poined out, slows an ummistakable apical cell of somewhat irregulat form. Compased with the other genera, the primary leaf trace in Angepteris las the xylem beter developed, and composed of about half a dozen tracheids, where the trace enters the stem. This primary leaf erace is concentric, as it in the later leaves, and not collateral, as it is in Danaa (fig. 179).

Near the point of the junction of the three primary traces, there may be seen in the young traces from the second and third leaves the first tracheary tissue, consisting of one or two tracheids. As the sections are examined lower down the tracheary tissue of the second and third leaf traces increases in amount until it forms a solid band, separated from the corresponding xylem of the primary leaf trace by a band of parenchyma. The three leaf traces are now completely fused, but the sections of the two xylems are perfectly evident, and this band of tissuc between
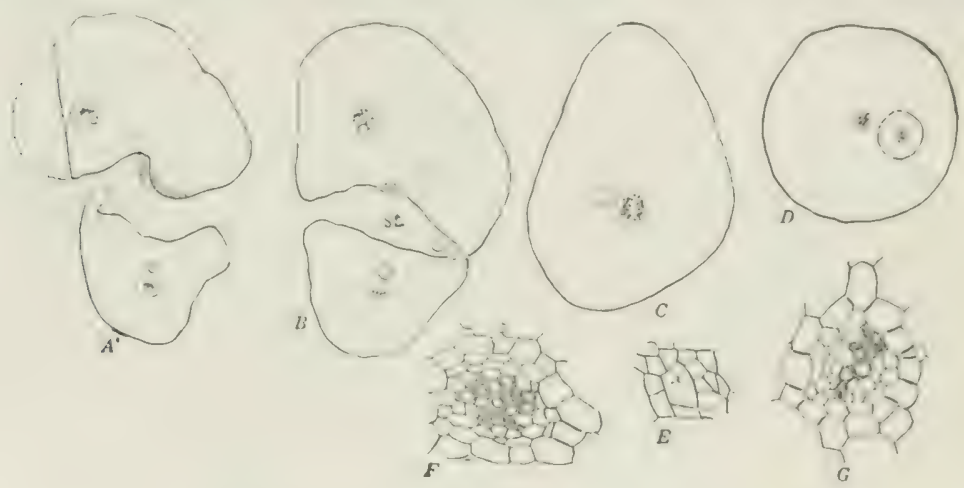

Fin. ISo.

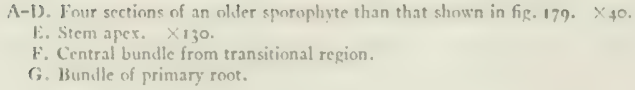

the two xylems (which really belongs to the ground tissue of the stem and not to the stele itself) corresponds to the "pith" figured by Farmer and Hill for the transitional region between the root and stem (fig. $180, C$ ). Sometimes, in still lower sections, the two xylems are connected, but I have found no cases where the pith was entirely surrounded by the xylem, and the two xylems of this axial strand merge gradually into the two xylems of the diarch primary root (fig. I 79, G). The endodermis is clearly evident in the intermediate region and is recognizable also at higher levels, but is less easy to distinguish.

In a series of sections, from a plant in which the fifth leaf was just recognizable, a section at the level of the stem apex shows the apical meristem to be composed of several large cells, one of which is probably the single apical cell, but this is not casy to determine. The base of the fifth leaf is close to the apical group and the section of its stele is indicated by a group of small cells close to the stem apex. The stcle of the third leaf is clearly seen, separated from the fourth leaf by about onethird the circumference of the stem. Below the stem apex these two leaf traces 
approach, but are still separated by a considerable mass of tissue, lying directly under the stem apex. The two bundles finally join and between them there seems to be a sort of connective tissue which may perhaps belong to the stem itself, so that this central stele of the stem may possibly have a certain amount of cauline tissue in addition to that derived from the leaf traces; but it is quite as likely that this connective tissue between the bundles is nothing more than a lateral extension of the leaf trace itself, very much as is the case in Melminthestaihys and Botrichium.
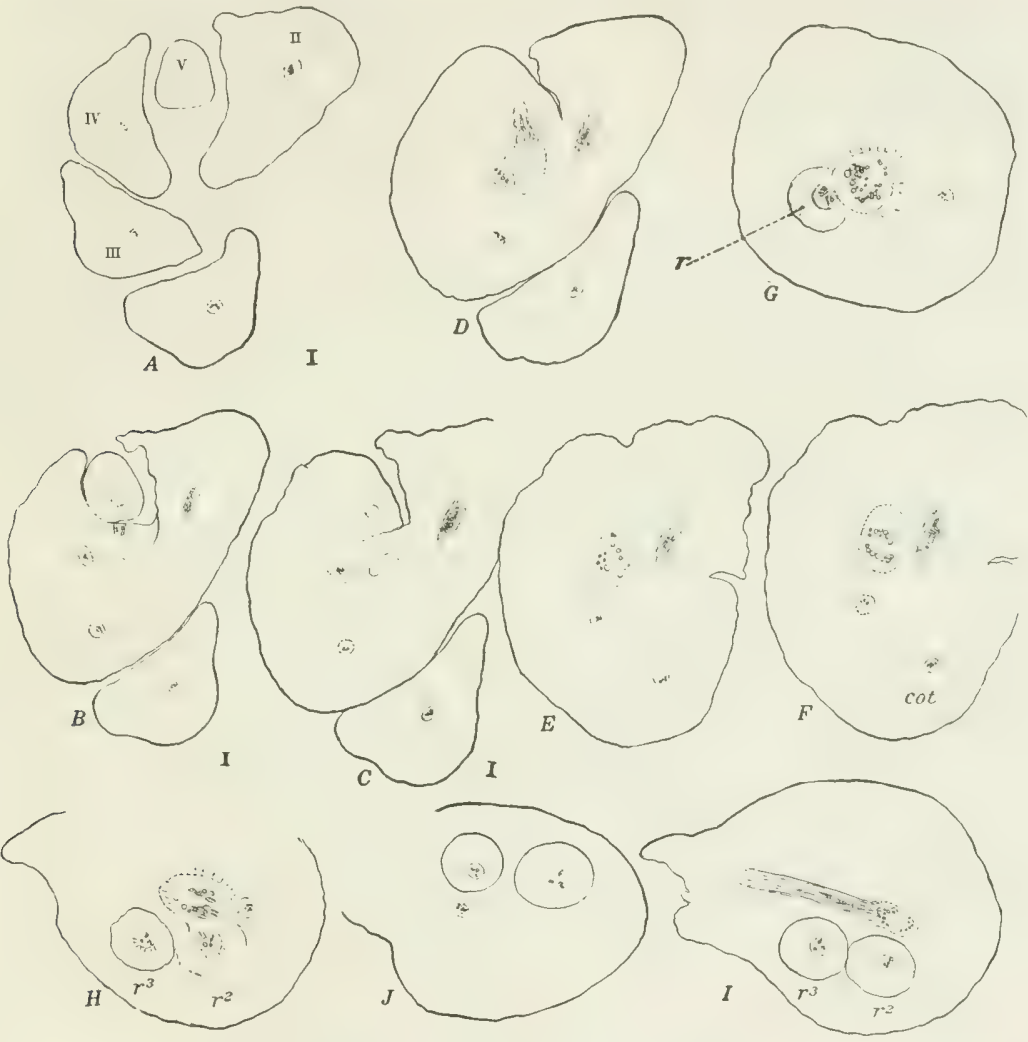

Fia. 181.- Series of transverse sections from a sporophyte of Angiopteris, showing 5 leaves.

$r^{2}, r^{3}$, second and third roots. $\times 25$. B, traverses the stem apex.

When the fusion is complete, the section of the stele appears circular in outline and the whole of the tissue is apparently quite uniform, with the exception of a single tracheid marking the position of the xylem of the older leaf trace. There follows almost immediately the older leaf trace which joins the solid stele, formed by the fusion of the traces from the third and fourth leaf, without causing any break. At this level the first tracheary tissue can be seen in the fourth leaf trace also. The structure of the stem below the junction of the second and third leaf traces is the same as that already described for the younger sporophyte. A very young root was 
formed just opposite where the second leaf trace joined the stele. The apical cell, which had apparently developed from an endodermal cell, had only undergone the first division. This root was probably not the first lateral root, or if it was, it had formed very much later than is usual. The base of the plant had been somewhat injured and there was what looked like the remains of another root, which was probably the first lateral root.

The oldest specimen of which sections were made had four fully developed leaves and the rudiments of the fifth and sixth. An examination of the lower series of sections showed the remains of one or two other leaves and it was probable that eight leaves all together had been formed. At the level of the stem apex (fig. 181, B) six separate leaf traces could be seen and the relation of the younger ones to the apex was exactly the same as in the younger sporophyte. Below the apex, the central stcle of the stem shows a broken ring of procambium inclosing larger parenchyma, representing the pith. The procambium ring is made up evidently of two portions, one of which is certainly referable to the sixth leaf trace, while the opposite one perhaps represents the beginning of the next leat trace, although the leaf to which it belongs is not yet evident above (fig. $181, D$ ). The junction of the leat traces so) close (o) the stem apex makes this point very difficult to decide.

The fusion of the fith and fourth traces follows quickly and the resulting stele shows plainly the three separate xylems of its component bundles. The older portion of the stele shows that it is still solid, with no evident leaf gaps (fig. 18\%. $(E-G)$, but with several groups of tracheids probably corresponding to as many leat traces, though less distinct than in the younger plant. 'This is complicated by the fusion of the root traces, which disturbs the arrangement of the xylems from the leat tlaces, hut he whem is less compact than is tigural he Fame and llill and the "pith" much less definite; indeed, one can hardly speak of a pith in this connection. No trace could be seen of the central commissural strand which later makes its appearance and which presumably arises in the same way that it does in Danara.

In the early stages Angiopteris appears to agree closely with the other Marattiacese in the development of its vascular system, but the single central stele without leaf gaps is retained much longer than in the other genera and it also becomes much larger and has a better-developed xylem, and the open dictyostele, formed from the anastomosing of the early single leaf traces, characteristic of Dance and Marattia, is not present. It is not quite clear whether the "siphonostele" with its small leaf graps, which is the next stage in the development, is made up entirely of leaf traces, and it is possible that the stelar tissue, connecting the adjacent leaf traces, may be composed in part of cauline tissue. On the other hand, it is quite as likely that the connection of the leaf traces is brought about merely by a broadening at the point of contact, such as occurs in Helminthostachys. Indeed, at this stage, the stele of Angiopteris is more like that of Helminthostachys than like that of the other Marattiacese.

THF ADULT SIOROPHYTE OF A.NGIOPTFRIS.

In habit Angiopteris closely resembles the larger species of Maratia. The enormous leaves are arranged spirally about the thick upright caudex, which is covered completely by the persistent bases of the old leaves. The leaves are usually twice-pinnate; the linear leaflets have more or less conspicuously serrate margins with a venation very much like that of $D$ anca, the veins being more closely set than in Marattia. In addition to the ordinary subterranean roots, large aerial roots are not infrequent, but it is doubtful if there is any essential difference between the two kinds of roots. 
The anatomy of the stem closely resembles that of Marattia, but the bundles seen in section are much more numerous and instead of being arranged in two circles, exclusive of the central commissural strand, are usually arranged in"four or five. The first complete study of the arrangement of the bundles in the stem was made by Mettenius (Mettenius 2). A summary of his results is given in the paper by Miss Shove. Briefly stated, Mettenius describes the distribution of the bundles as follows (Shove 1, p. 498 ):

"The vascular bundles form funnel-shaped zones, with their lower ends in the axis of the stem and their upper portions continued out into the leaves as leaf traces. It is the transverse sections of these concentrically arranged funnels which appear as the rings of separate bundles in the section of the stem. Segments from the outer zone pass into the leaves as the leaf traces and the gaps thus left are filled up by corresponding segments from the next inner zone."

The detailed account made by Miss Shove was based upon a moderate-sized specimen from Ceylon. This stem is described as being somewhat dorsiventral in structure, which is certainly not usual in Angiopteris and may perhaps be explained by the conditions under which the plant was growing. I found Angiopteris growing frequently upon steep banks and it is quite possible that plants growing in such a position might be obliged to bend upward, in which case a somewhat dorsiventral structure would be developed. Plants growing upon level ground, so far as my observations go, are always strictly radial in structure.

Miss Shove found essentially the same structure as that described by Mettenius, except that she states that the leaf traces are developed exclusively from the strands of the outer zone, while Mettenius states that strands are also contributed to the leaf trace from the second zone. 'The following is taken from her paper (Shove 1):

"The general scheme of the arrangement of the vascular tissue in Angiopteris is almost clearly conceived by considering it in connection with the insertion of the leaves. The leaf bases, which are set in a rough spiral on the stem, show in their lower parts a meshed segment of vascular tissue having the form of part of the surface of a cylinder. This segment passes from the leaf base into the outermost zone of the stem, uniting right and left with the strands of this zone. Then, continuing in an obliquely descending direction, it passes on into the second zone and so on until it reaches the longitudinal axis of the stem, where it unites with other leaftrace bundles and loses all individuality."

Miss Shove found that the steles in the stem were both mesarch and endarch in structure. The protoxylem is found in groups of two or more spiral tracheids, some of them at the periphery and some in the center of the stele. The number of protoxylems varies with the size of the stele, the larger ones usually containing five or six such groups. The earliest protoxylem appears at the periphery of the stele. Protophloem is developed upon the outer side of the stele in the form of discontinuous, small, thick-walled elements, which Miss Shove regards as sieve tubes. This protophloem does not occur upon the inner side of the xylem. A remarkable peculiarity of the bundle is the fact that the secondary sieve tubes are formed outside the protophloem instead of within it. The phloem is of greater breadth on the outer side of the stele than on the inner. No endodermis could be detected about the steles in the stem. The usual absence of sclerenchyma was noted for the stem. Miss Shove was unable to determine the nature of the apical meristem and the question still remains open, whether the stem grows from a single apical cell or from a group, such as is found in the larger roots.

It appears from the account of both the older and more recent investigators that the complicated system of concentric meshed zones in the adult stem of Angiop- 
teris is really built up of leaf traces, gle se-called "compensating segment" being menhing more than the lower part of a leat eace which higher up emerges as a meshed serencent fum the outer zone and passes into the base of the leaf.

The structure of the periole (fig. $182, d$ ) is like that of Maratiat, except that the vascular bundles ate mote numerous and are arranged in several circles, inclosing one or two small bundles in the center. A couss-section of a leaflet (fig. $182, B$ ) shows the vascular hundle which traverses the michib on be horseshoe-shape in section, having a central mass of tracheids, with reticulare or scalariform markings, and surrounded by the phloxm, largely made up of large sieve tubes, but having also protophloem cells and bast. The ground tissue is composed largely of parenchyma, but on both sides below the epidermis is a conspicuous band of collenchyma. In the larger divisions of the leaf the collenchyma, as in Marattia, is replaced by. sclerenchyma. The structure of the lamina is very much like that of Danca, but the palisade parenchyma is even better developed.

A comparison was made of the leaves of two forms (species?) of Angiopteris, one from Australia, the other from Ceylon. These showed several notable differences. The leaflets of the Ceylonese specimens were thinner and sharply serrate,
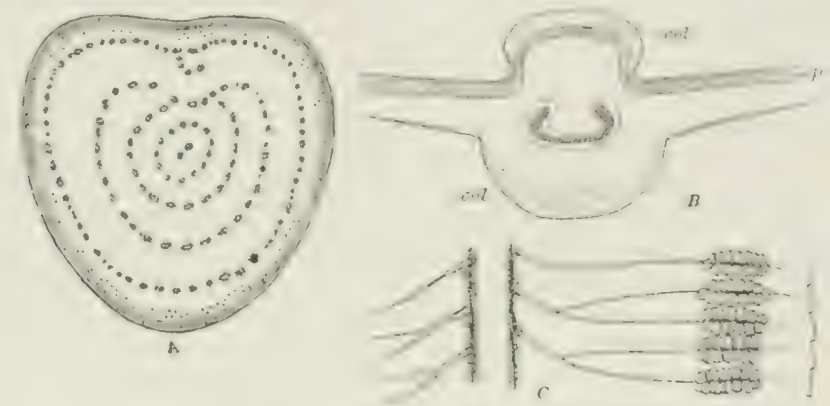

Fuc. $15 z$.- Ingiopteris.

A. Section of petiole from an adult sporophyte, somewhat reduced.

13. Section of a leaffet. col, collenchyma: $p$, palisade tissue. $X_{14}$.

C. Part of spornphull, showing the sori. $x_{4}$.

while in the Australian specimens the serrations were almost wanting, except at the tapering apex of the leatlet. There were also marked anatomical differences. In the Australian form the palisade cells are very much elongated and are separated from the epidermis by a layer of colorless hypodermal cells, and the spongy mesophyll of the lower part of the leaf is decidedly more compact than in the form from Ceylon. In the latter, the palisade cells are noticeably shorter and abut directly upon the epidermis. Undoubtedly the differences in the anatomy of the two forms are associated with the difference between the moist, tropical climate of Ceylon and the drier and cooler climate of Australia, and perhaps do not necessarily imply that the two species are distinct, although it is highly probable that such is the case.

The roots originate, for the most part, in the inner zones, but a few may arise in connection with the bundles of the outer zones and must necessarily traverse a very large amount of tissue before they finally emerge.

Russow (Russow I) described two sorts of roots-earth roots which were branched and had but five xylem rays completely lignified to the center of the bundles, and acrial roots which were much larger and unbranched and had twelve to 
twenty xylem rays, only the outer tracheids being lignified. In the plant which was examined by Miss Shove only the earth roots were found, and these, instead of having only five xylems as Russow asserts, had from ten to thirteen and the xylem elements were entirely lignified. The probabilities are that there is no sharp line to be drawn between the aerial roots and the earth roots. Figure 183 shows a section of a root from the base of a small plant from Australia, in which there were fourteen xylem masses. As will be seen, there is the same circle of large mucilage ducts and the tannin cells that are found in the root of Marattia, which it very closely resembles. Root hairs are nearly or quite absent, in which respect these resemble the older roots of other Marattiacere. In two cases Miss Shove found a dichotomous branching of the root. This, while probably anomalous, is interesting, as it recalls the method of branching in the roots of Ophioglossum.

\section{ARCHANGIOPTERIS}

The genus Archangiopteris, with a single species, $A$. henryi Christ and Giesenhagen, is at present known only from a single locality in southern China. Archangiopteris in habit resembles a large Danca. The leaves, which reach a length of

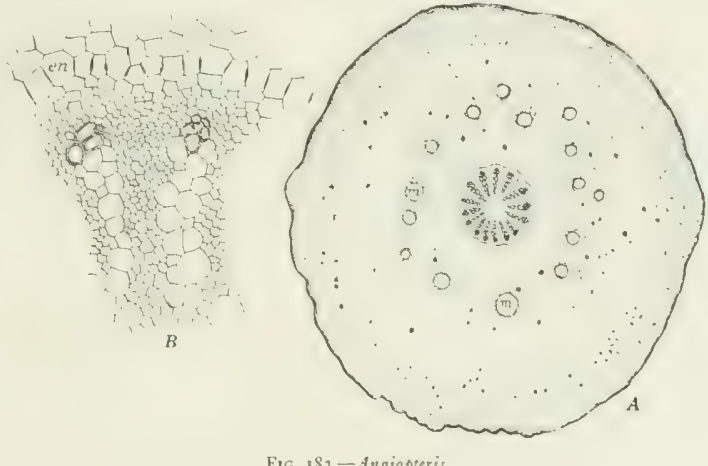

A. Section of a large root. $m$, mucilage ducts. $\times 14$.

B. Part of the central cylinder of the root. en, endodermis. $\times 70$,

about a meter, have from seven to twelve leaflets, much like those of Danaa elliptica, both in form and venation. The stalk of each leaflet is swollen in a manner that suggests the nodular sivellings in the petiole of Danca elliptica (fig. I 84 ).

The only account of the structure of the plant is that of Gwynne-Vaughn (Gwynne-Vaughn 2), but as he had only a fragment of a stem he was not able to make a complete study of the rascular system. To judge from the fragment of the stem which he examined, the leaves seem to be arranged spirally and the stem is probably radial in structure. The general structure of the leaf base seems to be most like that of $K$ coulfusso. The leat trace consists of only two vascular strands, which divide up later into several (eight or nine) separate strands, arranged at the base of the leaf in a horseshoe curve, quite like that of Kaulfussia. The arrangement of the rascular sistem of the stipules is probably the same as in the other Marattiacex. The structure of the stem is also apparently very much like that of Kaulfussia, a section showing only one circle of bundles with a single central strand. The root, which is like that of the other Marattiacex, has from seven to ten xylem rays. 


\section{MACR()(ILOSSLIT.}

This represents a new genus of Maratiacea, the one species of which, $M$. alide Copeland, has recently been described (Copeland 1). It is a large fern from Borneo, and is evidently related to Angiopteris, from which it differs mainly in its simply pinnate leaves, which may reach a length of about 3 meters (see Copeland 1, plate V).

\section{TISSUES OH THE MARATHACEA.}

There are often present upon the leaf bases of the Marattiacea peculiar lenticellike structures to which German writers have given the name "Staubgrubchen." These arise beneath the stomata, and form small cavities whose peripheral cells become detached and dried up, forming a dust-like powder.

Rod-shaped bodies, mainly composed of calcium pectate, are of common occurrence in the intercellular spaces of the tissues of the Marattiaceat. Siliceous deposits and crystals of calcium oxalate have also been observed in Angiopteris (sec Bitter 1 ).

The elements of the vascular bundles are much like those in the bundles of the ordinary ferns. 'The macheary tissue is composed manly of scalariform clements, and the sicve tubes have numerous lateral sieve plates, like those of the other ferns. Lill and famer have noted a slight secondary formation of wood in Angiopteris, somewhat similar to but much less marked than that in the stem of Botrychimm virginianum (see Hill 1, Farmer 3).

THE SPOROPHYII, OH: 'THE MARATTLCE.:

The Marattiacese differ most strikingly from the Ophioglossace in the character of the sporophylls. In all of the living Marattiacex the sporan-

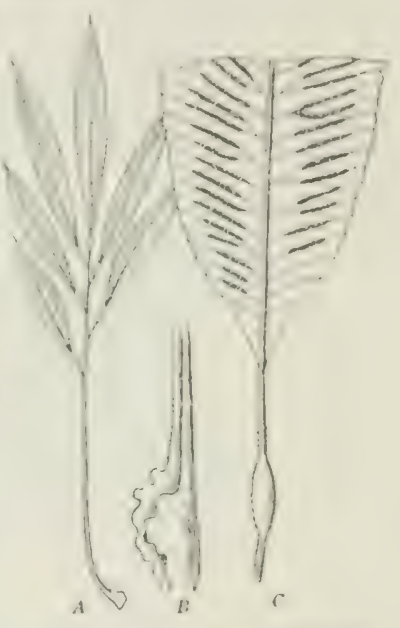
gia or synangia are borne upon the lower surface ric. $1 \$_{4}$-.-Archangioperis henrys (after Christ of the leaves, which usually are not at all different from the sterile ones. In Danca (fig. 189 ) the sporophylls are decidedly contracted and the very large synangia almost completely cover the lower surface of the leaflets, but in the other genera the sporophyll is not at all contracted and much the greater part of the leaf surface is free (figs. $182,184,185,188$ ).

Kaulfussia (fig. 188) differs most from the other genera, the very peculiar circular or rarely oval synangia being scattered apparently without any definite order over the whole lower surface of the leaf. In Danca the elongated synangia, which lie over the veins, extending from the midrib nearly to the margin of the leaflet, are crowded so that they leave very little of the surface free. In Marattia and Angiopteris the synangia lie over the veins as they do in Danas, but they are very much shorter and are formed near the margin of the leatlet, within which they form a single line which occupies only a very small part of the leaf. Archangiopicris, except that the synangia are very much longer, agrees closely with Angiopieris.

No proper indusium is present in the Marattiacex, although very commonly about the base of the synangium there are found a few hairs or scales which have sometimes been considered to represent an indusium. In Dana a there is a growth of tissue between the elongated synangia, which grows up into a sort of ridge, the 
top of which is expanded so that it overarches the synangia. This ridge in section appears T-shape. Whether this growth of leaf tissue between the synangia in Danca is to be considered as an indusium may be questioned. It appears to be very similar in structure to the oblong cavity or fovea, within which is sunk the not very dissimilar synangium of Isoëtes (fig. I $89, B$ ).

THE SPORANGIUM OF THE MARATTIACE E

In Angiopteris and Archangiopteris there are formed separate sporangia not very unlike those found in Botrychium or Helminthostachys, but in all the other genera the sporangia are fused into a synangium which might be compared with the spike of Ophioglossum. The stnangium in Donses simplicifolio may reach a length of over 3 centimeters and contain upward of roo loculi. The first study of the development was made upon Marattia by Luerssen (Luerssen 3). According to his statement, the differentiation of the synangium begins while the leaf is still very small and rolled up between the stipules. The tissue about a vein begins to develop into an elevated cushion following the vein. Upon this receptacle there are developed two parallel ridges of tissue, separated by a cleft. These two ridges later grow upward and meet above, so that their edges completely close up the cleft, which no longer shows from the outside. In each half of this synangium, very much as is the case in the sporangial spike of Ophioglossum, there are developed separate archesporial groups corresponding to the separate chambers that are found in the fully developed synangium. Luerssen states that the whole process takes
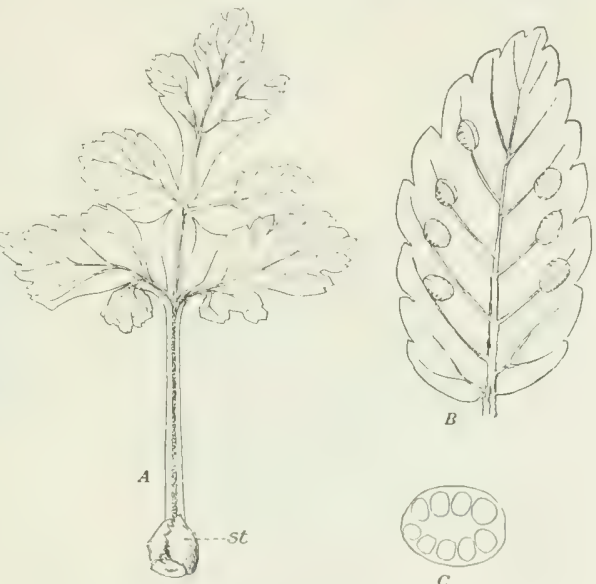

Fic, 185,-Maratia douglasii.

A. Leaf from a young sporophyte. st, stipules. $X_{2}$.

B. Leaflet with synangia, $X_{4}$.

C. Horizontal section of a synangium. $\times 10$. about six months for its completion (fig. I86).

In Angiopteris (fig. 187 ) the development of the sporangium begins at a much later period, when the leaf is almost completely developed. The sporangia here are arranged in an oblong group or sorus, which corresponds to the synangium in Marattia. The formation of the sorus begins, according to Goebel, as an oblong depression above a young vein, and about this depression there is formed a circle of short hairs which are sometimes supposed to represent an indusium. Two ridges corresponding to those found in the young synangium of Marattia are formed, but upon these the young sporangia develop separately, very much as they do in Botrychium.

Goebel states that the archesporium in Angioptcris can be traced back to a single hypodermal cell. This cell divides repeatedly but apparently without any definite order, and there is finally formed a large mass of sporogenous tissue, each cell of which gives rise in the usual way to four spores. The cells about the archesporium develop the tapetum. Goebel states that these tapetal cells are destroyed before the division of the spore mother cells, but I have found that this is not the 
case and that ele tapetal eetls persist umeil the division of the sposes is emmplete. Bower has confinmed this statement and found that the same condition of things obtains in the other genera.

The most complete account of the develepment of the sporangium is that of Buwer (Bower 6), whes has studied the development in all of the genera except Arthangioprevis. Exeept for the difference in form, there is mo essential difference

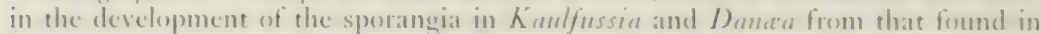
Marattia. In Danate, however, the individuality of the loculi of the synangium is less clear than in the other genera. Very often Bower found that the archesporium became divided more or less completely by parts of the sterile eissue, somewhat in the same fashion that the so-called "trabeculae" are formed in Isoctes. In Dance, moreover, the synangium from the first is solid, and the cleft which is present in the young synangium of Marattio is absent. In Kaulfussiat the development of the synangium differs in that a single circular ridge is formed instead of the

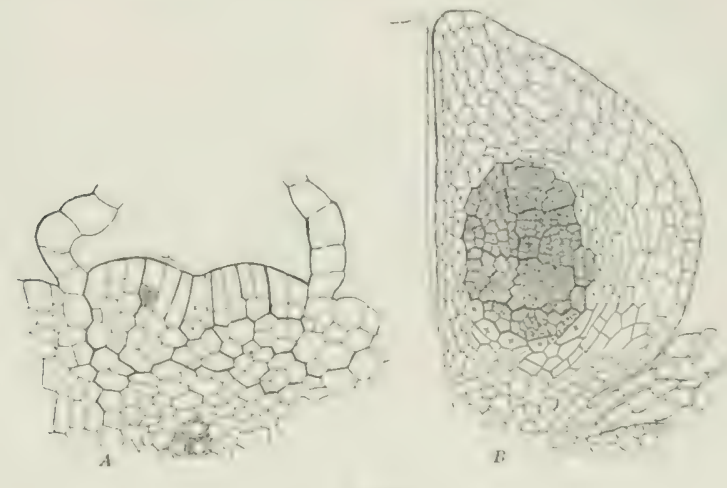

Fic. 186.

A. Section of a young synangium of Marattia fraxinent. $\times 225$.

13. Loculus from an older synangium. $x$, the tapetum (after Bower). Xi12

two parallel ones found in Marattia, and the loculi or ctrambers of the symangium are thus arranged in a circle around a central pit-like depression. Bower states that the sporogenous tissue of each loculus in all the forms he examined can usually. be traced to a single mother cell. He also found that the tapetum always arises from the cells adjacent to the archesporium, and that nomally all of the sporogenous tissue develops into spores. In these respects the Marattiacea closely resemble Helminthostachys and Botrychium.

In Danca and $K$ aulfussia there is no mechanical tissue representing the annulus found in the more specialized ferns. The dehiscence of the sporangium in these forms is brought about merely by a shrinking of the cells on either side of the slit by means of which each loculus opens. This slit is very short in Danaa and may tinally. appear as a circular pore, but it is not essentially different from the more clongated slit found in Kaulfussia and Maratria. In the latter there is developed, in the ourer tissues of the synangium, mechanical rissue which causes the two halves of the synangium to separate, very much like the two covers of a book, and the elongated slit from each loculus opens into this space between the widely separated halves of the synangium. 
The dehiscence of the individual loculi is affected by the contraction of the thinner-walled cells surrounded by firmer tissue. The sporangium of Angiopteris is undoubtedly a more specialized structure than the synangium of the other Marattiacex. In Angiopteris each individual sporangium has the wall on the outer side much thicker than that on the inner one, and the superficial cells have their walls much thickened. The inner wall is sometimes composed of but one layer of cells outside of the tapetum, but more commonly there are one or two layers of cells between the tapetum and the epidermis. Near the top of the sporangium on its outer side there is a transverse band of cells with thicker walls, and these constitute a rudimentary annulus very much like that found in the Osmundacex. By the contraction of this thickened annulus the longitudinal slit on the inner face of the sporangium is made to open widely at maturity. The number of spores produced in each loculus, according to Bower, is approximately 1,75 for Danaa, 7,500 for Kaulfussia, 2,500 for Marattia, and I, 450 for Angiopteris.

Which type of sporangium in the Marattiace is the more primitive is very difficult to say, as both the free sporangium like that of Angiopteris and the compact

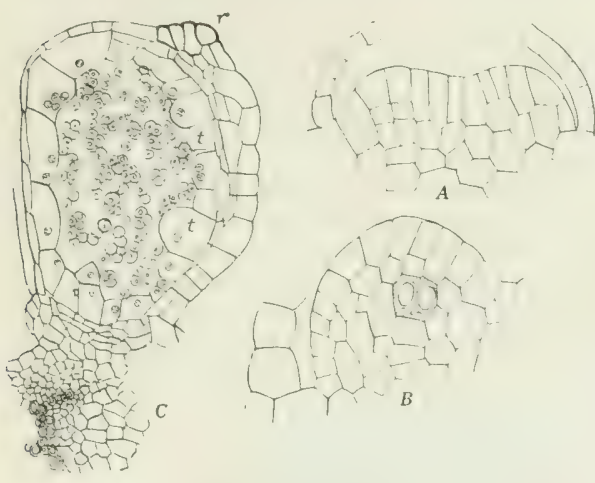

Fic. 187,-Angiopteris.

A, B, sections of young sporangia (after Goebel). C, an older sporangium. $r$, the annulus; $t$, the persistent tapetum. $\times 75$. synangium like that of Maratia and Danca are of about equal antiquity, so far as the geological record goes. It must be remembered that the living Marattiacez are almost certainly merely a few isolated fragments of a once large group, and it is by no means necessary to assume that the sporangia of the living forms must necessarily all conform to a common primitive type. It seems quite as likely that the free sporangia, like those of Angiopteris, may have originated directly from some ancient prototype which resembled, perhaps, forms like Botrychium or Helminthostachys, while the genera with the solid synangium like Danaa may have come from forms with completely united sporangia like Ophioglossum.

It appears from a study of the most ancient ferns that these had dimorphic leaves, the sporophyll probably resembling the fertile spikes of Botrychium or the fertile leaf segments of Osmunda. How the modern Marattiacex originated from forms of this type is not by any means clear. The development in Helminthostachys of sterile leaf-like lobes associated with the sporangia may perhaps afford a clew to the method of sterilization by which the sporangiophores of some type allied to the Ophioglossacex may gradually have developed sterile green leaf segments, bearing upon their lower surface sporangia or synangia like those of the modern Marattiaceae. These sterile segments found in Helminthostachys are occasionally strikingly leaflike, and as the groups of sporangia in Helminthostachys are sometimes united into small synangia, the development of similar synangia upon the lower surface of such green sterile segments of the sporangiophore is quite conceivable.

Another explanation might be the coalescence of the fertile and the sterile parts of a sporophyll like that found in the Ophioglossacea, but the fact that the spo- 
rangiophore in all of the living Ophioglessacese is adaxial, while in the Maratraceac the synangia are abaxial, is a serious objecrion to such a hypothesis; and the most plausible explanation at present seems to be that of a progressive sterilization of part of the sporophyll itself and the expansion of the sterile tissue into the broad lamina of the leaf bearing the separated sporangia or synangia upon its lower surface.

It must be admitted that the difference between the sporophylls of the existing Marattiacese and those of the Ophioglossacea is very great, and the leaves of the former, superficially at least, are much more like those of the leptosporangiate ferns; but the sporangia themselves are very similar in their development to those of the

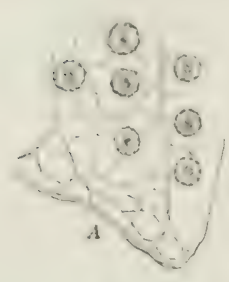

A. Lowet surface of a sporophyll of $\mathrm{K}$ aulfussio, showing circular synangia. X1.5.

13. Median section of a synangiun, $\times 12$.
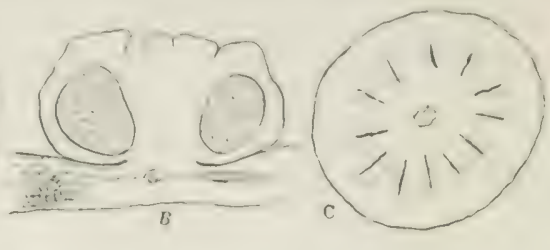

C. I). Crnss-sections of a sunangium.

C. Near top, showing mpeninge of leculi.

1). Near miditle. X12.

Ophioglossacere, and offer no obstacle to the assumption of a fairly close relationship between the Ophioglossacere and the Marattiaces, which is indicated by the history of the development of the gametophyte, and the vegetative organs and tissues of the sporophyte. Perhaps the most marked difference between the tissues of the Marattiacere and the Ophioglossace is the prevalence of the mucilage ducts in the tissues of Marattiacex, but these arise rather late in the history of the sporophyte, and it is

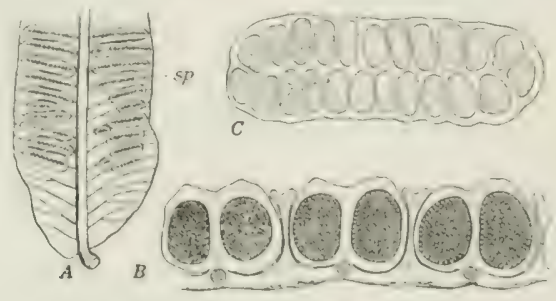

FıG. 189.-Danaa jamaicensis.

1. Base of a fertile leatlet, showing synangia, sp. $\times 2$.

13. Transwerse sections of three synangia, $\times 12$.

C. Horizontal section of a svangium.

significant that they are less developed in the presumably more primitive Kanlfussia than they are in the more specialized types like Angiopteris. Another difference is the development of sclerenchyma, which is quite absent from the Ophioglossacea: but this again is also quite absent from Kaulfussia, which, on the whole, must be considered to be the most primitive of the living Marattiaces and also the form which most closely approaches the Ophioglossacex. 


\section{PART III. THE ORIGIN AND RELATIONSHIPS OF THE EUSPORANGIATÆ.}

The eusporangiate ferns as they now exist represent but a few isolated fragments of what in earlier geologic time was presumably a very much larger and more connected group. As the geological history of these forms is very far fiom clear (this being especially true of the (Ophioglossacea), we are, perforce, dependent mainly upon a comparative study of the few existing types for information concerning their relationships. In the foregoing pages an endeavor has been made to trace the development of these forms, both in their gametophytic and early sporophytic stages, and the result of these studies has been to confirm the belief that a real genetic relationship exists between the Marattiacex and the Ophioglossacex.

While the three genera of the Ophioglossacex differ in certain particulars from each other, there is no question as to their being comparatively closely related, and the same is true of the different genera of the Marattiacex, although perhaps the differences here are somewhat greater than in the Ophioglossacer.

It has been assumed in these studies that the sporophyte of the ferns is the result of a progressive specialization of the sporogonium of some form allied to the Bryophytes, though it is highly improbable that any of the existing Bryophytes are directly related to this progenitor of the primitive ferns. No attempt will be made here to discuss the reasons for accepting the "antithetic" theory of the alternation of generations, rather than the homologous theory. These reasons have been set forth at length elsewhere.

It is hopeless to expect that any satisfactory fossil traces will be found of these predecessors of the true ferns. The fern type is exceedingly ancient, but it must have been preceded by simpler forms connecting it with some bryophytic type. These forms, as well as the earlier true Pteridophytes, were almost certainly plants of small size and delicate texture, probably not very unlike some of the small and delicate species of Ophioglossum. Such plants, composed entirely of soft, perishable tissues, could hardly be expected to leave recognizable fossil traces, and their absence from the ancient Paleozoic rocks is not to be wondered at.

There still exist, however, among the Bryophytes, certain forms which, if they are not directly related to the eusporangiate ferns, nevertheless show many striking similarities in structure, which help to explain at least what may very well have been the character of the liverwort-like ancestors from which the ferns are descended. Among the living Bryophytes, as is well known, an interesting series of types may be traced, showing the gradual increase in the importance of the neutral generationthe sporophrte-starting as little more than a mass of spores, finally by a progressive sterilization of what was originally sporogenous tissue, and an accompanying specialization of the sterile tissues thus formed, attaining a condition of almost complete independence. The importance of this process of sterilization of potentially sporogenous tissue, has been especially clearly expounded in the works of Professor Bower.

In two classes, the true mosses or Musci and the horned liverworts or Anthocerotes, the sporophyte continues its growth for several months and develops an elaborate system of green, assimilative tissue, quite comparable to that found in the vascular plants. The spore-producing function is correspondingly subordinated and the spore formation is delayed until a late period in the life of the sporophyte. 
The lange, gecen sporephyte, however (fig. 10), $d$, sp), never attains complefe independence, as mo proper root is developed and it is dependent for its water supply upun the gametophyte.

In all of the liusporangiates, the cmbryo is much later in developing its organs than in the I,eptosporangiates, and thus resembles the Bryophytes; moreover, the embryo reaches a very much larger size before it attains its independence. Fiven after the young sporophyte has developed several roots and leaves, it may still

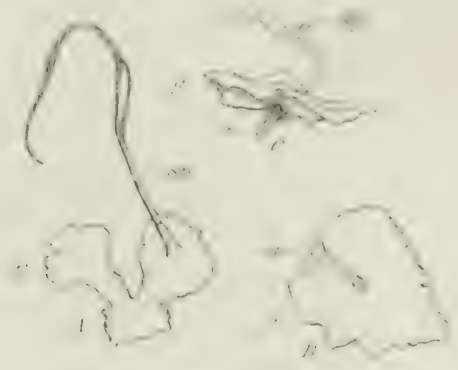

Fisi. 2 to.

1. Ciatnctophate of Inthoreros sp, with the lasce spotoplinte, sp, attactect to it. C'pler pant of eprorenchute is split inte valves which allow the escape of spures.

H, C. Tiwo pametuplyzes of Marathia douglasii, with attached sporophise. Sporophyte emeress upon upper side of gametophyte, very much as in Inthoceras, but a root, $r$, is developed which penetrates louer side of gametuphiste and connests the young sporephyte with the carth. E. gamctophyte; sp, sporophyte; $l$, first leaf; $r$, primary root.

maintain its connection with the gametophyte and be to a certain extent dependent upon it in a way which forcibly recalls the relation of gametophyte and sporophyte in the mosses. This condition, which furnishes a very strong argument in favor of the primitive nature of the Eusporangiates when compared with the Leptosporangiates, is especially pronounced among the Ophioglossacea, where it may even go so far that spores are developed before the connection of gametophyte and sporophyte is finally sundered.

In the true mosses the sporophyte is exceedingly specialized and shows but a very remote resemblance to that of the P'teridophytes. In Anthoceros, however, the
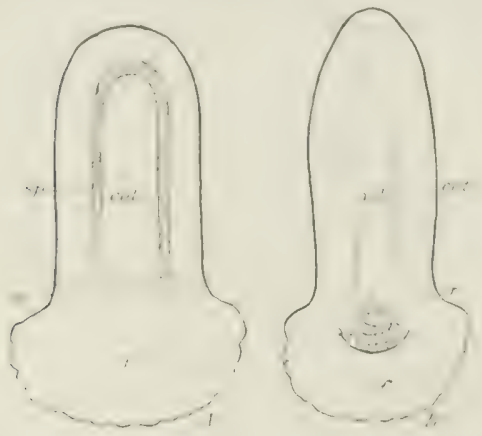

Fig. 291 .

Diagrams which show the similarity in form of the very young sporophyte in Anthoceros, $\mathrm{A}$, and Ophioglossum, B. In the former the upper portion becomes an elongated carsule within which spores are produced. The shaded portion shows layer of sporogenous tissue surrounding central sterile tissue or columella. The zone, $m$, between capsule and foot, $f$, is composed of necristematic tissue. In $O$ phioglossum the upper part of the youne sporophyte forms the primary leaf, or cotyledon, cot, which is not sporogenous. The columclla of Inthaceros is replaced by the axial vascular bundle, $\tau, b$. At the junetion of the cotsledon and foot arises the primary root, $r$, which finally penetrates the fout and enters the ground.

must highly developed of the horned liverworts, there are a number of very significant structural details that are very strongly reminiscent of the young sporophyte of Ophioglossum moluceanum. In both of these forms the young embryo has a very Iare fort and a conical upper region (fig. 101). This upper portion in Ophioglossum develops into the cotyledon; in Anthoceros, into the spore-bearing part of the sporophyte. Above the foot in Anthoceros there is developed a zone of meristematic tissue by means of which new cells are added to the base of the growing sporo- 
phyte, and in Ophioglossum much the same thing occurs in the cotyledon, although at first this grows from a single apical cell. It is probable that in the ancestors of the Ophioglossacex this upper conical portion of the embryo was developed directly into a spore-bearing organ. There is, however, a marked difference which soon appears, viz, the development of a true root in Ophioglossum. This root, pushing down through the foot, penetrates the lower side of the gametophyte and places the young sporophyte directly into communication with the water supply from the earth, and thus the latter becomes entirely independent. Were the large sporophyte of Anthoceros to develop a similar root from the basal meristem, it also would become entirely self-supporting. Indeed, so marked are the resemblances in the early stage of development that they make the inference almost irresistible that the ()phioglossacex must have descended from some simpler forms whose sporophyte bore a strong resemblance to Anthoceros. This "pro-Ophioglossum," if we may call it so, presumably produced spores upon the first leaf, instead of its being a sterile cotylcdon as in the existing forms. From a study of the development of the sporophyte

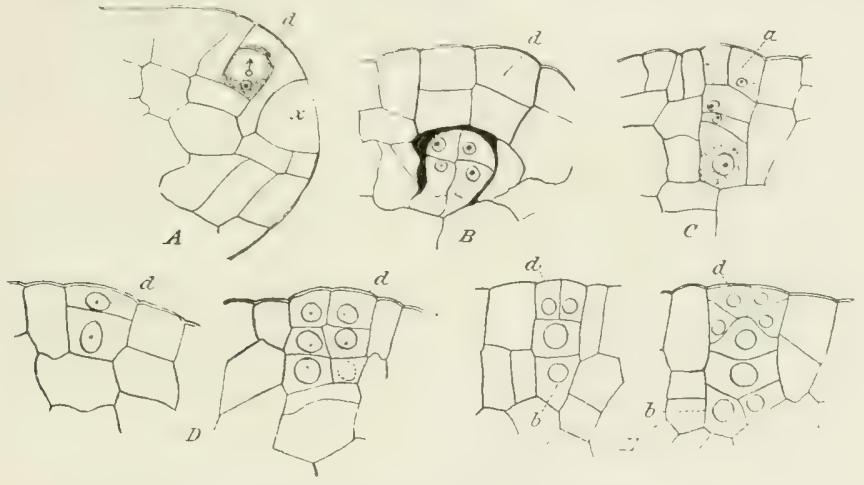

FiG. 192,-Comparison of sexual organs in Anthocerotaceze and Maratia.

A. Longitudinal section of the thallus of Anthoceros pearsoni Howe, showing an antheridium mother cell, with the superimposed cover cell $(d)$.

B. An older antheridium within a cavity covered by a double layer of corer cells.

C. Young archegonium of Megaceros tijbodensis Campbell, a form closely related to Anhoceros.

D. Sections of young antheridia of Maratia douglasii Baker. The inner cell divides at once into the sperm cells, and the cover remains single-layered. $d$, the cover.

E. Young archegonia of Maratia douglasii. $b$, the basal cells of the archegonium; $d$, neck.

in $O$. moluccanum, it may be inferred that this ancestral form had no stem, but consisted simply of this spore-bearing leaf and a root. The sporangia were presumably simpler than in the existing forms of Ophioglossum, and perhaps intermediate in character between such sporangia as those of the smaller species of Ophioglossum and the imperfectly segregated spore groups which occur in the Anthocerotes.

Not only does the sporophyte of Anthoceros show important resemblances to that of Ophioglossum, but the development of the sexual organs also shows striking analogies. The archegonium, unlike that of other Bryophytes, is sunk below the surface in much the same fashion as that of the eusporangiate ferns, and the short neck of the archegonium in the latter is probably to be compared to the four terminal neck cells which may occur in the Anthocerotes (fig. 192). The endogenous antheridia of the Anthocerotes also may perhaps be compared to the sunken antheridia of the eusporangiate ferns, and in their early stages the resemblances are very close. 
The most marked difference in the character of the eproductive organs is the spermatemenid. The spermatomoids in the Eusporangiares, especially in ()phioequssum, are very large and possess numerous cilia, while in Authoseres they are minute and have hut two cilia, like the other Bryophytes. This is perhaps she strongest reason for assuming that there is not a direct connection between the Anthocerotes and she (Ophioglossaces; but both gameenphyte and sporophyte have so many peints in common that it may be prety safely assumed that the progenitors of the ()phioglossacea were not very different, in appearance at least, from the living . Inshoceros. Whether the differences in the spermatezesd are secondary remains to he seen, but in view of the extraordinary constancy of the form of the spermatozoids in all of the main groups of the Archegeniates, one would certainly expect that large

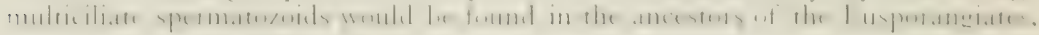
supposing these should ever be discovered.

There is no question that the subterranean prothallium of the ()phioglossacea is a secondary condition, derived from some green gametophyte, probably very much like that of the Marattiaces. Not only has the chlorophyll been lost, but in Ophioghossum and Helminthostachys the dorsiventral form of the gametophyte has been replaced by a radially symmetrical thallus. While this may be partially explained as the result of the absence of light, it must be remembered that the equally subexranean prothallium of Botrychium is dorsiventral, alehough the reproductive maans are borne upon the dorsal surface and not upon the ventral one, as they are in most ferns. Whether this position of the reproductive organs is the result of the conditions of growth or whether it indicates that the green gametophyte from which this saprophytic underground form is descended also bore the reproductise organs dorsally, as most liverworts do, can only be conjectured. In the Maratriaccat antheridia are not uncommon upon the dorsal surface, and according to Jonkmann archegonia also may occur dorsally. Whether this is normal or is the result of unusual light conditions was apparently not investigated. The formation of archegonia in the ordinary ferns may be induced upon the dorsal side of the prothallium, provided it is illuminated from below. If the illumination is equal on both sides, archegonia will develop both on the ventraliand dorsal surface.

Of the investigated species of Ophioglossum, O. moluccanum and the nearly rolated and perhaps identical $O$. pendunculosum probably represent the most primitive type. In these species there may be a feeble development of chlorophyll in the gametophyte under certain conditions and the saprophytic habit is much less pronounced than it is in the other species of Ophioglossum and Botrychium.

The development of an endotropic mycorrhiza in the prothallium of the Marattiacex is an interesting suggestion as to the probable beginning of the saprophytic habit which characterizes the gametophyte of the ()phioglossacex. There seems to be good reason to suppose that the peculiar type of symbiosis, which is

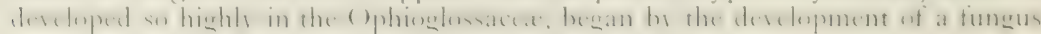
associate in some green gametophyte like that of the Marattiacea.

The reproductive organs of the Ophioglossacex and Marattiacex are very similar indeed. It is probable that the short-necked archegonium found in the Maratiacese and in Oplioglossum is more primitive than the long-necked archeannium of Botrvelium or Helminthostacleys. This conclusion is based upon the assumption that the four-necked archegonium of the ferns is a development of the four terminal cells in the neck of the Bryophyte archegonium, Anthoceros most nearly approachiner this hrpothetical ancestral tipe. This being the case, the forms with the shortest neck would most nearly rescmble this assumed ancestral type. 
The question of the canal cells is a puzzling one. In the Marattiacex, with the exception of Danea, two neck canal cells, or at any rate two nuclei, are present and the ventral canal cell is conspicuous. In Danca, however, the canal cells are very much less perfectly developed, the ventral canal cells especially being exceedingly difficult to demonstrate. In the latter respect Danca shows a remarkable resemblance to the Ophioglossacer, especially to Ophioglossum, where the ventral canal cell is equally difficult to demonstrate. This apparent degeneration of the ventral canal cell is probably secondary, as all of the Bryophytes and the other Pteridophytes have the ventral canal cell conspicuous.

The antheridium in all of the Marattiacex is almost exactly like that of Ophioglossum, while Botrychium and Helminthostachys differ in having the outer wall of the antheridium more or less completely two-layered. If the antheridium is derived from a type like that of Anthoceros (fig. I92), where the antheridial cavity is covered by a double layer of cells, it would seem that Botrychium and Helminthostachys are more primitive than Ophioglossum or the Marattiacere in this respect.

Of the Eusporangiates, there is no question that the type of embryo found in Ophioglossum moluccanum comes the nearest to the assumed ancestral form. This hypothetical pro-fern may be assumed to have developed simply a spore-bearing organ or sporangiophore, perhaps more or less leaf-like, and a root developed from the inner part of the massive foot in the same way that the root actually does develop in the embryo of the Marattiacex and Ophioglossum moluccanum. Except that the cotyledon of $\mathrm{O}$. moluccanum is sterile, the young sporophyte in this species is actually like this hypothetical type, viz, it is composed simply of root and leaf. It is probable that the fertile spike of Ophioglossum is not unlike the primitive sporangiophore, and the ancestral form presumably developed such a spike-like sporangiophore from the first, the sterile lamina being a secondary structure arising perhaps from a basal meristem, like that found in the sporophyte of Anthoceros. The carly development of the spores in the Ophioglossacex is a further indication of their primitive nature.

The monophyllous condition which prevails among the Ophioglossacex must also be regarded not as a secondary condition but as a primitive one, and a study of the development of the sporophyte lends no support to the theory that we have to do with a reduced strobilus. Of the Marattiacex, Kaulfussia normally approaches the monophyllous condition more closely than any other genus. The older plants, as a rule, have only two or three leaves expanded at one time and there may frequently be but one. In strong contrast with this is the dense crown of leaves found in Marattia and Angiopteris, although even in these forms the number of leaves is less than it is in the majority of leptosporangiate ferns. The tendency to the monophyllous condition is shown in the younger plants of Marattia, developed from the buds on the old leaf bases, where, as a rule, only one leaf is expanded at a time.

The young sporophyte of $O$. moluccanum has no stem. Without exception, for a considerable time at least, the vascular system of the sporophyte is composed exclusively of tissue belonging to the leaves and roots, the stem apex playing no part in the building up of the vascular skeleton. The theory that there is a special stele belonging to the stem, of which the leaf traces and the root traces are subsidiary structures, is not borne out by a detailed study of the evolution of the vascular system in either the Marattiacex or Ophioglossacex. In all of these that I have examined the vascular system begins as a single strand common to the primary leaf (or cotyledon) and the primary root, and the more complicated vascular system of the older stem for a vers considerable period is built up exclusively by additions of new leaf traces or root steles. This condition is permanent in the Ophioglos- 
sacece. In the Maratriacea small cauline bundles (commissural bundles) may be developed at later stages, but these are insigniticant compared with the complex of united leat traces.

The antithetic theory of alternation implies that the sporophylls are older structures than the sterile leaves, and those ferns in which the sporogenous function of the sporophylls is most pronounced may be assumed, other things being equal, to be the most primitive. In this respect, as well as in the usually monophyllous condirion, the Ophioglossacea are distincty more primitive than the Marattaces. The sporangiophore or fertile leaf segment is a practically independent structure, being differentiated at an extremcly early period in the development of the leaf. In the Marattiaces the sporangia are subordinate and the leaves upon which they are borne usually differ in no respect from the sterile leaves. The most marked exception to this is Danar, in which the sporophylls differ decidedly from the sterile leaves and the synangia are much larger than those of the other genera, although the leaves themselves are usually smaller.

Bower thinks that the circular synangium of $K$ aulfussia is the most primitive type among the existing Maratiacex, but there is some reason to doubt the soundness of this conclusion; at any rate, on theoretical grounds, the large synangia and contracted sporophylls of Danca must be assumed to be more primitive than the type of leaf found in Kaulfussia. In regard to the character of the sporophylls, therefore, none of the living Maratiacea can be regarded as being very primitive. All of the oldest fern fossils show the sporangia to be borne upon special leaves or leaf segments, in which the lamina is nearly or quite absent (Scott 1, Bower 9). In this respect, therefore, these ancient fossil ferns were more like the Uphioglossacese than like the Maratiaces, although their sporangia came nearer to the type of Marattiacex. It is by no means impossible that these oldest ferns, e. g., the Botryopteridea, were related to the Ophioglossacea.

The single apical cell found in the stem apex throughout the life of the sporophyte in Ophioglossum is probably a more primitive condition than the group of cells found in Angiopteris. It still remains to be seen whether the single apical cell found in the other Marattiacex in their early stages is persistent throughout life or is replaced, as in the roots, by a group of initial cells.

The single axial strand of collateral structure throughout cotyledon and root may be taken as the starting point for two types of vascular skeleton which have arisen from it. The first is that of Ophioglossum, where, with the development of the new leaves, there is built up the wide-meshed cylindrical network or dictyostele, c mposed of single collateral leaf traces. A further development of the same type results in the much more complicated dictyosteles of the Maratriacex, where, moreover, the collateral bundles are replaced by concentric ones. This greater compleaty is due primarily to the much larger leaves of the Maratraceas, in which the leaf traces are compound. In the earlier stages of these forms, however, we have seen that the young leaf traces are single and the structure of the vascular skeleton cxactly as it is in Ophioglossum. Of the Marattiacere, Kaulfussia more nearly. retains this primitive condition than the other genera and next to this comes Danar, while further removed from the primitive type is the exceedingly complex skeleton found in the massive stem of Angiopteris. The concentric bundles, characteristic of the Marattiacex, are presumably of secondary origin and we find that in the early bundles, especially of Danaa, a true collateral structure is present.

The second type of skeleton is that found in Botrychium and Hclminthostachys. This is a solid, hollow cylinder with inconspicuous leaf gaps, resulting from the union of the broad leaf traces, which fuse completely to form this hollow stele. That 
the cylindrical bundle, or siphonostele, is not due to the formation of a pith within a protostele is clearly shown by the study of the development of the bundle in the young sporophyte of Botrychium, where it can easily be scen that the component bundles are separate at first, and that the pith, so-called, of the siphonostele is merely a portion of the ground tissue that is included between them, and which later becomes entirely separated from the cortical tissue. A similar condition of things may be found in tracing the development of the vascular cylinder in the young stem of Helminthostachys. The development of the young bundles in Angiopteris is more like Botrychium than Ophioglossum, and this, in connection with the separate sporangia that occur in Angiopteris, suggests that perhaps the type of the Marattiacex represented by Angiopteris may have originated independently from forms like Helminthostachys, instead of having had the same origin as those forms in which true synangia are developed.

The essential similarity of the leaf structures throughout the Ophioglossacer is sufficiently clear, and the steps in the increasing complexity of the sporophyll can be easily traced in existing forms, ranging from the undivided fertile and sterile segments of Ophioglossum to the decompound leaves and much-branched panicle of Botrychium. Helminthostachys is much the most aberrant of the Ophioglossacex and in many respects shows a marked resemblance to the Marattiacex. The form and venation of the leaves strongly recall Danca or Angiopteris, except that the leaves are not pinnately divided, in which respect they closely resemble Botrychium. It must be remembered, however, that the ternate form of leaf characteristic of Botrychium and Helminthostachys is very generally met with in the early stages of the sporophyte in the Marattiacere. The anatomy of the leaf in Helminthostachys very closely resembles that of the Marattiacex, there being a well-developed palisade layer in the mesophyll, a character which is either wanting entirely or very imperfectly developed in Botrychium.

The leaves of the Marattiacex, except in Kaulfussia, in their form and in the circinate coiling of the young leaves, suggest a relationship with the leptosporangiate ferns rather than with the Ophioglossacere. However, the larger species of Botrychium and Helminthostachys show an approach to this circinate form of the young leaf, this being especially conspicuous in the young sporophylls of Botrychium virginianum. With the exception of Kaulfussia, the general form and venation are alike in all the Marattiacee and have their nearest analogy in Helminthostachys. There seems no reason to assume that the stipular sheath in the Marattiaceæ is different in its nature from that of the Ophioglossacex, especially Helminthostachy's and Botrychium. The ternate form of the leaf may be persistent in Kaulfussia, where, however, the venation is more like that of Ophioglossum. Whether this occurrence of both reticulate and pinnate venation in the two families is a case of parallel development, or whether it indicates the comnection of the families at different points, it is at present impossible to say.

In the structure of the roots the Marattiacex find their nearest ally in $\mathrm{Hel}$ minthostachys, where the number of the xylem rays, four to seven, equals that of Kaulfussia, which has the simplest structure among the Marattiacere, and, as we have seen, probably on the whole is most nearly related to them. Helminthostachys also resembles the Marattiacere in the character of the apical growth of the root, where, although there is a single apical cell, such as occurs in the young roots of the Marattiacex, its form is more like that of the Marattiacex than it is like that of Botrychium. The endophyte which occurs in the older roots of the Ophioglossacex, as well as in the primary one, I have not found in the older roots of the Marattiacex, at least not as a regular thing, although it seems to be always present in the primary root. 
The Ophioglossacese and Maratiacea are alike in the absence of any mechanical tissues in the cortex of the stem. Sclerenchyma, which is well developed in the leaves of most of the Maratiacex, scems to be entirely wanting in all of the Ophioglossace:e, but the collenchyma which replaces sclerenchyma in certain organs of the Marattiace:e, and is the only form of mechanical tissue in $K$ aulfussia, is occasionally found in the Ophioglossaces. A notable case of this is the broad and very conspicuous zone of collenchyma surrounding the root bundle in Ophioglossum pelmutum. The mucilage ducts so characteristic of Marattiacea are apparently quite wanting in all of the Ophioglossacea, and the tannin sacs which are a nearly constant feature in the Maratiacex are absent in Botrychium and Ophioglossum. but occur in Helminthostachys.

In the general structure of the vascular bundles there are important resemblances. In both families the first-formed tracheids in the young sporophyte are all of the short, reticulate form, and this is retained permanently in Ophioglossum, but is replaced later by pitted tracheids in Helminthostachys and Botrychium. IVelminthostachys alone among the Ophioglossacea shows spiral protoxylem elements like those found in the later bundles of the Maratriacere.

It is probable that the collateral bundles of Ophioglossum represent the primitive type from which the concentric type found in the Marattiacee has been derived. In Botrychium and Helminthostachys, while the collateral type of bundle is found in the stem, in the petioles the bundles are concentric, as they are in the Maratiacea. The collateral type of bundle reappears again in the early stages of the sporophyte in Danar.

Angiopteris, which is probably the most specialized of the living Marattiaces. , has concentric bundles only. 


\section{CONCLUSION.}

While the more specialized Marattiacex, like Marattia and Angiopteris, apparently differ very much from the Ophioglossacex, it appears from a study of the development of these forms, as well as that of the simpler and presumably more primitive genera Danca and Kaulfussia, that the most conspicuous differences are of secondary rather than of primary importance, and the conclusion is justified that the two families of the Eusporangiate really arose from the same primitive stock. Of the Ophioglossacex, Helminthostachys is undoubtedly the form which, on the whole, comes nearest to the Marattiacex, although Ophioglossum is more like them in the character of the reproductive organs and in the vascular skeleton of the sporophyte. Ophioglossum also recalls Kaulfussia in the form and venation of its leaves.

While the green gametophyte in the Marattiacex is undoubtedly a more primitive structure than the saprophytic prothallium of the Ophioglossacex, the sporophyte of the latter is certainly a more primitive one than that of the Marattiacex. The monophyllous condition, the early development of the sporangia, and the fact that the whole of the sporangiophore is spore-bearing, all point to this.

The way in which the sporophyll of the Marattiacea has been derived from a type like that of the Ophioglossacex is not clear, and it is by no means certain that all of the Marattiacex have been developed in the same way. The occurrence of fossil forms with sporangia of the marattiaceous type grouped together-much like the sporangia of Botrychum or Osmunda-suggests that such a condition might have been preliminary to the separation of the sporangia by the development of sterile green tissue in the sporangiophore, such as sometimes occurs in Helminthostachy's. The converse is not tenable unless we accept the view that the sterile leaf is an older structure than the sporangiophore, a view which we believe is not warranted by the facts. It has been suggested in a previous chapter that the sporophyll of the Maratriacee might be accounted for by a theory of concrescence of the sporangiophore and sterile lamina in the Ophioglossacex. Ophioglossum palmatum, with the two series of small sporangiophores and broad leaf lamina, is the form which comes nearest to such a condition. A very serious objection to this view was mentioned, however - the fact that the sporangiophore is an adaxial structure, whereas the synangia of the Marattiacex are always abaxial in their position.

Comparing the eusporangiate ferns with the leptosporangiate, it is generally conceded that the ()smundacex are the ferns which most closely approach the Eusporangiate. The Osmundacex show points of resemblance to both the Ophioglossacer and Marattiacer, this being true both of the vegetative tissues and the sporangia. In Osmunda the arrangement of the sporangia suggests Botrychium, while in Todea the sporangia are borne upon the backs of the leaves, much as they are in the Marattiacex. Bower has suggested that the Gleicheniacex, which are, however, certainly allied to the Osmundacex also, show certain suggestions of a marattiaceous affinity, especially in the arrangement of the sporangia.

We may then briefly summarize our conclusion as follows: From some form, allied to the simpler existing species of Ophioglossum, the whole fern series is descended. In this whole series the leaf is the predominant organ, the stem at first being quite subordinate in importance. This ancestral fern was monophyllous and the leaf at first was a sporophyll, perhaps without any definite sterile segment. 
lirom this central type presumably several lines diverged, of which only a few fragments persist. (One of these is seen in the different forms of Botrychium, en which Helminthostachys is probably not very remotely allied. "The whole of this series is characterized by a suberranean gametophyte, and a more or less saprophytic habit of the sporophyte is indicated by the development of a mycorrhiza in the roots.

The Marattiacere, as they now exist, probably do not represent a single unbroken line of descent, and show strong evidences of a possible multiple derivation from the earlier stock. The point of contact with the Ophioglossaces is probably in the neighborhood of Hclminthostachys, which, on the whole, is more like the Marattiacere than are the other Ophioglossacex; but it is improbable that the solid synangium, such as characterizes most of the Marattiacex, was derived from a group of separated sporangia like those in Botrychium or Helminthostachys, and it is more likely that they arose from a structure which resembled the spike of Ophioglossum. Angiopteris is, with little question, the most specialized of the living Marattiacea and has probably departed further from the ancestral type than any of the other forms, while Kaulfussin, on the other hand, is probably the most primitive. On the whole the Marattiacea are nearer to the leptosporangiate ferns

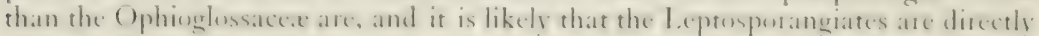
descended from some ancient fern forms, allied to the Marattiacex, but differing from any of the existing types. 


\section{BIBLIOGRAPHY.}

ARber, E. A. NewELL.

I. On the Past History of the Ferns. Ann. Bot., 1906, 20, 215.

Atkinson, G. F.

I. Symbiosis in the Ophioglossacex. Bull. Torrey Bot. Club, I893, 20, 356.

BARY, A. DE

I. Comparative Anatomy of the Vegetative Organs of the Phanerogams and Ferns. Oxford, $188_{4}$.

BEER, R.

I. On the Development of the Spores of Helminthostachys zeylanica. Ann. Bot., 1906, 20, I77.

BELAJEFF, W.

I. Ueber Bau und Entwickelung der Spermatozoiden der Gefässkryptogamen. Ber. d. deutsch. bot. Gesell., I888, 7, 122 .

2. Ueber Bau und Entwickelung der Spermatozoiden der Pflanzen. Flora, I894, 79, Ergänzsb., $\mathrm{r}-48$.

3. Ueber den Nebenkern in spermatogenen Zellen und die Spermatogenese bei den Farnkräuter. Ber. d. deutsch. bot. Gesell., I897, 15, 339.

4. Ueber die Cilienbildner in den spermatogenen Zellen. Ber. d. deutsch. bot. Gesell., I898, I6, I 40.

5. Ueber die Centrosomen in den spermatogenen Zellen. Ber. d, deutsch. bot. Gesell., I899.

BITTER, G. 17, 199-205.

I. Marattiacex. Engler and Prantl. Die natürlichen I'flanzenfamilien, I900, Th. I, Abt. Iv, $422-444$.

2. Ophioglossacex, Ibid., 449-472.

BOWER, F. O.

I. Comparative Morphology of the Leaf of the Vascular Cryptogams and Gymnosperms. Proc. Roy. Soc., I884, xxxviI, 6I; Phil. Trans. Royal Soc., 1884, 175, 565.

2. The Comparative Examination of the Meristems of Ferns as a Phylogenetic Study. Ann. Bot., I889, 3, 305.

3. Is the Eusporangiate or the Leptosporangiate the more Primitive Type of Fern? Ann. Bot., I891, 5, rog.

4. Studies in the Morphology of the Spore-producing Members: Equisetinex and Lycopodinex. Phil. Trans. Roy. Soc., 1894, ser. B, 185, 473-572.

5. Studies in the Morphology of Spore-producing Members, II: Ophioglossacex. London, I896.

6. Studies in the Morphology of Spore-producing Members, nI: Marattiacex, Phil. Trans. Roy. Soc., I897, ser. B, I89, 35-8I.

7. Studies in the Morphology of Spore-producing Members, v. General Comparisons and Conclusions. Phil. Trans. Roy. Soc., 1903, ser. B, 196, 191-257.

8. Ophioglossum simplex Ridley. Ann. Bot., 1904, 18, 205.

9. The Origin of a Land Flora. London, 1908.

ro. Note on Ophioglossum palmatum. Report Brit. Assoc. Adv. Sci, Sheffield, Sept. I9ro.

BOODLE, L. A.

1. On some Points in the Anatomy of the Ophioglossacex. Ann. Bot., I899, 13, 377-394.

BREBNER G.

1. On the Mucilage Canals of the Marattiacex. Journ. Linn. Soc., London, I895, 33, 444.

2. On the Prothallus and Embryo of Danaa simplicifolia Rudge. Ann. Bot., 1896, 10, 109.

3. On the Anatomy of Danca and other Marattiacer. Ann. Bot., 1902, 16, 517-552.

Britton, E. G.

I. A Revision of the North American Species of Ophioglossum. Bull. Torrey Bot. Club, i897,

BRUCHMAN, H. $24,545-559$.

I. Ueber das Prothallium und die Keimpflanze von Ophioglossum vulgatum L. Bot. Zeit,, I904, $62,227-247$.

2. Ueber das Prothalfium und die Sporenpflanze von Botrychium lunaria L. Flora, 1906, 96, 203.

Burlingame, L. L.

I. The Sporangium of the Ophioglossales. Bot. Gaz., 1907, 44, 34 . 
('imerit.1., 1). 11 .

1. ()n the Athinies of the Filicinese. Bot. Gaz. $18 \% 0,15,1$.

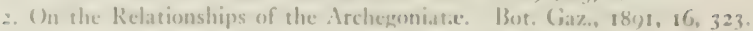

3. ()hervasions on the Development of .Marabia douglasii Baker. Ann. Boe., 1894, 8, 1.

f. The Siructure and Development of the Mosses and Ferns. London and New York, 1895. Second edition, 1905 .

5. The ()rigin of 'lerreserial Plants. Proc. Amer. Assoc. Adv. Sci., 1903, 52, 463.482.

6. Antiehetic versus Ilomologous Alternation. Amer. Nat., 1903, 37, 153.

7. Aftinicies of the ()phioglossaceae and Marsiliacex. Amer. Nas., 1904, 38, 761-775.

5. Studies on the Ophioglossacea. Ann. du Jardin botanique de Buitenzorg. Iopo, ze sér., 6, 138-194.

9. The l'rothallium of Kaulfussia and Gieichenia. Ibid., 1908, ze sír., 8, 6r-102.

10. The P'rothallium and Embryo of Dania. P'reliminary Note. Ann. Bot., Oct. 19or), 23.

11. The Embryo and Young Sporophyte of . Ingiopteris and Kaulfussia. Ann. du Jardin boranique (.ARMIFF, 1. 1). de Buitenzorg, 1010, 2e suppl., 3, 6r-82.

1. Development of the Sporangium in Brtrychium. Bot. (iaz., 1905, 39, 340.

Citikles, (ir.icF MI.

1. The Anatomy of the Sporeling of Marania alata. Bnt. Gaz., 1911, 51, 81-10r.

Civers, F.

1. On Saproplyytism and Mycorrhiza in Ilepatica. New Plyytologist, 1903, 2, 30-35.

Crickovsky, I.

I. Untersuchungen über die Ifomologien der generativen l'rexdukte der Fruclicbläter bei den Phanerogamen und (iefasskryptogamen. l'ringsheim's Jahrb. für wiss. Bot., I884.

Cirrist, H. 14. 201

1. Die Farnkräuter der Erde. Jena, 1897.

2. (and K. Giesenhagen). P'teridugraphische Notizen. Flura, 18m, 86, 72-85.

Ciristensen, C.

ऽ. Index Filicum. Copenhagen, Igo6.

Cirrysler, M. A.

r. The Nature of the Fertile Spike in the Ophioglossacea. Ann. Bot., 1010, $24,1-18$.

Coptand, E. 13.

I. Ferns of the Malay Asiatic Region. Philipnine Journ. Sici. Inon, Sec. C. But. 1 :

DAventort, G. E:

1. Vernation in Botrychium. Bull, Torrey Bot. Club, IS8 $\mathbf{1}, 8$, 100.

FirMER, J. BRETLAND.

1. The Fimbryogeny of Angtopteris esecta Hofm. Ann. 13ot., 1802, 6, 265.

2. (and W. G. Freeman). On the Structure and Affinities of IIclmimhostachys zeylanica. Ann. Bot., Sepr. $1899,13$.

3. (and T. G. Mill). On the Arrangement and Structure of the Vascular Strands in Angiopteris cvecta and some other Marattiacex. Ann. Bot., I002, 16, 371-q02.

(iorenEL, K.

1. Beiträge zur vergleichenden Entwickelungsgeschichte der Sporangien. Bot. Zeit., r880, 545 : $188 \mathrm{r}, 68 \mathrm{r}$.

2. Vergleichende Entwickelungsgeschichte der P'Hanzenorgane. Schenk. Handbuch der Botanik. $1884,3$.

3. Outlines of Classification and Special Morpholngv. (Translation of the German edition.) Oxford, Clarendon l'ress, is87.

4. Organographie der l'Hanzen. + pts. Jena, 1898-19or.

(iRISFBACH. A. H. R.

1. Flora of the British West Indian Islands. London, 1864 .

(irynn:-VAçux, D). T.

1. On an Unexplained l'oint in the Anatomy of Ilelminthosfachys zeylanica. Ann. Bot., Igoz. 16,170 .

2. On the Anatomy of Arehangiopteris henryi and other Marattiacex. Ann. Bot., 1905, 19, fII.

IIINisio, I:

1. lieber dic Staubgrubchen an den Stammen und |3lattstielen der Cyatheacen und Marrattiaceen. But. \%eit., $1808,56,0-33$. 
HiLl, T. G.

I. See Farmer (3).

2. On Secondary Thickening in Angiopteris evecta. Ann. Bot., 1902, 16, 173.

Hillebrand, W. F.

I. Flora of the Hawaiian Islands. I888.

Hofmeister, W.

1. The Higher Cryptogamia. Ray Society, 1862. This contains a translation of the "Ver-

Holle, 4. G. gleichende Untersuchungen," as well as the later papers upon the Archegoniatie.

I. Ueber Bau und Entwickelung der Vegetationsorgane der Ophioglosseen. Bot. Zeit., 1875, 241 .

2. Vegetationsorgane der Marattiaceen. Bot. Zeit., I876, 215 .

Holtzman, C. L.

I. On Apical Growth of the Stem, and the Development of the Sporangium of Botrychium virginianum. Bot. Gaz., 1892, 17, 2 I 4.

HoOker, Sir J., and J. G. BAKer.

I. Synopsis Filicum. London, 1874 .

JANSE, J. M.

I. Les endophytes radicaux de certaines plantes javanaises. Ann. du Jardin botanique de

JEFFREY, E. C.

Buitenzorg, I895, It, 5t-20I.

I. The Gametophyte of Botrychium virginianum. P'roc. Canad. Inst., 1898, 5.

2. The Development, Structure, and Affinities of the Genus Equisetum. Mlem. Boston Soc. Nat. Hist., 1899,5 , no. 5 .

3. The Structure and Development of the Stem in Pteridophytes and Gymnosperms. Phil. JonkMANN, H. F.

Trans. Roy. Soc., 1902, ser. B, 195, 119-146.

1. La génération sexuée des Marattiacées. Arch. néerland., etc., 1880, t. 15, r99. Also in Bot. Zeit., 1878,129 .

2. Over de Keimung van Kaulfussia asculifolia. Nederland. Kruidkdg. Archicf, 1879, ser. 2, deel 3 , stuck 2, p. 262.

KосH, L

3. L'embryogénie de l'Angiopteris et du Marattia. Arch. néerland., t. 30, 213-230. (Separate, not dated.)

Ueber Bau und Wachstum der Wurzelspitze von Angiopteris execta. P'ringsheim's Jahrb. fur wiss. Bot., 1895, 28, 369 .

KüHN, R.

I. Untersuchungen über die Anatomie der Marattiaceen und anderen Gefasskryptogamen. Flora, 1889, 72, 457 .

2. Ueber den anatomischen Bau von Danca. Flora, 1890, 73, I47.

LANG, IV. H.

1. On the Prothalli of Ophioglossum pendulum and Helminthostachys zeylanica. Ann. Bot., 1902, I6, 23-56.

2. On a Suspensor in Helminthostachys. Ibid., 1910, 24, 611.

LUERSSEN, C.

I. Spaltoffnungen von Kaulfussia. Bot. Zeit., 1873,625 .

2. Ueber die Entwickelungsgeschichte des Marattiaceenvorkeims. Bot. Zeit., I875, 535.

3. Handbuch der systematischen Botanik. Bd. I: Kryptogamen. Leipzig, I879.

4. Die Farnpflanzen oder Gefässbündelkryptogamen (Rabenhorst, Kryptogamentlora). Leip-

LYoN, H. L. zig, 188 -1 1889 .

I. A New Genus of Ophioglossacere. Bot. Gaz., 1905, ło, 455 .

Magnus, W.

I. Studien an der endotrophen Mycorrhiza von Neoltia nidus-avis L. l'ringsheim's Jahrb. fur iviss. Bot., 1900, 35 .

Metteniles, Grors.

I. Filices Horti Botanici Lipsiensis. Leipzig, 1856.

2. Ueber den Bau von Angiopteris. Abhandl. der. K. Sähs. Gesell. der Wiss., I864, 6, 501.

MotTier, D. M.

Fecundation in Plants. Publication no. 15, Carnegie Institution of Washington, 1904.

Poirault, G.

I. Sur l'Ophioglossum vulgatum. Journ. de botanique, I891, 6 .

2. Recherches anatomiques sur les cryptogames vasculaires. Ann. des sci. naturelles, 1893, sér. 7, t. 18,113 . 
Porosir, II.

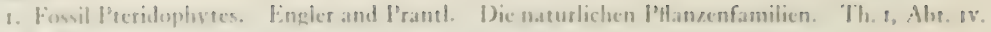
l'Hestl., K.

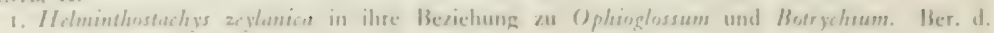
deutsch. hese, (iesell., $8883,1,155$.

2. Sistenatisches liebersicht der (Ophioglossecen. Ibid., $34^{8}$.

Racmokk1, II.

1. Die P'eridephyten der Flora von Buitenzorg. Leiden, 1 sogs.

Restumas:w, S.

1. Beiträge zur Kenneniss der Gefasskryptogamen. 1. Umbildung von Wurzeln in Sprosse. lilura, 18 (so, 73.855.

2. (Ophioglessacee (Russian). Moscow, 1892.

Ressow, I:

1. Vergleichende Untersuchungen, betreffend die Histologie der vegetativen und spurenbildenten Organe und die Entwickelung der Sporen der Lecibüudelkryptogamen. Mém. de l'Acad. imp. des sciences de St. l'étersburar, 1872, sir. 7,19, no, 1.

2. Betrachtungen uber das Leithundel und Grundgewebe aus vergleichend morphologischem und physiologischem (iesichtspunkte. Dorpat, 1875.

3. Developpement des tubes cribreux. Ann. des sci. naturelles, 1882, sér. 6, 14,167 . SADEHECK, R.

1. Der Embryo von Eiquisclum. Bot. Leit., 1877, 44. Also, Pringsheim's Jahrb. fur wiss. Bot., Schoute, J. C. $1878,11,575$.

Die Stelartheoric. Groningen, זyos.

ScotT, D. 11.

1. Studies in Fossil Botany. London, 1100. Second edition, 1900. (Also many monographs on fossil plants.)

SEWARD, A. C.

I. Fossil Plants. z vols. Cambridge, $1897-1910$.

SHAw, IV. R.

1. The Fertilization of Onoclea. Ann. Bot., 1898, 12, 251-285.

2. Ueber die Blepharoplasten bei Onoclea und Marsilia. Ber. d. deutsch. bot. Gesell., 1898, Sitove, R. F. $16,177-18_{4}$.

1. On the Structure of the Stem of Angiopteris escta. Ann. But., 1900, $14,497$.

Solms-Laubaci, H., Graf $2 u$.

1. Fossil Botany. Oxford, Clarendon P'ress, 1891.

Strasmurger, E.

1. Die Befruchtung bei den Farnkrautern. Pringsheim's Jahrb. für wiss. Bot., $7,390$.

2. The P'eriodic Reduction of Chromosomes in Living Organisms. Ann. Bot., 1894, 8, 281.

3. Ueber Reductionsteilung. Sitzungsber. der K. l'reuss. Akad. der Wiss, 1904, 18.

TANSLEY, A. G.

1. Lectures on the Evolution of the Filicinean Vascular System. Cambridge, Igon.

Ternetz, Charlotte.

I. Ueber die Assimilation des atmosphaerischen Stickstoffes durch Pilze. P'ringsheim's Jahrb.

TREUB, M. für wiss. Bot., 1907, 44, 353.

1. Érudes sur les Lycopodiacies. Ann. du Jardin botaniçuc de Buitenzorg, 1894-1890, 4, 5. 7, 8 . UnDERWOON, L. M.

1. Our Native Ferns and their Allies. 6th ed. New York, 1900.

2. A Review of the Genus Dancia. Bull. Torrey Bot. Club, 1902, 29, 669.

VAN liegueM, I'Ir.

I. Sur quelyues pointes de l'anatomie des cryptogames vasculaires. Bull. de la Soc. bot. de France, $188_{3}, 25,160$.

2. Sur la limite du cylindre centrale et de l'écorce dans les cryptogames vasculaires. Journ. de botanique, 1888,369 .

3. (and Duliort) Recherches comparatives sur l'origine des membres endogènes dans les plantes vasculaires. Ann. des sci. naturelles, I888, sér. 7, t. 8, I.

4. Remarques sur la structure de la tige des Ophioglossíes. Journ. de botanique, i $890,365$.

5. Traité de botanique. 2. éd. l'aris, 1802 . 


\section{LIST OF PLATES.}

Plate r.

1. Two spores of Ophioglossum moluccanum Schlecht, showing range in size. $\times 500$.

2. Two-celled gametophyte of $O$. moluccanum.

3. A three-celled stage. sp, ruptured spore membrane.

4. A four-celled stage seen from above.

5. Two transverse optical sections of a four-celled gametophyte.

6. Three-celled gametophyte of $O$. intermedium $\mathrm{Hk}$.

7-0. Young gametophytes of $O$. pendulum L., showing mycorrhizal infection. $m$, mycorrhizal filaments.

10. Adult gametophyte of $O$. moluccanum. $\times 10$. $t$, basal tuber; $\hat{o}$, antheridia.

II-I4. Gametophytes of $O$. pendulum. $\times 3 . \quad b$, adventitious buds; sp, young sporophyte.

15. Upper part of ripe antheridium of $O$. pendulum. $\times 275.0$, opercular cell.

16-20. Development of the spermatozoid in 0 . moluccanum. $\times 950 . \mathrm{bl}$, blepharoplasts.

PIATE 2.

21-29. Spermatogenesis in Ophioglossum pendulum. $\times 950.21$ shows spermatocyte before final nuclear division, with two blepharoplasts, $b l ; 22,23$, nuclear spindle from side and pole; $2 f-29$, development of spermatozoid; $n$, nucleus of spermatozoid; $c$, cilia; $v$, protoplasmic vesicle.

30-32. Three stages in the development of the archegonium of 0 . pendulum. $\times 275 . \quad b$, basal cell; $n^{1}, n^{2}$, neck canal cells.

33. Venter of the archegonium, showing apparently a ventral canal cell, $v$; $n$, one of the nuclei of the neck canal cell. $\times 650$.

34-37. Spermatogenesis in B. virginianum; $38-41$, in Kaulfussia; 42,43 , in Danaa. All $\times 950$.

4. Nearly ripe spermatozoids of Angioptcris. $\times 950$. $n$, nucleus; bl, blepharoplast; $c$, cilia; $\vartheta$, vesicle.

45. Nearly ripe archegonium of Danaa, showing apparent ventral canal cell, $v$.

$4^{6-4}$. Recently fertilized egg-cells of Danaa. sp, spermatozoid (?) within the egg-nucleus.

Plate 3.

Ophioglossum moluccanum Schlecht.

Several types collected at Buitenzorg, Java, and referred to O. moluccanum Schlecht. There are at least three species. Fig. 5 is the typical 0 . moluccanum. All figures about natural size.

Plate 4.

A. Six plants of Ophioglossum (Ophioderma) intermedium Hk. reduced one-half. Collected at Buitenzorg, Java.

B. Ophioglossum (Ophioderma) pendulum L., collected in the Hanwella Reserve Forest, Ceylon.

1, 2. Full-grown sporophytes of $O$. pendulum, much reduced. In 2 the sporangial spike, sp, is forked.

3-6. Details of the sporophyll and sporangiophore.

Plate 5.

Ophioglossum (Cheiroglossa) palmatum L., collected in Jamaica.

I. The whole plant.

2, 3. Sporophylls. In 3 there is a single median spike.

Plate 6.

A. 1, Botrychium obliquum Mühl.; 2, B. lunaria L.

B. B. virginianum (L.) Swz.

Plate 7.

Botrychium silaifolium P'r. California. 


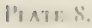

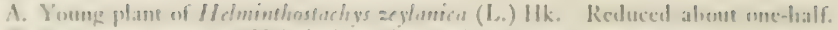

13. Full-grown plant of Hdminthostachys, reduced alout two-thirds. Cullected in the Hanwella keserve lorese, Ceylon.

I'I.ATE: 0 .

A. 1, small plant of Daners jenmani Underweod; 2, rlizone of the same species; 3 apex of sterile. leaf; 4 , fertile leaf; 5 , stcrile leaf of $D$ ). jamaicensis Underwoxd.

13. 1, young plant of Damara alliptica Sm. (?); 2, sporophyll of $D$. jamaicensis; 3 , 4, very young plants of $D$, jumaicensis (?).

All specimens collected in Jamaica.

I'IATI 10.

Adule sporoplyte of Danaca clliptica. Jamaica.

I'TAT: 11.

Kualfussin resculifolia 131 .

1. Young plant showing the rhizone.

2. Sporophyll. Specimens collected near liuiteneutg. Java.

L'B.AT: 12.

1. Maraftic alatn Siwz.

r. Part of fertile leaf.

2. A single fertile pinna.

3. Fallen leaf-base with adventigious luuds, $k$.

B. Mrattia alate.

1. I.eaf from young plant developed from an adventirious bud.

2, 3. Young sporophytes arising from fertilization. All specimens from Jamaica.

L'ATE: 13.

Angiopteris ruecta (Forst.) Hoffm.

1-3. Specimens from Auseralia; 4, 5, specimens from l'eradeniya, Ceylon.

1, caudex of a small plant; 2, part of a sporophyll; 3, cross-section of the periole of a full-grown

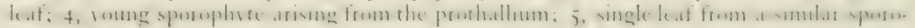
phyte. 


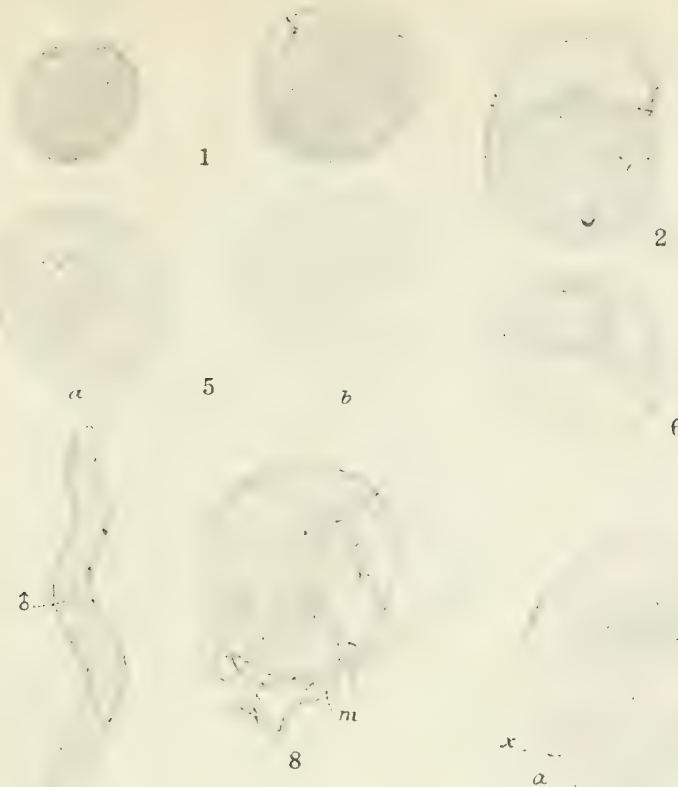

2

¿

6

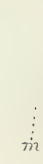 (n)

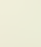

.
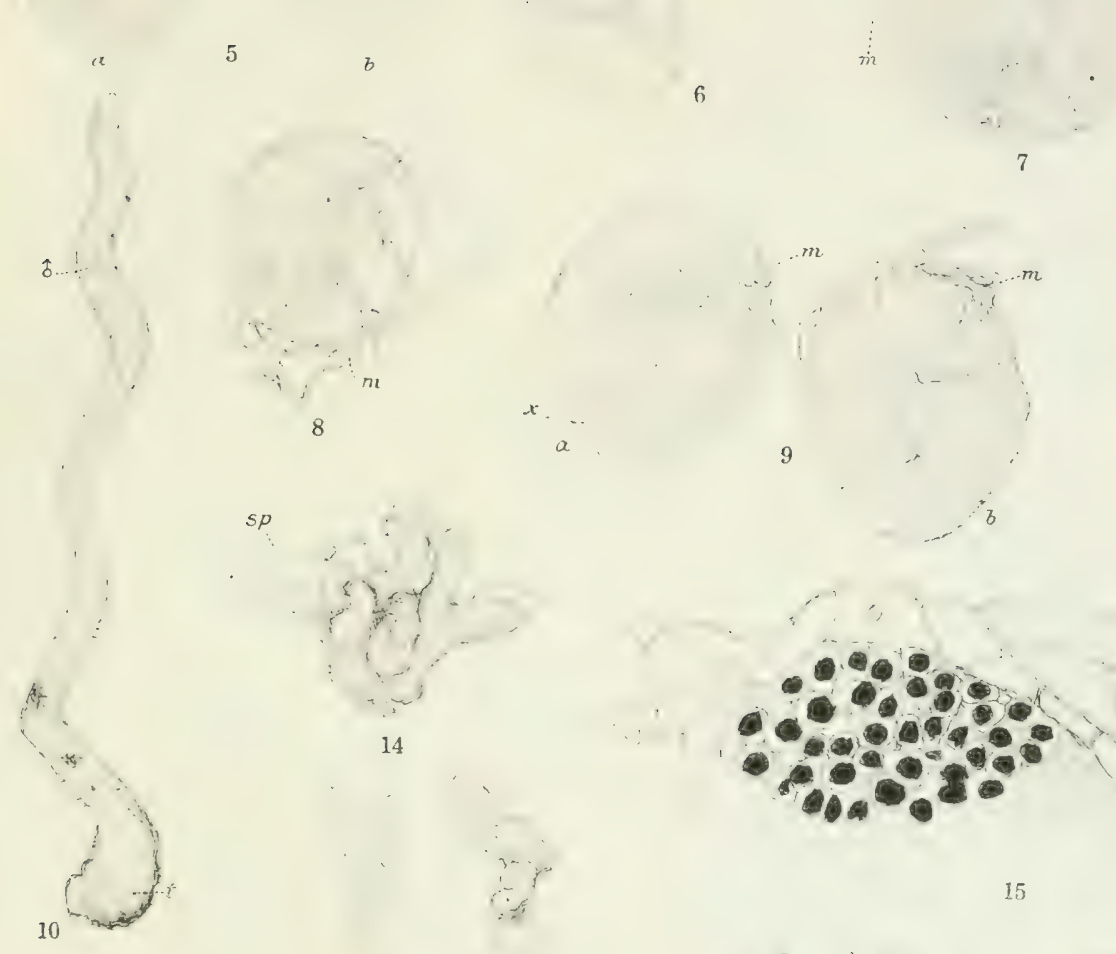

14

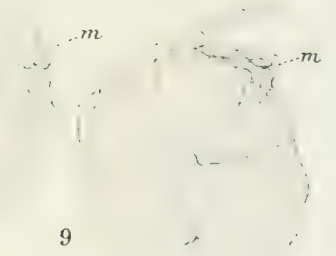

15
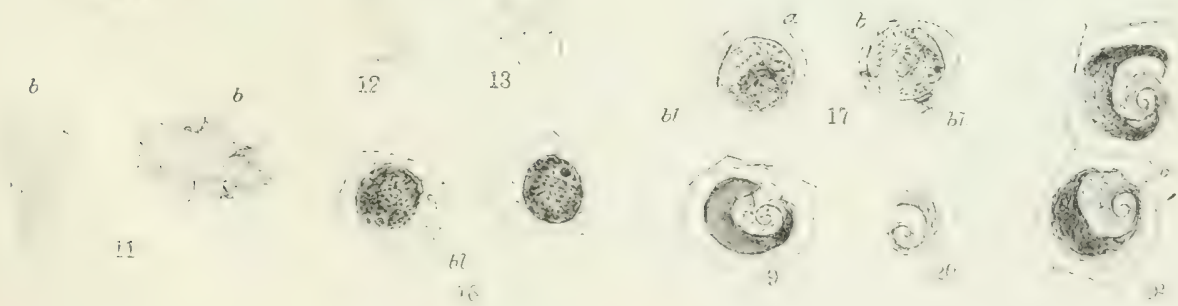

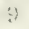
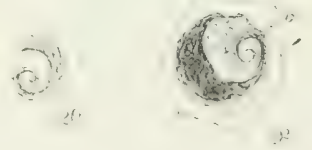

1. Two spores of 0 . moluccanum, showing range in size. $\times 500$.

2. Two-celled gametophyte of $O$. moluccanum.

10. Adult gametophyte of $O$, moluccanum. $\times 10, t$, basal tuber; $\hat{\delta}$, antheridia.

3. A three-celled stage. $s p$, ruptured spore membrane.

4. A four-celled stage, seen from above.

5. Two transverse optical sections of a four-celled gametophyte.

6. Three-celled gametophyte of $O$. inlermedium Hk.

7.9. Young gametophytes of $O$. pendulum L., showing mycorrhizal infection. $m$, mycorrhizal filaments.

11-14. Gametophytes of $O$. pendulum. $\times 3 . b$, adventitious buds; $s p$, young sporophyte.

15. Upper part of ripe antheridium of 0 . pendulum. $\times 275$. 0 , opercular cell.

16-20. Development of the spermatozoid in O. moluccanum, $\times 950$. bl, blepharoplasts. 



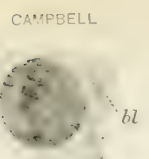

21

. bl

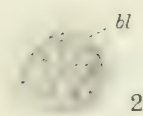

26

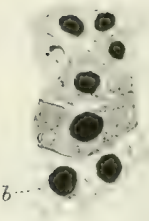

30

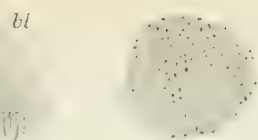

23

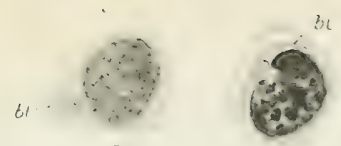

24
25
22

bl

$t l \cdot \cdots$

27

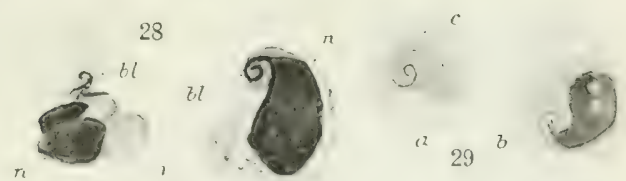

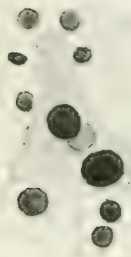

31

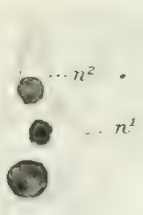

32

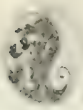
29

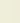
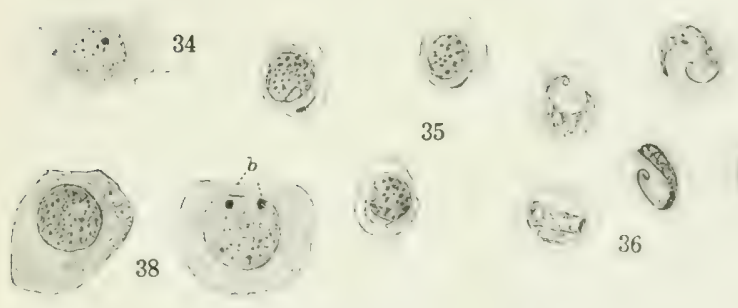

35
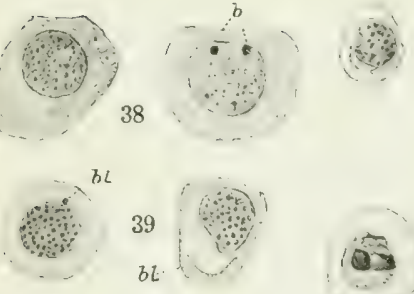

$y^{2}$
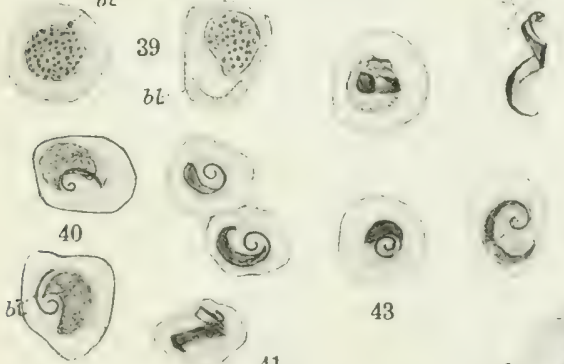

37

43
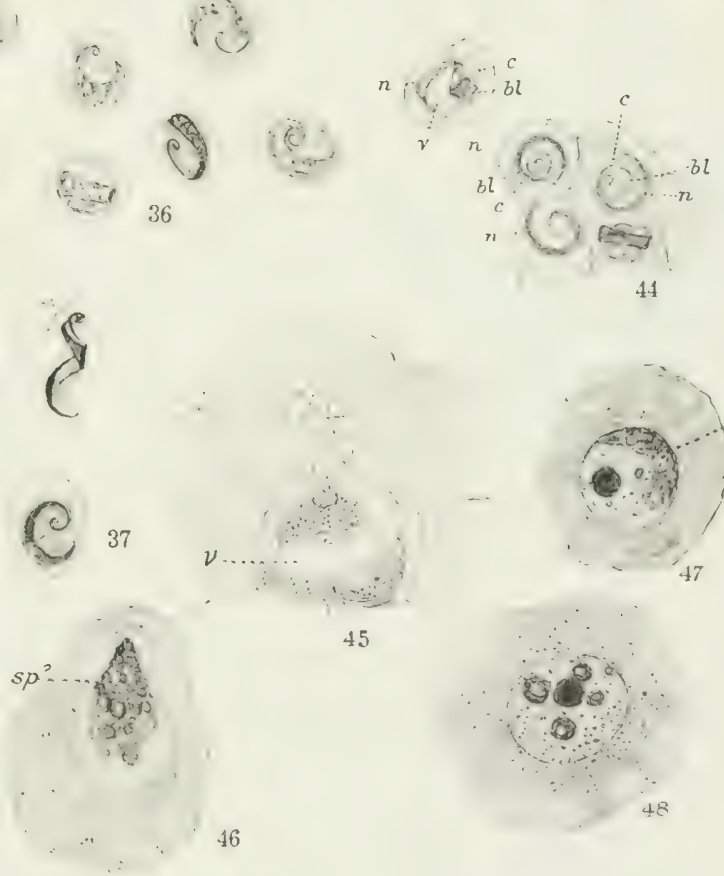

33
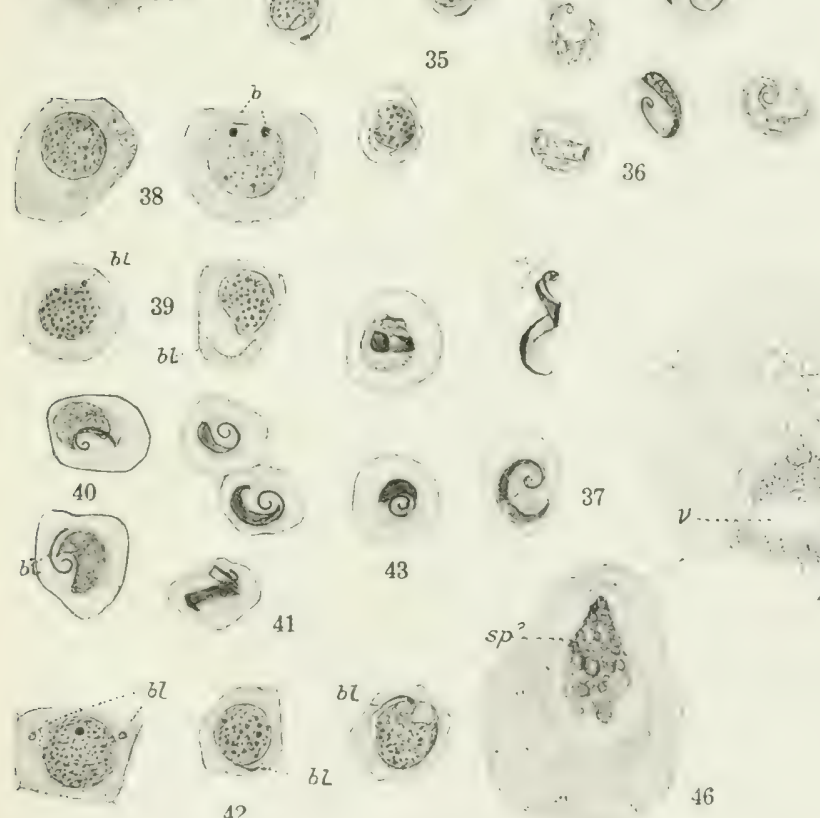

42

21-29. Spermatogenesis in Ophioglossum pendulum. $\times 950 ; 21$ shows spermatocyte before final nuclear division, with two blepharoplasts, $b l ; 22,23$, nuclear spindle from side and pole; $24-29$, development of spermatozoid; $n$, nucleus of spermatozoid; $c$, cilia; $v$, protoplasmic vesicle.

30-32. Three stages in development of archegonium of $O$. pendulum. $\times 275, b$, basal cell; $n^{1}, n^{2}$, neck canal cells.

33. Venter of archegonium showing apparently a ventral canal cell, $v$. $n$, one of the nuclei of the neck canal cell. $\times 650$.
34.37. Spermatogenesis in B. virginianum; 38-41, in Kaulfussia; 42,43 , in Dana. All $\times 950$.

44. Nearly ripe spermatozoids of Angiopteris. $\times 950 . n$, nucleus; bl, blepharoplast; $c$, cilia; $v$, vesicle.

45. Nearly ripe archegonium of Danca, showing apparent ventral canal cell, $v$.

46-48. Recently fertilized egg-cells of Danca. $s p$, spermatozoid (?) within the egg-nucleus. 



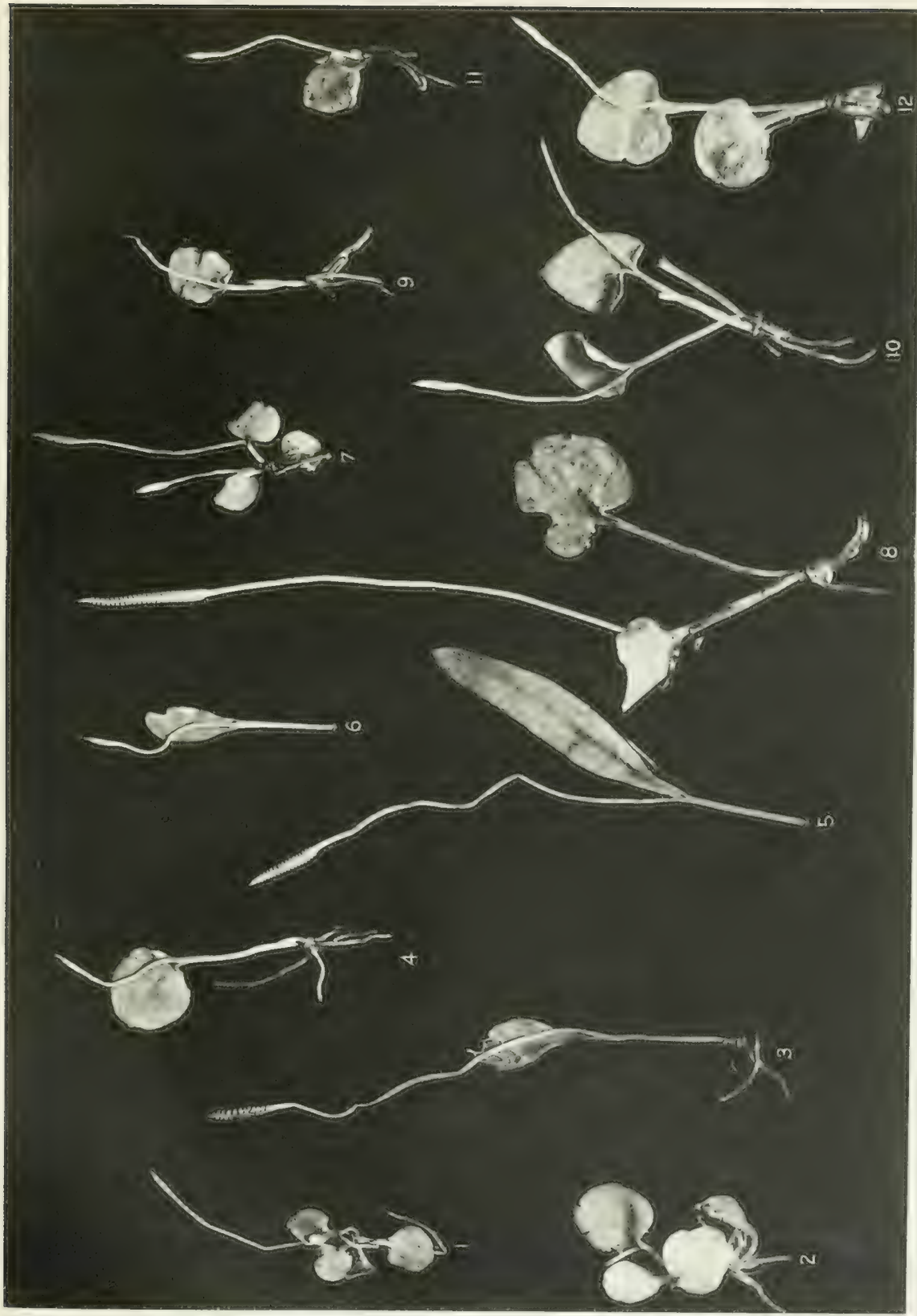




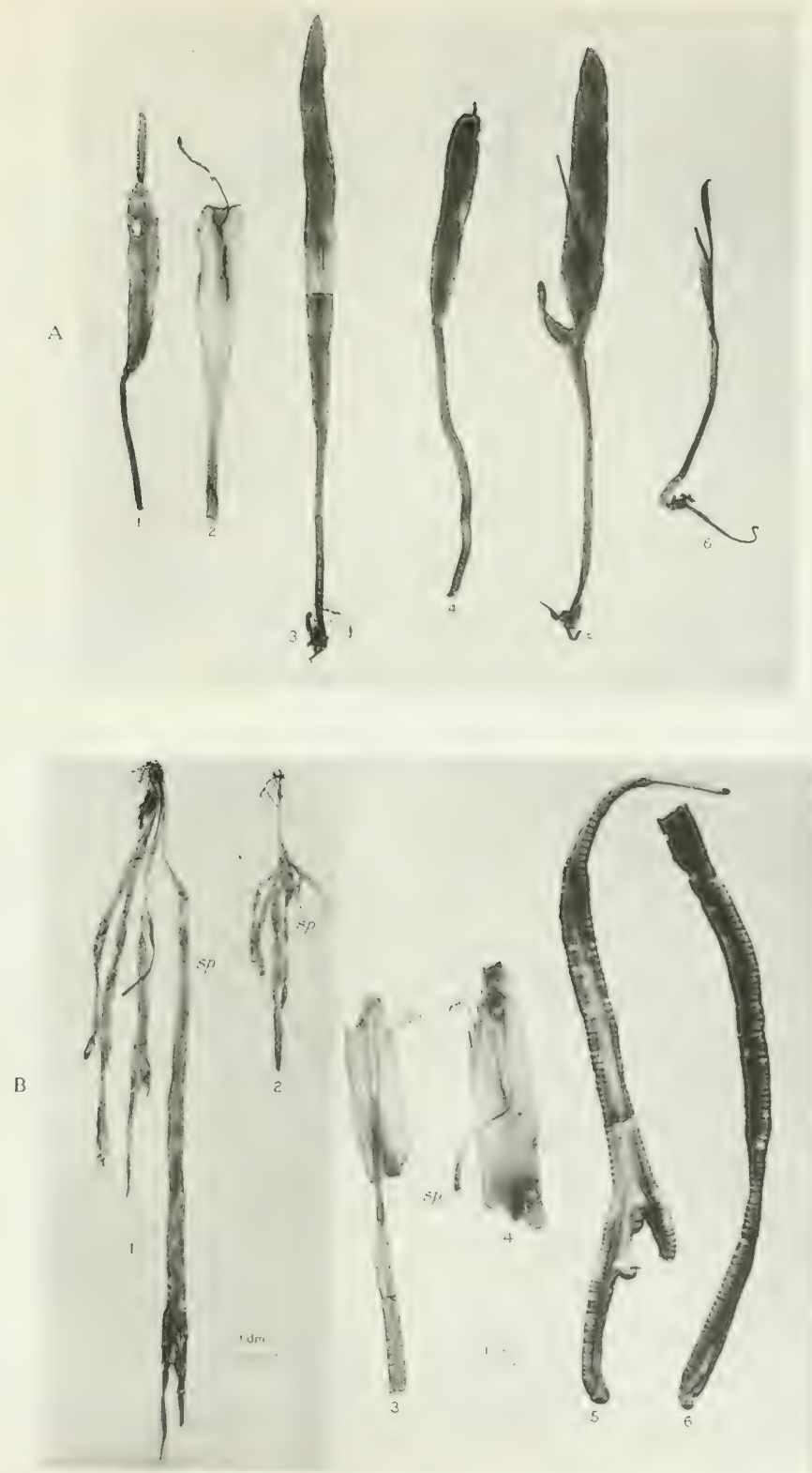

A. Six plants of Ophioglossum (Ophioderma) intermedium Hk., reduced one-half. Collected at Buitenzorg, Java.

B. Ophioglossum (Ophioderma) pendulum L. Collected in the Hanwella Reserve Forest, Ceylon.

1.2. Full-grown sporophytes of $O$. pendulum, much reduced. In 2 the sporangial spike, $s p$, is forked. 3-6. Details of the sporophyll and sporangiophore. 



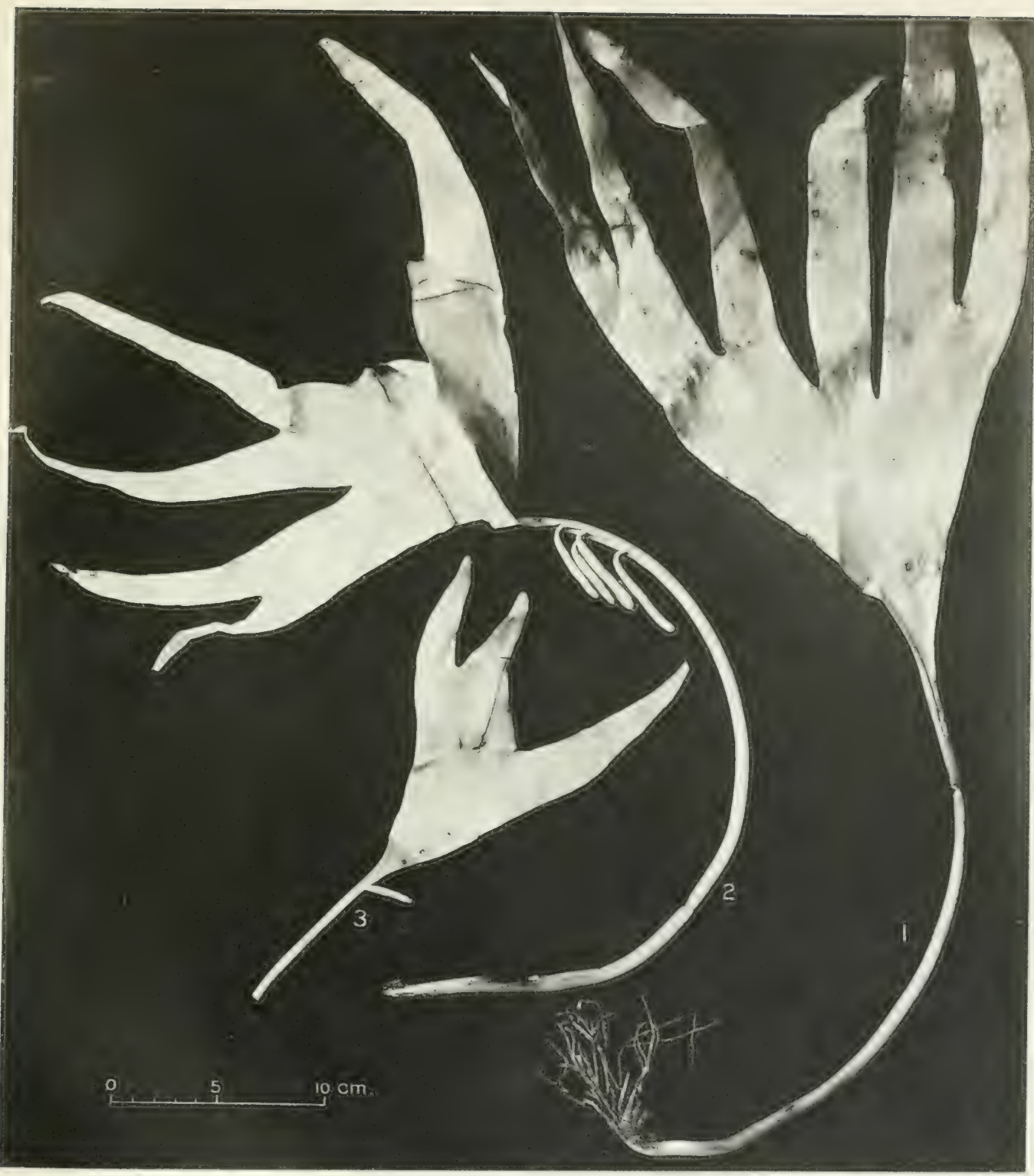

Ophioglossum (Cheiroglossa) palmafum L. Collected in Jamaica.

1. The whole plant. 2, 3. Sporophylls; in 3 there is a single median spike. 


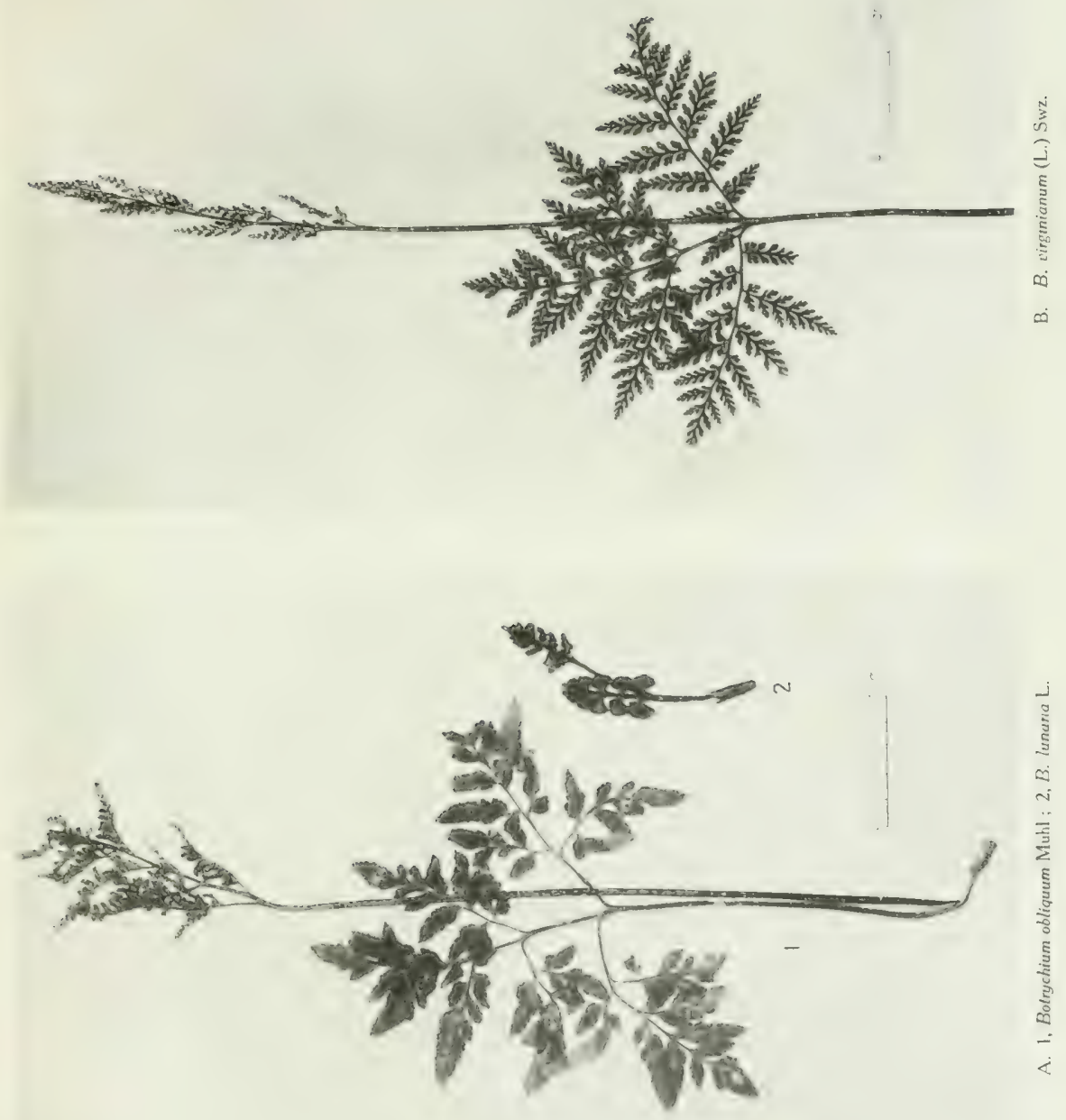



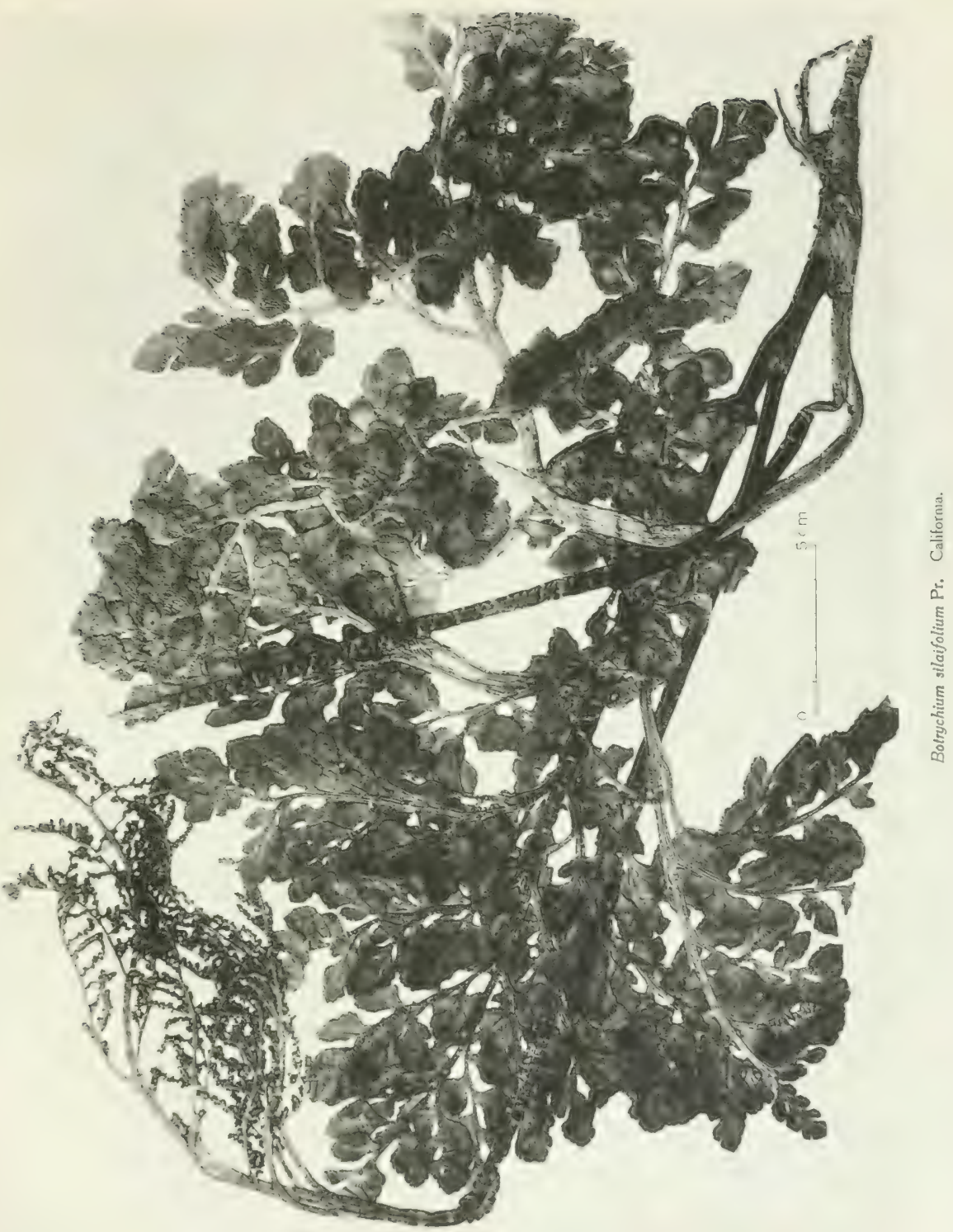




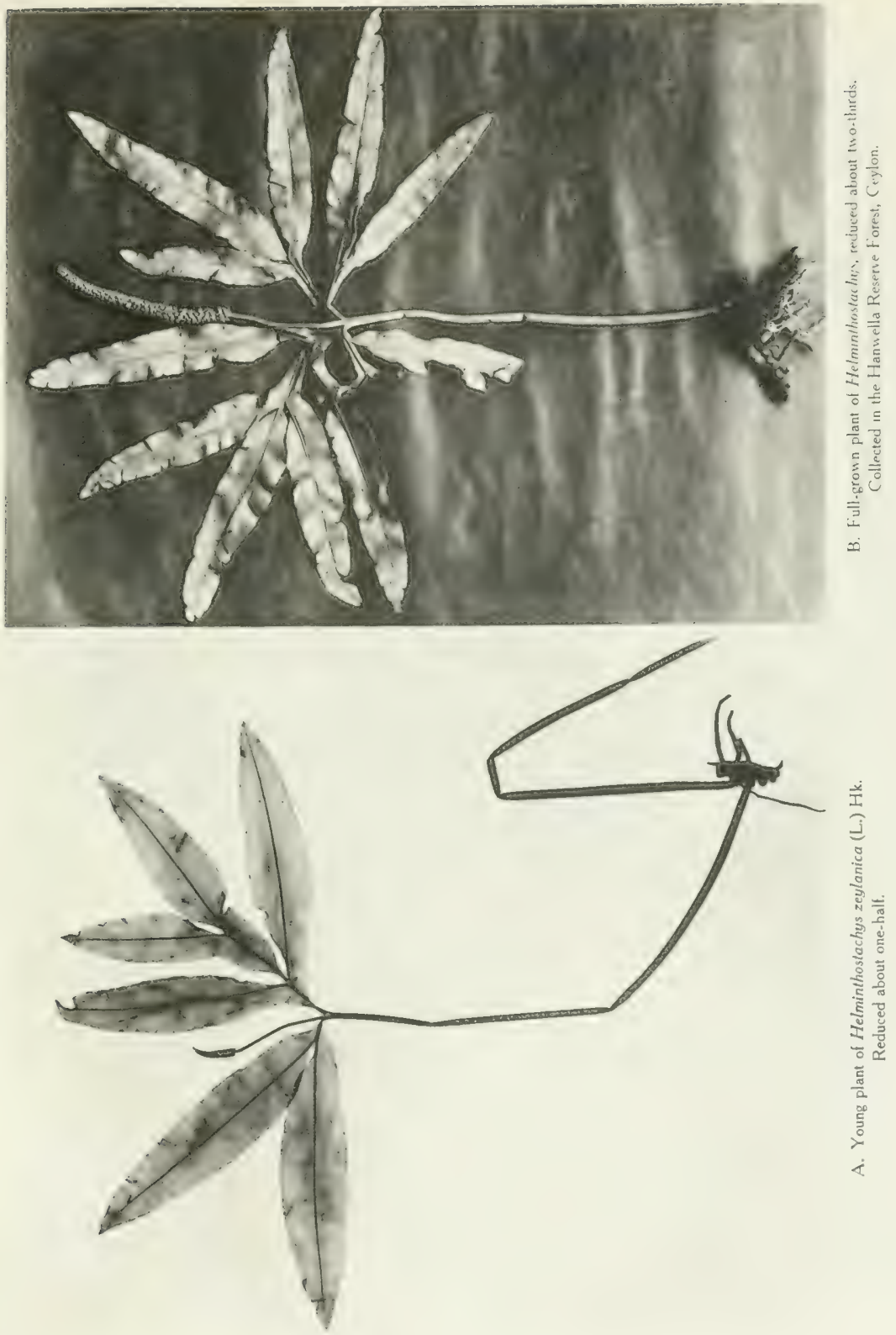

A
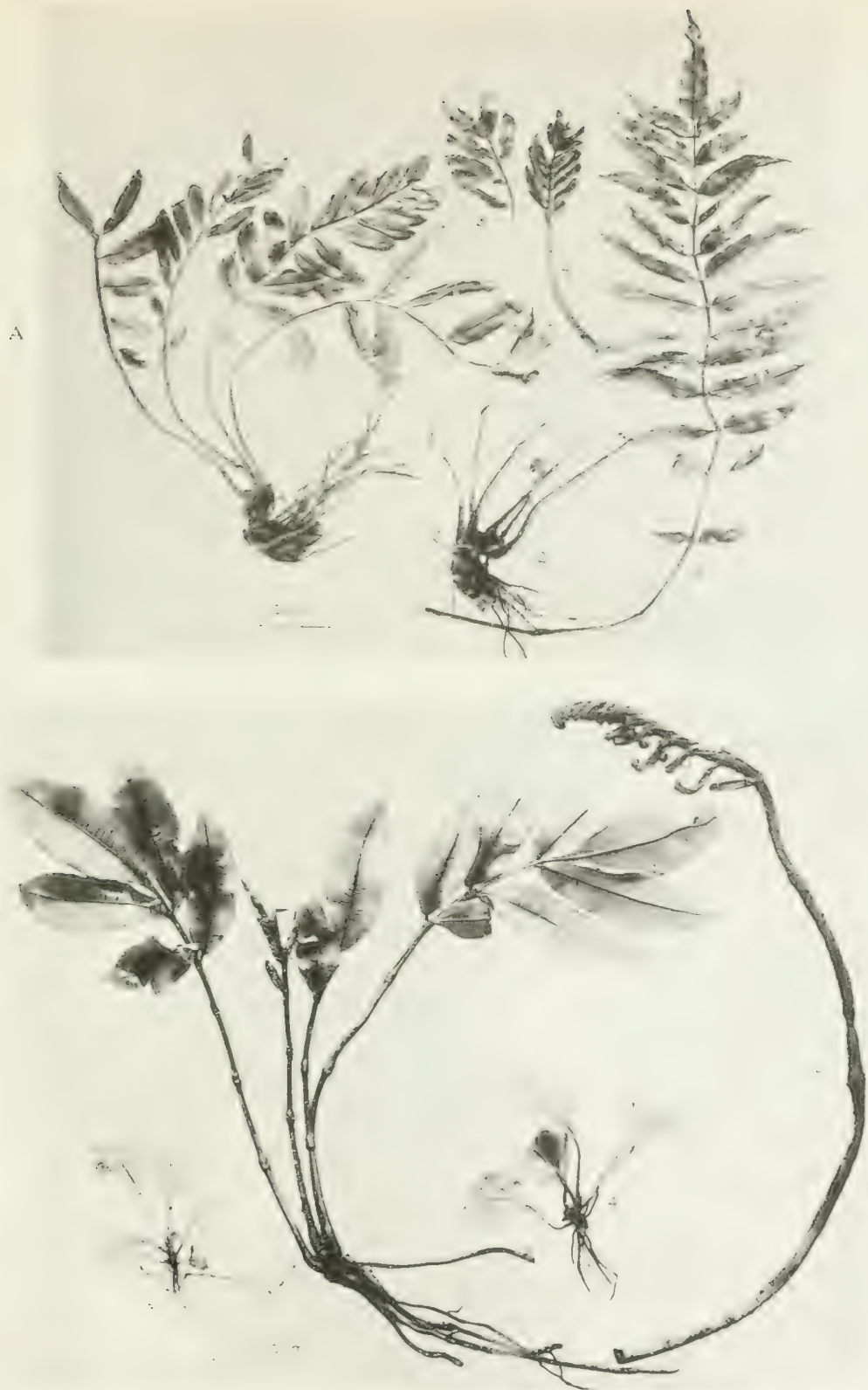

A. 1, small plant of Danca jenmani Underwood; 2, rhizome of the same species; 3, apex of sterile leaf;

4. fertile leaf; 5, sterile leaf of $D$. jamaicensis Underwood.

B. 1, young plant of Danca elliptica Sm.i 2, sporophyll of D. jamaicensis; 3, 4, very young plants of D. jamaicensis (?). 



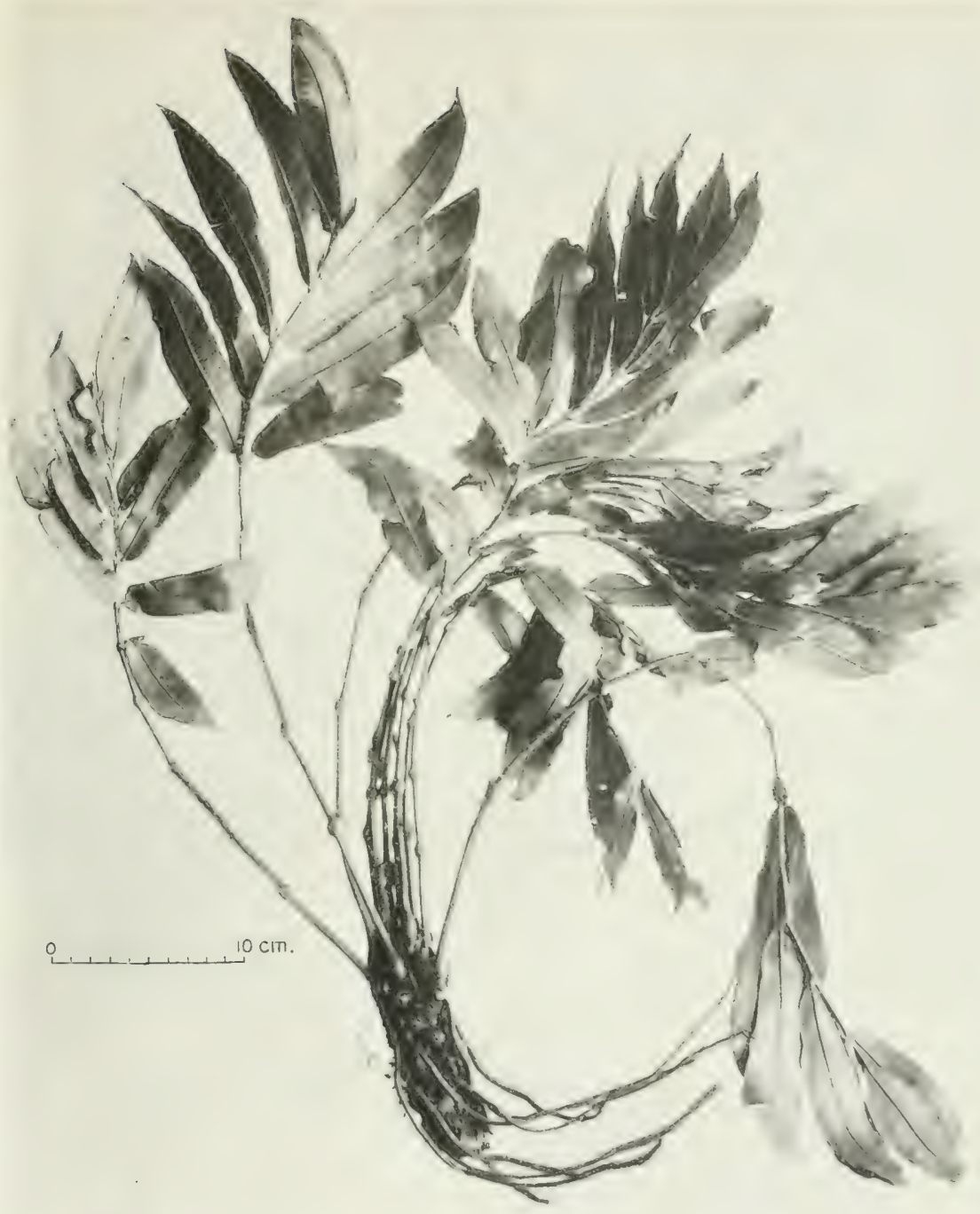

Adult sporophyte of Danea elliptica. Jamaica. 



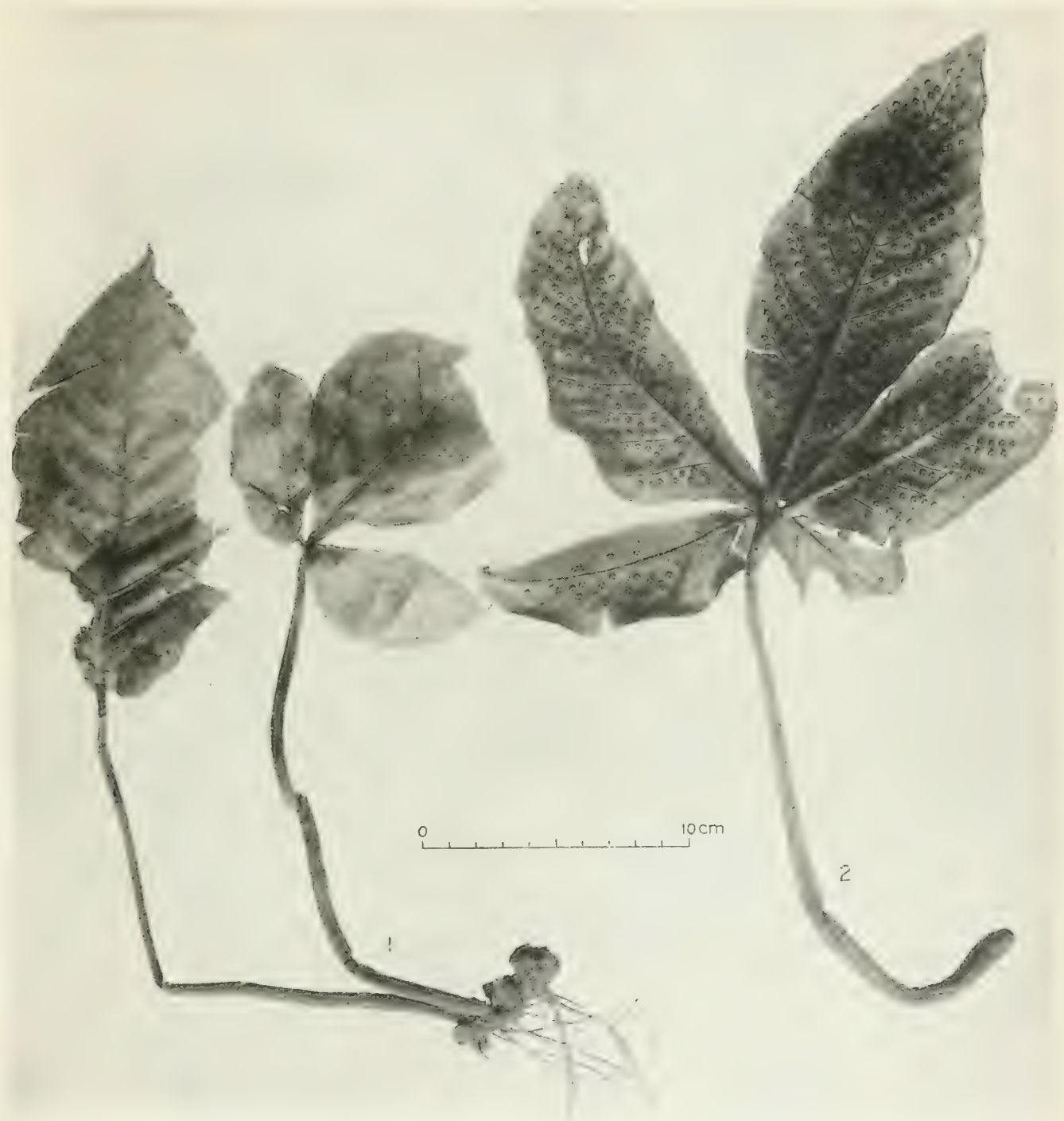

Kaulfussia æasculifolia BI.

1, young plant showing the rhizome; 2, sporophyll.

Specimens collected near Buitenzorg, Java. 


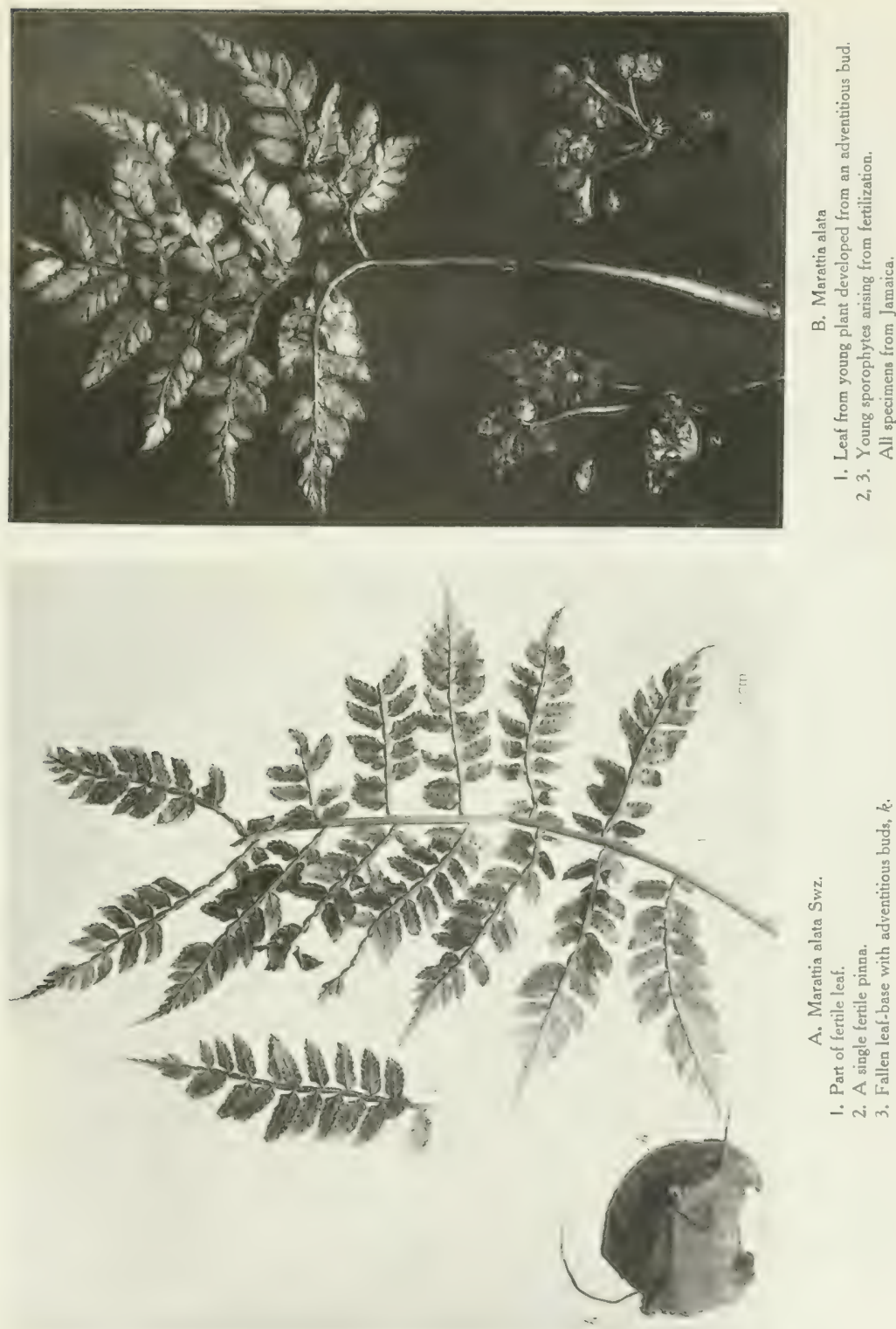



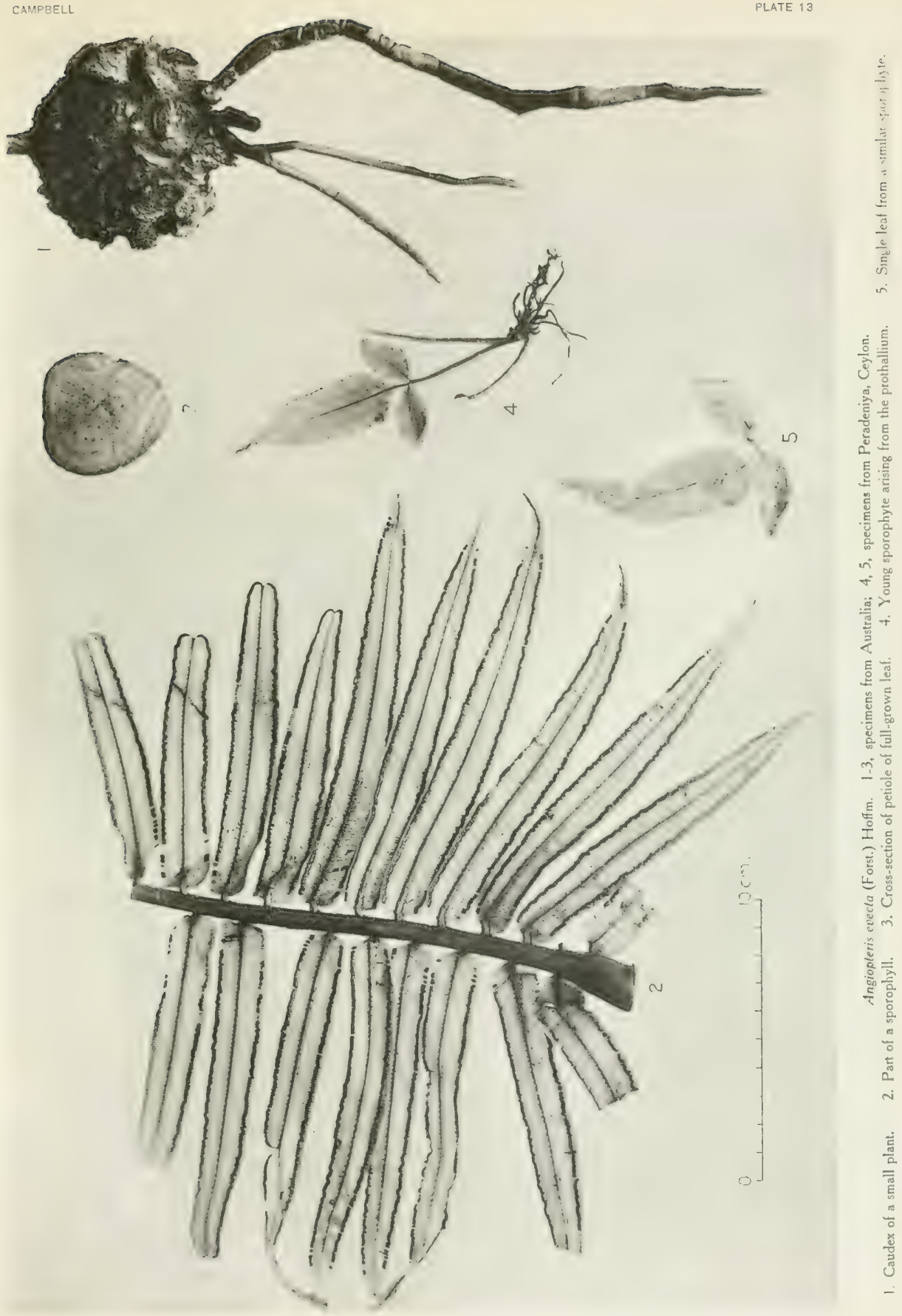





\section{N D E X}

Adder-tongue fern. See Ophioglossum.

Adventitious buds. See Buds.

Alternation of generations, 209

Aneura, 120

Angiopteris, 4, 11 7, I18, 120, 12 1, 126, 139, 140, $141,146,150,152,153,154,155$, $158,164,196,198,199,201,202$, $203,204,205,207$

Figs. $88,89,95$, I0I, 109, 110,111 , II 2 ,

Plate I3

I 24, I30, 134, I S0, 181, 182, 183, I 87

Angiopteris, species of, 196

Angiopteris evecta (Forst.) Hoffm., II9

Angiopteris pruinosa var. hypoleuca, 122

Annulus of sporangium, 208

Antheridium:

Angiopteris, 126

Anthoceros, 42, 122, 211

Botrychium, 18, 24, 25

Danxa, 126, 128

Equisetum, 24

Helminthostachys, 20, 21

Kaulfussia, 127

Lycopodium, 24

Marattia, 126, 128

Marattiacex, 24, I29

Ophioglossum, 22, 23, 24

Anthoceros, Anthocerotes, 42, I22, 2 10, 2 I 1

Apical growth. See Leaf, Root, Stem.

Apogamy (in Botrychium), 52

Archangiopteris henryi, f, I1 17, 203, 204

Fig. 184

Archegonium:

Angiopteris, I3 1

Botrychium, 30, 3 I

Danæa, 132, 133, 134

Helminthostachys, 20, 21

Kaulfussia, 13

Marattia, 126

Ophioglossum, 28, 29

Archesporium:

Botrychium, II 5

Helminthostachys, II 5

Marattiaceæ, 206

Ophioglossum, II 5

Asplenium nidus L., 10, 13

Blepharoplast, $26,128,129$

Botrychium, 3, 5, 16, 17, 18, 19, 25, 27, 28, 30, $31,32,39,46,47,48,49,50,52,66$, $82,83,99,101,102,103,109,110$, $136,1+2,213$

Classification of, 99

Botrychium lanuginosum Wall., 99, 101, 103 Fig. 74
Botrychium lunaria (L.) Sw., $6,16,17 ; 28,34,46$ $48,50,52,65,83,99,111$

Figs. $8,36,71$

Plate 6

B. matricarixfolium A. Br., 16

B. obliquum Mühl., $16,34,39,53,54,103,136$, $1+2$

Plate 6

B. silaifolium Pr., 99

Plate 7

B. simplex Hitchcock, 5, 6, 16, 83, 99, 100, 109, I 15

Fig. 7I

B. ternatum (Thbg.) Sw., 100, 103

Fig. 71

B. virginianum (L.) Siv., 6, 16, 17, 18, 27, 28, 32, $34,46,47,50,52,53,54,59,60$, $61,63,67,69,83,99,100,101,103$, IIO, 112,114

Figs, $7,14,15,17,28,29,32,33,40$, $41,42,43,44,71,72,74,76,77,85$ Plate 6

Botryopteridex, 3, 214

Bryophytes (see also Mosses, Liverworts), 2 I 2 Buds:

in Botrychium, IOI

on leaf of Danxa sintensis, 178

on gametophyte of Marattiacex, 121

on gametophyte of Ophioglossum, 14

on primary root of Ophioglossum, to

root buds in Ophioglossum vulgatum, 58, 59

Calcium pectate in Marattiacere, 204

Calcium oxalate crystals in Marattiacere, 204

Cambium, 65, 82

Canal, so-called "canal" in Helminthostachys, $7.4,79$

Cauline fibro-vascular bundles (see also Commissural strand), $174,175,184$, I9I, 197

Cheiroglossa (see also Ophioglossum palmatum), 5,88

Fig. 70

Plate 5

Chlorophyll in gametophyte of Ophioglossum, 9, 12

Christensenia = Kaulfussia, 122

Collateral bundles, Primitive nature of, 214

Collenchyma in:

Angiopteris, 202

Kaulfussia, 186

Marattia, 194

Commissural vascular bundles in-

Angiopteris, 197

Danxa, I74, 175 


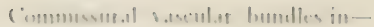

M.ur.atri.t, Tut

haullussias thi

(immonimure (of stipules), 187

(ompleteri. complens, 2:

Cistolloshisa, 33

Cinvlectom of -

Anginpleris, 1.46, 1.47, 151

Burrothum, 50, 51, 52,64, 67, 8;

D.an.e.s, 1 1, 5,$2 ; 0$

lfelmuintheseacloys, if. (r)

K.ulfussia, 147, 14')

Marattia, 138, $147,150,151$

() phioglossum, 35, +12

Criseals. See Calcium oxalate.

Circads, 30

1).12.:1, 47, $33,82,84,117,118,124,125,126$. $128,135,142,151,154,160,163$, $164,205,212$

Danea elliptica Smith, 124, 125, 126, 132, 136 . $1+2,148,154$

ligs. 192, 93, 103, 105, $117,125,131,143$, $147,151,152,161$. Plates 9, 10

1). jamaicensis linderwoud, $124,126,136,142$, $144,146,148,854,155,156$

Figs. $91,93,98,90,100,104,114,115$. $116,118,119,120,121,125,120$, $138,140,143,144,145,146,148$, Plate ()

$149,150,153,160,161,189$

D. jenmani Underwood, 124

Figs. 91, 154, 155, 156, 157, 162

l'late 9

D. simplicifolia Rudge, $124,127,136,142,154$,

1). sintensis, 178 $160,175,176,206$

1). trichomanoides Spruce, 178

Dehiscence of -

Antheridium, 24, 25, 129

Sporangium, 10 9

Synangium of Marattiace:e, 207

Dichotomy of -

l'rothallium in Marattiacer, I 2 r

Root in Ophioglossum, 93

Dicutyledons, 6;

Dictyostele in -

Angiopteris, 197

Danaca, 175

Kaulfussia. 185

Mlarattia, 102

Drosera, 32

Embryo of -

Angiopteris, 130

Butry chium, $46,47,48,51,136$

1) anxa, $118,136,14$ 2

Helminthostachys, 5+. 67

Kaulfussia, I 1

Marattia, 135, 136, 137

Marattiacex, 118,135

Ophioglossum, $34,35,36,37,38,43$
Findendermis:

Angiopteri, 161, $=08$

D.tn.e:i, 163, 167

Helminthestaclyys, 72

Kaulfussia, 161, 182, 15:

Marattia, 164, 193

()plicuglossum, 1) =

Findarch bundles in Iledminalustachys, 77

Eindepherte. Siee Mfecorthiza.

Encomophelsereac, 22

Equicetum, Eiquisetisex, 26, 27, 3\%, 13:, $13 \%$

Fuberrychium (see : itsen Brotychium), 100

Euophinghlossum (sce also) (Ophioglewsum), 83 .

linporangiate,

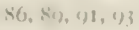

Comparison with Bryophytes, 200, 210, 212

Nature of vaseular svstem, 214

Relation to Leptosporangiate, 217

Fegatella, 33

Ferns, origin of, zor)

Fertilizasion:

Butrychium, 32

Maratiacex, 134

()phinglossum, 31

Fibro-vascular sysecm (secalso leaf-erace, Sitcle):

Angiopteris, $1(x), 1(2,1(x), 201$

Bintrychium, 60, 62, 66

Danaea, $160,162,163,164,166,172,174$. 176

Ilelminthostachys, 73, 76, 77, 78, 106

Kaulfussia, $181,182,184,185$

Maratia, 18\%, 191, 193

Fossils:

Bryophytes, 209

Ferns, 3

Maratriacex, I 87

Gametophyte:

Angiopteris, 121

Botrychium, 16,17, 18

Daniea, 124, 125

Helminthostachys, 20, 21, 22

Kaulfussia, 122,123

Maratia, 119, 121, 122, 210

Ophioglossum, 6, 10, 11, 12, 13,14, 15, 211

Germination of spores:

Marattiacex, I 19, 120

Ophioglossacese, $7,8,9$

Gleichenia, mycorrhiza in, 33

Gymnogramme, 26

Hairs:

Marattiacere, 150

Ophioglossum palmatum, on

Helminthostachys, 5, 8, 10, 19, 20,21, 25, 31, 32, $54,67,68,69,70,71,72,73,74,75$. $76,77,78,79,80,81,82,84,104$, $10,7,106,107,108,112,115,116$, 213,214

Figs. $10,11,45,46,47,48,49,50,51,52$, l'late 8 
Horned liverworts (see also Anthocerotes), 209 Indusium, 204

Isoëtes, 205, 206

Kaulfussia, 1, 82, 84, II 7, II 8, I 19, I 22, I23, I32, $1+1,1+7,149,152,153,154,155$, $157,158,164,178,179,180,181$, $182,183,185,186,187,206,208$ Figs. $90,96,102,113,123,128,136$, $141,163,164,166,167,168,170$ I 71,188

Plate II

Lacunz:

Internodal in Helminthostachys, 75 Leaf:

Internodal in Kaulfussia, 184

Angiopteris, 20I

Botrychium, 61, 101

Danxa, 176, 178

Helminthostachys, 67, 70, 74

Kaulfussia, 185

Marattia, 194

Marattiacex, II $8,157,159,214$

Ophioglossum, $57,8+87,88$

Leaf, anatomy:

Angiopteris, 202

Botrychium, 102

Danxa, 160

Helminthostachys, 107

Kaulfussia, 187

Maratria, I94, 195

Ophioglossum, 93, 96

Leaf, ferrile (see also Sporophyll), 5, 85, 109, 204. 213

Leaf, gaps, 78,173

Leaf, trace, $66,72,80,173,186,191,197$

Leptosporangiat $x, 3,217$

Liverworts, mycorrhiza in, 33

Lycopodium, 9, I0, 24

L. cernuum, 9, 10

Mantle cells (of antheridium), 24, 129

Marattia, $117,119,120,122,126,128,132,135$, $136,137,147,149,152,153,155$. $156,164,188,189,192,193,19.4$ I $95,204,206$

M. alata Swartz, 138, 188, 191, 192, 193, 194 Figs. $175,176,177$. Plate 12

M. cicutæfolia KIf., I19, 132,136

M. douglasii (Pr.) Baker, I 19, I 20, I22, I26, I35, I36, $137,147,149,151,153,156$, I88, $189,190,205,210$

Figs. $87,88,94,106,107,108,122,127$, $132,133,141,172,173,174,177$, $185,190,191$

M. fraxinea Smith, 120, 188, I91, I93

Figs, $87, \mathbf{1} 86$

M. salicifolia Schrad., I93

M. sambucina Blume, I2O, I 88

Fig. 87

M. weinmannixfolia Liebm., 136
Marattiacex, $3,35,39,48,53,61,83,84,117$, $129,130,134,135,209,212,214$, 215

Macroglossum, I17, 204

M. alida Copeland, 204

Mesarch vascular bundles in Helminthostachys, 78

Monotropa, 33

Mosses, 200

Mucilage cells, $168,170,173,177,182,185,187$, 190

Mucilage ducts, 168, I70, 173, 177, 182, 185, 187, 190

Mycorrhiza, 6, 9, II, 15, 18, 19, 20, 21, 22, 32, $33,127,179,181,212$

Operculum (of antheridium), 24, 25, I 28,120

Ophioderma (see also Ophioglossum), 5, 87, 94

Ophioglossacex, $3,5,6,7,34,82,86,108$, I00, $208,2 \mathrm{I} 3,2 \mathrm{I} 4$

Ophioglossum, 5, 6, 7, 9, I0, I1 $, 12,13,14,15$, $22,24,26,27,28,35,39,42,43,56$, $60,82,83,85,86,87,89,91,20 \%$. $209,210,213,214,215$

O. bergianum Schlecht, 5,87, 92

O. capense Siw., 92

O. californicum P'rantl. 5

O. ellipticum Hk., 92

O. intermedium Hooker, 88,97 .

Fig. 69

Plate 4

O. Lusitanicum L., 86,87

O. moluccanum S'chlecht., 5, 6, 7, $11,12,26,28$, $34,35,36,38,39,40,42,45,55$ $56,57,59,86,90,94,112,210,212$ Figs. $2,4,12,18,22,23,24,25,26,27$, $37,38,39,55,56,57,58,59,60,6 \mathbf{I}$. $62,81,83,192$

Plates $\mathbf{I}, 3$

O. palmatum L., $88,89,98,99$

Fig. 70

Plate 5

O. pedunculosum Desv., I0, I I, I 3, 34, 36, 39, 40, $+2,57$

Fig. 3

O. pendulum L., 5, 6, 7, 9, 10, I 4, 18, 26, 28, 29 . $36,37,38,40,42,44,56,88,95,96$, I09, 112

Figs. 1, 3, 4, 13, 16, 20, 21, 63, 64, 65, 66, $67,68,82,84$

Plates 1, 2, 4

O. reticulatum L., 6, 40, 90

O. simplex Ridley, 88, 98, 100

Fig. 71

O. vulgatum L., 3, 5, 6, 10, 13, 15, 27, 28, 29, 34 , $43,44,57,58,59,86,87,92$

Figs. 3, 5, 19

Orchids as humus saprophytes, 33

Osmunda, Osmundacex, 12 I, I23, 207

Osmundopteris. See Botrychium virginianum.

Palisade tissue, 107, 178, 195, 202 
l'ellia, 122

['erildem, 66, 80, 193

P'eronosporeat, 2z

I'hylloerichium (sec also Botrychiom), 100, 102

Pieh, in Ileminthostachys, 76, 70)

I'olypodium quercifolium, 10

Prothallium. Sece (iametoplyyte.

I'romoplicoglossum, 211

I'rutucorm, 53

I'rotophloem in Anginguteris, 201

l'rotostcle, 175, เ88

l'rotoxylem:

Angiopteris, 201

Helminthostachys, 79,82

Kinulfussia, 185

l'teris cretica, 53

l'ythium, $2 z$

Rhizoids:

Botrychium, Is

Danxa, 127

Ilelminthostachys, 20

Kaulfussia, 123

Ophioglossum, 82

Rhizome (see also Stem):

Botrychium, 101

Danea, $175,176,177$

Helminthostacliys, 106

Kaulfussia, 186

Ophioglossum, 9r, 94

Ront:

Angiopteris, $140,202,203$

Botrychium, 47, 51, 64, 103, 104

Danxa, 157, 164, 177, 179

Ilelminthostachys, 70, 80, 81, 105, 107, 108

Kaulfussia, 187

Maratria, 138, 156, I92, I95

Ophioglossum, $35,39,43,56,83,87,89.93$, 97,98

Root apex:

Botrychium, 49

Danxa, 178

Helminthostachys, 72,80

Marattia, 138, 156,195

Ophioglossum, 9f

Root hairs, multicellular, of Kaulfussia, 183,187

Cicales, cpidermal:

Danxa, I 5 I

Helminthostachys, 7٪, 75

Kaulfussia, 180

Marattiacex, 150

Sceptridium. Sec Botrychium obliquum.

Siclerenchyma, 170, 171, 19.4

Secondary wood:

Angiopteris, 204

Botrychium, 6, 82

Helminthostachy's, 78

Sex-organs. See Antheridium, Archegonium.

Sieve tubes, 15 I, 163, 201, 202

Siliccous deposits in Marattiacex, 204
Siplonessecle:

1 Angiopteris, 107

Kaulfussia, 184

Marattial, IRS

Sivermatogenesis:

Botrychium, 28

Maratriace: $x, 12 \%, 130$

Ophienglosstm, 26, 27

Sincrmatoroids :

Botrychium, 25

Maratriaceat, $\$ 30$

Ophioglossum, 26, 27

Spike of Uphioglossacese. See Sposangiophere.

Sporangium (sec also Symangium):

Angiopteris, 205

Botrychium, 100, 111, 11.4, 115

Danixa, 205, 206, 207

Helminthostachys, 111, I16

Kaulfussia, 207

Marattia, 205

Ophioglossum, 109, 111, 1 I 3

Sporangiophore:

Botrychium, son, 110

Helminthostachys, 105,106

Ophioglossacex, 5, 85, 10\%, 100, 208

Ophioglossum, 109, 110

Spore:

Mlarattiacex, 208

Ophioglossacex, 6, 7

Spore division, IIt

Sporophyll:

Angiopteris, 20.4, 206

Archangiopteris, 204

Botrychium, 100, 102

Dan:ea, 204

Helminthostaclyss, II I, II6

Kaulfussia, 204, 208

Marattia, 204

Marattiacer, 204, 208, 214

Ophioglossum, $85,88,93,109,110,112,214$

Sporophyte (see also Embryo):

Angiopteris, 196, 198, 199, 201

Botrychium, 51, 59, 60, 62, 63, 99

Dansea, 163,178

Helminthostachys, 54, 67, 68, 77, 104,105

Kaulfussia, 179, 180,186

Marattia, 18\$, 180

()phioglossacex, comparison of young sporophyte, 8z

Ophioglossum, 38, 39, 44, 45. 55

Staubgrubchen of Marattiacex, 204

Stele:

Botrychium, 82

Helminthostachys, 52, 75, 8:

Stem, stem apex:

Angiopteris, $153,198,199$

[3otrychium, 49, 53, 101, 103

D) anxa, $118,136,156,170$

Helminthostachys, 70, 71, 74

Kaulfussia, 185,187 
Stem, stem apex:

Marattia, 192

Marattiacex, 154,162

Ophioglossum, 42, 50, 56, 89, 91, 94, 97, 99

Sterilization of sporogenous tissue, 209

Stipule, stipular sheath:

Botrychium, 6I, IoI

Danæa, 170

Helminthostachys, 71, 73, 105

Kaulfussia, 185,187

Marattia, 195

Marattiacex, in 8

Ophioglossacex, $83,8+$

Ophioglossum, 9I

Stomata:

Botrychium, Ior

Danea, I 5 I

Helminthostachys, I06

Kaulfussia, I 52,187

Marattia, 195

Ophioglossum, 96

Suspensor:

Botrychium, 47, 48, 53, 136

Danxa, I 18,136
Synangium, 204, 205, 206, 207, 208

Tannin cells:

Angiopteris, 146

Danxa, 165, 169, I7!

Helminthostachys, 79, 84

Kaulfussia, 185

Marattia, 189

Marattiacex, 150

Tapetum, III, 116, 206

Trabeculax, 207

Tracheary tissue:

Angiopteris, 20I

Botrychium, 66

Helminthostachys, 68, 79, 82

Kaulfussia, I 85

Marattia, 189

Ventral canal-cell, 30, 31, I33, I34, I 76, 187, 194 201,213

Vestigial leaves:

Botrychium lunaria, $5 \mathbf{I}$

Helminthostachy's, 69, 8I

Ophioglossum vulgatum, 35 




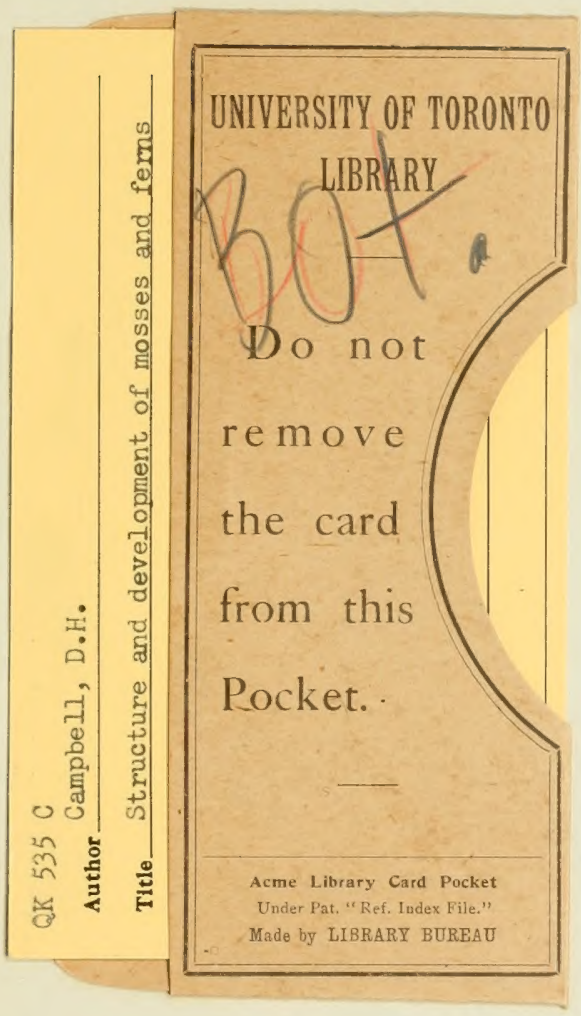




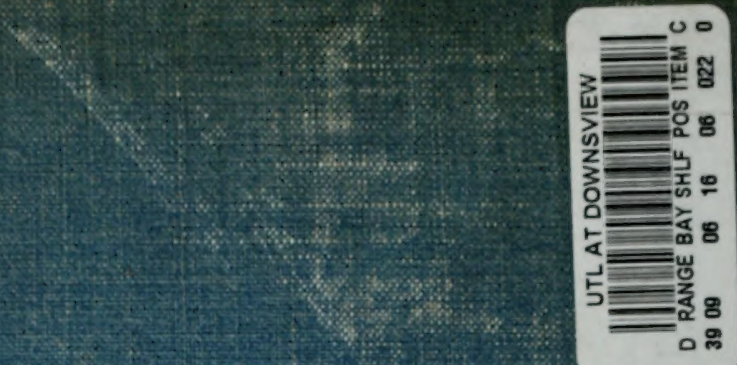

ii:
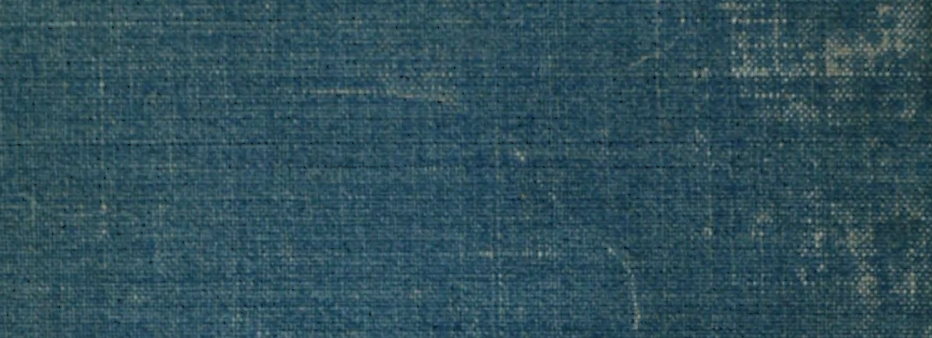

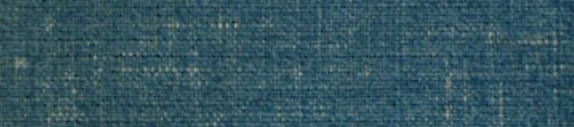
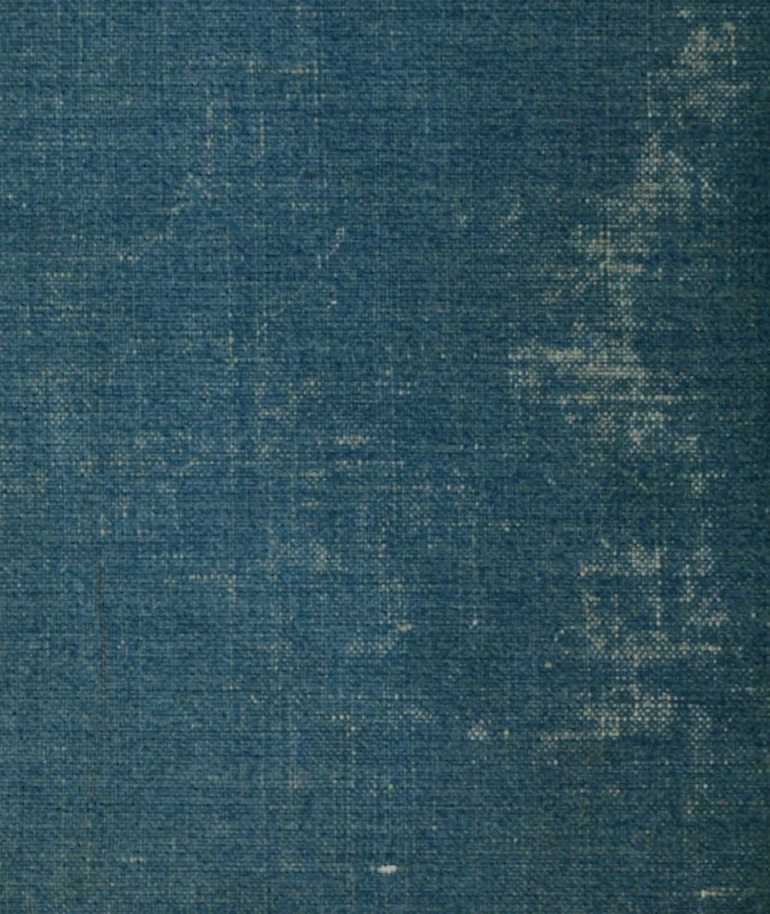